
1

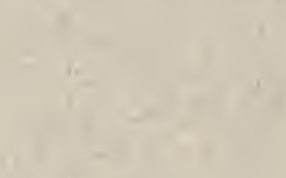




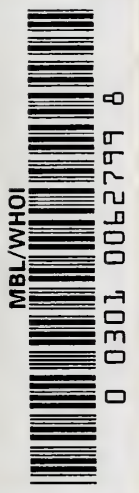






\title{
Dr. L. Rabenhorst's
}

\section{Kryptogamen-Flora von}

Deutschland,Oesterreich und der Schweiz.

\author{
Zweite Auflage \\ vollständig neu bearbeitet \\ von
}

Andr. Allescher, Prof. Dr. A. Fischer, Prof. Dr. Ed. Fischer, Dr. F. Hauck, G. Limpricht, Dr. W. Limpricht fil., Prof. Dr. G. Lindau, Prof. Dr. Ch. Luerssen, Prof. Dr. W. Migula, Dr. K. Müller, Dr. H. Rehm, Prof. Dr. H. Schinz, Dr. G. Winter.

Erster Band:

\section{Die Pilze.}

Leipzig.

Akademische Verlagsgesellschaft m. b. H. 


\title{
Die Pilze
}

\section{Deutschlands, Oesterreichs u. d. Schweiz}

mit Berïcksichtigung der übrigen Länder Europas.

\author{
X. Abteilung: \\ Myxogasteres \\ (Myxomycetes, Mycetozoa)
}

mit 182 in den Text gedruckten Abbildungen

bearbeitet von

Professor Dr. Hans Schinz.

Leipzig.

Akademische Verlagsgesellschaft m. b. H. 1920. 


\section{Alle Rechte vorbehalten.}

$\overline{ }$ 


\section{Vorwort.}

Die nachfolgende Bearbeitung der deutschen, österreichischen und schweizerischen Schleimpilze ist weit über den sonst der Rabenhorst'schen Kryptogamenflora gezogenen Rahmen hinausgewachsen und ist $\mathrm{zu}$ einer Monographie, umfassend alle zurzeit beschriebenen Gattungen und Arten, geworden. Wie notwendig diese Erweiterung ist, das zeigen gerade die floristischen Studien der letzten Jahre. Die Anregungen, die von der unübertroffenen Monographie Arthur Lister's und seiner Tochter ausgegangen sind und noch immer ausgehen, haben den Anstoß gegeben, daß in allen Erdteilen diesen kleinen Organismen erneute Aufmerksamkeit geschenkt wurde und immer mehr und mehr befestigt sich die Überzeugung, daß sicherlich die überwiegende Mehrzahl der Myxogasteres, wenn nicht gar alle, im wahren Sinne des Wortes Ubiquisten sind und wenu sich heute noch diese oder jene Art anscheinend eines begrenzten Areals erfreut, so dürfen wir doch mit allergrößter Sicherheit damit rechnen, daß früher oder später auch dieses Areal sich erweitern wird, nicht auf Grund von Wanderungen, sondern vielmehr einzig und allein als Resultat erweiterter Kenntnisse. Das ist verständlich, stehen doch einzelne der Vertreter (z. B. Barbeyella) beinahe auf der Grenze der makroskopischen Wahrnehmbarkeit.

Nicht minder bedeutungsvoll sind die entwicklungsgeschichtlichen Studien, die in den sechziger Jahren des verflossenen Jahrhunderts hauptsächlich von A. de Bary, später von E. Strasburger gefördert und die in neuerer Zeit in so ausgezeichneter Weise von E. Jahn wieder aufgenommen worden sind. Beide Forschungsrichtungen gehen Hand in Hand und immer mehr und mehr bricht sich die Erkenntnis Bahn, daß ein weiterer Ausbau der phylogenetischen Klassifikation der Schleimpilze der Resultate ganz besonders dieser Studien nicht wird entraten können. 
Ich habe in der vorliegenden Monographie die zurzeit aus Deutschland, Österreich und der Schweiz bekannten Arten insofern etwas anders behandelt als die in obgenannten Gebieten vorläufig nur vermutet als vorkommend, indem ich die Diagnosen let^terer, abgekürzt, in den Schlüssel verwiesen habe. Die Materie ist mir aber, möchte ich fast sagen, im Laufe der Jahre gewissermaßen aus den Händen entglitten und eine ganze Reile von Arten, die zurzeit der Inangriffuahme noch unbekannt gewesen sind, gehören heute zu den unbeanstandeten Bürgern.

Der „Schlüssel“ weicht stark von der Schlüsselbehandlung in den übrigen bis jetzt erschienenen Bänden der Rabenhorst'schen Kryptogamenflora ab, doch glaube ich nicht, daß dies der Bearbeitung zum Schaden gereichen wird, da dadurch entschieden das Bestimmen erleichtert wird und dieses Ziel erschien mir, ob mit Recht oder Unrecht mögen Berufenere entscheiden, mindestens erstrebenswert.

Der „Nachtrag“ ist viel umfangreicher geworden als ich mir anfangs vorgestellt habe und als ich es wünschte. Er hätte sich vermeiden lassen, wenn die einzelnen Lieferungen - wie dies der Wunsch des Herausgebers der Rabenhorst'schen Kryptogamenflora gewesen ist - rascher aufeinander gefolgt wären. Daß dies nicht geschah, gehört ins Schuldkonto des Unterzeichnenden, der durch anderweitige Arbeiten, namentlich durch seine berufliche Beanspruchung nur allzuoft die übernommene Bearbeitung aus der Hand legen mußte. In der $Z$ wischenzeit ist aber durch Fräulein G. Lister in England, Dr. E. Jahn in Deutschland, Charles Meylan in der Schweiz eifrig publiziert worden und ich habe nun gesucht, im Nachtrage auch noch die Resultate der allerletzten Publikationen zu berücksichtigen ohne die vorliegende Bearbeitung allzusehr zu belasten.

Wer sich heute mit den Schleimpilzen beschäftigen will, der kann und darf nicht abstellen auf die Lister'sche Monographie, noch weniger auf die vorliegende Bearbeitung, er wird vielmehr die zahlreichen Einzelpublikationen von Arthur Lister und Tochter Gulielma im Journ. of Botany, von E. Jahn, von Ch. Meylan mit zu Rate zu ziehen haben, denn sie bergen eime Fülle wichtiger Beobachtungen aus älterer und neuerer Zeit.

Ich habe keineswegs gesucht, etwas "Besseres" als die Listersche Monographie zu liefern, aus dem höchst einfachen Grunde, 
weil meines Erachtens dies unmöglich gewesen wäre. An mehr als einer Stelle hebe ich hervor, daß meine eigene Bearbeitung zum Teil eine Anlehunng an die Lister'schen Beschreibungen sei, und wie wäre dies auch anders möglich, da doch die Diagnosen Lister's Muster von Genauigkeit und Präzision sind.

So bin ich der Familie Lister in vielfacher Hinsicht zu großem Dank verpflichtet. Durch Hrn. Arthur Lister und seine Tochter bin ich in das Studium der Schleimpilze eingeführt worden, von ihnen habe ich eine erste kleine Sammlung zu Vergleichszwecken erhalten, sie haben mir immer und immer wieder zweifelhafte Fundstïcke bestimmt und Bestimmungen revidiert, unermüdlich Aufschluf gegeben wenn ich von $Z$ weifeln geplagt, um ihren Rat gebeten habe. Diesem Dank auch an dieser Stelle Ausdruck zu verleihen, ist mir mehr als nur Bedürfnis.

Zïrich, Text und Nachträge abgeschlossen am 21. Oktober 1919.

\section{Hans Schinz.}




\section{Druckfehlerverzeichnis.}

S. 17. In der Figurenerklärung lies chrysospora anstatt chryrospora.

S. 54. In der Erklärung der Figur 24 lies pyriformis anstatt pyriaeformis.

S. 87. In der Figurenerklärung ist zu Badhamia foliicola der Autor Lister nachzutragen.

S. 204. Der Autor von Leptoderma iridescens (Figur 77) ist Lister, nicht G. Lister.

S. 269 (unter 5). Anstatt dictyospora lies dictyosporum.

S. 275. In der Figurenerklärung lies Sowerby anstatt Sowbery.

S. 312, 3 tes Synonym. Lies arachnoidea anstatt aranchnoidea.

S. 316. In der Überschrift zu Fig. 136 ist die Klammer beim Autornamen Bull. zu streichen.

S. 359. Unter H. leiotricha ist in "Synonyme" das Schluß-e zu streichen.

S. 361. Der Autor zu Hemitrichia stipitata heißt Macbride und nicht Macbridc.

S. 365. Die Seitenzahl 265 ist zu corrigieren.

S. 367. In der Figurenerklärung lies chrysospora anstatt chryrospora.

S. 374. Anstatt C. denudata lies A. denudata.

S. 394. Der Autor von Cornuvia dictyocarpa (Synonyme) ist Krupa. 


\section{Inhaltsübersicht.}

Vorwort

Druckfehlerverzeichnis

Seite

Geschichtliches

Literatur (Klassifikation und Allgemeines)

Allgemeine Charakteristik der Myxogasteres

Literatur (Bau der Sporen, deren Keimung und Keimungsbedingungen)

Myxomonaden und Myxoamöben

Literatur (Myxomonaden und Myхoamöben)

Plasmodium

Literatur (Plasmodium)

Fruchtkörperbildung

Literatur (A. Reduktionsteilung, Fruchtkörperbildıug, Sporen- und Capillitiumbildung; B. Bastardierung, Dimorphismus, Generationswechsel)

Ruhezustände

Literatur (Ruhezustände)

Vorkommen und Verbreitung

Kultur

Literatur (Kultur der Myxogasteres)

Fixierung, Färbung, Präparation

Literatur (A. Fixierung, Färbung ete.; B. Dauerpräparate) 76

Systematischer Teil

Klasse Myxogasteres Fries em. Schröter

I. Unterklasse Exosporeae Rost.

Familie Ceratiomyxaceae Schröter $\quad 80$

Ceratiomyxa Schröter $\quad 80$

II. Unterklasse Endosporeae Rost.

Reihe Amaurosporales Lister

Unterreihe Calcarineae Rost.

Familie Physaraceae Rost.

83,86

Badhamia Berkeley

Physarum Pers.

Fuligo Haller

$86,88,152$

Erionema Penzig

$86,88,158$

Trichamphora Jungh.

$87,89,159$

Physarella Peck

$87,89,161$ 
Cienkowskia Rost.

$86,90,163$

Craterium Treutepohl

$87,90,165$

Leocarpus Link

$87,91,170$

Diderma Pers.

$87,91,172$

Colloderma G. Lister

$87,91,193$

Physarina Höhnel

$87,92,195$

Diachaea Fries

Familie Didymiaceae Rost. pr. p.

87. 92,196

84,202

Didymium Schrader

Mncilago Adanson

Lepidoderma de Bary

Leptoderma Lister

Unterreihe Aumaurochaetineae Rost.

Familie Stemonitaceae

Stemonitis Gleditsch

Comatricha Preuß

Enerthenema Bowman

Lamproderma Rost.

Clastoderma Blỵtt

Echinostelium de Bary

Familie Amaurochaetaceae Lister

Amaurochaete Rost.

Brefeldia Rost.

Reilie Lamprosporales Lister

Unterreihe Anemineae Rost. em. Lister

Familie Heterodermaceae Rost em. Lister

Lindbladia Fr.

Cribraria Pers.

Dictydium Schrader pr. p.

Familie Liceaceae Rost. em. Lister

Licea Schrader

Orcadella Wingate

Hymenolobus Zukal

202, 203, 204

203,222

$203,204,224$

203, 204, 227

81,229

84,229

$229,230,232$

230,242

$230,231,254$

$229,230,231,258$

$229,232,270$

$229,232,271$

$84,27 \%$

273,274

273,276

84,277

84,277

84,278

278,279

$278,279,282$

$278,279,300$

84, 305

305,306

305,309

441

81,310

Familie Tubulinaceae Lister

Tubifera Gmelin

310,311

Alwisia Berkeley et Broome

Familie Reticulariaceae Rost. em. Lister

Dictydiaethalium Rost.

Enteridium Ehreuberg

11,314

81,315

315,317

Reticularia Bulliard

Liceopsis Torrend

Familie Lycogalaceae de Bary

Lycogala Adanson

$315,316,318$

$315,317,320$

$315,317,322$

85,323

323

Unterreihe Calonemineae Rost.

85,328

Familie Trichiacea Rost. en. Lister

85,329

Trichia Haller

329,331

Oligonema Post.

329,352 
Calonema Morgan

$329,331,354$

Hemitrichia Rost.

$329,331,356$

Cornuvia Rost.

$329,331,367$

Familie Arcyriaceae Rost. em. Lister

85,368

- Arcyria Wiggers

369,370

Lachnobolus Fr.

369,389

Perichaena Fr.

369,390

85,399

349,401

Margarita Lister

Dianema Rex

$399,400,403$

Prototrichia Rost.

Listerella Jahn

$399,400,407$

$399,400,408$

Gattung noch unbestimmter Stellung

Barbeyella Meylan

410

413

Anhang: Nachträge und Berichtigungeu

Verzeichnis der Abbildungen

Exsikkaten-Werke

Erscheinungszeit der einzelnen Lieferungen

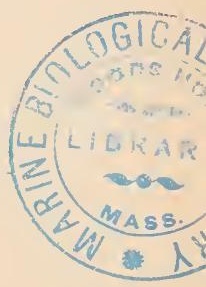





\section{Myxogasteres}

(Myxomycetes, Mycetozoa)

oder Schleimpilze.

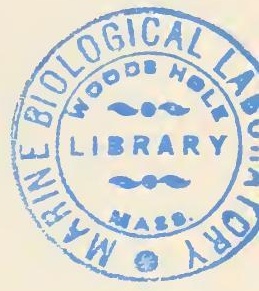

\section{Geschichtliches.}

"In der Geschichte der systematischen Erforschung der Myxogasteres oder Schleimpilzel) bezeichnet", wie W. Zopf in seiner fuir die damalige Zeit vortrefflichen Bearbeitung der "Pilztiere oder Schleimpilze" ausführt," das Erscheinen von Elias M. Fries's Systema mycologicum einen entscheidenden Wendepunkt. Bis dahin hatten die Botaniker die hier in Betracht kommenden Organismen den verschiedensten Pilzgruppen (teils den Bauchpilzen, teils den Hymenomyceten, teils den Discomyceten, teils den mucorartigen Pilzen) zugeordnet,

1) Dr. Georg Winter, der leider so früh verstorbene erste Autor der Pilze der Rabeuhorst'schen Kryptogamen-Flora, der seinerzeit als Dozent der Botanik in Zürich den Schreiber dieses in die Aufangsgründe der Kryptogamenkunde eingeführt hat, hatte in seinem im 1. Band (1884) dieses Florenwerkes, pag. 32 entworfenen Programme der Bearbeitungen der verschiedenen Kryptogamengruppen, den Schleimpilzen eine ganz andere Stellung als die gegenwärtige zugewiesen. Damals wurden die Schleimpilze noch aufgefaßt als echte Pilze, angehörend der sogenamuten geschlechtlichen oder sexuellen Reihe derselben, nmfassend die Klassen der

\section{Myxomycetes,}

Zygomycetes $u$.

Oomycetes.

An äuBern Verhältnissen lag es dam, in erster Linie am Hinscheiden de Bary's, der die Bearbeitung der Schleimpilze zugesagt hatte und für den sich daun in der Folge kein Stellvertreter finden ließ, daß diese Gruppe nicht an programmgemäß zugedachter Stelle denı Gesamtaufbau der Fungi eingefügt werdeu bonnte.

Inzwischen haben dann aber die Ansichteu bezüglich der systematischen Stellung der Myxogasteres eine gründliche Wandlung erfahren; keinem Systematiker fällt es heute mehr ein, ihren AnschluB in der Abteilung der echten Pilze suchen zu wollen und man streitet sich zurzeit höchsteus noch darum, ob sich der Botaniker oder der Zoologe ihrer mit größerm Recht anzunehmen habe. 
sie hatten außerdem meist nur die fertigen „Früchte“ derselben kennen gelernt und die regetativen Zustände (Plasmodien) für selbständige Formen gehalten, die sie demnach auch generisch und sperifisch unterschieden".

Allerdings war schon dreifig Jahre rordem H. A. Schra der zu der Überzengung gekommen, daß diese sonderbaren Lebewesen durchans verschieden ron allem seien, was sonst unter der Bezeichnung eines Pilzes damals ging; er hatte bereits sehr richtig Gattungen wie Didymium, Licea etc. abgegrenzt, hatte dieser seiner Überzengung in seinen $\mathrm{N}$ ova Plantarum Genera Ausdruck rerliehen, aber es unterlassen. dieser besonderen Gruppe einen Namen zu verleihen. Dies ist dann, wie erwähnt, von Elias Fries nachgeholt worden, indem dieser die bis dahin bekannt gewordenen Gattungen und Arten aus ihren unnatürlichen Verbänden loslöste und sie zu einer besonderen Gruppe der Myx ogastres rereinigte. Wohl war es auch ihm aufgefallen, daß diese von uns heute als Schleimpilze bezeichneten Organismen eine ganze Reihe von Eigentümlichkeiten aufweisen, die den übrigen Pilzen abgehen, er unterließ es aber, gleich den weitern Schritt, den einer völligen Scheidung von den Pilzen zu wagen, und beließ sie vielmehr in deren Kreis, sie mit den Trichogastres vereinigend zur Ordnung der Gastromycetes. Vier Jahre später befaßten sich H. F. Link und C. F. Wallroth mit derselben Gruppe. Ersterer erkannte ihre unzweifelhafte Selbständigkeit — den übrigen "Pilzen" gegenüber gestellt und schlug für sie die Bezeichnung Myxomycetes vor, Wallroth gelangte zu demselben Schlusse, brachte aber in die Nomenklatur insofern eine Konfusion, als er sich das Epitheton Myxomycetes offenbar an Stelle der Bezeichnung Gastromycetes placiert dachte. Einen gewaltigen Fortschritt in der Erforschung der Schleimpilze zeitigt dann das Jahr 1858. An die Stelle der vorwiegend makroskopischen Betrachtungsweise tritt die mikroskopische Untersuchung und es ist ein glïcklicher Umstand, daß es kein Geringerer als de Bary war, der nun sein Interesse den Schleimpilzen zuwandte und, ansgerüstet mit den notwendigen Hilfsmitteln, den Entwicklungszyklus der Schleimpilze untersuchte und als Frucht dieser Arbeiten eine Reihe sorgfältig vorbereiteter umfassender Studien publizierte. 
De Bary vertrat die Ansicht. daß die Schleimpilze nicht nur eine von den Pilzen durchaus verschiedene Gruppe darstellten, sondern daß man auch, wenn man deren Stellung im System zu bestimmen suche, unter den dermalen bekannten unzweifelhaften Pflanzen keine anderen Organismen finden könne, mit welchen sie eine nähere Verwandtschaft zeigten. „Ich habe”. schreibt de Bary 1864. „diese Frage früher dahin beantwortet. daß die Myxomyceten oder Mycetozoen aus dem Pflanzenreiche ins Tierreich zu verweisen seien und finde in dem vielfachen Widerspruch, welchen diese Ansicht erfahren hat, keinen zureichenden Grund, von derselben abzugehen " und 1884 wiederholt er in seiner letzten eingehenderen Publikation über die Pilze dieses Bekenntnis mit den Worten: .. aus allen diesen, zu verschiedenen Zeiten nach dem Stande der Kenntnisse verschieden klar entwickelten Gründen habe ich seit 1858 die Myxomyceten als Mycetozoen außerhalb des Pflanzenreichs gestellt und halte diese Stellung auch heute noch für die bestbegründete."

De Bary ist es also gewesen, der die Abteilung der Mycetozoen schuf und dieser die beiden Unterabteilungen der Myxomyceten und der Acrasieen unterordnete. Er hielt, entgegen der gegenwärtigen Anschauung, die beiden Unterabteilungen als ,augenscheinlich mit einander nahe verwandt". Das trennende Moment liegt, und dies ist hente für uns für die Trennung von Bedeutung, im sogenannten Plasmodium, das bei den II yxomyceten ein echtes Fusionsplasmodium (entstanden durch Verschmelzung zahlreicher Schwärmer oder Amoeben) ist, wogegen im Aggregationsplasmodium der Acrasieen die zusammengetretenen Schwärmer oder Amoeben ihre Individualität beibehalten.

De B ary's hervorragender Schïler Rostafinski, der auf Anregung seines Lehrers den Versuch einer Klassifikation unternahm, akzeptierte de Bary's Bezeichnung der Abteilung, verschob aber inkorrekterweise insofern deren Anwendung, als er nun, unter Abtrennung der Acrasieen, die von de Bary als Myxomyceten eingeführte Unterabteilung zum Range einer Abteilung oder Klasse erhob und auf sie allein nun das Epitheton Mycetozoa anwandte.

Von den drei Bezeichnungen Myxogastres, Myxomycetes 
und Mycetozoa hat nun unzweifelhaft die erstere die Priorität, obschon sie zur damaligen Zeit beschränkt gewesen ist auf die sogenannten endosporen Schleimpilze; gar keine Notwendigkeit liegt ror, dem von de Bary vorgeschlagenen Namen Myceto zoa den Vorzug zu geben, umsoweniger, als de Bary selbst darunter nicht blob unsere Schleimpilze im heutigen Umfange verstanden wissen wollte und es könnte sich nur noch fragen, ob nicht vielleicht die ganze Gruppe als die der Myxomyceten Link em. de Bary bezeichnet werden sollte. Die Fries'sche Umgrenzung der Myxogastres ist nun eine für die damalige Zeit so scharfe, daß man nicht im geringsten $Z$ weifel über deren Charakter sein kann und der Umstand, daß der seine Sporen exogen bildende Schleimpilz Ceratiomyxa von ihm noch nicht $\mathrm{zu}$ dieser Abteilung gestellt worden ist, kann uns nicht zwingen, der Bezeichnung Myxomycetes gegenüber der ältern Mycogastres oder Myxogasteres den Vorzug zu geben. Mit dieser Auffassung finden wir uns auch in Einklang mit Engler's Syllabus der Pflanzenfamilien (1909). - Rostafinski’s Dissertation (1873) ist dann rasch (1875) dessen Monographie der Mycetozoen gefolgt, bedanerlicherweise in polnischer Sprache; sie ist daher für viele Interessenten ein verschlossenes Buch geblieben, obschon M. C. Cooke 1877 eine englische Übersetzung unter dem Titel „The Myxomycetes of Great Britain" geliefert hat, sich aber dabei, wie der Titel ja schon andeutet, auf die in Groß-Britannien vorkommenden Vertreter beschränkte.

Die Rostafinski'sche Monographie als Grundlage, sind dann einerseits im Laufe der folgenden 20 Jahre eine Reihe ron Modifikationen an dessen System vorgenommen und sind anderseits wertvolle und bedentsame „Floren“, die größere Gebiete beschlagen, publiziert worden, die alle wertvolle Bausteine für die 1895 erschienene Monographie der Mycetozoen ron Arthur Lister, der eigentlichen Standart-Monographie, wurden. Aus der Flucht der Erscheinungen dieser Art seien genannt von Autoren (vergl. das Literaturverzeichnis zu diesem Abschnitt) die Namen M. Raciborski, W. Zopf, J. Schröter, C. Raunkiaer, G. Massee, A. P. Morgan, Macbride, L. Celakowsky.

ArthurLister's "A Monograph of the Mycetozoa", bescheiden bezeichnet als "beeing a descriptive catalogue 
of the species in the Herbarium of the British Museum", ist viel mehr als dies, es ist eine gründliche Sichtung aller bis dahin beschriebenen Gattungen und Arten, aller aufgestellten Systeme, vermehrt durch zahllose Eigenbeobachtungen und, was namentlich auch not tat, eine Feststellung alles dessen, was im Laufe der vorangegangenen Jahre die Cytologie, dieser neue Forschungszweig, in Bezug auf die Schleimpilze, hinsichtlich deren Entwicklungszyklus zu Tage gefördert hatte.

Lister charakterisiert die Schleimpilze, er nennt sie, wie aus dem Titel seines Werkes hervorgeht, Mycetozoa, wie folgt: „es sind Organismen, die mit Zellwand versehene Sporen erzeugen, aus denen sich bei der Keimung amoeboide Schwärmzellen entwickeln, die sehr rasch eine Geissel erhalten, sich durch Teilung vermehren und sich sodann zu Plasmodien vereinigen, die rhytmische Plasmaströmungen aufweisen. Aus den Plasmodien gehen in der Folge "Früchte" hervor, die aus Stützvorrichtungen und Sporen bestehen und die bei den Endosporeen den Charakter von Sporangien haben, die in ihrem Innern Sporen und (meist) Faserfäden (Capillitium) ausbilden, während bei den Exosporeen die Früchte an ihrer Oberfläche zahlreiche Sporen tragenden Sporophoren entsprechen."

Diese präzise Charakteristik ist eine äußerst glückliche und kann, allermindestens in den Hauptpunkten, auch heute noch aufrecht erhalten werden.

Recht schwierig gestaltet sich immer noch die Beantwortung der Frage nach der Stellung der in dieser Weise umschriebenen Gruppe der Schleimpilze innerhalb des Reiches der belebten Organismen: soll ihr eine Stellung im Pflanzenreich oder eine solche im Tierreich zugewiesen werden? Für die erstere Auffassung spricht der Bau der an die Pilze erinnernden Fortpflanzungskörper, der Sporangien und Sporophoren, für ihre tierische Natur der Bau der beweglichen Entwicklungszustände, der Plasmodien, namentlich aber, und dies ist entschieden von Bedeutung, daß wir im Stande sind, den Myxogasteres im Tierreich mindestens vermutungsweise eine bestimmte Stellung anzuweisen, unverkennbare und mannigfache Beziehungen zu andern, auf niedriger Stufe stehenden tierischen Organismen aufzudecken, wogegen die Schleimpilze im weitern Sinne im natürlichen System 
der Pflanzen eine völlig isolierte, jedes Anschlusses nach oben und unten entbehrende Stellung einnehmen.

Solange die Protistensystematik an der Anschaunng festhielt, daß der Besitz eines nackten Protoplasmaleibes unbedingt ein primitives Merkmal sein müsse, war man gezwungen in den Schleimpilzen Vertreter einer sehr tiefen Organisationsstufe zu sehen. Nun zeigen aber gerade die My ogasteres alle Kennzeichen einer über der Flagellatengruppe, von der die Algenstämme abzweigen, stehende Organisationshöhe, und Botaniker wie Zoologen suchen daher auch zurzeit unter den Rhizopoden den Anschluß für die Schleimpilze und zwar verweist $\mathbf{J}$ ahn, zurzeit der erfolgreichste Erforscher unserer Gruppe auf cytologischem Gebiete, auf die höchsten Rhizopoden, die Heliozoen, Thekamoeben und Foraminiferen. Maßgebend für diese Anffassung sind hauptsächlich die Resultate der Zellenforschung der letzten Jahre, die UntersuchungenSchaudinn's und H ertwig's über Actinophrys sol bezw. Actinosphaerium. Wir wissen heute, daß bei diesen die Kerne fast während des ganzen Lebens diploid sind und dab der haploide Zustand nur wenige Kernteilungen überdauert. Wir werden an anderer Stelle, fußend auf den grundlegenden Untersuchungen $J$ ahn's, zeigen, daß sich die Myxogasteres ähnlich verhalten.

So hat denn Doflein auch in seinem klassischen .. Lehrbuch der Protozoenkunde" die Myxogasteres der Klasse der Rhizopoden als 5te Ordnung der Mycetozoa der Ordnung der Radiolarien angereiht, sie einteilend in

\section{Unterordnung: Acrasiae van Tieghem \\ 2. Unterordnung: Phytomyxinae Schröter \\ 3. Unterordnung: Myxogasteres de Bary, Mycetozoa} s. str. oder Myxomycetes s. str.

Ähnlich klassifiziert sie auch, beiläufig bemerkt, Engler; Abteilung Phytosarcodina, Myxothallophyta:

Myxomycetes:

1. Klasse: Acrasiales.

2. Klasse: Plasmodio phorales.

3. Klasse: Myxogasteres. 


\section{Literat no}

Klassifikation und Allgemeines.

1805. Albertini et Schweinitz. Conspectus Fungorum. Leipzig.

1859. Bail, Th. Über die Myxogasteres Fr. (Myxomycetes Wallroth). Verh. Zool.-Bot. Ges. Wien, IX.

1858. de Bary, A. Über die Myxomyceten. Bot. Zeitung, XVI.

1859. - Die Mycetozoen in Zeitschr. f. wissenseh. Zoologie, Band X.

1862. - Die nenern Arbeiten über die Schleimpilze und ihre Stellung im System. Flora., N. R., XX.

1864. - Die Mycetozoen (Schleimpilze), zweite Auflage. Leipzig.

1866. - Morphologie und Physiologie der Pilze, Flechten und Myxomyceten. Leipzig.

1884. - Vergleichende Morphologie und Biologie dar Pilze, Mycetozoen und Bacterien. Leipzig.

1888. Berlese, A. N. Myxomyceteae Wallr, in Saceardo Sylloge Fungorum, VII, VIII, (1889), vergl. auch Suppl. X (1892), (1895) und XV (1901).

1809. Bulliard et Vetenat. Histoire des Champignons de la France. Paris. 1869. Brefeld, 0. Dictyostelium mucoroides in Abh. Senckenb. Naturf. Ges. 1884. - Untersuchungen aus dem Gesantgeb. der Mykologie, VI.

1893. Celakorsky, L. Die Myxomyceten Böhinens. Arehiv der Naturw. Landesdnrchforschung von Böhmen. VII. (Bot. Abt.) Nr. 45.

1877. Cooke, M. C. Myxomycetes of Great Britain. London,

1911. Doflein, F. Lehrbuch der Protozoenkunde, 3. Aufl. Jena.

1909. Engler, A. Syllabus der Ptlanzenfamilien, 6. Aufl. Berliu.

1829. Fries, Elias M. Systema mycologicum. Greifswald.

1895. Fry, Sir Edward and Fry, Agnes. The Iycetozoa. London.

1907. Hertwig, Rich. Lehrbuch der Zoologie. 8. Aufl. Jena.

1910. Hilton, A. E. The life-phases of Mycetozoa. Jonru. Quekett micr. Club, 2, XI.

1899. Jahn, E. Der Stand unserer Kenutnisse über die Schleimpilze. Naturwissenschaftl. Rundschau, XVI.

1911. - Myxomycetenstudien. 8. Der Sexualakt. Ber. Deutsch. Bot. Ges., XXIX.

1833. Liık, H. F. in C. L. Willdenow. Grmudriss der Kräuterkunde, Teil IV. Berlin.

1912. Lindau, Gustav. Die mikroskopisehen Pilze (Krygtogamenflora für Anfänger, Band II). Berlin.

1895. Lister, Arthmr. A monograph of the Mycetozoa. London.

1905. - Guide to the British Mycetozoa. Second edition. London.

1906. - Presidential Address. Trans. Brit. Mycol. Soc.

1907. - Synopsis of de orders, genera and species of Mycetozoa. Journ. of Bot., XLV.

1909. - Guide to the British Sycetozoa. Third edition, London.

1911. - A monograph of the Mycetozoa. Second edit, revised by G. Lister. Loudon. 
1909. Lister, J. J. Mycetozoa, Chlamydomyxa, and Labyrinthula in Ray Lankester, A Treatise on Zoology. Vol. I, Fasc. 1. London.

1907. Lotsy, J. P. Vorträge über botanische Stammesgeschichte, Band 1. Jena.

1899. Macbride, Th. H. The North American Slime-Moulds. New York.

1899. Martin, Ch. Ed. Clef dichotomique des Myxomycètes. Bull. Soc. Bot. Genève.

1892. Massee, G, A. monograph of the Myxogastres. London.

1909. Migula, Walter. Myxogasteres in Thomé's Flora vou Deutschland, Österreich und der Schweiz. Pilze: Lieferung 66, 67, 68. Gera.

1892-95. Morgan, A. P. Myxomycetes of the Miami Valley. Cincinnati.

1898. Olive, E. V. Affirities of the Mycetozoa. Proc. Indiana Acad. Sci.

1910. Pavillard, J. Etat actuel de la Protistologie végétale. Progressus Rei Botanicae, III, 3.

1884. Raciborski, M. Myxomycetes Agri Krakov. Genera, Species et Varietates novae. Rozpr. Spraw. Pos. Wyaz. Math. - Przyr. XII.

1888. Raunkiaer, C. Myxomycetes Daniae eller Dannmarks Slimsvampe tilli gemed et Forsog till en Myxomyceterues Systematik. Bot. Tidskr. XVII.

1902. Rosen, F. Die systematische Stellung der Spalt- und Schleimpilze, Jahresber. schles. Ges. f. vaterländ. Kultur, IIb, Abt. LXXVIII.

1873. Rostafinski, J. Th. Versuch eines Systems der Mycetozoen. Diss. Straßburg.

1875. -- Sluzowce Monografia. Paryz.

1873. Roze, E. Des Myxomycètes et leur place dans le système. Bull. Soc. Bot. France, XX.

1906. Schinz, Hans. Die Myxomyceten oder Schleimpilze der Schweiz. Mitteil. Naturw. Ges. Winterthur, V1.

1896. Schilbersky, K. Neuere Beiträge zur Morphologie und Systematik der Myxomyceten. Bot. Centralbl., LXVI, No. 3.

1899. Schmidt, F. Schlempilze. Die Natur, N. F., XXV.

1797. Schrader, H. A. Nova Genera Plantarum. Leipzig.

1885. Schröter, J. Cohn, Kryptogameuflora von Schlesien. Pilze III, 1.

1889. - Myxomyceten in Engler und Prantl Natürl. Pflanzenfam. I, 1.

1833. Secretan, L. Iycographie Suisse. Lansanne.

1902. Strasburger, E. Das botanische Praktikum. 4. Aufl. Jena.

1911. Strasburger, Jost, Schenck, Karsten. Lehrbuch der Botanik. 11. Aufl. Jena.

1912. Sturgis, W. C. A guide to the Botanical Literature of the Myxomycetes from 1875-1912. Colorado College Publ. Sci., Ser. X11. Nr. 11.

1907. Torrend, C. Les Myxomycètes, étude des espèces connues jusqu'ici. Broteria, VI, 2.

1880. Van Tieghem, P. Sur quelques Myxomyeètes à plasmode aggrégé. Bull. Soc. Bot. France, XXVII.

1911. Vouk, V. Über den Generationswechsel bei Myxomyceten. Oesterr. Bot. 'Zeitschr., LXI.

1907. Vuillemin, Paul. Les bases actuelles de la systématique en mycologie. Progressus Rei Botanicae, II, 1. 
1833. Wallroth, C. F. Flora Cryptogamica Germanicae., II. Norimbergae. 1911. Wettstein, Rich. Handbuch der Systematischen Botanik. 2. Aufl. Leipzig und Wien

1863. Wigand, A. Zur Morphologie und Systematik der Gattungeu Trichia und Arcyria. Pringsheins Jahrb. Wiss. Bot., III.

1900. Zeitler, R. Schleimpilze oder Pilztiere, Myxomycetes resp. Mycetozoa. Die Natur, N. F. XXVI.

1885. Zopf, W. Die Pilztiere oder Schleimpilze. Schenk, Handbuch der Botanik, III, 2.

\section{Allgemeine Charakteristik der Myxogasteres.}

Die jungen Schleimpilze stellen sich als nackte, einkernige, unter der Grenze der makroskopischen Wahrnehmbarkeit stehende, nach der Art der Amoeben sich bewegende Protoplasmamassen, Myxoamoeben, dar, die saprophytisch, zum Teil holozoisch von faulenden organischen Substanzen leben. In diesem Amoebenzustand können Teilungen vorkommen. Bei den einen Formen

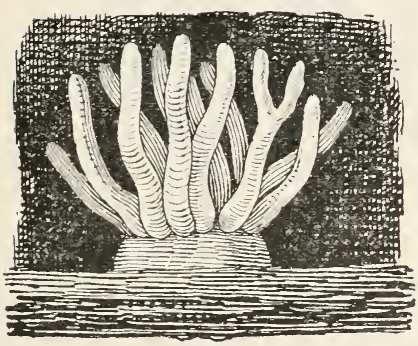

Fig. 1.

Ceratiomysa fruticulosa (Muell.) Macbr. Sporophore - $20 \times-$ Nach Famintzin und Woronin.

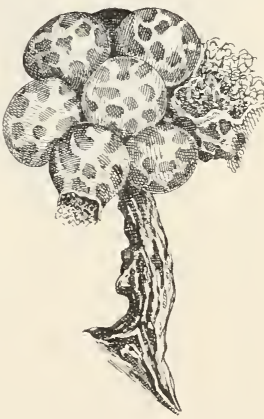

Fig. 2.

Trichia Botrytis. Pers. Sporangien. - $15 \times-$ Nach Lister.

gehen die aus den Sporen herausgekrochenen Amoeben (Fig. 8) sehr rasch in den Flagellatenzustand über. bei andern wiederum vollzieht sich diese direkte Umwandlung erst, nachdem der Amoebenzustand einige Zeit angedauert hat. Die in dieser Weise entstandenen Myxomonaden oder Myxoflagellaten be- 
wegen sich mittelst einer Geißel, sie teilen und ernähren sich gleich den Myxoamoeben, fressen vielfach Bakterien und organischen Detritus, können gleich den Myxoamoeben ihre Gestalt verändern und führen positive und negative chemo-. und positive heliotactische Reizbewegungen aus. Nach längerer oder kürzerer Zeit verlieren diese einkernigen Myxomonaden ihre Geißel wiederum $u m$ sich neuerdings in Mrxoamoeben umzuwandeln, in welchem Zustande sie sich weiterhin, gleich den Myxomonaden durch Teilung zu vermehren vermögen. Sie kopulieren sodann paarweise und bilden $/ y$ goten, die durch fortgesetzte Kernteilungen

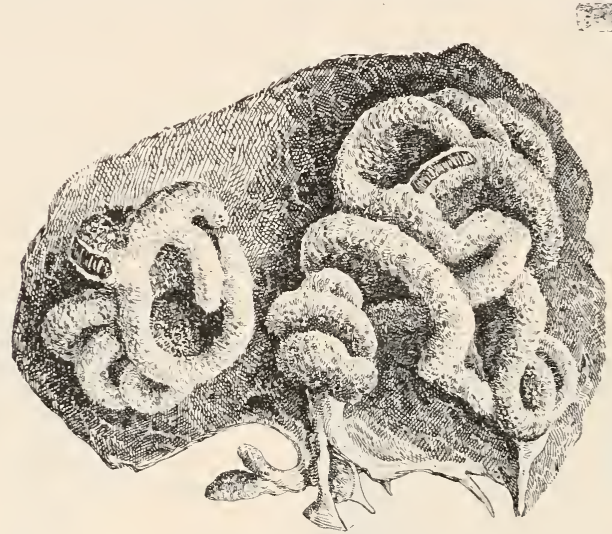

Fig, 3.

Physarum gyrosum Fost. Wurmförmige, einem Kiudenstück aufsitzende sporangien. $-\times 20-$ Nach Lister.

und durch gegenseitige T'erschmelzungen (Plasmogamie) vielkernig werden und durch reichliche Nahrungsaufnahme bis zu $\mathbf{1}^{1 / 2}$ qm großen (Brefeldia maxima) Plasmodien (Fusionsplasmodium) heranwachsen. Die Plasmodien bewegen sich durch Aus- und Einziehen von Rhizopodien (Plasmafortsätzen) und lassen sehr lebhafte Plasmaströmungen erkennen. Sie sind sehr häufig in fïr die einzelnen Arten charakteristischer Weise gefärbt, bald ralımweiß, bald gelb, rot, grün etc. Als Stoffwechselprodukt ist Glykogen erkannt worden. Bei Nahrungsentzug und andern uns unbekannten reizauslösenden, durch Temperatur, 
Feuchtigkeit u. s. w. bedingten. zum Teil wohl auch innern Faktoren, schreiten die Plasmodien zur Sporangien-(Fig. 2.) oder (bei den exosporen Schleimpilzen) zur sporophor-Bildung. (Fig. 1.) Die bald gestielten, bald der Unterlage (Hypothallus) ungestielt aufsitzenden, kugeligen, birn- oder kreiselförmigen, walzlichen oder wurmförmigen (Fig. 3) Sporangien haben meist die Größe eines Stecknadelknopfes und nehmen zur Zeit der Sporenreife eine für jede Art charakteristische Färbung an, die durchaus nichts zu tun hat mit der bereits erwähnten Färbung

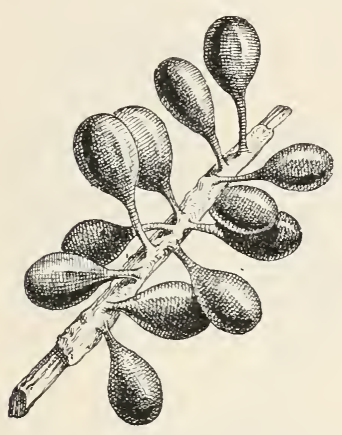

Fig. 4.

Leocarpus fragilis (Dicks.) Rost. Sporangien, einem Zweigstück aufsitzend. - $7 \times-$ Nach Massee.

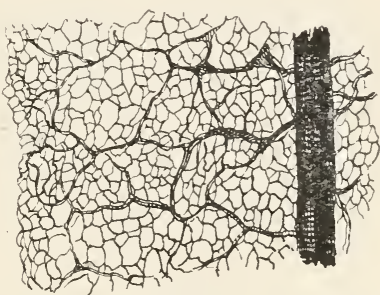

Fig. 5.

Stemonitis flavogenita Jahn var. Smithii (Macbr.) Lister. Ausschnitt aus dem Capillitium mit Columella. - $180 \times$ - Nach Lister.

der Plasmodien. Der Sporenbildung geht eine Reduktionsteilung voraus, indem die Plasmodienkerne sich teilen und hierbei ihre Chromosomenzahl auf die Hälfte der Chromosomenzahl der Zygoten (entstanden durch Kopulation der Gameten [Myxoamoeben]) reduzieren. Die Sporangiumwand (Peridium) zeigt \%. T. Cellulosereaktion; sie umschließt das Sporangiuminnere, bestehend aus zahlreichen einkernigen Sporen (Fig. 7) und dem (gewissen Gattungen auch mangelnden) Capillitium (Fig. 5, Fig. 6), das entweder aus zarten, freien Fasern oder aus einem Netzwerk anastomosierender Fäden besteht. Bei einigen Gattungen entstehen durch Vereinigung von zahlreichen Einzelsporangien 
sogenannte Aethalien. Zur Zeit der Sporenreife öffnet sich das Sporangium; durch hygroskopische Bewegungen der Capillitiumbestandteile wird das Sporenpulver herausgedrängt. Nach kürzerer oder längerér Ruhe beginnt der Zyklus durch Keimung der Sporen, Bildung von Myxomonaden und Myxoamoeben aufs neue. Eine Ausnahme von diesem allgemeinen Schema macht in Bezug auf verschiedene Punkte die Gattung Ceratiomyxa, indem bei deren Vertretern die Sporen nicht in Sporangien, sondern auf Stielchen auf der Außenseite sogenannter Sporophoren gebildet werden: hierüber mehr im speziellen Teil.

Nach dieser gedrängten allgemeinen Charakteristik der Entwicklung treten wir näher auf die einzelnen Entwicklungsstadien ein.

\section{Die Sporell.}

Die nur selten farblosen (Ceratiomyxa), meist in für die verschiedenen Arten charakteristischer Weise gefärbten Sporen sind meist + kugelig, seltener ellipsoidisch oder ovoid (Ceratiomyxa, Badhamia) und messen durchschnittlich $5-13 \mu$; kleinere Sporen besitzt u. a. Tubulina stipitata (N.-Amerika, Indien) mit nur $3 \mu$ großen Sporen, größere kommen z. B. bei Lamproderma-Arten vor, nämlich bis $20 \mu$ große, doch dürften dies die untern und obern Grenzwerte sein.

Die Sporenmembran, auf deren Färbung sicherlich in den allermeisten Fällen die Farbe der Spore selbst beruht, wird als teils einschichtig, teils zweischichtig angegeben (bej Didymium, Trichia etc. zweischichtig); ich vermute, daß sie stets zweischichtig sein wird, wobei allerdings die innere Schicht unmeßbar dünn sein mag. Die Sporenmembran zeigt keine reine Cellulosereaktion und wird, soweit die Versuche reichen, von Schwefelsäure nicht restlos gelöst. Die Oberfläche ist entweder glatt oder, häufiger, skulptiert: die Skulptur (Fig. 7, Fig. 9) besteht zumeist entweder aus feinen Warzen oder Stacheln (z. B. Trichia varia, Botrytis u. a. m.), aus netzförmig anastomosierenden Leisten (Trichia affinis, Hemitrichia Serpula z. B.) oder aus unterbrochenen Leisten (Trichia persimilis z. B.). Die Membranskulptur erstreckt sich entweder gleichmäßig über die ganze Sporenoberfläche oder die Sporen sind wie z. B. bei Badhamia nitens bilateral in dem Sinne, daß sie zur Hälfte skulptiert, zur andern Hälfte glatt sind. Letzteres Verhalten zeigen namentlich 
jene Sporen, die zu kleinen Paketchen vereinigt zu bleiben pflegen. Bei andern Arten wiederum weist die eine Halbkugel der Spore warzige, die entgegengesetzte netzförmige Skulptur auf (Reticularia Lycoperdon z. B.).

An dieser Stelle sei auch auf die Untersuchungen Lü stner's hingewiesen, aus denen hervorgeht, daß bei den Netzsporen die Leisten nicht frei nach außen endigen, sondern von einem Häutchen iiberspannt sind; dadurch werden Kammern gebildet, in denen Luft eingeschlossen ist. Tatsächlich sind denn auch

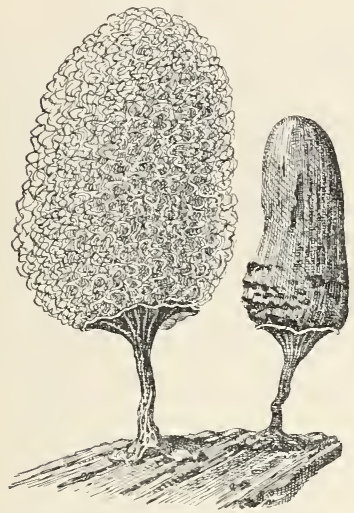

Fig. 6.

Areyria denudata (L.) Sheldon. Sporangien, rechts geschlossen, links geöffuet, mithervordringendem Capillitium. $-16 \times-$ Nach Lister.
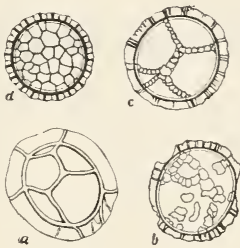

Fig. 7.

Sporen. a. von Trichia favoginea (Batseh) Pers., b. von T. persimilis Karsten, e. von 'T. affin is de Bary, d. von Stemonitis fusea Roth $-900 \times-$ Nach Lister.

die mit netzartiger Skulptur versehenen Sporen der TrichiaArten z. B. von einem bald breitern, bald schmälern Rand umgeben. Lüstner bringt die bekannte Schwierigkeit, die Sporen zur Keimung zu bringen, mit dieser Eigentümlichkeit in Beziehung, darauf hindeutend, daß sie erst benetzbar werden, wenn das Außenhäutchen durchgerieben sei. Es wird noch zu untersuchen sein, ob wirklich eine Correlation besteht zwischen der Netzskulptur und den negativen Keimungsergebnissen, vielleicht 
auch zwischen jener und der behaupteten Notwendigkeit der Anwesenheit ron spaltpilzen für die Sporenkeimung.

Nit Ansnahme der zu den Exosporeen gehörenden Gattung Ceratiomyxa laben alle Schleimpilze einkernige sporen, ab und zu kommt es vor. daß man Sporen wahrnimmt, die mehrere Kerne einschließen, doch handelt es sich dann stets $\mathrm{mm}$ abnorm gebildete. gewöhnlich schon durch ilıre Deformation und durch

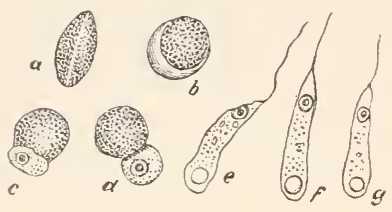

Fig. 8.

Didymium difforme (Pers.) Duby. a) eine trockene zusammengefaltete

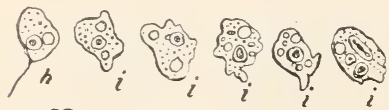
Spore. b) eine geschwollene Spore, c) und d) Austritt des Inhaltes aus der Spore, e) f) g) Schwärmer, h) Übergang des

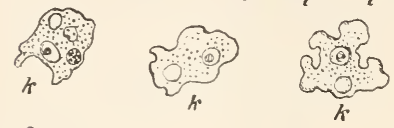
Schwärmers zur Amoebe, i) jüngere, k) ältere Myxamöben, 1) an einander liegende Myxamöben kurz vor der Verschmelzung, m) ein kleines Plasmodium.
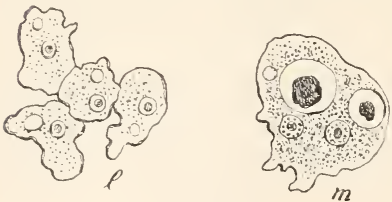

$-540 \times-$ Nach Strasburger.

ihre Größe auffallende Sporen. Die Sporen der Gattung Ceratiomyxa dagegen sind normalerweise vierkernig, dementspreshend weicht auch ihr Verhalten bei der Keimung von jenem aller übrigen Myxogasteres-Gattungen ab.

Die Keimung der Sporen, die wie ich bereits in aller Kürze ausgeführt habe, in einem Herausschlüpfen des vordem die ganze Sporenhöhlung ausfüllenden Protoplasten besteht, wird offenbar eingeleitet von einem rein physikalischen Vorgang, einem durch erhöhten Druck bewirkten Zerreißen der Membran. Für die Richtigkeit dieser Anschauung spricht der Jahn'sche Versuch, wonach eine Sprengung der Sporenhülle durch Erhöhung des osmotischen Druckes der Flüssigkeit, in die die Sporen 
gelegt werden, verunmöglicht wird. "Wenn man die Sporen leicht keimungsfähiger Arten nicht in reinem Wasser, sondern in Rohrznckerlösung anssät, so keimen sie, sagt Jahn, in geringprozentigen Lösungen sämtlich. Bei steigendem Zuckergehalt aber erhält man eine Grenzkonzentration, für jede Art eine andere, oberhalb deren eine Keimung nicht mehr stattfindet." Jahn gibt hierfür auch einige Zahlen. Durch die schwächste von allen Konzentrationen werden die Sporen von Reticularia gehemmt. Sie keimen schon in einer $t^{\%} \%$ Rohrzuckerlösung nicht mehr, wogegen die Grenzkonzentration für Didymium difforme erst bei $25 \%$ o $(100$ Wasser und 25 Rohrzucker) liegt. Reticularia beansprucht anch noch in anderer Hinsicht eine Ausnahmestellung: deren Sporen keimen nach Jahn, wenn sie ein halbes Jahr trocken liegen, in destilliertem $\mathrm{W}$ asser bei 21 Grad etwa in 30 Minuten; die Schwärmer von Amaurochaete kommen, wenn sie ein halbes Jahr alt sind, unter denselben Bedingungen in etwa $2 \frac{1}{2}$ Stunden heraus, Stemonitis flaccida keimt in 1 stunde, Didymium difforme in $4-5$ Stunden.

Die Keimungszeit jeder Art ist abhängig vom osmotischen Druck der Flïssigkeit, von ihrer Temperatur und vom Alter der Sporen, dies geht sowohl aus den überaus zuverlässigen Angaben Jahn's, wie aus den Zusammenstellungen Constantine an u's, zu denen wir gleich übergehen werden, hervor. Vorerst sollen noch die Angaben Jahn's gewürdigt werden. Für Reticularia ». B. zeigt Jahn, daß man für jede der drei Abhängigkeiten, wenn man den beiden anderen während der Versuche konstante Werte gibt, eine stetige Reihe von Zahlen, die sich in Form einer Kurve darstellen lassen, erhält. Jahn führt die sich bei diesen Versuchen ergebenden Tatsachen, hinsichtlich der sogenannten Wärmekurve etwas näher aus, nachweisend, daß z. B. 8 Monate hindurch trocken gelegene Reticularia-Sporen bei $+21^{\circ} \mathrm{C}$ Zimmertemperatur nach etwa 30 Minuten keimen. Sät man sie in Wasser von 37 Grad aus, läßt sie bei dieser Temperatur im Thermostaten liegen, so keimen sie überhaupt nicht, wohl aber tritt eine Keimung ein, wenn man den Aufenthalt im $+37^{\circ} \mathrm{C}$ warmen Wasser auf 5 Minuten abkürzt und zwar alsdann schon nach 11 Minuten! Jahn schliebt daraus, daß es offenbar eine 
der ersten Phasen der Wiedererweckung des Plasmas ist, die ein hohes Optimum hat und daß sich an der Aktivierung dieses ersten hypothetischen Stoffes, Jahn nennt ihn Erweckungstoff, die Belebung anderer Stoffe, die ein um mindestens 6 Grad niedrigeres Optimum haben, anschließe.

Die Einwirkung hoher Temperaturen äußert sich verschieden je nachdem die Sporen längere oder kürzere Zeit gelegen haben und zwar in dem Sinne, daß z. B. wenig Wochen alte Sporen, die bei $+21^{\circ} \mathrm{C}$ eine Keimzeit von 15 bis 20 Minuten hatten, sich durch erhöhte Anfangswärme nicht oder nur wenig bestimmen ließen, früher zu keimen, oder es durfte allermindestens die erhöhte Temperatur nur ganz kurze Zeit (bei 34 Grad z. B. nur für die Dauer von 2 Minuten) einwirken, in welchem Spezialfalle eine Beschleunigung um 3 Minuten bewirkt werden konnte gegenüber Sporen vom selben Alter, die bei 20 Grad eine Keimzeit von 17 Minuten beansprucht hatten.

J ahn weist des weiteren darauf hin - und zwar ist dies eine Erfahrung, die mit Ausnahme von Constantineanu alle Forscher gemacht haben, die sich mit der Kultur von Schleimpilzen schon befaßten -, daß gerade die Sporen recht gewöhnlicher Arten (Fuligo septica, Lycogala epidendrum, Stemonitis fusca, Trichia varia) überhaupt nicht oder nur sehr schwer zur Keimung gebracht werden können; ferner bestätigt er die Entdeckung Lister's, daß unter gewöhnlichen Verhältnissen nicht- oder nur sehr schwer keimende Sporen zur Keimung gebracht werden können, wenn man sie nach einer ersten Befeuchtung austrocknen läBt und sie sodann neuerdings befeuchtet. Aus diesen und anderen Erfahrungen, die man im Original nachlesen möge, schließt Jahn, daß bei gewissen Arten sein hypothetischer Erweckungsstoff zunächst noch in einer Muttersubstanz verborgen liegen müsse und zwar nennt er drei Faktoren, die die Abspaltung aus der Muttersubstanz seiner Ansicht nach bewirken können : 1. Austrocknung, 2. Einwirkung einer Holzabkochung auf die Sporen und 3. Einwirkung von Maltoselösung.

Was die Natur dieses fraglichen Erweckungsstoffes anbetrifft, so wird man sicherlich mit Jahn in der Vermutung einig gehen, daß man zunächst an ein Enzym zu denken hat. Jahn weist aus 
am angegebenen Orte näher ansgeführteñ Überlegungen auf ein aus Glykogen Maltose abbanendes Enzym, auf eine Glykogenase hin.

Bedeutend glücklicher, nicht nur als Jahn, sondern überhaupt als alle diejenigen, die sich bis zur Stunde mit der Kultur

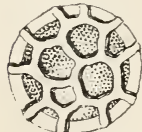

a

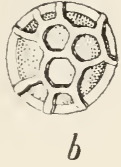

Fig. 9.
Sporen: a. von Hemitrichia chryrospora Lister.

b. von Hemitrichia Serpula (Scop.) Rost. $-1200 \times-$ Nach

Massee. der Schleimpilze befaßt haben, ist J. C. Constantineanu gewesen, der über seine außerordentlich mannigfaltigen und von überraschendem Erfolg gekrönten bezüglichen Versuchen in seiner , Über die Entwicklungsbedingungen der Myxomyceten" betitelten Dissertation berichtet.

Aus seinen Resultaten ergibt sich, dab die Sporen aller Endsporen bildenden Myxogasteres in

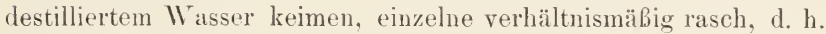
nach 30 Minuten (Reticularia und Fuligo), andere erst viel später, nach 5 bis sogur erst nach 20 (Dictydium cancellatum [umbilicatum] var. anomalum) Tagen. Die Sporen von Ceratiomyra keimen, wie bereits Famintzin und Woronin festgestellt haben, nicht in destilliertem Wasser.

An dieser Stelle mag auch der iibereinstimmenden Angaben von Vuillemin (beziehen sich auf die Acrasieen) und Pinoy, denen Constantineauu hinsichtlich der von jenen daran geknüpten Schlubfolgerung widerspricht, gedacht werden. Vuillemin und Pinoy behaupteten nämlich, daß, wenn man sterilisierte Sporen von Didymium (Chondrioderma) difforme oder von Dirlymium (effusum) squamulosum auf sterilisierter Holzextraktgelatine kultiviere, Keimung ausbleibe, wohl aber eintrete, wenn man dafür sorge, dab sich in den betreffenden Kulturen Bakterien, Pinoy nennt von solchen die Keimung veranlassenden Spaltpilzen den Bacillus luteus vorfinden. Constantineanu gibt zu, daß die Bakterien für die weitere Entwicklung der Schleimpilze, d. h. zu deren Einährung, von ,großer“ Bedeutung sein mögen, bei der Keimung indessen kaum eine Rolle spielen dürften, da die Sporen einzelner Arten ja so schnell keimen, daß die in die Kultur eingeführten Spaltpilze kaum so 
rasch ron Einfluß auf die Keimung sein dürften. Ich meinerseits halte die Untersuchungen Tuillemin's und Pinoy's noch keineswegs für so weit abgeschlossen, daß ich die Anwesenheit von spaltpilzen als eine conditio sine qua non für die Keimung hinstellen möchte, anderseits aber scheint mir die Zurückweisung seitens Constantineanu's mit der obigen Begründung als unberechtigt. Warum sollte nicht an eine Wirkung durch Ausscheidung eines Encyms gedacht werden können?

Constantineanu hat auch das V'erhalten der sporen gegenüber hohen Temperaturen geprüft und konstatiert, daB.. wie zu erwarten gewesen war, trockene sporen ihre Keimfähigkeit erst bei bedeutend höheren Temperaturen verlieren (Didymium [effusum] squamulosum Sporen keimen noch, nachdem sie einer Temperatur von $+80^{\circ} \mathrm{C}$ ausgesetzt gewesen waren, allerdings treten dann nur noch Anfänge von Keimung auf, wogegen nach einem Verweilen in einer Temperatur von $+70^{\circ} \mathrm{C}$ die Keimung noch ziemlich gut verläuft) als feuchte sporen (Maximum der zulässigen Temperatur $+40^{\circ} \mathrm{C}$ ).

Jahn gegenüber bestreitet Constantineanu die Bedoutung des osmotischen Druckes für die erste Phase der Keimung, die Membransprengung. Aus seinen Experimenten würde sich ergeben, daß Versuche mit isotonischen Lösungen einen Unterschied zu gunsten des Zuckers bei einem Vergleich der Keimungen ergeben.

Sicher ist, daß auch in Bezug auf die Keimungsvorgänge noch eine Reihe grundlegender Fragen der Lösung harren und dab der Forschung noch ein weites Feld offen steht.

\section{Literatux.}

Ban der Sporen, deren Keimung und Keimungsbedingnngen.

1912. Benecke, W. Bau und Leben der Bakterien. Leipzig und Berlin. 1894. Mc. Clatehie, A. J. Notes ou germinating Myxomycetous spores. Bot. Gazette, XIX.

1906. Constantineanu, J. C. Über die Entwicklungsbedingungen der Myxomyceten. Anuales mycologiei, 1V.

1873. Famintzin und Woronin. Über zwei neue Formen von Schleimpilzøn: Ceratium hyduoides A. et S. und Ceratium porioides A. et S. Mém. Ac. Imp. St. Pètersb. VII, Vol. XX, Nr. 3.

1859. Hoffmann, H. Über Pilzkeimungeu. Bot. Zeitung, XVII.

1905. Jahu, E. Myxomycetenstudien. 4. Die Keimung der Sporen. Ber. Deutsch. Bot. Ges., XXIII. 
1907. Kïster, E. Anleitung zur Kultur der Mikroorganismen. Leipzig und Berlin.

1902. Lendner, A. Essai de eulture de Myxomycètes. Bull. Herb. Boiss., 2me sér., II.

1901. Lister, Arthur. On the cultivation of mycetozoa from spores. Journ. of. Bot, XXXix.

1898. Liistner, Gustav. Beiträge zur Biologie der Sporen. Diss. Jena.

1898. Miller, Caspar 0 . The aseptic cultivation of mycetozoa. The Quarterly Journ. of microscop. seience, XLI, 1 and 2, new ser.

1902. Pinoy, E. Nécessité d'une symbiose mierobienne pour obtenir la culture des Myxomycètes. Bull. Soc. Mycol. France, XVIII et Comptes Rendus Acad. Sc. nat. Paris, OXXXVII (1903).

1907. - Rôle des Bactéries dans le développement de certains Myxomycètes. Thèse. Paris. Anual. Iustitut Pasteur, XXI.

1912. Schmidt, Alfr. Die Verbreitung der eoprophileu Pilze Schlesiens. Diss. Breslau.

Wenden wir nunmehr unsere Aufmerksamkeit dem der keimenden spore sich entwindenden Protoplasten zu.

Wir unterscheiden zwei gänzlich verschiedene Typen des Keimungsvorganges, einen Typus von Ceratiomyxa und einen die übrigen Myxogasteres umfassenden 2. Typus.

1. Ceratiomyxa. Aus der Spore kriecht eine vierkernige Amöbe heraus, die sich unmittelbar darauf in 4 Tochteramöben teilt, worauf jedes Tochterindividuum sich nochmals teilt, sodaß acht Amöben entstehen, deren jede nunmehr eine GeiBel bildet ${ }^{1}$ ) und damit zum schwärmer wird. Die minutiösen Untersuchungen Jahn's stellen fest, daß bei diesen Teilungen die Chromosomenzahl (8) sich immer gleich bleibt, dab daher die etwa bei diesem Vorgange zu vermutende Reifeteilung nicht vollzogen wird.

๖. Die Sporen aller übrigen Schleimpilze sind einkernig. Der Verlauf der Keimung läßt 2 Untertypen unterscheiden.

1) Vouk will an Schwärmern von Didymium difforme und D. nigripes nicht bloß eine, sondern zwei Geißelu beobachtet habeu und auch Miller zeicbnet „Zoosporen“ einer nicht näher bezeichneten Art mit 1, 2 und 4 Wimpern und sagt ausdrücklich im T'ext: "The zoospores of plasmodia usually bave a siugle flagellum, but they may have two or four." Mit dem Befunden Plenge's und Jahu's sind diese in der Literatur einzig dasteheuden Angabeu schwer in Einklang zu bringen. Sollten sich die Beobachter vielleicht dadurch haben irre führen lassen, dab, wenn vei amöbenartig kriechenden Schwärmern der Kern im Plasma umherwandert, die Geißel mit witndert? 
a) Reticularia-Typus. Bei Reticularia Lycoperdon kommt aus der Spore eine Amöbe (Myxoamöbe) heraus, die nach kurzer Ruhezeit unter lebhafter Plasmaströmung einen schnabelartigen Fortsatz erhält und sodann aus diesem eine Geißel hervortreibt, wonach eine Streckung des Plasmakörpers folgt. Die Bildung der Geißel erfordert durchschnittlich 15 Minuten.

b) Didymium-Typus. Die Bildung der Geißel erfolgt noch innerhalb der Spore, ja es findet unter Umständen noch vor der Keimung eine Teilung des Sporeninhaltes in 2 oder 3 Portionen statt und der oder die Protoplasten treten daher als Schwärmer mit mehr oder weniger vollkommener Geißel heraus. Die eigenartigen Krümmungen des Schwärmers, die beim Reticularia-Typus die Bildung der Geißel begleiten, fehlen bei diesem zweiten Typus. Das Schwärmerstadium dauert kaum länger als 2 bis 3 Stunden.

Jahn's Ausführungen nach, denen wir in diesen Darlegungen gefolgt sind, kommen bei den Stemoniteen Übergangsformen zwischen $2 \mathrm{a}$ und $2 \mathrm{~b}$ vor.

\section{Myxomonaden und Myxoamöben.}

Verfolgen wir in erster Linie an der Hand der Jahn'schen Untersuchungen die Geißelbildung bei den Schwärmern oder Myxomonaden (Myxoflagellaten) von Stemonitis flaccida. Bereits Plenge hat uns mit den Bau der schwärmer einer DidymiumArt (?) bekannt gemacht und dessen Angaben sind in der Folge mehrfach nachgeprüft und als richtig bestätigt worden. Plenge fand, daß von der Basis der Geißel aus eine etwa birnenförmige Masse sich ins Innere der Schwärmzelle fortsetze und daß sich unmittelbar unter der Geißelbasis, die durch ein kleines, etwas dickeres Körnchen bezeichnet ist, sich stets ein heller Bezirk im Zellkörper vorfindet, der sich sowohl gegen das dunklere, innere und hintere Körnchenplasma als gegen den helleren nmgebenden äußeren Plasmasaum mit einer feinen Kontur scharf absetzt (Jahn). „Er stellt sich dar als ein Bläschen, das nach der Geißelbasis zu in eine Spitze ausgezogen ist und endigt unmittelbar an der Geißelbasis, er hängt an ihr wie eine Seifenblase an dem Strohhalm, mit dem sie aufgeblasen worden ist." Der übrige Teil der birnenförmigen Masse ist der Kern, in dem der Nukleolus deutlicher sichtbar ist. Fig. 10. 


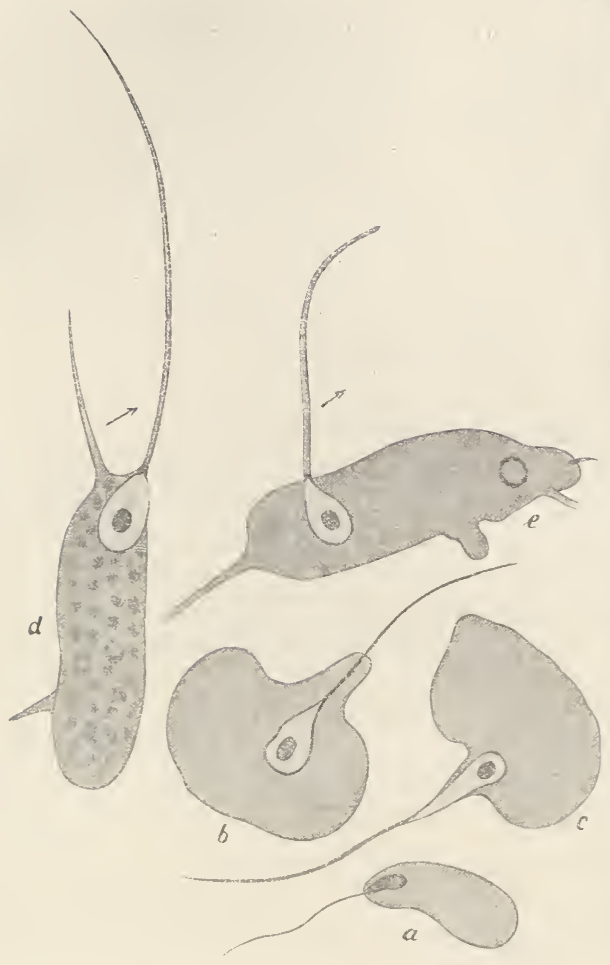

Fig. 10 .

a) Myxogasteresschwärmer bei schwacher Vergrößerung mit Osmiumsäuredämpfen abgetötet und mit Heidenh. Hämatoxylin-Eisenlackfärbung kurze Zeit behandelt. b) e) d) e) Skizzen nach Beobachtungen im Leben. In b) hat sich der birnförmige Körper mehr ins Innere der Zelle zurïckgezogen, die Geißel ist nachgezogen und dadurch verkïrzt, ein breiter Protoplasmafortsatz ist zurückgeblieben. In d) hat die Geißel gerade einen Sprung gemacht in der Pfeilrichtung und hat einen Protoplasmafortsatz zurückgelassen. In e) ist die Geißel auf der Fortwanderung begriffen und hinterläßt bei der Wanderung über die Vakuolengegend hinweg wiederum zwei Pseudopodien. (Nach Plenge). 
Bej Anwendung von Färbungen kann man mitunter zwischen dem Nukleolus und der Kernmembran noch eine radiär angeordnete Substanz, das Chromatin sichtbar machen. Ferner kann in dem kegelförmigen, rom Kern zur Geißel führenden Verbindungsstück noch ein dunklerer Gürtel einer stärker tingierbaren Substanz wahrgenommen werden. Manchmal scheint auch von der GeiBelhasis aus zum Kern durch den eben erwähnten Kegel ein Faden zu gehen, der sich innerhalb des Kegels kappenartig auf den Kern ansetzt oder bisweilen bis zum Nukleolus verfolgt werden kann.

Dies die Untersuchungsresultate ron Plenge, soweit sie die Schleimpilze betreffen und uns an dieser Stelle interessieren können.

$J$ ahn hat dessen Studien spez. bei den Myxogasteres weiter verfolgt und rervollständigt und es sollen nachfolgend die wichtigsten Befunde der $\mid J a h n$ 'schen Forschung skizziert werden. Zur Cntersuchung eignen sich namentlich die Schwärmer von Amaurochaete fuliginosa, da sie sich durch besondere Größe auszeichnen. C̈ber dem etwas verlängerten Kern (in diesem Falle verlängert in der Längsachse des Schwärmers) befindet sich die Glocke und über dieser, unmittelbar am Grunde der Geißelinsertion das im ungefärbten Zustande stark lichtbrechende Knötchen (Fig. 11). Die Wandung der Glocke läßt mitunter. insofern sie nicht von Plasma verdeckt ist, eine feine Längsstreifung erkennen. Der Nukleolus findet sich annähernd in der Mitte des Kernes, ringsum umgeben von einem Alveolarsaum, der mitunter den Eindruck hervorruft, als ob der Nukleolus in einem Bläschen im Kerne liege. An diesen Saum schließt sich das Chromatin strahlig an, beginnend mit dunkeln und stark färbbaren Körnchen. Diese Körnchen bilden mitunter eine Reihe und Jahn's Figur (Fig. 11 a) läßt, worauf auch Jahn ausdrïcklich aufmerksam macht, deren acht zwischen Nukleolus und Geißelglocke erkennen.

Entsprechend sind die Verhältnisse bei den Schwärmern der von $\mathrm{J}$ ahn hierauf untersuchten Stemonitis flaccida, nur ist das Chromatin dichter und körniger, der Nukleolus und überhaupt der ganze Kern ist kleiner als bei Amaurochaete, was zur Folge hat, daß die Einzelheiten weniger deutlich erkennbar sind.

Verfolgen wir an der Hand von $\mathrm{J}$ ahn $\mathrm{s}$ Bildern und dessen Text die sich abspielenden Vorgänge bei der Schwärmerteilung und der Entstehung der Geißeln. 
Die Anlage der achromatischen Figur erfolgt intranuklear, die Richtung der Längsachse der Spindel scheint von der lebhaften Plasmabewegung, die im Verlaufe des Teilungsvorganges an Intensität noch zunimmt, beeinflußt zu werden und erklärt wohl ungezwungen die Lage der Spindel in Fig. 11b. Während der Teilungsvorbereitungen vollziehen sich offenbar im Innern der Schwärmer lebhafte und intensive Umwälzungen, die sich in einer Krümmung der Spindelachse (Fig. 11d), namentlich aber in einem Zerreiben der Fasern, was schlieblich zu cinem Zerreißen der Spindel überhaupt führt (Fig. 11 d, e), äußern. Schon in diesem Stadium der Teilung fallen dem Beobachter lebhaft glänzende, in der Mittellinie nahe den Polen liegende Flecken auf, die sich raseh verdicken und schlieblich zwei Platten bilden: die .Chromosomen. Plötzlich erscheint jederseits ïber ihnen dentlich am Rande die junge Geißel, an deren FuB sich eine kleine Vakuole befindet, die rhythmisch auftritt, zusammenfällt und nach zirka einer halben Minute aufs neue erscheint. Inzwischen wächst die Geibel langsam heran. Zweierlei stellt. $\mathrm{J}$ a h $\mathrm{n}$ fest: erstens die Geißeln wachsen aus denSpindelpolen hervor und zweitens, ihre Entstehung fällt ziemlich genau mit den ersten Vorbereitungen der Zellteilung zusammen.

1)ie spindelpole besitzen schon in den frühesten Stadien zwei dunkle, stark färblare (mit Hämalaun und mit Eisenhämatoxylin) Punkte, die Jahn wohl nicht mit Unrecht mit Centrosomen indentifiziert.

Die spindelfasern anßerlualb der Chromosomen bleiben nunmehr in ihrer Gesamtheit jederzeit als dunkler Kegel erhalten; die Chromosomen der Tochterkerne bleiben zunächst als Platten liegen, dann nehmen sie eine $\mathrm{V}$-förmige Gestalt an und umgeben sich mit der Kernmembran (Fig. 11 e) und nun erfolgt auch die Teilung des Schwärmers in zwei Tochterschwärmer, deren Längsachsen zuerst gegeneinander geneigt sind (Fig. 11 k) und die alsobald von einander wegkriechen, indem namentlich an deren Hinterende größere oder kleinere Psendopodien erseheinen (Fig. 11 e, m). Der eben geschilderte Vorgang vollzieht sich überaus rasch. Jahn hat konstatiert, daß wohl kaum mehr als 10 bis 12 Minuten dafür notwendig sind. 


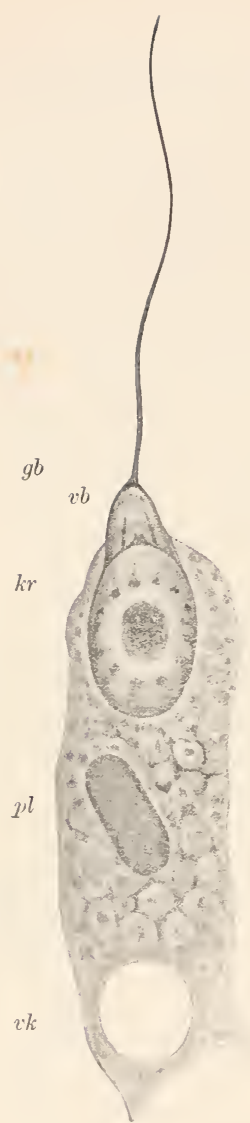

a
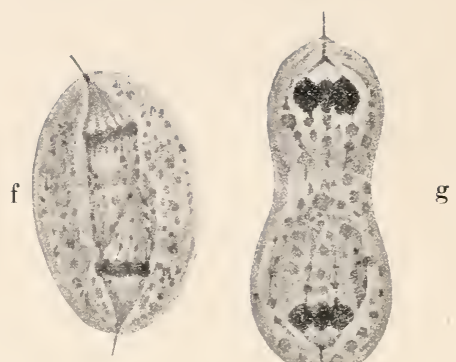

d

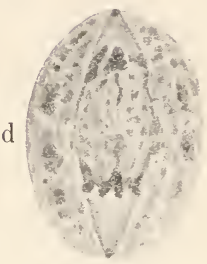

b)

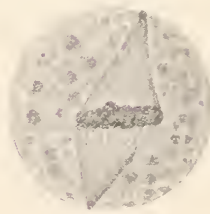

g
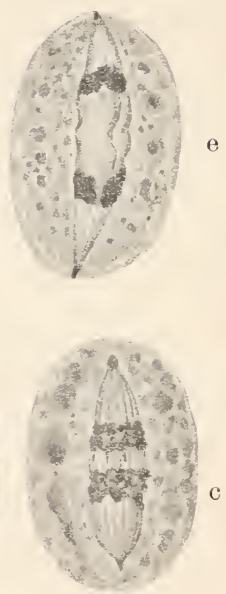

Fig. 11 .

a) Schwärmer von Amaurochaete fuliginosa (Sow.) Macbr.; gb GeiBelbasis; $v b$ Verbindungsstück (Geißelglocke); $k r$ Kern; $p l$ vom Schwärmer gefressene Zelle eines hefeartig sprossenden Pilzes; $v k$ pulsierende Vakuole; b bis 1n) Teilungsstadien der Schwärmer vouStemonitis flaceida (Morg.) Jahn $(=\mathbf{S}$. splendens Rost. var. flaceida (Morg.) Lister); b die Spindel ist im Begriff sich

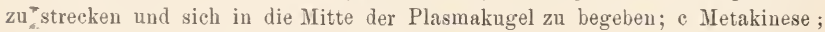
d Auflösung der mittleren Spindelfasern durch Sprengung von innen; e Auflösung der mittleren Fasern; f Beginu der Geißelbildung; g fortschreitende Zellteilung. 
Was geht nun aus diesen prächtigen Untersuchungen Jahn's hervor? 1., daß die Kernglocke Plenge's der (vielleicht nachträglich) verstärkte Rest der Kernspindel, das dunkleKörnchen am Grunde der Geißel das Centrosom ist. Dem Centrosom ist also hier dieselbe Aufgabe zugewiesen wie anch noch anderwärts im Pflanzen- und Tierreich, so bei der Ausbildung der Spermatozoiden der Lebermoose (Ikeno's C'ntersuchung der Spermatogenese von Marchantia) oder dem Auswachsen der Cilien bei den verschiedensten tierischen Spermatozoiden.

Die Myxoflagellaten sind sehr metabolisch, sie bilden mehr oder minder feine Pseudopodien und gehen früher oder später in den Amöbenzustand über. Die Aufnalıme ron geformter Nahrung erfolgt in der Regel bei den Myxoflagellaten am Hinterende und zwar ernähren sich Myxoflagellaten wie Myxoamöben teils saprozoisch mit gelösten organischen Substanzen, teils auch durch Aufnahme ron geformter Nihrung. Beide, Myxoflagellaten wie Myxoamöben, besitzen eine kontraktile Vakuole und können sich (für die Myxoflagellaten ist der Vorgang eben geschildert worden)

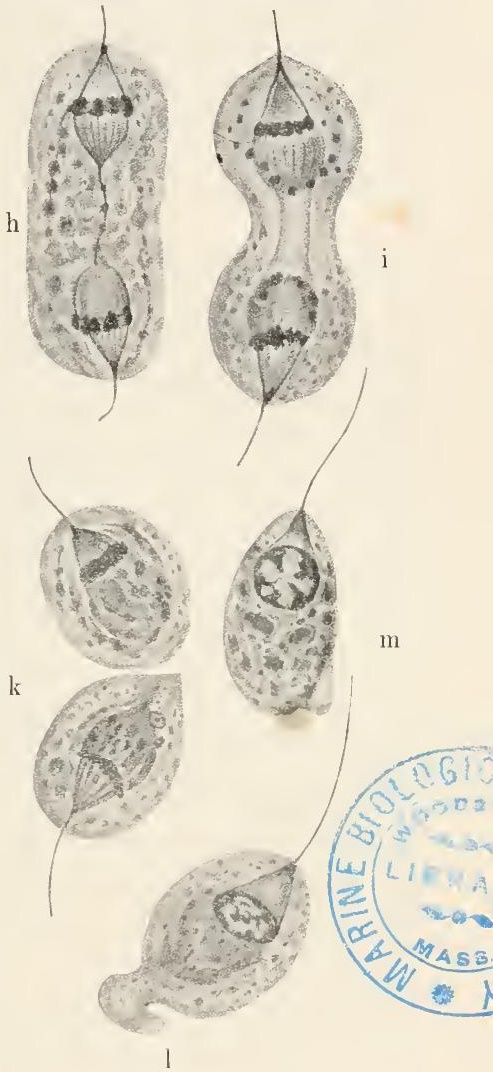

Fig. 11 A. (Fortsetzung von Fig. 11.) Schwärmer vou Amaurochaete fuliginosa h-k Treunung der Zellen, Wachstum der GeiBel; h Neubildung der Kermmembran, Entstehung von Pseudopodien; m völlige Rekonstitution des Kernes.

- 4000 X - Nach Jahn. 
teilen, wobei der Kern eine Mitose durchmacht (Fig. 12). Es gilt dies, beiläufig bemerkt, nicht bloß für die als Amöben aus den Sporen ausschlüpfenden Myxoamöben, sondern auch für die ans den Schwärmern sekundär entstandenen Amöben.

Die Lmwandlung eines Schwärmers in eine Amöbe vollzieht sich unter gleichxeitigem Verlust der Geißel. Bei den StemonitisArten scheint den Schwärmern ein längeres Dasein gewährt zu werden; für die Schwärmer von Didymium (effusum) squamulosum und nigripes gibt Jahn an, daß die Geißel schon bei der ersten Schwärmerabteilung verloren gehe.

„Sehr merkwürdig,“ sagt Gaidukow, „erscheint uns bei ultramikroskopischer Betrachtung die Bewegung der Myxoamöben. Bei der Bildung der Pseudopodien entsteht zuerst zwischen der Endoplasma- und der Ektoplasmaschicht ein optisch leerer Raum. Dann strömen in diesen Raum die Endoplasma-UTltramikronen, drücken auf die Ektoplasmaschicht und bilden einen Ausläufer. So entsteht ein Pseudopodium. Dagegen findet beim Verschwinden dieses Pseudopodiums ein Zurückströmen der Teilchen statt, Bildung des optisch leeren Raumes und das Zurückziehen der äuBeren Schicht. Alle Protoplasma-Ultramikronen befinden sich in permanenter Bewegung“.

J a hn gilot interessante Aufschlïsse über die Raschheit mit der sich z. B. die Abkömmlinge eines Schwärmers ron Didymium (effusum) squamulosum zu vermehren (durch Teilung) vermögen. "Wenn man eine Spore in eine Nährflïssigkeit bringt." sagt Jahn, ,kommt ein Schwärmer heraus, dessen Abkömmlinge sich sehr schnell hintereinander teilen. Sie fressen fortgeset/t Bakterien und haben schon nach 3 Tagen die Zahl von über 20 erreicht, soweit ich (Jahn) bei oberflächlicher Zählung feststellen konnte."

Auf diese Weise erhält man also Kulturen, die aus lauter kleinen, einkernigen Amöben bestehen. Nach einiger Zeit tauchen nun plötzlich unter diesen größere, gleichfalls durch amöboide Bewegungen ausgezeichnete, nun aber zumeist mehrkernige Plasmamassen auf., die als solche den Forschern längst bekannt gewesen sind und denen man die Bezeichnung Plasmodien beigelegt hat. Hier, im Hinblick auf die Bildung der Plasmodien, setzen nun wiederum die Untersuchungen Jahn's ein. 
Bisher hat man nämlich, zumeist auf Grund der Untersuchungen Cienkowsky's u. a. angenommen, dab die mehrkernigen Plasmodien durch Verschmelzung der Myxoamöben (Plasmogamie) untereinander und den schon entstandenen Plasmodien sich bildeten. Nun hat aber Jahn festgestellt, dab die Plasmodien keineswegs mit den Amöben verschmelzen, wohl aber solche umfließen und auffressen (Figur $12 \mathrm{~h}$ ) sofern sie ihnen auf ihrem Wege begegnen, dagegen verschmelzen zufällig einander

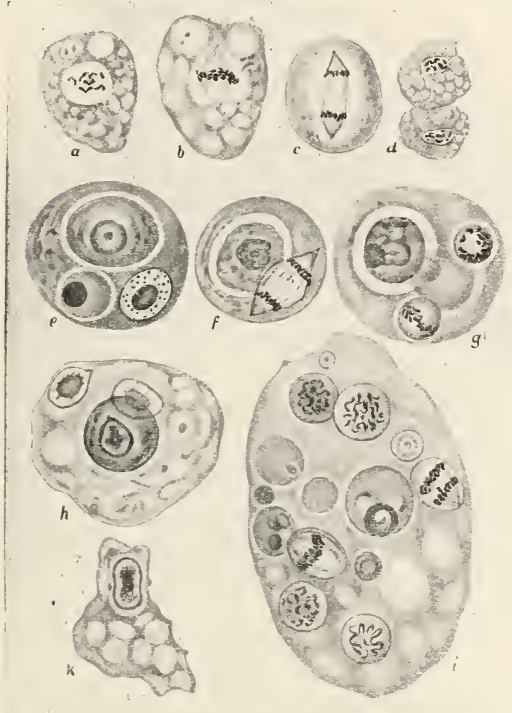

Fig. 12.

Physarum didermoides (Acharius) Rost. - a) Kernteilung einer haploiden Amöbe, Prophase, Chromosomen deutlich; b) dasselbe, Spindel; c) Tonmenstadium ; d) Zellteilung nach erfolgter Kernteilung, die Chromosomen sind wieder dentlich; e) einkerniges Plasmodium, in den Verdanungsvakuolen liegen eine haploide Amöle und eine Flagellate; $f$ ) einkerniges Plasmodium mit Kernteilung, in der Verdaunngsvaknole eine hajloide Amöbe ; g) zweikerniges Plasmodium, die Kerue sind noch in Rekoustrultion begriffen, die Chromosomen deutlich, große Verdauungsvakuole; h) zweikernig. Plasmodium, in der Verdauungsvakuole wiederum eine haj-

loide Amöbe; i) sechskerniges Plasmodium in Kernteilung. die beiden mittlern Kerne in einer andern Phase als die vier äuBern; k) Kopulationsstadium zweier haploider Amöben, die Kerne sind in Fusion begriffen. $-2000 \times-$ Nach Jabn. treffende junge Plasmodien, wobei es sich aber keineswegs um eine gegenseitige Anlockung (man dachte vordem an eine chemotaktische Anziehung) handelt, sondern vielmehr um ein ganz zıfälliges Begegnen.

Die jüngsten Plasmodien haben nur einen einzigen Keru. schleppen aber in großen Verdaunngsvakuolen Sporen, Spaltpilze, 
Flagellaten, unverdaute Amöben mit sich herum; die Unterscheidung gegenüber den zwischen ihnen noch herumkriechenden Amöben ist nicht leicht, insofern man wenigstens nicht die Chromosomenzahl zu Hilfe nimmt.

Die Vergleichung dieser Zahlen, von $J$ ahn durchgeführt, hat nämlich das entscheidende Resultat gezeitigt: die Kerne der aus den Sporer herauskriechenden Amöben besitzen gleich den

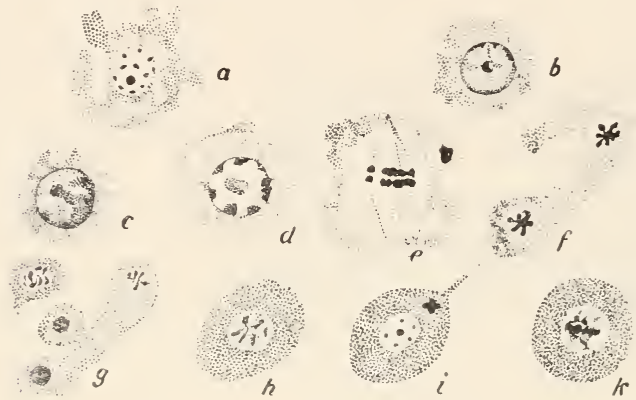

Fig. 13.

Ceratiomyxa fruticulosa (Müll.) Macbr. Reduktionsteilung während der Fruchtkörperbildung. a) diploider Kern; b) und c) Syuapsis; d) Diakinesse; e) heterotypische Mitose; f) die Tochterkerne im Maschenstadium des Plasmodiums; g) desgleichen, zum Teil degenerierend; h) Schnitt durch eine Amöbe des Pflasterstadiums; i) junge Spore mit ruhendem und einem degenerierten Kern; k) Spirem im dichten Plasma. Vorbereitung auf die erste Sporenmitose. $800 \times-$ Nach Jahn.

Kernen der Schwärmer und den Kernen der aus den Scchwärmern wieder entstandenen Amöben, verglichen mit den Kernen der auch allerjüngsten - Plasmodien, nur die halbe Chromosomenzahl, d. h. bei Physarum didermoides 8; die Kerne der Plasmodien lassen dagegen 16 Chromosomen erkennen.

Es bleibt somit nichts anderes übrig, als in der Entstehung der Plasmodien den längst gesuchten Sexualakt zu erkennen, erfolgt durch Kopulation ron Gameten (Myxoamöben) (Fig. 12 k) unter Bildung von Zygoten (Plasmodien oder Plasmodiellen nach Bruck's Nomenklatur). 
Jahn gibt am selben Orte auch eine durchaus plausible Deutung der von Cienkowski wahrgenommenen Vorgänge, die zu der bis anhin geltenden Ansicht geführt haben und deren Richtigkeit Jahn im übrigen bestätigt. Die in Kulturen von Didymium (effusum) squamulosum-Sporen herumkriechenden kleinen Protoplasten vereinigen sich in der Tat, wie Cienkowski angegeben hat, zu Gruppen, aber es sind, wie schon aus den mit ihren schwestern angefüllten Verdaunngsvakuolen hervorgeht, keine haploide Myxoamöben mehr, sondern bereits kleine diploide Plasmodien.

\section{Literatur.}

Myxomonaden und Myxoamöben.

1854. de Bary, A. Euglenaartige Gebilde aus Sporen vou Trichia rubiformis. Sitzungsber. Göttingen.

1907. Bruck, W. Fr. Beiträge zur Physiologie der Mycetozoen. Zeitsehr. f. Allg. Physiologie, VII.

1906. Celakorsky, L. Beiträge zur Fortpflanzungsphysiologie der Pilze. Prag.

1863. Cienkowski, L. Zur Entwicklungsgeschichte der Myxomyceten. Pringsheim's Jahrb. f. wissenschaftl. Botanik, III.

1900. Harper, R. A. Cell and nuelear division in Fuligo varians. Bot. Gazette, XXX.

1904. Jahn, E. Myxomycetenstudien. 3. Kernteilung und Geißelbildung bei den Schwärmern von Stemonitis flaceida Lister. Ber. Deutsch. Bot. Ges., XXII.

1907. - Myxomycetenstudien. 6. Kernverschmelzung und Reduktionsteilungen. Ber. Deutsch. Bot. Ges., XXV.

1911. - Myxomycetenssudien. 8. Der Sexualakt. Ber. Deutsch. Bot. Ges., XXIX.

1903. Ikeno, S. Die Spermatogenese von Marchantia polymorpha. Beihefte zum Bot. Centralbl., IV.

1907. Kränzlin, Helene. Zur Entwicklungsgeschichte der Sporaugien bei den Trichien und Areyrien. Archiv für Protistenkunde, IX.

1906. Kusano, S. Preliminary notes on the chemotaxis of the swarmspores of Iyxomycetes. Bot. Mag. Tokyo, XX.

1907. - Phobo-chemotaxis of the swarmspores of Myxomycetes. Bot. Mag. Tokyo, XXI.

1909. - Studies on the chemotactic and other related reactions of the swarm-spores of Myxomycetes. Journ. Coll. Agr. Imp. Univ. Tokyo, II.

1893. Lister, Arthur. On the division of nuclei in the Mycetozoa. Journ. of Linn. Soc., XXIX.

1890. - Notes on the ingestion of food-material by the swarm cells of Mycetozoa. Journ. of Linn. Soc., XXV.

1901. - On the cultivation of Mycetozoa from spores. Journ. of Bot., XXXIX. 
1894. Me Clatchie, A. J. Notes on germinating Myxomycetous spores. Bot. Gazette, XiX.

1898. Miller, Caspar 0. The aseptic cultivation of Mycetozoa. Quaterly Jouru. Microse. Sc., N. S, XLI.

1899. Plenge, Henriqne. Über die Verbindungen zwischen Geißel und Kern bəi den Schwarmzellen der Mycetozoen und bei Flagellaten und über die an Metazoen aufgefundenen Beziehungen der Flimmerapparate zum Protoplasma und Kern. Verh. d. naturhist.-mediz. Ver. Heidelberg, N. F., VI, Heft 3.

1904. v. Prowazek, S. Kernverhältnisse in Myxomycetenplasmodien. Oesterr. bot. Zeitschr., LIV.

1890. Stange, B. Ïber chemotactische Reizbewegungen. Bot. Zeit., IIL.

1878. Strasburger, E. Wirkung des Lichts und der Wärme auf Schwärmsporen. Jena.

1911. Vouk, V. Ïber den Generationswechsel bei Myxomyceten. Oesterr. bot. Zeitschr., LXI.

Vergleiche auch die ältern Publikationen vol de Bary (citiert Seite 7) und Zopf, Die Pilztiere oder Schleimpilze (Seite 9).

\section{Plasmodium.}

Aus dem Vorangegangenem wissen wir nun, daß das Plasmodium einer Zygote entspricht, daß deren Kern diploiden

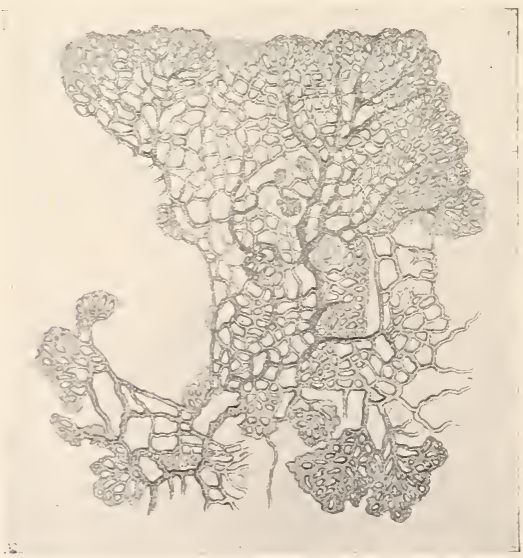

Fig. 14 .

Teil eines Plasmodiums von Fuligo septica (L.) Gmelin - 12 Nach Rosanoff.

Charakter besitzt. Ich habe bereits an früherer stelle darauf hingewiesen, daß die Plasmodien sehr verschiedene Größe haben können, man kennt solche von nur wenigen Quadratmillimetern 
und darunter, und solche von bis zu $1^{1 / 2}$ qm Ausdehnung (Plasmodium von Fuligo septica z. B.). Die Plasmodien pflegen sehr kernreich zu sein, was darauf zurückzuführen ist, daß sie einerseits sich vergröBern durch Verschmelzung von sich begegnenden Plasmodien, andererseits darauf, daß ihre Kerne sich teilen. Ein großes, kernreiches Plasmodium kann daher auch ausschließlich durch reichliche Nahrungsaufnahme entstehen. Die Plasmodien bewegen sich durch Ausstülpung von Rhizopodien; letztere verzweigen sich außerordentlich reichlich, anastomosieren durch feinere und stärkere Querbrücken und bilden in ihrer Gesamtheit ein Net\% von bewunderungswürdiger Zartheit (Fig. 14). Die Verschiebungen gehen rastlos vor sich, bald präsentiert sich das Plasmodium als ein formloser Schleimklumpen, bald in der eben geschilderten, aus dickern, feinern und feinsten ,Adern" aufgebauten Netzform. „Es gehört", sagt Doflein und alle Beobachter werden ihm rïckhaltslos beistimmen, ,zu den wundervollsten Anblicken, unter dem Mikroskop das ruhelose Durcheinanderwirbeln der Plasmabestandteile, die Bildung und Verschmelzung neuer Fortsätze, die Umfließung von Gegenständen, die rastlose Bewegung der ganzen Masse zu beobachten." Dabei läßt sich an den einzelnen Strängen eine dichtere Innenmasse und ein flüssigeres, von einer etwas zäheren klaren Schicht umgebenes Ektoplasma unterscheiden.

$\mathrm{W}$ as die eben erwähnten Plasmaströmungen, die jedes Plasmodium zeigt, betrifft, so sind diese schon sehr lange bekannt; sie bestehen in einem Hin- und Herströmen des flüssig körnigen Endoplasmas. „Nach kürzerer oder längerer, in keinem Fall $\mathbf{5}$ Minuten iibersteigender Dauer der Strömung in einer gegebenen Richtung ", sagt H of meister, ,verlangsant sie sich sehr rasch und steht daun still. Bald tritt dann eine Strömung in anderer Richtung ein, in der Regel eine genau entgegengesetzte, welche von dem bisherigen Zielpunkt fernstehend, allmählich bis zu diesem zurückgreift und das hier aufgesammelte Protoplasma großenteils zu der Stelle zurückbefördert, von der es kam". In feineren Strängen geht immer nur ein Strom der Länge nach, während in dickeren Ästen oft zwei Ströme in entgegengesetzten Richtungen aneinander vorbeifließen. In platten, hautartigen Ausbreitungen, welche sich hie und da im Netzwerk bilden, laufen meist zahl- 
reiche verzweigte Ströme entweder nach der gleichen oder nach verschiedenen Richtungen, und nicht selten gehen, wie eben bemerkt, entgegengesetzte Strömungen dicht nebeneinander her. Dabei kann die Geschwindigkeit der Strömung an den einzelnen Stellen eine verschiedene sein und kann sich anch allmählich ändern, sie kann so groß sein, daß man bei starker Vergrößerung den rorbeieilenden Körnchen kaum mit dem Auge folgen kann, kann aber auch so langsam werden, daß ein Körnchen kaum seinen Ort zu verändern scheint (Hertwig).

In jüngster Zeit ist die Rhythmik der Protoplasmaströmung (a) Untersuchungsobjekt dienten in Petrischalen auf festem Substrat kultivierte Plasmodien von Didymium nigripes) ron V. Vouk studiert worden. Er faßt die gewommenen Resultate in nachfolgenden Sätzen zusammen: 1. Die Protoplasmaströmung der Plasmodien ist ein rhythmischer Vorgang. 2. Der Rhythmus der Strömung hesteht aus zwei Komponenten, aus einem progressiven (darunter ist der centrifugale Strom zu verstehen) (P) und einem regressiven (centripetal verlaufenden) ( $R$ ) Strom, wobei jener in der Regel längere Zeit danert als dieser. 3. Die Dauer eines rhythmischen Ganges. dh. die Summe der Dauer des progressiven und regressiven Stromes ist für ein bestimmtes Plasmodium eine bestimmte und konstante Gröbe. Diese Gröbe nennt Vouk die Rhythmusdauer $(\mathrm{P}+\mathrm{R}=\mathrm{T})(\mathrm{T}=$ Rhythmusdaner $)$. 4. Die Rhythmusdauer ist nur in den Hauptströmen konstant, in den Neben- und Seitenströmen, welche im Entstehen und Auslöschen begriffen sind, ist sie einer stetigen Veränderung unterworfen. 5. Die Rhythmusdaner nimmt mit der Entwicklung eines Plasmodiums stetig an Größe zu. 6. Die rhythmische Strömung des Protoplasmas kann durch mechanische Reize (Erschütterung) gestört werden. Die Störung gibt sich in Sinken oder Steigen der Rhythmusdaner kund.

Es ist zu erwarten, daß Vouk seine diesbezïglichen Studien auch noch in der Folge auf andere Objekte ausdehnen wird; wichtig im Hinblick auf die Möglichkeit einer Vereinheitlichung der mechanischen Erklärung der Protoplasmaströmungen wäre es, zu erfahren, ob auch die Strömungen des Innenplasmas (Staubfadenlaare der Tradescantia-Arten. Elodea etc.) einem ähnlichen Rhythmus unterworfen sind. 
W as die Bewegungsschnelligkeit anbetrifft, so gibt $\mathrm{H}$ of meister fïr Didymium (Serpula) complanutum (Batsch) Rost. eine solche von $0.4 \mathrm{~mm}$, für Stemonitis fusca eine solche von $0,15 \mathrm{~mm}$ in 1 Minute an.

Hinsichtlich des Mechanismus der Strömungen mub ich mich an dieser stelle damit begnügen, auf Verworn hinzuweisen, der, gestït/t auf die Versuche Kïhne's an Schleimpilzplasmodien, zu dem Satze gelangt, daß „es die chemische Einfügung des Sauerstoffes in die lebendige Substanz sein mub. welche die ()berflächenspannung au bestimmten stellen herabsetzt und so \%ur Pseudopodienbildung führt. Die Protoplasmaströmung aher geht Hand in Hand mit der Protoplasmahewegung, dh. mit der Bildung der Pseudopodien.

Die thermotaktischen Eigenschaften der Plasmodien haben namentlich stahl. Wortmann und Clifford studiert: ersterer hat gereigt. daß sie bis zu einer Temperatur von $+30^{\circ} \mathrm{C}$ positiv thermotaktisch sich verhalten, negativ - nach Wortmann -- bei ïber $+36^{\circ} \mathrm{C}$. Clifford hat ähnliche Resultate zu Tage gefördert und namentlich anch nachgewiesen, daß die Plasmaströmungen sistiert werden wischen +2 und $+3^{0} \mathrm{C}$ und bei $+48^{\circ} \mathrm{C}$; Temperaturen unter, bezw. ̈̈ber diesen ( Frenzwerten sollen bei längerer Einwirkung tötlich wirken (vergl. auch Molisch). Für gewisse Plasmodien mag dies zutreffen, andere dagegen vermögen nachgewiesenermaßen bedentend niedrigere Temperaturen auszuhalten und wahrscheinlich auch höhere, der Todesgefahr entgehend indem sie sich encystieren.

Eine Sistierung der Plasmaströmung wird, wie Clark gezeigt hat. auch durch sauerstoffentzug bewirkt und zwar bereits nach ¿ bis 20 Minuten; wird dann neuerdings Sauerstoff zugeführt, so helt die Strömung wiederum an

Hofmeister, Baranet/ky, stahl berichten äbereinstimmend, dab sich die Plasmodien vom Lichte weg bewegen und Pfeffer vermutet, dab diese negativ phototaktische Bewegung durch die Lichtdifferenz und nicht durch die Lichtrichtung veranlabt werde. Bei schwachem Licht will Hofmeister eine + phototaktische Reaktion konstatiert haben: mäßige Lichtintensität soll ïbrigens auf Plasmodien (sicher lange nicht auf alle) tödlich wirken.

Schinz, Myxogasteres (Rahenhorat Krypt. Flora I, Pilze Abt. X). 
Bekannt ist, daß sich Plasmodien, die sich im Laubversteck aufhalten, zur Zeit der Fruchtkörperbildung a uf das Substrat hegeben; es wird dies in der Regel als eine phototaktische Imstimmung gedeutet, wobei übersehen wird, dab dies auch im Dunkeln geschieht (rergl. Hydrotropismus).

Wird das Ende eines Filtrierpapierstreifens in ein Wasserglas getaucht und bringt man das entgegengesetzte Ende in Berührung mit einem Plasmodium, so kriecht dasselbe den Filtrierpapierstreifen entlang, dem Wasserstrom entgegen, infolge der positiv rheotaktischen Reizwirkung seitens des Wasserstromes und gleicherweise läßt sich von einem positiven Hydrotropismus der Plasmodien, mindestens zu gewissen Zeiten ihrer Entwicklung sprechen, indem die Plasmodien feuchtes Substrat aufsuchen; kurz vor der Fruchtkörperbildung geht dann aber der positive Hydrotropismus in einen negativen über, das Plasmodium kriecht damit aus dem Substrat hervor. Diese Erscheinung ist früher (so von Rosanoff) als geotaktische Reaktionsfähigkeit der Plasmodien gedeutet worden und erst die Untersuchungen Stahl's haben dann hierfür die richtige Erklärung geliefert.

Nach Stah\} werden die Plasmodien durch Loheauszug zu einer + chemotaktischen Kriechbewegung veranlaßt und nach Stange werden die Schwärmer von Fuligo und Chondrioderma in hervorragender Weise durch Milchsäure, Buttersäure, Apfelsäure angelockt. Eine stärkere saure Reaktion, sowie konzentrierte Lösungen etc. üben indessen auf Schwärmer und Plasmodien eine abstoßende Wirkung aus; andererseits berichtet Stalıl, daß die Plasmodien unter Umständen von einer verdünnteren nach einer konzentrierteren Zuckerlösung hinkriechen.

Neuern Datums sind die (zum größten Teil sich allerdings auf das Verhalten der schwärmer beziehanden) Untersuchungen Kusano's, die zum Teil diejenigen stange's bestätigen und ergänzen, zum Teil aber auch berichtigen. Chemotaktisch wirksam erwiesen sich Kusano alle sauren Stoffe und zwar nach Maßgabe ihrer sänrewirkung, dh. ihrer H-Ionen -Konzentration. Durch /ucker, salze, Pepton konnte keine Anlockung erzielt werden. Apfelsäurediäthylester (Stange), $100_{0}^{0}$ Schwefelsäurełösung (Kusano) wirken abstoßend. Die V'ergleichung der von den verschiedenen Forschern gewonnenen Resultate und deren 
Deutung werden wesentlich erschwert durch den Umstand, daß während der Entwicklung ganz unzweifelhaft Umstimmungen stattfinden, daß auch die Herkunft des Materials als Faktor in die Rechnung zu setzen ist, daß, um mich eines Ausdruckes Pringsheim's zu bedienen, die Plasmodien als reizphysiologisch sehr launisch zu taxieren sind.

Alle echten Plasmodien sind Sparophyten. Wohl können, durch Umfließen, lebende Algen, Spaltpilze, Infusorien aufgenommen werden, sie sollen aber, mindestens von ältern Plasmodien (Celakovsky), unversehrt wieder ausgestoben werden, wogegen Lister die Aufnahme und Verdaung ron Bakterien seitens von Schwärmern beobachtet und beschrieben hat. Wortmann hat festgestellt, dab Weizenstärke im Innern von Vakuolen korrodiert wird. Kartoffelstärke in gequollenem Zustande; von bestimmten Plasmodien wissen wir durch Lister, daß sie Pilzmembranen auflösen. Trotz der saprophytisehen Lebensweise sind die Plasmodien bestimmter Arten außerordentlich wählerisch, gehen entweder nur auf Laub- oder nur auf Nadelholz, überkriechen reichlich die Fruchtkörper bestimmter IV aldschwämme (Stereum hirsutum z. B.), umgehen dagegen andere wiederum vorsichtig, ja ich habe die Beobachtung gemacht, daß sich Plasmodien, die ich aus von $\mathrm{Hrn}$. Lister mir überlassenen sclerotien gezogen hatte, ohne Verzug über Stereum-Schnitzel, die ich aus England erhalten hatte, hermachten, Stücke derselben Pilzart aber aus unsern heimischen Wäldern unberïcksichtigt ließen und es vorzogen, die Wände des Kulturgefäßes zu überziehen.

Was die chemische Zusammensetzung der Plasmodien anbetrifft, so liegen bereits verschiedene ( $\%$. B. von Krukenberg, Reinke und Rodewalı u. a.) diesbezïgliche Untersuchungen vor; am bekanntesten ist die Analyse von Reinke und Rodewald, die der Vollständigkeit halber hier wiedergegeben werden mag.

Annäherude Zusammensetzung des lufttrockenen Plasmas ron

\section{Fuligo septica.}

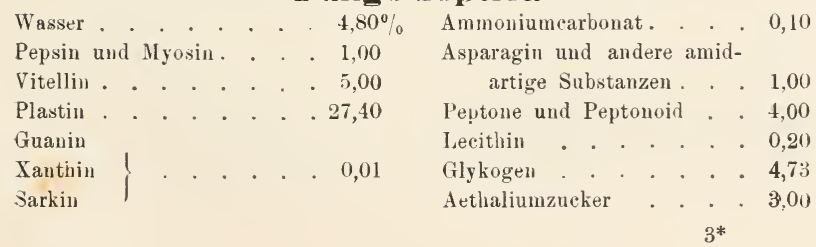


Calciumverbindungen der höhern fetten Säuren . . 5,33

Calciumformat ।

Calciumacetat

Calciumkarbonat . . . . 27,70

Chlornatrium . . . . . 0,10

Bikaliumphosphat . . . . 1,21

Eisenphosphat . . . . 0,07
Maguesiumammoniumphosphat 1,44

Tricalciumphosphat . . . 0,91

Calciumoxalat . . . . . 0,10

Cholesterin . . . . . . 1,40

Fettsäuren im Ätherextract . $\quad 4,00$

Harz . . . . . . . 1,00

Glycerin, Farbstoffe u. a. . . 0,18

Unbestimmte Substanzen . . 5,00

100,00

Manche Plasmodien führen in mehr oder minder großen Quantitäten Kalk und zwar vorwiegend in der Form des Karbonates, daneben aber auch in andern Verbindungen: bei hestimmten Vertretern (ich nenne \%. B. die Physareen) dürfte der kohlensaure Kalk ein Stoffwechselprodukt sein, in andern Fällen mögen die mitgeführten Kalkkörner auch andern Ursprunges sein, wie dies Celakovsky annimmt in Bezug des von ihm bei Trichia contorta nachgewiesenen oxalsauren Kalkes.

Als im allgemeinen für die Plasmodien besonders charakteristisch muß die Pigmentbildung bezeichnet werden. Die Farbstoffe sind mannigfacher Art, gelb in allen Nïancen, desgleichen rot, braun, violett, grün (selten), rein weiß bis rahmweiß u. s. w.

Zopf. Minakata. Lister, Massee, haben in Tabellen die Färbungen einzelner Plasmodien zusammengestellt, aus denen wir folgende Angaben entnehmen:

A manrochaete fuliginosa

Arcyria cinerea

- denudata

- ferruginea

- incarnata.

- insignis

- nutans

Badhamia panicea

- utricularis

Brefeldia maxima

Ceratiomyxa fruticulosa

Comatricha nigra

Comatricha typhoides

Craterium aureum

- leucocephalum gelblichweiß

grauweib

weib

rosa

weiß

milchweiß

weib

grauweib

orangegell

rahmweib

weib, fast durchsichtig

wässerigweil

wässerigweiß

zitronengelb

gell) 
Craterium minutum Cribraria argillacea

- a urantiaca

Diachaea leucopoda.

Dictydiaethalium plumbeum Dictydium cancellatum

Diderma hemisphericum

Diderma spumarioides

I)idymium Clavus

- difforme .

- dubium

- nigripes.

- squamulosum

Enteridium olivaceum Fuligo septica. Hemitrichia Vesparium

Lamproderma sciutillans Lycogala Epidendrum . Margarita metallica. Mucilago spongiosa. Perichaena vermicularis Physarum compressum

- crateriforme.

- nutans

- lencopus.

- melleum

— tenerum

- viride

Reticularia Lycoperdon Stemonitis ferruginea .

_ flavogenita

- fusca

Trichia affinis

- varia. gelb

bleifarbig

saftgrün

weib

rosa

purpurrot zur Zeit der Sporangienbildung

opakweiß

wässerigweiß

grau

weiß bis orangegelb

farblos

bräunlichgrau

wässerigweiß

rosa

gelb

purpurrot zur Zeit der sporangienbildung farblos

rosa

wässerigweiß

weiß

wässerigzimtbraun

grauweib

dunkelokergelb

wässrigweiß bis grünlich

opakweib

orangegelb

hellschlüsselblumengelb

gelb

weiß

weiß

zitronengelb

weiß

rein weib

weib

Bei vielen Arten unterliegt die Färbung der Plasmodien mit den successiven Entwicklungsstadien einem bald mehr, bald 
weniger auffallenden Wechsel. Auch hierfür gibt Zopf (auch Minakata, für außereuropäische Arten) bestimmte Angaben:

Amaurochaete fuliginosa erst weiblich, dann schwach rosa, schwächer dann stärker violett. endlich glänzend blauschwarz

Arcyria denudata .

Comatricha nigra .

Cribraria argillacea

Cribraria macrocarpa

Dictydium cancellatum.

Physarum virescens

Stemonitis ferruginea

Stemonitis fusca

Trichia decipiens. erst weiblich, dann heliziegelrot. später dunkelziegelrot

erst weiBlich, dann fleischfarbig. dann schmutzig rosarot, später intensiv rotbraun bis violettbraun oder schwarz - erst schwarz mit bleifarbigem

schimmer (Fries), dann lehmfarbig

erst schwarzblau (Fries), dann gelbhraun

erst veilchenblau, dann rotbraun erst gummiguttgelb, dann gelbgrün erst gelb, dann rostbräunlich oder

zimtbraun

erst weiblich, dann dunkelbraun erst leuchtend messingrot, dann bräunlichgelb, endlich strohgelb.

In übrigen sei auf den systematischen Teil verwiesen.

Die Farbstoffe scheinen teils in gelöster Form vorzukommen, teils auch an Körnchen gebunden zu sein, letzteres soll z. B. bei den Critrarien allgemein der Fall sein. Angaben hierüber bei Reinke und Rodewald und bei Zopf.

Zopf hat des weitern das Vorkommen von Fettfarbstoffen (Lipochromen) bei Schleimpilzen untersucht und ist zu folgenden Resultaten gelangt: im Plasmodium von Stemonitis ferruginea kommen mindestens drei Farbstoffe vor, ein in $\mathrm{W}$ asser unlösliches gelbes Lipochrom, ein wasserlösliches, amorphes Pigment von Säurecharakter (Stemonitinflacin) und ein dritter, nicht extrahierbarer Farbstoff, der dem Capillitium und den Sporen die charakteristische Färbung verleiht. Cbereinstimmende Befunde zeitigten die chemischen Untersuchungen der Plasmodien ron 
Stemonitis fusca, Lycogala Epidendrum und L. Havofuscum, sodaG also alle vier Schleimpilze als Lipochromproduzenten angesprochen werden können. Die Fettfarbstoffe aller vier Arten gehören der gelben Reihe an.

Ir eitere Untersuchungen liegen hierïber meines Wissens nicht vor.

Von verschiedener Seite sind anch Enzyme verschiedener Art nachgewiesen worden. So von Schroeder (allerdings nicht im eigentlichen Plasmodium, sondern vielmehr im Fruchtkörper von Fuligo septica) ein labendes Enzym, ein in saurer Lösung arbeitendes proteolytisches Ferment und daneben (wahrscheinlich) noch ein in neutraler oder alkalischer Lösung tätiges Ferment, des weiteren Katalase, Tyrosinase, Oxygenasen. Peroxydasen. Hertwig erwähnt das Vorkommen eines peptonisierenden Fermentes, als Gewährsmann Krukenberg vitierend, und Euler (Fuligo) ein proteolytisches, das durch Glyzerin ausgezogen werden kann und bei Gegenwart von $0,4^{0}{ }_{0}$ Salzsäure Fibrin löst.

Unsere Kenntnisse bezïglich der Plasmodien sind im großen und ganzen noch sehr lïckenhaft. was zu einem guten Teil dirauf zuriickzuführen ist, daß in der freien Natur draußen die Plasmodien in der Regel unter Laub und im Innern der Baumstrünke versteckt leben, um erst ganz kurz vor der Fruchtkörperhildung an die Oberfläche zu krjechen, zи einem andern Teil auch darauf, daß die Heranzucht ron lebenskräftigen Plasmodien aus Sporen und Schwärmern erst bei einer geringen $/ a$ ahl von Arten gelungen ist.

\section{Citeratur.}

\section{Plasmodium.}

1899. Bänmler, J. A. Notiz über Brefeldia. Verh. Zool.-Bot. Ges., Wien, XIIX.

1876. Baranetzki, J. Influence de la lumière sur les Plasmodia des Myxomycètes. Iémoires de la Soc. Nat. Se. Nat. de Cherbourg, XX.

18.4. de Bary, A. Vergleichende Morphologie und Biologie der Pilze, Mycetozoen und Bacterien. Leipzig. Vergl, anch die übrigen Publikationen von de Bary, aufgeführt auf S. 7.

1886. Berthold, G. Studien über Protoplasmamechanik. I,eipzig.

18!1. Braconnot, Heuri. Recherches analytiques sur la nature des Champignons, Vll. Auuales de Chimie, LXXX.

1908. Bruck, W. Fr. Beiträge zur Physiologie der Mycetozoen. Zeitschr. f. Allg. Physiologie, ViI.

1892. Celakovsky, L. Über die Aufnahme lebender und toter ver- 
daulicher Körper in das Plasmodinm der Myxouyceten. Flora LXXVI, Ergänzungsband.

1910. Celakorsky, L. O Tyskytorání se oxalátu vápenatého u vyšších myxo mycetů. (Über das Vorkommen von oxalsaurem Kalk beihöheren Myxomyceten.) V'ěstník král. české spol. nauk. Třida II.

1863. Cienkowski, L. Zur Entwicklungsgeschichte der Myxomyceten. Pringsheim's Jahrb. f. wissensehaftl. Bot., III.

1863. - Das Plasmodium. Pringsheim's Jahrb. f. wissenschaftl. Bot., IIl. 1886. Clark, James. Über den Einfluß niederer Sauerstoffpressungen anf die Bewegungen des Protoplasmas. Ber. Dentsch. Bot. Ges., Vl.

1899. Clantrian, Georges. Les réserves hydrocarbouées des Thallophytes. Miscellanées biologiques dediées an Prof. Alfr. Giard, Paris.

1898. Clifford, J. B. Notes on some physiological properties of a Myxomycete plasmodium. Ann. of Bot., XI.

1899. Ensch, Norb. Notes sur les Myxomycètes. Miscellanées biologiques dediées au Prof. Alfr. Giard, Paris.

1882. Errera, L. L'épiplasme des Ascomycètes et le glycogène des végétaux. T'hèse d'agrégation, Bruxelles.

1908/09. Enler, H. Grundlagen der Pflanzenchemie. Braunsehweig.

1906. Gaidukov, N. Über die nltramikroskopischen Eigenschaften der Protoplasten. Ber. Weutseh. Bot. Ges., XXIV.

1901. Harsberger, John W. Observations npon the feediug plasmodia of Fuligo septica. Bot. Gazette, XXX1.

1909. Hertwig, 0. Allgemeine Biologie. 3. Aufl. Jena.

Hilton, A. E. On the cause of reserving eurrents in the plasmodia of Mycetozoa. Journ. Quekett Microse. Club.

1867. Hofmeister, IV. Die Lehre von der Pflanzenzelle. Leipzig.

1901. Jahn, E. Myxomycetenstudien. I. Dictydium umbilicatum schrader. Ber. Dentsch. Bot. Ges., XIX.

1908. - Myxomycetenstudien. 7. Ceratiomyxa. Ber. Deutsch. Bot.Ges., XXVIa.

1907. Jelinek, J. Zersetzung der Gelatine durch șchleimpilze. Sitzungsber. k. Böhm. Ges. Wiss.

1902. Jensen, P. Die Protoplasmabewegung. Ergebuisse der Physiologie, I.

1883. Jöusson. Bengt. Der richtende Einfluß strömenden Wassers auf wachseude Pflanzen und Pflanzenteile (Pheotropismns). Ber. Deutsch. Bot. Ges., 1.

1864. Klemm, P. Einige Beobacht. an Plasmodien von Myxonyceten, bei Kühne, Unters. ü. d. Protoplasma.

1897. Kolkwitz, R. Die Bewegung der Schwärmer, Spermatozoiden und Plasmodien nud ihre Abhäugigkeit von änBern Faktoren. Bot. Centralbl., LXX.

1876. Krnkenberg. Über ein peptisches Enzym im Plasmodium der Myxomyceten und im Eislotter vom Huhne. Unters. aus dem physiol. Institut Heidelberg, Il.

1866. Kïhne, W. Lehrbuch der physiolog. Chemie. Leipzig. 
1881. Kiilz, E. Bildet der Muskel selbständig Glycogen? Arehiv f. d. ges. Physiologie, von PHüger, XXIV.

1888. Lister, Arthur. Notes on the Plasmodium of Badhamia utricularis and Brefeldia maxima. Amn. of. Bot, IJ.

1890. - Notes on Chondrioderme difforme and other Mycetozoa. Ann. of Bot., $1 \mathrm{~V}$.

1901. - On the eultivation of Mycetozoa from spores. Journ. of Bot., XXXIX

1910. Minakata, Kumagusu. Colours of Plasmodia of some Mycetozoa. The Nature, LXXXIII.

1897. Molisch, H. Unters. ï. d. Erfrieren d. Pfinzen. Jena.

1911. Palladin, W. Pflanzenplissiologie. Berliu.

1890. Pfeffer, W. Über die Aufnahme und Ausgabe ungelöster Körper. Abh. math.-phys. Ǩl. Sächs. Ges. Wiss., XVI.

1891. - Plasmahant und Vakuolen. Abh. math.-phys. Kl. Sächs. Ges. Wiss, XVI.

1897/1904. - Pflanzenphysiologie. 2te Aufl, I. und II.

1912. Pringsheim, Erust G. Die Reizbewegungen der Pflanzen. Berlin.

1863. Reichert. Über die neueren Reformen in der Zellenlehre. Reichert's und IDu Bois' Arehiv.

1881. Reinke und Rodewald. Studien über Protoplasma. Entersuch. ans dem bot. Laboratorium Götting., Heft 2 und 1883 Heft 3.

1901. - Einleitung in die theoretische Biologie. Berlin.

1868. Rosanoff, S. Sur l'influence de l'attraction terrestre sur la direction des Plasmodia des Myxomcètes. Mém. Soc. Se. nat. Cherbourg, XIV.

1893. Rosen, Felix. Beitrige zur Kenntuis der Pflanzenzellen. Cohn's Beiträge zur Biologie der Pflanzen, VI.

1906. Schroeder, H. Nachweis einiger Euzyme in dem Fruchtkörper der Lohblitte. Beiträge zur chem. Physiologie und Pathologie, IX.

1861. Schultze, Max. Über Muskelkörperchen. Reichert's n. Dn Bois'Arehiv.

1884. Stahl E. Zur Biologie der Myxomyceten. Bot Zeitung, XLlI.

1890. Stange, B. Über chemotactische Reizbewegungen. Bot. Zeitung IIL. 1909. Verworn, M. Allgemeine Physiologie, 5. Aufl. Jena.

1910. Vouk, V. Untersuchungen ïber die Bewegung der Plasmodien. Sitzungsber. k. k. Akad. Wiss. Wien, math.-naturw. Klasse, CXIX, Abt. 1.

1885. Wortmann, J. Der Thermotropismus der Plasmodien von Fuligo varians (Aethalium septicum d. A.). Ber. Dentsch. Bot. Ges., III.

1885. Zopf, W. Die Pilztiere oder Schleimpilze. Schenk's Handbuch der Botanik, III.

1889. - Vorkommen von Fettfarbstoffen bei Pilztieren (Mycetozoen) Flora, N. R., XLVII.

Vergl. auch die auf S.7/8aufgeführten Monographien von Lister, Massee and Macbride, die zahlreiche Angaben hinsichtlich der Farbe der Plasmodien enthalten. 


\section{Fruchtkörperbildung.}

Ich habe bereits einleitungsweise darauf hingewiesen, daß die Sporen der Schleimpilze exospor auf sogenannten Sporophoren (Ceratiomyxa) (Fig. 1) oder endospor (bei allen ïbrigen Myxogasteres) in Sporangien, Plamodiokarpien oder Aethalien gebildet werden können und wir werden daher in der folgenden Besprechung zweckmäßigerweise auch diese verschiedenen Modifikationen auseinanderbalten.

Wir heginnen mit Ceratiomyxa. Über die Bildung der Sporenträger bei Ceratiomyxa lagen bereits recht sorgfältige Beohachtungen ron Famintzin und Woronin vor, als sich J ahn mit deren Studium zu beschäftigen begann. sein Augenmerk hauptsächlich auf den Moment der Kernverschmelzung und der Reifeteilung richtend. Verweisend anf die eben erwähnte sehr

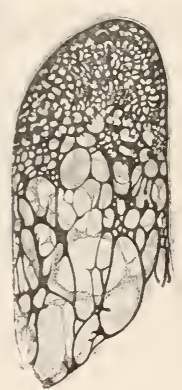

Fig. 15.

Teil eines Plasmoliums von Ceratiomyxa fruticulosa (Mïill.) Macbr., in der Bildung eines Höckers begriffen; das innere körnige Plasma rïickt beim Wachsen des Hornes gegen die Oberfläche desselben zu einer netzartigen schicht, die von außen vou einer ảuBerst dünnen Lage der durchsichtigen, glashellen Gallerte bedeckt ist. $-80 \times-$ Nach Famintzin und Woronin.

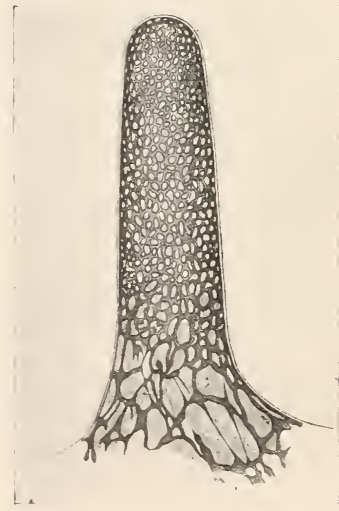

Fig. 16 .

Ein in der Entwicklung noch weiter vorgeschrittenes Horı v. Ceratiomyxa fruticulosa (Müll.) Macbr. $-45 \times-$ Nach Famjutzin und Woronin. 
eingehende Schilderung der Gesamtentwicklung seitens Famintzin's und Woronin's halte ich mich an diesem Orte an die knappe und doch zutreffende Jahn'sche (Myxomycetenstudien, 7.) Charakteristik. Das Plasmodium von Ceratiomyxa ist auBerordentlich lichtscheu und tritt erst unmittelbar vor der Fruchtkörperbildung aus dem Innern der faulenden Baumstrünke, gewöhnlich nach starken Sommerregen, an die Oberfläche des Holzes und erhebt sich nun alsbald vom Substrat, wobei es säulchenoder plattenförmige, häufig auch geweihähnliche Höcker bildet.

Unter dem Mikroskop erkennt man, daß schon in den polsterförmigen Anlagen der Fruchtkörper das Plasma soviel Schleim absondert, daß es ganz darin eingebettet ist. Beim Aufbau der Höcker wird immer neuer schleim erzeugt. Dichteres Plasma findet sich nur an der spitze der wachsenden Hörnchen und an deren Oberfläche. Sind die Fruchtkörper fertig, so sieht man, daß die Hörnchen innen glasig und durchsichtig sind und nur ringsum von einer schmaleu schicht weißen Plasmas bekleidet werden (Fig. 15, 16). Das Plasma hat sich auf der Oberfläche zu einem feinen Netz angeordnet, das zwischen den Fäden erst größere, dann langsam kleiner werdende Maschen frei läßt. Zunächst führen Fäden auch nach innen, dann zieht es sich immer mehr auf der Oberfläche zusammen und zerfällt plötzlich in lauter eng aneinander geschmiegte, amöbenartige Teile. Die Höckerchen erscheinen nun von oben gesehen, wie mit Pflaster bedeckt (Fig. 17). Diese Segmente sind die Anlagen der Sporen. In jedem Segment ist ein Kern wahrnehmbar. Nach einiger Zeit wächst das Plasma der Segmente senkrecht zur Oberfläche empor. wird zu einem zylindrischen, am Grunde sich einschnürenden und damit zum Stiel werdenden Vorsprung. Die Sporen schnüren sich nun ab und nehmen allmählich elliptische Gestalt an (Fig. 18, 19). Daß in diesen Ceratiomyxa-Sporen je 4 Kerne vorhanden sind, wissen wir bereits, wie auch das weitere Schicksal der Sporen, bezw. dieser vier Energiden, bereits bekannt ist. Aus den früheren Ausführungen ist hervorgegangen, da $B$ wir in den Myxoamöben Gameten zu erblicken haben, durch deren Kopulation Zygoten, die Plasmodien gebildet werden und wenn also die Plasmodienkerne infolge dieser Kopulation diploiden, die fertigen Sporenkerne aber gleich den Kernen der Myxoflagellaten 
und Myxoamöben haploiden Charakter besitzen, so muß unbedingt irgendwo im Entwicklungszyklus eine Reduktionsteilung eingeschaltet sein. Jahn hat nun gezeigt, daß diese Chromo-

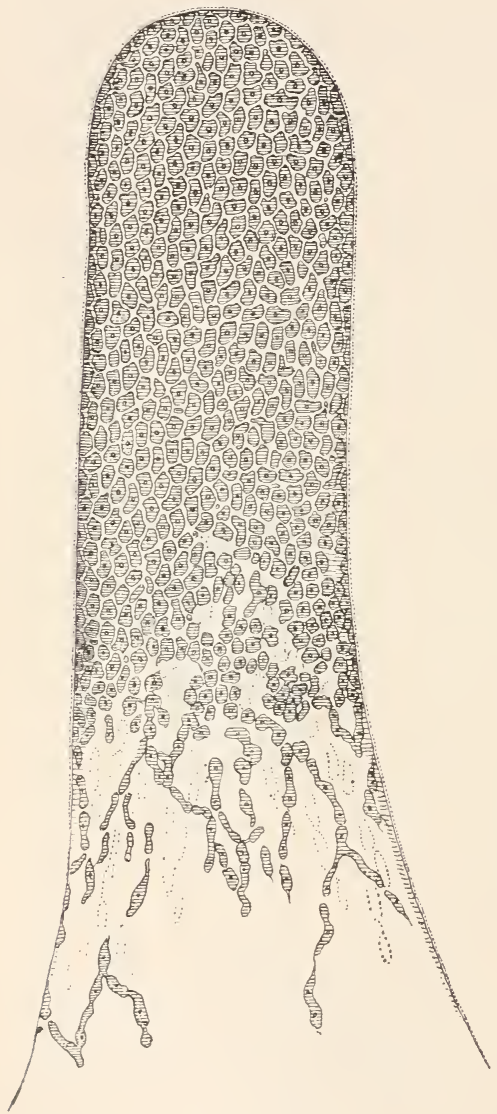

Fig. 17

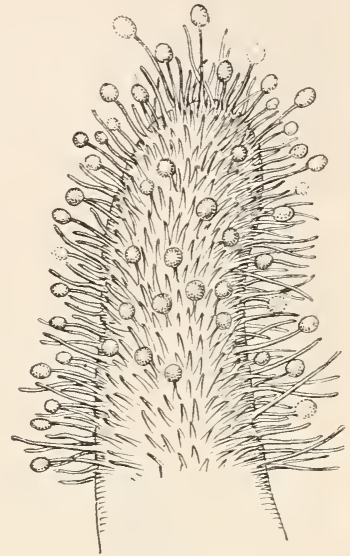

Fig. 18

Ceratiomyxa fruticulosa (Müll.) Macbr. - Die Spitze eines völlig entwickelten Hornes, dessen ganze Oberfläche mit den sporentragenden Stielen besetzt ist. Auf eimzelnen Stieleu sitzen noch halbreife Sporen; die reiferen, schon völlig entwickelten Sporen sind dagegen von ihren Stielen schon abgefallen. - $160 \times-$ Nach

Famintzin und Woronin.

Fig. 17.

Ceratiomyxa fruticulosa (Müll.) Macbr. - Ein völlig ausgewachsenes Horn, in welchem die körnige Plasmaschicht in eine Menge eng an-

einander liegender, abgerundeter, polygonaler Segmente zerfallen ist. $-90 \times-$ Nach Famintzin und Woronin. 
somenreduktion kurz vor der Sporenbildung durchgeführt wird. Er unterscheidet (ich verweise anf die oben reproduzierte Schilderung der Entwicklung der Ceratiomyxa-Fruchtkörper) mit Famintrin und Woronin in der Entwicklung der Fruchtkörper von Ceratiomyxa fünf Stadien: 1. Ein Polsterstadium, 2. ein Streckungsstadium (das der Hörnchenbildıng), 3. ein Maschenstadium (das Plasma bekleidet die Oberfläche der Hörnchen in gewundenen Fäden), 4. ein Pflasterstadium (das der runden Amöben) und 5. ein Sporenstadium. Die Reduktionsteilung (Fig. 13) vollzieht sich offenbar zwischen dem Stadimm 2 und 3, denn auf dem Maschenstadium lassen sich in den sich teilenden Kernen nur noch acht Chromosomen zählen, währenddem vorher sehr deutlich deren 16 wahrnehmbar gewesen sinct. $\mathrm{J}$ a h $\mathrm{n}$ ist mit anderen urspränglich der Ansicht gewesen, daß der Reduktionsteilung eine Karyogamie vorangehe, da tatsächlich in dem sich zur Fruchtkörperbildung anschickenden Protoplasma des Plasmodiums Kernverschmelzungen einer bald größeren, bald

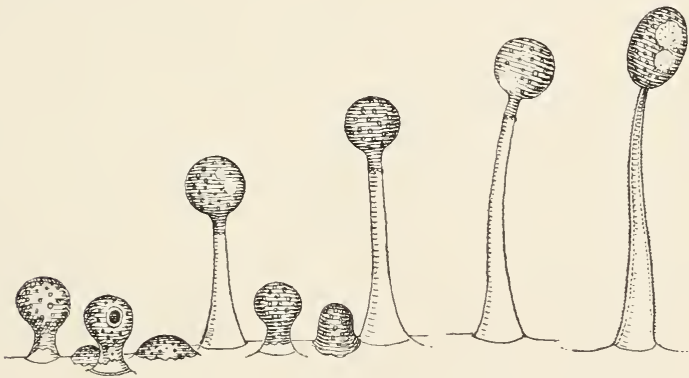

liig. 19 .

Ceratiomyxa fruticulosa (Müll.) Macbr. - Allmählich fortschreitende Entwicklung der stiele und Sporew. $-620 \times-$ Nach Famintzin und Woronin.

kleineren Zahl offenbar degenerierter Kerne konstatiert werden kann; seitdem wir nun aber dank seiner eigenen Untersuchungen wissen, daß die Kernverschmelzungen im Amöbenstadium stattfinden, mubte dieser Gedanke fallen gelassen werden und anstatt, daB die Kerndegeneration als eine Folge nicht erfolgter Paarung betrachtet wird, fassen wir heute umgekehrt die zu Beginn der 
fruktifikativen Periode anftretenden Kernfusionen als eine Folge der Kerndegeneration auf.

Die bei der Fruchtkörperbildung verschmelzenden Kerne sind ,somatische" Kerne, welche aus der Keimbahn ausgeschaltet sind und für vegetative Zwecke: Bau des Fruchtkörpers etc. geopfert werden (Doflein).

Die eben besprochene, der sporenbildung unmittelbar vorangehende Karyokinese ist hereits 1884 von Strasburger entdeckt (Trichia decipiens) und in der Folge vielfach bestätigt worden, so von Rosen, Arthur Lister, Harper, Jahn. Helene Kränzlin u. a. m.: sie spielt sich in allen hierauf untersuchten Fällen während der Bildnng der jungen sporangien ab, und ist stets eine Reduktionsteilung. Als bemerkenswerte. zweifellos sicher gestellte Tatsache sei noch bemerkt, dab die Reduktionsteilung durch einen Teilungsschnitt erreicht wird, daß mit andern Worten die Karyokinese eine einfache ist.

Die Kerne der Sporen haben somit wohl ausnahmslos bei allen Schleimpilzen haploiden. die Kerne der Plasmodien diploiden Charakter. Nach dieser Feststellung wenden wir unsere Aufmerksamkeit nunmehr der Bildung der Fruchtkörper der endosporen Schleimpilze, den mit Sporangien oder Plasmodiokarpien ausgestatteten Myxogasteres zu. Wir können makroskopisch an einem sporangium in der Regel ohne weiteres einen Stiel, einen Sporenbehälter und an letsterem eine mohr oder minder lederige Haut (Peridium), ein Fasernetz oder Fasergerüst (Capillitium und er. eine Säule [Columella] und das Sporenpulver unterscheiden; bei den Plasmodiokarpien fällt der stiel. als fehlend, außer Betracht.

Ueber die Entstehung dieser Gebilde liegen nun, abgesehen von den Sporen, sehr wenige nenere Untersuchungen vor, ich erwähne von solchen die Studien von Jahn, von strasburger und von Helene Kränzlin. Jahn hat in erster Linie die Bildung der sporangien bei Comatricha (olitusata) nigra untersucht und wir können nichts besseres tun, als ihn im Nachfolgenden zur Hauptsache selbst sprechen zu lassen. "Die Sporangien orscheinen auf dem Holz in der Form eines kleinen milchweiben Tröpfchens, gewöhnlich zu mehreren, oft in großen scharen auf einer bestimmten stelle vereinigt, denen sich abseits einige 


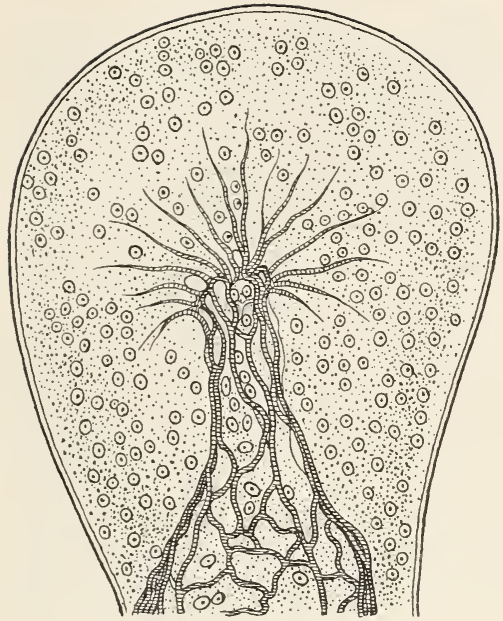

Fig. 20.

Comatricha nigra (Pers.) Schröter. - Medianer Längsschnitt durch ein sehr junges Sporangium, das eben den FuB des Stiels gebildet hat. - $300 \times$ - Nach Jahn.

Fig. 21.

Comatricha nigra (Pers.) Schröter. - Längsschnitt durch den obern Teil eines etwas äIteren Stadiums. Die Fasern bilden noch keine geschlossene Röhre.

- $175 \times$ - Nach Jahn.

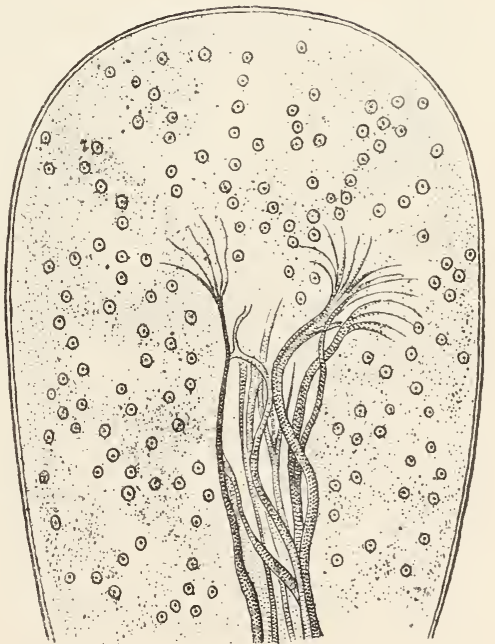


vereinzelte zugesellen. Schon in dem kugelrunden Tröpfchen bemerkt man nach kurzer Zeit die Anlage der untersten Stielteile. bald nimmt die Kugel eine mehr gestreckte Gestalt an, während der Stiel nach oben wächst. An dem Sticl, der immer weiter emporgebaut wird, klettert nun das Plasma empor, und es kommt zunächst eine etwa birnförmige Entwicklungsstufe zustande (Fig. 22.2). Während der Fertigstellung des Stiels rundet die Birne sich allmählich wieder zu einer Kugel ab. Die weiße Farhe des Plasmas geht jetzt in eine rosenrote ïber, die sich langsam durch Schmutzigbraun in Schwar verwandelt. Das Capillitiumnetz wird in der Kugel schon sichtbar, während das

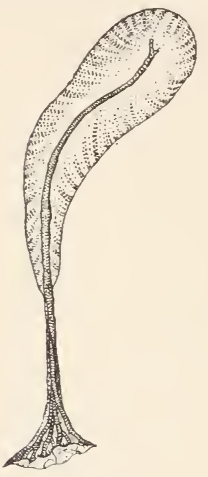

l'ig. 22

Comatricha $n$ igra (Pers).Schröter. - Sporanyium, dessen stiel nahe$z u$ vollendet ist. durch Xylol durehsichtig gemacht. $-30 x-$ Nach Jahu. Plasma noch hell gefärlot ist." Der mit diesen Worten beschriebene Vorgang verläuft verhältnismäßig rasch: $J$ a hn beobachtete hald nach $6 \mathrm{Uhr}$ abends das Erscheinen der winzigen Tröpfchen auf dem Holz, um $8 \mathrm{Uhr}$ hatten die sämtlichen Tröpfchen die Gestalt der Birne angenommen, um $93 / 4$ Uhr war die Bildung des langen Stiels vollendet, das ihn oben abschliebende Plasmakïgelchen war noch weiß gefärbt. Weitere Angaben hetreffend die zur Ausbildung der Sporangien benötigte Zeit finden sich bei Lister. Lister hatte eine Plasmodiumkultur ron Badlamia utricularis auf Auricularia mesenterica (auf welches substrat in meinen eigenen Kulturen die aus Sclerotien derselben Art [Lister'scher Quelle sogar] gezogenen Plasmodien wiederum nur widerwillig gehen) angesetzt. Am 28. Januar (1893) heobachtete er gegen 10 Chr abends. dab sich das Plasmodinm zusammenzog. ein Zeichen heginnender sporangiumbildung. I $\mathrm{m}+\mathrm{Uhr}$ folgenden Morgens hingen an dem zur Nahrung dienenden Pilzkörprr zwischen 1- und 2000 wohlgeformte Sporangien, 4 Thr 15 Min. war mikroskopisch der Beginn der Capillitiumbildung nachweisbar. $11 \mathrm{Uhr} 45$ bis $12 \mathrm{Uhr}$ t5 allgemeine karyokinetische Teilung der Pasmodiumkerne (als Reifeteilung später von Jahn erkannt) und 
um ti Uhr desselben Tages sind die sämtlichen Sporangien schwar\% gefärbt: die Bildung hat damit ihren Abschluß erreicht.

Eine sehr eingehende Schilderung der Ausbildung der Fruchtkörper von Physarum cinerum Pers. var. ovoideum Sace. entwirft Lippert, der wir hier, da es sich un eine durch Kalkausscheidung ausgezeichnete Art handelt, Raum gewähreu. „I)as am ․․ Febr. um 6 Uhr frïh beobachtete baumförmige, weibliche Plasmodium hat sich am substrat verdichtet und die fortschreitende Bewegung sistiert. die noch vorhandenen baumförmigen Ansläufer ziehen sich in die Hauptmasse ein, an Rande und an sonstigen Stellen des Plasmodiums entstehen dicke Anschwellungen. welche sich nach und nach zu sporangien formieren: gegen 11) Uhr erscheint die Formierung abgeschlossen, (s habrn sich 17 milchweiße, rundliche, gegen die Basis verjiingte. meist eiförmige Śporangiumansätze gebildet, welche genan die Grösse der reifen Sporangien haben und noch gan\% weich, mit slatter glänzender Oberfläche und kamm etwas fester als ilas Plasmodimm sind.

I)as um 10 Lhr der Anlage entnommene Sporangium zejgt in II asser unter das Decliglas gehracht, eine gleichmäBige mattweibe Körnchenmasse, welche noch ganz den Charakter des l'lasmodiums besitzt. Durch den Druck des Deckglases wurden yahlreiche kreisrunde Partien aus der Plasmamasse herausgepıebt. welche hyalin und nut äuBerst feinen Körnchen angefüllt erscheinen, ähnlich den Pseudopodien des Plasmodiums. Am liande der Körnchenmasse haben sich die Körnchen dichter rruppiert, den Beginn der Peridienbildung andentend.

I. Uhr. Die sporangien sind gelblichweib, noch gan\% weich: die Oberfiäche derselben erscheint durch aufgelagerte Kalkkörnchen etwas rauh.

In $\mathbb{V}$ asser unter das Deckglas gebracht, zeigt sich bereits die Peridie als feine hyaline Membran. anf deren Anbenseite eine Schichte rundlicher Kalkkörner sichtbar ist, welche sich zum Teile in Wasser von der hyalinen Peridie loslösen und zerstreuen.

Die Ausscheidung des Kalkes hat stattgefunden, derselbe hat sich in viele vom Sporenplasma scharf abgegrenzte milch-

Schinz, Myxogasteres Rabenhorst Krypt. Flora 1, Pilze Abt. X). 4 
weiße Gruppen formiert, an welchen keine bestimnte Wandung zu erkennen ist, sondern nur eine dichtere randweise Aneinanderreihung der runden Kalkkörnchen. Die Gruppierung des Kalkes hat eine den künftigen Capillitiumdrusen ähnliche Form; einige derselben zeigen kurze Aufstülpungen, welche aus dicht aneinander gereihten Kalkkörnchen bestehen.

Im Sporenplasma werden einzelne glänzend helle, runde Körperchen konstatiert, in deren Mitte ein dunkler Kern sichtbar ist.

t Uhr. Die Sporangien sind gelblichweiß, etwas fester: die Oberfläche durch aufgelagerten Kalk ziemlich rauh. Die hyaline Peridie schärfer konturiert; die milchweißen Kalkknoten haben genan die Form der Kalkdrusen des Capillitiumnetzes, die einzelnen Knoten sind vielfältig durch weiße, kalkführende Stränge verbunden; die Außenseite der Kalkknoten zeigt eine hyaline Membran. Im Sporenplasma haben sich die runden glänzenden Körperchen bedentend vermehrt.

6 Uhr. Sporangien gelblichweiß, Oberfläche rauh. Die milchweißen Kalkknoten sind von einem bräunlichen Sporenplasma umgeben.

10 Uhr nachts. Sporangien gelblichweiß, etwas härter, Oberfläche durch ziemlich viel aufgelagerte Kalkkörnchen rauh.

Das Capillitium nähert sich der vollständigen Ausbildung, das Röhrennetz ist erkennbar. Im Sporenplasma hat die Sporenbildung begonnen.

23. Februar, 10 Uhr morgens. Sporangien rötlich, ziemlich fest; die Oberfläche hat sich mit zahlreichen Gruppen von Kalkkörnern bedeckt, welche aus einem Konglomerat äußerst kleiner Körnchen bestehen.

Das Sporenplasma hat sich in seiner ganzen Ausdehnung zu Sporen formiert; farblose runde, 14-21 " große Körper, mit dunklen polygonalen Körpern gefüllt, welche scharf umrandet sind. Die Sporen infolge der dichten Lagerung und des gegenseitigen Druckes polygonal.

Capillitium bereits schön entwickelt.

12 Uhr. Sporangien ins Rotbraune spielend, über und 
über mit Kalkkörnern bedeckt, so daß die Oberfläche bläulichgrau erscheint.

Sporen schwach rötlich, mit feinkörnigem Plasma angefüllt, meist mit einigen dunklen, teils runden, teils polyedrischen Körpern. Die Grösse der Sporen variiert von 14-18 ", meist polygonaler Form.

Die die Kalkdrusen verbindenden Fäden als hyaline Röhren deutlich sichthar, ohne Kalkinhalt; das Capillitiumnetz ist vollständig ausgebildet. Die Drusen sind teils mit runden, teils mit eckigen Kalkkörnern angefüllt.

24. Februar, 10 Uhr morgens. Sporangien schwarzbraun, Oberfläche dicht mit Gruppen von Kalkkörnchen übersät, so daß die Sporangien aschgraı erscheinen.

Sporen braunviolett, $10-12 \mu$ groß. Das Sporangium ist reif.

Die vollständige Reife des Sporangiums ist somit in einem Zeitraume von 48 Stunden erfolgt.

Die einzelnen Entwicklungsphasen verfolgend, finden wir hier die Bildung des Capillitiums jener der Sporen zeitlich ziemlich vorangehend, dagegen die Bildung der glänzenden Kernkörperchen zeitlich mit dem Beginne der Capillitiumbildung zusammenfallend. Zu seiner vollständigen Entwicklung hat das Capillitium fast den doppelten Zeitraum als die Sporen benötigt, welche erst nach etwa 20 Stunden in ihrer eigentlichen Form auftreten, während die ersten Anfänge des Capillitiums schon sehr kurze Zeit nach der erfolgten Formvollendung des Sporangiums aus dem Plasmodium sich gezeigt haben.

Fast unmittelbar nach der Formung des Sporangiums ans dem Plasmodium hat die Ausscheidung des Kalkes aus dem Sporenplasma stattgefunden, der größte Teil desselben wird in den Drusen des Capillitiums abgelagert, während der andere Teil sich an der AuBenfläche der Peridie absetyt.

Unmittelbar nach der Formung des Sporangiums ist die Außenfläche desselben glatt und glänzend, mit einer dicken Schicht aufgelösten Kalkes überzogen: nach ganz kurzer Zeit scheidet sich der Kalk in Körnchenform aus und die Außenfläche wird rauh und erscheint mit glänzenden, eckigen Körnchen- 
partien netzförmig überlagert; je weiter die Entwicklung des sporangiums vorschreitet, desto dichter und massiger werden diese Ablagerungen, welche schlieBlich als weiße Punkte oder krustenförmiger C̈berzug meist schon dem bloßen Auge sichtbar sind.

Der im Innern des Sporangiums zurückgebliebene Kalk füllt die Blasen des Capillitiums aus. In ersten Entwicklungsstadiun werden diese Blasen oder Knoten von einer Aneinanderlagerung ron Kalkkörnchen gebildet, welcher jegliche Spur einer Wandun mangelt, an den Rändern zeigt sich nur eine dichtere Aneinanderreihung dieser Körnchen, und erst in einem zwei Stunden älteren Stadium umschließt sie eine zarte, hyaline Membran. welche sich auch auf die feinen Fortsätze ausdehnt: im weiteren Verlaufe werden diese Fortsätze kalkfrei; wahrscheinlich zieht sich der Kalk in die Knoten zurück und es entstehen schlauchoder röhrenförmige Gebilde, welche die einzelnen Knoten zum charakteristischen Capillitiumnetz verbinden.

Gleichzeitig mit der Ausscheidung des Kalkes ans den sporenplasma, die auch der Beginn der Capillitiumbildung ist. findet die Bildung der Kernkörperchen statt; es zeigen sich dunkle, von einem hellen Plasmahofe umgebene Kerne, dies sind die ersten Anfänge der Sporenbildung; im jüngsten Entwicklungsstadium des sporangiums treten diese Kernkörperchen nur vereinzelt auf, später werden dieselben zahlreicher und schließlich wird das ganze Sporenplasma von ihnen angefüllt. Im weiteren Verlaufe wird der helle Plasmahof getrübt, er vergrößert sich durch Hinzutreten der freien Plasmapartien, bis sich schließlich 1 m jeden Kern eine der Größe der Sporen entsprechende Plasmamasse angesammelt hat; in diesem Stadium ist eine diese Sporengebilde umschließende Membran noch nicht zu erkennen, diese entwickelt sich jedoch rasch darnach und mit ihrer Entstehung nehmen die Sporen eine mehr regelmäBigere polygonale Gestalt an.

Im weiteren Verlaufe verdichtet sich die durch die Membran eingeschlossene Plasmamasse, die polygonalen Körper werden kleiner, bis sie schließlich im Zeitpunkte der Reife sich zur Kugelgestalt umbilden. In diesem letzten Entwicklungsstadium tritt die Färbung der sporen ein, welche im Beginne sehr blab und kaum bemerkbar ist, aber rasch alle Nuancen durch- 
macht, um schlieblich bei der charakteristischen dunklen Farbe anzulangen. Unaufgeklärt ist, in welcher Form dieser Farbstoff sich im Sporangium befunden hat."

In entsprechender Weise hat Lippert auch noch die Ausbildung der Sporangien bei Chondrioderma difforme und bei Didymium microcarpm verfolgt und in allen Fällen konstatiert, daß die Bildung des Capillitiums jener der Sporen zeitlich vorangeht.

Ich kehre zu Jahin zurück. Der allmähliche Aufbau des Stiels und die Absonderung seiner Substanz aus dem Plasma hat schon de Bary interessiert und ihn zu einer genauen Untersuchung bei Stemonitis veranlaßt. Seine Beschreibung des Torganges deckt sich im wesentlichen mit jener Jahn's und ich kann mich dalrer damit begnügen, anf die de Bary'schen Untersuchungen hingewiesen zu haben. "Der Stiel," ich halte mich wiederum an die Ausführungen $J$ a hn's, ,bildet nun im unfertigen Zustand eine Röhre, deren Wand mindestens an der Spitze eine Sonderung in eine farblose Außen- und eine gefärbte Innenschicht erkennen läßt. Am Ende breitet sich der stiel in eine trichterförmige, längsstreifige Haut aus. Aber nur beim Herausziehen des Stiels ans dem Plasma oder auf Querschnitten," sagt Jahn, "wenn das Plasma sich beim Fixieren in günstiger Weise von der Columella abgelöst hat, ist sie als zarte durchsichtige Membran sichtbar, auf Längsschnitten kann man sie nicht unterscheiden, sondern sieht nur die pinselförmige Ausbreitung der Fasern. In den unteren Teilen besteht der Stiel nicht aus einem Zylinder. sondern einem Gerüst einzelner, bandförmiger, derber Fasern, von denen die meisten im Kreise angeordnet sind, manche sich aber auch im Innern befinden. Jede dieser Fasern rerliert sich einzeln pinselartig im Plasma, die Endigungen werden jedenfalls auch durch eine feine Haut verbunden sein, wenn diese auch schwer sichtbar gemacht werden kann." Fig. 20, ㄴ1.

"Vermutlich“, fährt Jahn fort, "geht der Aufbau in der Weise vor sich, dab zu unterst erst einzelne Fasern abgesondert, bald durch eine Membram verbunden und mit steigender Regelmäßigkeit zu einer Säule vereinigt werden. Ist erst eine geschlossene Röhre zustande gekommen, so erfolgt die Verbindung der Faser durch die Haut, die sich nun zu einem Trichter zu- 
sammenschließt, frühzeitiger." Während des Aufbanes des Stieles noch beginnt bereits die Anlage des Capillitiums und zwar werden die ersten Äste desselben als Fortsetzung der Säule angelegt, weitere folgen dann in der Reihenfolge von oben nach unten.

Dies die Hauptpunkte der de Bary'schen und Jahn'schen Untersuchungen an Stemonitis und Comatricha; daß auch hier noch weite Lücken unüberbrückt, und weitere Studien sehr erwünscht sind, ist unverkennbar.

Anders verläuft die Sporangienbildung bei Dictydium cancellatum (Fig. 23), welchen Schleimpilz J a h n in den zwei Varietäten fuscum und alpinum untersucht hat. Die Plasmodien erscheinen

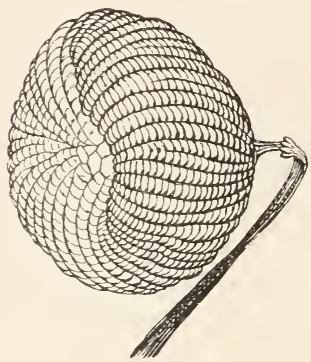

Fig. 23.

Dictydium cancellatum (Batsch) Macbr. - Sporangium. $-35 \times-$ Nach Jahn.

Fig. 24.

Cribraria pyriaeformis Schrader Sporangium, $-40 \times-$ Nach Rostafinski.

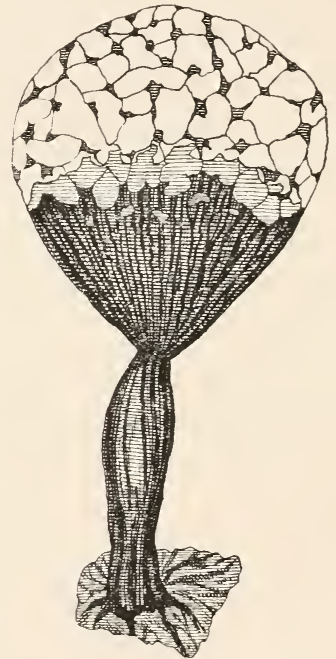

Fig. 24.

bei diesem auf dem Substrat in der Form kleiner, breit aufsitzender, schwarzblauer Tröpfchen, von denen ein jedes sich nach kurzer Zeit unten unregelmäßig einschnürt, wodurch der Plasmaklumpen auf massigem Stiel in die Höhe gehoben wird. Die Erhöhung ist eine Folge einer unterwärts stattgehabten 
Faltelung der die Kugel umgebenden Haut. Der Stiel setzt sich nicht wie bei Stemonitis und Comatricha in das Innere der Plasmakugel fort, der Aufban des Sporangiums erfolgt denn auch bei Dictydium, bei Cribraria (Fig. 24) etc. nicht wie dort dadurch, daß Plasma an der Außenseite des Stieles emporkriecht, sondern das Plasma strömt durch den Stiel, dessen Wandung erhärtet ist, nach oben.

Trichia und Arcyria sind ron Strasburger und Helene Kränzlin eingehender untersucht worden. Der Vorgang der Sporangienbildung hat hier einige Ähnlichkeiten mit dem bei den Cribrarieen (Dictydium). Die jungen Sporangien treten gleichfalls in Form kleiner Tröpfchen auf, nehmen hierauf Zylinderform an unter gleichzeitiger Einschnürung des untern T'eiles, was geschieht, indem die Hauptmasse des Plasmas aus dem untern Teil nach oben wandert. Der FuB zeigt nun Schrumpfungserscheinungen, d. h. seine Wand legt sich in Falten, ähnlich einem zusammengelegten Schirm. Durch den Stiel strömt nun das Plasma in die zum Zylinder oder eiförmigen Sporangium sich streckende Plasmakugel. Im Gegensaty zu Dictydium bleibt aber ein beträchtlicher Teil des Plasmas in Stiel zurück, beteiligt sich zwar an allen im Sporangium erfolgenden V'eränderungen, liefert aber keine normalen einkernigen sporen. Unter der Glashälle der Trichien und Arcyrien versteht man eine glasartig durchsichtige, das ganze Sporangium ïberziehende Haut, die auf dem Sporangiumscheitel dünn, seitlich dagegen kräftig ist und am Grunde in den Hypothallus übergeht; das ist ein in vielen Fällen das Substrat in Form einer oft silberglänzenden Hant überziehender und nicht zur Bildung der Sporangien aufgebrauchter Rest des Plasmodiums.

Das Aethalium ist die seltenste Fruktifikationsform, es wird nur bei den Endosporeen angetroffen und auch dort nur bei einer beschränkten Zahl von Arten. Die Aethalien von Dictydiaethalium, Enteridium, Reticularia, Mucilago (Fig. 25), Fuligo (Fig. 26) repräsentieren die höchsten Fruchtformen der Myxogasteres, es sind gewissermaßen Sporangiensori, in welchen jedes Sporangium seine Individualität mehr oder weniger verliert, wodurch eine ziemlich geschlossene Einheit zustande kommt. Hinsichtlich Fuligo (Fig. 26), Plyysarum gyrosum (Fig. 3) etc. 
kann man allerdings im Zreifel dariber sein, ob man nicht besser dessen Aethalium als eine Sammlung ron Plasmodiokarpien bezeichnet. wie denn auch eine scharfe Grenze zwischen den drei Fruchtformen schwierig $\%$ ziehen ist. Einige der Aethalien sind nackt. andere sind dentlich berindet.

Bei Lindluladia effusa ist der Crsprung des Aethaliums ans Sporangien noch sehr leicht konstatierhar: es hesteht ans z. T.

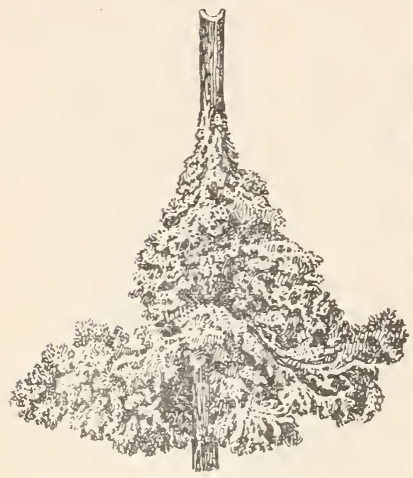

Fig. 25.

Aethalium vou II cilago spongiosa (LeyBer) Morgan - $1 \times-$ Nach Postafiushi.

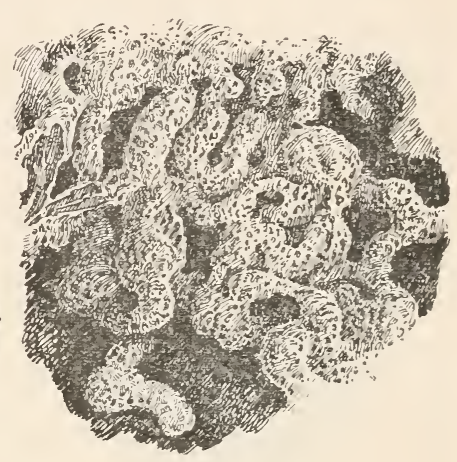

Fig. 26.

Fuligoseptical L. Gmelin - Aethalium. - $20 \times-$ Narh Lister.

säulenförmig nebeneinander stehenden, unter einander rerwachsenen Einzelsporangien, deren zentralste infolge des Inruckes polygonalen Querschnitt besitzen (Fig. 34-36). Bei Mucilago sind die sporangien rersweigt und üher den srößten Teil ihrer Länge miteinander rerkleht: sie stehen sehr dicht zusammen und bilden in dieser Weise ein traubenartig gelapptes Aethalium, das, da die spitzen der Einzelsporangien frei bleiben, entfernt an eine Koralle erimnert. Bei Lycogala werden die Einzelsporangien iiberhaupt nicht mehr angelegt oder sie obliterieren frïhzeitig, die ganze ron der dick lederigen Peridie mmkleidete /entralmasse bildet sich in sporen und Capillitinnfäden um.

Die Entricklung der Aethalien haben de Bary und Zopf untersucht. eine Nachuntersuchung mit Hiilfe der modernen 
mikroskopischen Technik und unter Berïcksichtigung der neuen cytologischen Erkemntnisse ist dringend notwendig, schwierig

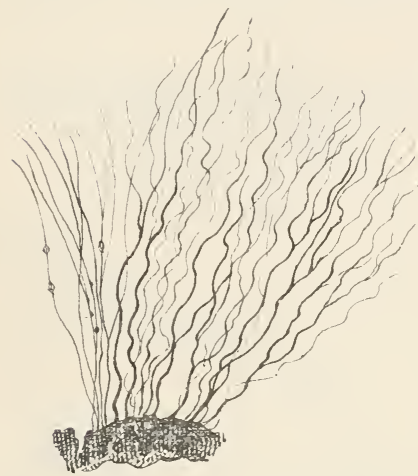

Fig. 27.

Capillitium von Lepidoderma tigrinum (Schrad.) Post.

- $200 \times$ - Nach Lister. allerdings -schon aus dem einfachen Grunde, weil die Plasmodien lichtschen sind und die Kultur immer noch anf große schwierigkeiten stößt.

Die Peridie oder Sporangiumhaut, der Rinden schicht des Protoplasmas entsprechend, scheint in ihrer äußersten Lage öfters kuticularisiert zu sein, zeigt mitunter die charakteristischen Reaktionen der Zellulosa und sehr häufig Auf- oder Einlagernngen ron kohlensaurem Kalk in Form ron Krystallen oder Schülferchen (Fig. 28), von oxalsaurem Kalk bei Trichic contorta und Perichaena-Arten, wobei es sich allerdings nach der Anschauung von Celakovsky beim oxalsauren Kalk um fremde, zufällige.
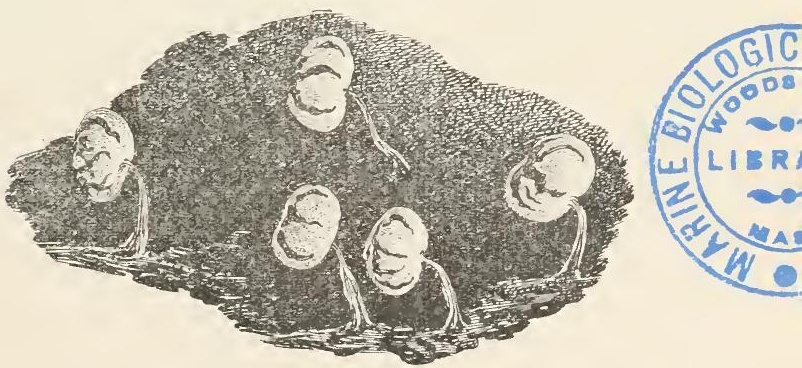

Fig. 28.

Sporangien von Physarum nutans Pers., mit Kalkanflagerung. - $20 \times$ - Nach Lister.

dem Substrate entstammende Beimengungen handeln würde. CriIraria und Dictydium sind ausgezeichnet durch das Vorkommen 
von sogenannten Dictydinkörnern $(J$ a $h n)$, die bei der Sporangienbildung dieser beiden Gattungen eine bestimmte Rolle zu spielen scheinen, die eine auffallende Resistenz gegen Säuren und Al-
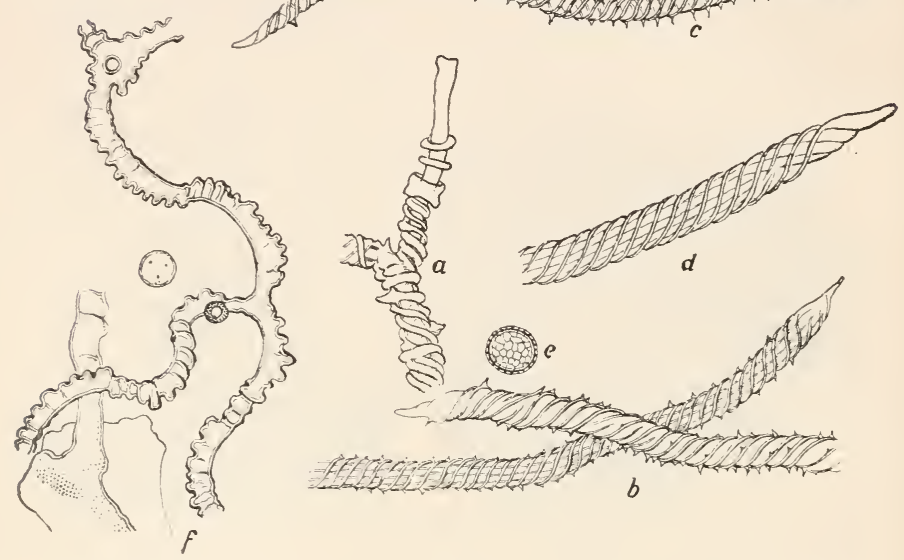

Fin. 29

Capillitiunfäden: a) vou Trichia scabra Rost,, b) von Trichia versimilis Karst.; c) von 'Trichia erecta Rex; d) von Trichia favoginea (Batsch) Pers. e) Sprore von Trichia persimilis Karst.; f) Spore und Capillitum von Areyria denudata (L.) SheJdon, $-600 \times$ - Nach Lister.

kalien zeigen und ron dunkler Färbung sind. Jahn hält es nicht für ausgeschlossen, dab es sich trot\% des Ausbleibens der charaliteristischen Reaktionen um eine der Zellulose verwandte Substanz handelt.

I)as Capillitium (Fig. 27, 29, 32) besteht, wie wir bereits erfahren hahen, entweder aus netzartig untereinander verbundenen Röhren oder Fasern. oder aus freien Elateren, d. h. isolierten Faserröhren mit mehr oder minder zugespitzten Enden. Die Elateren und die aus anastomosierenden Fasern bestehenden Netze zeigen bei bestimmten Arten in lokalen Anschwellungen oder in den Mascluenecken blasenförmige Erweiterungen mit kohlensaurem Kalk (Fig. 36), die ('apillitien und Elateren anderer Arten 
wiederum sind charakterisiert durch Verdickungsleisten, die der Außenseite aufgelagert sind in der Form ron spiralförmig ver-

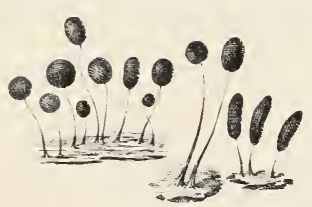

Fig. 30 .

Comatricha nigra (Pers.) Sehröter Sporangien. $-4 \times-$ Nach Lister.

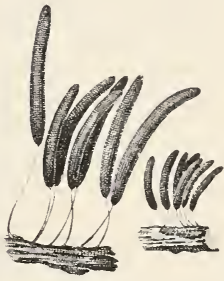

Fig. 31 .

Stemonitis Smithii Nacbr. Sporangien. $-2 \times-$ Nach Lister.

laufenden schmalen Bändern, von halben oder ganzen Ringen, von Kämmen oder von Spitzen. Mit der Bildung der Elateren haben

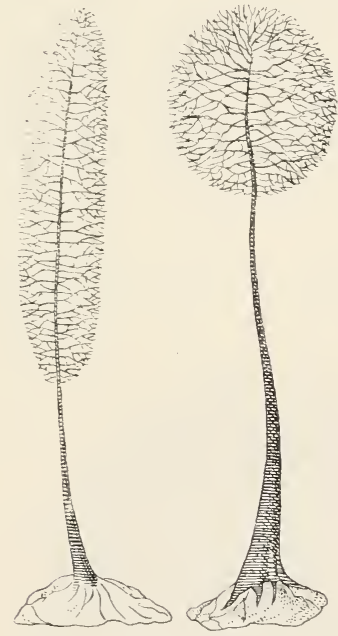

Fig. 32.

Rechts Sporangium von Comatricha nigra (Pers.). Sehröter, links vou Comatricha typhoides (Bull.) Rost. - $30 \times-$

Rost., beide mit Columella aber ohne Peridie. $-15 \times-$ Nach Raunkioer. 
uns Strasburger und in jüngster Zeit Helene Kränzlin bekannt gemacht. Ihre Untersuchungen zeigen, daß die Elateren der Trichien aus Saftvakuolen, die nach Helene Kränzlin aus dem Centrosomenapparat zugrunde gehender Kerne gebildet

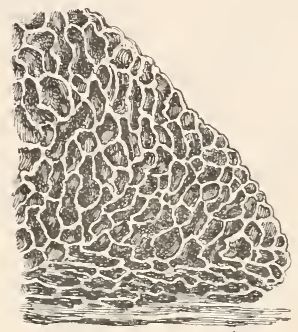

Fig. 33.

Lindbladia effusa (Ehrenb.) Rost.

Vertikalschnitt durch ein polster-

förmiges Aethalium - $9 \times-$

Nach Lister.

werden, hervorgehen, wobei $\mathrm{W}$ and und die spiralbänder aus Mikrosomen sich bilden sollen (Strasburger). Über die Bildung der nicht (das Vorkommen solcher ist nicht unbestritten) hohlen Fasern anderer Schleimpilze wissen wir zur Stunde noch nichts sicheres.

Des Vorhandenseins einer Säule oder Columella bei einer Reihe von Gattungen(Stemonitis, Comatricha, [Fig. 32] Didymium, Lepidoderma, Diderma [Fig. 37] и. a. m.) ist zum Teil bereits

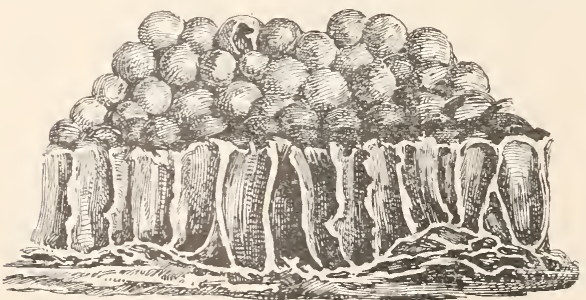

Fig. 34.

Lindbladia effusa (Ehreub.) Rost. var. simplex Rex. Sporangien zu ت̈thalien zusammengedrängt. $-10 \times-$

Nach Lister.

gedacht worden, ich werde hierauf zurückzukommen Gelegenheit im systematischen Teil haben. 
Auch hier mangelt es sehr an neueren Untersuchungen, ausgefïhrt unter Zuhilfenahme der modernen, namentlich in den letzten Jahren so ausgiebig ausgebauten mikroskopischen Technik.

Die Capillitiumbestandteile sind hygroskopisch und führen entsprechende Bewegungen aus, die von Ursprung näher untersucht worden sind; er hat gezeigt, daß nicht, wie man etwa ans Analogie zu den Lebermoos-Elateren hätte schließen können, Kohäsion beteiligt ist, sondern daß es sich um reine Hygroskopie handelt.

Das Öffnen der Fruchtkörper zum Zwecke der Sporenentlassung geschieht durch mehr oder minder unregelmäßiges Aufreißen der Peridie und zwar infolge von Spannungen beim Austrocknen dieser, wobei dann das sich ins Freie drängende Capillitium noch aktiv mitwirken mag. Bei Dictydium-Arten bleiben bestimmte Peridienpartien in der Form von Längs- und Querverstrebungen in überaus zierlicher Ausbildung erhalten, desgleichen bei Cribraria etc.; ich verweise in dieser Hinsicht vorlänfig auf die Fig. 2:3 und 24. Sind die Sporen einmal frei und bieten sich ihnen die passenden, und in der Hauptsache leider noch unbekannten Keimungsbedingungen, so beginnt der Entwicklungsgang, von dem wir ausgegangen sind, in unserer gedrängten Schilderung, aufs neue.

Vouk hat jüngst auf Grund der frühern Untersuchungen Jahn's etc. den Generationswechel bei den Myxogasteres diskutiert: seine Ausführungen sind inzwischen überholt worden von den neuern Studien Iahn's, aus denen, wie wir an anderer Stelle bereits dargetan haben, hervorgeht, daß es sich bei der Karyogamie um eine Erscheinung der Degeneration, und nicht um eine „Befruchtung“ handelt.

Im Anschlub an diese Ausführungen sei auch noch kur\% auf die Frage der Bastardbildung bei den Myxogasteres eingetreten. Experimentell will M assee solche Bastarde erzeugt haben, indem er in einem Fall ,junge Plasmodien“ von Physarum leucolus zu solchen von Physarum nutans leucophaeum gebracht hat, im zweiten Fall kam es zur Bildung eines Bastardes zwischen zwei Trichia-Arten. Im ersterwähnten Bastardierungsversuch wurden die beiden artverschiedenen Plasmodien so 
einander genähert, daß sie sich an der Berührungsstelle vermischten; die Folge hiervon war. daB sich an der Vermischungs-

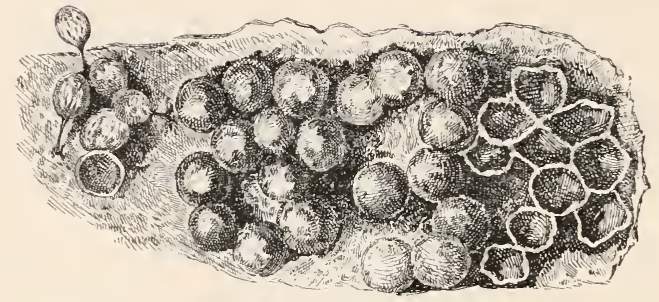

Fig. 35.

Lindbladia effusa (Ehrenb.) Rost. var. simplex Rex. - Zum Teil gestielte, zum Teil ungestielte, frei oder verwachsene Sporangien. $-10 \times-$ Naci Lister.

stelle Sporangien entwickelten, die intermediär zwischen den beiden Arten in ihrer Ausbildung waren, während aus den unvermischten Plasmodienpartien Sporangien der entsprechenden Art sich ausbildeten. Auf den "Trichia-Bastard" geht der Experimentator leider gar nicht ein. Aus Jahn's Untersuchungen wissen wir nun, dab die Kerne der Plasmodien somatische Kerne sind und wir können uns daher nicht vorstellen, wie durch Vereinigung der beiden artfremden Plasmodien Bastarde - die Frage der Pfropfbastarde steht vorläufig noch nicht auf genügend befestigten Füßen - entstehen sollen, es sei denn, jene Bastardsporangien seien gewissermaßen Periklinalchimären gewesen, d. h., ein Physarum nutans leucophaeum Capillitium steckend gleich der Hand in einem Handschuh, in einer Physarum leucopus Peridie! Sexualcharakter besitzen die Kerne der aus Schwärmern hervorgegangenen Amöben; diese sind aber bekanntlich so unscheinbar, dab keine Rede davon sein kann, es habe sich hier etwa um eine absichtliche Vermählung von $P$. nutans Amöben mit solchen von $P$. leucopres gehandelt.

Auch Ch. Martin glaubt einen Bastard, Trichia contorta Rost. X Hemitrichia Karsteni Lister gefunden zu haben, im Sporangienzustand, der die Eigentümlichkeiten beider Genera in sich vereinigte. 
Dem gegenüber sei auf die äußerst sorgfältigen experimentellen Untersuchungen Bruck's verwiesen, aus denen her-

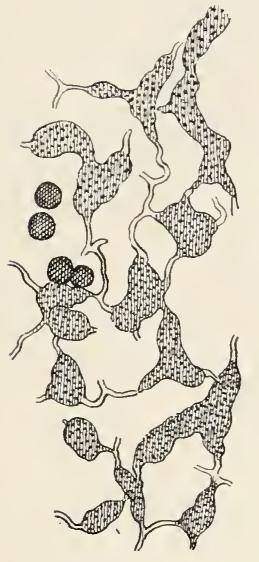

Fig. 36 .

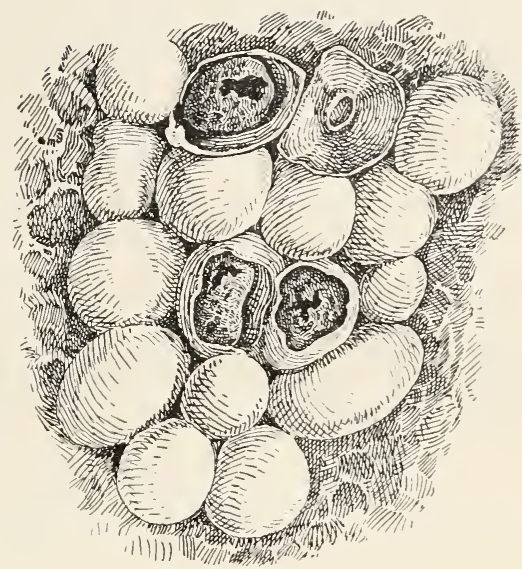

Fig. 37.
Capillitium von Fuligo muscorum (Fries) Alb. et. Schw., mit Kalkknoten. $-280 \times-$ Nach Lister.
Sporangien von Diderma spumarioides Fries zum Teil geöffuet und dann mit zu Tage tretender Columella $-20 \times-$ Nach Lister.

vorgeht, daß Plasmodien von Didymium difforme (Pers.) Duby (= Chondrioderma difforme Rost.) und Didymium squamulosum Alb-et Schw.) Fries (Didymium effusum Link) nicht miteinander verschmelzen, vielmehr kontraktorische Erregung aufweisen, daß dagegen Plasmodien derselben Art untereinander verschmelzen und zwar $\alpha$ wenn das Aussaatmaterial von verschiedenen Sporangien, $\beta$ aus einem Sporangium, $\gamma$ einer isolierten Spore entstammt.

Vorläufig bleibt nichts anderes übrig als zu betonen, daß die Bastardierungsexperimente Massee's in ihren Resultaten noch von keiner Seite Bestätigung gefunden haben; sie sind wohl mehrfach wiederholt worden, doch ausnahmslos ohne Erfolg.

Einer Bestätigung harren auch noch die Angaben Pinoy's betreffend den geschlechtlichen Dimorphismus von Plasmodien. Pinoy züchtete Plasmodien von Didymium nigripes und beob- 
achtete hichbei zweierlei Plasmodien dieser Art, gelbe und lunkelviolette, die er beide isoliert kultivierte. Für sich allein bildeten diese Plasmodien niemals Fruchtkörper, sondern nur sklerotien. Erst als er Cysten, bezw. Sporen vom einen und vom andern Plasmodium zusammen kultivierte. bekam er ein weißgraues Plasmodium. welches fruktifizierte. Pinoy erklärt diese Erscheiumng mit der Theorie der sexuellen Dynamik von Blakeslee und nimmt zweierlei Kerne an, positive und negative. welche nur durch gegenseitige Verschmelzung Sporen bilden (nach dem Referate vou V. Vouk). Pinoy's Dimorphismus wäre event. diskutierbar, wenn es sich anstatt um Plasmodien, um schwärmer oder $11 \mathrm{~m}$ Amöben handelte; es ist aber nicht einzuselsen, wie er zu haploiden Kernen gelangt sein kann, da seine dimorphen Plasmodien ja doch nur encystierten und keine Fruchtkörper ausbildeten.

\section{Literatur.}

\section{A. Reduktionsteilung, Fruchtkörperbildung, Sporen- und Capillitiumbildung.}

[908. Auonymus. Nuclear Fusion and Reduction Phenomena in Myxomycetes. New Phytologist, VIII.

1910. Conrad, Henry S. Spore Formation in Lycogala exiguum Morg. Proc. lowa Ac. Science, XVII.

1873. Famintzin und Woronin. Über zwei neue Formen von Sehleimpilzen Ceratium hydnoides A. et. S. und Ceratium porioides A, et. S. Mem. Ac. Imp. St. Petersburg, VII, Vol. XX.

1837. Corda, A. C. I. Über Spiralfaserzellen in dem Haargeflechte der Trichien. Prag.

1900. Harper, R. A. Cell and nuclear division in Fuligo varians. Bot. Gazette, XXX.

1905. - Sexual reproduction and the organisation of the nucleus in certain mildews. Carnegie Institution of Washington, Nr. 37.

1854. Henfrey, Arthnr. Note on the Elaters of 'Trichia.

1899. Jahn, E. Zur Kenntuis des Schleimpilzes Comatricha obtusata Preuss. Festschrift für Schwendener. Berlin.

1901. - Myxomycetenstıdien. 1. Dictydium umbilicatum Schrader. Ber. Deutsch. Bot. Ges., XIX.

1907. - Myxomycetenstudien. 6. Kermverschmelzungen und Reduktionsteilungen. Ber. Deutsch. Bot. Ges., XXV.

1908. - Myxomycetenstudien. 7. Ceratiomyxa. Ber. Deutsch. Bot (ies., XXVI a.

1907. Kränzlin, Helene. Zur Entwicklungsgeschichte der Sporangien bei den Trichien und Arcyrien. Archiv f. Protistenkunde, IX. 
1896. Lippert, Chr. Ein Beitrag zur Biologie der Myxomyceten. Verh. Zool.-bot. Ges. Wien, XLVI.

190\%. Olive, E. W. Cytological studies in Ceratiomyxa. Traus. Wisconsin Acad. of Sciences, XV.

1907. - Evidence of Sexual Reproduction in Slime Moulds. Science, N.S., XXV.

1904. Prowazek, I. Kernveränderungen in Myxomycetenplasmodien. Österr. Bot. Zeitschr., LIV.

1814. Schlechtendal, D. F. L. Über die Spiralfaserzellen bei den Pilzen. Bot. Zeitung, II.

1884. Strasburger, E. Zur Entwicklungsgeschichte der Sporangien von Trichia fallax. Bot. Zeitung, XLII.

1913. - Das botanische Praktikum. 5. Aufl. Jena.

1906. Ursprung, A. Über den Bewegungsmechanismus des Trichia-Capillitiums. Ber. Deutseh. Bot. Ges., XXIV.

1885. Zopf, W. Die Pilztiere oder Schleimpilze. Schenk's Handbuch der Botanik, III, 2.

1863. Wigand, A. Zur Morphologie und Systematik der Gattungen Trichia und Arcyria. Pringsheim's Jahrb. Wiss. Bot., III.

Vergleiche auch wiederum die Publikationen von de Bary.

\section{B. Bastardierung, Dimorphismus, Generationswechsel.}

1908. Bruck, W. Fr. Beiträge zur Physiologie der Mycetozoen. Zeitschr. f. Allg. Physiologie, VII.

1895. Ferry, R. Les phénomènes d'hybridation chez les Myxomycètes d'après M. Massee. Revue Mycologique, XVII.

1898/99. Martin, Ch. in Bull. Soc. Bot. Genève, Nr. 9.

1892. Massee, G. A monograph of Myxogastres. London.

1906. Pinoy, E. Sur l'existence d'un dimorphisme sexuel chez un myxomycète, Didymium nigripes Fries. Comptes rendus Soc. Biol. Paris, I،XIV.

1911. Vouk, V. Über den Generationswechsel bei Myxomyceten. Österr. Bot. Zeitschr., LXI.

\section{Ruhezustände.}

Hierher gehören die Mikro- und Makrocysten, die Sklerotien, die Ceratifikation. Mikrocysten entstehen entweder aus Schwärmern oder aus Myxoamöben und zwar dadurch, da $B$ diese Zustände ihre Bewegungsorgane (Geißeln und Rhizopodien) einziehen, ihren Plasmakörper abrunden und sich mit zarter oder derber Membran umgeben, nunmehr Körperchen bildend, die gewöhnlich noch kleiner sind als die Sporen der betreffenden Arten und die mit Rücksicht hierauf von Cienkowsky die obige Bezeichnung erhalten haben. Die eingekapselten Schwärmer von Didymium-Arten bleiben längere Zeit

Schinz, Myxogasteres, :(Rabenhorst Krypt. Flora I, Pilze, Abt. X.) 5 
trocken anfbewalırt lebenskräftig, mindestens bis zwei Monate. Wieder in Wasser gebracht, treten bei Didymium difforme nach de Bary hierbei folgende Erscheinungen ein: „zuerst treten wieder Vakuolen auf, 1 bis 4 und wenigstens eine immer unter der Randschicht liegend, welche entweder regelmäBig pulsieren oder unregelmäßig Gestalt und Größe fortwährend verändern. Dies kann stundenlang daueru, ohne daß der Körper seine Form und Lage im geringsten ändert. Plötzlich treibt er an irgend einer Stelle einen kleinen Fortsatz, andere Fortsätze folgen diesem und nun breitet sich der Körper amöbenartig kriechend auf dem Objektträger aus, genau wie es für die cilienlosen Schwärmer beschrieben wurde; er nimmt allmählich die länglich zugespitzte Schwärmerform an, ai dem spitzen Ende erscheint die Cilie, und nachdem er in dieser Gestalt noch kurze Zeit auf dem Objektträger gekrochen, erhebt er sich und beginnt die hüpfende Bewegung. Von einer Membran, welche beim Wiederanfangen der Bewegungen abgelegt würde, habe ich (de Bary) nichts gesehen. Die ersten amöbenartigen Fortsätze entstehen durch einfache Vortreibung der Randschicht, welche sich dabei gerade so verhält, wie die Randschicht des Plasmodiums. Mit der Zunahme der Beweglichkeit wird die ganze Randschicht allmählich blasser und zuletzt durch eine einfache Kontur ersetzt." Bei Perichaena (populina) corticalis dagegen soll nach de Bary's Schilderung der wiederauflebende Körper die ihn umhüllende Membran durchbohren. Es liegt auf der Hand, da $B$ auch für diese Verhältnisse weitere Untersuchungen sehr wïnschbar sind.

Bruck hat gezeigt, daß man die Amöben z. B. künstlich zur Encystierung veranlassen kann, indem man dem Kulturmedium destilliertes W'asser hinzufügt.

Die Makrocysten (derbwandige Cysten Cienkowsky's und de Bary's) entstehen aus Plasmodien. Cienkowsky hat deren Bildung namentlich bei Perichaena (populina) corticalis studiert. Darnach fragmentieren sich die Plasmodien, die Teilstücke ziehen ihre Psendopodien ein, runden sich ab und umgeben sich mit einer vielfach gefalteten Haut. Innerhalb derselben kontrahiert sich das Plasma und scheidet noch eine sekundäre Membran aus. Die Größe dieser Makrocysten scheint sehr verschieden zu sein, 
einzelne sollen kaum größer als eine Spore sein, andere etwa die Dimensionen eines Perichaena-Sporangiums besitzen.

Die Keimung soll sich nach Cienkowsky so vollziehen, dab bei Wasserhinzutritt der plasmatische Inhalt anschwillt, die sekundäre und primäre Wand durchbricht und als Plasmodium herauskriecht.

Die dritte Form des Ruhezustandes, welche de Bary Sklerotium genannt hat, kommt den erwachsenen Plasmodien zu. Sie tritt bald in Knötchenform, bald in Form netzartig verbundener Stränge oder in Kuchenform auf. Die Bildung beginnt auch mit einem Einziehen aller Plasmafortsätze, dem dann ein Abrunden des Plasmodiums folgt. Dieses zerfällt sodann in kleine Portionen von etwa 25 bis $40 \mu$ Durchmesser, welche eine \pm deutliche Membran erhalten und bei dichter Zusammenlagerung polyedrische Gestalt annehmen. (Vergl, auch Strasburger.) Durch allmähliche Wasserabgabe erhärtet die Masse und erhält schlieBlich hornartige Konsistenz. In Wasser gebracht, gehen die Sklerotien wieder in den Plasmodienzustand über, indem die Membranen sich auflösen und die Inhalte der einzelnen Zellen, nachdem sie wieder amöboide Bewegungen angenommen haben, miteinander verschmelzen. Lister berichtet für Didymium (effusum) squamulosum, daß beim Wiedererwecken der Sklerotien die Wände der einzelnen Cysten nicht aufgelöst werden, sondern nach dem Auskriechen der Inhalte als leere hyaline Säcke zurückbleiben.

Im Zustande des Sklerotiums vermag ein Plasmodium sehr lange Zeit lebensfähig zu bleiben; Lister erwähnt, daß er Sklerotien von Badhamia utricularis noch nach 3 Jahren Ruhe zu neuem Leben erweckt habe; ich selbst besitze Sklerotien derselben Art, die nun bereits sieben Jahre trocken aufbewahrt wurden und jederzeit mit großer Leichtigkeit wieder "belebt“ werden können.

Zukal hat uns 1898 mit einem weiteren, bis dahin unberücksichtigt gebliebenen transitorischen Ruhezustand bei Schleimpilzen bekannt gemacht, den er als Ceratifikation oder Verhornung bezeichnet und der darin besteht, daß in der Entwicklung begriffene Fruchtkörper ihre Weiterentwicklung einstellen und hornartige Konsistenz annehmen, brüchig und durchsichtig werden. Bringt man sie in diesem Zustande in eine feuchte 
Schale, so verlieren sie nach wenig Stunden das hornige, transparente Aussehen und nehmen dafür wieder das der gewöhnlichen, halbreifen Sporangien an, ihre Entwicklung nach $\mathrm{Zukal}$ wieder da fortsetzend, wo sie unterbrochen worden ist. Ich habe derartig ceratifizierte Sporangien schon sehr häufig, namentlich in höheren Lagen, im Herbst nach plötzlichen, starken Temperaturstürzen gefunden, ein Wiedererwecken derselben habe ich indessen noch nicht mit Sicherheit beobachten können.

Die Ursachen der verschiedenen Hemmungsbildungen mögen bald dieser, bald jener Art sein; in erster Linie sind wohl zu nennen Trockenheit, Sanerstoffmangel, Nahrungsmangel, Kälte, vielleicht auch mechanische Störungen dieser oder jener Art.

\section{Literatur.}

\section{Ruhezustände.}

1864. De Bary. Die Mycetozoen. 2te Anflage. Leipzig.

1908. Bruck, Werner Friedrich. Beiträge zur Physologie der Mycetozoen. Zeitschr. für allg. Physiologie, VII.

1863. Cienkowsky, L. Zur Entwicklungsgeschichte der Myxomyceten. Pringsbeim's Jahrb. f. wissenschaftl. Botanik, III und ebendaselbst: Das Plasmodium.

1888. Lister, Arthur. On Plasmodium of Badhamia and Brefeldia. Ann. of Bot., II.

1894. - A monograph of the Mycetozoa. First Edit and sec. Edit (19I1) London.

1884. Stahl, E. Zur Biologie der Myxomyeeten. Bot. Zeitung, XLII.

1913. Strasburger E. Das botanische Praktikum. 5. Auflage. Jena.

1885. Zopf W. Die Pilztiere oder Schleimpilze. Schenk, Handbuch der Botanik, III, 2.

1898. Zukal, H. Die Ceratifikation (Verhornung) bei Myxomyceten und Myxobakterien. Biol. Centralblatt, XVIII.

\section{Vorkommen und Verbreitung.}

Schleimpilze können überall vorkommen: im Stadium des Plasmodiums auf und in abgestorbenen Holzstrünken, auf totem Laub, verwesenden krautigen Stengeln, als Sporangien ebenso gut auf organischen wie auf anorganischen Materialien, also auf lebenden wie toten Pflanzen so gut wie auf Steinen und anderen leblosen Stoffen. Hierauf mag es zurückzuführen sein, daß mitunter die Schleimpilze als Parasiten angesprochen werden, mit Unrecht, denn wenn die Plasmodien zur Sporangien- 
bildung schreiten, so befassen sie sich offenbar gar nicht mehr mit der Nahrungsaufnahme. Die Sporangien finden sich gewöhnlich herdenweise, bald zerstreut auf dem Substrat, bald dicht gedrängt, mitunter zu vielen Tausenden dicht neben einander stehend. Die große Mehrzahl scheinen Ubiquisten zu sein, das heißt in identischen Arten auf der ganzen Erde mit Ausnahme der Pole, der mit ewigem Schnee bedeckten Gebirgshäupter und der trockenen Wüsten vorzukommen, allermindestens ist die Zahl derjenigen Arten, die unseres Wissens auf bestimmte Gebiete beschränkt sind, rerhältnismäßig sehr gering.

Immerhin scheint es, als ob mit steigender Höhe die Tiefenformen durch "Gebirgsformen " abgelöst würden, unsere diesbezüglichen Erfahrungen sind indessen noch so spärlich, daß dies nur als eine Vermutung ausgesprochen werden darf.

In der Schweiz ist offenbar der Jura sehr reich an Schleimpilzen, bedeutend ärmer das Molasseland und in den Alpen sucht man im Bereiche der V'acciniumsträucher vergeblich nach Vertretern dieser Gruppe, überhaupt vergeblich überall dort, wo die Holzstrünke eine sogenannte trockene Fäulnis zeigen, wogegen in der Nähe des schmelzenden Schnees die Ausbeute dann wieder eine reichlichere sein kann.

Eine sehr auffallende und gewiß jedem MyxogasteresSammler wohl bekannte Erscheinung ist, daß mitunter an gewissen Lokalitäten ein oder gar mehrere Schleimpilze ein- oder mehrmals hintereinander in großer Individuenzahl auftreten, und fruktifizieren, um dann auf viele Jahre, vielleicht für immer von derselben Lokalität zu verschwinden, obschon alle Bedingungen für deren Entwicklung anscheinend absolut dieselben geblieben sind.

\section{Kultur.}

Von Didymium kann man sich, wie bekannt ist, leicht Untersuchungsmaterial beschaffen, wenn man im Herbst die längere Zeit im Felde stehenden, zu Büscheln vereinigten, trockenen Stengel von Vicia Faba in Kultur nimmt. Man weicht sie ein paar Stunden lang in Brunnenwasser ein und legt sie in ein flaches, mit einer Glasscheibe bedecktes Gefä $B$ auf eine mehrfache Lage stark befeuchteten, schwedischen Fliesspapiers. Nach wenigen Tagen haben sich Didymium-Fruchtkörper 
auf den Stengelstücken und auf dem Fliesspapier gebildet und können nun zu Aussaaten benützt werden. Diese gelingen besonders leicht, wenn man die Sporen in einem Dekokt von Kohlblättern oder von Fabastengeln, dem Gewebsteile der betreffenden zur Herstellung des Dekokt gewählten Pflanze beigemengt sind, kultiviert. Das Dekokt ist längere Zeit im Kochen zu erhalten, um alle fremden Keime, Bakterien und Pilzsporen zu zerstören. Die Aussaat wird ausgeführt im hängenden Tropfen auf einem Deckgläschen, das vorher mehrere Male durch eine Flamme gezogen worden ist. Um dem eventuellen Sauerstoffmangel zu begegnen, schlägt Strasburger vor, dem Tropfen einige Algenfäden beizugeben, wodurch damn allerdings die Verunreinigung des Tropfens durch Bakterien möglich ist. Zum Zwecke der Aussaat sticht man mit einer ausgeglühten und hierauf mit dem sterilisierten (durch Kochen) Dekokt befeuchteten Nadel in ein Sporangium und taucht nun die Nadelspitze, an der Sporen hängen, in den auf dem Deckglas befindlichen Kulturtropfen ein. Das Deckglas wird hierauf umgekehrt, mit nach unten hängendem Tropfen, mit den Rändern auf einen auf dem Objektträger ruhenden, angefeuchteten Rahmen aus Karton gelegt. Schon nach 36 Stunden pflegt dann der Tropfen von Schwärmern erfüllt zu sein, die schon bei 300 facher Vergrößerung bequem beobachtet werden können.

Der Keimungsprozentsatz wird nach Bruck sichtlich erhöht, wenn man dem hängenden Tropfen einen winzigen Stengelsplitter von Ticia Faba zugibt.

Bruck benutzte, soweit das Material nicht im hängenden Tropfen untersucht wurde, Petrischalen, die entweder drei Maiskörner (kleinsamige Varietät) oder Stengelstücke von Ticia Faba in destilliertem Wasser enthielten, zu Kulturzwecken. Die Untersuchung in diesen Gefäßen erwies sich ihm als sehr praktisch, da man auf diese Weise immer größere Mengen Myxogasteres beobachten und ohne Schwierigkeit fixieren und färben kann.

Nach 2, 3 Tagen haben die Schwärmer von Didymium ihre Geißel eingebüBt, sie haben sich in das Stadium der Myxoamöben begeben, aus denen sich dann in der Folge durch Kopulation Plasmodien entwickeln. Will man solche Stadien 
färben, so fixiert man sie, indem man das ganze Deckgläschen in die hierfür bestimmte Fixierungsflüssigkeit (absol. Alkohol, 1 prozentige Chromsäure, concentrierte Pikrinsäure oder Flemming'sche Lösung) untertaucht und sodann nach sorgfältigem Auswaschen färbt (vergl. die betreffenden Anweisungen bei Strasburger).

Ich habe bereits darauf hingewiesen, daß für manche - sagen wir lieber viele - Schleimpilze die Kultur, bezw. Anzucht aus Sporenmaterial auberordentlich schwierig ist. Constantineanu hat allerdings gezeigt, daß die Sporen wohl der meisten Schleimpilze in destilliertem Wasser zur Keimung gebracht werden können, sehr häufig gehen dann aber die Kulturen zu Grunde. Anleitung zu solchen Kulturen geben sowohl Constantineanu wie Küster. Vorzügliche Nährlösungen sind Dekokte von Heu, Holz, Lohe, Kiefernadeln, Eicheln, Polyporus u. a. m. Auf $2^{0} \%$ Agar, dem z. B. Maiskörnerdekokt beigegeben ist, wachsen viele Schleimpilze vortrefflich. Vicia-Agar kann man sich so herstellen, da B man verflüssigtes Agar in Petrischalen oder dergl, auf trockene Vicia-Stengelstiicke aufgießt und hiernach sterilisiert: bei der Sterilisation diffundieren hinreichende Mengen von Nährstoffen in das Agar. Auch als feste Nährböden kommen die soeben genannten Objekte in Betracht. D egen kultivierteFuligo septica auf Löschpapier, das mit Lohedekokt durchtränkt war. Wichtig ist, daß man nicht allzu N-reiche Nährböden den Schleimpilzen bietet, da auf diesen die Bakterien zu üppig gedeihen. Von festen Nährböden wurden weiterhin bereits erprobt: Lohe für Fuligo septica, Stereum-Fruchtkörper für Badhamia, Mohrrüben für Licea u. s. w. (nach Kïster). Im übrigen sei auf Constantineanu verwiesen. Constantineanu tränkte auch Bimssteinstücke mit Nährlösungen, z. B. mit einer Mischung von Knop $1 \%$, und Dextrin $5 \%$ oder von Knop $1 \%$, Dextrin $5 \%$ und Glukose $2,5 \%$ und errielte zum Teil gute Resultate. Feuchtigkeit und Trockenheit üben auf die Ausbildung der Fruchtkörper bei den verschiedenen Arten offensichtlich eine verschiedene Wirkung aus: Trockenheit bewirkt z. B. bei Amaurochaete, Badhamia, Leocarpus Enzystierung, bei Fuligo fast stets Fruktifikation. Das Plasmodium von Didymium (effusum) squamulosum enzystiert sich unter dem Einflusse seiner Stoffwechselprodukte, bei Physarum didermoides wird 
dagegen dadurch die Sporangienbildung beschleunigt (vielleicht doch auch zwecks zeitlicher Abkürzung des Entwicklungszyklus).

Bei sorgfältigem Sammeln und Transport gelingt es, aufgenommene Plasmodien nach Hause zu bringen und, in eine feuchte Kammer gelegt, zur Sporangienbildung zu bringen; im allgemeinen wird man sich indessen auf das Sammeln der Fruchtkörper, auf die sich ja auch zur Hauptsache unsere systematische Klassifikation stïtzt, beschränken müssen. Das Einlegen des gesammelten Materials in Papierkapseln ist unzweckmäßig, da die Sporangien durch den Druck leicht abbrechen und es ist daher weitaus besser, die gesammelten Stïcke in kleinen Schachteln, z. B. von der Größe der schwedischen Zündholzschächtelchen, unterzubringen und sie etwa noch mittelst Gummi arab. am Boden derselben oder auf einem Streifen festen Papiers, das in die Schachtel „eingezwängt" wird, festzukleben. Befolgt man letztere Methode, so kann man die Probe nach Belieben untersuchen, ohne sie von der Unterlage ablösen zu müssen. Wer Sammlungen anlegt, wird überdies gut tun, seine Schätze vor Insektenfraß zu schützen; Naphthalin tut da, meiner Erfahrung nach, sehr gute Dienste, enthebt aber nicht der Aufgabe, von Zeit zu Zeit einzelne Schachteln nachzusehen und mit frischem Naphthalin zu versehen.

\section{Litergtur.}

\section{Kultur der Myxogasteres.}

1906. Constantineanu, 'J. C. Über die Eutwicklungsbedingungen der Myxomyceten. Anmales Mycologici, IV.

1905. Degen, A. Untersuchg. über die kontraktile Vakuole u. die Wabenstruktur des Protoplasmas. Bot. Zeitung, LXIII.

1901. Harshberger, John W. Observations upon the feeding plasmodia of Fuligo septica. Bot. Gazette, XXXI.

1900. Klebs, G. Zur Physiologie der Fortpflauzung einiger Pilze, III. Pringsh. Jahrb. Wiss. Bot., XXV.

1900. - Einige Ergebnisse der Fortpflanzungsphysologie. Ber. Deutsch. Bot. Ges., XV1II.

1907. Kiister, Ernst. Kultur der Mikroorganismen. Leipzig und Berlin.

1902. Lenduer, A. Essai de culture de Myxomycètes. Bull. Herb. Boiss., 2 me sér., II.

1888. Lister, Arthur. Notes on the Plasmodium of Badhamia utricularis and Brefoldia maxima. Anu. of Bot., II. 
1891. - On the cultivation of Iycetozoa from spores. Journ. of Bot., XXXIX.

1898. MHIer, Caspar 0. The aseptic cultivation of Mycetozoa. The Quarterly Journ. Hicrose. Science, N. S., XLI.

1902. Pinoy, E. Nécessité d'une symbiose microbienne pour obtenir la culture des Myxomycètes. Bull. Soc. Mycol. France, XVII et Comptes Rendus Acad. Sc. Nat. Paris, CXXXVII (1903).

1907. - Rôle des Bactéries daus le développement de certains Myxomycètes. Thèse. Ann. Institut Pasteur, XXI.

1873. Roumeguère, Cas. Singulière reproduction d'une Nyxogastrée. Bull. Soc. Bot. France, XX.

1907. Torrend, C. Les Myxomycètes, étude des espèces connues jusqu'ici. Broteria, VI.

\section{Fixierung, Färbung, Präparation.}

Für die Zwecke der Fixierung der verschiedenen Entwicklungsstadien sind von den Forschern, die sich damit befaßt haben, eine Reihe von Mittelı empfohlen worden. Strasburger hat für seine Untersuchung der Entwicklung der Sporangien und Elateren bei Trichia 1 prozentige Chromessigsäure $(0,7$ Chromsäure, 0,3 Essigsäure), konzentrierte Pikrinsäure, absoluten Alkohol und 1 prozentige Osmiumsäure in Anwendung gebracht. Als am wenigstens branchbar erwies sich ihm die Fixierung in Osmiumsäure. Gegenüber der Fixierung in absol. Alkohol und in Chromsäure hatte die in Pikrinsäure den allerdings nicht hoch einzuschätzenden Vorteil, daß die Präparate in ihr ihre Rosafärbung beibehielten.

In der Chromessig- und Pikrinsäure verweilten die Objekte 24 Stunden, worauf sie in ausgekochtes Brunnenwasser übertragen wurden. Dieses wurde so lange gewechselt, als es noch Spuren von Färbung zeigte. So brachten die Objekte 24 Stunden in Brunnenwasser zu, worauf sie Strasburger in 20 prozentigen Alkohol übertrug. Letzterer wurde nach einigen Tagen durch 30 prozentigen Alkohol ersetzt. In absolutem Alkohol und der 1 prozentigen Chromessigsäure waren die Sporangiumanlagen alsbald entfärbt. Der Chromessigsäure bediente sich auch Conard zur Fixierung seiner Lycogala-Äthalien.

Für die Zwecke der Färbung erwies sich das PikrinsäureMaterial im allgemeinen als das brauchbarste, doch stand ihm das Chromessigsäure- und das Alkohol-Material nur wenig nach. 
Die Tinktion gelang am besten in alten Hämatoxylin-Lösungen. die mit sehr viel destilliertem Wasser verdünnt zur Anwendung kamen. Für ein mit destilliertem Wasser angefülltes Uhrglas sind nur wenige Tropfen Hämatoxylin-Lösung nötig. Die Tinktion ist in einigen Stunden vollzogen. Bei Obberfärbung wird durch längeres Liegen in destilliertem Wasser der ÜberschuB an Farbstoff ausgezogen; will man rascher zu Werke kommen, so läßt sich mit Vorteil wässerige Alaunlösung (am energischsten wirkt Eisenalaun) anwenden (Strasburger).

Lister fixierte anläßlich seiner Kernteilungsuntersuchungen an Schwärmern und Amöben diese durch Osmiumdämpfe und färbte sodann mit Erfolg mittelst Gentianaviolett, dem er, obschon die Färbung sich für Dauerpräparate nicht empfiehlt, den Vorzug gab vor Methylgrün und Pikrokarmin. Jahn bedient sich und empfiehlt die Fixierung mit alkoholischer Sublimatlösung, immerhin darauf aufmerksam machend, daß bei Anwendung dieses Fixierungsmittels es bei Dictydium z. B. nicht gelinge, die Kerne mit irgend einem Farbstoff zu färben. An dessen Stelle brachte er die Flemming'sche Fixierungsflüssigkeit in Anwendung und erzielte dann sowohl mit Hämatoxylin, wie besonders mit Safranin und Gentianaviolett deutliche Kernfärbungen. Wenn man nach seiner Angabe Schnitte mit Safranin beliebig lange gefärbt und mit Salzsäure-Alkohol differenziert hat, geniigt ein kurzes Eintauchen in Gentianaviolett, um eine Kernfärbung zu erzielen.

Jahn fixierte auch in Sublimat und zwar nach manchen Versuchen in konzentrierter alkoholisch-wässeriger Lösung, die etwa $30 \%$ Alkohol enthielt. Als Kernfärbmittel benutzte er Hämatoxylin und zwar ausschließlich eine Lösung, die nach Vorschrift von Ehrlich hergestellt war. Damit die kleinen Sporangien, die zum Zwecke der Einbettung durch verschiedene Flüssigkeiten hindurchgehen miissen, nicht verloren gehen, kann man sie mit Eosin etwas vorfärben. Auch Z enker'sche Flüssigkeit kam zum Zwecke der Fixierung zur Anwendung.

Helene Kränzlin verwendete für ihre Untersuchungen Material, das in Flemming's verdünnter Lösung fixiert und in Alkohol anfbewahrt worden war. Gefärbt wurde sodann nach Flemming'scher Methode. 
Sehr eingehende Ratschläge erteilt Plenge, der sich mit dem Studium der Schwärmer, spez. der Beziehungen zwischen Geißel und Kern, befaßt hat. Er empfiehlt nach dem Rezept Lister, den am Deckgläschen haftenden, mit den Schwärmern versehenen und durch Osmiumdämpfe oder Vermischung mit einer anderen Fixierungsflüssigkeit abgetöteten Tropfen soweit an der Luft abdunsten zu lassen, bis nur noch eine ganz kleine Spur Flüssigkeit zurückgeblieben ist. Dann bringt er die Deckgläser oder die Objektgläser für 24 Stunden in eine Schale mit absolutem Alkohol, dem etwas Jodtinktur zugesetzt worden ist falls vorher Sublimat verwendet worden war. Auf diese Weise werden die meisten in dem Kulturtropfen enthalten gewesenen Schwärmer auf dem Glase sehr schön fixiert und können ohne große Gefahr des Abspülens, mit Wasser und Farbflüssigkeit in der gewöhnlichen Weise wie aufgeklebte Schnitte behandelt werden. Nur muß dafür Sorge getragen werden, daß die Präparate nicht wirklich eintrocknen. Außer Osmiumsäure in Lösung und Dampfform haben Plenge kaltgesättigte Sublimatlösung in Wasser oder in 0,5 prozentiger Kochsalzlösung, Hermann'sche Flüssigkeit und Pikrinschwefelsäure die besten Dienste geleistet. Weniger gute Erfolge verzeichnet er mit Pilłrinessigsäure, Alkohol oder dünner Chromsäurelösung. Letztere ließ sich wieder besser verwenden bei Zusatz von einigen Tropfen 1 prozentiger Osmiumsäurelösung. Die Deckgläschen versah Plenge vor dem Auflegen stets mit Wachsfïßchen.

Hinsichtlich der Färbungen empfiehlt Plenge die Heidenhain'sche Färbungsmethode mit $1 \frac{1}{2}$ bis 2 prozentiger Eisenalaunlösung und $1 / 2$ prozentiger Hämatoxylinlösung in Wasser.

Zum Zwecke des Studiums der Kernteilungsvorgänge empfiehlt Bruck Fixation mit einer heißen Mischung von zwei Teilen konzentrierter wässeriger Sublimatlösung und einem Teil absoluten Alkohols und darauffolgende Färbung mit Boraxkarmin und Delafield'scher Hämatoxylinlösung.

Will man die lebenden, frei herumschwimmenden Schwärmer untersuchen, so ist hierfür der hängende Tropfen natürlich ungeeignet, da man ganz auf die zufälligerweise am Deckglase anhaftenden Schwärmer angewiesen ist. Plenge hat sich in folgender sehr ingeniöser Weise geholfen: ein in absolutem Alkohol einige 
Tage aufbewahrtes. möglichst dünnes Deckglas wird sauber abgetrocknet, dann zwischen den Fingerspitzen mit einer Spur reinen Glycerins gerieben bis fast zur Trockenheit und mit einem saubern weichen Tuche vorsichtig gereinigt. Es gelingt auf diese Weise, eine äußerst dünne und gleichmäßige Schicht aus einem Tropfen Kulturflüssigkeit herzustellen indem man die überschüssige Flüssigkeit abgießt.

Die Präparate können je nach deren Zartheit in Canadabalsam, eingedicktem Zederöl oder in Glycerin-Gelatine aufbewahrt werden. Im allgemeinen wird wohl letzteres EinschluBmittel am häufigsten zur Anwendung kommen. Um zu verhindern, daß die zarten Objekte durch die Ueberführung in Glycerin schrumpfen und deformiert werden, empfiehlt es sich sehr, sie zuerst in Hantsche Flüssigkeit zu legen (1 Teil Glycerin, 2 Teile Wasser und 3 Teile Methylalkohol), Alkohol und Wasser verdunsten dann langsam und die Lösung wird allmählich konzentrierter. Als Verschlußmaterial kommen in Amerika und England mit Torteil vorzugsweise Hollis' Glue und Goldsize zur Anwendung und zwar in der Weise, daß nach dem Auflegen des Deckgläschens und dem Eindicken der Glyceringelatine deı Deckglasrand umfahren wird mit Hollis' Leim, unter Umständen zwei- dreimal und sodann, nachdem der Leim völlig trocken geworden ist, überfahren wird mit Goldsize. Zur Aufhellung und Quellung der infolge des Eintrocknens meist stark deformierten Sporen und Capillitiumfäden kommen Kalilauge und Karbolsäure zur Verwendung, doch eignen sich in dieser Weise behandelte Objekte dann nicht zu Dauerpräparaten.

\section{Literatur.}

\section{A. Fixierung, Färbung etc.}

1898. Ayers, H. Methods of study of the Myxoamœbre and the plasmodia of the Mycetozoa. Journ. of appl. Microse., Nr. 1, 2.

1891. Cook, O. F. Methodes of collecting and preserving Myxomycetes. Bot. Gazette, XVI.

1910. Conard, Henry S. Spore formation in Lycogala exiguum Morg.

1899. Fischer, Alfr. Fixierung, Färbung und Bau des Protoplasma. Jens.

1899. Jahn, E. Zur Kenntnis des Sehleimpilzes Comatricha obtusata Preuß. Festschrift für Schwendener. Berlin.

1901. - Myxomycetenstudien. 1. Dictydium umbilicatum Schrader. Ber. Deutsch. Bot. Ges., XIX. 
1907. Kränzlin, Helene. Zur Entwicklungsgesehichte der Sporangien bei den Trichien und Arcyrien. Arch. für Protistenkunde, IX.

1899. Plenge, Henrique. Über die Verbindungen zwischen Geißel und Keru bei den Schwärmzellen der Mycetozoen und bei Flagellaten und über die an Metazoen aufgefundenen Beziehungen der Flimmerapparate zum Protoplasma und Kern. Verh. naturhist,-mediz. Ver. Heidelberg, N. F., VI.

1884 Strasburger, E. Zur Entwicklungsgeschichte der Sporangien von Trichia fallax. Bot. Zeitung, XIJl.

1913. - Das botanische Praktikum. 5. Aufl. Jena.

\section{B. Danerpräparate.}

1908. Bruck, W. F. Beiträge zur Physologie der Aycetozoen. Zeitschr. Allg. Physiologie, VII.

1899. Macbrisle, Thomas H. The North Americau Slime-Monlds. New York. 1907. Torrend, C. Les Myxomycètes, étnde des espèces connues jusqu'ici. Broteria, VI.

\section{Systematischer Teil.}

Die den verschiedenen Monographien der Schleimpilze zugrunde gelegte systematische Gruppierung ist unseres Erachtens noch weit davon entfernt, ein auch nur einigermaßen befriedigendes Bild des phylogenetischen Zusammenhanges der einzelnen Gattungen zu geben. Torrend hat den Versuch gemacht, fußend auf den Studien seiner Vorgänger, de Bary, Rostafinski, Zopf, Schröter, Lister u. a. ein natürliches System aufzustellen, ausgehend, abgesehen von der gegebenen Einteilung in Exosporeae und Endosporeae, von dem Vorhandensein oder Fehlen eines Capillitiums; er dürfte sich damit wohl auf dem richtigen Wege befunden haben. Die Unsicherheit aber dariiber, was als echtes und was als unechtes Capillitium anzusprechen ist, führt ihn indessen \%. B. dazu, Gattungen wie Tubifera einerseits und Amaurochaete und Reticularia anderseits ganz verschiedenen Gruppen zuzuweisen, trotzdem alle drei Gattungen in Bezug auf den Ursprung der in den Fruchtkörpern nachzuweisenden Fäden und Strähnen eine gewisse Übereinstimmung $\%$ erkennen geben. Was in allererster Linie fehlt, das ist eine sorgfältige, vergleichend-entwicklungsgeschichtliche Untersuchung der echten und unechten Capillitien. So lange eine solche noch aussteht, dürfte es ein aussichtsloses Unterfangen sein, ein natïrliches System der Myxogasteres aufstellen zu wollen. 
Die Einteilung Listers' anf Grund der Sporenfarbe scheint eine künstliche zu sein, immerhin gelangt Lister doch zur Bildung einer Anzahl anscheinend natürlicher Untergruppen und da bis zur Stunde einzig und allein das Lister'sche System eine sichere Unterbringung der Gattungen der Schleimpilze gestattet, haben wir es, unter ausdrücklicher Betonung seines künstlichen Charakters, unserer Bearbeitung_zugrunde gelegt.

Die 2., 1911 erschienene Auflage von Lister's Mycetozoa ist eine so sorgfältige und die Beschreibungen der Gattungen, Arten und Varietäten ist eine so in alle Einzelheiten eingehende, daß es zurzeit kaum möglich sein dürfte, Neues hinzuzufügen.

Wie wir an anderer Stelle bereits hervorgehoben haben, suchen sich die Schleimpilze die allerverschiedensten Substrate zur Fruchtkörperbildung aus, eine und dieselbe Art kann auf Baumstrünken, auf Moos, auf Laubblättern, auf Steinen oder auf lebenden Stengelstücken vorkommen, es erscheint daher auch nicht von Nöten, bei allen Arten die sämtlichen Substrate aufzuzählen, auf denen ihre Sporangien gefunden worden sind, vielmehr dürfte es genügen, eine bezügliche Bemerkung dort einzuschalten, wo es sich um anscheinend substratstäte Formen handelt und die Zahl dieser ist erstaunlich gering.

Wir haben uns gezwungen gesehen, die vorliegende Bearbeitung nicht auf jene Arten zu beschränken, die bis zur Stunde innerhalb des Gebietes der Rabenhorst'schen Flora gefunden worden sind, sondern sie vielmehr auf alle beschriebenen Arten auszudehnen. Die überwiegend große Mehrzahl der Schleimpilze, ja wahrscheinlich alle, sind Ubiquisten und im Laufe der letzten Jahre konnte für eine große Zahl von Arten, die man auf Nordamerika, auf Neu-Seeland, auf Java etc. beschränkt geglaubt hatte, das gleichzeitige Vorkommen in Deutschland, in der Schweiz etc. festgestellt werden. Wenn daher die vorliegende Flora den sich für die Schleimpilze Interessierenden in den Stand setzen soll, mit Aussicht auf Erfolg die Schleimpilze Deutschlands z. B. zu studieren, so muß ihm unbedingt eine Bearbeitung in die Hand gelegt werden, die auch jene Formen allermindestens andeutungsweise berücksichtigt, deren Vorkommen innerhalb unseres Gebietes zwar noch nicht nachgewiesen, aber doch wahrscheinlich ist. 


\section{Klasse Myxogasteres}

(Fries em. Scliröter)

in Cohn Kryptogamen-Flora von Schlesien III, I (1885), 98.

Myxogastres Fries Syst. Mycol. III (1829), 3 (als Subord. II der

Gasteromyceten, nur die Endosporeae umfassend).

Myxomycetes Li n k in Willd. Grundr. der Kränterkunde IV (1833).

Hycetozoa de Bary in Zeitschr. f. wissenschaftl. Zoologie X (1859), 88.

Myxomycetes d e Bary in Bot. Zeitung XVI (1858), 357=Nycetozoa de Bary ohne Acrasieen.

Mycetozoa Rost. Vers. eines Systems der Mycetozoen (1873), = Mycetozoa de Bary pr. p.

Myxomycetes W a llroth. Flora Crypt. Germ. IV (I833), $333 \mathrm{im}$ Simue der Gasteromyceten Fries.

Chlorophyllfreie Organismen mit saprophytischer Lebensweise (mitunter auch auf lebenden Pflanzenteilen, Laubblättern etc. vorkommend, ohne jedoch diesen Nahrung zu entziehen, sie aber abtötend durch Luft- und Lichtentzug), während des größten T'eiles ihres Lebens aus einer membranlosen, kriechender Bewegung fähigen Protoplasmamasse bestehend. Bei der Keimung der Spore tritt der Inhalt derselben unter Zerreiben der Membran als Myxoamöbe oder als Myxomonade heraus; nach Abwerfen der Geißel tritt Vereinigung der (haploiden) Myxoamöben ein unter Bildung von Plasmodien. Letztere zeigen meist lebhafte Protoplasmaströmungen im Innern, bewegen sich kriechend und führen bei den Spumariaceen, Didymiaceen und Physaraceen reichlich kohlensauren Kalk, bei diesen und andern auch Farbstoffeinlagerungen. Schließlich entstehen aus den Plasmodien Fruchtkörper von charakteristischer Gestalt mit zahlreichen, mit einer Membran versehenen Sporen. Letztere sitzen entweder mit einem Stiel der Außenseite der mannigfach verbundenen Platten eines verzweigten Fruchtkörpers (Sporophor, so bei den Vertretern der Exosporeae) auf oder sind in den Fruchtkörpern (Sporangien) eingeschlossen. Stiel (bei den Endosporeae) und Hülle (Peridie) der Fruchtkörper ohne zellige Struktur. Im Sporangium neben den Sporen häufig noch ein aus einfachen oder verzweigten, beidendig spitzen oder netzförmig verbundenen Fäden oder Röhren bestehendes Capillitium. Durch Vereinigung 
von Sporangien entstehen Aethalien. Plasmodiokarpien sind dem Substrat \pm flach aufsitzende Fruchtkörper von \pm wurmförmiger, gewundener Gestalt. Bisweilen Ruhezustände; der Schwärmer: Mikrocysten; der jungen Plasmodien: Makrocysten; der erwachsenen Plasmodien : Sklerotien. Als Reservestoff tritt Glukogen auf. Terbreitung: ïber die ganze Erde mit Ausnahme der arktischen und antarktischen Region, die meisten (oder alle?) Arten Ubiquisten.

1. Sporen nicht in Fruchtkörpern eingeschlossen, sondern anf der Oberfläche von Trägern (Sporophoren), gestielt.

1. Unterklas e EXOSPOREAE.

1*. Sporen in Fruchtkörpern (Sporangien, Plasmodiokarpien oder Äthalien) eingeschlossen. 2. Unterklasse ENDOSPOREAE.

\section{Unterklasse EXOSPOREAE Rost.}

Vers. eines Syst. der Mycetozoen (1873), 2; Lister Monogr. ed. 1, 21, 25 und ed. 2, 21, 25.

Nur eine Familie umfassend:

Fam. Ceratiomyxaceae Schröter in Engler und Prantl Natïrl. Pflanzenfam. I. 1 (1889), 15; Lister Monogr. ed. 1, 25 und ed. 2, 25; Schinz in Mitt. Naturw. Ges. Winterthur VI, 23; Macbr. N. A. Slime-Moulds, 17; Torrend in Broteria VI, 63.

Mit nur einer Gattung:

\section{Gattung Ceratiomyxa Schröter}

in Engl. und Prantl Natürl. Pflanzenfam. I. 1 (1889), 16; Lister Monogr. ed. 1, 25 und ed. 2, 26; Schinz in Mitt. Naturw. Ges. Winterthur VI, 23; Macbr. N. A. Slime-Moulds 17; Torrend in Broteria VI, 63. Synonym: Ceratium Alb. et. Schw. Consp. Fung. (1805), 358 non Schrank (1793).

Mit einer Art:

1. Ceratiomyxa fruticulosa (Müller) Macbr. em. Li ste r Monogr. ed. 2 (1911), 25, pl. 1, Fig. a, b, c, e. Synonyme: Byssus fruticulosa Müller in Fl. Dan., fase. XII (1775), 6 t. 718 Fig. 2

Tremella hydnoidea Jacquin Mise. I (1778), 145 t. 16. 
Clavaria puceinia Batsch kilench. Fung. (1783), 139, fig. 49. Puccinia byssoides Gmelin Syst. Nat. (1791), 1462.

Clavaria byssoides Bull. Champ. (1791), 209 t. 415, fig. 2.

Isaria mucida Pers. in Roem. N. Mag. Bot. I (1794), 121.

pr. p. Cerat. mucidum Pers. Comm. fung. clavaeform. (1797), pg. ?;

Schröter in Cohn, Kryptog.-Flora IIl.1, 101.

Ceratium hyduoides A lb. et S chw. Cousp. Fung. (1805), 358, t. II, fig. 7; Fr. Syst. Myc. III, 294; Rabenh. Deutschl. Kryptog. Fl. I, 125; Woronin et Famintzin in Mém. Acad, Imp. St. Petersburg, sér. 7, XX, 4; Zopf Pilzthiere, 69 und 174;

pr. p. Ceratium pyxidatum Alb. et Schw. Consp. Fung. (1805), 359 , t. XII, fig. 9 .

Ceratiomyxa mucida S chröter in Engl. und Prantl Natürl. Pflanzenfam. I. 1 (1889), 16; Lister Mouogr. ed. I, 25, pl. I, A, fig. a bis c; Schinz in Mitt. Naturw. Ges. Winterthur VI, 23; Macbride in Bull. Nat. Hist. Iowa II, 114; Torrend in Broteria VI. 2, 63.

pr. p. Ceratiomyxa fruticulosa Macbride North Am. SlimeMoulds (1899), 18;

Exsikkaten: Fuckel Fungi rhen. Nr. 170.

Aus der Spore kriecht bei der Keimung eine vierkernige Amöbe, die sich unmittelbar daranf in 4 Tochteramöben teilt. Diese ordnen sich nach der Teilung so an, daß drei von ihnen ein Dreieck bilden und die vierte auf ihnen liegt. Die Zahl der

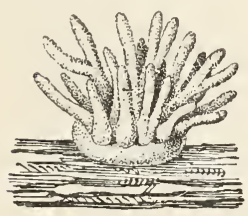

Fig. 38. Ceratiomyxa fruticulosa (Muell.) Macbr.var. flexuosa Lister Sporophore $(15 / 1)$.

Nach Famintzin und Woronin.

Chromosomen in jedem der Kerne der vier Amöben beträgt 8 , stimmt daher mit der Chromosomenzahl der vier Kerne der noch ungeteilten Amöbe. Hierauf teilt sich jede Amöbe nochmals in zwei kleinere, bei welchem Teilungsschritt nachgewiesenermaßen eine Chromosomenreduktion wiederum unterbleibt. Jede Amöbe bildet nunmehr eine Geißel und wird zum Schwärmer. Nach kurzem Schwärmstadium wird die Geißel wieder eingebüBt und - aller Wahrscheinlichkeit nach — der Sexualakt eingeleitet.

Plasmodium gewöhnlich farblos, mitunter gelblich oder rötlich. Zur Zeit der Bildung der Fruchtkörper (Sporophore) erscheint das Plasmodium auf dem Holze in Gestalt kleiner, opalweißer 
Plasmamassen, die bald eine gelappte Oberfläche bekommen und ron denen sich einfache oder gabelig verzweigte, $\pm 1 \mathrm{~mm}$ hohe und 0,7 mm dicke Höcker (Fig. 38) erheben, die die gestielten Sporen tragen (Fig. 18). An Stelle der Höcker oder aufrechten Säulchen mitunter Platten oder wabenartige, offene Gebilde, auf deren Oberfläche gleicherweise die Sporen auf kleinen Stielen inseriert sind. Sporen vierkernig, weiß, glatt, ovoid, 10 bis $13 \mu$ lang und 6 bis $7 \mu$ dick.

Auf moderndem Holz von Nadel- und Laubbäumen, vom Frühjahr bis in den Herbst in fruktifizierendem Zustande. Im ganzen Gebiet verbreitet und gemein von der Ebene bis ins Gebirge.

Eine sehr polymorphe Art, die Extreme in der Ausbildung der Sporophore lassen sich unterscheiden als:

var. flexuosa L i ster Monogr. ed. 2 (1911), 26, pl. 1, fig. b.

Syuonyme: Ceratium arbuscula Berk. et Broome in Journ. Linn. Soc. XIV (1873), 97.

Ceratium filiforme Berk. et Broome 1. c.

Ceratiomyxa mucida var. flexuosa Lister Monogr. ed. 1 (1894), 26, pl. I, A, fig. $d-\theta$.

Sporophore vom Substrat sich abhebend in der Form schlanker, 2 bis $5 \mathrm{~mm}$ langer, verzweigter aber nicht anastomosierender Bänder oder Säulchen, beim Austrocknen zusammenfallend und dann kleinen Wattenflöckchen ähnelnd.

var. porioides (Alb. et Schw.) Lister Monogr. ed. 2 (1911), 26.

S y 1 o n y $\mathrm{e}$ : Ceratium porioides Alb. et Schw. Consp. Fung. (1805), 359, t. 2, fig. 6; Fr. Syst. Myc. I11, 295; Fam. et Woron. Hém. Acad. Imp. St. Petersburg sér. 7, XX, 5; Schröter in Cohn Kryptog.-Flora Schles. I11. 1, 101.

Ceratiomyxa porioides Schröter in Engl. und Prantl Natürl. Pflanzenfam. I. 1 (1889), 16; Macbride N. A. Slime-Moulds, 19. Ceratiomyxa mucida var. porioides Lister Monogr. ed. 1 (1894), 26, pl. I, A, fig. c.

Sporophore dem Substrat angedrückt, in wabenartiger Ausbildung, an die Unterseite eines Röhrenpilzes (Polyporus z. B.) eriunernd. 
var. hydnoides (Jacquin) Schinz

Synonyme: Tremella hydnoides Jaequin Misc. 1 (1778), t. 16.

Ceratium hydnoides A Ib. et Schw. Consp. Fung. (1805), 3อ๊8; t. 2 , fig. 1 .

Ceratium pyxidatum Al b. et $\mathrm{S} c \mathrm{~h}$ w. Consp. Fung. (1805), 359, t. 2, fig. 9; Schröter in Cohn Kryptog.-Flora Schles. III. 1, 101.

Sporophore aufrecht, nur 2 bis $3 \mathrm{~mm}$ lang, am Grunde einfach, am obern Ende quastenartig.

Alle drei Spielarten im ganzen Gebiete vertreten. Hinsichtlich der var. porioides macht Sturgis neuerdings (The Myxomycetes of Colorado II [1913], 436), ihr den Rang einer Art zuerkennend, darauf aufmerksam, daß selbst da, wo beide zusammen vorkommen (der Typus und porioides), keinerlei Übergänge gefunden werden.

Es dïrfte sich lohnen, dieser Frage auch bei uns näher zu treten.

\section{Unterklasse ENDOSPOREAE Rost.}

Vers. eines Systems der Mycetozoen (1873), 2; Lister Monogr. ed. 1, 21, 26 und ed. 2, 21, 26.

Sporen endogen, in Sporangien, Plasmodiokarpien oder Äthalien gebildet.

\section{$\ddot{U}$ b e r s i c h t}

über die Reihen, Unterreihen und Familien der Endosporeae.

1. Sporen im durchfallenden Lichte bei Vergrößerung violettbraun oder purpurgrau (rotbraun bei Stemonitis ferruginea und Stemonitis flavogenita, farblos bei Echinostelium). Capillitium vorhanden.

Reihe AMAUROSPORALES Lister.

2. Sporangien mit kohlensaurem Kalk.

Unterreihe CALCARINEAE Rost.

3. Der kohlensaure Kalk in Form kleiner kugeliger Körnchen (mitunter bei Diachæa-Arten in Form kugeliger Krystallklümpchen).

Familie Physaraceae Rost. 
3*. Der kohlensaure Kalk in Form von Krystallen der Sporangiumwand aufgelagert.

Familie Didymiaceae Rost. pr. p.

2*. Sporangien kalkfrei.

Unterreihe AMAUROCHAETINEAE Rost.

4. Einzelsporangien, mit Stiel und Columella. Familie Stemonitaceae Rost.

4*. Fruchtkörper Äthalien bildend.

Familie Amaurochaetaceae Rost.

$1^{*}$. Sporen im durchfallenden Lichte bei Vergrößerung nicht violettbraun oder purpurgrau (ausgenommen Licea minima und Listerella paradoxa)

Reihe LAMPROSPORALES Lister.

5. Capillitium fehlend oder, wenn vorhanden, doch nicht aus gleichartigen Fäden bestehend.

Unterreihe ANEMINEAE Rost. em. Lister.

6. Peridie häutig, mit mikroskopisch kleinen, kugeligen plasmatischen Granulationen besetzt und im obern Teil (mit Ausnahme von Lindbladia) zur Zeit der Sporenentlassung ein Netz bildend.

Familie Heterodermaceae Rost. em. Lister.

$6^{*}$. Sporangien einzeln, Peridie ohne plasmatische Granulationen, pergamentartig (bei Licea biforis häutig).

Familie Liceaceae Rost. em. Lister.

$6^{* *}$. Sporangien gebüschelt, Peridie häutig, ohne plasmatische Granulationen.

Familie Tubulinaceae Lister.

$6^{* * *}$. Sporangien dicht gedrängt, meist Äthalien bildend. Peridie in der Regel unvollständig oder ein Pseudocapillitium bildend. Ächtes Capillitium fehlend oder (bei Liceopsis) aus einigen wenigen verzweigten Fäden oder Strähnen bestehend.

Familie Reticulariaceae Rost. em. Lister. 
$6^{* * * *}$. Fruchtkörper Äthalien bildend. Pseudocapillitium aus verzweigten, farblosen Rölıren bestehend.

Familie Lycogalaceae de Bary.

5*. Capillitium aus einem System einheitlicher Fäden bestehend.

Unterreihe CALONEMINEAE Rost. em. Lister.

7. Capillitiumfäden röhrig, entweder frei (Elateren) oder ein Netzwerk bildend. Verdickungen spiral- oder ringförmig.

Familie Trichiaceae Rost. em. Lister.

7*. Capillitiumfäden röhrig, ein Netzwerk bildend (aus freien Fäden nicht selten bei Perichæna corticalis), Verdickungen kammförmig oder in Form von halben Ringen (ringförmig bei Arcyria annulifera), Stacheln oder Warzen.

Familie Arcyriaceae Rost. em. Lister.

$7^{* *}$. Capillitium aus soliden, an der Peridie befestigten Fäden bestehend, die entweder gerade oder aufgewickelt sind.

Familie Margaritacea Lister.

\section{Reihe AMAUROSPORALES Lister.}

Monogr. ed. 1 (1894), 21, 26 und ed. 2, 21, 26.

Capillitium vorhanden. Sporen unter dem Mikroskop violettbraun oder purpurgrau, mit Ausnahme von Stemonitis ferruginea und flavogenita, wo sie rotbraun, und Echinostelium, wo sie farblos sind.

I. Unterreibe CALCARINAAE Rost.

Versuch eines Systems der Myzetozoen (1873), 9 und Monogr. App., 2; Lister Monogr. ed. 1, 21, 26 und ed. 2, 21, 26.

Sporangien mit Ein- oder Auflagerungen von kohlensaurem Kalk. 
I. Familie Physaraceae Rost.

Tersuch eines Systems der Mycetozoen (1873), 9 und Monogr. App., 2; Schröter in Cohn Krypt.-Flora Schles. III, 120; und in Engler und Prantl Natürl. Pflanzenfam. I. 1 32; Lister Monogr. ed. 1, 26 und ed. 2, 26; Schinz in Mitt. Naturw. Ges. Winterthur VI, 24; Macbride N. A. Slime-Moulds 21.

Der kohlensaure Kalk in Form kleiner kugeliger Körnchen oder (bei Diachæa) kugeliger, sternförmiger Krystallklïmpchen der Peridie eingelagert und in den Capillitiumfäden, hier manchmal nur in blasigen Erweiterungen (Kalkknoten). Diderma, Colloderma und Physarina ohne Kalkknoten und bei Diachæa nur der Stiel und die Columella Kalk führend.

\section{Schlïssel zur Bestimmung der Gattungen der Familie der Physaraceae.}

1. Capillitium aus in ihrer ganzen Ausdehnung mit kohlensaurem Kalk erfüllten, reichlich anastomosierenden, + flachen, bandartigen (ab und zu fädlich zusammengezogenen) Fäden bestehend. 1. Badhamia Berkeley.

$1^{*}$ (vergl. 1**). Capillitium ein Netzwerk zarter Fäden mit blasenartigen, kalkerfüllten Verbreiterungen (Kalkknoten).

2. Fruchtkörper polster- oder kissenförmige Äthalien bildend.

3. Fuligo Haller.

2*. Fruchtkörper als Einzelsporangien ausgebildet, zerstreut oder gehäuft.

3. Sporangien \pm kugelig, linsenförmig oder Plasmodiokarpien bildend.

4. Capillitium ohne freie, hakenförmig gekrümmte Ästchen. 2. Physarum Pers.

4*. Plasmodiokarpien. Capillitium mit zahlreichen, freien, gekrümmten, scharfen Ästchen, gelb. 7. Cienkowskia Rost.

$3^{*}$ (vergl. $3^{* *}$ ). Sporangien lang zylindrisch, einfach oder verzweigt, mitunter zu Plasmodiokarpien ausgebildet. Capillitium, abgesehen vou den gelben Kalkknoten, farblos.

4. Erionema Penzig. 
$3^{* *}$. Sporangien entweder kurz zylindrisch, ei-, becheroder schüsselförmig.

5. Sporangien schüsselförmig.

5. Trichamphora Junghuhn

5* Sporangien kurz zylindrisch, lang gestielt.

6. Physarella Peck.

$5^{* *}$. Sporangien becher- oder eiförmig. Stiel pergamentartig, so lang oder häufiger kïrzer als das Sporangium. 8. Craterium Trentepohl.

$5^{* * *}$. Sporangien eiförmig, gebüschelt. Stiel häutig.

9. Leocarpus Link.

$1^{* *}$. Capillitium fädlich (bei Diachæa ein zartes Netzwerk bildend) ohne Kalkknoten.

6. Peridie undurchsichtig, glatt.

10. Diderma Pers.

$6^{*}$ Äußere Peridieschicht gelatinös, innere häutig.

11. Colloderma G. Lister.

$6^{* *}$. Peridie undurchsichtig, nit zahlreichen Höckerchen besetzt. 12. Physarina Höhnel. $6^{* * *}$. Peridie dünnhäutig, ohne Kalk.

13. Diachaea Fries.

\section{Üb ersicht der Gat tungen.}

Badhamia. Gestielte oder ungestielte Sporangien oder Plasmodiokarpien. Capillitiumnetz aus breiten, kalkführenden Fäden bestehend. Sporen frei oder gruppenweise zusammenhängend.

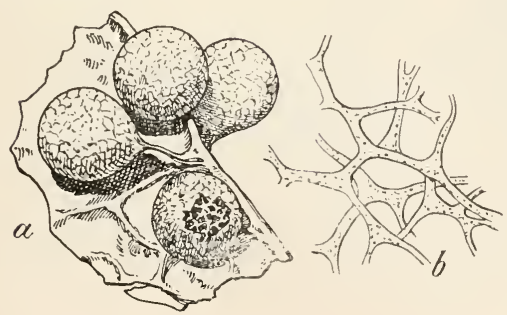

Fig. 39.

Badhamia foliicola (z. T. nach Lister). a) ein Laubblatt mit aufsitzenden Sporangien $(15 / 1)$. b) Ein Stück Capillitium $(260 / 1)$. 
Physarum. Sporangien gestielt, ungestielt, oder Plasmodiokarpien bildend. Peridie mit ihr eingelagertem kohlensaurem Kalk in Form von Körnchen, Schülferchen oder Krusten. Capillitiumfäden nicht breit, mit \pm zahlreichen, oft großen, blasenförmigen Kalkknoten.

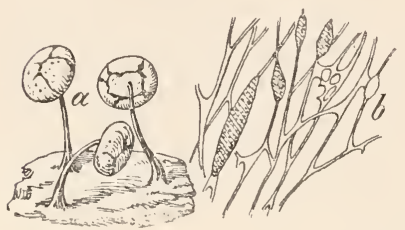

Fig. 40.

Physarum viride (nach Lister).

a) drei am Substrat befestigte, aufspringende Sporangien $(15 / 1)$. b) Ein Stück des Capillitiums mit Kalkknoten $(260 / 1)$.

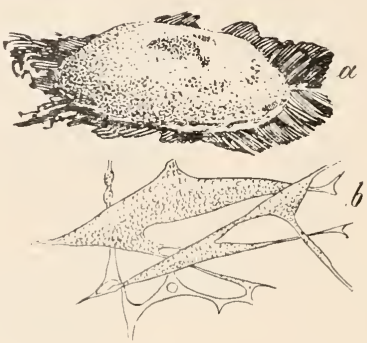

Fig. 41 .

Fuligo septica (z. T. nach Lister). a) Ein Äthalium, dem Substrat aufsitzend $(1 / 1)$. b) Ein Teil des Capillitiums, mit Kalkknoten $(260 / 1)$.

Fuligo. Sporangien vereinigt zu einem mitunter handgroßen, meist aber kleineren Äthalium; die äußerste Sporangienlage mitunter steril, d. h. olne Sporen, eine Art von Rindenschicht bildend. Capillitium bald mit vielen, bald mit wenigen Kalkknoten.

Erionema. Sporangien lang zylindrisch, einfach oder verzweigt, mitunter Plasmodiokarpium-artig. Capillitiumfäden zart, farblos, mit wenigen, kleinen Kalkknoten.

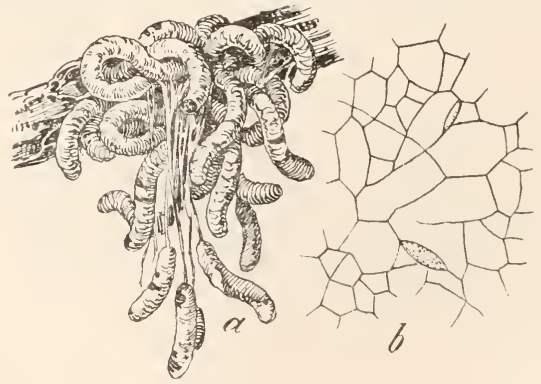

Fig. 42 .

Erionema aureum

(nach Lister).

a) Sporangienbüschel, vom Substrat herunterhängend $(15 / 1)$. b) Ein Teil des Capillitiums, mit spindelförmigen Kalkknoten $(260 / 1)$. 
Trichamphora. Sporangien scheiben- oder schüsselförmig, gestielt. Capillitium aus farblosen, verzweigten Fäden mit Kalkknoten oder aus kalkbeladenen oder kalkfreien Röhren bestehend.

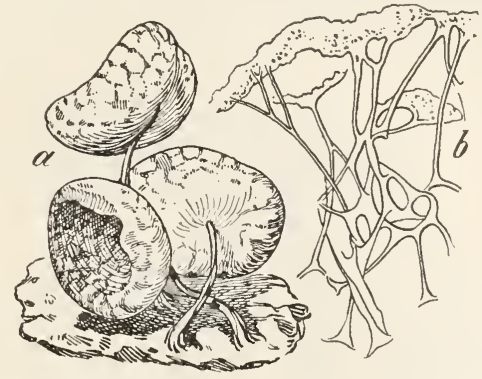

Fig. 43. Trichamphora pezizoides (nach Lister).

a) drei auf dem Substrat stehende Sporangien $(15 / 1)$. b. Teil des Capillitiums, der Peridie anhaftend $(260 / 1)$.

Physarella. Sporangien lang gestielt, kurz zylindrisch, oberseits mit vertieftem Nabel, selten Plasmodiokarpien bildend, Peridie in sternförmig abstehende Lappen aufspringend. Capillitiumfäden zart, mit spindelförmigen Kalkknoten; außerdem dornartige, von der Peridie abstehende, kalkbeladene Fortsätze.
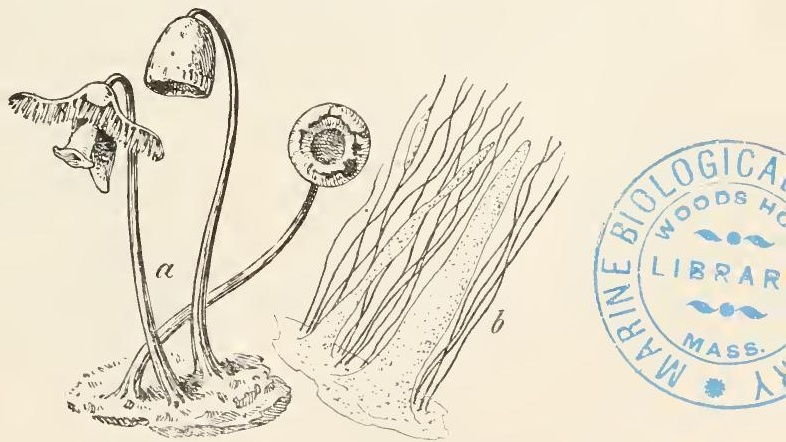

Fig. 44. Physarella oblonga (nach Lister).

a) Drei, am substrat befestigte Sporangien, eines davon anfgesprungen $(15 /$,

b) Teil des der Peridie auhaftenden Capillitiums mit Kalkknoten und zwei kalkführenden, doruartigen Fortsätzen $\left({ }^{260} / 1\right)$. 
Cienkowskia. Fruchtkörper netzartig anastomosierende, wurmartige Plasmodiokarpien bildend. Capillitium ein lockeres Netzwerk straffer Fäden mit zahlreichen freien, spitzen, gekrümmten Ästchen und durchlöcherten, an der Peridie befestigten, rertikal gestellten Kalkplatten.

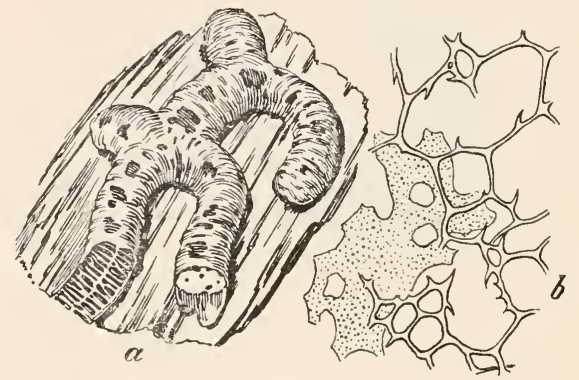

Fig. 45. Cienkowskia reticulata (nach Lister).

a) Plasmodiokarp, an einem Ende die Peridie entfernt, die vertikal gestellten Kalkplatten zeigend $(15 / 1)$. b) Teil des Capillitiums mit durchlöcherter Kalkplatte $(260 / 1)$.

Craterium. Sporangien gestielt, becherförmig und mit dünnwandigem Deckel oder ohne ausgesprochenen Deckel und dann eiförmig oder kugelig. Stiel + kräftig, nicht häutig. Capillitium aus hyalinen Fäden bestehend, die durch breite Kalkknoten verbunden sind und die mitunter in der Mitte des Sporangiums eine Art Columella bilden.

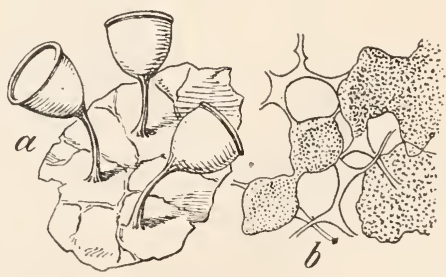

Fig. 46. Craterium minutum (nach lister).

a) Drei, einem Blatt aufsitzende Sporangien $\left({ }^{18} / 1\right)$. b. Teil des Capillitiums mit Kalkknoten $(260 / 1)$. 
Leocarpus. Sporangien gestielt oder ungestielt, meist gebüschelt, verkehrt eiförmig oder kugelig, mit kastanienbrauner, glänzender Peridie. Stiel schwächlich, häutig. Capillitium aus + breiten Fäden mit verzweigten, anastomosierenden, braunen Kalkknoten bestehend.

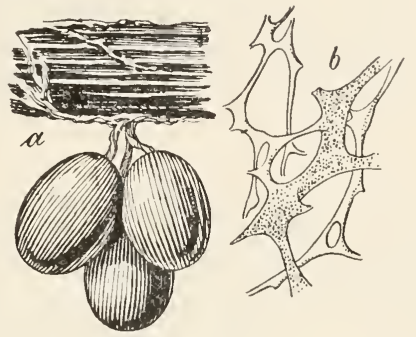

Fig. 47. Leocarpus fragilis (nach Lister).

a) Drei, am Substrat befestigte Sporangien $(15 / 1)$. b. Teil des Capillitiums mit Kalkknoten $(260 / 1)$.

Diderma. Sporangien gestielt, ungestielt oder Fruchtkörper Plasmodiokarpien bildend. Peridie aus zwei Schichten bestehend (bei D. simplex aus nur einer Schicht) mit körnigen Kalkeinlagerungen (bei D. Trevelyani die Körnchen krystallinisch). Columella gewöhnlich vorhanden. Capillitium aus zarten, mitunter verzweigten Fäden bestehend, ohne Kalkknoten.

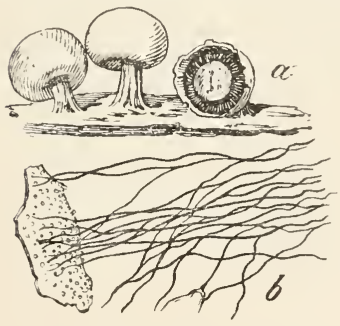

Fig. 48.

Diderma radiatum (nach Lister). a) Drei am Substrat befestigte Sporangien, eines davon geöffnet, die mittelständige Columella zeigend $(15 / 1)$. b. Ein Teil des Capillitiums mit einem Stück der Peridie $(260 / 1)$.

Colloderma. Sporangien gewöhnlich ungestielt, kugelig oder kurze Plasmodiokarpien bildend. Peridie zweischichtig, äußere Schicht angefeuchtet, gelatinös dick, innere häutig. Capillitium aus purpurroten Fäden ohne Kalkknoten bestehend. 


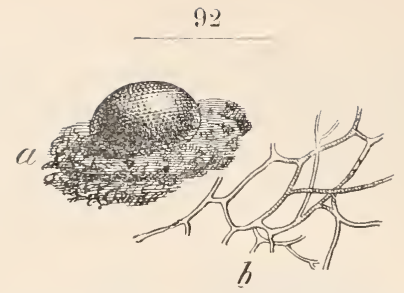

Fig. 49. Colloderma oculatum (nach Lister).

a) Ein dem Substrat aufsitzendes Sporangium $(13 / 1)$. b. Teil des Capillitiums $(260 / 1)$.

Physarina. Sporangien kugelig, gestielt, stumpfstachelig infolge dicht stehender, der Peridie aufgesetzter, stumpfer Höcker. Stiel in das Sporangiuminnere als kugelige oder halbkugelige Columella fortgesetzt. Capillitiumfäden zart, ohne, nur selten mit Kalkknoten, mit sich verzweigenden Enden.

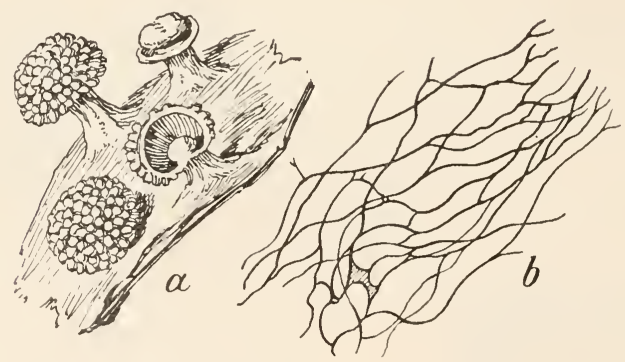

Fig. 50. Physarina echinocephala (nach Lister).

a) Vier am Substrat befestigte Sporangien, eines längs durchschnitten, die Columella zeigend, eines mit verschwundener Peridie, der Stiel überragt von der Columella $\left({ }^{15} / 1\right)$. b. Ein Teil des Capillitiums $(260 / 1)$.

Diachaa. Gestielte oder ungestielte Sporangien oder Plasmodiokarpien. Peridie häutig, irisierend, ohne Kalkeinlagerungen. Stiel und Columella kalkführend, selten kalkfrei. Capillitium ein weitmaschiges Netzwerk purpurroter Fäden ohne Kalkknoten. 


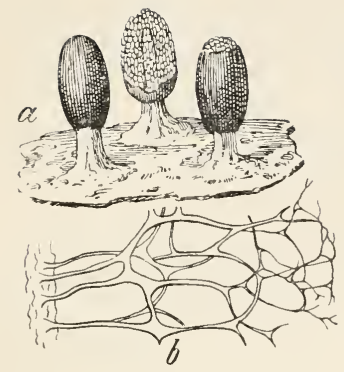

Fig. 51. Diachæa leucopoda (nach Lister). a) Drei am Substrat befestigte Sporangien, eines mit zum T'eil zerstörter Peridie, das Capillitium mit der durchscheinenden Columella zeigend $(15 / 1)$. b) Ein Teil des an der Peridie haftenden Capillitiums $(260 / \mathrm{s})$.

\section{Gattung Badhamia Berkeley}

in Trans. Linn. Soc. XXI (1852), 153; Rost Monogr. App., 2; Schröter in Cohn Krypt.-Fl. Schles. III. 1, 131 und in Engler und Prantl Natïrl. Pflanzenfam. I. 1, 34; Massee Monogr., 316 ; Lister Monogr. ed. 1, 29 und ed. 2, 30; Schinz in Mitt. Naturw. Ges. Winterthur VI, 26; Macbride N. A. Slime-Moulds, 62; Torrend in Broteria VI, 59 und VII, $14 t$.

Gestielte oder ungestielte Sporangien oder Plasmodiokarpien. Peridie düın, zerbrechlich, unregelmäßig aufbrechend, mit eingelagertem kohlensaurem Kalk. Sporangien mit oder ohne Columella. Sporen häufig gruppenweise zusammenhängend.

Capillitium in der Regel in seiner ganzen Ausdehnung aus zusammenhängenden, reichlich anastomosierenden, flachen, bandartigen Fäden, die im ganzen Verlauf Kalk führen, bestehend, mitunter die Kalkbänder stellenweise verbreitert und dam durch \pm dünne, hyaline Verkindungsfäden untereinander verbunden (Capillitium demjenigen der Plyssarum-Arten sich nähernd).

Die Arten der Gattung Badhamia unterscheiden sich von denen der Gattung Physarum namentlich durch das Fehlen hyaliner, dünner Verbindungsfäden zwischen den Kalkknoteu; die nahe Verwandtschaft beider Gattungen gibt sich aber schon in dem Umstand zu erkennen, daB bei einzelnen Badhamia-Arten derartige Verbindungsfäden vorkommen (B. nitens, decipiens, panicea, rubiginosa), wie auch Physarum-Arten bekannt sind, deren Capillitium Badhamia-ähnlich ist. Bei einer starken Aus- 
bildung der Kalkknoten können diese im Zentrum des Fruchitkörpers zu einer mittelständigen Kugel, einer Pseudocolumella zusammenschließen, bei Badhamia so gut wie bei Physarum.

Macbride 1. c. läßt den Autornamen Berkeley fallen und ersetzt ihn durch Rostafinski; ich vermag aber seiner Begründung nicht zu folgen.

Von den 16 beschriebeneu Arten der Gattung Badhamia kommen $13 \mathrm{im}$ Gebiete vor, anscheinend aber keine davon so häufig wie einzelne derselben in Großbritannien unter dem sichtbaren Einflusse des feuchten Seeklimas. Die Häufigkeit scheint gegen das Innere des Kontinentes abzunehmen. Für die Schweiz ist das Vorkommen einer Varietät von B. foliicola interessant, die anscheinend den Typus in der subalpinen und alpinen Region ersetzt. Ist die Vermutung richtig, dann findet sich diese Spielart wahrscheinlich auch im Norden, in Schweden etc.

1. Sporen gruppenweise verbunden.

2. Sporenwand hauptsächlich auf der freien Seite warzig.

3. Sporangien $1-1,5 \mathrm{~mm}$ dick.

4. Kalk in der Peridie und im Cappillitum weiß.

5. Sporangien grau, ungestielt oder mit häutigem Stiel.

1. B. capsulifera (Bull.) Berkeley in Traus. Linn. Soc. XXI (1852), 153; Macbride N. A. Slime-Moulds, 68; Torrend in Broteria VI, 59, VII, 145; Lister Monogr. ed. 2, 31, pl. 3, fig. $a-c$.

Synonyme: Sphærocarpus capsulifer Bull. Champ. (1794), 139, t. 470 , fig. 2.

Physarum hyalinum Pers. in Roem. N. Mag. Bot. I (1794), 88?; Rabenh. Deutschl. Kryptog.-Fl. I, 274.

Trichia capsulifer D C. Fl. Fr. II. (1805), 254.

Physarum botryoides Fr. var. hyalinum Fr. Stirp. Fems. (1825-26), pg.?

Physarum cinereum Link in Berl. Mag. IlI (1808), 27 ?

Physarum capsuliferum Chev. Fl. Par. I (1826), 339.

Physarum cancellatum Wallr. Fl. Crypt. Germ. (1833), 351 ?

Diderma papaverinum Wallr. Fl. Crypt. Germ. (1833); 375. 
Badhamia hyalina Berkeley in Trans. Linn. Soc. XXI (1852), 153; Rost. Nonogr. 139; Schröter in Cohn Krypt.Fl. Schles. III, 131; Ćelakovský Myxomyceten Böhmens, 75; Lister Monogr. ed. I, 30 pl. I, B, fig. a-f; Schinz in Mitt. Naturw. Ges. Winterthur VI, 27 pr. p.

Physarum gracileutum Fucke I Symb. Mycol. (1867/70), 342 non Fr. (= Physarum nutans).

Badhamia varia M a s s e Monogr. (1892), 319 pr. p.

Plasmodium gelb. Sporangien gruppenweise verbunden (gebüschelt) od. herdenweise, kugelig oder verkehrteiförmig, meist ungestielt, grau oder grauweib, entleert schneeweiß. Stiel, wenn vorhanden, häutig, strohgelb. Capillitium aus maschenartig anastomosierenden, flachen, in den Ecken der Maschen wenig verbreiterten Bändern bestehend. Sporenmasse dunkelpurpurbraun; Sporen in Gruppen von 5 bis 20, auf der freien Seite grob warzig, im ïbrigen fein stachelig, $2-13 \mu$.

Deutschland, Schweiz, Österreich,

Großbritannien, Frankreich, Portugal, Schweden, Rußland, 0.-Afrika, N.-Amerika.

$5^{*}$. Sporangien grauweib, auf dunkelbraunen oder seltenerstrohfarbigen, gedrungenen, $0,2-0,3 \mathrm{~mm}$ langen Stielen.

2. B. papaveracea Berk. et Rav. in Grev. II (1873), 66; Rost. Monogr. App., 3 ; Massee Monogr., 323 pr. p.; Macbride N. A. Slime-Moulds, 69, pl. X, fig. 6, 6a, 6b; Lister Monogr. ed. 2, 32, pl. 3, fig. d-e.

Sy u on yme: Badhamia hyalina Berk. var. papaveracea Lister onogr. ed. 1 (1914), 30, pl. 1, B, fig. g.

Badhamia capsulifera Berk, var. papaveracea Torrend in Broteria VII (1908), 145, pl. VI, fig. 10, 11.

Plasmodium? Sporangien meist gestielt, ab und zu auch sitzend, kugelig, 0,7-1 $\mathrm{mm}$ im Durchmesser, mitunter etwas metallisch glänzend. Peridie mit spärlicher Kalkeinlagerung, glatt oder etwas uneben. Capillitium demjenigen der vorigen Art entsprechend. Sporenmasse dunkelbraun; Sporen im durchfallenden Lichte bei Vergrößerung purpurbraun. Die Sporen sind zu 6 bis 10 zu Paketen vereinigt, ihre äußere Seite ist stärker warzig als die innere; $10-13 \mu$. 
Österreich.

N.-Amerika, Japan.

Diese Art unterscheidet sich von B. capsulifera durch die gedrungenen, nicht häutigen Stiele und durch die kleineren Sporenhaufen.

\section{$5^{* *}$. Sporangien wei $B$ oder gelb- lichweiß, gehäuft.}

3. B. populina List e $\mathrm{r}$ in Journ. of Bot. XLII (1904), 129, t. 459, fig. 1a, 1b, 1 c. XLIII, 152 und Monogr. ed. 2, 32, pl. 2, fig. a-c; Torrend in Broteria VII, 146, pI. VI, fig. 14.

Sporangien weiß, meist gehäuft, selten einzeln auf kurzen, gelblichbraunen Stielen. Capillitium kalkreich. Sporenmasse schwarz. Sporen in Gruppen zu 16 bis 20 und mehr, im durchfallenden Lichte purpurbraun, meist gerippt, fein warzig und zwar die Warzen auf der freien Seite etwas stärker, $10-12 \mu$.

Deutschland.

Großbritanuien, Frankreich, N.-Amerika.

$$
\begin{aligned}
& \text { t*. Sporangien und Capillitium }^{*} \text { zitronengelb. }
\end{aligned}
$$

4. B. nitens Berkeley in Trans. Linn. Soc. XXI (1852), 153, t. 29, fig. 1; Rost. Monogr. App., 3; Massee Monogr., 324, fig. 176-179, Torrend in Broteria VII, 147; Lister Monogr. ed. 1, 32 pl. III, A, fig. a-d, ed. 2, 34, pl. 5, fig. a-d und Journ. of Bot. XXXVI, 115, 153.

Synonyme: Badhamia pallida Berkeley l. c. (1852), 153.

Badhamia fulvella Berkeley l. c. (1852), 154?

Badhamia inaurata Currey in Trans. Linn. Soc. XXIV (1863), 156 , t. 25 , fig. 8 .

Badhamia Alexandrowiczii de Bary et Rost. Monogr. (1875).

146; Schröter in Cohn Kirypt.-Fl. Schles, III, 1, 132. Didymium reticulatum Berk. et Br. in Journ. Linn. Soc. XV (1876), 83.

Lepidoderma reticulatum Massee Monogr. (1892), 252, pr. p.

Badhamia decipiens Lister Monogr. ed. I (1894), 32.

Plasmodium gelb. Sporangien wohl meist ungestielt, kugelig, herdenweise, häufig gedrängt, mitunter zu Plasmodiokarpien entwickelt, goldgelb, höckerig oder grünlich mit gelben Warzen und Riefen. Peridie kalkführend. Capillitium 
zitronen- bis orangegelb. Sporen im durchfallenden Lichte purpurbraun, $10-13 \mu$, zu 4 (selten) oder zu 6 bis 10 Pakete bildend, auf der äußeren Seite \pm grob warzig.

Deutschlaud, Österreich. Wohl ïberall selteu.

GroBbritaunien, Fraukreich, Rußlaud, Ceylon, Westindien, S.-Amerika.

$3^{*}$. Sporangien $0,3-0,5 \mathrm{~mm}$ breit. Capil-

litium weiß oder aprikosenfarbig.

5. B. versicolor Lister in Journ. of Bot. XXXIX (1901), 81. t. +19, fig. 2a-e und Monogr. ed. 2, 35, pl. 6, fig. a-c; Torrend in Broteria VII, 147.

Plasmodium ? Sporangien \pm kugelig, sitzend, sehr klein, zerstreut oder in kleinen Häufchen, grau oder fleischfarbig, \pm höckerig. Sporen ovoid, $10 \times 8$ bis $12 \times 9 \mu$, am breitern Ende fein warzig und im durchfallenden Lichte mattpurpurn, sonst fast farblos und glatt, zu 10 bis 40 in Gruppen.

Dentschland (Mark Brandenburg), Schweiz (Jura).

Großbritaunien, N.-Amerika.

2*. Sporen allseitig gleichmäßig warzig.

6. B. utricularis (Bull.) Berkeley in Trans. Linu. Soc. XXIX (1852), 153; Rost. Monogr. 142, fig. 110-112; Schröter in Cohn Krypt.-Fl. Schles. III, 1, 132 ; Macbride N. A. SlimeMoulds, 67, pl. XIV, fig. 1; Schinz in Mitt. Naturw. Ges. Winterthur VI, 27 ; Torrend in Broteria VII, 146, pl. VIII, fig. 6, 7, 8; Lister Monogr. ed. 1, 31, pl. II, A, fig. a-d und ed. 2, 33, pl. 4, fig. $a-d$.

Synonyme: Sphærocarpus utricularis Bull. Champ. II (1791), 128.

Trichia cerulea Trentep. in Roth Cat. Bot. I (1797), 229?

Physarum ovoideum Sehum. Enum. Sæll. II (1803), 198.

Physarum hyalinum $\beta$ chalybæum Alb. et Schw. Cousp. Fung. (1805). 92.

Trichia utricularis DC. Fl. Fr. (1805) 251.

Trichia rubiformis Purt. in Brit. Fl. of. Midl. Count. III (1821), 291, t. 37 non Pers.

Physarum botryoides Fr. Stirp. Femsion. (1825), 83.

Physarum botrytes Somm. Fl. Lapp. (1826), 242.

Physarum utriculare Fries Syst. Mycol. IlI (1929), 139; Rabenh

Deutschl. Kryptog.-Fl. I, 274.

Diderma reticulatum B e r k. et B r, in Journ. Linn. Soc. XV (1876), 83.

Diderma papaveriuum Wallr. F'. Crypt. Germ. (1833), 375.

Badhamia varia Massee Monogr. (1892), 319 pr. p.

Exsikkaten: 0. Jaap. Myxom. exsicc. 41, 62, 81 .

Schinz, Myxogasteres (R abenhorst Krypt. Flora I, Pilze Abt. X). 


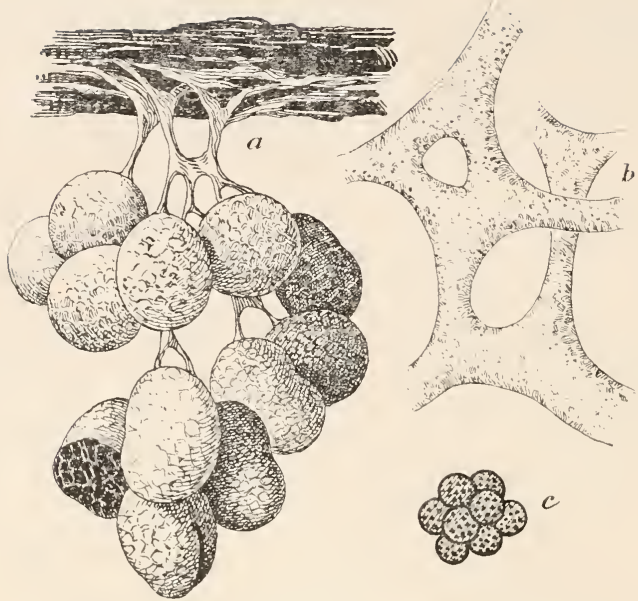

Fig. 52. Badhamia utricularis (Bull.) Berk.

a) Sporangienbüschel $(20 / 1)$; b. Capillitium-Fragment $(280 / 1)$; c. Sporengruppe $\left({ }^{300} / 1\right)$ Z. T. nach Lister.

Plasmodium chromgelb. Sporangien eiförmig, mehr minder kugelig oder zu zweien oder mehr verwachsen und gelappt, meist gebüschelt, sitzend oder mit langen, häutigen, strähnenartigen, strohgelben, verzweigten Stielen, mehr minder blaugrau, violett irisierend oder aschgrau. Capillitium weiß. Sporen im durchfallenden Lichte hell- oder violettbraun bis leuchtend kastanienbraun, in lockeren Gruppen zu 7 bis 10, rundum fein stachelig, $9-12 \mu$.

Die Sporangien vou B. utricularis erinnern an jene von B. capsulifera, sie unterscheiden sich aber durch eine etwas stärker höckerige Peridie, namentlich aber durch die allseitig stacheligen Sporen.

Plasmodien dieser Art können durch Entzug der Nahrung und durch Austrocknen sehr leicht zur Encystierung gebracht und in diesem Zustande dann jahrelang aufbewahrt und zu beliebiger Zeit wieder durch Befeuchten zu neuem Leben erweckt werden. 
Kleine Sclerotienstückchen lassen sich in dieser Weise durch Fütterung mit Stereum hirsutum im Laufe weniger Tage zu ansehnlichen Plasmodien heranziehen. Die Sclerotien dieser Art eignen sich daher sehr zu Laboratoriumsversuchen.

Deutschland, Oesterreich, Schweiz,

Grobbritannien, Frankreich, Schweden, Italien, Portugal, N.- und S.-Amerika.

1*. Sporen frei, nichtzu Gruppen zusammengeballt.

b. Sporangien gelb oder orangefarbig.

7. B. decipiens (Curt.) Berkeley in Grev. II (1873), 66; Macbride N. A. Slime-Moulds, 63; Torrend in Broteria VII, 148; Lister Monogr. ed. 1, 32, pl. III, B, fig. a -i und ed. 2, 35, pl. 7, fig. a-c, in Journ. of Bot. XLII, 129 und XXXVI, 115.

Synonyme: Physarum decipiens Curtis in Aun. Am. Journ Sc. VI (1848), 352.

Physarum ehrysotrichum Berk. et Curt. in Grev. II (1873), 66 ;

Massee Monogr., 300.

Badhamia ehrysotricha Rost. Monogr. App. (1876), 4.

Plasmodium ? Sporangien herdenweise, sitzend, kugelig oder an deren Stelle wurmförmig gekrümmte Plasmodiokarpien, höckerig oder nahezu glatt, gelb bis orangefarbig, mitunter mit einem Stich ins Grünliche. Capillitium gelb; Kalkknoten mitunter mit hyalinen Verbindungsfäden. Sporenmasse \pm schwarz; Sporen im durchfallenden Lichte violettbraun, fein stachelig, $10-13 \mu$.

Deutschland (Harz, Hannover), Großbritannien, Frankreich, Schweden. N.- und S.-Amerika.

W. C. Sturgis (Colorado College Publ. Gen. Ser. No. 68, science ser. vol. XII, No. 12, pag. 437) berichtet von Sporangien dieser Art, die kalkfrei sind, eine bronceirisierende Peridie und $8-10 \mu$ große Sporen besitzen. Es ist im Gebiet hierauf zu achten.

$6^{*}$. Sporangien weiß oder grau.

7. Sporangien kugelig, sitzend oder auf kurzen, häutigen Stielen. Sporen im durchfallenden Lichte violettbraun oder dunkel. 
8. B. foliicola Lister in Journ. of Bot. XXXV (1897), 209, XXXIX, 82, XLII, 129, und Monogr. ed. 2, 34, pl. 11, fig. a-c; Schinz in Mitt. Naturw. Ges. Winterthur VI, 28, Torrend in Broteria VII, 150.

Syuonyme: Badhamia microcarpa Sehröter in Cohn Krypt. Fl. Schles. III, 1 (1889), 131.

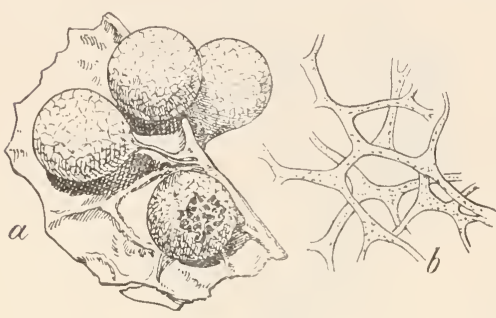

Fig. 53. Badhamia foliicola Lister.

a. Sporangiengruppe, $(20 / 1)$;

b. Capıllitium $(280 / 1)$. Nach Lister.

Plasmodium orangegelb. Sporangien kugelig oder verkehrt eiförmig, $1 / 2-1 \quad \mathrm{~mm}$ breit, bläulichgrau irisierend, kalkarm, sitzend und gehäuft oder zerstreut auf schlanken, blaß gelblichbraunen, $0,2-0.5 \mathrm{~mm}$ langen Stielen. Capillitium weiß, kalkarm. Sporen mitunter gruppenweise zu $3--6$ leicht zusammenhängend, fein stachelig, $9-12 \mu$.

Deutschland, Schweiz, die aus der Schweiz (von der Fürstenalp, von Arosa und vom Jura) stammenden Funde muterscheiden sich samt und sonders von der typischen Form durch blaße, fast glatte Sporen und Frl. G. Lister schlägt daher (brieflich) für diese alpine Furm die Bezeichnung var. alpina G. Lister vor.

GroBbritaunieu, Frankreich, Schweden, Portugal.

$7^{*}$. Sporangien \pm kugelig, violettgrau irisierend, zu 4 und mehr auf langen, häutigen Stielen gebüschelt. Capillitium weib. Sporenmase schwarz. Sporen im durchfallenden Lichte dunkel kastanienbraun bis lurpurbraun, einseitig sehr fein stachelig, $9-10 \mu$.

9. B. manna Peck in Rep. New York Mus. XXXI (1879), 57; Torrend in Broteria VII, 147; Lister Monogr. ed. 1, 33 pl. II, B, fig. a-b und ed. 2, 34, pl. 9. fig. a, b.

Synonyme: Dietydium magnum Peck 1. c. XXIV (1872), 84.

Badhamia varia II assee llonogr. (1892), 319 pr. p. 
N.-Amerika.

Scheint B. utricularis sehr nahe zu stehen und unterscheidet sich in der Hauptsache nur durch die auffallend lang gestielten, nicht eiförmigen Sporangien und die dunkel- und nicht blaß-bis leuchtendkastanienbraunen Sporen. Macbride (N. A. SlimeMoulds, 68) vereinigt, allerdings nicht ohne?, diese Art mit B. capsulifera.

$7^{* *}$. Sporangien kugelig, ungestielt oder mit kräftigem, gelbem oder braunem Stiel. Sporen dicht stachelig, im durchfallenden Lichte dunkelpurpurbraun.

10. B. macrocarpa (Ces.) Rost. Monogr. (1875), 143, fig. 118, 120, 121; Schröter in Cohn Krypt.-Fl. Schles. III, 1, 132; Massee Monogr. 317, fig. 79-81, 294-297; Schinz in Mitt. Naturw. Ges. Winterthur V1, 28; Torrend in Rrot. VII, 146; Lister Monogr. ed. 1, pl. IV, A, fig. a-e und ed. 2, 36, pl. 8, fig. a-c. Syuonyme: Physarum macrocarpon Ces. in Rabenh. Fungi Eur. Cent. XX (1854), No. 1968 und in Flora XXXVIII (1855), 271. Badhamia macrocarpa var. sessilis Rost. Monogr. (1875), 143 Badhamia macrocarpa var. stipitata Rost. 1. c. (1875), 143.

Exsikkaten: O. Jaap Myxom, exsice. 82.

Plasmodium weiß (nach Constantineanu gelb). Sporangien gestielt oder ungestielt, vereinzelt, herdenweise oder gehäuft, mitunter gebüschelt, $0,5-1 \mathrm{~mm}$, grauweiß, böckerig. Stiel, wenn vorhanden, kräftig, $\pm 0,7 \mathrm{~mm}$ lang, gefurcht, gelb oder unterwärts braun. Capillitium weiß, kalkreich. Sporenmasse schwarz; Sporen $11-15 \mu$.

Deutschland, Schweiz, Oesterreich.

GroBbritannien, Holland, Frankreich, Schweden, RuBland, Italien, N.- und S.-Amerika, Antigua, Japan.

$7^{* * *}$. Sporangien \pm kugelig, etwas niedergedrückt, wnterseits abgeflacht oder genabelt, ungestielt oder gestielt, höckerig, grauweiß. Stiel bis $1 \mathrm{~mm}$ lang, schwarz in seiner ganzen Länge oder am Grunde schwarz und oberwärts weib, gefurcht. Sporen im durchfallenden Lichte violettbraun, fein stachelig, $12-15(-17$ ?) $\mu$. 
11. B. affinis Rost. Monogr. (1875), 143; Macbride N. A. Slime-Moulds, 66; Torrend in Broteria VII, 149; Lister Monogr. ed. 1,36 und ed. 2, 37.

GroBbritannien, N.- und S.-Amerika, Jayan.

$7^{* * * *}$. Sporangien + kugelig oder scheibenförmig, grauweib, sitzend oder auf schwärzlichem, an der Insertionsstelle braunem Stiel, mitunter an deren Stelle + flacheoder gewölbte Plasmodiokarpien. Stiel $0,1-0,3 \mathrm{~mm}$ lang (Sporangien bis $0,7 \mathrm{~mm}$ breit), gefurcht. Capillitium weib, dessen Stränge mitunter zu einer zentralen Kalkplatte zusammenfließen. Sporen im durchfallenden Lichte violettbraun, fein warzig, $12-15 \mu$.

12. B. orbiculata Rex in Proc. Acad. Nat. Sc. Phil. (1893), 372 ; Macbride N. A. Slime-Moulds, 67, pl. XIV, fig. 4; Torrend in Broteria VII, 148, pl. VI fig. 12; Lister Monogr. ed. 2, 37, pl. 8, fig. $d-f$.

Synonyme: Badhamia macrocarpa Lister Monogr. ed. 1 (1894), 34 pr. p.

Ersikkaten: O. Jaap Myxom. exsice. 101.

N.-Amerika, Westindien, Japan.

$7^{* * * * *}$. S porangien kugelig, ungestielt oder a uf kurzem, dunkelrotem Stiel. Sporen im durchfallendem Lichte violettbraun, sehr fein warzig.

13. B. panicea (Fries) Rost. in Fuckel Symb. Myc. Nachtr. (1873), 71; Rost. in Monogr., 14t, fig. 114, 116; Čelakorsky Myxom. Böhmens, 75; Massee Monogr. 318, fig. 74-76; Schinz in Mitt. Naturw. Ges. Winterthur VI, 28; Macbride N. A. SlimeMoulds, 64; Torrend in Broteria VII, 149; Lister Monogr. ed. 1, 34, pl. IV, B, fig. a-e und ed. 2, 37, pl. 10, fig. a-c.

Synonyme: Physarum paniceum Fr. Syst. My. III (1829). 141.

Badhamia verna Rost Monogr. (1875), 145.

Reticularia Schmitzii Debey in Verh. Nat. Hist. Ver.

PreuB. Rheinl. IV (1817), fig. 1-4.

Exsikkaten: Fuckel Fungi rhen. 2499 (sub Didymium cinereum); 0. Јaаp Мухот. exsice. 63. 
Plasmodium weiß. Sporangien $0,4-1,2 \mathrm{~mm}$ breit, herdenweise oder sogar dicht zusammengepackt und dann durch den gegenseitigen Druck seitlich abgeplattet, weiß oder aschgrau, meist ungestielt, höckerig. Capillitium weiß, gegen die Mitte und den Grund zu zusammenfließend und derart häufig eine falsche Columella bildend. Sporenmasse schwärzlich. Sporen im durchfallenden Lichte violettbraun, sehr feinwarzig, 10-13 $(-14) \mu$.

Deutschland, Schweiz, Oesterreich.

Großbritannien, Frankreich, Schweden, Portugal, N.- und S.-Amerika, Antillen (fide Torrend).

Raciborski beschreibt (in Hedwigia XXVIII (1889), 120) eine var. conferta, die in der Umgebung von Krakau häufig sein soll. "Kleine weiße, sitzende Sporangien, die seltener einzeln stehen und dann bis $0,5 \mathrm{~mm}$ breit und kugelig sind oder häufiger gedrängt zusammenwachsen und dann etwas unregelmäßig an Gestalt und confluierend sind. Membran und Capillitium stark verkalkt und deswegen schneeweiß, die jungen Sporangien gelblich, Sporenmasse beim Reifen schwarz. Capillitium ganz wie bei B. panicea Fr., mit großen Knoten, die im unteren Sporangienteile besonders groß sind, dicht stehen und eine unregelmäßige Columella bilden. Sporen mit dicker, schwarzvioletter, dicht mit kleinen Wärzchen bedeckter Membran, 13-15 $\mu$ breit."

"Unterscheidet sich", wie Raciborski schreibt, , von $B$. panicea nur durch die größeren, deutlich warzigen Sporen, von B. marrosperma Cesati forma sessilis (Rabh. Fungi europ. Nr. 1968), mit welcher sie der Sporen wegen sehr verwandt ist, durch die kleineren Sporangien und besonders durch ganz anderen Bau des Capillitiums und den Mangel der Pseudocolumella." (Letztere Beınerkung ist unverständlich, da ja in der Diagnose ausdrücklich erwähnt wird, daß im untern Teil des Sporangiums die großen Kalkknoten zu einer Art Columella zusammentreten). „Es nimmt“, fügt Raciborski hinzu, ,diese Krakauer Badhamia eine Mittelstellung zwischen den erwähnten zwei Arten ein und man kann sie fast mit demselben Rechte zur einen wie zur andern rechnen, oder auch als Repräsentant einer neuen Spezies (im engern Sinne) auffassen." 
6**. Sporangien kreideweiß oder ockerfarbig. ungestielt, halbkugelig oder an deren Stelle Plasmodiokarpien. Sporen ellipso id is ch.

14. B. ovispora Racib. in Rozpr. Mat.-Przyr. Akad. Krak. XII (1884), 72, t. 4; fig. 2; Massee Monogr. 326; Torrend in Broteria VII, 150; Lister in Journ. of Bot. XXYY, 35t, XXXVI, 165 pl. 386, fig. $3 \mathrm{a}, 3 \mathrm{~b}, 3 \mathrm{c}$, XXXIX. 82 Monogr. ed. 1, 36 und ed. 2, 38, pl. 12, fig. a-c.

Plasmodium ? Sporangien weiß oder ockerfarbig, glatt oder höckerig, 0,4-0,6 mm, an deren Stelle mitunter unregelmäßig geformte, oft verzweigte Plasmodiokarpien. Peridie kalkreich und daher sehr spröde. Capillitium weiß, brüchig, mit Tendenz zur Columellabildung. Sporen im durchfallenden Lichte violettbis purpurbraun, ellipsoidisch, 10,8 bis $16,10 \mu$, häıfig mit einer Längslinie (?) oder Längsfalte (?).

Österreich.

Großbritannien.

$6^{* * *}$. Sporangien fleischfarbig oder purpurbra un.

8. Sporangien fast stets ungestielt. ohne echte Columella.

15. B. lilacina (Fr.) R ost. Monogr. (1875), 145. fig. 108, 109; Macbride N.-A. Slime-Nloulds, 65; Torrend in Broteria YII, 151, pl. VI, fig. 13; Lister in Journ. of Bot. XXXIX, 82, Monogr. ed. 1, 34, pl. V, A, fig. a-d und ed. 2, 38, pl. 13, fig. a-c.

Synonyme: Physarum Jilacinum Fr. Syst. Myc. III (1829), 141;

Rabenh. Deutsenl. Kryptog.-Fl. I, 274.

Physarum concinnum Masse e Monogr. (1892), 308, fig. 22-24.

Craterium lilacinum Massee Monogr. (1832), 271, fig. 307, 308.

Plasmodium zitronengelb. Sporangien $\mathrm{kng}$ lig bis verkehrtkegelförmig, $0,5 \mathrm{~mm}$, ungestielt, seltener kurz gestielt, zerstreut oder gruppenweise dicht gedrängt und durch gegenseitigen Druck seitlich abgeplattet, glatt, fleischfarbig bis lilabraun, seltener weißlich. Capillitium blaßrosa oder weiß, mit breiten Kalkknoten, 
letztere häufig in der Mitte zusammenfließend und eine falsche Columella bildend. Sporenmasse schwarz; Sporen im durcht fallenden Lichte dunkelviolett, braun, warzig oder mit netzartiger Skulptur, $10-15 \mu$.

Deutschland, Schweiz.

Großbritannien, Schweden, Frankreich, N,-Amerika.

8*. Sporangiengestielt, Stielals Columella in das Sporangium sich fortsetzend.

16. 13. rubiginosa (Cher.) Rost. Monogr. App. (1876), 5, fig. 115; Schröter in Cohn Krypt.-Fl. Schles. III, 1, 132; Macbride N.-A. Slime-Moulds, 70, pl. X, fig. 1, $1 \mathrm{a}, 1 \mathrm{~b}, 1 \mathrm{c}$; Torrend in Broteria VII, 151, pl. VIII, fig. 9, pl. IX, fig. 4, 4a, 5; Lister in Journ. of Bot. XLII, 130, XLIII, 151, Monogr. ed. 1, 35 , pl. $\mathrm{V}, \mathrm{B}$, fig. a-f und ed 2, 39, pl. 14, fig. a. b.

Sy onyme: Physarum rubiginosum Chev. Fl. Paris. I (1826), 338;

Pabenh. Deutschl. Kryptog.-Fl. I, 275.

Didymium Curtisii Berk. in Grev. II (1873), 65

Craterium obovatum Perk in Rep. New-York Mus. XXVI (1874), 75

Scyphium rubiginosum Rost. Monogr. (1875), 148.

Badbamia Curtisii Rost. Monogr. App. (1876), 5.

Craterium Curtisii Massee Monogr. (1892), 272.

Craterium rubiginosum M as se Jonogr. (1892), 270, fig. 309, 310.

Badhamia subaquila Macbride N. A. Slime-Moulds (1899), 64

Plasmodium gelb. Sporangien verkehrteiförmig, fast stets gestielt, 0,5 mm, graubraun, purpurbraun oder gelblichrot. Peridie oberwärts dünn und zerbrechlich, zur Zeit der Sporenreife in Stücke zerbrechend, blasser als im untern resistenteren Teil. Stiel walzlich, nach dem Grunde zu sich verdickend, purpurbraun, sich im Sporangium his zu dessen halber Höhe als blasse, keulenförmige oder walzliche Columella fortsetzend. Capillitium blaßgelblichrot, dunkelbraun oder weiß, von der Columella nach der Wand ausstrahlend, Kalkknoten mitunter durch hyaline Verbindungsfäden verbunden. Sporenmasse dunkelbraun; Sporen purpurbraun oder lebhaft violett im durchfallenden Lichte, fein stachelig, warzig oder mit netzartiger Skulptur, $11-15 \mu$. 
Gliedert sich in folgende Varietäten:

var. genuina Liste r Monogr. ed. 1 (1894), 35; Torrend in Broteria VII (1908), 152.

Sporangien verkehrteiförmig, $0,5 \mathrm{~mm}$. Stiel rotgelb. Sporen fein stachelig.

Deutschland.

Frankreich, N.-Amerika.

var. dictyospora Lister Monogr. ed. 1 (1894), 35, pl. V, B, fig. g und ed. 2, 39, pl., fig. c, d, e.

S ynonyme: Badhamia dictyospora Rost. Monogr. App. (1876), 4.

Craterium dictyospermum Ma s s e e Monogr. (1892), 270, fig. 305, 306.

Exsikkaten: O. Jaap Myxom. exsice. 2, 64, 83.

Sporangien verkehrteiförmig, Sporen grobwarzig oder mit netzartiger skulptur.

Deutsehlaud.

GroBbritannien, Portugal, Frankreich.

Var. globosa Lister in Journ. of Bot. XLII (1904), 130 und Monogr. ed. 2, 39, pl. 14, fig. f, g; Torrend in Broteria VII, 152; Jngham in Naturalist (1904). 342.

Synonyme: Diderma Hookeri Berk. in Hook. Fl. Nov. Zel. II (1855), 191 ?

Lamproderma Hookeri Rost. Monogr. App. (1876), 24?

Diachaa Hookeri II asse e Monogr. (1892), 260?

Chondrioderma Hookeri Lis ter Monogr. ed. 1 (1894), 85?

Sporangien kugelig, $0,7 \mathrm{~mm}$. Columella dunkelbraun, keulenförmig. Sporen stark warzig oder mit netzartiger Skulptur.

Großbritanuien, Neu-Seeland.

Aus Japan ist kürzlich von Minakata eine neue Varietät der B. rubiginosa (var. concinnum G. Lister) beschrieben worden, die möglicherweise auch in unserm Gebjete vorkommt und deren Diagnose hier folgen mag:

Var. concinnum G. Liste $r$ ap. Minakata in Bot. Mag. Tokyo XXYII (1913). 40\&. Plasmodium hellgelb, später orangefarbig. Sporangien in Größe und Gestalt sehr wechselnd (erinnernd an solche von Craterium leucocephalum var. scyphoides), einzelne ganz ungestielt. Der obere Teil der Peridie 
ist deckelartig ausgebildet, zerreißt aber unregelmäßig. Sporenskulptur entsprechend der der var. dictyospora. Kalkknoten zum Teil mit hyalinen Verbindungsfäden, also nicht ganz Badhamia-artig, indessen ist dies ein Merkmal auf das weder bei Badhamia noch bei Physarum entscheidend abgestellt werden kann. Columella vorhanden, sehr spröde, leicht sich an der Basis loslösend.

Japan.

\section{Gattung Physarum Persoon}

in Usteri Ann. Bot. XV (1795), 37; Rost. Vers., 10 (inkl. Tilmadoche) et Monogr., 93 (inkl. Tilmadoche pr. p.): Massee Monogr. (inkl. Tilmadoche), 273; Celakorský Mrxom. Böhmens, 70 (inkl. Tilmadoche); Lister Monogr. ed. 1, 37 und ed. 2, 40; Schinz in Mitt. Naturw. Ges. Winterthur VI, 29; Torrend in Broteria VI, 54 et VII, 117.

Gestielte oder ungestielte Sporangien oder Plasmodiokarpien. Peridie einfach oder doppelt, mit Kalkeinlagerungen, die zuweilen zu einer Kalkkruste zusammenschließen. Stiel mindestens anfänglich hohl (solid bei $P$. penetrale), durchsichtig oder opak infolge reichlicher Kalkeinlagerung in der Stielwand, der röhrige Stiel häufig ausgefüllt mit vom Plasmodium ausgestoßenem plasmatischem Ausschuß oder mit Kalkgranulationen. Capillitium ein Maschenwerk hyaliner Fäden mit blasenförmigen Kalkknoten.

Die Arten der Gattung Physarum unterscheiden sich von jenen der Gattung Badhamia hauptsächlich durch das Vorhandensein \pm zarter Verbindungsfäden zwischen den Kalkknoten, aber wie wir Badhamia-Arten kennen gelernt haben, die derartige Fäden aufweisen, so sind auch verschiedene Physarum-Arten (P. pusillum, javanicum, crateriforme, reniforme, cinereum) beschrieben worden, die gewissermaßen den Übergang zu Barlhamia bilden, indem bei diesen die Kalkknoten, ohne durch Verbindungsfäden verbunden zu sein, direkt zusammenschließen.

Die Gattung Tilmadoclie, von Fries Summa Veg. Scand (1849), 454 aufgestellt und von Rostafinsky (1875) erweitert, ist hier mit Lister in die Gattung Physarum einbezogen. Sie soll sich von Physarum dadurch unterscheiden, daß „die Capillitiumfäden von 
der basalen Sporangiumwand in konzentrischen Kreisen büschelweise entspringen und im weiteren Verlauf sich unter spitzem Winkel abzweigen, wogegen bei Fhysarum die Capillitiumfäden überall gleichmäßig an die Sporangiumwand angewachsen sind und durch zahlreiche Anastomosen Netze darstellen." Lister hat indessen nachgewiesen, dab aus einem und demselben Plasmodium beide Capillitiumformen gewonnen werden können und daß daher die Gattung Tilmadoche nicht aufrecht erhalten werden kann.

1. Sporangien gestielt, nur ausnahmsweise ohne Stiel.

2. Stiel mit Kalk ausgefüllt.

3. Capillitium ein lockeres Maschenwe rk bildend.

4. Stiel weiB. Sporangiengrau oder graugrïnlich. Kalkknoten des Capillitiums breit, weiß. Columella feblend.

1. P. lencopus Link in Mag. Ges. Naturf. Freunde Berlin III (1809), 27; Rost. Monogr., 101; Massee Monogr., 287 pr. p.; Macbride N. A. Slime-Moulds, 48, pl. IX, fig. 7, 7 a, 7 b; Torrend in Broteria VII, 130; Lister Monogr. ed. 1, 39, pl. VI, A, fig. a-c und ed. 2, 45, pl. 15, fig. a-c.

Synoll yme: Physarum bullatum Link l. c. (1809), 27.

Didymium leucopus Fr. Syst. Myc. III (1829), 121; Rabenh. Deutschl. Kryptog.-Flora I, 281.

Plasmodium milchweiß. Sporangien herden- oder büschelweise auf kurzem Stiel, gran oder grünlichweiß, mit reichlicher Kalkeinlagerung. Stiel weiß, gedrungen, oberwärts etwas verjüngt, gefurcht, mit Kalkausfüllung und ohne plasmatischen Ausschuß. Kalkknoten $10-15 \mu$ breit. Sporenmasse schwarz; sporen im durchfallenden Lichte violettbraun, fein stachelig, $7-10 \mu$.

Deutschland, Schweiz (anscleinend sehr selten).

Großbritaunien, Frankreich, Schweden, Portugal, Java, N,- und S.-Amerika. Neugranada.

$4^{*}$. S porangien kugelig, gelb oder gelbbraun, auf weiBem, braunem oder gelbrotem, aufrechtem, gefurchtem, kalkführendemund 
daher undurchsichtigem stiel. Capillitinm mit gelben oder weiben, meist breiten Kalkknoten. Sporenmasse braun, fast schwarz; Sporen im durchfallenden Lichte violett, nalezu glatt, $7-8-10 \mu$.

2. P. melleum (Berk. et Br.) Massee Monogr. (1892), „7s; Macbride N. A. Slime-Moulds, 47; Torrend in Broteria VIl, 129; Lister in Journ. of Bot. XXXVI, 114, Monogr. ed. 1, 43, pl. IX, B, fig. a-d und ed. 2, 46, pl. 23, fig. a-c.

S y no n y e: Didymiun melleum Berk, et Br. in Journ, Linı. Soc. XIV (1873), 83 .

Didymium ehrysopeplum Berk. et Curt. in Grev. II (1873), 53. Physarum Schunacheri Spr. var. melleum Rost, Monogr. App. (1876), 7.

Physarum Kalchbremeri M a s e e Monogr. (1892), 297.

Physarum rubropunctatum Pat. in Bull. Soc, Mye. Fr. IX (1893), 143 ?

Physarum tucumanense Speg. in Rev. Agr. Veter. la Plata (1896), 237.

Cytidium melleum Morgan Mys, Miami Valley (1896), 83.

Portugal, N.- und S.-Amerika, Antillen, Malay, Arehipel, Ceylon, Philippinen, Japan, S.-Afrika,

$4^{* *}$. Stiel weiB, schmutzigweiß oder gelblich. Sporangien schwefelgelb, ohn e Columella.

3. P. sulphureum A lb. et Schw. Consp. Fing. (1805), 93, t. 6. fig. 1; Rabenh. Deutschl. Kryptog.-Fl. 1, 276; Rost. Monogr., 101 ; Schröter in Cohn Krypt. Flora Schles. 111, 129; Massee Monogr. 311; Lister Monogr. ed 1, 62 und ed 2, 46, pl. 65, fig. a-c, Syno nyme: Physarum flavum Fr. Syınb. Gastr. (1818), 22; Rabenh. Dentschl. Krypt.-Fl. I, 276.

Physarum lepidodernoides Blytt in Bidr. Norg. Sop. III (1892) 4? Craterinm flavum Fr. Summ. Veg. Scand. (1849), 454.

Plasmodium? Sporangien + kugelig, herdenweise, schwefelgelb. Peridie kalkreich, höckerig. Stiel gedrungen, 0,1-0,3 mm hoch, gefurcht, im Innern kalkreich. Kalkknoten breit, weiß. Sporen im durchfallenden Lichte violettbraun, stachelig, $9-11 \mu$. Deutschland, Österreich.

Schweden, Frankreich. 
$4^{* * *}$. Sporangien herdenweise, $\quad+$ kugelig, eiförmig, birnförmig oder walzlich keulenförmig, gestielt oder ungestielt, gelblichgrün bis bräunlichockerfarbig, mit höckeriger Peridie. Stiel gedrungen, kegelförmig, gelblichweiß bis dunkelbräunlichgrau. Capillitium ein enges Maschenwerk hyaliner Fäden mit membranösen Verbreiterungen in den Maschenwinkeln und weißẹn oder blaßgelben Kalkknoten. Sporenim durchfallenden Lichte violettbraun, stachelig, $9-10 \mu$.

4. P. variabile Rex in Proc. Acad. Nat. Sc. Phil. (1893), 371; Macbride N. A. Slime-Moulds, 39; Torrend in Broteria VII, 128; Lister in Journ. of Bot. XXXVI, 113, XXXVII, 146, Monogr. ed. 1, 43, pl. IX, A. fig. a-d und ed. 2, 47, pI. 21, fig. a-c. Die Plasmodiokarpien bildende Form ist von Lister in Journ. of Bot. XXXVI (1898), 114 als var. sessile Lister unterschieden worden.

Sichweden, N.- und S.-Amerika, Antillen.

$4^{* * * *}$. Stiel und Sporangien hellgelb oder orangefarbig. Columella breit, halbkugelig.

5. P. luteo-album Lister in Journ. of Bot. XLII (1904), 130, t.459, fig. 2 und Monogr. ed. 2, 48, pl. 24, fig. a --c.; Torrend in Broteria VII, 129.

Plasmodium? Sporangien \pm kugelig, am Grunde breit genabelt, herdenweise, gestielt, \pm hell- bis weißlichgelb, mit etwas höckeriger Peridie. Stiel gedrungen, 0,5--1 $\mathrm{mm}$ hoch, glänzend gelb, lederfarbig oder oberwärts orange, gegen den Grund zu fast weiß, mit Kalkgranulationen ausgefüllt. Columella blaßgelb oder orange. Capillitium meistens aus hyalinen, zarten, anastomosierenden Fäden oder breiten, gelben, einfachen oder gabelig verzweigten Strähnen bestehend. Kalkknoten spärlich, klein, spindelförmig, gelb. Sporen dunkelpurpurbraun im durchfallenden Lichte, stachelig, $10-12 \mu$. 
Großbritannien, Italien. N.-Amerika.

var. aureum Rönn in Schriften Naturw. Ver. SchleswigHolstein $\mathrm{XV}$ (1911), 51.

Exsikkaten: O. Jaap Myxom. exsice. 8 t.

Peridie hellorange bis goldgelb. Capillitium fast ohne Kalkknoten, ans breiten, durchsichtigen, an der Spitze stark verzweigten Fäden bestehend. Sporen $13-14 \mu$, etwas blasser als beim Typus.

Deutschland (Holstein).

IV. C. Sturgis (Colorado Publ. Gener. Ser. No. 68, Sc. ser. vol. XII, No. 12 (Apr. 1913), 439) fand in Colorado kalkfreie Sporangien dieser Art mit metallischglänzender Peridie und $12-14 \mu$ großen Sporen. Möglicherweise kommt diese Form auch bei uns vor.

$3^{*}$. Capillitium ein dichtes Maschenwerk bildend, bleibend.

5. Stiel weiß oder weißlich, unterwärts bräunlich bis rotbraun. Sporangien weiB. Kalkknoten klein, weib, selten blabockergel.b.

6. P. globuliferam (B u ll.) P e rs. Syn. (1801), 175, t. IIl, fig. 10, 11, 12; Schröter in Cohn Krypt. Flora Schles. III. 1, 130; Rost. Monogr., 98, fig. 86; Massee Monogr. 297; Schin\% in Mitt Naturw. Ges. Winterthur VI, 34; Macbride N. A. SlimeMoulds, 45; Torrend in Broteria VII, 125; Lister Monogr. ed. 1, 40. pl. Y'l, B, fig. a-d und ed. $2,48 \mathrm{pl}$.

synouyme: Spherocarpus globulifer Bull. Champ. (1791), 134, t. 484, fig. 3 .

Stemonitis globulifera Grmel. Syst. Nat. II (1791), 1469.

Trichia globulifera D C. Fl. F'r. (1805), 253.

Diderma globuliferum Fr. Syst. Myc. III (1829), 100.

Physarum Petersii var. Farlowii Rost. Monogr. App. (1876), 6. Physarum albicans Peckin Rep. New. York Mus. XXX (1878), 5) .

Didymium suberosuın Peck l. c. XXVIII, (1876), 54.

Physarum columbinum Macbride in Bull. Nat. Hist. Jowa II (1893), 384.

Physarum relatum Morgan Myx. Miami Valley (1896), 98.

Physarum delicatissimum Speg. in Ann. Mus. Nac. Buen. Arres VI (1899), 199?

Didymium longipes Massee Monogr. (1892), 236, fig 226?

Cytidiun globuliferum Morgan Myx. Miamy Valley (1896) 82.

Exsikkaten: O. Janp Myxom. exsicc. 42. 
Plasmodium ? Sporangien $1-1 \frac{1}{2} \mathrm{~mm}$ hoch, herdenweise. gestielt, kugelig oder leicht abgeflacht, blaß blangrau oder weiß. Stiel meist länger als das Sporangium, schlank, leicht gerunzelt, weib oder gelblich, mitunter unterwärts rotbraun, mit Kalkgranulationen ansgefüllt. Columella weiß, kegelförmig, mitunter fehlenıl oder rudimentär. Capillitium reichlich entwickelt, aus einem zarten. + engmaschigen Netzwerk hyaliner Fäden bestehend, mit weißen, gelblichen oder blaßockergelblichen, spindelförmigen oder abgerundeten Kalkknoten. Sporen im durchfallenden Lichte violettbraun, fein warzig bis nahezu glatt, $6-9 \mu$.

Deutschland (Schlesien), Schweiz (verbreitet), Böhmen.

Rußland, Schweden, Frankreich. N-Amerika, Neu-Seeland, Japan, Java.

$5^{*}$. Stiel, Sporangien und Kalkknoten rot. Sporangien $1-2 \mathrm{~mm}$ hoch, gestielt, kugelig, orangegelb, orangerot bis dunkelbraum, bei fehlendem Kalk grau: Stiel $0,5-1,5$ mm. Columella kegelfö rmigoder fehlend. Capillitium dem dervorigen Art entsprechend, aber mit roten Kalkknoten. sporenmasse schwarz; Sporen im durchfallenden Lichte violettbraun, nahezu glatt, $6-8 \mu$.

7. P. pulchripes Peck in Bull. Buff. Soc. Nat. Hist. I 1873), 64; Massee Monogr., 315; Lister Monogr. ed. 1, 43, pl. I'II, A, fig. $\mathrm{a}-\mathrm{c}$ und ed. 2, 49, pl. 17, fig. $\mathrm{a}-\mathrm{c}$.

synonyme: Physarum aurantiacum Alb. et Schw. var. rufipes Alb. et Schw. Consp. Fung. (1805), 54 ?

Physarum rufipes Macbride N. A. Slime-Moulds (1899), 50. Diderma rufipes Fr. Syst. Myc. III (1829), 101.

Weitere, uns hier nicht interessierende synonyme in Macbrido N. A. SlimeMoulds, 50.

Angesiehts der Unınöglichkeit mit Sicherbeit festzustellen, was unter var. rufipes Alb, et Schw. zu verstehen ist, halten wir es mit Lister für richtiger, dieses Epitheton ïberhaupt fallen zu lassen und uns der eimleutigen Benennung Peck's zu bedienen.

N.-Amerika. 
$5^{* *}$. Stiel, sporangien und Kalkknoten mausbraun.

8. P. murinum Li ster Monogr. ed. I (1894), 41, pl. VII, B, fig. a-d, in Journ. of Bot. XXXVI, 117 und Monogr. ed. 2, 50, pl. 18, fig. a-c.; Torrend in Broteria VII, 125.

Synonyme: Physarum Braunianum Lister in Journ. of Bot. XXIX (1891), 259 non kost.

Physarum Ravenelii M acbride N. A. Slime-Moulds (189y), 48 uon Massee.

Cytidium Ravenelii Morgan Myx. Miami Valley (1896), 82.

Plasmodium ? Sporangien zerstreut oder herdenweise, kugelig, gestielt oder ungestielt, mitunter Plasmodiokarpien bildend. Stiel gerade, $\pm 0,5 \mathrm{~mm}$, gefurcht, mit weißen oder braunen Kalkeinschlüssen. Columella, soweit vorhanden, kegelförmig. Capillitium entweder ein engmaschiges Netzwerk hyaliner Fäden mit eiförmigen braunen Kalkknoten bildend oder das Netzwerk lockermaschig mit zahılreichen länglichen, unregelmäßig verzweigten Kalkknoten. Sporenmasse braun; Sporen im durchfallenden Lichte blaßviolettbraun bis lebhaft lila, nahezu glatt, $8-10 \mu$.

Deutschland, Schweiz.

Großbritannien, Schweden, N.-Amerika.

5***. Stiel, Sporangien und Kalkknoten purpurrot. Sporangien mit $1 \mathrm{~mm}$ langem Stiel, kugelig. Columella klein oder fehlend. Capillitium ein engmaschiges Netzwerkzarter, purpurroter Fäden mit zahlreichen, kleinen, rundlichen Kalkknoten. Sporenmasse dunkelbraun; Sporen i m durchfallenden Lichtedunkelrot, \pm glatt, $7-8,5 \mu$.

9. P. pulcherrimum Berk. et. $\mathrm{R}$ a v. in Grev. II (1875), 65 ; Rost. Monogr., 105, fig. 84; Massee Monogr., 293; Macbride N. A. Slime-Moulds, 49; Torrend in Broteria VII, 126; Lister Monogr. ed. 1, 42, pl. VIII, A, fig a-c und ed. 2, 50, pl. 19, fig. $a-c$.

Schinz, Myxogasteres (Rabenhorst Krypt. Flora I, Pilze Abt. X). 
Synouyme: Physarum atrorubrum Peck in Rep. New York Mus.

XXXI (1879), 40; Massee Monogr., 294.

Cytidium puleherrimum Morgan Myx. Miamy Valley (1896), 80. N.-Amerilsa, Ceylon.

$5^{* * * *}$. Stiel (gedrungen), Sporangien und Kalkknoten gelb.

10. P. citrinum Schumacher Enum. Pl. Sæll. II (1803), 201; Macbride N. A. Slime-Moulds, 56; Torrend in Broteria VII, 127; Lister Monogr. ed. 1, 42, pl. VIII, B, fig. a-d und ed. 2, 51, pl. 20, fig. a-c.

Synouyme; Physarum Schumacheri Spreng. Syst. Veg. V (1827), 528; Post. Mouogr., 98; Massee Monogr., 275, fig. 287, 288; Čelakorský Myxom. Böhmens, 72.

Physarum aurenm var. ehrysopus Lev. in Ann. se. Nat, sér, 3, V (1846), 166.

Physarum Schröteri Rost. Monogr. (1875), 4!y?

Physarum Leveillei Rost. Monogr. App. (1876), 7 pr. p.; Massee Monogr., 296.

Cytidium eitrinum Morgan Myx. Miami Valley (1896), 81.

Plasmodium leuchtend gelb. Sporangien zerstreut, gestielt, selten fast ohne Stiel (var. sessile Meylan in Bull. Soc. Vand. Sc. Nat. XLIT [1908], 288), samt stiel 0,8-2 mm hoch, kugelig. Stiel kräftig, undurchsichtig, \pm gefurcht, mit Kalk ausgefüllt. Columella \pm kegelförmig, kurz. Capillitium engmaschig, mit zahlreichen, meist abgerundeten, selteu in den Maschenecken befindlichen Kalkknoten. Sporenmasse schwarz; Sporen im durchfalleuden Lichte violettbraun, fast glatt, $7-10 \mu$.

Deutschland, Schweiz, Österreicin.

Großbritanuien, Schweden, S.-Amerika.

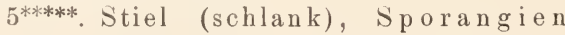
(selten grau) und Kalkknoten strohfarbig. Sporangieuzerstreut oder herdenweise, $1-2 \mathrm{~mm}$ hoch, kugelig, anfrecht oder nickend. Stiel undurchsichtig, oberwärts blaß und mit Kalk erfüllt, unterwärts dunkler und im Innern plasmatisches Ausschumaterial führend. Columella f ehlend. Capillitium ein aus zarten Fäden 
gebildetes, regelmäßiges Netzwerkmitzahlreichen, rundlichen oder abgerundeten Kalkknoten. Maschenwinkel zart und meist kalkfrei. Sporen im durchscheinenden Lichte braunviolett, nahezu glatt, $7-8 \mu$.

11. P. tenerum Rex in Proc. Acad. Nat. Sc. Philad. (1890), 192; Lister in Journ. of Bot. XXXVI, 114 und Monogr. ed 2, 52 , pl. 25, fig. a c.

Synonyme: P. maculatum Il acbride in Bull. Lab. Nat. Hist. Iowa II (1893), 383 et N. A. Slime-Moulds, 47, pl. XIV, fig. 6, 6a, 6b; Torrend in Broteria VII, 129, pl. VI, fig. 12a. Plyysarum obrusseum II acbride N. A. Slime-Moulds (1899), 52 pr. p.

Lepidoderma Kurzii Berk. in Herb. ex Lister Monogr. ed. 2 (1911), 52; Massee Monogr., 255?

Portugal, N.- und S.-Amerika, Antillen, Ceylon, Borneo, Japan.

$5^{* * * * * *}$. Stiel weiß oder gelblichweiß, gerade oder gebogen, gefurcht, pfriemlich, oberwärtskalkreich, unterwärts braun oder schwarz und mit plasmatischem Ausschußmaterial erfüllt oder in seiner ganzen Länge weiß. Sporangien kugelig oder unterseits etwas abgeflacht, grau oder bronzefarbig und irisierend, mit weißen Flecken. Peridie dünn, zur Zeit der Sporenreife kelchartig in 6 bis 12 Lappen aufreibend. Columella fehlend oder an deren Stelle ein von zu sammengedrängten Kalkknoten gebildeter mittelständiger, kugeliger Kalkkern. Capillitium aus sehr zarten, 
verzweigten und anastomosierenden Fäden bestehend, Maschenwinkel ohne Verbreiterungen. Kalkknoten, abgesehen von dem Kalkkern spärlich, weib, klein, spindelförmig. Sporenmasse braun; Sporen im durchfallenden Lichte violettbraun, fein warzig, $7-9 \mu$.

12. P. compactum (Wingate) Lister Monogr. ed. 1 (1894), 44, pl. X, B, fig. a -d und ed. 2, 52, pl. 26, fig. a-d; Torrend in Broteria VII, 131, pl. VI, fig. 8.

Synouyme: 'lilmadoche compactum Wingate in Proc. Acad.

Nat. Sc. Philad. (1889), 48; Massee Monogr., 332; Macbride

N. A. Slime-Moulds, 61 .

Lepidoderma stellatum MI as see Monogr. (1892), 252, fig. 225-225.

Didymium Barteri Massee Monogr. (1892), 231.

N.-, Mittel- und S.-Amerika, Antillen, Java, W.-Afrika.

$5 * * * * * * *$. Stiel (s of ern vorhanden) ockerfarbig. Sporangien weib, eiförmig oder zylindrisch, mit langer Pseudocolumella.

13. P. mutabile (Rost.) Lister ed. 2 (1911), 53, pl. 44, fig. $a-c$.

Syuonyme; Crateriachea mutabilis Rost. Monogr. (1875), 126;

Massee Monogr., 344.

Physarum cinereum Lister Mono ed. 1 (1894), 56 pr. p.

Physarum Crateriachea Lister in Journ. of Bot. XXXIII (1 $\$ 95)$, 323.

Plasmodium? Sporangien gestielt oder ungestielt, mit höckeriger Peridie oder an deren Stelle längliche, verzweigte Plasmodiokarpien. Stiel schlank oder gedrungen, ockergelb, meist mit KalkgranulationeneinschluB, mitunter \pm kalkfrei. Capillitium ein Netzwerk straffer, hyaliner Fäden mit Verbreiterungen in den Maschenwinkeln. Kalkknoten weiß, von wechselnder Form, zerstreut oder zusammengedrängt zu einer kugeligen, in der Nähe des Stielendes befindlichen Pseudocolumella. Sporen im durchfallenden Lichte purpurbraun, stachelig, $7-8 \mu$. 
Deutschland (Holstein).

Großbritannien, Frankreich, Italien, Schweden, W.-Afrika, Ceylon.

2*. Stiel entweder kalkfrei oder der Kalk nur in der Stielwandung (vergl. auch 13).

6. Kalkknoten grob, purpurrot. Sporangien rosenrot, kugelig, herdenweise, fast glatt. Stiel pfriemlich, schlank, hellbraun, durchsichtig. Columella fehlend. Capillitium aus einem lockeren Netzwerk zarter, blaBlilafarbiger Fäden gebildet. Sporen im durchfallenden Lichte rötlich oder rötlichbraun, fein stachelig, $7-10 \mu$.

14. P. roseum Berk. et B roome in Journ. Linn. Soc. XIV (1873), 84; Rost. Monogr. App., 10; Massee Monogr., 294; Torrend in Broteria VII, 132; Lister Monogr. ed. 1, 45, pl. XI, fig. $a-c$ und ed. 2, 54, pl. 27, fig. a-c.

Ceylon, Borneo, Java, Japan.

$6^{*}$. Kalkknoten zahlreich, groß, eckig, violettpurpurn. Sporangien kurz gestielt oder ungestielt, kugelig oder oben abgeflacht und genabelt, violettpurpurn. Peridie oberwärts häutig, unterwärts verdickt, tiefpurpurn. Stiel sehr kurz. Columella fehlend. Capillitium ein Netzwerk zarter, violetter Fäd en. Sporen im durchfallenden Lichte dunkelpurpurbraun, rauh, 8 bis $10 \mu$.

15. P. Newtoni Ma cbride in Bull. Nat. Hist. Iowa II (1893), 390 und in N. A. Slime-Moulds, 37, pl. XIV, fig. 5, 5a, 5b; Lister Monogr. ed, 1, 45, pl. XVII, B, fig. a-c und ed. 2, 54, pl. 22, fig. a-c.

N.-Amerika.

$6^{* *}$. Kalkknoten orangefarbig. Sporangien glänzend, blau oder rot gescheckt, Stiel rot oderorangefarbig. 
16. P. psittarinum Ditm. in Sturm Deutschl. Fl., Pilze (1817), 125, t. 62; Rabenh. Deutschl. Kryptog.-Flora I, 276; Rost. Monogr., 104, fig. 75, 76; Schröter in Cohn Krypt. Fl. Schles. III, 1, 129; Massee Monogr., 274, fig. 290, 291; Čelakovský Myxom. Böhmens, 72; Macbride N. A. Slime-Moulds, 51; Torrend in Broteria VII, 134; Lister Monogr. ed. 1, 46 pl, XI, B, fig. a--c und ed. 2, 55, pl. 29, fig. a-d.

Synonyme: Physarum Carlylei Massee Monogr. (1892), 293, fig. $240,241$.

Dydimium fulvipes Fries Symb. Gast. $(1817-18), 24$.

Exsikkaten: O. Jaap Myxom, exsicc. 22.

Plasmodium orange. Sporangien gestielt, herdenweise, $1 \mathrm{~mm}$ hoch, kugelig oder \pm abgeflacht, irisierend. Peridie zarthäutig, gesprenkelt mit orangefarbigen Flecken. Stiel aufrecht oder gekrümmt gefurcht, orangerot oder zinnoberrot. Columella fehlend. Capillitium aus einem engmaschigen Net\%werk flacher, farbloser oder gelber Fäden mit breiten Maschenwinkeln bestehend. Kalkknoten zahlreich, scharfeckig und häufig verzweigt, \pm leuchtend orange. Sporenmasse braun; Sporen im durchfallenden Lichte blaßbraun bis grauviolett, fast glatt, $7-8 \mu$.

Deutschland, Schweiz, Österreich.

Großbritannien, Frankreich, Schweden, N.-Amerika; eine var. fulvum Lister in Journ. of Bot. XLIV (1906), 228 (Stiel und Basis der Sporangien rotgelb und nicht zinnoberrot) in Japan und auf Ceylon.

$$
\begin{aligned}
& 6^{* * *} \text { Kalkknoten orangefarbig. Spo- } \\
& \text { rangien bronzefarbig; Stiel } \\
& \text { schwarz. Sporenmitnetzartiger } \\
& \text { Skulptur. }
\end{aligned}
$$

17. P. dictyosporum Lister in Journ. of Bot. XLIII (1905), 112 und Monogr. ed. 2, 55, pl. 30, fig. a-c (sub P. dictyospermum); Torrend in BroteriaVII, 135 (sub dictyospermum).

Plasmodium? Sporangien \pm kugelig, zerstreut, kurz gestielt, dunkel orange oder dunkel olivebraun, glänzend. Stiel mit plasmatischem Ausschußmaterial und schwarz oder oberwärts \pm blaßgelb. Columella schwarz, kegelförmig oder halbkugelig, kurz oder bis zu $1 / 3$ der Sporangiumhöhe. Capillitium ein reiches Netzwerk farbloser Fäden mit kleinen, spindelförmigen, orangeroten Kalkknoten. Sporen im durchfallenden Lichte blaß purpur- 
grau, $10-11 \mu$, auf der einen Seite mit dentlichen und regelmäßigen 5 bis 6 Maschen, auf der andern Seite mit weniger regelmäßiger und etwas schwächerer skulptur.

Schweiz (Jura).

Neu-Seeland.

$6^{* * * *}$. Kalkknoten gelb oder orangefarbig. Sporangien gelb, orangefarbig oder grau.

7. Sporangien \pm kugelig oder linsenförmig, auf schlanken Stielen. Capillitium locker. Kalkknoten spindelförmig.

18. P, viride (Bull.) Pers, in Usteri Ann. Bot. XV (1795), 6; Ditm. in Sturm Deutschl. Fl., Pilze, 49, t. 24; Schinz in Mitteil. Naturw. Ges. Winterthur V1, 36; Torrend in Broteria III, 140; Lister Monogr. ed. 1, 46, pl. XII, A, fig. a-c und ed. 2, 56, pl. 31, fig. a-e pl. 199, fig. a-c.

Synonyme: Sphærocarpus viridis Bull. Champ. (1791), t. 407, fig. 1. Stemonitis viridis Gmel. Syst. Nat, II (1791), 1469.

Physarum aureum Pers. in Roem. N. Mag. Bot. (179t), 88; Rabenh. Deutschl. Kryptog.-Fl. I, 277.

Physarum nutans var. viride u. var. aureum Fr. Syst. Myc. IIl (1829), 129.

Trichia viridis D C. Fl. Fr. II (1805), 253.

Tilmadoche mutabilis Rost. Monogr. (1875), 129; Nassee Monogr., 329, fig. 236-239.

Tilmadoche viridis Sacc. in Michelia II (1880), 263; Macbride N. A. Slime-Moulds 59, pl. VIII, fig. $8,8 \mathrm{a}, 8 \mathrm{~b}, 8 \mathrm{c}$.

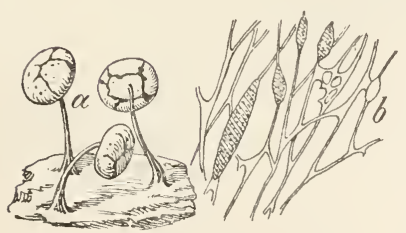

Fig. 54. Physarum viride (Bull.) Pers. a. Sporangiengruppe $(18 / 1)$; b. Capillitium $(250 / 1)$. Nach Lister.

Plasmodien gelb. Sporangien gestielt, nickend, gelb. Sporangienwand unregelmäßig aufspringend, häutig. Stiel schlank, pfriemlich, gestreift, grau oder strohfarbig, mitunter oberwärts gelb und unterwärts rötlich, meist gegen den Grund zu braun, mit plasmatischem Ausschußmaterial erfüllt. Columella fehlend. Capillitium ein lockeres Netzwerk mit spitzen 
Maschenwinkeln und spindelförmigen, gelben Kalkknoten. Sporen im durchfallenden Lichte bräunlichviolett, fast glatt, $7-10 \mu$.

Deutschland, Schweiz, Österrejch.

Kosmopolit.

var. aurantium (B u ll.) Lister Monogr. ed, 1 (1894), 47 und ed. 2, 56, pl. 31, fig. b.

Synonyme: Sphærocarpus aurautius Bull, l. c. (1791), t. 484, fig. 2.

Stemonitis aurantia Gmel. l. c. (1791), 1469.

Plyssarum aurantium Pers. Syn. Fung. (1801), 173.

Physarum nutans var. coccineum Fr. l. c. (1829), 129.

Physarum striatum var. coccineum Fr. l. c. (1829), 131.

Trichia aurantia D C. 1. c. (1805), 253.

Tilmadoche mutabilis var. aurantiaca Rost. l. e. (1875), 1E9;

Čelakovský Myxom. Böhmens, 70.

Exsikkatell: 0. Jaap Myxom. exsicc. 65.

Sporangien und Kalkknoten orange. letztere spindelförmig.

Deutschland, Schweiz, Österreich.

var. incanum Lister Monogr. ed. 1 (1894), 47 et ed. 2, 56, pl. 31, fig. c.

Synonyme: Sphærocarpus luteus Bull. 1. c. (1791), t. 407, fig. 2 ?.

Stemonitis bicolor Gmel. l. c. (1791), 1469.

Physarum luteum Pers, Syn. Fung. (1801) 172.

Trichia lutea D C. 1. c. (1805), 2 ñ3.

Tilmadoche mutabilis var. lutea Rost. 1. c. (1875), 129; Celakovsky Myxom. Böhmens, 70.

Physarum viride var. luteum Lister Monogr. ed. 1 (1894), 47 und in Journ. of Bot. XXXVI, 114.

Exsikkaten: O. Jaap. Myxom. exsiec. 23.

Deutschland, Schweiz, Österreich.

var. rigidum Lister Monogr. ed. 2 (1911), 56, pl. 199, fig. a-c.

Sporangien gelb oder dunkelorange. Kalkknoten zerstreut, orange; Sporen $9-12 \mu$.

Japan.

var. Bethelii (M a c b r i de) Sturg is in Colorado College Publ. Gen. Ser. No. 68 Sc. ser. vol. XII (1913), 439.

Syuonym: Physarum Bethelii Macbride in Lister Monogr. ed. 2 (1911), 57, pl. 200, fig. a-d. 
Sporangien gedrungener, mit kürzerem Stiel, grünlichgelb oder glänzend gelb, Sporen meist dunkler gefärbt.

N.-Amerika.

7*. Sporangiengestielt, längs zus a m m engedr ü ckt, wellig oder gelappt, of t wurmförmig ge$\mathrm{kr} \ddot{\mathrm{mm} t}$, selten einzeln, meist zu 5-10 büschelweise zusammenfließend, gelb oder grau. Stiele z u 5 bis 10 bis zu halber Höhe gebüschelt, gelblich lederbraun bis rötlichbraun, durchsichtig. Columella fehlend. Capillitium ein lockeres Maschenwerk hyaliner Fäden mit zahlreichen, flachen Verbreiterungen in den M a s chenwinkeln. Kalk knoten 土spindelförmig, gelb. Sporen violettbraun, fein stachelig, $8-10 \mu$.

19. P. polycephalum Schwein. Syn. Fung. Carol (1822), 63; Lister Monogr. ed. 2, 58, pl. 34, fig. a-c; Torrend in Broteria VII, 136, pl. VI, fig. 7a.

Synonyme: Didymium polycephalum Fr. Syst. Mycol. III (1829), 122.

Didymium polymorphum Mont. in Aun. Sc. Nat., ser 2, VIII (1837), 361.

Didymium gyrocephalum Mont. l. c., 362 .

Didymium lnteogriseum Berk et Curt. in Grev. II (1873), 65.

Physarum polymorphum Rost. Monogr. (1875), 107; Massee Monogr., 283; Lister Monogr. ed. 1, 48, pl. XIII, A, fig. $a-d$.

Tilmadoche gyrocephala Rost. Monogr. (1875), 131; Massee Monogr., 335 .

Tilmadoche polycephala Macbride N. A. Slime-Moulds, (1899), 57, pl. V1ll, fig: 2, 2a, 2b.

Physarum polymorphum var. gyrocephalum Lister Monogr. ed 1 (1894), 48.

N.-Amerika, Borneo.

Diese Art ist von Trog auch für Thun (Schweiz) angegeben worden, die Angabe hat aber keine Bestätigung gefunden. 
Eine Form mit nicht gebüschelten Sporangien wird von Lister als var. obrusseum Lister Monogr. ed. 1 (1894), 48 und ed. 2, 58 (= Physarum obrusseum Rost. Monogr. App. [1876], 11; Macbride N. A. Slime-Moulds, 52) abgetrennt.

N.-Amerika, Cuba, Japan.

$$
\begin{aligned}
& 7^{* *} \text { Sporangien } \pm \text { kugelig, gelb } \\
& \text { odergraumitgelber Basisoder } \\
& \text { metallisch glänzend. Stiel rot- } \\
& \text { braun, pfriemlich, schlank ge- } \\
& \text { streift, ohne Kalkausfüllung. } \\
& \text { Kalkknoten eckig, gelb, meist } \\
& \text { klein. }
\end{aligned}
$$

20. P. flavicomum Berk. in Hook. Loudon Journ. Bot. IV (1845), 66; Macbride N. A. Slime-Moulds, 53; Torrend in Broteria VII, 134, pl. VI, fig. 7; Lister Monogr. ed. 2, 58, pl. 32 , fig. $a-b$.

Synonyme: Physarum cupripes Berk. et Rav. in Grev. II (1873), 65; Massee Monogr., 284.

Physarum Berkelevi Rost. Monogr. (1875), 105; Lister Monogr. ed. 1, 47, pl. XII, B, fig. a-c und in Journ. of Bot. XXXVI, 114.

Didymium flavicomum Massee Monogr. (1842), 242, fig. 76, 78 .

Plasmodium gelbgrün. Sporangien herdenweise, klein, mitunter unterseits abgeflacht, gestielt. Capillitium ein dichtes Netzwerk hyaliner Fäden mit zahlreichen gelben, flachen Verbreiterungen der Maschenwinkel. Columella fehlend. Sporenmasse braun, Sporen im durchfallenden Lichte violettbraun, schwach papillös, $7-10$.

Schweiz (Jura).

Portugal. N.-Amerika. Nell-Seeland, Japan.

$7^{* * *}$. Sporangien zerstreut, kugelig, leuchtend gelb auf schlanken. durchsichtigen, gelben oder unterwärts o rangerote n Stielen. Columella fehlend. Capillitium ein dichtes Netzwerk blaBgelber Fäden oder flacher Strähnen, dessen 
Maschenwinkel gelbliche Kalkeinlagerungen (Kalkknoten) a ufweisen. Sporen blaßviolett, nahezu glatt, $7-9 \mu$.

21. P. galbeum W in gate in Macbr. N. A. Slime-Moulds (1899), 53; Torrend in Broteria VII, 134; Lister Monogr. ed. 2, 59, pl. 199, fig. d-f.

GroBbritannien, Portugal, N.-Amerika.

$7^{* * * *}$. Sporangien \pm kugelig oder verkehrteiförmig, zerstreut oder herdenweise, gestielt, glän zend gelb oder dunkelgelb, of t unterwärts rötlich. Peridie gegen den Sporangiumgrund z u verdickt, sonst dünn. Stiel dunkelrotbraun, gedrungen oder schlank, 0,1-0,6 mm hoch. Capillitiumnetz mit verbreiterten M a schenwinkeln. Kalkknoten zahlreich, verzweigt, eckig, grob, gelb, mitunter zu e ine r Pseudocolumella zusammengedrängt. Sporen im durchfallenden Lichte blabviolett, nahezu glatt, $8-10 \mu$.

22. P. maydis (Morgan) Torrend in Broteria VII (1908), 133; Lister Monogr. ed. 2, 59, pl. 32, fig. c-e; Sturgis in Colorado College Publ. Gen. Ser. Nr. 68 Sc. ser. vol. XII, 440.

Synonyme: Craterium maydis M or g an Myx. Miami Valley (1896), 87: Macbr. N. A. Slime-Moulds, 74, pl. III, fig. 6, 6 a. $\mathrm{N}$,-Amerika, Ceylon, Java.

$7^{* * * * *}$. Sporangien \pm kugelig, Stiel rotbraun od er schwärzlichbraun und kurz oder fehlend. Kalkknoten grob, verzweigt. 
23. P. amriscalpium Cooke in Ann. Lyc. Nat. Hist. New York XI (1877), 384; Lister in Journ. of Bot. XXXVI, 115, XLII, 131 und Monogr. ed. 2, 60, pl. 33, fig. a-c; Macbride N. A. Slime-Mloulds, 38, pl. XIV, fig. 3, 3 a, 3 b, pl. III, fig. 7, 7a; Torrend in Broteria VII, 133, pl. VI, fig. 19.

Synonyme: Physarum ornatum Peck in Rep. New-York Mus. XXXI (1879), 40.

Physarum oblatum M a $\mathrm{c}$ bride in Bull. Lab. Nat. Hist. Iowa II (1893), 384.

Physarun sulphureum sturgis in Bot. Gazette XVIII (1893), 197, t. XX, fig. $5-8$ non Alb. et Schw.

Badhamia citrivella Čelakovsky Myxom. Böhmens (1893), 76, t. IV, fig. 1 .

Exsikkaten: 0. Jaap Myxom. exsiec. 21.

Plasmodium gelblich. Sporangien gestielt oder ungestielt, gelb, orange oder bräunlich. Stiel $0,1-0,4 \mathrm{~mm}$ hoch. Columella fehlend. Capillitiumfäden sehr zart, kurz, große, verzweigte, orangegelbe Kalkknoten verbindend. Sporenmasse bräunlich, schwarz. Sporen im durchfallenden Lichte bräunlichviolett, fein stachelig, 7-11 $\mu$.

Deutschland, Schweiz, Böhmen.

Großbritannien, Portugal, Frankreich, N.-Amerika.

$7^{* * * * * * * . ~ S p o r a n g i e n ~ k u g e l i g ~ o d e r ~ v e r-~}$ kehrteiförmig, rahmweiB, gelblich oder blabbraunrot. Stiel fast häutig, schwach.

24. P. fulvum (M a cbride) Lister Monogr. ed. 2 (1911), 61 , pl. 66, fig. a-c.

Synonyme: Leocarpus fulvus Macbride N. A. Slime-Moulds (1899), 82, pl. XVI, fig. 4, 4 a; Torrend in Broteria VII, 111. pl. VII, fig. 7 .

Plasmodium gelb. Sporangien $0,6-0,8 \mathrm{~mm}$ breit, sitzend oder gestielt, mit glatter oder höckeriger Oberfläche. Peridie doppelt, brüchig, äußere \pm kalkführend, innere häutig. Stiel $0,1-0,5 \mathrm{~mm}$ hoch, auffallend schwach, am Grunde in Hypothallustränge übergehend, gestreift, rotbraun oder rötlichgelb. Columella feblend. Capillitiumnetz engmaschig, aus blassen Fäden mit Verbreiterungen 
in den Maschenwinkeln bestehend. Kalkknoten groß, eckig, blaßgelb. Sporenmasse schwarz; Sporen im durchfallenden Lichte dunkelpurpurbraun, stachelig, $10-15 \mu$.

Schweiz (Wiesen im Ct. Graubünden).

N. Amerika.

$7^{* * * * * * *}$. Columella als schlanke Fortsetzung des Stieles ${ }^{4 / 5}$ des Sporangiums durchziehend.

25. P. penetrale $R$ ex in Proc. Acad. Nat. Sc. Philad. (1891), 389; Macbride N. A. Slime-Monlds, 55, pl. XV, fig. 6, 6 a; Torrend in Broteria VII, 14l, pl. VI, fig. 16, pl. IX, fig. 11: Lister Monogr. ed. 1, 49, pl. XIV, A, fig. a-e und ed. 2, 61, pl. 36, fig. $\mathrm{a}-\mathrm{d}$.

Synonyme: Cytidium penetrale Morgan Myx. Miamy Valley (1896), 83.

Plasmodium? Sporangien zerstreut, gestielt, anfrecht oder auf gebogenem Stiel, ellipsoidisch, birnförmig, selten kugelig, grau oder blaßgrünlichgelb. Peridie halbdurchsichtig. Stiel 0,5 -2 mm hoch, schlank, dunkelrot oder rötlich goldgelb, gegen den Grund flach verbreitert. Columella schlank, stumpf oder oben plötzlich etwas verbreitert, gelb. Capillitiumnetz engmaschig, Maschenwinkel dreieckig verbreitert, blaßgelblich. Sporenmasse braun; Sporen blaßbraunviolett, zart stachelig, $5-7 \mu$.

Deutschland (Holstein), Schweiz (Jura).

Großbritannien, Portugal, Frankreich, Schweden, Java, N.-Amerika.

6*****. Kalkknote $\mathrm{n}$ w e i B; S p or angie n gelb oder braun.

8. Sporangien \pm kugelig, runzelig, zitronengelb oder ockergelb; Stiel orangerot.

26. P. citrinellum Peck in Rep. New York Mus. Nat. Hist. XXXI (1879), 55; Massee Monogr., 278; Lister Monogr. ed. 2, 62, pl. 68, fig. a-d.

Synonyme: Physarum cespitosmm Schwein. in Trans. Amer. Acad. Phil. Soc. n. s. IV (1832); 258. Macbride N. A. Slime-Moulds, 37 ; Torrend in Broteria VII, 132.

Didymium flavidum Peck in Rep. New York Mus. Nat. Hist. XXVIII (1879), 54 non Fries. 
Diderma citrinum Peck l. c. X XII (1869, 89.

Craterium citrinellum Lister Monogr. ed. 1 (1894), 74, pl. XXVIII, B, fig. a-c.

Plasmodium? Sporangien herdenweise, gestielt, aufrecht, am Grunde orangefarbig. Peridie \pm deutlich aus 2 Schichten bestehend, äußere brüchig, kalkreich, runzelig, gelb, innere häutig und farblos. Columella fehlend. Stiel $0,3-0,4 \mathrm{~mm}$ lang, gefältelt, am Grunde verbreitert in den Hypothallus übergehend. Capillitium ein Netzwerk farbloser, hyaliner Fäden mit zahlreichen, großen, unregelmäßigen, + sternförmigen Kalkknoten. Sporenmasse schwarz; Sporen im durchfallenden Lichte purpurbraun, deutlich stachelig, $10-13 \mu$.

Deutschland (Holstein).

N.-Amerika, Japan.

8*. Sporangien \pm kugelig, blaßgelb mit fleischrotem Grund; Stiel fleischrötlich (nach Sturgis goldgelb), durchsichtig, kalkfrei, $0,2-0,3 \mathrm{~mm}$. Capillitiumnetz a us brüchigen, eckigen und verzweigten, weiben, von kurzen hyalinen Fäden verbundenen Kalkknoten bestehend. Sporen im durchfallenden Lichte purpurbraun, stachelig, $8 \mu$.

27. P. carneum G. Lister et Sturgis in Journ. of Bot. XLVIII (1910), 73; Lister Monogr. ed. 2, 63; Sturgis in Colorado Coll. Publ. Gen. Ser. No. 68, Sc. ser. XII, 440.

N.-Amerika.

Physarum carneum zeigt Anklänge sowohl an Ph. citrinellum wie an $P h$. citrinum. Ph. citrinellum unterscheidet sich durch eine härtere Peridie, ein weniger engmaschiges Capillitiumnetz, orangerote, gedrungene Stiele und kleinere Sporen. Ph. citrinum hat zum Unterschied von $P h$. carneum kalkführende Stiele und gelbe, nicht weiße Kalkknoten.

$8^{* *}$. Sporangien herdenweise, ku gelig oder leicht von oben zu sammengedrückt, gestielt 
oder ungestielt, gelbbraun und glänzend, glatt. Peridie zur Zeit der Sporenreife in sich zur ückrollende Lappen oder durch einen KreisriB aúfreibend, aus zwei Schichten bestehend, einer äuberen brïchigen und einer inneren häutigen und kalkreichen. Stiel kräftig, rotbraun bis fast schwarz, kalkfrei, $0,2-0,4$ mm. Kalkknoten grob, unregelmäbig, wei $B$, verbundendurch hyaline, farblose Fäden, mitunter zusammenschliebend zu einer Pseudocolumella. Sporen im durchfallenden Lichte purpurbraun, stachelig, 8$10-11 \mu$.

28. P. brunneolum Phillips ex Massee Monogr. (1892), 280, fig. 221, 222; Macbride N. A. Slime-Moulds, 32; Torrend in Broteria VII, 120, pl. IX, fig. 10; Lister Monogr. ed. 2, 63, pl. 69, fig. a-d.

Synonym: Diderma brunneolum Phill. in Grev. V (1877), 114; Lister Monogr. ed. 1, 71.

Portugal, N.-Amerika.

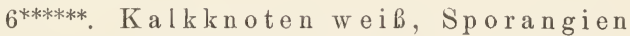
grau oder weib.

9. Stiel im Innern ohne plasmatisches Ausschumaterial.

10. Stiel strohfarbig; Sporangien kugelig, Capillitium mit zentralem Kalkkern.

29. P. nucleatum $R e x$ in Proc. Acad. Nat. Sc. Philad. (1891), 389; Lister Monogr. ed. 1, 49, pl. XIII. B, fig. a-d und ed. 2, 63, pl. 35, fig. a-c; Macbride N. A. Slime-Moulds, 54 ; Torrend in Broteria VII, 15. 
Synonyme: Physarum simile Rost. Mouogr. App. (1876), 6 ?; Massee Monogr., 286?

Plasmodium ? Sporangien herdenweise, kugelig, gestielt, weiß, bei fehlendem Kalk irisierend. Peridie häutig, unregelmäßig aufreißend. Stiel pfriemlich oder \pm zylindrisch, 0,7-1,5 mm, runzelig, Ł gelblichweiß, oberwärts durchsichtig, unterwärts mit plasmatischem Ausschußmaterial. Columella fehlend. Capillitium ein sehr enges Netzwerk zarter Fäden mit sehr kleinen, runden oder abgerundeten Kalkknoten, an deren Stelle mitunter ein glänzender, zentraler, vom Stiel freier Kalkballen. Sporenmasse schwarz; Sporen im durchfallenden Lichte blaß violettbraun, fein stachelig, $6-7 \mu$.

Schweiz (Zürich), Österreich (Galizien).

$\mathrm{N}$-Amerika, Westindien, Java, Borneo, Japan.

$10^{*}$. Stiel strohfarbig, schlank; Sporangien + kugelig, ellipsoidisch, verkehrteiförmig oder keilförmig. Sporen mit Warzenfeldern.

30. P. straminipes Lister in Journ. of Bot. XXXVI (1898), 163, t. 386, fig. 2, XXXIX, 84 und Monogr. ed. 2, 64, pl. 42, fig. a-c. 1901, 8t; Torrend in Broteria VII, 137.

Plasmodium milchweiß. Sporangien grauweiß, gebüschelt oder einzeln zerstrent, auf bis $2 \mathrm{~mm}$ langen, mitunter auch sehr kurzen Stielen oder ganz ungestielt. Stiel bald häutig, bald resistenter, ałgeflacht oder fädlich, ohne plasmatisches Ausschußmaterial, am Grunde hypothallusartig verbreitert. Capillitium ein Netzwerk kräftiger, hyaliner Fäden mit Verbreiterungen in den Maschenwinkeln und zahlreichen, verhältnismäßig großen, abgerundeten Kalkknoten, mitunter auch mit einem Kalkkern. Sporen im durchfallenden Lichte purpurbraun, 10-11 $\mu$.

Deutschland (Mark Brandenburg). Großbritannieu, Frankreich.

10**. Stiel rotbraun. Sporangien tkugelig, seltener verkehrteiförmig oder linsenförmig, am Grunde oft becherförmig vertieft, weiß mit rötlichem Grunde. 
31. P. pusillum (Berkeley et Curtis) Lister Monogr. ed. 2 (1911), 64, pl. 43, fig. a-e.

Synonyme: Didymium pusillum Berkeley et Curtio in Grev. II (1873), 53.

Physarum nodulosum Cooke et Balf. in Macbride N. A. SlimeMoulds (1898), 51; Torrend in Broteria VII, 138

Physarum calidris Lister in Journ. of Bot. XXIX (1891), 258 et Monogr. ed. 1, 52, pl. XIV, B, fig. a-c.

Physarum gravidum Mo rgan Myx. Miami Valley (1896), 96.

Badhamia nodulosa Massee in Journ. Myc. V (1889), 136, t. 14, fig. 6 et Monogr., 322.

Craterium nodulosum Cooke et Balf. ex Morgan Myx. Miami Valley (1896), 15.

Physarum mucoroides Schilberczky in Bot. Centralbl. LXVI (1896), 84?

Plasmodium wässerigweiß. Sporangien $1-2 \mathrm{~mm}$ hoch; Stiel pfriemlich oder zylindrisch, gefurcht, $0,5-1,5 \mathrm{~mm}$, frei von plasmatischem AusschuBmaterial. Columella fehlend. Kalkknoten sehr variierend, entweder spärlich und klein, oder groß, verzweigt, weiß und in großer Zahl vorhanden, oft ähnlich wie bei den Arten der Gattung Badhamia zusammenfließend und der hyalinen Verbindungsfäden entbehrend. Sporen im durchfallenden Lichte braunviolett, nahezu glatt, 8-11 $\mu$.

Deutschland (Holstein), Schweiz, Ungarn.

GroBbritannien, Frankreich, Italien, Portugal, Nordamerika, Südamerika, Antillen, Ceylon, Indien, Java, Australien, Japan.

$10^{* * *}$. Stiel vorhanden und kurz o der fehlend, weiß, häutig. Sporangien eiförmig oder \pm kugelig und in diesem Falle ungestielt, ohne Pseudocolumella.

32. P. didermoides (Achar.) Rost. Monogr. (1875), 97, fig. 87; Schröter in Cohn Krypt.-Flora Schles. III, 128; Massee Monogr. 291, fig. 82-84; Čelak. Myxom. Böhmens, 73; Lister Monogr. ed. 1, 55, pl. XIX, A, fig. a-c, ed. 2, 65, pl. 45, fig. $a-c$ und in Journ. of Bot. XXXVI, 152; Macbride N. A. Slime-Moulds, 40, pl. IX, fig. 1, 1a, 1 b, 1c; Torrend in Broteria VII, 136.

Synonyme: Spumaria? didermoides Achar. in Pers. Syn. Fung. Addenda (1801), XXIX. 
Diderma oblongum Schum. Enum. Pl. Saell. II (1803), 197.

Physarum conglobatum Fr. Symb. Gaster. (1818), 21?

Diderma oblongum Fr. Syst. Mycol. III (1829), 103.

Spumaria licheniformis Schwein. in Trans. Amer. Phil. Soc. n. s. IV (1832), 261.

Physarum cinereum var. ovoideum Sacc. in Michelia II (1832), 334.

Claustria didermoides Fr. Summ. Veg. Seand. II (1849), 451.

Didymium congestum Berkeley et Broome in Ann. Mag. Nat.

Hist. ser. 2, V (1850), 365.

Physarum lividum var. licheniforma Schwein. in Rost. Monogr. (1875), 96.

Physarum platense Spegazz. in Ann. Mlus. Nac. Buen. Aires VI (1899), 199.

Badhamia? pulcherrima Spegazz. in B. Acad. Nac. Cienc. Cordoba XI (1889), 474?

Plasmodium weiß. Sporangien in Gruppen gehäuft oder einzeln, gestielt oder ungestielt, eiförmig oder \pm kugelig, weiß oder dunkelgrau (wenn sich die Kalkkruste gelöst hat). Peridie aus drei Lagen gebildet: einer äußern Kalkkruste, einer mittlern, zarten, farblosen und einer innern purpurrötlichen Lage. Columella fehlend. Kalkknoten zahlreich, abgerundet, weiß, verbunden durch kurze, selten verzweigte hyaline Fäden, die an der Anheftungsstelle an die Sporangiumwand rötlich sind. Sporenmasse schwarz; Sporen im durchfallenden Lichte sehr dunkelpurpurbraun, dicht- und feinstachelig, 10-16 $\mu$.

Deutschland, Böhmen.

Großbritannien, Dänemark, Schweden, Portugal, W.-Afrika, Ceylon, Java, Japan, Nord- und Südamerika.

Aus Großbritannien und Portugal ist eine var. lividum Lister (Journ. of Bot. XXXVI [1898], 161, pl. 386, fig. 4 und Monogr. ed. 2, 66, pl. 46, fig. a-c; Torrend in Broteria VII, 137) bekannt, mit stets ungestielten, grauen, dicht gehäuften Sporangien, stärker eckigen Kalkknoten und ungleichmäßig warzigen, auf einer Seite blassern Sporen, die auch in unserm Gebiete vorkommen dürfte.

9*. Stiel mit plasmatischem AusschuBmaterial erfüllt.

11. Stiel lederfarbig, schwarz oder weiß. Sporangien \pm kugelig. Sporen im durchfallenden Lichte bräunlichviolett. 
33. P. nutans Pers. in Usteri Ann. Bot. XV (1795), 6; Fr. Syst. Myc. III, 128; Rabenhorst Deutschl. Krypt.-Fl. I, 277; Lister Monogr. ed. 1, 50, pl. XV, A, fig. a-f, B, fig. a-e und ed. 2, 67, pl. 37, fig. a-f; Schinz in Mitt. Naturw. Ges. Winterthur VI, 37; Torrend in Broteria VII, 139, pl. VIII, fig. II, 12, 16.

Synonyme: Stemonitis violacea Roth Fl. Germ. I (1788), 548?

SIhærocarpus albus Bull. Champ. (1791), 137, t. 407, fig. 3 , t. $470,1, \mathrm{~A}-\mathrm{G}$.

Stemonitis alba Gmelin Syst. Nat. (1791), 1469.

T'richia nutans Trentep. in Roth Cat. Bot. I (1797), 227.

'Trichia alata Trentep. in Roth Cat. Bot. I (1797), 228?

Trichia hemispherica Trentep. in Roth Cat. Bot. 1 (1797), 228?

Physarum bulbiforme Schnm. Enum. Pl. Saell. II (1803), 200.

Physarum albo-punctatum Sch u m. Enum. Pl. Saell. II (1803), 200.

Physarum Didymium Schum. Enum. Pl. Saell. II (1803), 202?

Physarum marginatum Schım. Enum. Pl. Saell. II (1803), 202?

Physarum Pini Schum. Enum. Pl. Saell. II (1803), 203?

Physarum solutum Schum. Enum. Pl. Saell. II (1803), 204?

Physarum furfuraceum Schum. Enum. Pl. Saell. II (1803), 204.

Physarum globosum Schum. Enum. Pl. Saell. II (1803), 204.

'Trichia cernua Sc hum. Enum. Pl. Saell. II (1803), 211.

Physarum albipes Link in Mag. Ges. Naturf. Freunde Berlin III (1809), 27 ?

Physarum sulcatum Link in Mag. Ges. Naturf. Frennde Berlin III (1809), 27 ?

Physarum connatum Ditm. in Sturm Deutschl. Fl., Pilze (1817), 83 , t. 41 .

Physarum gracilentum Fr. Syst. Myc. III (1829), 133.

Physarum cernuum Fr. Syst. Mye. III (1829), 130.

Didyminm marginatum Fr. Syst. Myc. III (1829), 115.

Didymium furfuraceum Fr. Syst. Myc. III (1829), 116.

T'ilmadoche soluta Fr. Summ. Veg. Sicand. (1849), 454; Čelak. Myxom. Böhmens, 68.

'Tilmadoche nutans Rost. Monogr. (1875), 127; Schröter in Cohn Krypt.-Fl. Schles. III, 125; Massee Monogr., 327, fig. 19-21.

Tilmadoche Pini Rost. Monogr. (1875), 128.

Tilmadoche gracilenta Rost. Monogr. (1875), 129 ; Massee Monogr., 330.

Tilmadoche anomala Massee Monogr. (1892), 333?

Tilmadoche alba Macbride N. A. Slime-Moulds (1899), 58.

Exsikkaten: Fuckel Fungi rhen. 1456, 1457, 2500.

Rabenhorst Fungi eur. 10, 366.

Jack-Stitzenberg 423.

Sydow Myc. March. 491.

Wiener Hofmuseum Kryptogamae exsicc. 938.

O. Jaap Myxom. Exsice. 3, 102. 

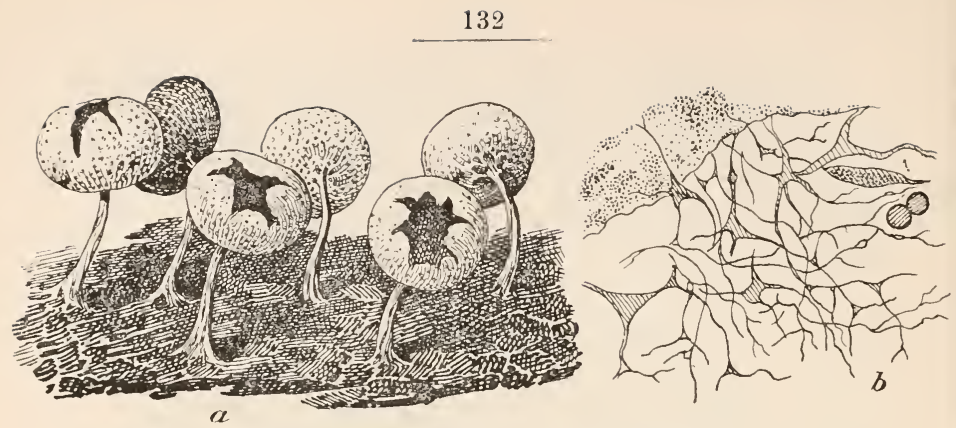

Fig. 55. Physarum nutans (Bull.) Pers.

a) Sporangiengruppe $(25 / 1)$; b) Capillitium, Sporen $\left({ }^{280} / 1\right)$. Nach Lister.

Plasmodium wässerigweiß oder gelblichgrau. Sporangien herdenweise, gestielt oder (bei ssp. leucophæum mitunter) ungestielt und ab und zu zu Plasmodiokarpien zusammenfließend, aufrecht oder nickend, \pm kugelig oder linsenförmig, unterwärts oft \pm abgeflacht oder genabelt, weiß, grauweiß oder violettgrau. Peridie mit \pm dicker Kalkki'uste. Stiel pfriemlich oder (bei ssp. leucophæum) \pm gedrungen, längs gestreift, grau, gelblich, olivenfarbig oder schwarz, oberwärts durchsichtig, mitunter auch undurchsichtig, mit Kalkeinlagerung in der Wandung und dann weiß. im Innern ohne Kalk, aber mit plasmatischem Ausschußmaterial erfüllt. Capillitium aus anastomosierenden, zarten, farblosen Fäden mit scharfwinkeligen, wenig zahlreichen Verbreiterungen der Maschenwinkel bestehend. Kalkknoten spärlich, klein, weiß. Sporen im durchfallenden Lichte hellbraunviolett, nahezu glatt oder mitunter stachelig, $8-10 \mu$.

ssp. leucophaum (Fr.) Lister Monogr. ed. I (1894), 50, pl. $\mathrm{XV}, \mathrm{B}$, fig. a-e (als Var.) und ed. 2, 67, pl. 38, fig. a-e; Schinz in Mitt. Naturw. Ges. Winterthur VI, 38 (als Var.); Torrend in Broteria VII, 139 (als Var.)

Synonyme: Spherocarpus albus Bull. Champ. Champ. (1791), 137, t. $470, \mathrm{H}-\mathrm{L}$.

Trichia filamentosa Trentep. in Roth Cat. Bot. I (1797), 227. Physarum comexum Link in Mag. (ies. Naturf. Freunde Berlin III (1809), 28?

Physarum confluens Link in Mag. Ges. Naturf. Freunde Berlin VII (1815), 43? 
Physarum hypnorum Link in Mag. Ges. Naturf. Frennde Berlin VII (1815), 43?

Physarum conglobatum Ditm. in Sturm Deutschl. Fl., Pilze (1817), 81, t. 40.

Physarum leucophæum Fr. Syuıb. Gaster. (1818), 24; Rost.

Monogr., 113, fig. 77, 78, 89; Schröter in Cohn Krypt.-Fl.

Schlesien III, 129; Nassee Monogr., 288, fig. 63-66, 96;

Macbride N. A. Slime-Moulds, 44.

Didymium terrestre Fr. ex. Weimm. Hymen. et Gaster. (1836), 574.

Physarum albipes de Bary in Zeitschr. wissensch. Zoolog. X (1860), 95.

Physarmm granulatum Balf. in Grev. X (1882), 115; Massee

Monogr., 289, fig. 68-70.

Physarum imitans Racib. in Rozpr. mat.-przyr. Acad. Krak. XII (1884), 73.

Physarum imitans Racib. f. stipitata Racib. in Myxom. agri Cracov. (1884), 5?

Physarum imitans Racib. f. flexuosa Racib. in Hedwigia XXVIII (1889), 120 ?

Physarum Readeri Massee Monogr. (1892), 282.

Tilmadoche nephroides Čelak. Iyxom. Böhmens (1893), 69.

Sporangien gewöhnlich aufrecht, oft ungestielt und zu Plasmodiokarpien zusammenflieBend. Stiel mitunter als Columella in den Fruchtkörper fortgesetzt. Maschenwinkel des Capillitiums stärker verbreitert. Kalkknoten größer, oft verzweigt und in der Mitte des Fruchtkörpers zusammenfließend. Sporen 9-11 $\mu$.

Var. ovicarpum Meylan in Bull. Soc. bot. Genève 2 me sér. VI (1914), 87, aus dem Kanton Neuenburg vom Nordabhang des Creux-du- $Y a n$, hat violette, eiförmige Sporangien mit gelblichem oder rötlichem Stiel.

Die früher auch von Lister (Monogr. ed. 1) unterschiedenen Varietäten violascens, robustum sind in der 2 ten Auflage dieses Werkes in den Typus einbezogen worden.

Typus nnd Unterart (von Sammlern und Floristen vielfach nicht anseinandergehalten) nicht nur durch das ganze Gebiet hänfig, sonderu überhaupt kosmopolitisch.

Da die Bezeichnung Physarum album vielfach von den Autoren für die verschiedensten Schleimpilze Verwendung gefunden hat, empfiehlt es sich das Epitheton album überlaupt fallen zu lassen und der nicht mißverständlichen Benennung nutans den Vorzug zu geben.

11*. Stiel schlank, oft gedreht, 1,5$1,8 \mathrm{~mm}$ lang, oberwärts grauweiß oder blaB-strohfarbig, unter- 
wärts dunkler. Sporangien zerstreut, scheibenförmig, oben nabelartig vertieft, grauweib bis graurötlich-weiB, Capillitium mit langen, spindelförmigen, verzweigten Kalkknoten. Sporenimdurchfallenden Lichte braun-oder grauviolett, nahezu glatt, $10 \mu$.

34. P. javanicum Racib. in Hedwigia XXXVII (1898), 53; Lister Monogr. ed. 2, 69, pl. 197, fig. a-c.

Java.

$11^{* *}$. Stiel kegelförmig, schwarzoder schwarz unterwärts und weib oberwärts, undurchsichtig. Sporangien zerstreut oder in Gruppen, grauweiß, entweder walzlichverkehrteiförmig, kugelig oder nierenförmig, mitunter zusammengedrückt, meist mit langer, weißer, gelbbrauner oder schwarzer, walzlicher, keulenförmiger oder kurzkegelförmiger Columella (selten 0). Capillitium mitunter Badhamia-ähnlich. Sporen im durchfallenden Lichteviolettbraun, dicht stachelig, $10-13 \mu$.

35. P. crateriforme Petch in Ann. R. Bot. Gard. Perad. IV (1909), 304; Torrend in Broteria IX, 52; Lister Monogr. ed. 2, 69, pl. 76, fig. a-f.

Portugal, Ceylon, Japan, W.-Indien.

11***. Stiel schwarz, bräunlich oderweiB, gedrungen. Sporangien zus ammengedrückt. Kalkknoten abgerundet. Sporen 
im durchfallenden Lichte dunkelpurpurbraun.

36. P. compressum Alb. et Schwein. Consp. Fung. (1805), 97; Rabenhorst Deutschl. Kryptog.-Fl. I, 277; Schröter in Cohn Krypt.-Fl. Schles. III, 128; Schinz in Mitt. Naturw. Ges. Winterthur VI, 39; Torrend in Broteria VII, 137; Lister Monogr. ed. 1, 53. pl. XVII, A, fig. a-c und ed. 2, 70, pl. 39, fig. $a-c$, pl. 40 , fig. $a-b$.

Synonyme: Physarum griseum Link in Mag. Ges. Naturf. Fr. Berlin III (1809), 27 ?

Physarum nefroideum Rost. Monogr. (1875), 93, fig. 80-82; Massee Mouogr., 285; Macbride N. A. Slime-Moulds, 41 pr. p. Physarum candidum Rost. Monogr. (1875), 96.

Physarum affine Rost. l. c. App. (1876), 5.

Physarum lividum var. conglobatum Rost. l. c. (1875), 95 pr. p. Physarum Phillipsii Balf. in Grev. X (1882), 116.

Physarum glaucum Massee Monogr. (1892), 284.

Didymium glaucum Phill. in Grev. V (1876), 114.

Plasmodium weiß. Sporangien zerstreut oder in Gruppen und mitunter zu Plasmodiokarpien zusammenfließend, meist nierenförmig, 士 kugelig, oft unterwärts genabelt, gestielt oder ungestielt, aschgrau, rauh oder warzig. Stiel kräftig, gefurcht. Capillitium ein enges Netzwerk mit zahlreichen abgerundeten, weißen Kalkknoten und kurzen, \pm hyalinen Verbindungsfäden. Columella fehlend. Sporenmasse schwarz, Sporen im durchfallenden Lichte \pm stachelig, 9-15 $\mu$.

Deutschland (nicht selten), Schweiz (?), Oesterreich.

Kosmopolitisch.

P. compressum ist eine Art mit sehr großer Variationsbreite; die $\mathbf{A b -}$ grenzung von andern Arten begegnet daher mituuter großen Schwierigkeiten. $P$. nutans hat im Allgemeinen weniger zahlreiche Kalkknoten und hellere Sporen, desgleichen hat $P$. vernum hellere Sporen, $P$. didermoides hat doppelschichtige Peridie und sporenlose Stiele. Die verschiedenen Autoren haben eine ganze Reihe von Abäuderungen beschrieben und benanut, die Aufrechterhaltung derselben ist aber wertlos, da sich alle diese Formen aus einem und demselben Plasmodium erziehen lassen.

11****. Plasmodien weiB. Sporangien gestielt, zerstreutoder zu 2 oder mehr gebüschelt, kugelig, kreisel-oder nierenförmig, 
grauweiß. Stiel kräftig, ge drungen, gefurcht, dunkel-oder blaBbraun, lederfarbig oder weiBlich, bis $1 \mathrm{~mm}$ lang, ausgefüllt mit plasmatischem Ausschußmaterial. Peridie häutig, mit körnigen Kalkeinlagerungen, mitunter auch kalkfrei und dann metallisch glänzend. Columella O. Capillitium reichlich entwickelt, aus zahlreichen, abgerundeten oder kantigen Kalkknoten und hyalinen Verbindungsfäden bestehend. Sporenmasse schwarz; Sporen im durchfallenden Lichte dunkel purpurbraun, fein stachelig, $10-12 \mu$.

37. P. connatum (Peck) Lister Monogr. ed. 2 (1911), 71, pl. 40, fig. $\mathrm{c}-\mathrm{e}$ non Schum.

Synonyme: Didymium comnatum Peck in Rep. New York Mus. XXVI (1874), 74 .

Physarnm connexum Mo rgan Myx. Miami Valley (1896), 92 non Link.

Physarum compressum Alb. et Schwein. var. $\delta$ Lister Monogr. ed. I (1894), 54.

Physarum nefroideum Rost. Monogr. (1875), 23 pr. p.

Physarum tropicale Macbride N. A. Slime-Houlds (1899), 45. pl. $\mathrm{XV}$, fig. $4,4 \mathrm{a}, 4 \mathrm{~b}$; Torrend in Broteria VII, 140 .

GroBbritannien, Schweden, N.-Amerika.

Die von Macbride abgebildeten (1. c.) Sporangien mexikanischen Ursprungs ähneln außerordentlich solchen einer Craterium-Art, die innere Struktur entspricht aber durchaus nicht dieser Gattung, das Capillitium hat ausgesprochenen Physarum-Charakter.

$11^{* * * * *}$. Stiel runzelig, meist schlank und gekrümmt, entweder bla $B$. gelb, gelbbraun oder braunrot, unterwärts mit plasmatischem AusschuBmaterial erfüllt. Sporangien zerstreut oder gebü- 
schelt, nierenförmig, verkehrtkegelförmig, polsterförmig od er gelappt, meist zusammengedrückt, mitunter ungestielt und bis zu 20 zusammenfließend, grauweiß. Capillitium aus kurzen, hyalinen Fädeu und zahlreichen eckigen, mitunter eine Pseudocolumella bildenden Kalkknoten bestehend. Mitunter fehlen die die Kalkknoten verbindenden Fäden auch vollständig, soda $B$ dann das Capillitium den Charakter eines Badham ia - Capillitiums er hält. Sporenim durchfallenden Lichte purpurbraun, \pm deutlich stachelig, $9-15 \mu$.

38. P. reniforme (Massee) Lister Monogr. ed. 2 (1911), 72 , pl. 41 , fig. a-c.

Synonyme: Tilmadoche reniformis Massee Monogr. (1892), 336.

Didymium echinospora Massee l. c., 239.

Plysarum nicaragnense Macbride in Bull. Nat. Hist. Iowa II (1893), 383 et in N. A. Slime Moulds, 43, pl. XV, fig. 7, 7 a, 7 b. Physarum compressum Lister Monogr. ed. 1 (1894), 54 pr. p. Physarum fasciculatum Jungh. Fl. Crypt. Java (1838), II, pl. 2, fig. 8 ?

Badhamia faseiculata Rost. Monogr. App. (1876), 2 ?

Ceylon, Java, Philippinien, Japan, Nicaragua.

Physarum connatum und reniforme dürften beide $P$. compressum nahe stehen; ersteres unterscheidet sich von compressum durch mehr symmetrische, nicht zusammengedrückte Sporangien und kantigere Kalkknoten. $P$. reniforme weicht von $P$. compressum durch kleinere und stärker gebüschelte oder zusammenfließende Sporangien, schlankere Stiele und kalkreicheres Capillitium ab.

1*. Sporangien niemals gestielt.

12. Kalkknoten weiB.

13. Peridie einschichtig.

14. Sporangien grauweib.

15. Sporenim durchfallenden Lichte blabbraunviolett, $7-10-12 \mu$. 
39. P. cinereum (Batsch) Pers. in Roem. N. Mag. Bot. I (1794), 89; Rost. Monogr. 102, fig. 71, 72, 85; Schröter in Cohn Krypt.-Fl. Schles. III, 128; Celakowský Myxom. Böhmens. 70; Massee Monogr., 298, fig. 71-73; Schinz in Mitt. Naturw. Ges. Winterthur VI, 39; Torrend in Broteria VII, 123; Lister Monogr. ed. 1, 55, pl. XVIII, A, fig. a-c u. B, fig. a-b, ed. 2, 73, pl. 47, fig. a-c; Macbride N. A. Slime-Moulds, 34, pl. IX, fig. $4,4 \mathrm{a}, 4 \mathrm{~b}, 4 \mathrm{c}$.

Synonyme: Lycoperdon cinereum Batsch Elench. Fung. (1783), 155.

Trichia cœrulea Trentep. in Roth Cat. Bot. I (1797), 229? Physarum violaceum Schum. Enum. Pl. Saell. II (1803), 199? Physarum plumbeum Fr. Syst. Myc. III (1829), 142; Macbride

N. A. Slime-Moulds, 35.

Physarum capense Rost. Monogr. (1875), 113, fig. 93 ?

Physarum scrobiculatum Massee Monogr. (189), 300.

Didymium cinereum Fr. Syst. Myc. III (1829), 126; Rabenhorst Deutschl. Kryptog.-Fl. I, 279.

Didymium scrobiculatum Berkeley in Hooker London Journ. Bot. IV (1845), 66.

Didymium oxalinum Peck in Rep. N. Y. Mus. XXXI (1879), 41.

Plasmodium wässerig weiß. Sporangien \pm kugelig, vereinzelt oder häufiger herdenweise oder gehäuft, oft einfache oder verzweigte, polsterförmige oder verlängerte, $0,3-0,5 \mathrm{~mm}$ breite Plasmodiokarpien bildend, grauweiß, \pm weiß-warzig oder weiß geadert. Y'eridie mit \pm dichter Kalkkruste. Columella O. Zahlreiche, abgerundete oder kantige Kalkknoten, verbunden von verzweigten, mitunter sehr zurücktretenden hyalinen Verbindungsfäden. Sporenmasse braun, Sporen im durchfallenden Lichte leuchtend violettbraun, $7-10-12 \mu$, deutlich stachelig (?), mitunter fast glatt.

Verbreitet durch Deutschland, die Schweiz und durch Oesterreich. Kosmopolitisch.

Die von Meylan (Bull. Soc. Bot. Genève 2 me sér. VI (1914), 87 aufgestellte rar. macrospora Meylan hat $9-10 \mu$ große Sporen (Neuenburg).

15*. Sporen im durchfallenden Lichte dunkel violettpurpurbraun, $9-12 \mu$.

40. Physarum vernum Sommerfelt ap. Fries Syst. Myc. III (1829), 146; Lister in Journ. of Bot. XXXV, 210 und Monogr. ed. 2, 75, pl. 48, fig. a-c; Torrend in Broteria VII, 123.

Synonym: Badhamia verna Rost. Monogr. (1875), 145 pr. p. 
Plasmodium weiß. Sporangien \pm kugelig oder an deren Stelle kurze oder verlängerte, bis $1 \mathrm{~mm}$ breite und mehrere mm lange, häıfig gedrängte, grauweiße Plasmodiokarpien bildend. Peridie meist mit Kalkkruste, bisweilen einer solchen entbehrend und dann metallisch glänzend. Capillitium aus zahlreichen, kantigen Kalkknoten und kurzen, hyalinen Verbindungsfäden bestehend. Kalkknoten mitunter zusammenfließend und dann eine Pseudocolumella bildend. Sporen im durchfallenden Lichte dunkler und meist größer als jene von cinereum, d. h. $9-12 \mu$.

Deutschland (Holstein), Schweiz (hier vorzüglich in der montanen und alpinen Region: Jura, Arolla im Wallis), Oesterreich.

Großbritanuien, Frankreich, Schweden, Portugal, Cuba.

Wohl kaum spezifisch von cinereum verschieden (siehe unten). Die kalkarme oder kalkfreie Form, deren Sporangien metallisch glänzen, hat von Frl. G. Lister die Bezeichuung var. iridescens erhalten (cf. G.. Lister ap. Rönn in Schrift. Naturw. Ver. Schlesw.-Holst. XV (1911), 54). Versuche werden zeigen müssen, ob nicht auch hier Sporangien beiden Charakters aus einem und demselben Plasmodium entstehen können; vergl. auch Meylan in Bull. Soc. Bot. Genève 2 me sér. VI (1914), 87.

Meylan (Bull. Soc. Vaud. sc. nat. 5 me sér. L (191£), 4) hält die alpinen Vorkommnisse von $P$. vernum Sommerfelt, die dem Typus entsprechen sollen, für nicht identisch mit denjenigen der Ebene. Letztere sollen zu $P$. cinereum gehören, wogegen $P$. vernum Sommerfelt mit dieser letztgenanuten Art nichts zu tun haben soll. Auch hier bedarf es meines Erachtens weiterer Beobachtungen; meine Erfahrungen haben mich gelehrt, daB ausnahmslos abnorme Standorts-, Witterungs- und Temperaturverhältnisse eine abnorme Ausbildung der Sporangien inkl. Capillitium bedingen.

P. vernum Sommerfelt f. badhamioides Meylan l. e. ist eine Form, dessen Capillitiumkalkknoten der hyalinen Verbindungsfäden nach Art der Badhamia-Arten fast ganz entbehren.

\section{$14^{*}$. Sporangien dunkelviolettbraun; Sporen $10-12 \mu$.}

41. P. atrum Schwein. in Trans. Am. Phil. Soc. n. s. IV (1882), 258; Morgan Myx. Miami Valley, 90; Macbride N. A. Slime-Moulds, 36, pl. XV, fig. 1, 1a, 1b; Torrend in Broteria VII, 123, pl. VI, fig. 1; Lister Monogr. ed. 2, 74, pl. 64, fig. a-c. Synonyme: Physarum reticulatum Berl. in Sacc. Syll. Fung. VII (1888), 350.

Physarum cinereum Ellis ex Macbride N. A. Slime-Mioulds (1899). 36.

Plasmodium gelb oder weiß ? Sporangien \pm kugelig, gehäuft, gebüschelt oder zusammenfließend, $0,2-0,4 \mathrm{~mm}$ im Durch- 
messer, dunkelviolettbraun, oft weiblich gesprenkelt oder geadert, Peridie dünn, mit oder ohne Kalk. Capillitium spärlich entwickelt; Kalkknoten grauweiß, klein, kantig, verzweigt, mit hyalinen Verbindungsfäden. Sporen im durchfallenden Lichte braunviolett, deutlich feinwarzig, $10-12 \mu$.

Deutschland (Berlin).

Nordamerika.

Unschwer an der auffallenden Färbung der kleinen, gehäuften Sporangieu erkennbar.

14**. Plasmodiokarpien (oder Sporan-
gien) rötlichgrau bis schwarz-
braun, rosetten- oder netzförmig;
Sporen blabbraunviolett, $7-10 \mu$.

42. P. gyrosum Rost. Monogr. (1875), 111 pr. p.; Massee Monogr., 307 pr. p.; Lister in Monogr. ed. 1 (sub Fuligo septica pr. p.), 66, pl. XXIV, A, fig. a, in Journ. of Bot. XL, 210, t. 438, fig. 2 und in Monogr. ed. 2, 75, pl. 52, fig. a-c; Torrend in Broteria VII, 119, pl. VIII, fig. 17.

Synonyme: Lignidium reniforme Fr. Syst. Gaster (1817), 10 ?

Fuligo septica Lister Monogr. ed. 1 (1894), 66 pr. p. non Gmel. Fuligo gyrosa Jahn in Ber. Deutsch. Bot. Ges. XX (1902), 272, t. XIII, fig. 3,4 .

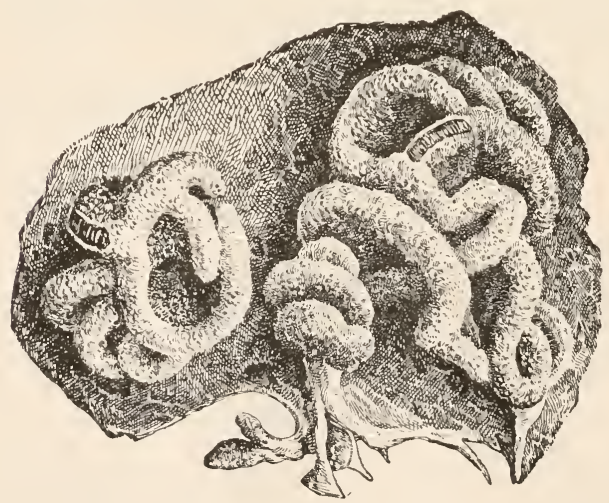

Fig. 56. Physarum gyrosum Rost.

Wurmförmige, einem Rindenstück aufsitzende Sporangien $\left({ }^{20} / 1\right)$. - Nach Lister. 
Plasmodium bleigrau, rahm- oder dunkelgelblichweib. Plasmodiokarpien wurmartig oder seitlich zusammengedrückt, meist 土 labyrinthartig durcheinandergerollt oder rosettenförmig, mitunter mehrere $\mathrm{mm}$ breit, meist einem rosa- oder dunkelroten Hypothallus aufsitzend, mit rötlicher, graurötlicher, seltener weißlicher Kalkkruste; selten gestielte, seitlich zusammengedrückte Sporangien: Kalkknoten in großer Zahl, entweder von unregelmäßiger Gestalt oder ausgesprochen spindelförmig, mit zarten Verbindungsäden. Sporen fein stachelig.

Dentschland (Bot, Gärten in Berlin und Leilzig), Schweiz (Botanischer Garten in Zürich, Versuchsgarten in Wadenswil), Ceylon, Java, New-York, Brasilien.

Es ist auffallend, daß die Fruchtkörper dieser Art sowohl in Berlin wie in Zürich nud Leipzig auf Keimpflanzen in Vermehrungskästen anftraten und zwar z. B. in Zürich auf einzelnen Ptlanzen in solcher Zahl, daß von der grünen Farbe der Lanbblätter des Wirtes rein nichts mehr zu sehen war. Die Pflanzen starben ab, sicherlich nicht infolge Nahrungsentzuges seitens der ihr aufsitzemlen Fruchtkörper, sondern infolge der T'nterbindung jeder photosynthetischen Tätigkieit.

Wir haben es bei P. gyrosum mit einer Physarum mit Fuligo verbindenden Art zu tun, ja man kam tatsächlich in Zweifel sein, ob man die Fruchtkörper als Plasmodiokarpien oder als Äthalien ansprechen soll. Jedenfalls fehlt aber eine gemeinschaftliche, mehrere Frnchtkörper bedeckende Peridie.

$$
\begin{aligned}
& 14^{* * *} \text {. Sporangien bräunlichgelb oder } \\
& \text { kastanjenbraun; Sporen } 10-12 \mu \text {. }
\end{aligned}
$$

43. P. Famintzini Rost. Monogr. (1875), 107; Rob. E. Fries in Svensk Botanisk Tidskrift VI, 740.

Synonym: Physarum Gulielme Penzig Die Hyxom. d. Fl. v. Buiteuzorg (1898), 34; Lister in Journ. of Bot. XXXVII, 147, XXXIX, 83 und Monogr. ed. 2, 76, pl. 63, fig. a-c; Torrend in Broteria VII, 122.

Plasmodium gelb. Sporangien \pm kugelig oder nierenförmig, $0,4 \mathrm{~mm}$ im Durchmesser, höckerig, gebüschelt oder gehäuft, schmutziggelb, gelblichbraun bis kastanienbraun. Peridie knorpelig, mit braungelben Kalkkörnern, die durch helle Zonen von einander getrennt sind. Kalkknoteu des Capillitiums groß, weißlich, gelblich oder gelb, kantig und zum Teil verzweigt, unter einander durch kurze hyaline Fäden verbunden. Sporen im durchfallenden Lichte purpurbraun, stachelig, $10-12 \mu$. 
Dentschland (Holstein), Schweiz (Jura, Flims), Österreich (Galizien). Schweden, Java.

Die Identität von Physarum Famintzini Rost. und P. Gulielma Penzig steht nicht ganz außer Zweifel. Rostafinsky sagt, daß das Capillitium der ron ihm nach Famintzin benannten polnischen Exemplare sich beim Öffnen der Sporangien bis um das Vierfache verlängere, elastisch sei und daß die Kalkblasen des Netzes milchig gelb seien. Die schwedischen Funle (siehe Rob. E. Fries in Svensk Botanisk Tidskrift VI [1912], 740), diejenigen des schweizerischen Jura (Meylan brieflich) und Graubündens (Jahn briefl.) stimmen in beiden Punkten hierin überein, wogegen Penzig und Lister die elastische Dehmung oder Streckung des Capillitiums nicht beobachtet haben und angeben, daß die Kalkblasen von weißer Farbe seien. Es muß daher vorläufig noch dahingestellt bleiben, ob es sich im letzeren Falle um eine blasse leichte Modifikation oder $\mathrm{m}$ eine Varietät oder gar besondere Art handelt. Sollte letzteres der Fall sein, so hätten die polnischen, sehwedischen und schweizerischen Funde die Bezeichnung P. Famintzini zu tragen, die javanischen und deutschen (ef. Tister in Journ. of Bot. XXXI, 83) dagegen würden das spez. Epitheton Gulielma erhalten.

13*. Peridie zweischichtig.

16. Fruchtkörper zerstreut, als Plasmodiokarpien ausgebildet.

17. Plasmodium ? Plasmodiokarpien kalkweiß, meist buchtig gewunden, seitlich auffallend zusammengedrückt, durch Längsrisse a ufspringend. Äu Bere Peridieschicht gleich einer Eierschale glatt, spröde, reichlich mit Kalkkörnchen beladen, innere dünn, blaßpurpur metallisch g länzend. Kalkknoten zahlreich, weiB, in Gestalt und Größe gleicherweise sehr ungleich, verbunden durch kurze, hyaline Fäden. Sporen purpurrot im durchfallenden Lichte, mit feinen Stacheln und kräftigen Leisten, $8 \mu$.

44. P. echinosporum Lister in Journ. of Bot. XXXVII (1899), 147, t. 398, fig. 1, 1 a, 1 b, 1 c und Monogr. ed. 2, 77, pl. 53, fig. a-c; Torrend in Broteria VII.

Antillen. 
17*. Sporangien buchtig gekrümmt, seitlich zusammengedrückt, innere Peridieschicht farblos. Sporen ohne Leisten.

45. P. sinuosum (Bull.) Weinm. ex Fr. Syst. Myc. III (1829), 145 non Link; Rabenhorst, Deutschl. Krypt.-Fl. I, 273; Rost. Monogr., 112, fig. 91; Schröter in Cohn Krypt.-Fl. Schles. III, 130; Massee Monogr., 305, fig. 292, 293; Macbride N. A. Slime-Moulds, 28, pl. VIII, fig. 6, 6a ; Torrend in Broteria VII, 117, pl. V, 27; Lister Monogr. ed. 2, 77, pl. 49, fig. a-c.

Synonyme: Reticularia sinuosa Bull. Champ. (1791), 94, t. 446, fig. 3 .

Physarum bivalve Pers. in Usteri Ann. Bot. XV (1795), 5; Lister Monogr. ed. 1, 57, pl. XIX, B, fig. a-c; Schinz in Mitt. Naturw. Ges. Winterthur VI, 40.

Diderma valvatum Fr. Syst. Myc. III (1829), 109.

Carcerina valvata Fr. Summ. Veg. Scand. (18t9) 451.

Augioridium sinuosum Grev. Scot. Crypt. Fl. (1828), t. 310.

Exsikkaten: Rabenhorst Fungi eur. 798, 1070, 1913, 2139.

Fuckel Fungi rhen. 1466.

Sydow Myc. Mareh. 257.

O. Jaap Myxom. exsice. 1, 145 .

Plasmodium weiß. Fruchtkörper entweder Sporangien oder häufiger zerstreute, verlängerte, seitlich zusammengedrückte, buchtig gekrümmte, oft verzweigte und netzartig anastomosierende, abgeflachte und längsaufspringende oder kissenförmige und unregelmäßig aufreißende, weiße, graue oder gelbliche Plasmodiokarpien. Äußere Peridieschicht kalkreich, glatt oder netzartig, spröde, innere farblos, runzelig. Capillitium-Kalkknoten körnchenreich, weiß, oft verzweigt, hinsichtlich Größe und Gestalt variierend, mit kurzen Verbindungsfäden. Sporen fein stachelig, im durchfallenden Lichte violettbraun, 8-10 $\mu$.

Deutschland, Schweiz, Österreich.

Kosmopolitisch.

17**. Fruchtkörper zerstreut oder herdenweise, entweder in Form eiförmiger, mitunter seitlich abgeflachter Sporangien oder buchtig gekrümmter Plasmo- 
diokarpien, lederfarbig, rötlichbraun, gelb oder nahezu weib. AeuBerePeridieschicht glatt, kalkreich, gefeldert, sich von der innern Schicht in sich rü ckwärts kr ümmende Lappen loslösend. Kalkknoten groß, wei $B$, verzweigt, abgerundet mit zarten Verbindungsfäden. Sporen im durchfallenden Lichte blabviolettbraun, nahezu glatt, $8 \mu$.

46. P. bogoriense Racib. in Hedwigia XXXVII (1898), 52; Petch in Ann. Perad. IV, 338; Lister in Journ. of Bot. XXXVI, 122 und Monogr. ed. 2, 78, pl. 50, fig. a-c; Torrend in Broteria VII, 118, pl. IX, fig. 13.

Synouyme: Diderma pallidum Berkeley et Curtis ex Lister Monogr. ed. 2 (1911), 78.

Physarum pallidum Lister in Journ. of Bot. XXXVI (1898), $117,122$.

Portugal, W.-Afrika, Ceylon, Java, Australien, N.-, Mittel- und S.Amerika.

I'nterseheidet sich von $P$ simosum sofort dureh nicht seitlich zusammengedrückte Fruchtkörper und dureh die Art des Aufspringens zur Zeit der Sporenreife.

$17^{* * *}$. Plasmodiokarpien weiB, meist seitlich zusammengedrückt. Innere Peridieschicht blaBpurpurrot, \pm bleibend. Sporen im durchfallenden Licht purpurbraun, fein stachelig.

47. P. bitectum Lister Monogr. ed. 2 (1911), 78, pl. 51, fig. $a-c$.

Synonym: Physarum Diderma Lister in Journ. of Bot. XXIX (1891), 260, XLII, 131 und Monogr. ed. 1, 57, pl. XX1I, A, fig. a-c nou Rost.

Plasmodium weiß. Fruchtkörper zerstreut, entweder in der Form \pm kugeliger oder verkehrteiförmiger Sporangien oder 
wurmförmig gekrümmter, abgerundeter oder seitlich zusammengedrückter Plasmodiokarpien. Āußere Peridie glatt, weiß oder ledergelb, kalkreich, oberwärts zerbrechlich und sich beim Aufreißen zurückkrümmend, gegen den Grund zu bleibend; innere Schicht glatt, häutig, blaßpurpurrot, minder spröde als die äußere. Kalkknoten z. T. auffallend groß, weiß, in Größe und Gestalt variierend. Sporen im durchfallenden Lichte purpurbraun, fein stachelig, einseitig blasser und glatter, $10-12 \mu$.

Deutschland (sowohl in Holstein wie in der Mark Brandenburg gefunden).

Großbritannien, Frankreich, Schweden, Portugal, N.- und S.-Amerika.

Unterscheidet sich von $P$. sinuosum hauptsächlich durch die glatte, rötliche, innere Peridie und die mindestens auf einer Seite nahezu glatten Sporen.

$16 *$ Sporangien gehäuft, nierenförmig oder \pm kugelig.

18. Sporangien weib, \pm kugelig, gebüschelt, seitlich \pm abgeflacht infolge des gegenseitigen Druckes der gedrängten Fruchtkörper, 0,7 mm im Durchmesser. Äuere Peridieschicht eierschalenartig, sich vonder farblosen inneren Schicht trennend. Capillitium aus groben und kleinen, verzweigten, kantigen Kalkknoten und kurzen, hyalinen Verbindungsfäden bestehend. Sporen im durchfallenden Lichte purpurbraun oder graupurpurn, fein stachelig, auf einer Seite etwas dunkler und dichter stachelig, $8-10 \mu$.

48. P. testaceum Sturgis in Colorado Coll. Publ. Sc. Ser. XII (1907), 18; Lister Monogr. ed. 2, 79, pl. 54, fig. a-c.

Syuonym: Physarum didermoides Rost. var. lividum Lister in Journ. of Bot. XXXVI (1898), 162 pr. p.

N.-Amerika.

Schinz, Myxogasteres (Rabenhorst Krypt. Flora I, Pilze Abt. X). 
18*. Sporangien gelb, ockerfarbig oder gelblich. Sporen dunkelviolettbraun, stachelig, $10-13 \mu$.

49. P. contextum Pers. Syn. (1801), 168; Rost. Monogr., 109 ; Schröter in Cohn Krypt.-Fl. Schles. III, 130; Čelak. Myxom. Böhmens, 73; Schinz in Mitt. Naturw. Ges. Winterthur VI, 41; Lister Monogr. ed. 1, 58, pl. XX, A, fig. a-c, in Journ. of Bot. XXXIX, 82 und Monogr. ed. 2, 79, pl. 55, fig. a-c; Macbride N. A. Slime-Moulds, 31, pl. IX, fig. 3, 3a; Torrend in Broteria VII, 120.

Synonyme: Diderma contextum Pers. Obs. Myc. I (1796), 89 ; Rabenhorst Deutschl. Krypt.-Fl. I, 281.

Diderma ochroleucum Berkeley et. Curtis in Grev. II (1873), 52.

Diderma flavidum Peck in Rep. N. Y. State Mus. XXVIII (1879), 54.

Physarum conglomeratum Massee Monogr. (1892), 304, fig. $210-212,284-286$.

Lycoperdon luteum Jacq. Misc. (1778), 138, t. 8 ?

Leocarpus contextus Fr. Summ. Veg. Scand. (1849), 450.

Exsikkaten: Fuckel Fungi rheu. 1400.

O. Jaap Myxom. exsicc. 5 .

Plasmodium gelb. Sporangien \pm kugelig, ei- oder nierenförmig und et was verlängert auf breiter Basis $0,+-0,6 \mathrm{~mm}$ im Durchmesser, oft seitlich etwas abgeflacht als Folge des gegenseitigen Druckes der gedrängten Fruchtkörper, oben abgerundet oder \pm flach, glatt, weißlichgelb oder ockerfarbig. Äußere Peridieschicht knorpelig, kalkreich im obern Teil und zerbrechlich, sich oft von der dünnen, gelben innern Schicht lösend und schwindend. Capillitium aus zahlreichen großen, unregelmäßig verzweigten Kalkknoten und spärlichen Verbindungsfäden bestehend. Trotz des Zurücktretens der Verbindungsfäden scheint es aber nicht zur Bildung einer Columella zu kommen.

Deutschland, Schweiz, Österreich.

Großbritannien, Frankreich, Portugal, Dänemark, Schweden, Rußland, Tasmanien, N.-Amerika.

Die Unterschiede gegenüber der folgenden Art sind zur Hauptsache in den Schlüsselsätzen ausgedrückt.

18**. Sporangien blasser gelb als bei der vorigen Art, weißlich- 
gelbgefleckt. Sporen bla $B$ violettbraun, fast glatt, 8$10 \mu$.

50. P. conglomeratum (Fr.) Rost. Monogr. (1875), 108, fig. 73, 79, 90; Lister Monogr. ed. 1, 58, pl. XX, B, a-c, ed. 2, 80, pl. 56, a--c; Schinz in Mitt. Naturw. Ges. Winterthur VI, 41; Macbride N. A. Slime-Moulds, 31; Torrend in Broteria VII, 120.

Syn on yme: Diderma conglomeratum Fr. Syst. Myc. Ill (1829), 111.

Spumaria minuta Schum. Enum. Pl. Saell. II (1803), 196?

Spumaria granulata Schum. 1. c., 196?

Diderma minutum Fr. l. c., III?

Diderma granulatum Fr. l. c., Ill?; Rabenhorst Deutschl. Krypt.Fl. I, 282.

Diderma flavum Weinm. Hymen. et Gaster. (1836), 593?

Diderma rugulosum Wein $\mathrm{m}, \mathrm{l}$. c., 594?

Leocarpus granulatus Fr. Summ. Veg. Scand. (1849), 451?

Leocarpus minutus Fr. Summ. Veg. Scand. (1819), 450.

Carcerina conglomerata Fr. Summ. Veg. Scand. (1849), 451.

Physarum Rostafinskii Massee Monogr. (1892), 301.

Exsikkaten: Fuckel Fungi rhen. 1468, 2400.

Plasmodium? Sporangien ungestielt, \pm kugelig, häufig etwas niedergedrückt, gedrängt, \pm kantig infolge seitlichen Druckes, 0,3-0,5 mm; äußere Peridieschicht dick, mit reichlichem Kalkkörnchenbelag, unregelmäßig aufreißend und sich zurückrollend, innere zarter. Kalkknoten des Capillitiums weiß oder gelblich, mit zarten, verzweigten Verbindungsfäden, mitunter derselben entbehrend und dann zusammenfließend.

Unterscheidet sich von $P$. contextum durch die größeren und glatteren Sporen und die größeren, nicht gar selten zusammenfließenden Kalkknoten.

Deutschland, Schweiz, Österreich.

Großbritannien, Dänemark, Finnland, Indien, N.-Amerika, Antillen.

12*. Kalkknoten gelb, rot oder braun.

19. Sporangien rot oder braun.

20. Plasmodium? Kalkknoten dunkeloder bla B-braun. Sporangien rosenrotbraun oder bronzefarbig, glänzend, kugelige oder an deren Stellewurmartige, häufig gekrümm- 
te, einfach verzweigte oder verzweigt anastomosierende, strangartige Plasmodiokarpien von $0,3-$ $0,4 \mathrm{~mm}$ Breite. Äußere Peridieschicht \pm spröde, kalkreich, sich von der glänzenden innern Schicht ablösend und zurückrollend. Kalkknoten zahlreich, verhältnismäBig klein, mitunter zu einer Pseudocolumella zusammenfließend. Sporen im durchfallenden Lichte blabbraunviolett, nahezu glatt, $6-8 \mu$.

51. P. aeneum Rob. E. Fries in Arkiv Bot. I (1903), 62; Lister Monogr. ed. 2, 81, pl. 58, fig. a-c.

Synonym: Physarum murinum Lister var. aeneum Lister in Jonrn. of Bot. XXXVI (1898), 117, t. 385, fig. 4 und XLII, 131. Westindien, Bolivia.

$20^{*}$. Kalkknoten orangerot, rotbraun o der gelb.

21. Kalknoten kantig, orangerot o der rotbraun.

52. P. rubiginosum Fr. Symb. Gaster. (1817), 21 non Chevall.; Rabenhorst Deutschl. Krypt.-Fl. I, 275; Rost. Monogr.. 104; Schröter in Cohn Krypt.-Fl. Schles. III, 129; Massee Monogr., 302 ; Lister Monogr. ed. I, 61. pl. XXIII, A, fig. $a-c$ und ed. 2, 82, pl. 59, fig. a-d; Macbride N. A. Slime-Moulds, 55; Torrend in Broteria VII, 124.

Synonym: Physarum fulvum Fr. Syst. Myc. III (1829), 143.

Plasmodium orangerot (?.) Sporangien zerstreut, gesellig oder gehäuft, \pm kugelig, $0,5-1 \mathrm{~mm}$, glatt oder höckerig, rot oder olivenbraun. Peridie mit gelben Kalkeinschlüssen. Kalkknoten groß, verzweigt, kantig, Verbindungsfäden hyalin, oft mit dreieckigen Verbreiterungen in den Verzweigungsstellen. Sporenmasse dunkelbraun; Sporen im durchfallenden Lichte blabviolettbraun, fein stachelig, $8-11 \mu$.

Dentschland, Schweiz.

Großbritannien?, Schweden, Norwegen, Rußland, N.-Amerika, 
$21^{*}$. Kalkknoten abgerundet, gelb, gewöhnlich mit rotem Mittelfeld.

53. P. Iateritium Berkeley et Rav. Morgan Myx. Miami Valley (1896), 95; Macbride N. A. Slime-Moulds, 33; Lister Monogr. ed 2, 82, pl. 60, fig. a-d; Torrend in Broteria VII, 121.

Synonyme: Didymium lateritium Berkeley et Rav. in Grev. II (1873), 65.

Didymium croceoflavum Berkeley et Broome in Journ. Limn. Soc. XIV (1873), 84 .

Physarum Braunianum de Bary ex Rost. Monogr. (1875), 105. Physarum Ditmari Rost. var. lateritium Rost. Monogr. App. (1876), 9.

Physarum Ditmari Rost. var. croceoflavum Rost. Monogr. App. (1876), 9.

Physarum inæquale Peck in Rep. N. Y. Mus. Nat. Hist. XXXI (1879), 40; Lister Monogr. ed. 1, 60, pl. XXII, B, fig. a-c. Physarum ehrysotrichum II assee Monogr. (1892), 300 pr. p.

Plysarum fulgens Patonill. in Bull. Soc. Myc. Fr. VIII (1892), 122 ?

Plasmodium? Sporangien gesellig, aber seltener gehäuft, kugelig, 0,3-0,7 $\mathrm{mm}$ im Durchmesser, oder einfach verzweigte oder netzförmig anastomosierende, wurmförmige oder seitlich zusammengedrückte, orangegelbe, ziegel- oder rosenrote oder rotbraune Plasmodiokarpien. Fruchtkörper höckerig, unregelmäßig aufspringend. Peridie dünn, mit roten oder orangegelben Kalkeinschlüssen. Kalkknoten abgerundet, sehr variierend in Größe und Gestalt, Verbindungsfäden blaßgelb oder farblos. Capillitium sich am Lichte rasch entfärbend und weiß werdend. Sporenmasse violettbraun; Sporen im durchfallenden Lichte blab violettbraun, nahezu glatt, $6-9 \mu$.

Deutschland (Grunewald bei Berlin).

Ceylon, Java, N.- und S.-Amerika.

Nach Macbride entbehren die Kalkknoten der amerikanischen Exemplare des roten Mittelfeldes.

19*. Sporangien gelb oder orangefarbig.

22. Sporangienwand einschichtig. Sporangien kugelig oder unregelmäßig e iförmig. Sporen nahezu glatt, $7-10 \mu$. 
54. P. virescens Ditm. in Sturm Fl. Deutschl. I (1817), 123, pl. 61; Rabenhorst Deutschl. Krypt.-Fl. I, 274; Rost. Monogr., 103; Schröter in Cohn Krypt.-Fl. Schles. III, 128; Massee Monogr., 277; Čelak. Myxom. Böhmens, 71; Lister Monogr. ed. 1, 59, pl. XXI, A, fig. a-c, B, fig. a-b, und ed. 2, 83, pl. 61, fig. a-c, e, pl. 62, fig. a-c; Schinz in Mitt. Naturw. Ges. Winterthur V1, 41; Macbride N. A. Slime-Moulds, 33 , pl. VIII, fig. $7,7 \mathrm{a}, \mathrm{pl}$. IX, fig. $5,5 \mathrm{a}, 5 \mathrm{~b}$; Torrend in Broteria VII, 121, pl. VI, fig. 17, 18.

Synon yme:Physarum thejoteum Fr. Symb. Gaster. (1818), 21 ; Rabenhorst Deutschl. Krypt.-Fl. I, 274.

Physarum anceps de Bary ex Fuckel Symb. Hyc. (1869, 70), 343 [nom. nud.]

Didymium nectriæforme Berkeley et Curtis in Grev. II (1873), 66.

Physarum Ditmari Rost. Monogr. App. (1876), 8.

Didymium sinapinum Cooke Myx. Brit. (1877). 33.

Physarum virescens var. genuinum Lister Monogr. ed. 1, 59 pl. XXI, A, fig. a-c; Torrend in Broteria VII, 122.

Exsikkaten: Fuckel Fungi rhen. 1460.

O. Jaap Myxom. exsice. 6.

Plasmodium zitronengelb. Sporangien gehäuft oder gesellig, mitunter gebüschelt, $a b$ und zu längliche Plasmodiokarpien bildend, höckerig oder nahezu glatt, blaßgelbgrün, orangerot oder bei fehlendem Kalk purpurbraun. Peridie \pm dünn, spröde, meist mit Kalkeinlagerung in Form sehr kleiner gelber Kalkkörnchen. Kalkknoten des Capillitiums gelb, abgerundet spindelförmig oder von unregelmäBiger Form, Verbindungsfäden zart. Sporen fast glatt, im durchfallenden Lichte blaßviolettbraun, $7-10 \mu$.

Deutschland, Schweiz (Jura), Österreich.

Großbritannien, Frankreich, Belgien, Schweden, Rußland, N.-Amerika, Java.

Wir unterscheiden mit Lister folgende Abänderungen:

var. obscurum Lister Monogr. ed. I (1894), 59 , pl. XXI, B, fig. a, b und ed. 2, 84, pl. 61, fig. e; Torrend in Broteria VII, 122.

Sporangien $(0,4-0,8 \mathrm{~mm}$ im Durchmesser) oder Plasmodiokarpien, herdenweise oder gehäuft, grünlichgelb, häufig blaßgelb- oder olivenbraun gesprenkelt, etwas glänzend. Peridie 
oberwärts farblos, gegen den Grund zu gelb, entweder kalkfrei oder mit zerstreuten Schülfern weißlicher Kalkkörnchen. Kalkknoten leuchtend gelb. Sporen $6-8 \mu$.

Deutschland, Ungarn.

Großbritannien.

var. nitens Lister Monogr. ed. 1 (1894), 59 und ed. 2, 84, pl. 62, fig. a-c; Torrend in Broteria VII, 122.

Synonyme: Physarum luteolum Peck in Rep. N. Y. Mus. Nat. Hist. XXX (1878), 50 ?

Physarum auriscalpium Macbride in Bull. Nat. Hist. Iowa II (1893), 158 non Cooke.

Sporangien kugelig, 0,5-0,8 mm im Durchmesser, herdenweise aber nicht gebüschelt, leuchtend gelb. Sporen $7-9 \mu$.

Deutschland, Schweiz.

GroBbritannien, N.-Amerika.

22*. Sporangienwand doppelt. Sporangien gebüschelt oder zerstreut, mitunter gedrungene, gekrümmte oder geradegestreckte Plasmodiokarpien. Sporen dicht- und fein warzig, $9-14 \mu$.

55. P. alpinum (Lister) G. Lister in Journ. of Bot. XLVIII (1910), 73 und Monogr. ed. 2, 84, pl. 62, fig. d-f; Meylan in Bull. Soc. Vaud. sc. nat. 5 me sér. L, 5.

Synonym: Physarum virescens Ditm. var. alpina Lister in Journ. of Bot. XLVI (1908), 216.

Plasmodium ? Sporangien 1-1,3 $\mathrm{mm}$ im Durchmesser, blaßgelb oder ockerfarbig, schuppig oder glatt. Äußere Peridieschicht kalkreich, von der häutigen innern Schicht sich ablösend. Kalkknoten zahlreich, groß, einfach oder verzweigt, verbunden von einem spärlichen Netzwerk starker, hyaliner Fäden mit Verbreiterungen in den Astwinkeln. Sporen im durchfallenden Lichte purpurbraun, $9-14 \mu$.

Schweiz (Jura, Arolla im Wallis, Pont de Nant ob Bex).

Schweden, Californien. 
var. badhamioides Meylan in Bull. Soc. Vaud. sc. nat. 5 me sér. L (1914), 7, Verbindungsfäden der Kalkknoten fast 0 (Neuenburger Jura).

Eine ausgezeichnete alpine und subalpine (so in Schweden) Art.

\section{Gattung Fuligo Haller}

Hist. Stirp. Helv. III (1768), 110; Pers. Syn. (1801), 159; Rost. Vers. eines Syst. der Mycetozoen, 11 und Monogr. 134; Čelakowksy' Myxom. Böhmens, 80; Schröter in Cohn Krypt.-Fl. Schlesien III, 132 und in Engler und Prantl Natürl. Pflanzenfam. I, 35; Massee Monogr. 339; Lister Monogr. ed. 1, 65 und ed. 2, 85; Schinz in Mitt. Naturw. Ges. Winterthur VI, 44; Macbride N. A. Slime-Moulds, 22; Torrend in Broteria VII, 141, VIII, 15 .

Synonyme: Hucor L. Gen. Pl. ed. 5 (1754), 493.

Äthalium Link Diss. I (1809), 42.

Sporangien wurmartig verlängert, in großer Zahl in- und durcheinander verwoben, ein grobes, kissenartiges Āthalium bildend, dessen äußere Sporangien häufig steril sind und eine sporenfreie, kalkreiche, spröde Rinde bilden. Capillitium mit wenigen oder vielen Kalkknoten.

1. Sporen $6-14 \mu$.

2. Äthalium und die meist spindelförmigen Kalkknoten gelb, seltener rötlich oder weib. Sporen $7-9 \mu$.

1. F. septica (L.) Gmelin Syst. Nat. (1791), 1466; Schröter in Cohn Krypt.-Fl. Schlesien III, 132; Lister Monogr. ed. 1, 66, pl. XXIV, A, fig, b-d und ed. 2, 86, pl. 74, fig. a-f; Schinz in Mitt. Naturw. Ges. Winterthur VI, 44; Torrend in Broteria VII, 142, pl. VIII, fig. 20.

Synonyme: Mucor septicus L. Spec. Pl. ed. 2, II (1763), 1656;

G. Lister in Journ. of Bot. LI, 161.

Mucor primus (ovatus) Schaeff. Fung. Bav. (1763), 132, fig. 92.

Huccr Mucilago Scop. Fl. Carn. ed. 2, II (1772), 492.

Lycoperdon luteum Schrank Fl. Bav. II (1789) 629 .

Reticularia lutea Bull. Champ. (1791), 87, t. 380, fig. 1.

Reticularia hortensis Bull. Champ. (1791), 86, t. 424, fig. 2. 
Reticularia carnosa Bull. Champ. (1791), 85, t. 424, fig. 1 ? Fuligo flava Pers. in Roemer N. Mag. Bot. I (1794), 88.

Fuligo candida Pers. in Roemer N. Mag. Bot. 1 (1794), 88.

Fuligo rufa Pers. in Roemer N. Mag. Bot. I (1794), 88.

Fuligo vaporaria Pers, Obs. I (1796), 92.

Fuligo pallida Pers. Obs. II (1799), 36.

Reticularia septica Withering Arrang. ed. IV (1801), 463.

Reticularia ovata var. Withering Arrang. ed. IV (1801), 463.

Fuligo lævis Pers. Syn. (1801), 160.

Fuligo violacea Pers. Syn. (1801), 160; Macbride N. A. SlimeMoulds, 24.

Fuligo carnea Schum. Enum. Pl. Saell. II (1803), 194.

Fuligo flavescens S chum. Enum. Pl. Saell. II (1803), 194.

Äthalium flavum Link in Mag. Ges. Naturf. Fr. Berlin III (1809), 42.

Fuligo cerebriua Brondeau in Mém. Soc. Linn. Paris III (1824) 74 , t. 3 , fig. $1-4$.

Fuligo varians Somın. Fl. Lapp. (1826), 239; Rost. Monogr., 134; Čelak. Myxom. Böhmens, 80; Massee Monogr., 340, fig. 190-192.

Reticularia vaporaria Chevall. Fl. Par. I (1827), 342.

Äthalium violaceum Spreng. Syst. IV (1827), 533.

Äthalium candidum Schlechtd. in Sprengl. Syst. IV (1827), 533. Äthalium septicum Fr. Syst. Myc. 111 (1829), 93; Rabenh. Deutschl. Krypt.-Fl. I, 253.

Reticularia carnea Fr. Syst. Myc. III (1829), 91.

Fuligo carnosa Duby Bot. Gall. II (1830), 863.

Fuligo hortensis Duby Bot. Gall. II (1830), 863.

Äthalium ferrincola Schwein. in Trans. Am. Phil. Soc. n. s. IV (1832), 26?

Reticularia rufa Schwein. in Trans. Am. Phil. Soc. n. s. IV (1832), 261.

Äthalium rufum Wallr. Fl. Germ. IV (1833), 341.

Äthalium vaporarium Fr. ex Berkeley in Gard. Chron. (1860), 409.

Äthalium rufum Alexandrowicz Strojen. (1872), t. 11, fig. $6-11$.

Licea Lindheimeri Berkeley in Grev. II (1873), 68.

Fuligo tatrica Racib. in Hedw. XXIV (1885), 169.

Tubulina Lindheimeri Massee Monogr. (1892), 42.

Physarum cerebrinum Massee Monogr. (1842), 306, fig. 275.

Fuligo orata M acbride N. A. Slime-Moulds (1899), 23, pl. X, fig. $2,2 a, 2 b$.

Plasmodium leuchtend gelb, selten weiß. Äthalium sehr verschieden in der Größe, $2 \mathrm{~mm}$ bis $20 \mathrm{~cm}$ breit, blaßbraun, gelblichbraun, rötlich, rotbraun oder schmutzig weiß, polsterförmig, $1 / 2 \mathrm{~cm}$ 
bis $3 \mathrm{~cm}$ hoch, meist überkleidet von einer kalkreichen, gewöhnlich gelben Kruste. Sporangienwände innerhalb des Ätha-
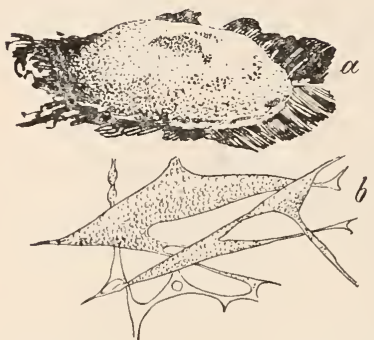

Fig. 57. Fuligo septica (L.) Gmelin. a berindetes Äthalium auf Rinde aufsitzend $\left({ }^{2} / 3\right)$; b Capillitium mit spindel-

förmigen Kalkknoten $(\mathbf{8 9 0} / 1)$.

Nach Lister.

liums häutig, sehr spröde, farblos, kalkführend. Columella O. Capillitium spärlich oder reichlich entwickelt, ein lockeres Netzwerk \pm schlanker hyaliner Fäden, die an den Verzweigungsstellen \pm verbreitert zu sein pflegen, mit spindelförmigen oder verzweigten gelben oder weißlichen Kalkknoten. Spórenmasse schwarz, rußartig; Sporen im durchfallenden Lichte violett, nahezu glatt, $6-10 \mu$.

Durch das ganze Gebiet verbreitet und überaus häufig, anf allen möglichen Substraten, häufig auch an lebenden Baumstämmen und mehr über dem Erdboden, unter der Bezeichnung Lohblüte als salbenartige Masse auf Gerberlohe.

Kosmopolitisch.

Die Äthalien dieser Art zeigen hinsichtlich ihrer Färbung eine überraschend große Variation, die auch darin ihren Ausdruck findet, da $B$ derartige Abänderungen entweder zum Range von Arten oder Varietäten erhoben worden sind. Wir können uns dieser Bewertung vorläufig nicht anschlieBen, sehen vielmehr in diesen Farbenvariationen individuelle Standortseinflüsse. So unterscheidet z. B. Rabenhorst 1. c. 253:

f. flava (Pers.): Plasmodium salbenartig, lebhaft gelb, Sporen sehr klein, braun.

f. vaporaria (Pers.): Äthalium schaumig körnig, lebhaft dottergelb, dann fast kirschbraunschwarz, Sporen ziemlich groB, violett, rundlich.

f. rufa (Pers.): Äthalium halbkugelig, rotbraun, häutig, mit Rinde, Sporen braunschwarz.

f. violacea (Pers.): mit gelber, bald schwindender Rinde, innen purpurviolett.

DaB mit derartigen Diagnosen heute nichts anzufangen ist, liegt anf der Hand; dies gilt auch in Bezug auf die Var. violascens Rönn in Schrift. Naturw. Ver. Schlesw.-Holst. XV (1911), 56. 
Macbride 1. c. $23 / 24$ und Torreud l. c. 142 halten an der Unterscheidung von $F$. septica und $F$. violacea fest; ersterer erblickt in letzterer eine eigene Art, Torrend subordiniert sie als Varietät der F. septica. Bei $F$. septica sollen die Sporen im durchfallenden Lichte blaßpurpurbraun, bei violacea violett sein (Macbride), ferner wäre bei septica der Hypothallus weiß oder gelblich, bei violacea dagegen violett (Torrend). Ich meinerseits halte es zurzeit noch mit Schröter und Lister und ziehe violacea zu septica.

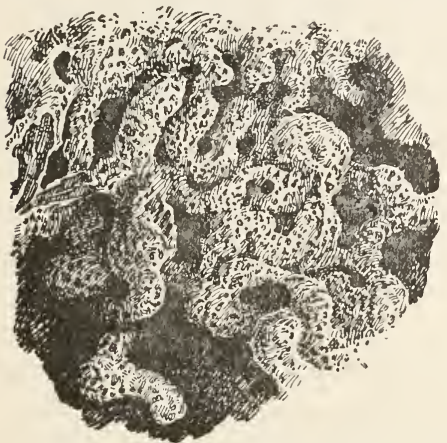

Fig. 58.

Fuligo septica (L.) Gmelin. Unberindetes, in Sporangien aufgelöstes Äthalium $\left({ }^{20} / 1\right)$. Nach Lister.

Was die Ausbildung der Rinde anbetrifft, so steht diese ganz sicher in Beziehung zur Luftfeuchtigkeit; an vor austrocknendem Luftzug geschützten Lokalitäten unterbleibt die Rindenbildung entweder ganz (Physarum cerebrinum Massee) oder doch nahezu vollständig.

Jahn stellt in Rönn, Die Myxomyceten des nordöstlichen Holsteins (1911), 56 1) eine Fuligo candida auf, die vielleicht der candida Persoon's entspricht und die er wie folgt charakterisiert: Plasmodium weiß, Capillitium mangelhaft ausgebildet, die Kalkknoten fehlen fast ganz, wenn vorhanden, weiB. Die Äthalien bestehen aus unregelmäßig gewundenen Fächern, deren Wände sehr dünn, durchscheinend bellgrau und matt irisierend sind. Sporen $7-10 \mu$, braunviolett, schwach warzig. Es wird auch in Bezug auf diese Funde noch abzuwarten sein, ob wir es wirklich mit einer von septica verschiedenen Art oder nur mit einer Standortsmodifikation zu tun haben.

Endlich sei noch einer von C. Engelke beobachteten aber nicht benannten Form aus Hannover gedacht (1. u. 2. Jahresber. d. niedersächsischen bot. Ver. zu Hannover (1910), bei der die Plasmodien außergewöhnlich klein und zu vielen über das Moos verteilt waren und dabei gar keine Neigung zeigten, sich zu einem größern Plasmodium zu vereinigen. Die Äthaliumfruchtform war klein, $2 \mathrm{~mm}$ lang, $1 \mathrm{~mm}$ breit, von dunkelgrüngelber Farbe und in der Form nicht unähnlich Wurmexcrementen.

$2^{*}$ A Athalien gelblichgrau. Kalkknoten zahlreich, nicht spindelförmig, orangegelb. Sporen $10-11 \mu$.

1) Schrift. Naturw. Ver. Schlesw.-Holst. XV (1911), Heft 1. 
2. F. muscorum Alb. et Schwein. Consp. Fung. (1805), 86, t. VII, fig. I; Macbride N. A. Slime-Moulds, 24; Torrend in Broteria VII, 142; Lister Monogr. ed. 2, 87, pl. 77, fig. a-c.

S ynonyme: Lignidium griseoflavum Link in Mag. Ges. Naturf. Fr. Berl. III (1809), 24.

Lignidium muscicola Fr. Symb. Gaster. (1817), 10.

Lignidium reniforme Fr. Symb. Gaster. (1817), 10?

Reticularia muscorum Fr. Syst. Hyc. III (1829), 91.

Physarum gyrosum Rost. Monogr. (1875), 111 pr. p.

Licea ochracea Peck in Rep. N. Y. Mus. Nat. Hist. XXVIII (1879), 55.

Fuligo ochracea Peck in Rep. N. Y. Mus. Nat. Hist. XXXI

(1879), 56; Massee Monogr., 342; Lister Monogr. ed 1, 67, pl. XXIV, A, fig. e-f und in Journ. of Bot. XXXIX, 84.

Fuligo simulans Karst. in Bidr. Kämn. Finl. Nat. XXXI (1879), 108. Exsikkaten: Fuckel Fungi rhen. 1474.

Jaap Myxom. exsice. 7.

Plasmodium aprikosengelb, durchscheinend. Äthalium polsterförmig oder kugelig, $2 \mathrm{~mm}$ bis $5 \mathrm{~cm}$ im Durchmesser, zerstreut, gebüschelt oder dachziegelartig gehäuft, nahezu glatt, gelbgrau oder \pm grau, auf orangefarbigem Hypothallus aufsitzend. Rinde

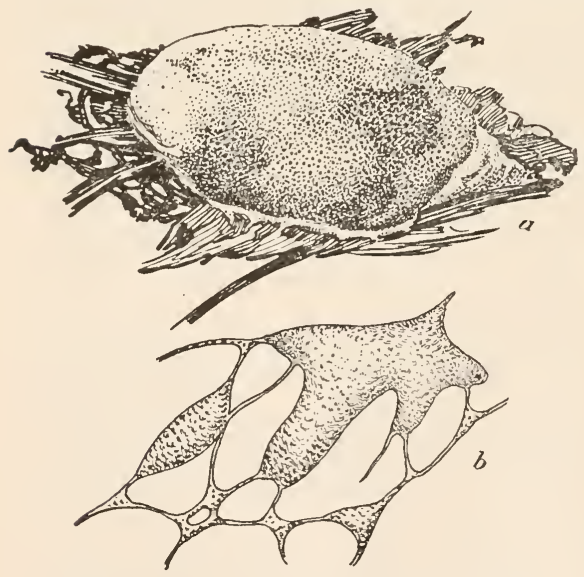

Fig. 59. Fuligo muscorum Alb. et Schwein.

a) Berindetes Äthalium (20/1); b) Capillitium mit Kalkknoten $\left({ }^{280} / 1\right)$. - Nach der Natur.

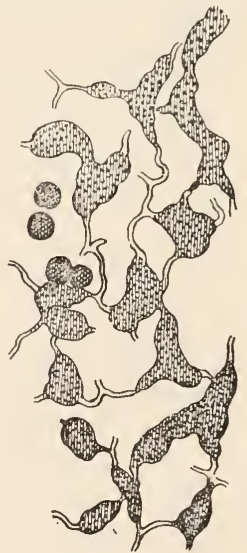

Fig. 60. Fuligo musc orum Alb. et Schwein. Capillitium mit Kalkknoten u. Sporen $\left({ }^{280 \%}{ }_{1}\right)$. Nach Lister. 
spärlich entwickelt oder sogar ganz fehlend. Sporangienwände mit zerstreuten, orangefarbigen Kalkeinlagerungen. Capillitium aus zahlreichen, häufig verzweigten, orangefarbigen Kalkknoten, die durch \pm kurze, hyaline Fäden verbunden sind, bestehend. Sporen fein stachelig, violettbraun im durchfallenden Lichte.

Deutschlaud, Schweiz.

Großbritannien, Schweden, Finnland, Cẹlon, N.-Amerika.

Namentlich in nassen Sommern häufig und damn mehr als handgroße Plasmodien bildend. Bleiben solche vor Luftzug und damit vor dem raschen Austrocknen geschützt, so werden mitunter anstatt der Äthalien einfache oder mannigfach verzweigte Plasmodiokarpien gebildet.

$2^{* *}$. Sporen entweder ellipsoidisch, $13-17 \times 8$ $12 \mu$ oder \pm kugelig und $9-12 \mu$. Äthalien und Kalkknotengan\% weib.

3. F. cinerea (Sch wein.) Morgan Myxom. Miami Valley (1896), 105; Lister Monogr. ed. 2, 88, pl. 75, fig. a-d.

Synonyme: Enteridium cinereum Schwein. in Trans. Am. Phil. Soc. n. s. IV (1832), 261.

Physarum ellipsosporum Rost. Monogr. App. (1875), 10; Massee Monogr., 310, fig. 214; Macbride N. A. Slime-Moulds, 27, pl. $\mathrm{X}$, fig. $3,3 \mathrm{a}, 3 \mathrm{~b}$.

Badhamia coadnata Rost. Monogr. (1875), 146; Massee Monogr., 325. Aethaliopsis stercoriformis Zo p f Pilztiere (1884), 150, fig. 26.

Fuligo stercoriformis Racib. in Hedw. XXVI (1887), III; Massee Monogr., 342.

Fuligo ellipsospora Lister Monogr. ed. I (1894), 67, pl. XXIV, B, fig. a-d, in Journ. of Bot. XXXVII, 148, t. 398, fig. 2, 3, XXXIX, 84, und XLII, 132.

Exsikkat: 0 . Jaap Myxom. exsice. 147.

Plasmodium milchweiß. Äthalium kissenförmig, verlängert, 4 bis $60 \mathrm{~mm}$ lang, einfach oder verzweigt, häufig gewunden, zerstreut oder gedrängt, die durcheinander gewobenen Sporangien meist von einer in den Hypothallus übergehenden, weißen, glatten, kalkführenden Rinde überkleidet. Die kalkhaltigen Sporangienwände sind in der Regel \pm wohlausgebildet, sodaß jedes Sporangium des Äthaliums in seinem Verlauf verfolgt werden kann. Kalkknoten mitunter zu einer Pseudocolumella zusammentretend, wie überhaupt das Capillitium infolge des Zurücktretens der Verbindungsfäden oft an das der Badhamia-Arten erinnert. Sporen bräunlichviolett, fein stachelig. 
Rindenlose, aus locker verbundenen Sporangien bestehende, weiße, ledergelbe, blaßrötliche oder braune Äthalien mit $9-12 \mu$ großen, häufig kugeligen Sporen, werden als var. ecorticata Lister (Monogr. ed. 2 [1911] 88, pl. 75, fig. a), bezeichnet.

Hannover, Mark Brandenburg, Galizien.

Großbritannien, Frankreich, Italien, Cevlon, N.-Amerika, Cuba.

1*. Äthalium polsterförmig, 15 bis $40 \mathrm{~cm}$ im Durchmesser, bedeckt von einer kalkreichen, dickschwammigen, weißen, oder gegen die Basis gelblichen Rinde. Sporangienwände weiß, kalkführend. Capillitium \pm spärlich entwickelt, Kalkknoten verzweigt, weiB. Columella fehlend. Sporen im ausgewachsenen Zustande kugelig oder etwas ellipsoidisch, dunkelpurpurbraun, dicht und grobwarzig, die Warzen mitunter in unregelmäBigen Linien ange ordnet, $15-20 \mu$.

4. F. megaspora St urgi in Colorado Coll. Publ. Gen. Ser. Nr. 68, sc. ser. XII (1913), 443.

N.-Amerika (Colorado), Afrika (Albert Eduard Nyanza).

Diese Art, deren Vorkommen in unserm Gebiete sicherlich nicht in den Bereich des Unmöglichen fällt, unterscheidet sich von $F$. septica und von F. muscorum durch die weiße Farbe der Kalkknoten und lie großen Sporen, von $F$. cinerea durch die schwammige Äthalium-Rinde und die auffallend größern und dunkler gefärbten sporen.

\section{Gattung Erionema Penzig}

Die Myxom. d. Flora v. Buitenzorg (1898), 36; Torrend in Broteria VI, 42, 58 und VII, 143; Lister Monogr. ed. 2, 89.

Fruchtkörper als lange, hängende, walzliche, einfache oder verzweigte Plasmodiokarpien oder Sporangien ausgebildet. Capillitium ein elastisches Netzwerk von mehrfacher Länge des Fruchtkörpers. Kalkknoten sehr spärlich.

Nur eine Art:

1. E. aureum Penzig Die Myxom. d. Flora v. Buitenzorg (1898), 37; Lister in Journ. of. Bot. XLII, 98, tab. 458 und Monogr. ed. 2, 89, pl. 73, fig. a-c; Torrend in Broteria VII, pl. VIII, fig 9, 10 . 


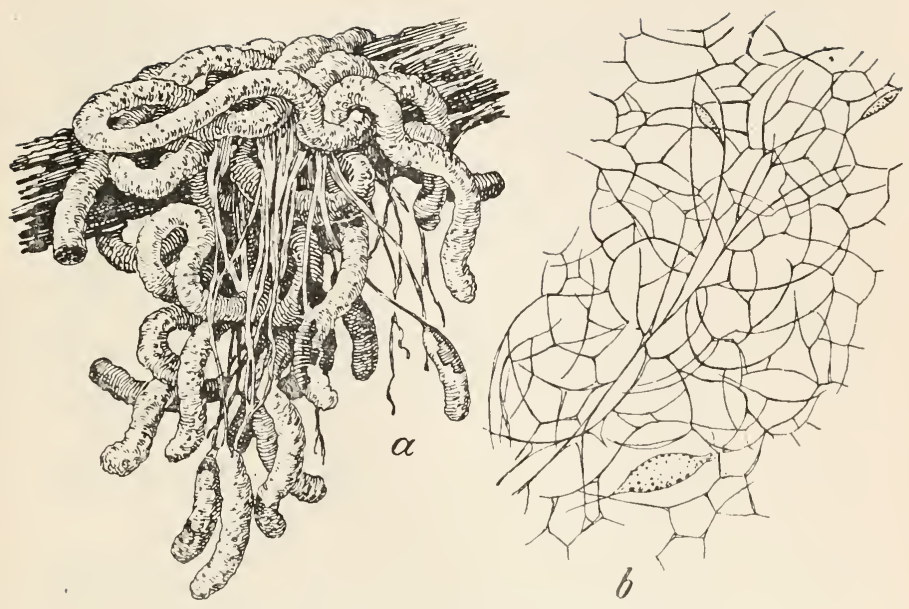

Fig. 61. Frionema aureum Penzig

a) Sporangienbüschel $(20 / 1)$; b) Capillitium mit Kalkknoten $\left({ }^{280} \%_{1}\right)$. Nach Lister.

Plasmodium farblos oder gelblich. Sporangien lang, walzlich, 0,2 bis $0,3 \mathrm{~mm}$ dick, zitronengelb oder grauolivenfarbig gesprenkelt und gelb gebändert, gehäuft oder an langen schlanken, gelben, einfachen oder verzweigten, in den Hypothallus ïbergehenden Stielen vom Substrat hängend oder an Stelle der Sporangien \pm wurmförmig gekrümmte, oft anastomosierende Plasmodiokarpien. Capillitium aus sehr zarten, farblosen, ein Netzwerk bildenden Fäden und gelben, spindelförmigen, spärlich vorkommenden Kalknoten bestehend. Zur Zeit der Sporenreife zerfällt das Sporangium und das sehr elastische Capillitium streckt sich nun in die Länge. Sporen im durchfallenden Lichte blaß bräunlichviolett, glatt oder sehr fein stachelig, 6-7 $\mu$.

Java, Japan.

\section{Gattung Trichamphora Jungh.}

Fl. Crypt. Jav. (1838), 12; Rost. Versuch (1873), 10 und Monogr., 137; Lister Monogr. ed. 1, 89 und ed. 2, 89; Torrend in Broteria VI, 42, 59 und VII, 144. 
Nur eine Art:

1. T. pezizoidea Jungh. Fl. Crypt. Jav. (1838), 12, t. 2, fig. 9; Lister Monogr. ed. I, 89, pl. XXXV, B, a-c, in Journ. of Bot. XXXIX, 85 und XLII, 132, Monogr. ed. 2, 90, pl. 72, fig. $\mathrm{a}-\mathrm{d}$; Torrend in Broteria VII, 144, pl. VII, fig. 13-15.

Synonyme: Didymium zeylanicum Berkeley et Broome in Hook. Journ. of Bot. VI (1854), 230.

Physarum macrocarpum Fuckel Symb. Myc. (1869), 343 non Ces. Trichamphora Fuckeliana Rost. in Fuckel Symb. Myc. 2. Nachtrag (1873), 71 und Rost. Monogr., 138.

Chondrioderma pezizoides Rost. Monogr. (1875), 424, fig. 122. Chondrioderma zeylanicum Rost. Monogr. App. (1876), 15.

Chondrioderma Muelleri Rost. Monogr. App. (1876), 15.

Chondrioderma Berkeleyanum Rost. Monogr. App. (1876), 16.

Badhamia Fuckeliana Rost. Monogr. App. (1876), 2; Massee Monogr., 321.

Didymium australe Massee in Grev. XVII (1888), 7.

Didymium parasiticum Sacc. et Syd. Syll. Fung. XIV (1899), 836.

Didymium pezizoideum Ma s ве

Physarum Muelleri Berkeley ap. Lister Monogr. ed. I (1894), 89. Exsikkaten: Fuckel Fung. rhen. 1458.

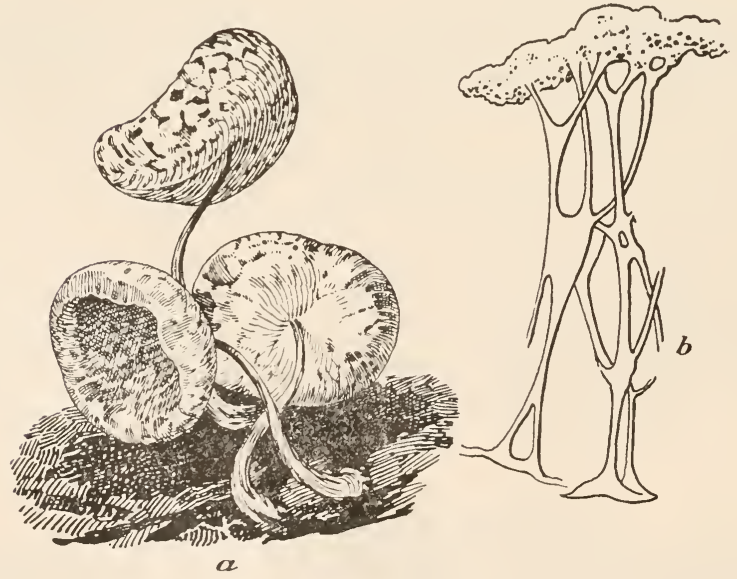

Fig. 62. T'richamphora pezizoidea Jungh.

a) Sporangiengruppe $(20 / 1)$; b) Capillitium $\left({ }^{980} / 1\right)$. - Nach Lister. 
Plasmodium grauweiß. Sporangien herdenweise, $1-2,5 \mathrm{~mm}$ hoch, gestielt, scheiben- oder schüsselförmig nach Art einer kleinen Peziza, aufrecht oder geneigt, 0,8 bis $1,3 \mathrm{~mm}$ breit und 0,2 bis $0,3 \mathrm{~mm}$ dick, grauweiß. Peridie kalkführend, zur Zeit der Sporenreife felderartig aufreißend. Stiel schlank, pfriemlich, längsgestreift, durchsichtig, rötlich braun. Capillitium entweder Badhamia-artig aus häutigen, kalkerfüllten Schläuchen bestehend oder ein Netzwerk farbloser, mit ihren verbreiterten Enden an der Peridie befestigter und an den Verzweigungsstellen gleicherweise verbreiterter Fäden mit oder ohne spindelförmige Kalkknoten. Sporen im durchfallenden Lichte dunkel- oder blaß purpurbraun, fein- oder grob stachelig oder nahezu glatt, $9-17 \mu$.

Dentschland, Österreich.

Frankreich, Schweden, O.-, W.-, S.-0.-, S.-Afrika, Madagascar, Malay. Archipel, Australien, Philippinen, Tahiti, Brasilien, Bolivien.

Hat einige Ähnlichkeit mit Physarum javanicum, doch sind bei diesem die Stiele auffallend heller und oft spiralig gedreht, die Sporen heller und meist anch kleiner.

\section{Gattung Physarella Peck}

in Bull. Torrey Bot. Club IX (1882), 61; Lister Monogr. ed. 1, 68 und Monogr. ed. 2, 91; Schröter in Engler und Prantl Natürl. Pflanzenfam. I, 33; Macbride N. A. Slime-Moulds, 71; Torrend in Broteria VI, 42, 54 und VII, 112.

Nur eine Art:

P. oblonga (Berkeley et Curtis) Morgan Myx. Miami Valley (1896), 79; Macbride N. A. Slime-Moulds, 71, pl. VIII, fig. $4,4 \mathrm{a}, 4 \mathrm{~b}, 4 \mathrm{c}, \mathrm{pl}$. XVI, fig. I; Torrend in Broteria VII, 112, pl. VII, fig. I, pl. IX, fig. 12, 12a; Lister Monogr. ed. 2, 91, pl. 71 , fig. $a-d$.

Synonyme: Trichamphora oblonga Berkeley et Curtis in Grev. II (1873), 66.

Physarum rufibasis, Berkeley et Broome in Journ. Linn. Soc. XIV (1873), 85.

Chondrioderma inflatum Rost. Monogr. (1875), 425.

Tilmadoche oblonga Rost. Monogr. App. (1876), 13; Massee Monogr., 334.

Schinz, Myxogasteres (Rabenhorst Krypt. Flora I, Pilze Abt. X). 
Tilmadoche hians Rost. Monogr. App. (1876), 14.

Physarella mirabilis Peck in Bull. Torrey Bot. Club IX (1882),

61, pl. 24, fig. 1-6; Lister Monogr. ed. 1, 68, pl. XXV, B, fig. a-c.

Tilmadoche minuta Berl, in Sacc. Syll. VII (1888), 361.

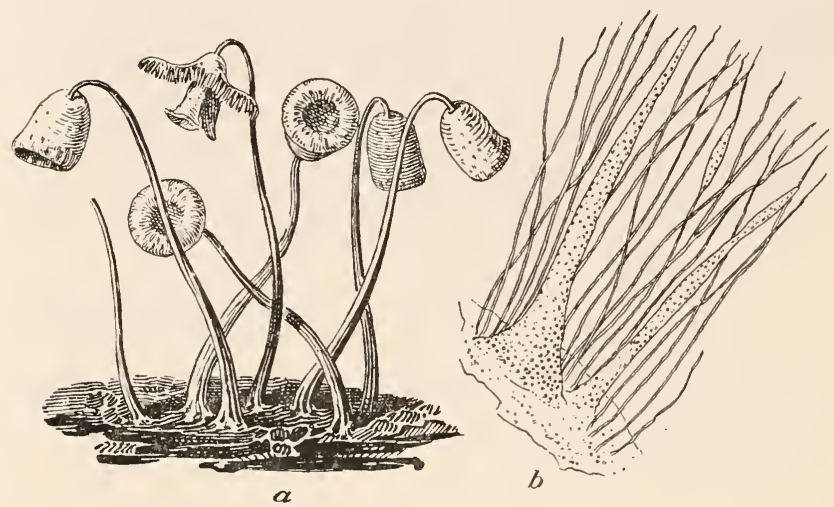

Fig. 63. Physarella oblonga (Berkeley et Curtis) Morgan.

a) Sporaugiengrup ${ }^{\prime}$ ( $(5 / 1)$; b) Capillitium mit Kalliknoten und 2 kalkfülnrenden, dormartigen Fortsätzen $(260 / 1)$. - Nach Lister.

Plasmodium gelb. Sporangien lang gestielt, samt Stiel 2 bis $3 \mathrm{~mm}$ hoch, nickend, kurz zylindrisch, 0,8 mm lang und 0,6 mm breit, oben nabelartig eingestoBen, $a b$ und zu bei anomaler Entwicklung anstatt nickend aufrecht oder an Stelle von Sporangien Plasmodiokarpien, grünlich oder rötlichgelb. Peridie mit gelben Kalkeinlagerungen, zur Zeit der Sporenreife in sternförmig abstehende oder zurückgerollte Lappen aufreißend, der eingestoßene Nabel als hohle, orangegelbe Columella stehenbleibend. Stiel am Grunde meist dicker als oberwärts, gestreift, rotbraun, durchscheinend. Capillitiumfäden blaßgelb, gabelig verzweigt, nicht anastomosierend, mit wenigen, kleinen, spindelförmigen, gelben Kalkknoten und gelben oder orangefarbigen, 0,2 mm langen und $20 \mu$ dicken, spitzen, von der äußern Peridieschicht zur Columellawand reichenden, kalkbeladenen Dornfortsätzen. In Plasmodiokarpien mitunter ein Netzwerk anastomosierender gelblicher Fäden 
mit großen, unregelmäßigen Kalkknoten, aber ohne Dornfortsätze. Sporen violett braun, kugelig, fast ganz glatt, $6-8 \mu$.

Portugal (?), N.-, Central- und S.-Amerika, Westindien, Aquatorialafrika, Ceylon, Malay. Arehipel, Philippinen.

T'orrend in Bull. Soc. Port. Se. Nat. (1908), 66 und in Broteria VII, 113, pl. IX, fig. 12 und 12 a, beschreibt eine $P$. lusitanica Torrend, die in der Folge von Frl. G. Lister zu $P$. oblonga gezogen worden ist. Bei dieser Form sind die Sporangien manchmal nahezu kugelig und entbehren des vertieften Nabels, sie springen anch unregelmäßig und nicht in sternförmig abstehende Lappen auf. Das Capillitium besteht aus einem Netzwerk gelber Fäden mit wenigen oder zahlreichen Kalkknoten. Weitere Untersuchungen werden zeigen, ob wir es hier mit einer zweiten Art oder nur mit einer Form unserer $P$. oblonga zu tun haben.

\section{Gattung Cienkowskia Rost.}

Versuch Syst. Myc. (1873), 9 und Monogr. 91; Schröter in Cohn Krypt.-Fl. Schles. III, 1, 131 und in Engler und Prantl Natürl. Pflanzenfam. I, 33; Massee Monogr., 337; Lister Monogr. ed. 1, 68, ed. 2, 92; Macbride N. A. Slime-Moulds, 79; Schinz in Mitt. Naturw. Ges. Winterthur VI, 43; Torrend in Broteria VI, 42, 54 und VII, 110.

Fruchtkörper als wurmförmige, netzartige Plasmodiokarpien ausgebildet, mit unregelmäßig aufreißender, dünner, spröder Peridie, letztere mit Ausnahme der an ihr befestigten Kalkplatten des Capillitiums kalkfrei. Capillitium ein lockeres Netzwerk starrer, gelber Fäden mit zahlreichen freien, hakig gekrümmten, spitzen Astenden, außerdem große, gelbe, durchlöcherte Kalkplatten, die mit ihren Rändern an der Peridie befestigt sind, sodaß der geöfnete Fruchtkörper wie gekammert aussieht.

\section{Nur eine Art:}

C. reticulata (Alb. et Schwein.) Rost. Monogr. (1875), 91; Schröter in Cohn Krypt.-Fl. Schles. III, 1, 131; Massee Monogr., 337, fig. 266, 267; Lister Monogr. ed. 1, 68, pl. XXV, A, fig. a-d und ed. 2, 93, pl. 70, fig. a-d; Macbride N. A. SlimeMoulds, 80, pl. XIV, fig. 2, 2a, 2b; Schinz in Mitt. Naturw. Ges. Winterthur VI, 43; Torrent in Broteria VII, 110, pl. VIII, fig. $18,19,23$ und pl. IX, fig. 50 . 
Synonyme: Physarum reticulatum Alb. et Schwein. Consp. Fung. (1805), 90.

Diderma retienlatum Fr. Syst. Hyc. 111 (1829), 112; Rabenhorst Deutschl. Krypt.-Fl. I, 281.

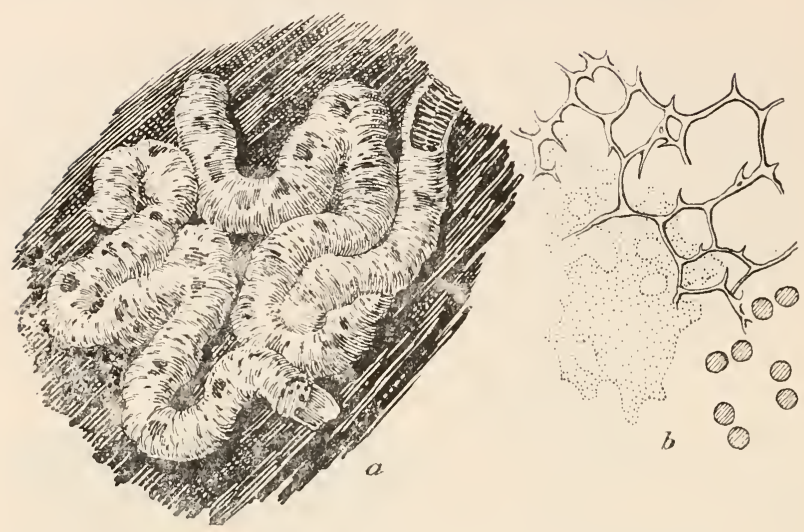

Fig. 64. Cienkowskia reticulata (Alb. et Schwein.) Rost. a) Plasmodiokarp $(15 / 1)$; b) Capillitium mit durchlöcherter Kalkplatte $\left({ }^{260} / 1\right)$. Nach Lister.

Plasmodium tieforangerot. Plasmodiokarpien wurmförmig hin und her gebogen, gewöhnlich verzweigt und anastomosierend, oft handgroße Flächen bedeckend, $0,5 \mathrm{~mm}$ breit, gelbbraun oder orangefarbig, mit blassen Querstreifen, rotgefleckt. Columella O. Capillitiumfäden starr, gelb, die Enden der Verzweigungen scharfspit\%ig und meist hakig gekrümmt. Kalkplatten quer zur Längsachse des Fruchtkörpers gestellt, durchlöchert, blaßgelb und verbunden mittelst breiter oder schmaler Verbindungsstïcke mit der Peridie, ab und zu kommen auch vereinzelte Kalkknoten vor. Sporenmasse pechschwarz; Sporen im durchfallenden Lichte hellviolettbraun, sehr fein stachelig, 9-11 $\mu$.

Dentschland, Schweiz; seheint selten zu sein.

Großbritamien, Frankreich, Portugal, Ceylon, Java, N.-Amerika.

Kömnte ev. mit Physarum Serpula verwechselt werden, für C. reticulata sind indessen die vertikal gestellten Kalkplatten und ist die Farbe der Plasmodiokarpien charakteristisch. 


\section{Gattung Craterium Trentepohl}

in Roth Cat. Bot. II (1797), 224; Rost. Vers. Syst. Myc. (1873), 10 und Monogr., 118; Schröter in Cohn Krypt.-Fl. Schles. III, 1, 126 und in Engler und Prantl Natürl. Pflanzenfam. I, 33; Čelak. Myxom. Böhmens, 7т; Massee Monogr., 262; Lister Monogr. ed. I, 69 und ed. 2, 93; Macbride N. A. Slime-Moulds, 73; Schinz in Mitt. Naturw. Ges. Winterthur VI, 46 ; Torrend in Broteria VI, 46, 54 und VII, 115.

Sporangien gestielt, entweder becherförmig mit einem papierartigen Deckel oder eines solchen entbehrend und dann \pm kugelig oder verkehrteiförmig. Peridie kalkhaltig, aus 2 oder sogar 3 Schichten bestehend. Der basale Teil der Sporangienwand \pm knorpelig und bleibend. Kalkknoten des Capillitiums oft zu einer Art von Pseudocolumella zusammenfließend.

1. Sporangien mit glatter, glänzender Peridie und a usgesprochenem Deckel.

2. Kalkknoten des Capillitiums weiB.

1. C. minutum (Leers) Fr. Syst. Myc. III (1829), 151; Rabenhorst Deutschl. Krypt.-Fl. I, 271; Rost. Monogr. 120; Schröter in Cohn Krypt.-FI. Schles. III, 1, 127, Čelak. Myxom. Böhmens, 78; Macbride N. A. Slime-Moulds, 78, pl. XV, fig. 5; Schinz in Mitt. Naturw. Ges. Winterthur VI, 46; Torrend in Broteria VII, 115; Lister Monogr. ed. 2, 94, pl. 78, fig. a-e.

Synouyme: Peziza minuta Leers Fl. Herbern. (1775), 277.

Cyathus minutus Hoffm. Veg. Crypt. (1790), 6, t. II fig. 2.

Sphærocarpus turbinatus Bull. Champ. (1791), 132, t. 484, fig. 1. Craterium pedunculatum Trentep. in Roth Cat. Bot. I (1797), 224; Rabeuh. Deutschl. Krypt.,-Fl. I, 271; Lister Monogr. ed. 1, 70, pl. XXVI, A, fig. a-c.

Sphærocarpa operculata Schum. Enum. PI. Saell. II (1803), 220. Physarum turbinatum Schum. Enum. Pl. Saell. II (1803), 205.

Trichia turbinata DC. Fl. Franç. II (1805), 252.

Craterium vulgare Ditm. in Sturm Deutschl. Fl., Pilze I (1813), 17 , t. 9.

Craterium pyriforme Ditm. 1. c., 19, t. 10.

Craterium turbinatum Fr. Syst. Myc. III (1829), 152.

Craterium Oerstedtii Rost. Monogr. (1875), 120.

Craterium Friesii Rost. 1. c., 122.

Craterium confusum Massee Monogr. (1892), 263, fig. 289. 
Craterium minutum Fr. var. pyriforme Čelak. und campanulatum C̉elak. Myxom. Böhmens (1893), 78.

Exsikkaten: Fuckel Fungi rhen. 1453 (?), 1454.

Sydow Myc. March. 489.

O. Jaap Myxom. exsice. 25.

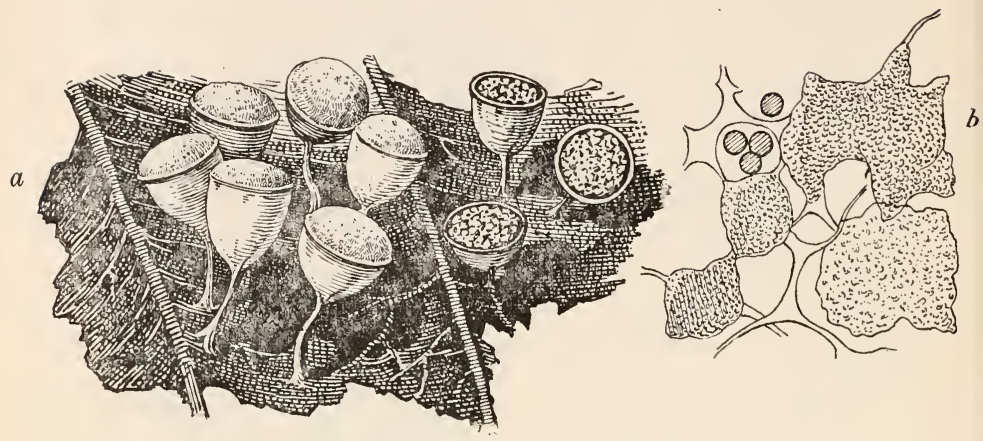

Fig. 65. Craterium minutum (Leers) Fr.

a) Sporangien, z. Teil geöffuet $(2 \%)$; b) Capillitium mit großen Kalkknoten; rechts unten ein Stück der Peridie $\left({ }^{280} / \mathbf{1}\right)$. - Nach Lister.

Plasmodium lebhaft gelb. Sporangien herdenweise, samt Stiel $(0,3-0,5 \mathrm{~mm})$ bis $11 / 2 \mathrm{~mm}$ hoch, becherförmig, aufrecht, mit erweitertem Schlund oder fast glockenförmig, blaß ockerfarbig, nuß- oder olivenbraun; Deckel gewölbt oder flach, mitunter etwas einwärts gedrückt, entweder von der Farbe der übrigen Sporangienwand oder etwas blasser. Peridie zweischichtig, äußere Schicht am Kelchrand etwas verdickt, innere reich mit weißen Kalkkörnchen beladen. Stiel gefältelt, dunkelbraun, orangebraun oder gelblich. Capillitiumfäden weiß oder gelb, Kalkknoten groß und weiß, mitunter zu einer Pseudocolumella zusammenfließend. Sporen im durchfallenden Lichte violettbraun, 8-9 $\mu$.

Deutschland (verbreitet), Schweiz (selten), Österreich (anscheinend auch selten).

Kosmopolitisch.

2. Kalkknoten braun. Sporangien zerstreut, samt Stiel $(0,1-0,2 \mathrm{~mm}) 0,5-0,7 \mathrm{~mm}$ hoch, breit trichterförmig oder \pm kelchförmig, 
glattwandig, rosenrot oder olivenbraun, häufig oberwärts etwas blasser, mit wohlausgebildetem, auswärts gekrümm tem Deckel. Stiel tdunkelbraun, längs gerippt. Columella O. Kalkknoten zahlreich, eckig oder abgerundet, mit verzweigten, kurzen, zarten Verbindungsfäden. Sporen im durchfallenden Lichte purpurbraun, fein warzig, $8-9 \mu$.

2. C. concinnum Rex in Proc. Acad. Nat. Sc. Philadelphia (1893), 370; Lister Monogr. ed. 1, 71, pl. XXVI, B, fig. a-d und ed. 2, 95, pl. 79, fig, a-d; Macbride N. A. Slime-Moulds, 78.

N.-Amerika, Japan (?).

1*. Sporangiumwand mehlig bestäubt, oft hö ckerig. Deckel wenig ausgeprägt.

3. Sporangien violett, herdenweise, zy lindrisch oder kelchförmig, oberwärts konvex auswärts gewölbt, aufrecht, gestielt, $0,7-0,8 \mathrm{~mm}$ lang und $0,3-0,6 \mathrm{~mm}$ breit, höckerig, oft geadert. Zur Zeit der Sporenreife fällt der obere Teil der Sporangiumwand bei unregelmäbig verlaufender Riblinie ab. Kalk zur Hauptsache gehäuft in Taschen der Sporangiumwand, wodurch die Aderung der Peridie bedingt wird. Kalkknoten unter sich durch blabviolette Fäden verbunden, grob, violett, in der Mitte zu einer in manchen Fällen dem Stiel aufitzenden Columella zusammenfliebend. Sporen violett, fast glatt, $7-9 \mu$.

3. C. paraguayense (Spegazz.) Lister Monogr. ed. 2 (1911), 95, pl. 80, fig. a-f.

Synonyme: Didymium paraguayense Spegazz. in Anal. Soc. Cient. Argent. XXII (1886), I86; Massee Monogr., 250. 
Didymium guarapiense Spegazz. 1. c. XXVI (1888), 60.

Craterium rubescens Rex in Proc. Acad. Nat. Sc. Phil. (1893), 370; Lister Monogr. ed. 1, pl. XXVII, A, fig. a-c; Macbride N. A. Slime-Moulds, 75 .

Iocraterium rubescens Jahn in Hedw. XLIII (1904), 302, fig. 1, $\mathrm{A}-\mathrm{E}$.

Iocraterium paraguayense Torrend in Broteria VII (1908), 114, pl. VII, fig. 4, 18 a.

N.-Amerika (Luisiana), S.-Amerika.

Die Art scheint eine echte, dem Stiel aufsitzende Columella zu besitzen, was Jahn veranlaßt hat, hierfür eine besondere Gattung aufzustellen. Nach Lister soll dieses Merkmal aber keinen konstanten Charakter besitzen und wir belassen daher, mit Lister, diese Art vorläufig noch in der Gattung Craterium.

3*. Sporangien braun, oberwärts mehlig bestäubt.

4. C. leucocephalum (Pers.) Ditm. in Sturm Deutschl. Fl., Pilze (1813), 21, t. 11; Rost. Monogr., 123; Schröter in Cohn Krypt.-Fl. Schles., III, 1, 127; Čelak. Myxom. Böhmens, 79; Lister Monogr. ed. 1, 72, pl. XXVII, B, fig. a-l und ed. 2, 96, pl. 82, fig. a, b, e, f; Macbride N. A. Slime-Moulds, 76, pl. VIII, fig. 5; Schinz in Mitt. Naturw. Ges. Winterthur VI, 47; Torrend in Broteria VII, 116.

Synonyme: Peziza convivale Batseh Elench. Fung. (1783), 121 ? Stemonitis leucocephala Pers. in Gmelin Syst. Nat. II (1791). 1467.

Arcyria leucocephala $\mathrm{H}$ offm. Fl. Crypt. Germ. (1795), t. 6. Physarum leucostictum Chevall. Fl. Paris, I (1826), 336 ? Physarum xanthopus Wallr. Fl. Crypt. Germ. II (1833), 358. Cupularia leucocephala Link Handb. III (1833), 421; Rabenh. Deutschl. Krypt.-Fl. I, 270.

Craterium xanthopus Wallr. Fl. Crypt. Germ. II (1833), 358. Craterium deoperculatum Fr. in Weinm. Hymen. et Gaster. (1836), 597.

Cupularia xanthopus Rabenhorst Deutschl. Krypt.-Fl. I (1844), 271.

Craterium pruinosum Corda Ic. VI (1854), 13, t. II, fig. 33.

Craterium Fuckelii Massee Monogr. (1892), 272.

Craterium leucocephalum D itm. var. genuinum Ċelak. und inclusum Ċelak. Myxom. Böhmeus (1893), 79.

Craterium convivale Morgan. Myxom. Miami (1896), 86. 
Exsikkaten: Fuckel Fungi rhen. 1452.

Rabeuhorst - Winter Fung. eur. 2674.

Sydow Myc. March. 1500.

0. Jaap. Myxom. exsice. 87.

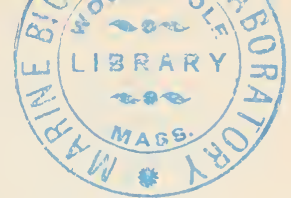

Plasmodium gelb. Sporangien herdenweise, gestielt, samt Stiel (dieser $0,3-0,5 \mathrm{~mm}$ ) bis $1 \mathrm{~mm}$ hoch, aufrecht, kurz walzlich oder eiförmig, $0,4-0,6 \mathrm{~mm}$ breit, rotbraun mit weißen Kalkinkrustationen und im obern Teil häufig mit kleinen, gelben Warzen besetzt und dem entsprechend gefleckt. Deckel weib, auswärts gewölbt, mitunter auch fehlend (var. scyphoides). Stiel rotbraun, durchscheinend. Kalkknoten groß, unregelmäßig gestaltet, weiß oder gelblich, mitunter zu einer Pseudocolumella zusammenfließend, sonst durch gelbliche, verzweigte, an den Verzweigungsstellen verbreiterte Fäden verbunden. Sporenmasse schwarz; Sporen im durchfallenden Lichte violettbraun, fein stachelig, $7-9 \mu$.

Deutschland, Schweiz, Österreich; scheint nirgends im Gebiet häufig zu sein.

Großbritamnien, Frankreich, Portugal, Italien, Belgien, Dänemark, Schweden, N.- und S.-Amerika, Antigua.

Lister nnterscheidet zwei Varietäten, von denen bis zur Stunde erst die zweite in Europa und zwar im schweizer-Jura nachgewiesen werden konnte.

var. cylindricum (M a s see) Lister Monogr. ed. 2 (1911), 97, pl. 82 fig. c.

Synonyme: Craterium minimum Berkeley et Curtis in Grev. II (1873), 67; Massee Monogr., 272; Macbride N. A. Slime-Moulds, 77, pl. XVI, fig. 6; Torrend in Broteria VII, 116, pl. VIII, fig. 8 .

Craterium cylindricum Massee Monogr., 268, fig. 213.

Sporangien \pm cylindrisch, nahezu ganz weiß, am Grunde rötlichbraun, durch eimen Kreisriß sich öffnend, die Kalkknoten zusammenfließend.

Ceylon, Java, Japan, N.- und S.-Amerika.

var. scyphoides (Cooke et Balf.) Lister Monogr. ed. 2 (1911), 97, pl. 82, fig. d.

Synonym: Physarum scyphoides Cooke et Balf. ap. Massee in Journ. Myc. V (1889), 186, t. 14, fig. 7 et Monogr., 282, fig. 231. 
Sporangien kreiselförmig, Peridie häutig und oberwärts grau, am Grunde rot, unregelmäßig, ohne Deckel sich öffnend, unregelmäßig aufreißend.

Schweiz (Jura).

N.-Amerika, Galapagos Inseln.

$3^{* *}$. Sporangien leuchtend gelb.

5. C. aureum (Schum.) Rost. Monogr. (1875), 124; Schröter in Cohn Krypt.-Fl. Schles. Ill, 1, 127; Massee Monogr., 269, fig. 257-261; Macbride N. A. Slime-Moulds, 73 ; Lister Monogr. ed. 2, 97, pl. 67, fig. a-c.

Synonyme: Trichia aurea Schum. Enum. Pl. Saell. II (1803), 207. Craterium mutabile Fr. Syst. Myc. III (1829), 154; Wallr. Fl. Crypt. Germ. III, 357; Lister Monogr. ed. I, 73, pl. XXVIII, A, fig. a-f; Torrend in Broteria VIl, 117.

Cupularia mutabilis Rabenhorst Deutschl. Krypt.-Fl. I (1814), 271.

Exsikkat: Fuckel Fungi rhen. 1455.

Plasmodium zitronengelb. Sporangien herdenweise, gestielt, aufrecht, kugelig, verkehrteiförmig oder eiförmig, höckerig, goldgelb oder grünlich und zwar gewöhnlich oberwärts etwas intensiver gefärbt, weißlich verblassend, unregelmäßig ohne eigentlichen Deckel aufreißend, mitunter in sternförmig abstehende Lappen einreißend. Stiel zylindrisch, 0,2 bis $0,5 \mathrm{~mm}$ hoch, kräftig, nach unten sich verbreiternd, tief längs gefurcht, von gelber, rotgelber oder braungelber bis braunroter Farbe, kalkführend. Kalkknoten gelb, unregelmäßig, mitunter zusammenfließend, Verbindungsfäden in den Verzweigungsstellen verbreitert. Sporen im durchfallenden Lichte violettbraun, sehr fein stachelig oder warzig, $8-10 \mu$.

\section{Deutschland.}

Großbritannien, Frankreich, Portugal, Schweden, Rußland, N.-Afrika, Java, Ceylon, Japan, N.-Amerika.

\section{Gattung Leocarpus Link em. Rost.}

Link in Mag. Ges. Nat. Fr. Berl. III (1809), 25; Rostafinski in Vers. Syst. Myc. (1873), 11 et Monogr., 132 ; Rabenhorst Deutschl. Krypt.- 
Fl. I, 284; Schröter in Cohn Krypt.-Fl. Schles. III, 1, 126 und in Engler und Prantl Natürl. Pflanzenfam. I, 33; Massee Monogr., 338; C̉elak. Myxom. Böhm., 77; Lister Monogr. ed. 1, 75 et ed. 2, 98; Schinz in Mitt. Naturw. Ges. Winterthur VI, 47; Macbride N. A. Slime-Moulds 80; Torrend in Broteria VI, 54, VII, 111.

Nur eine Art umfassend:

L. fragilis (Dickson) Rost. Monogr. (1875), 132, fig. 93; Schröter in Cohn Krypt.-Fl. Schles. III, 1, 126; Massee Monogr., 338, fig. 187-189; Macbride N. A. Slime-Moulds, 81; Torrend in Broteria VII, 111; Lister Monogr. ed. 2, 98, pl. 81. fig. a-c.

Synonyme: Lycoperdon fragile Dickson Pl. Crypt. Brit. I (1785), 25 , t. III.

Diderma vernicosum Pers. in Usteri Ann. Bot. XV (1795), 34. Trichia lutea Trentep. in Roth Cat. Bot. I (1797), 230.

Physarum nitidum Schum. Enum. Pl. Saell. II (1803), 205.

Physarum vernicosum Schum. l. c. (1803), 206.

Leocarpus vernicosus Link in Mag. Ges. Nat. Fr. Berl. III (1809), 25; Rabenhorst Deutschl. Krypt.-Fl. I (1884), 284; Lister Monogr. ed. 1, 75, pl. XXIX, A, fig. a-c; Člak. Myxom. Böhm., 77; Schinz in Mitt. Naturw. Ges. Winterthur VI, 47. Leocarpus spermoides Link 1. c. (1809), 25; Rabenh. Deutschl. Krypt.-Fl. I, 284.

Leocarpus atrovirens Fr. Symb. Gast. (1817), 13.

Leangium atrovirens F r. Stirp. Femsion. (18:7), 83.

Leangium vernicosum Fr. 1. c. (1827), 83.

Diderma atrovirens Fr. Syst. Myc. III (1829), 103.

Tripotrichia elegans Corda Icon. Fung. I (1837), 22, t. IV, fig. $288 \mathrm{~A}$.

Leocarpus ramosus Fr. Summ. Veg. Scand. (1849), 450.

Exsikkaten: Fuckel Fungi rhen. 1465.

Sydow Myc. March. 1297.

O. Jaap Myxom. exsice. 8, 66, 88, 103.

Plasmodium zitronengelb. Sporangien herdenweise, entweder einzeln und kurz gestielt oder sitzend oder zu mehreren gebüschelt, \pm kugelig oder häufiger verkehrteiförmig, 2-4 $\mathrm{mm}$ lang, gelbbraun, kastanienbraun oder purpurbraun, glänzend und wie lackiert aussehend, sehr spröde, zur Zeit der Sporenreife entweder unregelmäßig oder in sternförmig sich zurückrollende 


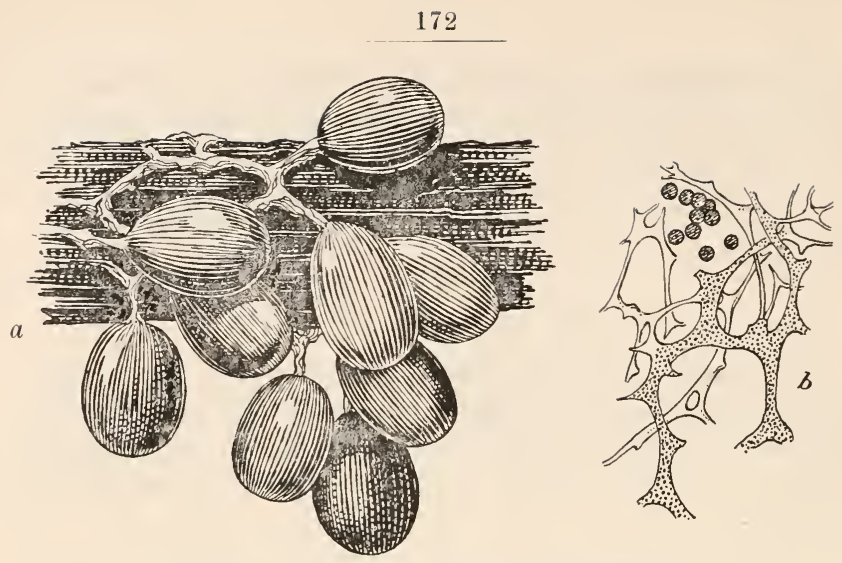

Fig. 66. Leocarpus fragilis (Dickson) Rost.

a) Sporangienbüschel $\left({ }^{10 / 1}\right)$; b) Capillitium mit Kalkknoten $(29 \%)$.

Nach Lister.

Lappen aufreißend. Stiel fädlich, schwach, gelblich, einem \pm strähnigen Hypothallus entspringend. Äußere Peridieschicht innenseits mit reichlicher Kalkablagerung. Columella fehlend. Das an der innern Peridieschicht befestigte Capillitium aus einem Netzwerk hyaliner, verzweigter, in den Maschenwinkeln verbreiterter und abgeflachter Fäden und aus verzweigten, 土 schmalen, braungelben Kalkknoten bestehend. Sporen im durchfallenden Lichte dunkel- oder violettbraun, stachelig, 11-14 $\mu$, mitunter gehäuft.

Deutschland, Schweiz, Österreich.

Kosmopolitisch.

Nicht selten in Nadelwäldern; die Sporangien mitunter in überraschend großer Zahl, wie Insekteneier aussehend. Meylan (Bull. Soc. Vaud. Sc. nat. XLIV (1908), 289) unterscheidet eine f. lignicola Meylan, mit tiefbraunen, sitzenden und dicht gedrängten Sporangien (Schweizer-Jura).

\section{Gattung Diderma Persoon}

in Römer N. Mag. Bot. I (1794), 89; Fr. Syst. Myc. III, 96, pr. p.; Wallr. Fl. Crypt. Germ. IV. 370, pr. p.; Rabenh. Deutschl. 
Krypt.-Fl. 1, 281; Macbride N. A. Slime-Moulds, 92; Lister Monogr. ed. 2, 99. - Chondrioderma Rost. Vers. Syst. Myc. (1873), 13; Schröter in Cohn Krypt.-Fl. Schles. III, 1, 123 und in Engler und Prantl. Natürl. Pflanzenfam. I, 31 pr. p.; Čelak. Myxom. Böhm. 64; Massee Monogr., 197; Lister Monogr. ed. 1, 75; Schinz in Mitt. Naturw. Ges. Winterthur VI, 48; Torrend in Broteria VI, 52, VII, 99, VIII, 15. - Leangium Link in Mag. Ges. Nat. Fr. Berl. III (1809), 26; Rost. Vers., Syst. Myc. 12; Rabenhorst Deutschl. Krypt.-Fl. I, 284.

Sporangien gestielt oder ungestielt oder an deren Stelle Plasmodiokarpien. Peridie in der Regel zweischichtig (einfach bei $D$. simplex ?), mit Kalkgranulationen (bei $D$. Trevelyani mit Kalkkristallen). Columella meist vorhanden. Capillitium ohne Kalkknoten, aus einfachen oder verzweigten, oft stellenweise knotig verdickten Fäden bestehend.

Wie bereits Macbride (1. c. 93) ausgeführt hat, hat Rostafinski ohne zwingenden Grund den Persoon'schen Namen Diderma ersetzt durch Chondrioderma, von der Annahme ausgehend, daß Persoon's Epitheton nur Anwendung finden dürfe auf solche Arten, deren Peridie zweischichtig ist. Einerseits frägt es sich nun aber, ob überhaupt Diderma-Arten vorkommen mit einfacher Peridie und anderseits würde Persoon's Diagnose der Gattung Diderma solche gar nicht ausschließen.

Die Arten der Gattumg Diderma sind in der Regel leicht daran zu erkemnen, daß von den beiden Wandschichten sich die änßere kalkreiche und daher \pm eiersehalenartige und brïchige von der imıern häutigen abhebt.

1. $\ddot{A} u B$ ere Peridieschicht mit kompakter, \pm eierschalenartiger Kalkkruste (einfach bei $D$. simplex?), vergl. a uch $D$. radiatum.

\section{Untergattung Eudiderma Lister}

Monogr. ed. 2 (1911), 99. (Subgenus Euchondrioderma Lister Monogr. ed. 1 (1894), 76.)

2. Sporen mit vollständiger, netzartiger Skulptur. Sporangien gehäuft, \pm kugelig oder halbkugelig, ungestielt, 0,3 bis $0,5 \mathrm{~mm}$ im Durchmesser, schneewei $B$, auf wohlent- 
wickeltem Hypothallus. Sporangiumwand aus einer brüchigen äuBern Kalkkruste und einer zarthäutigen innern Schicht bestehend. Capillitiumfäden rötlich, spärlich verzweigt, in der Nähe der Enden mittels kurzer, bandartiger Brücken an astomosierend. Sporen $10-12 \mu$, im durchfallenden Lichte violettbraun, mit unterbrochenem, $2 \mu$ breitem $R$ and versehen.

1. D. subdictyospermum (Rost.) Lister Monogr. ed. 2 (1911), 101, pl. 87, fig. d-f.

Synonyme: Chondrioderma subdictyospermum Rost. Monogr. App. (1876), 16; Lister Monogr. ed. 1, 77, pl. XXX, B, fig. d-g; Torrend in Broteria VII, 101.

Chondrioderma dealbatum Massee Monogr. (1892), 207.

Didymium dealbatum Berkeley et Curtis ap. Rost. Monogr. App. $(1876), " 16$.

S.-Afrika, Java, S.-Amerika.

$2^{*}$. Sporen nicht mit netzartiger Skulptur.

3. Sporangien weiß.

4. Sporangien scheibenförmig, meist gestielt.

2. D. hemispharicum (Bull.) H o rnem. Fl. Dan. fasc. XXXIII (1829), 13; Macbride N. A. Slime-Moulds, 101; Lister Monogr. ed. 2, 101, pl. 83, fig. a-e.

Synonyme: Reticularia hemisphærica Bull. Champ. Fr. I (1791), 93 , t. 446 pr. p.

Physarum depressum Schum. Enum. Saell. II (1803), 202.

Didymium hemisphæricum Fr. Syst. Myc. III (1829), 115 pr. p. Diderma depressum Fr. Syst. Myc. III (I829), 108 ?; Rabenh. Deutschl. Krypt.-Fl. I, 282.

Didymium Michelii Lib. Pl. Arduen. Exsicc. fasc. II (1832), Nr. 180.

Physarum Michelii Corda Icon. Fung. V (1842), 57, t. III, fig. 33. Chondrioderma Michelii Rost. in Fuckel Symb. Mycol., Nachtrag II (1873), 74; Rost. Monogr., 172, fig. 131, 146, 149, 150; Massee Monogr., 204, fig. 312; Lister ed. 1, 79, pl. XXXI, A, fig. a-e; Čelak. Myxom. Böhm., 64; Schröter in Cohn Krypt.-Fl. Schles. III, 1, 123; Schinz in Mitt. Naturw. Ges. Winterthur VI, 50. 
Chondrioderma Friesianum Rost. Monogr. (1875), 172?

Chondrioderma hemisphæricum Torrend in Broteria VII (1909), 103.

Exsikkaten: Fuckel Fungi rhen. 2691.

O. Jaap Myxom. exsicc. 67.

Plasmodium undurchsichtig weiß. Sporangien gesellig, linsenförmig, kreisrund, oben flach zusammengedrückt und oft unterseits genabelt oder gebuckelt, gestielt (f. stipitata [Rost.]) oder mitunter ungestielt (f. sessilis Rost.) und zusammenfließend, kalkweiß. Äußere Peridieschicht weiß, brüchig, krustenartig, sich leicht von der häutigen innern Schicht lösend. Stiel ockerfarbig oder braun, gedrungen, bis $1 \mathrm{~mm}$ lang und bis $0,25 \mathrm{~mm}$ dick, mit Furchen und Falten versehen, die sich auf die Unterseite des Sporangiums fortsetzen. Columella fleischrot oder fleischbraun, aus dem breiten verdickten Sporangiumgrund gebildet. Capillitiumfäden zart, oft wellig hin- und hergebogen, verhältnismäßig spärlich verzweigt, anastomosierend. Sporen im durchfallenden Lichte blaßviolettbraun, fast glatt, $7-9 \mu$.

Die Art ist, sofern die Sporangien gestielt sind, leicht an $\operatorname{der}_{\star}$ scheiben- oder linsenförmigen Gestalt der Fruchtkörper zu erkennen. Nachdem die Sporen entlassen sind, bleiben die Stiele oft noch lange auf dem Substrat, eine der Columella entsprechende Scheibe tragend. D. depressum Fr. ist entweder eine ungestielte Form obiger Art oder gehört (was mir weniger wahrscheinlich erscheint) zur nächstfolgenden Art.

Deutschland, Schweiz, Österreich.

Kosmopolitiseh.
4.* Meist flache, netzartig verzweigte oder ausgebreitete Plasmodiokar- pien. Columella bräunlich fleisch- farbig.

3. D. effusum (Schwein.) Morgan Myx. Miami Valley (1894), 71 non Link; Macbride N. A. Slime-Moulds, 94; Lister Monogr. ed. 2, 102, pl. 83, fig. f.

Synonyme: Physarum effusum S chwein. in Trans. Am. Phil. Soc. n. s. IV (1832), 257.

Didymium reticulatum Rost. in Fuckel Symb. Myc. Nachtr. 2 (1873), 73. 
Chondrioderma reticulatum Rost. Monogr. (1875), 170; Massee Monogr., 216; Lister Monogr. ed. 1, 79, pl. XXXI, A, fig. f; Schinz in Mitt. Naturw. Ges. Winterthur VI, 51; Torrend in Broteria VII, 99, IX, 40.

Chondrioderma Saumdersii Berkeley et Broome ap. Massee Monogr. (1892), 209.

Diderma reticulatum Morgan Myx. Miami Valley (1894), 7, non Fr.; Macbride N. A. Slime-Moulds, 95, pl. XVI, fig. 11.

Chondrioderma reticulatum Rost. var. effusum (Schwein.) M e y lan in Bull. Soc. Bot. Genève, 2 me sér. II (1910), 262.

Plasmodium weiß. Fruchtkörper flach dem Substrat aufsitzend, niedergedrückt, glatt, weiß, \pm kreisrundliche oder verlängerte, verästelte, mitunter netzartig anastomosierende oder zusammenfließende, $\pm 6 \mathrm{~cm}$ lange und $\pm 1 \mathrm{~cm}$ breite Plasmodiokarpien bildend. Äußere Wandschicht aus einer sehr brüchigen, sich leicht von der innern Schicht loslösenden, glatten Kalkkruste bestehend. Innere Wandschicht häutig, aschfarbig, bläulich oder farblos. Columella niedergedrückt kissenförmig, bräunlich fleischfarbig, weiße Kalkgranulationen einschließend. Capillitiumfäden zart, farblos oder blaßrot, spärlich verzweigt und wenig anastomosierend. Sporenmasse schwarz, Sporen im durchfallenden Lichte blaßviolettbraun, nahezu glatt, $6-10 \mu$.

Dentschland, Schweiz (Jura, Berner Oberland).

Großbritannien, Frankreich, Portugal, Dänemark, Schweden, Ceylon, Java, Japan, N.- und S.-Amerika.

4. ${ }^{* *}$ Sporangien halbkugelig. Columella weiß, gewölbt. Innere Wandschicht selten bleibend. Sporen violettbraun, $7-11 \mu$.

4. I. spumarioides Fr. Syst. Myc. III (1829), 104; Rabenhorst Deutschl. Krypt.-Fl. I, 283; Morgan Myx. Miami Valley, 67; Macbride N. A. Slime-Moulds, 97; Lister Monogr. ed. 2, 103, pl. 84, fig. a-c.

Synonyme: Reticularia spheroidalis Bull. Champ. (1791), 94, t. 446 , fig. 2 ?

Spumaria physaroides Pers. Syn. (1801), 163 ?

Didymium spumarioides Fr. Symb. Gast. (1818), 20; Massee

Monogr., 232.

Physarum sphæroidale Chevall. Fl. Paris 1 (1826), 339 ?

Physarum stromateum Link Handb. III (1833), 409; Rabenh.

Deutschl. Krypt.-Fl. I, 274. 
Carcerina spumarioides Fr. Summ. Veg. Scand. (1849), 451.

Chondrioderma spumarioides Rost. Monogr. (1875), 174, fig. 142-145, 151; Lister Monogr. ed. 1, 76, pl. XXIX, B, fig. a-e; Schröter in Coln Krypt.-Fl. Schles. III, 1, 123; Schinz in Mitt. Naturw. Ges. Winterthur VI, 51 ; Torrend in Broteria, VII, 101.

Chondrioderma stromateum Rost. Monogr. App. (1876), 18, fig. 151. Chondrioderma virgineum Massee Monogr. (1892), 207, fig. $216-220$.

Diderma cinereum Morgan Myx. Miami Valley (1894), 70;

- Macbride N. A. Slime-Moulds, 101.

Diderma stromateum Morgan 1. c. (1894), 68.

Exsikkaten: Rabenhorst Fungi eur. 432.

Fuckel Fungi rhen. 1459, 2495.

O. Jaap Myxom. exsicc. 104, 148.

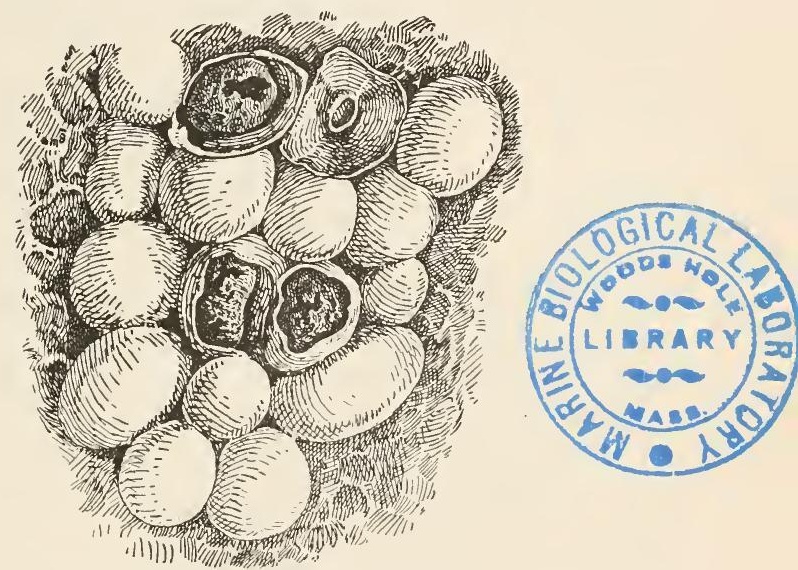

Fig. 67. Sporangien von Diderma spumarioides Fries, z. T. geöffuet $\left({ }^{20} / 1\right)$. (Nach der Natur.)

Plasmodium mattweiß. Sporangien herdenweise, dicht gedrängt, halbkugelig bis fast kugelig, mitunter infolge gegenseitigen Druckes von unregelmäßiger Gestalt, ungestielt, 0,5 bis $1 \mathrm{~mm}$ im Durchmesser, glatt oder höckerig, weiß, mitunter einem stark entwickelten Hypothallus aufsitzend. Äußere Wandschicht aus einer dicken, brüchigen Kalkkruste bestehend, mit der innern Schicht eng verbunden. Columella deutlich, konvex oder 
halbkugelig, weiß, blaß fleischfarbig oder gelblich. Capillitiumfäden reichlich oder spärlich (Sturgis in Colorado College Publ. Gen. Ser. Nr. 68 Sc. Ser. XII Nr. 12 [1913], 444 beobachtete an amerikan. Exemplaren spindelförmige CapillitiumKalkblasen), braunpurpurrot mit blassen Enden, unter spitzen Winkeln verzweigt, spärlich anastomosierend. Sporen im durchfallenden Lichte violettbraun, stachelig, 8-11 $\mu$.

Deutschland (verbreitet), Schweiz (verbreitet), Österreich.

Großbritannien, Frankreich, Dänemark, Schweden, Portugal, N.-Afrika, Ceylon, Westindien, N.- und S.-Amerika.

$4^{* * * *}$. Sporangien nahezu kugelig (bei var. alpinum an deren Stelle Plasmodiokarpien). Columella klein, konvex, weib (bei var. alpinum bräunlich fleischfarbig). ÄuBere Wandschicht eierschalenartig, sich von der innern bleibenden, farblosen (bei var. alpinum bräunlich fleischfarbigen) Schicht lösend. Sporen im durchfallenden Lichte purpurbraun, $10-$ $14 \mu$.

5. D. globosum Pers. in Roem. N. Mag. Bot. I (1794), IV, fig. 4, 5; Rabenhorst Deutschl. Krypt.-Flora I, 283; Macbride N. A. Slime-Moulds 97, pl. VII, fig. 5, 5a; Lister ed. 2, 104, pl. 85, fig. a-c und in Journ. of Bot. LI, 96.

Synonyme: Didymium candidum Sehrad. Nov. Pl. Germ. (1797), 25?

Didymium globosum Chevall. Fl. Paris I (1826), 334.

Diderma crustaceum Peck in Rep. New York Mns. XXVI (1871), 74; Macbride N. A. Slime-Moulds, 98, pl. VII, fig 7.

Chondrioderma globosum Rost. Monogr. (1875), 180, fig. 138; Schröter in Cohn Krylt.-Flora Schles. III, I 124; Massee Monogr., 206; Lister Monogr. el. 1, 78, pl. XXX, fig. a-c; Schinz in Mitteil. Naturw. Ges. Winterthur VI, 51; Torrend in Broteria VII, 101, pl. V, fig $2 \cdot 2$.

Chondrioderna affine Rost. Monogr. App. (1876), 18; Massee Momogr., 210.

Chondrioderma similans Rost. Monogr. Apl. (1876), 20; Massee Monogr., 209.

Chondrioderma crustaceum Berlese in Sace. Syll. VII (1888), 373; Massee Monogr., 215.

Chondrioderma frustulosum Patouill, in Bull. Herb. Boiss. III $(1895), 61$ ? 
Plasmodium weiß. Entweder Plasmodiokarpien oder \pm gedrängte, \pm kugelige oder polyedrische, ungestielte, glatte, weiße oder crêmefarbige, gewöhnlich einem deutlichen Hypothallus aufsitzende Sporangien. Äußere Wandschicht eine eierschalenartige Kalkkruste, oft von der innern dünnen, metallisch blauschimmernden Schicht weit getrennt. Columella mitunter sehr klein, mitunter groß, kugelig, ellipsoidisch oder sogar am Grunde stielartig verjüngt, weiß oder blaßfleischfarbig. Capillitiumfäden reichlich, blaßpurpur, schlank, unregelmäßig verzweigt und anastomosierend, häufig gegen die Ansatzstellen zu mit unregelmäßigen, einige Kalkgranulationen einschlieBenden Erweiterungen. Sporen im durchfallenden Lichte dunkelpurpurbraun, stachelig, 9-14 $\mu$.

Deutschland, Schweiz (Jura), Oesterreich, anscheinend nicht häufig. Großbritannien, Frankreich, Italien, Belgien, Schweden, Rußland, N.-Amerika.

Hierher

var. alpinum Meylan in Ann. Conserv. et Jard. Bot. Genève 15 me et 16 me année (1913), 310.

An Stelle der \pm kugeligen Sporangien meist Plasmodiokarpien; Columella und innere Wandschicht stets fleischrötlichbraun.

Verbreitet im ganzen Hochjura von 1000 bis $1500 \mathrm{~m}$, im Mai und Juni am Rande der schwindenden Schneetlecken, vorzugsweise an Zweigen von Rubusarten.

$4^{* * * *}$. Sporangien \pm kugelig, verkehrteiförmig oder eiförmig (an deren Stelle bei ssp. deplanatum Plasmodiokarpien), die orangegelbe, rotbraune oder blasse Columella (ssp. deplanatum entbehrt einer solchen) 士 kugelig oder keulenförmig. Innere Wandschicht bleibend, gegen den Grund zu orangegelb. Sporen im durchfallenden Lichte purpurbraun, $9-15 \mu$.

6. D. niveum (Rost.) Macbride (in sens. lat.) N. A. SlimeMoulds (1899), 100,

zerfällt in drei Unterarten:

ssp. niveum (Rost.) Schinz

Synonyme: Chondrioderma niveum Rost. Monogr. (1875), 170; Massee Monogr., 207; Lister ed. 2, 105, pl. 89, fig. a-c. 
Chondrioderma physaroides Rost. I. c. (1875), 170; Massee Monogr., 214, fig 89.

Chondrioderma niveum Rost. var. genuinum Lister Monogr. ed 1 (1894), 80, pl. XXXI, B, fig. a-d; Schinz in Mitt. Naturw. Ges. Winterthur VI, 52; Torrend in Broteria VII, 104.

Chondrioderma albescens Phillips ap. Massee Monogr. (1892), 209.

Diderma albescens Phillips in Grev. V (1877), 114.

Plasmodium zuerst kanariengelb, dann crêmefarbig (Meylan in Bull. Soc. Vaud. sc. nat. XLVI [1910], 50) oder weiß (so nach Lister). Sporangien gehäuft, \pm kugelig oder halbkugelig, ungestielt, $0,7-1,5 \mathrm{~mm}$ im Durchmesser, glatt, weiB, mitunter auf weißem oder mattgelbem Hypothallus. Äußere Wandschicht reich mit weißem Kalk beladen, sich von der innern, häutigen und oberwärts oft metallisch glänzenden, gegen den Grund zu knorpeligen und orangefarbigen Schicht lösend. Columella breit, polsterförmig oder halbkugelig, orange- oder lederfarbig. Capillitiumfäden verzweigt und anastomosierend, rotbraun, gegen die Enden zu blaß, mit zerstreuten, warzenförmigen Verdickungen. Sporen im durchfallenden Lichte purpurbraun, fein stachelig, $9-13 \mu$.

Dentschland, schweiz, Österreich.

Norwegen, Californien.

ssp. Lyallii (Massee) Lister in Journ. of Bot. XLVI (1908), 217 und Monogr. ed. 2, 105, pl. 90, fig. a-c.

Synonyme: Chondrioderma Lyallii Massee Mouogr. (1892), 201; Lister Monogr. ed 1, 81, pl. XXXIl, A, fig. a-c, in Journ. of Bot. XXXIX, 86, XLII, 133 und XLVI, 217; Jahn in Verh. Bot. Ver. Prov. Brandenb. XLI, 44.

Diderma Lyallii Macbride N. A. Slime-Moulds (1899), 99, pl. XVI, fig. 2; Torrend in Broteria VII, 102; Meylan in Bull. Soc. Vaud. 5̃me sér. I. (1914), 6.

Chondrioderma niveum Rost. var. Lyallii Lister ap. Schinz in Mitt. Naturw. Ges. Winterthur VI (1906), 52; Torrend in Broteria VII, 114, pl. V, fig. 24.

Sporangien \pm kugelig oder verkehrteiförmig, weiß, schmutzigweiß, blaß ockergelb oder bräunlich, 1-1,5 mm im Durchmesser, ungestielt oder auf kurzen, gedrungenen, gerillten, weißlichen Stielen auf einem Hypothallus. Äußere Wandschicht oft runzelig, unit der innern unzertrennbar verbunden (Meylan in Bull. 
Soc. Bot. Genève 2 me sér. II [1910], 263). Columella halbkugelig oder keulenförmig, am Grunde oft stielartig verjüngt, mitunter lanzenartig, ockergelb. Sporen im durchfallenden Lichte purpurbraun, stachelig, $11-15 \mu$.

Deutschland (bei Berlin), Schweiz (in den Alpen und in Jura nicht selten), Österreich.

Schweden, Norwegen, N.-Amerika.

ssp. deplanatum (Fr.) Lister Monogr. ed. 2 (1911), 106, pl. 89, fig. d.

Synonyme: Diderma deplanatum Fr. Syst. Myc. III (1829), 110.

Dillerma contortun Hoffm. Fl. Crypt. Germ. III (1795), tab. 9, fig 2a ?; Rabenhorst Deutsehl. Krypt.-Fl. I, 282 ?

Chondrioderma deplanatum Rost. Monogr. App. (1876), 17.

Choudrioderma mutabile Schröter in Cohn Krypt.-Fl. Schles. III, 1 (1885), 123 ?

Chondrioderma niveum Rost. var. deplanatum L i s ter Monogr. ed. 1 (1894), 80, pl. XXXI, B fig. e; Sehinz in Mitt. Naturw. Ges. Winterthur VI, 53; Torrend in Broteria VII, 104.

Exsikkaten: Fuckel Fungi rhen. 2199.

O. Jaар Нyxom. exsice. 9, 45, 89.

Fruchtkörper weiße oder crêmefarbige, ring- oder netzartige Plasmodiokarpien bildend. Columella fehlend; die Peridie mitunter am Grunde verdickt, orangefarbig und eine Art Pseudocolumella bildend. Sporen $9-10 \mu$.

Deutschland, Schweiz (Jnra), Oesterreich.

Von den drei Unterarten scheint die letztgenannte namentlich in der Tiefebene vorzukommen, ssp. niveum und Lyallii dürften dagegen mehr den Gebirgsregionen angehören. Hinsichtlich ssp. niveum konstatiert M e y la n mannigfache Variationen, so soll die Columella mitunter so blaß sein, daß sie anstatt gelb nahezu weiß erscheint und auch die Sporengröße soll erheblichen Schwankungen unterworfen sein. Ssp. Lyallii wird im Jura meist über $1400 \mathrm{~m}$ und nicht unter $1100 \mathrm{~m}$ gefunden und zwar wie Meylan wiederum berichtet (Bull. Soc. Bot. Genève 2me sér. II [1910], 263), häufig in Gemeinschaft mit ssp. niveum, ohne daß indessen Zwischenformen vorkommen. Meylan faßt dies als eine Bekräftigung seiner Anschauung auf, daß Lyallii überhaupt in gar keinem näheren Verhältnis zu niveum stehe, sondern vielmehr der Untergattung Leangium angehöre und in nächste Nähe von $D$. Trevellyani zu stellen sei, von weleher Art sich die Sporangien von Lyallii eigentlich nur durch das Fehlen der der Peridie eingelagerten Kalklinsen unterscheiden (Meylan in Bull. Soc. Bot. Genève 2me sér. II 1910, 262 und in Bull. Soc. Vaud. Se. nat. 5me sér. L (1914), 6. Weitere Untersuchungen werden hier licht schaffen. 
Abgesehen vom Gebiete unserer Flora ist der Typus aus Norwegen und Californien, die ssp. Lyallii ans Schweden und Oregon, ssp. deplanatum ans Großbritamnien, Frankreich und Portngal bekanmit.

$3^{*}$. Sporangien fleischfarbig, niedergedrückt.

7. D. testaceum (Schrader) Pers. Syn. (1801), 167; Fr. Syst. Myc. III, 107; Rabenhorst Deutschl. Krypt.-Fl. I, 282; Macbride N. A. Slime-Moulds, 99; Lister Monogr. ed. 2, 106, pl. 87, fig. a-c.

Synonyme: Didyminm testacenm Schrader Nov. Gen. Plant. (1797), 25 , t. 5, fig. $1-2$.

Diderma enbense Berkeley et Curtis in Journ. Limm. Soc: $\mathrm{X}$ (1869), 347.

Diderma sublateritium Berkeley et Broome in Journ. Linn. Soc. XIV (1873), 82 .

Chondrioderma testaceum Rost. Vers. Syst. Nye. (1873), 13 et Monogt., 179; fig. 135, 136; Sehröter in Cohn Krypt.-Fl. Schles. 111, 1, 135; Massee Monogr., 210; Člak. Myxom. Böhm., 66; Lister Monogr. ed. 1, 78, pl. XXX, B, fig. a-c; Schinz in Mitt. Naturw. Ges. Winterthor VI, 53; Torrend in Broteria VII, 102, IX, 49 .

Diderma Marie-Wilsoni Clinton in Rep. N. York Mus. XXVI (1874), 74 .

Chondrioderma vaccinum Rost. Monogr. (1875), 180 ?

Chondrioderma sublateritium Riost. Monogr. App. (1876), 19; Massee Monogr., 211.

Chondrioderma cubense Rost. Monogr. App. (1876), 19.

Exsikkaten: Fuckel Fungi rhen. 1467

O. Jaap. Myxom. exsice. 27,68.

Plasmodium ledergelb. Sporangien ungestielt, \pm halbkugelig, etwas niedergedrückt und mitunter zusammenfliebend, $\pm 0,8 \mathrm{~mm}$ im Durchmesser, glatt, rosenrot oder fleischfarbig, oft bleichend. Änßere Wandschicht kalkreich, brüchig, eierschalenartig, dünn, von der innern, rötlichgrauen, \pm bleibenden Schicht sich leicht lösend. Columella kräftig entwickelt, \pm halbkugelig, fleichfarbig oder rotbraun. Capillitium aus zarten, blabroten oder farblosen, spärlich verzweigten Fäden bestehend, Sporen im durchfallenden Lichte blaß violettbraun, nahezu glatt, $7-9 \mu$.

Deutschland, Schweiz (anscheinend, abgesehen vom Jura, nicht häufig), Oesterreich.

Großbritamien, Frankreich, Portugal, Belgien, Schweden, Finnland, N.-Afrika (?), Ceylon, Java, Japan, N.-Amerika, Westindien. 


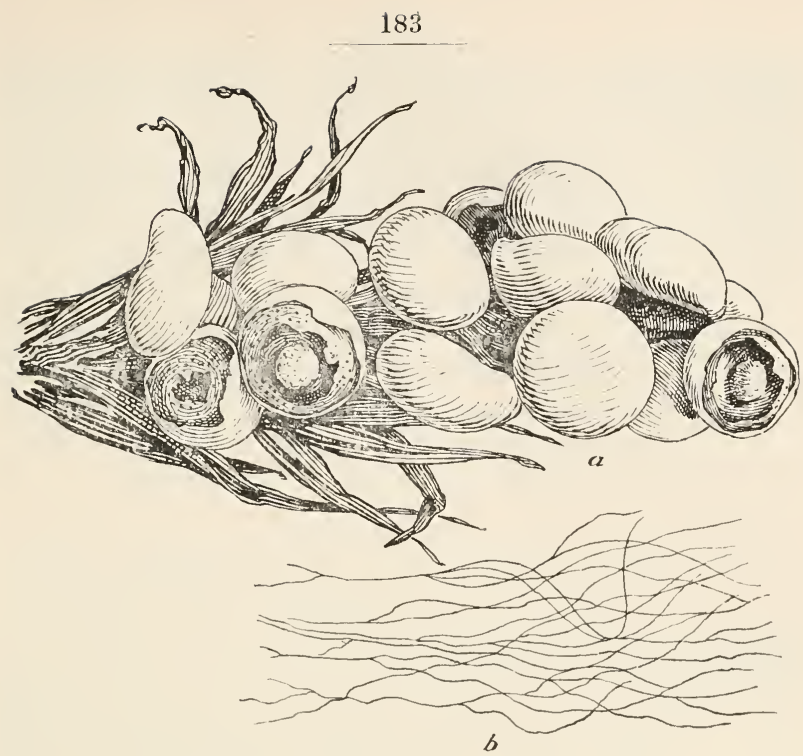

Fig. 68. Diderma testaceum (Schrad.) Pers.

a) Sporangienhänfehen $\left({ }^{20} / 1\right)$; b) Capillitiumfäden $\left({ }^{280} / 1\right)$. - Z. T. nach Lister.

Hinsichtlich der Unterscheidung dieser Art von Diderma effusum einerseits und $D$. radiatum anderseits sei anf die an letztgenannte Art angeknüpften Bemerkungen verwiesen.

$3^{* *}$. Sporangien rötlich lehmfarbig, schokoladen-oder lederbraun. Peridie einfach, häutig, mit Kalkgranulationen.

8. D. simplex (Schröter) Lister Monogr. ed. 2 (1911), 107, pl. 88, fig. a-d.

Syuonyme: Chondrioderma simplex Schröter in Cohn Krypt.-Fl. Schles. III, 1 (1885), 123; Lister in Journ. of. Bot. XXXIX, 85, t. 419, fig. 1, a-d, XLII, 132 und Monogr. ed. 1, 88; Massee Monogr., 217.

Plasmodium hellgelbbraun. Sporangien gedrängt oder zerstreut, ungestielt, halbkugelig oder häufig niedergedrückt, quer $0,3-0,7 \mathrm{~mm}$ messend, mitunter an deren Stelle kurze, gekrümmte 
Plasmodiokarpien, glatt oder höckerig, mitunter auf wohlentwickeltem Hypothallus. Peridie kalkreich. Columella mitunter ohne scharfe Umgrenzung, mitunter halbkugelig, mit rauher Oberfläche. Capillitiumfäden am Grunde mit kalkführenden Verdickungen, sonst zart und farblos, verzweigt. Sporen im durchfallenden Lichte violettbraun, fein warzig, 8-10 $\mu$.

Deutschland (bei Berlin, Schlesien).

$1^{*}$. Sporangien gestielt oder ungestielt. ÄuBere Wandschicht knorpelig, \pm mit eingelagerten Kalkgranulationen beladen, innig mit derinnern häutigen Schicht verbunden. Peridie häufig \pm sternförmig aufreißend.

\section{Untergattung Leangium Lister}

Monogr. ed. 1 (1894), 82 et ed. 2, 108.- Leangium Link em. Rost. Vers. Syst. Myc. (1873), 12.

5. Peridie auBenseits braun, innenseits weib und mit Kalkkristallen. Columella häufig fehlend.

9. D. Trevelyani (Grev.) Fr. Syst. Myc. III (1829), 105; Macbride N. A. Slime-Moulds, 102; Lister Monogr. ed. 2, 110, pl. 91, fig. a-d; Meylan in Bull. Soc. Vaud. sc. nat. 5 me sér. L (1914), 7.

Synonyme: Leangium Trevelyani Grev. Scot. Crypt.-Fl. (1825), t. 132.

Chondrioderma Trevelyani Rost. Monogr.(1875), 182, fig.161-163;

Massee Monogr., 202; Torrend in Broteria VII, 105; Lister Monogr. ed. 1, 82, pl. XXXIII, B, fig. a-e und in Journ. of Bot. XXXIX, 87, XLVI, 217.

Chondrioderma Oerstedtii Rost. Monogr. (1875̃), 184, fig. 154, 157; Massee Monogr., 203, fig. 87, 88.

Chondrioderma geasteroides Phillips in Grev. V (1877), 113.

Diderma laciniatum Phillips l. c. (1877), 113.

Lepidoderma obovatum Mas s e Monogr. (1892), 254, fig. 45-47 ?

Plasmodium? Entweder (selten) Plasmodiokarpien oder meist sitzende oder kurz gestielte, zerstrente oder gehäufte, kugelige oder ellipsoidische, warzige oder nahezu glatte, rötliche oder orangebraune, 1-1,5 mm dicke Sporangien. Peridie zur Sporen- 
reife unregelmäßig in sich zurückrollende Lappen aufreißend, aus drei unter sich engverbundenen Schichten bestehend: innerste Schicht zarthäutig, mittlere dick, aus einer Kalkkruste bestehend, äubere knorpelig, braun. Columella entweder fehlend, rudimentär oder seltener wohlentwickelt. Capillitiumfäden purpurrot oder purpurbraun, meist ein \pm straffes Netzwerk bildend und häufig mit perlenartigen Verdickungen, an den Verzweigungsstellen oft gleicherweise verdickt, die Fäden mitunter auch zarter und schlank. Sporen im durchfallenden Lichte dunkelviolettlraun, stachelig, $10-13 \mu$.

Dentschland, Schweiz.

Großbritannien, Frankreich, Dämemark, Schweden, N.- mnd S.-Amerika.

Var. nivale Meylan in Bull. Soc. Vaud. sc. nat. 5 me sér. L (1914), 8.

Sporangien graubraun, runzelig. Peridie unregelmäßig und nicht radienartig vom Gipfel aus aufreißend, von den 3 Wandschichten sind nur die erste und zweite eng verbunden, die innerste dagegen ist meist frei und metallisch glänzend. Columella lang und lanzettförmig.

Schweiz (im Jura bei $1400 \mathrm{~m}$ und dariiber, am Rande schmelzenden Schnees).

5.* Peridie ohne Kalkkristalle führende Schicht.

6. Sporen weit zerstreut warzig. Sporangien gestielt.

10. D. floriforme (Bull.) Pers, in Roem. N. Mag. Bot. I (1794), 89; Wallr. Fl. Crypt. Germ. IV, 377; Nacbride N. A. Slime-Moulds, 105, pl. VIII, fig. 1, $1 \mathrm{a}, 1 \mathrm{~b}$; Lister Monogr. ed. 2, III, pl. 92, fig. a-e.

Synonyme: Sphærocarpus floriformis Bull. Champ. (1791), 142, t. 371 .

Sphærocarpus antiades Bull. l. c. (1791), 127, t. 368, fig. 2 ? Didymium floriforme Sehrad. Nov. Gen. Pl. (1797), 25.

Diderma spurium Schum. Enum. Pl. Saell. II (1803); 197.

Leangium floriforme Link in Mag. Ges. Nat. Fr. Berlin III (1809), 26.

Leangium lepidotum Ditm. in Sturm Deutschl. Fl., Pilze (1817), 43, t. 21 . 
Diderma lepidotum Fr. Syst. Myc. III (1829), 100.

Physarum antiades Fr. Syst. Mye. III (1829), 135 ?

Chondrioderma floriforme Rost. Mouogr. (1875), 184; Massee Monogr., 198, fig. 58, 59; Lister Monogr. ed. 1, 85, pl. XXXIV, B, fig. a-e; Schinz in Mitt. Naturw. Ges. Winterthur VI, 54; Torrend in Broteria VII, 109, pl. V, fig. 25.

Exsikkat: Fuckel Fungi rhen. 2496.

Plasmodium grauweiß. Sporangien gruppenweise, oft zu sehr vielen, gestielt, 1-2 $\mathrm{mm}$ hoch, aufrecht, kugelig, glatt, $0,8 \mathrm{~mm}$ im Durchmesser, weiß bis ockerbraun. Peridie sternförmig in mehrere sich zurückrollende, auf der Innenseite blaßbraune, knorpelige Lappen aufreißend. Stiel weiß, auf stark entwickeltem Hypothallus, bis $1 \mathrm{~mm}$ lang, gefurcht, ockerbraun. Capillitiumfäden zart, spärlich verzweigt, etwas dicker und anastomosierend am Grunde, mit vereinzelten, perlenförmigen Verdickungen, dunkelbraun. Columella halbkugelig, ellipsoidisch oder eiförmig, am Grunde oft etwas verjüngt, braun. Sporen im durchfallenden Lichte violettbraun, auf einer Seite blasser, mit weit zerstreuten Warzen besetzt, $9-11 \mu$.

Dentschland, Schweiz (anscheinend selten), Österreich.

Großbritannieu, Frankreich, Portugal, Dänemark, Japan, N.-Amerika.

$6^{*}$. Sporen entweder dicht fein stachelig oder nahezu glatt.

7. Sporangien rosenrotbraun, ungestielt, \pm kugelig, Columella nicht scharf abgesetzt. Capillitium meist farblos.

11. D. Sauteri (Rost.) Macbride North American SlimeMoulds (1899), 103; Lister Monogr. ed. 2, 108, pl. 95, fig. a-d.

Synonyme: Chondrioderma Santeri Rost. Monogr. (1875), 181; Massee Monogr., 217; Lister Monogr. ed. 1, 83, pl. XXXIII, A, fig. a-c; Torrend in Broteria VII, 106.

Chondrioderma aculeatum Rex in Proc. Ac. Nat. Sc. Phil. (1891), 390.

Plasmodium undurchsichtig weiß. Sporangien mitunter etwas niedergedrückt und $a b$ und zu am Grunde nabelförmig vertieft, $0,7-1 \mathrm{~mm}$ im Durchmesser, roseurotbraun, namentlich anfangs, später häufig weißlich oder weißgelblich werdend. Äußere Peridieschicht knorpelig (mindestens am Grunde), dünn, spröde, 
glänzend, mit eingelagerten Kalkgranulationen, sich von der innern, aschgrauen oder metallisch glänzenden Schicht loslösend. Columella klein, oft rudimentär, häufig besetzt mit den bleibenden, haarartigen Basalteilen der Capillitiumfäden. Letztere spärlich, farblos oder violett, wenig verzweigt, $2-4 \mu$ breit. Sporen im durchfallenden Lichte dunkelviolettbraun, fein stachelig, 10-16 $\mu$.

Soll bei Salzburg gefunden worden sein.

Großbritamien, Portugal, N.-Amerika.

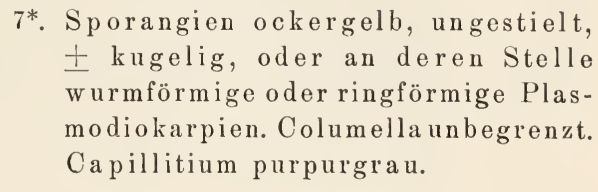

12. D. ochraceum G. C. Hoffm. Deutschl. Fl., Krypt. (1795), t. 9, fig. 2b; Rabenhorst Deutschl. Krypt.-Fl. I, 282; Lister Monogr. ed. 2, 109, pl. 95, fig. a-c.

Synonym: Chondrioderma ochraceum Schröter in Cohn Krypt.-Fl. Schles. III, 1 (1885), 124; Massee Monogr., 216; Lister Monogr. ed. 1, 89 u. in Journ. of Bot. XXXIX, 88, t. 419, fig. 3a u. 1. c. XLIII, 150; Torrend in Broteria VII, 106.

Plasmodium zitronengelb. Sporangien einzeln oder zu wenigen gehäuft, ungestielt, kugelig, halbkugelig und $0,7-1 \mathrm{~mm}$ im Durchmesser oder wurmförmig gekrümmte oder ringförmige Plasmodiokarpien, ockergelb. Äußere, reichlich mit kantigen oder abgerundeten Kalkgranulationen beladene Wandschicht knorpelig, unregelmäßig aufreißend, mit der innern, farblosen, dünnen Schicht verbunden oder sich von ihr trennend. Columella unbegrenzt. Capillitiumfäden reichlich, einfach oder verzweigt, purpurbraun, am Grunde häufig blaß. Sporen im durchfallenden Lichte purpurgrau, fein stachelig, $9-11 \mu$.

Deutschland (Schlesien), Schweiz (Jura).

Großbritamnien, Japan, N.-Amerika.

$7^{* *}$. Sporangien weiß, grau oder braun. Columella blab, halbkugelig. Stiel kräftig, kurz, ockergelb, mitunter die Sporangien auch ungestielt. 
13. D. radiatum (L. sens. lat.) Lister Monogr. ed. 2 (1911), 112, pl. 93, fig. a-d, 94, fig. a-b.

Syuonyme: Lycoperdon radiatum L. Spec. Pl. ed. 2 (1763), 1654;

G. Lister in Journ. of Bot. LI, 161 .

Didymium stellare Schrader Nov. Pl. Gen. (1797), 21, t. V, fig. 3,4 .

Diderma stellare Pers. Syn. (1801), 164; Wallr. Fl. Crypt. Germ. IV, 377; Macbride N. A. Slime-Moulds, 104.

Diderma umbilicatum Pers. 1. c. (1801), 165; Wallr. Fl. Crypt. Germ. IV, 377.

Diderma crassipes Schum. Enum. Pl. Saell. II (1803), 196.

Leangium stellare Link in Mag. Ges. Nat. Fr. Berlin II (1809),

26; Rabenhorst Deutschl. Krypt.-Fl. I, 284.

Didymium Geaster Link l. c. VII (1815), 42.

Cionium stellare Spreng. Syst. Orb. Veg. IV (1827), 529.

Diderma Carmichælianum Berkeley in Sm. Engl. Fl. V, part. 2 (1836), 311.

Didymium complanatum Fuckel Symb. Myc. (1869) 341.

Diderma concinnum Berkeley et Curtis in Grev. II (1873), 52; vergl. Lister in Journ. of Bot. XXXV, 212.

Chondrioderma radiatum Rost. Monogr. (1875), 182, fig. I52, 153, 155, 156, 170; Massee Monogr., 200, fig. 92-95; Schröter in Cohn Krypt.-FI. Schles. III, 1, 125; Lister Mlonogr. ed. 1, 83, pI. XXXIII, B, fig. a-c; Torrend in Broteria VII, 108, pl. $\mathrm{V}$, fig. 20.

Chondrioderma Carmichælianum Cooke Myx. Brit. (1877), 42; Massee Monogr., 202 pr. p.

Exsikkaten: O. Jaap. Myxom. exsicc. 90, 150.

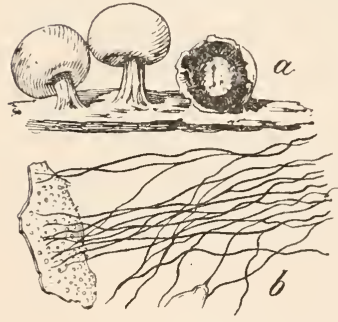

Fig. 69. Diderma radiatum (L.) Lister.

a) Sporangiengruppe; $d$. äußerste Sporangium rechts die Columella zeigend $(15 / 1)$; b) Capillitium mit einem Fragment der Peridie $(26 \% / 1)$. - Nach Lister.

Plasmodium weiß, blaßgelb oder sattgelb, selten korallenrot. Sporangien zerstreut oder herdenweise, kugelig oder halbkugelig und niedergedrückt, unterseits genabelt oder flach, gestielt oder ungestielt, glatt oder runzelig und gefältelt, $0,5-1,2$ $\mathrm{mm}$ im Durchmesser, blaßgrau, weib, bräunlich, rosarot, graugrünlich, gelblich oder braunrot. Peridie entweder unregelmäßig aufreißend oder sternförmig unter Bildung von sich zurückrollenden Lappen, auf der Innenseite weiß oder blaßbraun. Äußere Wandschicht kalkführend, knorpelig, 
nicht immer eng mit der innern verbunden. Stiel ockergelb, weiß oder braun, 0,2-0,6 $\mathrm{mm}$ hoch, mit weißem Kalk beladen. Columella halbkugelig oder kugelig, 0,5 mm im Durchmesser, kalkreich. Capillitium reichlich, dunkelviolettbraun, aus \pm straffen, mit Ausnahme der blassen, zarten Enden spärlich verzweigten, seltener in der ganzen Länge blassen Fäden bestehend. Sporen im durchfallenden Lichte dunkelviolettbraun, dicht- und feinstachelig, 7-12 $\mu$.

In Deutschland und in der Schweiz nicht selten.

GroBbritannien, Frankreich, Dänemark, Norwegen, Schweden, Finnland, Italien, Portugal, Japan, N.-Amerika.

Der Kalkreichtum der Peridie ist bei dieser Art sehr großen Schwankungen unterworfen und dementsprechend ist auch die Sporangienfarbe sehr wechselnd.

Wir unterscheiden folgende Spielarten:

var. genuinum (Torrend) Schinz nov. comb.

Synonym: Chondrioderma radiatum Rost. var. genuinum Torrend in Broteria VII (1908), 108.

Plasmodium gewöhnlich weiß. Sporangien grauweißlich, seltener braun oder gelblich, glatt, matt oder glänzend, unterseits genabelt, gestielt. Peridie unregelmäßig aufreißend, sich nicht in Lappen zurückrollend. Hierher f. flavogenitum (Meylan) in Ann. Conserv. et Jardin bot. Genève, 15 me et 16 me année (1913), 312, Plasmodium sattgelb, Sporangien graugrünlich oder gelblich und f. album Torrend in Broteria VII (1908), 108, Sporangien, Stiel und Columella weiß.

f. Alavogenita im Schweizer Jura; ob auch die f. album im Gebiet?

var. radiatum (L. sens. strict.) Schinz nov. comb.

Plasmodium weiB. Beide Wandschichten der Peridie verbunden, sternartig aufreißend. Sporangien braun, polyedrisch mit blassen, maschenartigen Dehiszenzlinien, ungestielt oder mit kurzen Stielen, Sporen $9-12 \mu$.

Verbreitung der Art.

var. montanum (Meylan) Schinz nov. comb.

Synonyme: Chondrioderma montanum Meylan in Bull. Soc. Bot. Genève 2 me sér. II (1910), 262.

Diderna montanum Meylan in Ann. Conserv, et Jard. Bot. Genève 15 me et 16 me anuée (1913), 312.

Beide Wandschichten der Peridie von einander getrennt, Sporangien weiß oder rosarot mit gelbem Stiel. Sporen $7-9 \mu$.

Schweizer Jura. 
var. rubrum Rönn in Schrift. Naturw. Ver. Schlesw. Holst. XV (1911), 59.

Plasmodium und die sämtlichen kalkhaltigen Teile der Sporangien lebhaft rot.

Holstein.

Ich balte es nicht für ausgeschlossen, da B man doch dazu kommen wird, diese Spielarten (vielleicht mit Ausnahme der var. rubrum?) zum Range von Arten zu erheben, wie dies $\mathrm{M}$ eylan auch bereits vorgesehlagen hat. Obschon die Beziehungen des $D$. montanum zu $D$. radiatum einerseits und zu testaceum anderseits enge sind, lassen sich bestimmte Unterschiede doch feststellen. D. montanum unterscheidet sich von testaceum durch seine gestielten nicht niedergedrückten Sporangien und sein tiefer gefärbtes Capillitium, von D. radiatum durch die gestielten, entweder weißen oder rosaroten Sporangien, deren äußere Wandschicht kalkreich und spröde ist und sich leicht von der innern Schicht trennt, die kleinere, kugelige, dunkelbraune Columella, die dunkler gefärbten, sehr fein stacheligen, 7-10 $\mu$ großen Sporen. Die Form mit unregelmäßig aufreißender Peridie (äußere Wandsehicht von der innern sich nicht lösend) nennt M e y lan D. umbilicatum Pers., sie entspricht der var. genuinum Torrend unserer Aufstellung. Meylan's $D$. radiatum (L.) Lister teilt mit $D$. umbilicatum zwei Merkmale: einmal sind beide Wandschichten eng verbunden und die Sporen sind $9-12 \mu$ groß, aber die Peridie reißt bei radiatum sternförmig in Lappen auf, die sich zurückrollen.

$7 * * *$ Sporangien zerstreut, gestielt, flach halbkugelig oder scheiben förmig, scheckig rotbraun mit helleren Dehiszenzlinien. Peridie unregelmäßig- oder sternförmig aufreibend, zweischichtig, beide Schichten verbunden, äußere innenseits weib. Stiel $0,1-0,7 \mathrm{~mm}$ hoch, gefurcht, schwarz. Columella flach konvex, scheibenförmig. Capillitiumfäden farblos, einfach oder verzweigt, zum Teil anastomosierend. Sporen im durchfallenden Lichte purpurbraun, stachelig, $10-$ $14 \mu$.

14. I. roanense (Rex) Macbride N. A. Slime-Moulds (1899), 104; Lister Monogr. ed. 2, 113, pl. 14, fig. c-d.

Synonym: Chondrioderma roanense Rex in Proc. Ac. Nat. Sc. Phil. (1893), 368.

N.-Amerika. 
7.**** Sporangien braun, mit dicht stehenden, meridianartig verlaufenden dunkeln Linien, meist sitzend und halbkugelig. Columella weib, gewölbt.

15. I). asteroides Lister Monogr. ed. 2 (1911), 114, pl. 97, fig. $\mathrm{a}-\mathrm{c}$.

Syuonym: Chondrioderma asteroides Lister in Journ. of Bot. XL (1902), 209, t. 438, fig. a-c und XLH, 132; Torrend in Broteria VII, 106, pl. IX, fig. 8-9.

Plasmodium weiß. Sporangien zerstreut, selten kurz gestielt, halbkugelig oder schwach kegelförmig, 0,6-0,8 $\mathrm{mm}$ hoch, mitunter an deren Stelle gestreckte Plasmodiokarpien, purpurbraun oder lebhaft schokoladebraun, oft dunkel gescheckt oder mit dunkeln, meridianartig vom Scheitel zur Basis verlaufenden Linien versehen, stemartig aufreißend. Die 8 bis 20 Peridielappen auf der Innenseite schneeweiß. Äußere Wandschicht braun, innenseits kalkreich, knorpelig, mit der häutigen innern Schicht eng verbunden. Stiel gedrungen, weiß, mit Kalkgranulationen ausgefüllt. Columella halbkugelig oder \pm kugelig und niedergedrückt, weiß oder crêmefarbig. Capillitiumfäden schlank, einfach oder anastomosierend, farblos oder rötlich. Sporen im durchfallenden Lichte purpurbraun, fein warzig, $10-12 \mu$.

Deutschland (Hamburg), Schweiz (Jura).

Italien, Frankreich, Portugal, N.-Amerika.

7.***** Sporangien aschgrau, braun am Grunde, unregelmäBig runzelig gefeldert, zerstreut, gestielt (Stiel $0,2-0,6 \mathrm{~mm}$ lang) oder ungestielt, 士 kugeligoder halbkugelig. Peridie einschichtig, papierdünn, spärlich mit sehr kleinen Kalkkörnchen besetzt. Stiel gefurcht, schlank, schwarz. Columella keulenförmig, halb so lang wie das Sporangium, höckerig, kalk- oder gelblichweiß. Capillitiumfäden farblos, weib oder rot, anastomosierend und namentlich gegen die Enden verjüngt. Sporen 
im durchfallenden Lichte violettbraun, fein warzig, $8-10 \mu$.

16. D. rugosum (Rex) Macbride N. A. Slime-Moulds (1899), 105, pl. XVI, fig. 5; Lister Monogr. ed. 2, 114, pl. 86, fig. $a-c$.

Synonym: Chondrioderma rugosum Rex in Proc. Acad. Nat. Sc. Phil. (1893), 369; Lister Monogr. ed. 1, 84, pl. XXXIV, B, fig. a-c; Torrend in Broteria VII, 108, pl. V, fig. 26.

Ceylon, Java, Japan, Westindien, N.-Amerika.

7.***** Sporangien lebhaft orangefarbig, scharlach- oder zinnoberrot, glänzend, gewöhnlich gestielt, zerstreut, \pm kugelig, am Grunde abgeflacht, unregelmäßig in 4 oder 5 , am Rande blasse Lappen aufreißend. Äußere Wandschicht durchscheinend orangegelb, innere gelb, beide verbunden. Stiel schlank, braunschwarz, 0,2 $0,5 \mathrm{~mm}$ hoch. Columella verkehrtkegelförmig oder \pm kugelig, am Grunde oft stielartig zusammengezogen, höckerig, kalkführend, weiß oder crêmefarbig. Capillitiumfäden ein sehr weitmaschiges, in den Maschenwinkeln oft verbreitertes Netzwerk bildend, braunrot. Sporen im durchfallenden Lichte purpurgrau, dicht stachelig, $13-15 \mu$.

17. D. Iucidum Berkeley et Broome in Ann. and Mag. Nat. Hist. ser. 3, VII (1861), 380, t. XV, a fig. 9; Lister Monogr. ed. 2, 115, pl. 98, fig. a-d.

Synonyme: Chondrioderma lucidum Cooke Myx. Brit. (1877), 42; Massee Monogr., 204; Lister Monogr. ed. 1, 86, pl. XXXV, A, fig. e-h und in Journ. of Bot. XXXIX, 87, XLII, 133, XLIII, 151.

pr. p. Chondrioderma Charmichælianum Massee Monogr. (1892), 202.

GroBbritannien, Ceylon (?). 
Von vorläufig noch unsicherer Stellung ist:

D. arboreum (Petch) G. Lister et Petch in Journ. of Bot. LI (1913), 2, t. 524, fig. 2, 2a, 2b.

Synonym: Diderma rugosum Petch in Aun. Bot. Garden Perad. IV (1910), 345 non Macbride.

Plasmodium ? Sporangien zerstreut, linsenförmig oder schüsselförmig, sitzend oder kurz gestielt oder flache, unregelmäßig ausgebreitete Plasmodiokarpien, weiß oder purpurgrau bei spärlicher Kalkeinlagerung, glatt oder runzelig. Peridie zerbrechlich, mit abgerundeten oder unregelmäßigen, kantigen Kalkfragmenten. Stiel blaßrötlich, brann oder nahezu schwarz, höckerig, schlank oder gedrungen. Columella gewölbt, fleischfarbig oder fehlend. Capillitiumfäden einfach oder verzweigt, häufig anastomosierend und gegen die Enden zu oft unregelmäßig verbreitert, farblos oder purpurrot. Sporen im durchfallenden Lichte blaß purpurbraun oder purpurfarbig, fein stachelig, $10-15 \mu$.

Schottland, Ceylon, Japan.

Unterscheidet sich vom nahestehenden $D$. effusum durch kräftigere, an den Enden verbreiterte Capillitiumfäden, größere Sporen und mitunter gestielte Sporangien.

\section{Gattung Colloderma G. Lister}

in Journ. of Bot. XLVIII (1910), 312, LI, 97, in Trans. Brit. Mycol. Soc. IV (1912), 40 et Monogr. ed. 2, 116.

Mit nur einer Art:

C. oculatum (Lippert) G. Lister in Journ. of Bot. XLVIII (1910), 312, und in Trans. Brit. Myc. Soc. IV (1912), 40, fig. 1, $1 \mathrm{a}-\mathrm{c}$, pl. I, Monogr. ed. 2, 116; Meylan in Ann. Conserv. et Jardin Bot. Genève 15 me et 16 me Année, 313, fig. 1-4; Minakata in Tokyo Bot. Mag. XXVII, 411.

Synonym: Didymium oculatum Lippert in Verh. Zoolog.-Bot. Ges. Wien XLIV (1894), 72, t. 4, fig. 13-18.

Plasmodium gelatineartig dnrchsichtig, schmutzig wasserhell mit grünlichem oder olivenfarbigom Stich, hierauf ockerfarbig, später rost- und schmutzigfarbig (Minakata l. c.) Das zuerst vollständig hyaline Plasmodium nimmt, wie Meylan berichtet, allmählich die Gestalt einer etwas abgeflachten Kugel an, dann 


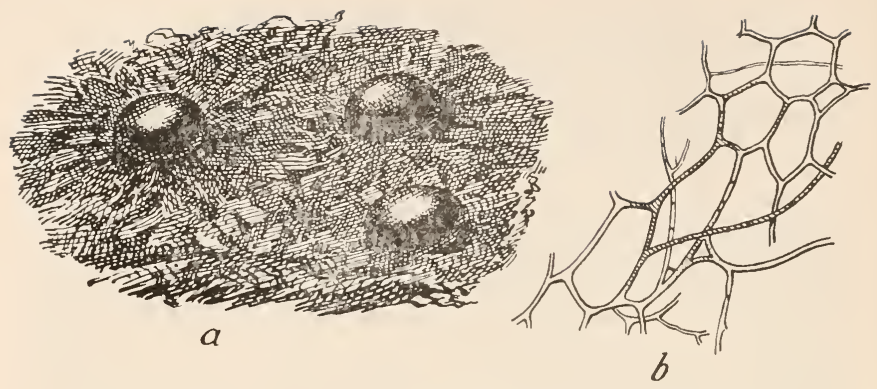

Fig. 70. Colloderma oculatum (Lippert) G. Lister.

a) Drei dem Substrat aufsitzende Sporangien $\left({ }^{12} / 1\right)$; b) Capillitium $\left({ }^{260} / 1\right)$. a nach der Natur, b nach Lippert.

wird die zentrale Partie zuerst weiß, alsdann gran, gegen die obere Kugelkalotte ansteigend, schärfere Umrisse annehmend und mehr und mehr undurchsichtig werdend. Dieses grane Kügelchen, das zum späteren Sporangium wird, färbt sich zusehends dunkler, wird mitunter sogar schwarz und sprengt in der Regel seine gelatinöse Umhüllung. Es hat in diesem Falle einige Ähnlichkeit mit einem von einer viel größern Gelatinekugel getragenen Lamproderma-Sporangium. Y'on oben gesehen gleicht dieses Gebilde in der Tat einem kleinen Auge. Wird die gelatinöse Umhüllung nicht gesprengt, so überkleidet diese das Sporangium als äußere Hülle, die bei Wasserzutritt leicht quillt. Gleicherweise quillt das gelatinöse Piedestal auf feuchtem Substrat, um bei Trockenheit an Volumen stark einzubïßen. Die meist vereinzelt, seltener in Gruppen von 2 bis 3, namentlich gerne auf Lebermoosrasen an Baumstämmen vorkommenden, zirka $1 \mathrm{~mm}$ im Durchmesser messenden Sporangien sind im reifen Zustande oliven- oder purpurbraun, glänzend, mitunter werden an deren Stelle kurze Plasmodiokarpien ausgebildet. Die Peridie ist entweder doppelt oder einfach, doppelt, wie oben bemerkt, wenn die gelatinöse Umhüllung nicht gesprengt wird, einfach, wenn dies eingetreten ist. In der äußern Hülle finden sich gelblich olivenfarbige Granulationen; die innere Wandschicht ist farblos, häutig, straff. Columella fehlend. Capillitiumfäden ein blasses oder dunkelpurpurbraunes Netzwerk ohne Kalkknoten 
bildend, in zarte, farblose Enden auslaufend. Sporen im durchfallenden Lichte bräunlich purpurrot, stachelig, $11-13 \mu$.

Schweiz (Arosa, Mürren, reichlich im Jura, namentlich über $1000 \mathrm{~m}$ Meereshöhe), Österreich, sehr wahrscheinlich verbreiteter, aber der Kleinheit der Sporangien wegen übersehen.

\section{Großbritannien, Japan, N.-Amerika.}

Lippertsagt, daß die Peridie stellenweise mit äuBerst kleinen, rundlichen Körperchen (Kalk) bedeckt sei, wogegen Frl. Lister hervorhebt, daß solche den ihr vorgelegenen Sporangien felılen. Wenn wirklich keine Kalkgranulationen vorkommen, so wäre die Gattung wolll besser, wie Frl. Lister vorschlägt, bei den Amaurochcetineae untergebracht, obschon sie auch dort eine völlig isolierte Stellung einnehmen würde.

\section{Gattung Physarina von Höhnel}

in Sitzungsber. Akad. Wien, Math.-Naturw. Klasse CXVIII (1909), 431, Lister Monogr. ed. 2, 117.

Nur eine, bis jetzt nur aus Java bekannte Art:

P. echinocephala von Höhnel l. c. (1909), 432, fig. 33; Lister Monogr. ed. 2, 117, pl. 198, fig. a-c.

Plasmodium ? Sporangien herdenweise, gestielt, \pm kugelig, $0,8 \mathrm{~mm}$ hoch, hellrosarot oder fleischrot (oder dunkelschokoladenbraun?), äußere Wandschicht knorpelig, Kalkgranulationen ein-

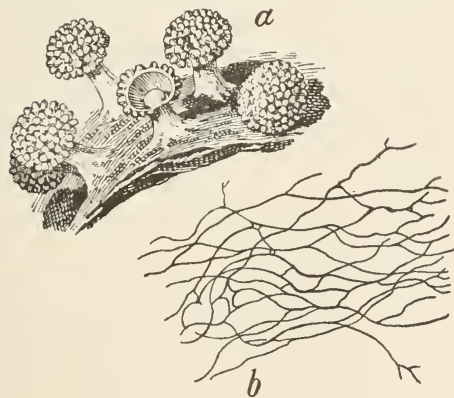

Fig. 71. Physarina echinocephala v. Höhnel.

a) Gruppe von Sporangien, eines davon geöffnet $(20 / 1)$; b) Capillitium $\left({ }^{280} / 1\right)$. - Nach Iister.

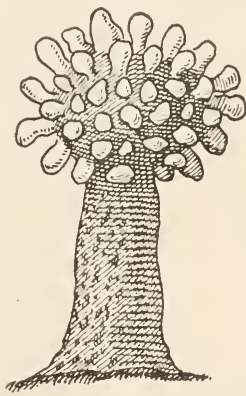

Fig. 72. Physarina echinocephala v. Höhnel. Sporangium $\left({ }^{60} / 1\right)$. - Nach v. Höhnel. 
schließend, dicht besetzt mit stumpfen, walzlichen, gedrungenen, $80 \mu$ langen, Kalkgranulationen führenden Warzen, innere glatt und häutig. Stiel gedrungen kegelförmig, gefurcht, matt fleischfarbig, $0,1-0,4 \mathrm{~mm}$ hoch, rauh, in das Sporangium hinein als \pm kugelige oder halbkugelige Columella fortgesetzt. Capillitiumfäden sehr zart, ohne Kalkknoten, violettbraun, an den Enden blasser und verzweigt. Sporen im durchfallenden Lichte violett, nahezu glatt, $7-9 \mu$.

Java.

\section{Gattung Diachæa Fries}

Syst. Orb. Veg. I (1825), 143; Fr. Syst. Mycol. III, 155; Rabenh. Deutschl. Krypt.-Fl. I, 270; Rost. Vers. Syst. Myc. 13 und Monogr., 190; Schröter in Cohn Krypt.-Fl. Schles. III, 1, 120 und in Engler und Prantl Natïrl. Pflanzenfam. 1, 1, 29; Massee Monogr., 258; Lister Monogr. ed. 1, 90 und ed. 2. 117; Schinz in Mitt. Naturw. Ges. Winterthur VI, 55; Macbr. N. Am. Slime-Moulds, 134; Torrend in Broteria VI, 51, VII, 85.

Sporangien kugelig oder zylindrisch mit metallisch glänzender, kalkfreier Peridie. Stielwand und Columella (letztere fehlend bei D. cerifera) häutig, mit oder ohne Kalk. Capillitium kalkfrei, ein die Columella umgebendes Netzwerk bildend, dessen äußerste Verzweigungen an die Peridie ansetzen.

1. Mit Columella.

2. Sporangien kugelig (vergl. D. leucopoda var. globosa mit kugeligen Sporangien und fein stacheligen Sporen).

3. Die Kalkeinlagerungen des Stieles weiß, Stiel seltener kalkfrei.

4. Sporangien metallblau. Sporen mit erhabenen dunkeln Linien und vorstehenden Warzen.

1. D. splendens Peck in Rep. N. York Mus. Nat. Hist. XXX (1877), 50; Massee Monogr., 261, fig. 37, 38; Lister Monogr. ed. 1, 91, pl. XXXVI, A, fig. d-f und ed. 2, 120, 
pl. 99, fig. d-f; Macbride N. Am. Slime-Moulds 185, pl. VII, fig. 1, 1a, 1b, 1c; Torrend in Broteria VII, 86, pl. VII, fig. 28.

Vnterscheidet sich von $D$. leucoporla var. globosa mur durch die Skulytur der sporen.

\section{N.-Amerika.}

4*. Sporen stachelig oder warzig.

2. D. bulbillosa (Berkeley et Broome) Lister in Penzig Die Myxomyceten d. Flora v. Buitenzorg (1898), 47, in Journ. of Bot. XXXVI, 165, t. 386, fig. 10 und Monogr. ed. 2, 119, pl. 99, fig. g, h; Torrend in Broteria VII, 86.

Synonyme: Didymium bulbillosum Berkeley et Broome in Journ. Limu. Soe. XIV (1873), 84.

Diachæa splendens Racib. in Hed. XXXVII, (1898), 54 non Peck.

Diachæella bulbillosa v. Hölnuel in Sitzmingsber. Akad. Wien Math.-Naturw. Klasse CXV1II (1909), 437, fig. 34.

Unterscheidet sich vou D. leucoporla var. globosa durch die stark warzigen Sporeu.

Ceylon, Java.

$4^{* *}$. Sporen mit zarter, engmaschiger Netzskulptur.

3. I. subsessilis Peck in Rep. New. York Mus. Nat. Hist. XXXI (1879), 41; Rex in Proc. Acad. Nat. Sc. Philadelphia (1893), 368; Massee Monogr., 262; Burrell in Trans. Norf. Nat. Soc. VI, 449 mit Tafel; Petch in Ann. Bot. Gard. Perad. IV, 347; Lister Monogr. ed. 1, 92 und ed. 2, 120, pl. 100, fig. a-d, in Journ. of Bot. XXXV, 213, XXXVI, 379, t. 368 fig. g; Torrend in Broteria VII, 86.

Synonyme: ? Lamproderma Fuckelianum Rost. Monogr. (1875), 208, t. XXXIII, fig. 6; Massee Monogr., 103.

? Lamproderma Fuckelianmm Rost. f. rhenana Racib. in Hedw. XXXYIII (1889), 117.

? Lamproderma Fuckelianum Rost. f. cracoviensis Racib. l. c., 118.

? Physarum Licea Fuckel Symb. Myc. (1869-70), 342 nou Fr. Fxsikkat: 0. Jaap Мухот. exsice. 152.

Plasmodium gelb. Sporangien herdenweise, kugelig, 0,5 mm im Durchmesser, meist gestielt, mitunter an deren Stelle kurze 
Plasmodiokarpien, metallisch g]änzend. Peridie dünn, farblos. Stiel gedrungen, kegelförmig, weiß und mit Kalkgranulationen oder braun und dann kalkfrei, $0,2-0,5 \mathrm{~mm}$ hoch. Columella kegelförmig, weiß, gelblich oder braun, selten fehlend. Capillitium von der Columella ausstrahlend, die Fäden verzweigt, anastomosierend und purpurbraun, meist etwas breiter und blasser gegen den Grund zu, schlanker und farblos an den Enden. Sporenmembran purpurgrau, Sporeninhalt gelb und die Sporen daher im durchfallenden Lichte grünpurpurfarbig, mit feinen netzartig angeordneten Warzen besetzt, $7-10 \mu$.

Deutschland (in einem Gewächshaus des botanischen Gartens in Kiel, Holstein), Oesterreich.

GroBbritannien, Frankreich, Ceylon, Westindien, N.-Amerika.

Für die Zugehörigkeit von Lamproderma Fuckelianum Rost. zu obiger Art sprechen nicht nur Rostafinsky's Beschreibung und Zeichnung des Fuckel'schen Exemplars von Eberbach, sonderu auch der Umstand, daß Raciborski, der in der Lage gewesen ist, letzteres untersuchen zu können, es als wenig versehieden von Exemplaren aus der Ungebung von Krakau, die er als f. cracoviensis des Lamproderma Fuckelianum publiziert hat, erklärt und diese letzteren werden von Lister als anscheinend kalkfreie (hinsichtlich des Stiels und der Columella) Formen von D. subsessilis aufyefaßt. Da mir Belegexemplare fehlen, wage ich es nicht, eine Entscheidung zu treffen und folge hinsichtlich der Benennung Lister, mich schenend eine Umtaufe vorzunehmen, sulange ich nicht die Möglichkeit der strikten Beweisführung habe.

$3^{*}$. Kalk der Stiele orangegelb. Sporangien kupferrot oder violettblau, metallisch glänzend, sitzend oder kurz gestielt. Stiel kurz, gedrungen, orangefarbig, sich als kegelförmige oder kurzzylindrische Columella in das Sporangium fortsetzend. Sporen im durchfallenden Lichte olivenfarbig, mit zerstreuten kleinen Warzen und 4 bis 8 größern Erhebungen, diesich bei starker VergröBerung in Gruppen sehr kleiner Warzen auflösen lassen, $9-11 \mu$.

5. D. Thomasii Rex in Proc. Acad. Nat. Sc. Phil. (1892), 329 ; Macbride N. Am. Slime-Moulds, 136; Torrend in Broteria VII, 87, pl. VII, fig. 22, 23; Lister Monogr. ed. 2, 121, pl. 101, fig. a-c.

N.-Amerika. 
2*. Sporangien zylindrisch, kugelig bei D. leucopoda var. globosa.

5. Sporen nahezu glatt. Stiel mit weißem Kalk.

6. D. leucopoda (Bull.) Rost. Monogr. (1875), 190, fig. 178; Schröter in Cohn Crypt.-Fl. Schles. III, 1, 120; Massee Monogr., 259, fig. 165, 166; Torrend in Broteria VII, 85, pl. VII, fig. 27; Lister Monogr. ed. 2, 118, pl. 99. fig. a-c.

Synonyme: Trichia leucopodia Bu1l. Clamp. (1791), 121, t. 502, fig: 2.

Stemonitis elegans Trentej. in Roth Cat. Bot. I (1797), 220. Stemonitis leucostyla Pers. Syu. (1801), 186.

Stemonitis lencopodia DC. Fl. Fr. III (1805), 257.

Diachæa elegans Fr. Syst. Orb. Veg. I (1825), 143; Rabenh. Deutschl. Krypt.-Fl. I, 270; Čelak. Myxom. Böhm., 58; Lister Nouogr. ed. I, 91, pl. XXXVI, A, fig. a-c.

Diachea confusa Massee Monogr. (1892), 259.

Exsikkaten: Rabenhorst Fungi eur. 434, 1071.

Fuckel Fungi rhelı. 1451.

Sydow. Mye. Mareh. 1900.

(1. Jaap Myxom. exsice. 10, 28, 107, 151.

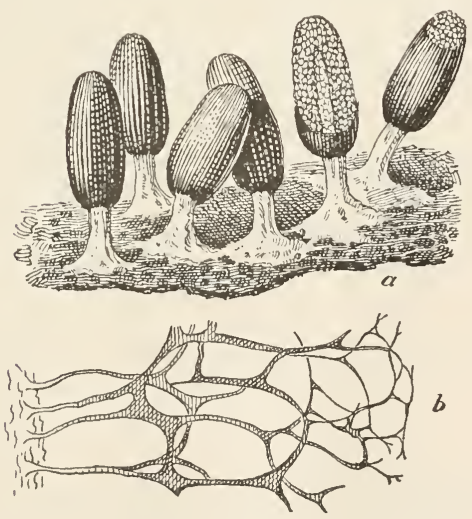

Fig. 73. Diachæa leu copoda (Bull.) Rost.

a) Gruppe von Sporangien, mit zum Teil zerstörter Peridie $(20 / 1)$; b) Capillitium $(280 / 1)$. Nach Lister. 
Plasmodium undurchsichtig weiß. Sporangien herdenweise, zylindrisch (kugelig bei var. globosa), gestielt, purpur- oder blau metallisch glänzend: 'Stiel kalkreich, weiß, gedrungen, spröde, am Grunde breit, auf weißem Hypothallus. Columella zylindrisch, oberwärts verjüngt, bis zur Mitte des Sporangiums oder bis fast ganz zum obern Pol vordringend, kalkreich. Capillitiumfäden reichlich verzweigt und anastomosierend, Sporangienwand und Columella verbindend, dunkelviolettbraun, an den Enden farblos. Sporen im durchfallenden Lichte trübviolett, sehr fein stachelig, $7-9 \mu$.

Deutschland (verbreitet), Schweiz (?), Oesterreich.

Kosmopolitisch.

var. globosa Lister Monogr. ed. 2 (1911), 118.

Sporangien kugelig.

N.- und S.-Amerika, Japan, Java.

5*. Sporangien herdenweise oder \pm ge büschelt, zylindrisch, ungestielt, stahlgrau oder broncefarbig, metallisch glänzend, kalkfrei, (ob immer?). Peridie in große Stücke zerfallend. Columella blaßbraun, schlank, entweder das Sporangium nahezu in der ganzen Länge durchziehend oder unterbrochen und in allseitig abgehende Stränge sich verzweigend. Capillitiumfäden in der ganzen Länge der Columella von dieser abgehend, mit Ausnahmeder Enden purpurbraun. Sporen im durchfallenden Lichte purpurgrau, 11-12 $\mu$, mit feinen, zu einem Maschenwerk angeordneten Stachelchen.

7. D. cylindriea Bilg ram in Proc. Acad. Nat. Sc. Phil. (1905), 524; Torrend in Broteria VII, 87; Lister Monogr. ed. 2, 121, pl. 103, fig. a-e.

N.-Amerika. 
$5^{* *}$. Sporangien zu $6-20$ geknäuelt, zylindrisch oder keulenförmig zylindrisch, sitzend oder kurz gestielt, blau-oder broncefarbig metallisch glänzend. Peridie unterwärts sich rasch ablösend, oberwärts bleibend. Stiel schlank, dunkelbraun, ohne KalkgranulationenEinschlub, sich von einem gelben Hypothallus erhebend. Columella als unterwärts brauner, oberwärts gelblicher Strang das Sporangium fast der ganzen Länge nach durchziehend. Capillitium die Columella allseitig umgebend, aus einem Netzwerk purpurbrauner Fäden bestehend. Sporen im durchfallenden Lichte bla $B$ bräunlichviolett, $9-11-13 \mu$, mit kleinen Warzen und mehreren Gruppen gröBerer Warzen besetzt.

8. I. caspitosa (Sturgis) Lister in Journ. of Bot. XLV 1907), 186 und Monogr. ed. 2, 121, pl. 103, fig. f--j.

S ynonyme: Comatricha cespitosa Sturgis in Bot. Gaz. XrIIl 1893), 186, t. XX, fig. 1-1; Macbride N. A. Slime-Moulds, 124, pl. XI, fig. 12-14; Torrend in Broteria V1I, 79, $1 \mathrm{I}$. V, fig. 18.

Diachea Thomasii Rex var.? Lister Monogr. ed. 1 (1894), 92. N.-Amerika.

$1^{*}$. Columella fehlend.

D. cerifera G. Lister in Journ. of Bot. LI (1913), 3, t. 525 , fig. $1-3 \mathrm{~b}$.

Plasmodium farblos oder weib (Meylan ap. Lister 1. c.) Sporangien zerstreut oder in kleinen Häufchen zu 2 bis 3, gestielt, kugelig oder ellipsoidisch, 0,7-1,2 mm im Durchmesser, purpurbräunlich und metallisch glänzend. Stiel gedrungen, zuerst gelblich, später sich braun färbend, längsgefältelt, $0,2-0,6 \mathrm{~mm}$ hoch und $0,15-0,5 \mathrm{~mm}$ dick, namentlich im obern Teil mit 
Wachsgranulationen ausgefüllt. Columella fehlend oder durch das abgeflachte obere Stielende ersetzt. Capillitiumfäden vom Stielende ausstrahlend, straff, mit vereinzelten knotenförmigen Verdickungen, nahezu schwarz mit Ausnahme der blassen Enden, \pm verzweigt und anastomosierend. Sporen purpurgrau, blaß oder dunkel im durchfallenden Lichte, fein stachelig, 10-18 $\mu$.

Im Schweizer Jura (Chasseron) bei $1400 \mathrm{~m}$.

Diese eigenartige Art steht innerhalb der Gattung Diachæa ganz isoliert, einerseits durch das Fehlen einer Columella und anderseits im Hinblick auf die Wachseinschlüsse. Sie ist auch noch aus Norwegen und aus Japan bekannt. Die norwegisehen und japanischen Exemplare zeigen an obern Eude des gedrungenen Stiels einen dicken, gelben Kragen, auf dem das kugelige Sporangium ruht und der den schweizerischen Vorkommnissen abzugehen scheint. Der Kragen führt gleich dem eigentliehen Stiel Wachseinschlüsse.

\section{Familie Didymiaceae Rost. pr.p.}

Vers. eines Systems der Mycetozoen (1873), 12 pr. p., Monogr. 149 pr. p. und App. 15 pr. p.; Schröter in Cohn Krypt.-Fl. Schles. III, 1, 121 pr. p. und in Engl. und Prantl Natürl. Pflanzenfam. I, 1, 30 pr. p.; Lister Monogr. ed. 1, 93 und ed. 2, 122; Schinz in Mitt. Naturw. Ges. Winterthur VI, 56 ; Macbride N. A. Slime-Moulds, 82 pr. p.; Torrend in Broteria VI, 51, VII, 88.

Kalk in Form von Kristallen oder kristallinischen Scheiben der Sporangiumwand aufgelagert. Capillitium dünnfädig (mit Ausnahme von Didymium complanatum und bestimmten Formen von Lepidoderma Carestianum), ohne Kalkknoten. Sporangien zerstreut oder (bei Mucilago) zu Aethalien vereinigt.

Rostafinski und die auf ihn unmittelbar folgenden Autoren subordinieren der Tribus Didymiaceae nicht nur die Gattungen Didymium und Lepidoderma, sondern auch Leangium (Diderma pr. p.) und Chondrioderma (=Diderma pr. p.), vereinigen dagegen z. 'T. Diachacea und Spumaria (= Mucilago $)$ zur Tribus Spumariaceae.

\section{Schlüssel zur Bestimmung der Gattungen der Familie der Didymiaceae.}

1. Sporangien nicht zu Aethalien vereinigt.

2. Kalkkristalle sternförmig. 1. Didymium Schrader 2*. Kalkkristalle nicht sternförmig. 
3. Kalkkristalle \pm scheiben- oder schuppenförmig.

4. Peridie knorpelig. 3. Lepidoderma de Bary

4*. Peridie häutig, oberwärts zart, unterwärts dicker, Kalkauflagerung spärlich oder fehlend. 4. Leptoderma G. Lister

1*. Sporangien Aethalien bildend.

2. Mucilago Adanson

\section{Übersicht der Gattungen.}

Didymium. Gestielte oder ungestielte Sporangien oder Plasmodiokarpien, nie Aethalien bildend. Peridie dünn oder knorpelig, unregelmäßig aufreißend, besetzt mit zerstreuten Kalkkristallen oder letztere eine abhebbare zusammenhängende, mitunter eierschalenartige Kruste bildend.

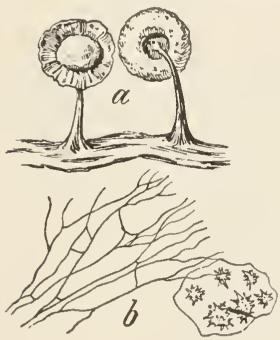

Fig. 7t. Didyminm nigripes (Link) Fr. Nach Lister.

a) 2 Sporangien; dasjenige links mit z. T. entfernter Peridie, die Columella zeigend; dasjenige rechts vou unten gesehen $\left({ }^{12 /} / 1\right)$. b) Capillitıum und Peridiefragment mit Kristallen $\left({ }^{\mathbf{8} 8} / 1\right)$.

Mucilago. Aethalien zusammengesetzt aus verlängerten, zusammengedrückten, gelappten und zusammenfliebenden grauen Sporangien, poröse, von einer weißen, meerschaumartigen, brüchigen Rinde aus Kalkkristallen überzogene Klumpen bildend.

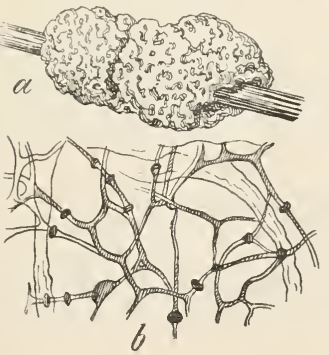

Fig. 75 .

Mucilago spongiosa (Leysser) Morgan Nach Lister.

a) Aethalium, ein Zweigstück umwickelnd $(2 / 1)$;

b) Capillitium $\left({ }^{260} / 1\right)$. 
Lepidoderma. Gestielte oder sitzende Einzelsporangien oder Plasmodiokarpien. Peridie mit zahlreichen Kristallschüppchen oder Kristallscheiben, daher gescheckt. Capillitium meist ohne Kalk.

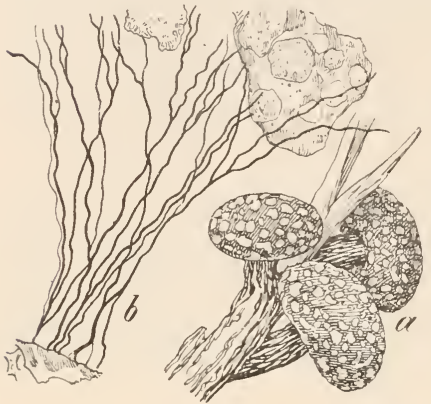

Fig. 76. Lepidoderma tigrinum (Schrader) Rost. - Nach Lister. a) Sporangiengruppe $\left({ }^{20} / 1\right)$; Capillitium, oben ein Fragment der Peridie mit Kristallschuppen $\left({ }^{\mathbf{2} 8} / \mathrm{1}\right)$.

Leptoderma. Sitzende oder kurz gestielte, kugelige oder halbkngelige Einzelsporangien mit oberwärts häutiger und dünner, unterwärts dickerer und mitunter mit sehr kleinen Kalkkristallschuppen besetzter Peridie. Stiel mit ausgestoßenem Material erfüllt.

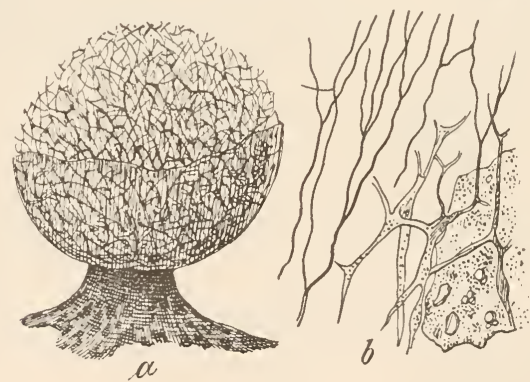

Fig. 77. Leptoderma iridescens G. Lister - Nach Lister.

a) Sporangium, Peridie in obern Teil entfernt $\left({ }^{40} \%\right)$; b) Capillitium, rechts daneben Fragment der Peridie nit eingebetteten Kalkschuppen (270/1).

\section{Gattung Didymium Schrader pr. p.}

Nov. Gen. Pl. (1797), 20; Fr. Syst. Myc. III, 113; Rabenhorst Deutschl. Krypt.-Fl. I, 278; de Bary in Rost. Vers. Syst. Myc. 13 und Monogr., 150; Schröter in Cohn Krypt.-Fl. Schles. III, 1, 121 und 
in Engler und Prantl Natiirl. Pflanzenfam. I, 1, 30) Massee Monogr., 218: Celak. Myxom. Böhm., 59; Lister Monogr. ed. 1, 93 und ed. 2, 123; Schinz in Mitt. Naturw. Ges. Winterthur VI, 56; Macbride N. A. Slime-Moulds, 84; Torrend in Broteria VI, 51, VII, 89.

Gestielte oder sitzende Einzelsporangien oder an deren Stelle Plasmodiokarpien. Peridie häutig oder knorpelig, bestäubt mit Kalkkristallen oder letztere eine abhebbare, schalenartige Kruste bildend. Die Kalkkristalle keine Schüppchen oder Scheiben bildend. Columella meist vorhanden. Capillitium aus verzweigten, häufig anastomosierenden, der Kalkknoten entbehrenden, aber oft unterbrochen knoten- oder verkürzt kelchartig verdickten Fäden bestehend.

1. Peridie häutig.

\section{Untergattung Eudidymium Lister}

ed. 2,123 .

2. Kalkkristalle auf der Peridie dieht genähert, eine dïnne, eierschalenartige Kruste bildend. Columella fehlend.

3. Sporangien kissenförmig mit breiter Basis dem substrat aufsitzend. Capillitium spärlich, entweder aus schlanken, dïnnen, oder aus gröbern, flachen, am Grunde etwas breitern Fäden bestehend, in beiden Fällen die Fäden namentlich gegen die Enden zu gabelig verzweigt.

1. D. difforme (Pers.) I) uby Bot. Gall. II (1830), 858; Lister Monogr. ed. 1, 94, pl. XXXVII, A, fig. a-e und ed. 2, 124, pl. 104, fig. a-d; Schinz in Mitt. Naturw. Ges. Winterthur VI, 58; Torrend in Broteria VII, 89, pl. VII, fig. 16.

Synonyme: Diderma difforme Pers. Disp. Meth. (1797), 9; Rabenhorst Dentsehl. Krypt.-Fl. I, 283.

Reticularia angulata Pers. in Gmel. Syst. Nat. (1791), 1472?

Licea crsia Schum. Eunm. Pl. Saell. II (1803), 219.

Physarum difforme Link in Mag. Ges. Nat. Fr. Berlin III, (1809), 27. 
Didymium eyanescens Fr. Symb. Gaster. (1817), 19.

Lycogala minutum Grev. Scot. Crypt.-Fl. (1823), t. 40.

Licea alba Nees in Kunze und schmidt Myc. II (1823), 66.

Physarum album Fr. Syst. Myc. III (1829), 147; Rabenhorst Deutsehl. Krypt.-Fl. I, 272.

Physarum casium Fr. 1. c., 147.

Diderma cyanescens Fr. Syst. Myc. III (1829), 109.

Diderma liceoiles Fr. syst. Mye. III (1829), 107?

Licea macrospora sichwein. in Trans. Am. Phil. Soc. n. s. IV (1832), 258.

Diderma niteus Klotzsch in Sm. Engl. Fl. V, 2 (1836), 311.

Diderna chalybeum Weinm. Hymen. et Gaster. (1836), 592?

Diderma Neesii Corda Icon. II (1837-54), 23.

Diderma Libertianum Fres. Beitr. Myk. (1850, 28, t. IV, fig. $16-27$.

Dirlymium Libertianum de Bary Mycetozoa (1864), 124.

Choudrioderma diftorme Rost. in Fuckel symb. Myc. Nachts. (1873, 73 und Monogr., 177, fig. 1:37, 164, 165; Masisee Monogr., 212, fig. 35-35.

Chondrioderma liceoides Rost. Monogr. Apl. (1876), 17; Massee Monogr., 215.

Diderma Persoonii Macbride N. A. Slime-Mfoulds (1899), 96.

Exsikkaten: Rabenhorst Fungi eur. 1423.

Fuckel Fungi rhen. 1461, 2300.

Rabenhorst-Winter 456.

O. Jaap. Myxom. exsicc. 11, 69, 108.

Plasmodium farblos oder gelb. Sporangien zerstreut, polsterartig mit breiter Basis dem Substrat aufsitzend, weiß und glatt oder an deren stelle weiße und glatte, unregelmäßig verlängerte, bis $2 \mathrm{~mm}$ lange Plasmodiokarpien. Kalkkristalle dicht stehend, eine weiße, glatte, eierschalenartige Kruste bildend, die sich von der innern, metallisch glänzenden, häutigen, oberwärts farblosen oder roten, unterwärts gelbbraunen Peridieschicht trennen läßt. Columella O. Capillitium, aus an den Enden gabelig verzweigten Fäden bestehend, diese zum Teil anastomosierend, entweder gleichmäbig dünn (var.) oder am Grunde etwas verbreitert. Sporen im durchfallenden Lichte dunkel purpurbraun, entweder \pm undeutlich- und dicht- oder gröber- und zerstreut warzig. 11-1 4 .

Deutschland, Schweiz, Österreich, häufig.

Großbritannien, Frankreich, Italien, Portugal, Belgien, Dänemark, Schweden, Indien, Seychellen, Japan, N.- und S.-Amerika. 


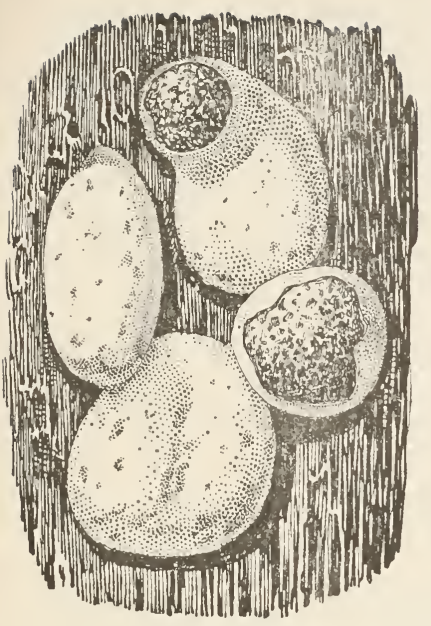

$a$

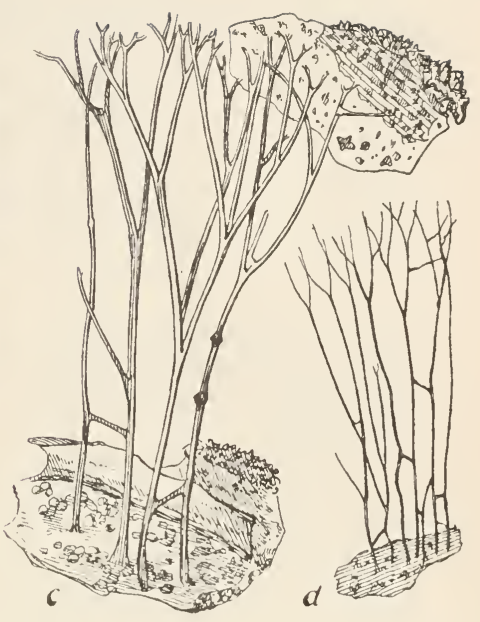

Fig. 78. Didymium difforme Pers.

a) (iruppe von sporangien, 2 geäfhet, die sprerenmasse zeigend $(20 / 1)$; e) T'eil des Cajillitinms mit einem obern und untern Wandframent $\left({ }^{280} / 1\right)$; d) Capillitium von var. comatm Lister mit einem Fragment der Peridie $\left({ }^{\mathbf{2 8 0}} / \mathbf{1}\right)$. a nach der Natur, e und d nach Lister.

Es lassen sich folgende Spielarten unterscheiden:

var. genuinum Torrend in Broteria VII (1908), 89. Capillitium spärlich; Fäden am Grunde verbreitert.

var. comatum Lister Monogr. ed. 2, 125, pl. 104, fig. c: Torrend in Broteria VII, 89.

Synonyme: Leocarpus calcareus Link in Mag. Ges. Nat. Fr. Berlin Ill (1809), 26?; Rabenh. Deutschl. Krypt.-Fl. I, 284? Chondrioderma ealeareum Rost. in Fuckel Symb. Nachtr. (1873), 74. Didymium comatum Lister in Journ. of Bot. XXXIX (1901), 7.

Capillitium reichlich entwickelt. Fäden gleichmäßig schlank, am Grunde nicht verbreitert. Sporen etwas blasser.

$3^{*}$. Sporangien zerstreut, sitzend, halbkugelig niedergedrückt, glatt weib. 
ÄuBere Wandschicht eierschalenartig und weib, sich von der blab purpurnen innern Schicht lösend. Ohne Columella. Capillitiumfäden schlängelnd, purpurbraun, am Grunde nicht verbreitert. Sporen im durchfallenden Lichte bräunlichpurpurn, warzig und mit unvollständiger netzartiger Skulptur, 13-14 $\mu$ (-18 $\mu$ nach Sturgis).

2. D. quitense (Patouill.) Torrend in Broteria VII (1908), 90; Lister Monogr. ed. 2. 126; Sturgis in Colorado College Publ. Gen. Ser. 68 Sc. ser. XII, Nr. 12, 446, pl. 2, fig. 13, 14 .

Synonym: Chondrioderma quitense Patouill. in Bull. Soc. Myc. France XI (1895), 212?

Ecuador, Colorado.

$3^{* *}$. Sporangien sitzend, kreisrunde oder flache, breite Plasmodiokarpien bildend. Capillitium reichlich, dunkel, straff, mit schlanken Enden (bei D. quitense in der ganzen Länge gleichmäßig dick).

3. I. dubium Rost. Monogr. (1875), 152; Ċelak. Myxom. Böhm., 64; Massee Monogr., 246, fig. 102, Lister Monogr. ed. 1, 95, pl. XXXVII, B, fig. a-g und ed. 2, 126, pl. 105, fig. a-c; Torrend in Broteria VII, 91, pl. VII, fig. 17, 18.

Synonym: Didymium Listeri Massee Mouogr. (1892), 244, fig. 97, 101.

Plasmodium wässerig weiß. Sporangien vereinzelt, kreisrunde oder unregelmäßig gestaltete, nahezu flache, $1-12 \mathrm{~mm}$ breite und $0,13 \mathrm{~mm}$ dicke Plasmodiokarpien bildend. Äußere Peridieschicht aus einer zusammenhängenden, aus großen, sternförmigen, fest verbundenen Kalkkristallen zusammengesetzten Kruste bestehend, die schlieBlich in zahlreiche Schuppen und Kalkblättchen zerfällt. Innere Wandschicht häutig. Columella fehlend. Capillitium reichlich entwickelt, Fäden dunkelpurpurbraun, straff, mit den farblosen, verzweigten Enden an der Sporangiumwand befestigt, mit Querbrücken und hin und wieder 
mit kleineren, seltener größeren knotenartigen Verdickungen versehen. Sporen im durchfallenden Lichte violettgran, stachelig oder fast glatt, $8-15 \mu$.

Bis anhin im Gebiet nur aus Böhmen bekannt.

Großbritannien.

Die Sporangien dieser Art unterscheiden sich von jenen des $D$. difforme namentlich dadurch, daß erstere mit freien Kalkkristallen mehlig bestäubt sind, während die von $D$. difforme ganz glatt sind.

$3^{* * *}$. Sporangien halbkugelig, kreisel-oder steinpilzartig, crêmefarbig oder weiß, sitzend oder kurz gestielt. Stiel kurz und gedrungen, verkehrtkegelförmig, gelblichbraun, angefüllt mit Kalkkristallen. Kalkkruste der Sporangien diesen gleich einem halbkugeligen Hute aufsitzend, a us Kalkkristallen béstehend. Columella vorhanden, gleich dem Stiel mit Kalkkristallen an gefült, breit konvex, am Rande verdickt, gelbbraun. Capillitiumfäden straff, farblos oder purpurbraun, einfach oder spärlich verzweigt, $a b$ und zu mit knotenförmigen Verdickungen und gegen den Grund zu mit blasigen Erweiterungen, die mit Kalkkristallen angefüllt sind, versehen. Sporen im durchfallenden Lichte braunrot, grobwarzig, a uf einer $\mathrm{Halbkugel}$ heller und feiner warzigals auf der ent gegenges etzten, 9 -10 $\mu$.

4. D. Trochus Lister in Journ. of Bot. XXXVI (1898), 164, t. 386, fig. $1 \mathrm{a}-\mathrm{c}$, und Monogr. ed. 2, 127, t. 106, fig. a-c; Torrend in Broteria VII, 90, pl. IX, fig. 6, 7 .

Großbritannien, Portugal.

2*. Die der Sporangiumwand aufgelagerten Kalkkristalle zerstreut oder nur locker verbunden.

Schinz, Myxogasteres (Rabenhorst Krypt. Flora I, Pilze Abt. X). 
4. Stets Plasmodiokarpien. Capillitium mit groben olivenfarbigen Blasen.

5. D. complanatum (Batsch) Rost. Monogr. (1875), 151, fig. 166, 180 non Schrad.; Torrend in Broteria VII, 93, pl. VII, fig. 10 ; Macbride N. A. Slime-Moulds 85, pl. XV'I, fig. 8; Lister Monogr. ed. 2, 127, pl. 107, fig. a-d.

Synonyme: Lycoperdon complanatum Batsch Elench. Fung. I (1786), 251?

Physarum confluens Pers. var. muscigenum Alb. et Schwein. Consp. Fung. (1805), 61 ?

Didymium Serpula Fr. Syst. Mye. III (1829), 126?; Rabenh. Deutschl. Krypt.-Fl. I, 278; Rost. Monogr. App., 21; Schröter in Cohn Krypt.-Fl. Schles. III, 1, 121; Massee Monogr., 234, fig. 55-57; Lister Monogr. ed. 1, 96, pl. XXXVIII, A, fig. a-d.

Exsikkat: Fuckel Fungi rhen. 1463.

Plasmodium zitronengelb. Plasmodiokarpien zerstreut und einzeln, kriechend, dem Substrat angedrückt. $2-8 \mathrm{~mm}$ lang, 0,1-0,15 mm dick, ring-, netz-, fladen- oder wurmförmig, grau. Peridie mit grauen, nicht zahlreichen Kalkkristallen. Columella fehlend. Capillitiumfäden blaß violett, sehr schlank und zart, verzweigt und anastomosierend, mit knotenförmigen Verdickungen und in Verbindung stehend mit 20-50 großen, gelben, fein warzigen Blasen. Sporen im durchfallenden Lichte blab violettbraun, fein warzig, $7-9 \mu$.

Deutschland, Schweiz.

GroBbritannien, Portugal, Frankreich, Belgieu, Finnland, N.-Amerika. 4*. Gestielte Sporangien oder an deren Stelle Plasmodiokarpien. Capillitium ohne Blasen. Sporen \pm stachelig.

5. Sporangien scheibenförmig. mit dunkel gefärbten Stielen.

6. D. Clarus (Alb. et Schwein.) Rost. Monogr. (1875), 153; Rabenhorst Deutschl. Krypt.-Fl. I. 280; Massee Monogr., 230, fig. 53, 54; Lister Monogr. ed. 1, 96, pl. XXXVill, B, fig. a-c und ed. 2, 128, pl. 108, fig. a-d; Macbride N. A. Slime-Moulds, 90; Torrend in Broteria VII, 93, pl. VII, fig. 21.

Synonyme: Reticularia hemisphærica Bull. Champ. (1791), 93, pl. 446, fig. 1 ?

Physarum Clavus Alb. et Schwein. Consp. Fung. (1805), 96. 
Didymium melanopus var. Clavus Fr. Syst. Myc. III (1829), 114; Rabenh. Deutschl. Krypt.-Fl. I, 280.

Didymium hemisphæricum Fr. 1. c., 115?; Rabenh. Deutschl. Krypt.-FI. I, 280?

Didymium commutabile Berkeley ot Broome in Journ. Linn. Soc. XIV (1873), 83; Rost. Monogr. App., 21.

Didymium radiatum Massee Monogr. (1892), 229, fig. 68-72 pr. p.

Didymium neglectum Massee Monogr. (1892), 231; fig. 207 non Berkeley et Broome.

Didymium Masseeanum Sacc. et Syd. Syll. Fung. XIV (1899), 836. Exsikkat: 0. Jaap Myxom, exsicc. 70 .

Plasmodium grau oder farblos. Sporangien zerstreut, 0,5-1 mm hoch, scheibenförmig, gestielt, aufrecht, grauweiß; Sporangienwand rotbraun gesprenkelt, bestäubt mit Gruppen sternförmiger Kalkkristalle, am Grunde braun und nackt. Stiel schlank, längsgestreift, blaßbraun oder schwarz. Columella fehlend, ab und zu ersetzt durch den verdickten Grund der Sporangiumwand. Capillitium reichlich, aus spärlich verzweigten, zarten, farblosen oder purpurbraunen Fäden bestehend. Sporen im durchfallenden Lichte violettbraun, nahezu glatt, $5-8 \mu$.

Deutschland, Schweiz.

Großbritannien, Frankreich, Portugal, Dänemark, Belgien, Rußland, N.- und S.-Amerika, Antigua.

$$
\begin{aligned}
& \text { 5*. Sporangien } \pm \text { kugelig oder an } \\
& \text { deren Stelle ausgebreitete Plas- } \\
& \text { modiokarpien. }
\end{aligned}
$$

6. Stiel und Columella dunkelbraun. Stiel undurchsichtig, angefüllt mit AusschuBmaterial.

\section{D. melanospermum (Pers.) Macbride N. A. Slime-} Moulds (1899), 88; Lister Monogr. ed. 2, 129, pl. 112, fig. a-f.

Synouyme: Physarmm melanospermum Pers. in Roem. Nat. Mag. Bot. (1794), 88.

Didymium farinaceum Sehrad. Nov. Gen. Plant. (1797), 26, t. 5, fig. 6; Rabenhorst Deutschl. Krypt.-Fl. I, 280; Rost. Monogr., 154, fig. 128, 171, 174; Schröter in Cohn Krypt.-F]. Schles. III, 1, 121; Čelak. Myxom. Böhm., 60; Massee Monogr., 219, fig. 2935; Lister Monogr. ed. 1, 97, pl. XXXIX, A, fig. a -f; Schinz in 
Mitt. Naturw. Ges Winterthur VI, 59; Torrend in Broteria

VII, 94, pI. VII, fig. 19, 20.

Didymium complanatum Schrader Nov. (ien. Plant. (1797), 24,

t. 5, fig. 5?; Rabenh. Deutschl. Krypt.-Fl. I, 280.

Trichia depressa 'T'rentep. in Roth Cat. Bot. (1797), 231.

'richia compressa Trentep. in Poth Cat. Bot. 1, (1797), 229.

Trichia farinosa Poiret in Lam. Encyel. VIII (1799), 53.

Trichia sphærocephala Sow. Engl. Fung. (1799), t. 240.

Spumaria physaroides Pers. Syn. Fung. (1801), 163?

Physarum farinaceum Pers. Syn. (1801), 174.

Physarum einerascens Schum. Enum. Pl. Saell. II (1803), 199?

Physarum globosum Schum. Euum. PI. Saell. II (1803), 203?

Physarum sinuosum Link in Mlag. Ges. Nat. Fr. Berlin 111 (1809), 27.

Physarum capitatum Link in Mag. (ies. Nat. Fr. Berlin III (1809), 27.

Didymium lobatum Nees syst. (1816), 112?; Rabenh. Deutschl. Krypt.-FI. I, 279?

Strongylium minus Fr. Symb. Gaster. (1817), 9.

Didymium physaroides Fr. Symb. Gaster. (1818), 21 ; Rost. Monogr., 158, fig. 147; Rabenh. Deutschl. Krytt.-Fl. 1, 279; Nassee Monogr., 233.

Chondrioderma lobatum Spreng. Sist. Orb. Veg. IV (1827), 529. Physarum nigrum Fr. Syst. Mye. III (1829), 146?; Rabenh.

Deutschl. Krypt.-FI. I, 273?

Didymium melanopus Fr. Syst. Mye. III (1829), 114?; Rabenh.

DeutsehI. Krypt.-FI. I, 280?

Chondrioderma farinaceum Link Handb. III (1833), 410.

Didymium Fairmani sace. in Jouru. IIyc. (1889), 79.

Exsikkaten: Rabenhorst Fungi eur. 369.

Fuckel Fungi rhen. 1461.

Jack, Leiner \& Stitzenb. 424.

O. Jaap Myxom. exsice. 12, 71, 91.

Plasmodium farblos oder gran. Sporangien herdenweise. \pm kugelig oder halbkugelig, unterseits tief genabelt, entweder gestielt oder ungestielt, häufig zusammenfließend, weiß oder grau. Stiel aus breitem Grunde eylindrisch verjüngt, gestreift, dunkelbraun, selten rotbraun, bis $0.7 \mathrm{~mm}$ lang, angefïllt mit ausgestoßenem Material und daher undurchsichtig. Sporangiumwand purpurbraun gefleckt und mit Kalkkristallsternen besetzt. Columella halbkugelig, unterseits konkav, dunkelbraun. selten weißlich, gekammert, die Kammern mit feinkörniger Kalkmasse erfüllt. Capillitium aus \pm wellig gebogenen, kräftigen oder zarten (var. minus), meist unverzweigten, farblosen oder purpurbraunen 
Fäden mit oft knotenförmigen Verdickungen bestehend. Sporen im durchfallenden Lichte dunkelpurpurbraun oder purpurgrau, nahezu glatt oder stachelig, 9-12 $\mu$.

Deutschland, Schweiz, Österreich.

Kosmopolitisch.

Mit Lister unterscheiden wir eine

var. minus Lister Monogr. ed. 2 (1911), 129, pl. 112, fig. d.

Synonyme: Didyminm farinaceum Schrader var. minus Lister Monogr. ed. 1 (1894), 97, pl. XXXIX, A, fig. d und in Journ. of Bot. XXXVI, 379.

Didymium minus Morgan Myx. Miami Valley (1894), 6I; Macbride N. A. Slime-Noulds, 89 , pl. X, fig. 4, 4a, 4 b.

Didymium humile Hazslinszky in üsterr. Bot. Zeitschr. XXVII (I877), 84 .

Capillitiumfäden zart, Sporen $7-9 \mu$.

$6^{*}$. Stiel olivenbraun oder orangefarbig, durchsichtig, ohne ausgestobene Materialien.

8. D. nieripes (Link) Fr. Syst. Myc. III (1829), 119; Lister Monogr. ed. 1, 98, pl. XXXIX, B, fig. a-e und ed. 2, 130, pl. 102, fig. a-g; Macbride N. A. Slime-Moulds, 90, pl. VII, fig. 2, 2a, 2b; Torrend in Broteria VII, 95.

synonyme: Physarum nigripes Link in Mag. Ges. Nat. Fr. Berlin III

Diss. I (1809), 27.

Physarum microcarpum Fr. Symb. Gaster. (1818), 23.

Didymium microcephalum Chevall. Fung. et Byss. IlI (1837), fig. 2.

Didymium porphyropus D urie u et II on tagne Fl. Alg. (1846), 409. Didymium microcarpon Rost. Monogr. (1875), 157, fig. 133, 177,

Massee Monogr., 226, fig. 44, 45.

Didymium tenue Patouill. in Bull. Soc. Myc. France IV (1888), 96.

Plasmodium grau oder farblos. Sporangien herdenweise, kugelig oder halbkugelig, unterwärts genabelt, gestielt, aufrecht, weiß. Sporangiumwand farblos oder braungefleckt, mit sternförmigen Kalkkristallen. Stiel 2 bis 3 mal länger als das Sporangium, zylindrisch, längsgestreift, durchsichtig, olivenbraun bis orangebraun. ('olumella kugelig, dunkelbraun. Capillitiumfäden zart, farblos oder purpurbraun, spärlich verzweigt, mit Querbrücken. Sporen im durchfallenden Lichte blaßviolettbraun, nahezu glatt, $8-11 \mu$. 
Als Spielarten hierzu:

var. eximium (Peck) Lister Monogr. ed. 1 (1894), 98, ed. 2, 131, pl. 102, fig. d.

Synonyme: Didymium megalosporum Berkeley et Curtis in Grev. II (1873), 53.

Didymium eximium Peck in Rep. New York Mus. XXXI (1879), 41; Macbride N. A. Slime-Moulds, 92, pl. XVI, fig. 9.

Didymium fulvellum Massee Monogr. (1892), 237.

Exsikkat: 0. Jaap Hyxom. exsice. 92.

Stiel dunkelorangefarbig, Columella orange- oder lederfarbig; Peridie verhältnismäßig dick.

var. Xanthopus (Ditm.) Lister Monogr. ed. 1 (1894), 98, ed. 2, 131, pl. 102, fig. e-g und in Journ. of. Bot. XXXVI, 119.

Synonyme: Cionium xanthopus Ditm. in Sturm Deutschl. Fl., Pilze (1817), 87, t. 43.

Diderma lobatum Somm. Suppl. Fl. Lapp. (1826), 240?

Didymium xanthopus Fr. Syst. Myc. III (1829), 120; Macbride

N. A. Slime-Moulds, 91, pl. XVI, fig. 10.

Cionium iridis Ditm. in Sturm Deutschl. Fl., Pilze (1817), 13, t. 7 .

Didymium iridis Fr. Syst. Mye. III (1829), 120.

Didymium lobatum var. stipitatum Fr. Syst. Hyc. III (1829), 123 ?

Didymium iridis Fr. Syst. Mye. III (1829), 120.

Didymium pertusum Berkeley Engl. Fl. V (1836), 313; Massee Monogr., 241.

Didymium proximum Berkeley et Curtis in Grev. II (1873),

52; Rost. Mlonogr. App., 23.

Didymium elegantissimum Massee Monogr. (1892), 243.

Stiel orangefarbig, Columella weiß.

Verbreitung der Art: kosmopolitisch.

$6^{* *}$. Stiel und Columella weiB oder gelblich. Kalkkristalle auf dem Sporangium entweder zerstreut oder eine runzelige Kruste bildend. An Stelle von Sporangien nicht selten unregelmäßig aufspringende Plasmodiokarpien.

9. D. squamulosum (Alb. et Schwein.) Fr. Symb. Gaster. (1818), 19 und Syst. Myc. III, 118; Rabenhorst Deutschl. Krypt.Fl. I, 280; Rost. Monogr., 150, fig. 148; Schröter in Cohn 
Krypt.-Fl. Schles. III, 1, 122; Macbride N. A. Slime-Moulds, 87; Massee Monogr., 223, fig. 46-52; Torrend in Broteria VII, 92; Lister Monogr. ed. 2, 131, pl. 109, fig. a-i.

Synonyme: Trichia rugosa T'rentep. in Roth Cat. Bot. I (1797), 228 ?

Trichia spherica 'T'rentep. in Roth Cat. Bot. I (1797), 230.

Physarum confluens Pers. Syu. (1801), 169 ?

Diderma squamnlosum Alb. et Sch wein. Consp. Fung. (1805), 88.

Tubulina pedicellata Po iret Encycl. bot. Suppl. VIII (1808) 373.

Licea stipitata DC. Fl. Franc. ed. 2 (1815), 101.

Didymium effusum Linko in Mag. Ges. Nat. Fr. Berlin (1815), 42; Rabenhorst Dentschl. Krypt.-Fl. I, 279; Rost. Mouogr., 163; Celak. Myxom. Böhm., 63; Mrassee Monogr., 236; Lister MLonogr. ed. 1, 99, pl. XI, A, tig. a-e; Schinz in Mitt. Naturw. Ges. Winterthur Vl, 58.

Chondrioderma squamulosmm Spreng. Syst. Veg. IV, (1827), 628. Didymium herbarum Fr. Syst. Myc. III (1829), 120; Rabenhorst Dentschl. Krypt.-Fl. I, 281.

Didymium leucopns Fr. Syst. Myc. III (1829), 121; Rabenh. Deutschl. Krypt.-Fl. I, 281.

Didymium costatum Fr. Syst. Myc. III (1829), 118.

Physarum liceoides Duby Bot. Gall. II (1830), 461?

Didymium filamentosum Wallr. Fl. Krypt. Germ. (1833), 368? Didymium praecox de Bary in Rabenhorst Fung. eur. (1861), Nr. 367.

Didymium radiatum Berkeley et Curtis in Jouru. Limn. Soc. $\mathrm{X}$ (1869), 348; Mlassee Monogr., 229, fig. 68-72.

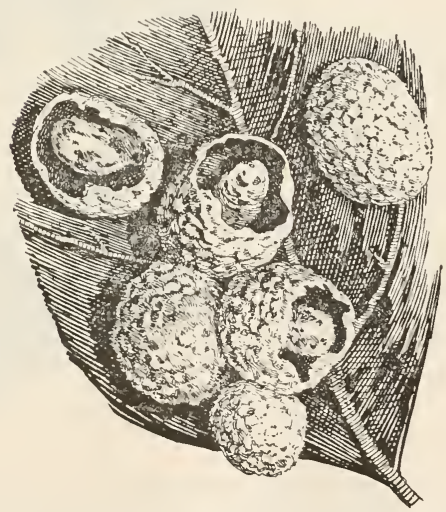

Fig. 79. Didymium squamulosum (Alb. et Schwein.) Fr. Gruppe von Sporaugien $\left({ }^{* 0} / 1\right)$. - Nach der Natur. 
Didymium Chondrioderma de Bary et Post. in Alex. Stroz. (1872), 89.

Didymium neglectum Berkeley et Broome in Journ. Limn. Soc. XIV (1873), 83.

Didymium Fuckelianum Rost. Monogr. (1875), 161, fig. 134; Massee Monogr., 222.

Didymium macrospermum Rost. Monogr. (1875), 161; Celak. Myxom. Bölım., 62; Massee Monogr., 228.

Didymium discoideum R ost. Monogr. (1875), 16ㄹ; Massee Monogr., 229.

Didymium eonfluens Rost. Monogr. App. (1876), 22.

Didymium platypus Hazsłinszky in Österr. Bot. Zeitsehr. XXVII $(1 \times 7 \bar{T}), 83$ ?

Didyminm angulatum Peek in Rep. New York Mus. XXXI $(1879), 41$.
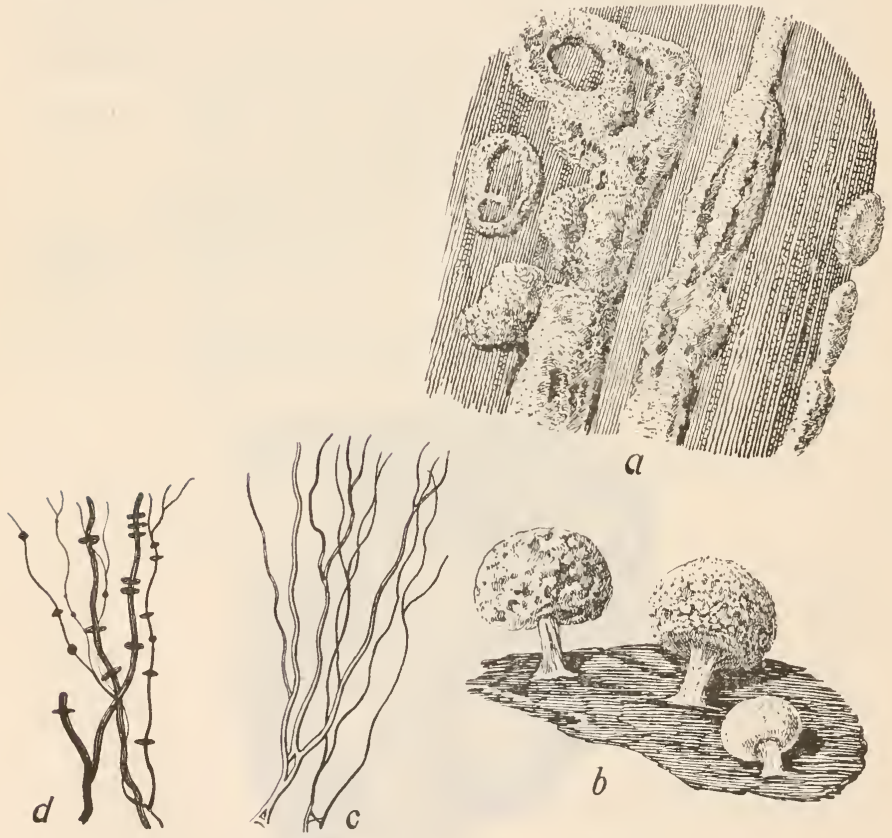

a

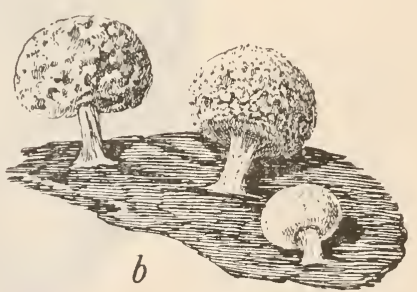

Fig. 80. Didyminm squamulosnm (Alb. et S'chwein.) Fr.

a) Plasmodiokarpien $(20 / 1)$; b) Gruppe von Sporangien $(20 / 1)$; c) und d) Capillitium zweier Formen $\left({ }^{280} / 1\right)$. - a nach der Natur, b, e und d wach Lister. 
Chondrioderma leptotrichum liacib. in Rozpr. Mat.-Przyr. Acad. lirakan XII (1884), 75?

Didymium Cookei Raunk. in Bot. Tidskr. XVHl (1888), 86.

Didymium Bonianum Patonill. in Jourı. de Bot. I (18:1), 316.

Didymium Alexandrowiezii Massee Monogr. (1892), 2:32.

Didymium T'ussilaginis Massee Monogr. (1892), 244.

Didlymium affine Raunk. in Bot. Tidskr. XV1I (1885), 88, t. Y, fig. 3, 4.

Physarum alatum Fr. Syst. Myc. 111 (1829), 132; Rabenhorst Deutschl. Kirypt.-Fl. 1, 277 .

Physarum Thssilaginis Berkeley et Broome in Am. Mag. Nat. Hist. ser. 4, XVII (1876), 139.

Chondrioderma anomalum Rost. Monogr. (1875), 169.

Physarum Alexandrowiczii Rost. Monogr. (1875), 169, fig. 176.

Choulrioulerma Cookei Rost. Monogr. A]') (1876), 17.

Exsikkaten: Rabenhorst Fungi eur. 367, 813.

Fuckel Fungi rhen. 1462, 2497, 2498, 2690.

Rabenhorst-Winter Fungi eur. 2675, 2969.

Sydow Myc. March. 396, 1387, 1388.

Wiener Hofmuseum Krypt. exsice. 1826.

0. Jaay Hyxom. exsice. 72 .

Plasmodium farblos. Sporangien herdenweise, \pm kugelig oder halbkugelig unterseits genabelt, gestielt oder sitzend oder an deren Stelle flache Plasmodiokarpien. Kalkkristalle oft sehr zahlreich, eine schuppige Kruste bildend und in diesem Falle die Sporangien oder Plasmodiokarpien schneeweiß oder die Kalkkristalle spärlicher nud die Sporenbehälter dann gran. Die Plasmodiokarpien pflegen im allgemeinen durch zerstrentere Kalkkristalle ausgezeichnet zu sein. Die Sporangiumwand mitunter gegen den Grund rotbraun gefleckt, zur Zeit der Sporenreife in kleine Stücke zerfallend. Stiel weiß oder blaß- oder orangegelb, zylindrisch, tieffurchig, mit rauher Oberfläche. Columella bald größer, bald kleiner, weiß oder gelblich, halbkugelig, in den Plasmodiokarpien fehlend. Capillitiumfäden entweder zart oder grob, einfach oder spitzwinkelig veřweigt, häufig mit knotenartigen Verdickungen. Sporen im durchfallenden Lichte violettbraun, undeutlich- oder deutlich stachelig, die Stacheln mitunter in Gruppen stehend, 7-11 $\mu$.

Durch das ganze Gebjet zerstrent und überhaupt losmopolitisch.

$6^{* * *}$. Sporangien als wurmförmige oder kreisrunde, oberseits t tief genabelte, graue oder bei 
Abwesenheit von Kalk glänzendbraune, sich mittelst eines Kreisschnittes öffnende Plasmodiokarpien ausgebildet. Columella 0. Die Capillitiumfäden zart, wellig, violettbraun, entweder einfach oder spärlich verzweigt und anastomosierend. sporen im durchfallenden Lichte purpurgrau oder purpurbraun, fein stachelig, $7-9 \mu$.

10. D. anellus Morgan Myx. Miami Valley (1894), 64, t. XII, fig. 41; Macbride N. A. Slime-Moulds, 85, pl. XVI, fig. 7; Torrend in Broteria VII, pl. VII, fig. 24; Lister Monogr. ed. 2, 134, pl. 110, fig. a-c.

Synonym: Didymium eftusum var. tenne Lister in Journ. of Bot. XXXV (1897), 214 und XXXVII, 149.

Großbritannien, N-Amerika.

$6^{* * * *}$. Sporangien lange und breite, kissenförmige, unregelmäBig aufspringende Plasmodiokarpien bildend. Columella 0. Capillitiumfäden ein reiches, elastisches Netzwerk bildend.

11. D. Wilezekii Meylan in Bull. Soc. Vaud. Sc. Nat. 5 me sér. XLIV (1908), 290 und L, 8; Lister Monogr. ed. 2, 134, pl. 194, fig. a-d und in Journ. Lin. Soc. LI, 96.

Exsikkat: O. Jaap Myxom. exsicc. 110.

Plasmodium grau. Plasmodiokarpien ausgewalzt, 1 bis $20 \mathrm{~cm}$ lang, 1 bis $8 \mathrm{~mm}$ breit und 0,3 bis $0,5 \mathrm{~mm}$ dick, kissenförmig dem Substrat (Torf- und Zweigstücke) angeschmiegt, matt grauweiß oder bei mangelndem Kalk bräunlichrot. Columella fehlend, ersetzt durch die farblose oder gelblichbraune Basis der Peridie. Capillitium reichlich entwickelt, aus blaßbräunlichroten, oft zarten, ein elastisches und sich leicht von der Peridie loslösendes Netzwerk bildenden Fäden bestehend. Die Ver- 

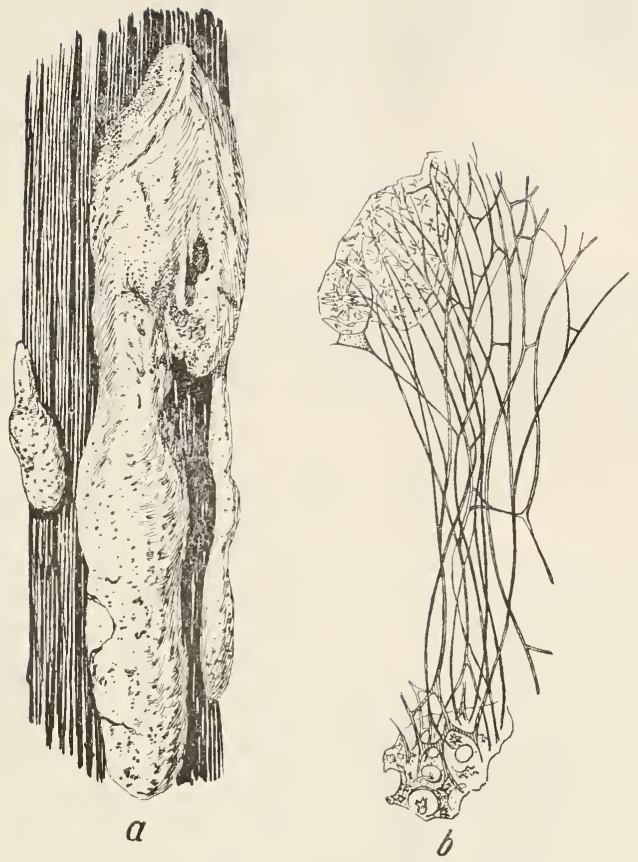

Fig. 81. Didymium Wilezekii Meylan

a) Plasmodiokarpien $\left({ }^{20} / 1\right)$; b) Teil des Capillitiums mit daran haftenden Fragmenten der Peridie $\left({ }^{280} / 1\right)$. - a nach der Natur, b nach Lister.

zweigungen, bezw. Anastomosen der Fäden unter rechtem oder stumpfem Winkel abgehend. Sporen im durchfallenden Lichte dunkelbraunrot, dicht- und fein stachelig, $9-13 \mu$.

Schweiz (Jura, Arolla im Wallis, Furka, Arosa, Schröteralp ob Vättis), Schweden, N.-Amerika.

Fine alpine, im Frühjahr am Rande des schmelzenden Schnees sich einfindende, im Jura und anscheinend auch in der Zentralschweiz verbreitete Art, die ihre Plasmodiokarpien mit Vorliebe auf alten Zweigen von Rubus idæus, Urtica dioica, Ribes, Lonicera entwickelt. Das Capillitium erinnert sehr an 
jenes von Didymium dubium Rost., in der Ausbildung der Kalkkruste unterscheidet sich aber $D$. Wilczekii von letztgeuanuter Art. M e y lan macht auch auf die große Übereinstimmung mit Didymium anomalumsturgis (pg. 222)aufmerksam.

$6^{* * * * *}$. Stiel kurz und häutig, blablederfarbig. Kristalle auf der Peridie eine glatte, dicke, hinfällige Kruste bildend.

12. D. crustaceum Fr. Syst. Myc. III (1829), 124; Rabenhorst Deutschl. Krypt.-Fl. I, 279; Rost. Monogr. App., 22; Macbride N. A. Slime-Moulds, 86; Lister Monogr. ed. 1, 101, pl. XL, B, fig. a-e und ed. 2, 136, pl. 111, fig. a-d; Torrend in Broteria VII, 91.

Synonym: Didymium confluens Rost. Monogr. 164 (1875); Schröter in Cohn Krypt.-Fl. Sehles, III, 1, 122; Massee Monogr., 235.

Plasmodium weiß. Sporangien kugelig, zerstreut oder gedrängt und sogar gebüschelt oder zusammenfließend, kurz gestielt oder sitzend, mit glatter und dicker, brüchiger und hinfälliger Kruste aus locker verbundenen Kalkkristallen. Nach Entfernung der Kruste sehen die Sporangien nierenförmig oder halbkugelig, grau aus. Stiel blaß lederfarbig, häutig, oft zu 8 oder 10 gebïschelt an gemeinsamen, vom Hypothallus ausgehenden, häutigen Strähnen, zuerst verborgen unter einer gemeinsamen Kalkkruste. Columella mitunter kaum wahrnehmbar, niedergedrückt, weiß oder blaß ledergelb, kalkhaltig. Capillitiumfäden farblos oder blaßviolett, abgesehen von den 2- und 3 gabeligen Enden meist einfach, seltener verzweigt, häufig mit knotenförmigen V'erdickungen. Sporen im durchfallenden Lichte purpurgrau, grob stachelig, $10-13 \mu$.

Österreich.

Frankreich, Schweden, Finnland, N.- und S-Amerika.

$4^{* *}$. Stiel blaBgelb oder lederfarbig, nach oben verjüngt, mit Kalkkügelchen angefüllt. Sporangien herdenweise oder geknäuelt, \pm scheibenförmig, oberseits \pm gewölbt, unterseits breit und tief genabelt, oft gelappt, an Leangium-Fruchtkörper erinnernd, grauweib, gestielt. 
Peridie häutig, mit Kalkkristalleı. Columella scheibenförmig, konvex, hla gelb oder weiB, am Grunde von einem Kragen begleitet. Capillitiumfäden einfach oder verzweigt, zart, farblos. Sporen im durchfallenden Lichte dunkelpurpurbraun, mit dichtmaschiger Netzskulptur, 9-12 u.

13. I. intermedium Schröter in Hedwigia XXXY (1896), 209: Lister Monogr. ed. 2, 135, pl. 110, fig. d-f und in Journ. of Bot. XLII, 133; Torrend in Broteria VII, 93, pl. VIII, fig. $10 \mathrm{a}$.

Synonym: Didymium excelsum Jahn in Ber. Deutseh. Bot. Ges. XX (1902), 275, t. XIII, fig. 5-10.

Brasilien.

$1^{*}$. Peridie knorpelig.

\section{Untergattung Lepidodermopsis}

Lister Monogr. ed. 2, 124.

Sporangien herdenweise, gestielt, + kugelig, entweder dunkelpurpurbraun und glänzend, breit geadert mit weißen oder lederfarbigen Kalkauflagerungen oder gleichmäßig mit Kalk bedeckt und dann gleichmäßig hellfarbig. Peridie zur Zeit der Sporenreife in einzelne Stïcke zerfallend. kastanienbrann, mit helleren Dehiscenzlinien (im durchfallenden Lichte). Stiele gelb, orangefarbig oder braun, gedrungen, am Grunde verdickt und of unter einander durch Hypothallussträhnen zu mehreren verbunden. Capillitiumfäden zart, purpurbram, wellig, verzweigt und anastomosierend, farblos an den Enden. Sporen im durchfallenden Lichte violettgrau, fein warzig, $7-9 \mu$.

14. D. Ieoninum Berkeley et Broome in Journ. Linn. Soc. XIV (1873), 83; Lister in Journ. of Bot. XLV, 187 und Monogr. ed. 2, 136, pl. 113. fig. a-d; Torrend in Broteria VII, 96.

Synonyme: Lepidoderma tigrinum Rost. Monogr. App. (1876), 23 pr. p.; Lister Monogr. ed. 1, 106.

Lepidodermopsis leoninus v. Höhnel in Sitzungsber. Akad. Wien

Math. Naturw. Kl. CXVIII (1909), 439, fig. 35. Ceylon, Java. 
Von unsicherer Stellung ist vorläufig noch:

15. D. anomalum Sturgis in Colorado College Publ. Gen. Ser. Nr. 68 Sc. Ser. XII (1913), 444, pl. 2, fig. 6, 7, 8.

2 bis $10 \mathrm{~cm}$ lange und $1 \mathrm{~mm}$ (oder weniger) dicke, graue, wie Farbflecken aussehende Plasmodiokarpien. Columella fehlend. Capillitiumfäden aus häutigen, geraden, aufstrebenden, meist mit Kalkkristallen erfüllten Röhren bestehend. Sporen im durchfallenden Lichte hellviolettbraun, fein- und unregelmäBig stachelig, $10^{1 / 2}-11^{1 / 2} \mu$.

\section{N.-Amerika (Colorado).}

Meylan macht auf die Ähnlichkeit mit Didymium Wilczekii aufmerksam.

\section{Gattung Mucilago Adanson}

Fam. Pl. II (1763), 7; Macbride N. A. Slime-Moulds 82; Lister Monogr. ed. ׳2, 137. - Spumaria Persoon in Gmelin Syst. Nat. II (1791), 1466; Rabenh. Deutschl. Krypt.-Fl. I, 252; Rost. Vers. eines Systems d. Mycetozoen, 13 und Monogr., 191; Schröter in Cohn Krypt.-Fl. Schles. III, 1, 120 und in Engler und Prantl. Natürl. Pflanzenfam. I, 1. 29; Massee Monogr., 256; Čelak. Myxom. Böhm., 58; Lister egd. 1, 104; Schinz in Mitt. Naturw. Ges. Winterthur IV, 61; Torrend in Broteria VI, 51 und VII, 88.

Mit nur einer Art:

1. I. spongiosa (LeyBer) Morgan in Bot. Gaz. XXIV (1897), 56; Macbride N. A. Slime-Moulds, 83; Lister Monogr. ed. 2, 137, pl. 117, fig. a-e.

Synonyme: Mucor spongiosus LeyBer Fl. Hal. (1783), 305.

Reticularia alba Bull. Champ. (1791), 92, t. 326 .

Spumaria Mucilago Pers. in Gmelin Syst. Veg. II, (1791), 1466. Reticularia ovata var. 2 Withering Bot. Arr. Ed. VI, v. 4 (1792), 463.

Spumaria cornuta Schum. Fnum. Pl. Saell. II (1803), 195.

Spumaria alba DC. Fl. Fr. II (1805), 261 : Rost. Monogr., 191; Rabenhorst Deutsehl. Krypt.-Fl. I, 253; Čelak. Myxom. Böhm., 58; Schröter in Cohn Krypt.-Fl. Schles. III, 1, 120; Massee Monogr., 257; Lister Monogr. ed. 1, 104, pl. XLI, A, fig. a-e; Schinz in Mitt. Naturw. Ges. Winterthur VI, 61; Torrend in Broteria VII, 88. 
Didymium spumarioides Fr. Syst. Myc. III (1829), 121.

Diderma spumariæforme Wallr. Fl. Germ. Crypt. (1833), 374. Exsikkaten: Rabenhorst Fungi eur. 1323.

Fuckel Fungi rhen. 1471.

Sydow Myc. March. 397.

O. Jaap Myxom. exsicc. 30.

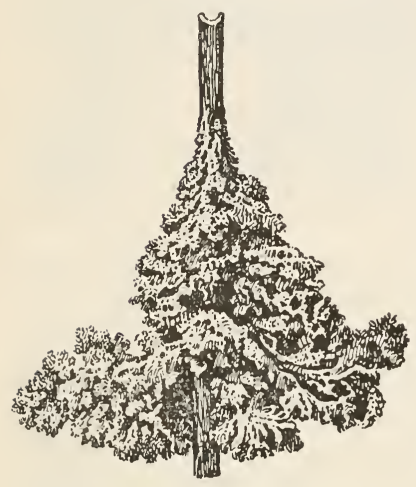

Fig. 82. Mucilago spongiosa (Leyßer) Morgan.

Aethalium (1/1). - Nach Rostafinski.

Plasmodium weiß oder gelb. Fruchkörper (Aethalien) aus am Grunde verwachsenen, baumartig verzweigten Einzelfruchtkörpern zusammengesetzt. Gesamtfruchtkörper eine \pm korallenartig verzweigte, poröse, \pm länglich kugelige, bis $6 \mathrm{~cm}$ lange und bis $6 \mathrm{~cm}$ breite Masse bildend, die von einer weißen, schaumartigen, aus Kalkkristallen bestehenden brüchigen Kruste überzogen ist. Columella, wenn vorhanden, hohl, zusammengedrückt, in ihren Verzweigungen dem Verlauf der zusammenfließenden Sporangien folgend. Capillitiumfäden kräftig, farblos oder purpurbraun, ein weitmaschiges Netzwerk bildend, einerseits an die Columella, anderseits an die Peridie ansetzend, oft mit dunkeln knotenartigen Verdickungen, ab und zu begleitet von röhrenartigen, die Peridie durchbrechenden und nach außen mündenden Fortsätzen der Peridie. Sporen im durchfallenden Lichte dunkelpurpurfarbig, stark stachelig, $10-15 \mu$.

Im ganzen Gebiet nicht selten, oft in groBen Mengen auf Rasen, Grashalmen und Grasblättern, Zweigen etc.

Kosmopolitisch.

Die beiden Varietäten var. dictyospora Fr. in Arkiv. Bot. I (1903), 66, Lister in Journ. of Bot. XLIII, 156 und Monogr. ed. 2, 138 (Sporen im durchfallenden Lichte sehr dunkel, mit engmaschiger Netzskulptur, 12-15 $\mu$ ) und var. solida Sturgis in Colorado Coll. Publ. Se. Ser. XII (1907), 29, lister Monogr. ed. 2, 138 (Sporeu stachelig, 9-11 $\mu$ ) sind aus unserem Gebiete noch nicht bekannt; letztere wurde in N.-Amerika (State of Colorado), erstere in Bolivia und neuerdings in GroBbritannien nachgewiesen. 


\section{Gattung Lepidoderma de Bary}

in Rost. Vers. eines Systems d. Mycetozen (1873), 13; Rost. Monogr., 187; Čelak. Myxom. Böhmen., 67; Massee Monogr., 251 ; Schröter in Cohn Krypt.-Fl. Schles. III, 1, 122 und in Engler und Prantl Natürl. Pflanzenfam. I, 1, 31; Lister Monogr. ed. 1, 105 und ed. 2, 139; Macbride N. A. Slime-Moulds, 106: Schinz in Mitt. Naturw. Ges. Winterthur VI, 62; Torrend in Broteria VI, 52 und VII, 97.

Sporangien mit oder ohne Stiel, mitunter an deren Stelle Plasmodiokarpien. Peridie knorpelig, besetzt mit kristallinischen Schuppen oder Scheiben aus kohlensaurem Kalk. Capillitiumfäden kräftig, meist kalkfrei.

1. Sporangien meist gestielt. Stiel orangegelb.

1. L. tigrinum (Schrader) Rost. Monogr. (1875), 187 , fig. 159, 160; Schröter in Cohı Krypt.-Fl. Schles. III, 1, 123; Massee Monogr., 253, fig. 41-43; Lister Monogr. ed. 1. 105 , pl. XLI, B, fig. a-d, Ed. 2. 139, pl. 114, fig. a-c und in Journ. of Bot. XXXIX, 88, pl. 419. fig. 3 und XLIII, 150; Macbride N. A. Slime-Moulds, 106, pl. XIV, fig. 7 ; Schinz in Mitt. Naturw. Ges. Winterthur VI, 62; Torrend in Broteria VII, 97, pl. VII, fig. 25,26 .

Sy 1 on yme: Didymium tigrinum S chrader Nov. Gev. Pl. (1797), 22;

Fr. Syst. Myc. III, 117; Rabenhorst Deutschl. Krypt.-Fl. I, 280.

Physarum squamulosum Pers. Syn. (1801), 174.

Physarum tigrinum Pers. Syn. (1801), 174.

Trichia squamulusa Poir. Encyel. VIII (1808), 53.

Trichia tigrina Poir. Encycl. VIII (1808), 53.

Leaugium squamulosum Fr. Stirp. Fennsj. (1827), 83.

Didymium rufipes Fr. Syst. Myc. III, (1829), 116.

Didymium versipelle Fr. Syst. Myc. III (18:9), 117?

Ciouium tigrinum Link Handb. III (1833), 410.

Diderma citrinum Berk. in Sm. Eugl. Fl. V (1836), 310.

Lepidoderma fulvum Massee Monogr. (1892), 253, fig. 39, 40.

Exsikkaten: O. Jaap Myxom. exsice. 48, 155.

Plasmodium orangegelb. Sporangien zerstreut, \pm kugelig abgeflacht und unterseits genabelt, meist gestielt, grünlich- oder purpurgran, besät mit bald abgerundeten, bald eckigen oder 


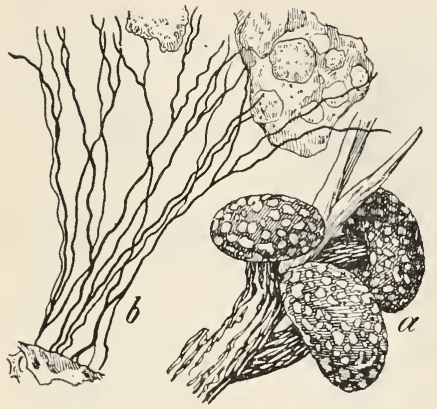

Fig. 83.

Lepidoderma tigrinum

(Schrader) Rost.

a) Gruppe von Sporangien $(\mathbf{2 0} / 1)$;

b) Teil des Capillitiums mit Fragmenten der Peridie (280/1). - Nach

Lister.

sternförmigen Kalkblättchen und daher auf dunkelm Grunde weiß gefleckt. Peridie aus 2 engverbundenen Schichten bestehend. Stiel gedrungen, walzlich, gefurcht, orangebraun, im Innern von schwammiger Struktur und mit Kalk angefüllt. Capillitium reichlich, aus geraden oder welligen, spärlich verzweigten, dunkelpurpurbraunen oder grauen Fäden bestehend. Columella halbkugelig, orangefarbig, schwammig, kalkführend. Sporen im durchfallenden Lichte dunkelpurpurgrau, fein- und dicht stachelig, $10-13 \mu$.

\section{Deutschland, Schweiz.}

Großbritannien, Frankreich, Italien, Dänemark, Schweden, Finnland, N.-Amerika, Java, Japan.

Forma gracile Meylan in Bull. Soc. Bot. Genève 2 me sér. Il (1910), 263 ist eine schlank- und langgestielte Form (Stiel 乞- bis 3 mal länger als der Sporenbehälter) aus dem Schweizer-Jura.

$1^{*}$. Sporangien in der Regel ungestielt, wenn gestielt, der Stiel graubraun.

2. L. Carestianum (Rabenhorst) Rost. Monogr. (1875), 188; Massee Monogr., 255; Lister Monogr. ed. 1, 106, pl. XLI, B, fig. e-f, in Journ. of Bot. XLVI, 217 und Monogr. ed. 2, 140, pl. 115, fig. a-d; Schinz in Mitt. Naturw. Ges. Winterthur VI, 63; Torrend in Broteria VII, 98.

Synonym: Reticularia Carestiana Rabenhorst Fungi eur. (1862), Nr. 436 .

Exsikkaten: Rabenhorst Fungi eur. 436.

O. Jaap Myxom. exsicc. 93. 


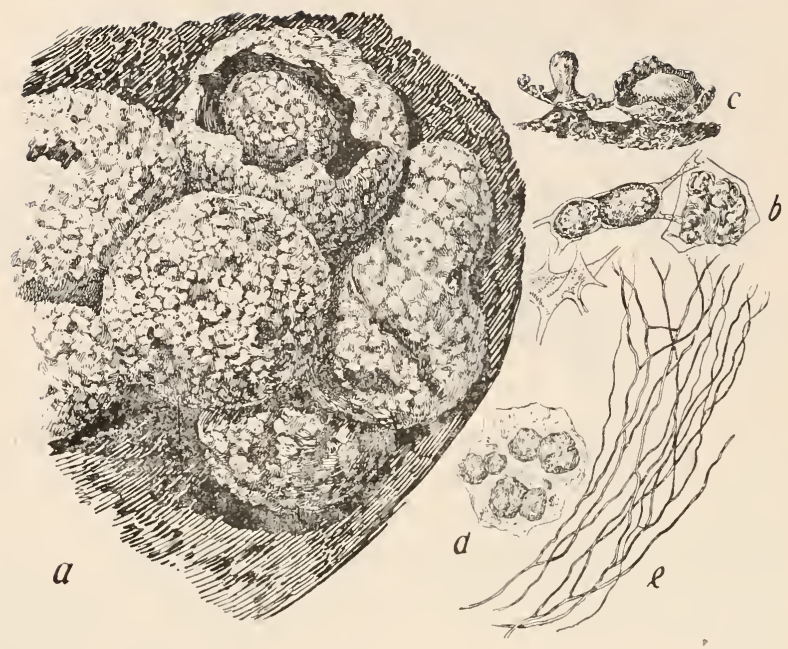

Fig. 84. Lepidoderma Carestianum (Rabenhorst) Rost.

a) Gruppe von Sporangien, aus dem geöffneten schaut die Columella hervor $(2 \%)$; b) Bruchstück der Peridie mit Kalkblättchen und daran haftendem Capillitiumstück, letzteres zum Teil mit Kalkblasen (var. granuliferum), zum Teil ohne solche $\left({ }^{280} / 1\right)$; c) Sporangien der var. Chailletii mit zerbrochener Peridie, die Columella zeigend $(20 / 1)$; d) Bruchstück der Peridie mit Kalkbelag von var. Chailletii $(280 / 1)$; e) Teil der Capillitiums von var. Chailletii $\left({ }^{280} / 1\right)$. Nach Lister.

Plasmodium schmutzigweiß (nach Meylan schwarz!). Sporangien fast kugelig, oft zusammenfließend oder verlängerte, polsterförmige, bis $15 \mathrm{~mm}$ lange Plasmodiokarpien bildend, braungrau, dicht mit kristallinischen, weißen Kalkschnppenbesetzt. Columella halbkugelig, mitunter auch ersetzt durch die verdickte Basis des Sporangiengrundes. Capillitiumfäden farblos oder purpurbraun, verzweigt und anastomosierend, mitunter mit runden Kalkblasen (var. granuliferum). Sporen im durchfallenden Lichte dunkelpurpurgrau, fein stachelig, $10-15 \mu$.

Deutschland, Schweiz, Österreich.

Großbritannien, Italien, Belgien, Dänemark, Schweden, N.-Amerika. 
var. Chailletii (Rost.) Lister in Journ. of Bot. XLVI (1908), 218 und Monogr. ed. 2, 140, pl. 116, fig. a-e; Schinz in Mitt. Naturw. Ges. Winterthur VI, 63, 64.

Synonym: Lepidoderma Chailletii Rost. Monogr. (1875), 189, fig. 179; Massee Monogr., 255; Čelak. Myxom. Böhm., 67; Lister Monogr. ed. I, 107; Torrend in Broteria VII, 98.

Sporangien kugelig oder halbkugelig, entweder kur\% gestielt oder ungestielt, Fruchtkörper mitunter als Plasmodiokarpien ausgebildet, oder schwarzbraun, dicht besetzt mit Kalkschuppen. Stiel, weun vorhanden, braun, reichlich Kalkklümpchen führend gleich der Columella; letztere blaß- oder dunkelbraun, selten gelb, keulenförmig, halbkugelig oder fehlend. Capillitiumfäden schlanker als beim Typus. Sporen $10-13 \mu$.

var. granuliferum (Phillips) Lister in Schinz Mitt. Naturw. Ges. Winterthur VI (1906), 63 und Monogr. ed. 2, 140, pl. 115, fig. b, c; Torrend in Broteria VII, 98.

Synonyme: Didymium granuliferum Phillips in Grev. V (1877), 114, t. 88, fig. 1a-f; Lister Monogr. ed. I, 106.

Badhamia granulifera Massee Monogr. (1892), 321.

Lepidoderma granuliferum Fr. in Arkiv Bot. VI (1906), 3.

Capillitiumfäden verzweigt und anastomosierend, mit Kalkklümpchen führenden Verbreiterungen (Schweiz).

Endlich unterscheidet Meylan noch zwei Formen: f. flavescens Meylan in Bull. Soc. Vaud. Sc. nat. 5 me sér. XLIV (1908), 292, Kalk graugelb, Colnmella sattgelb, Sporen 9-11 $\mu$ (Jura) und $f$. rosea II y lan Bull. Soc. Vaud. Sc. nat. 5 me sér. XLVI (1910), 50, mit rosaroten Kalkschuppen (Jura).

Die Verbreitung der beiden oben erwähnten Varietäten ist noch zu studieren.

\section{Gattung Leptoderma Lister}

in Journ. of Bot. LI (1913), 1.

Mit nur einer Art:

1. L. iridescens Lister in Journ. of Bot. LI (1913), 1, t. 524, fig. $1,1 \mathrm{a}-\mathrm{c}$.

Plasmodium schwarzbraun. Sporangien zerstreut oder in kleinen Häufchen, kugelig oder halbkugelig, purpurgrau oder 
purpurbraun, metallisch glänzend, ungestielt, selten mit sehr kurzem, mit ausgestoßenem Material angefülltem und daher fast schwarzem, am Grunde in einen häutigen Hypothallus übergehendem Stiel. Das Offnen der Sporangien erfolgt durch unregelmäßiges Aufreißen. Peridie unterwärts dicker als oberwärts und zudem infolge von Einschlüssen, bestehend aus braunen Körnchen und zerstreuten Kalkkristallblättchen, geadert. Colu-

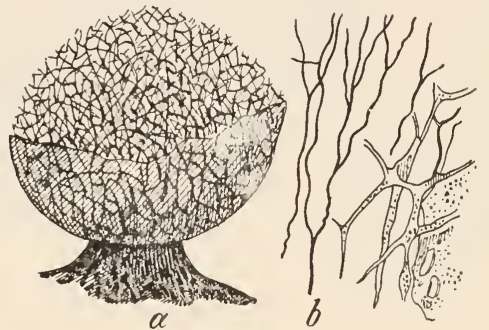

Fig. 85. Leptoderma iridescens Lister.

a) Sporangium mit oberwärts zerstörter Peridie uud heraustretendem Capillitium $\left({ }^{40} / 1\right)$; b) Teile des Capillitinms und Bruchstück der Peridie mit Granulationen und eingebetteten Kalkscheibchen $(\mathbf{3 6 0} / \mathbf{1})$. Nach Lister.

mella fehlend. Capillitium aus einem bleibenden Netzwerk schlanker, vom Grunde des Sporangiums ausstrahlender, an den Enden farbloser, im übrigen aber schwarzer Fäden bestehend, die basalen Enden dieser Fäden häufig rölırig und verbreitert, Granulationen einschließend. Sporen im durchfallenden Lichte purpurgrau, stachelig, $10-11 \mu$.

Schweiz (Mürren, La Vaux im Jura $1200 \mathrm{~m}$ ).

Großbritannien.

Dürfte mit Lepidoderma verwandt sein, unterscheidet sich indessen durch die häutige und nicht knorpelige, verhältnismäBig kalkarme Peridie. Von Lamproderma weicht Leptoderma ab durch die unterwärts verdickte, ab und zu kalkführende Peridie nnd die Ausfüllung des Stieles mit Aussehußmaterial. 


\section{Unterreihe ANAUROCHAFTINAAE Rost. $\left.{ }^{*}\right)$}

Versuch eines Systems der Mycetozoen (1873), 6 und Monogr. (1875), 193; Lister Monogr. ed. I, 21, 108 und ed, 2, 22, 141.

\section{Familie Stemonitaceae Rost.*)}

Versuch eines Systems der Mycetozoen (1873), 6 und Monogr. App., 24; Schröter in Cohn Krypt.-Fl. Schles. IIl, 1, 116 und in Engl. und Prantl Natürl. Pflanzenfam. I, 26; Lister Monogr. ed. I, 22 und 108 und ed. 2, 22 und 141; Schinz in Mitt. Naturw. Ges. Winterthur VI, 65; Macbride N. A Slime-Moulds, 110 pr. p.; Torrend in Broteria VI, 41 und VII, 63.

Sporangien gestielt. Sporangiumwand zart, oft frühzeitig schwindend. Stiel als Columella, von der die Capillitiumfäden abgehen, in das Sporangium fortgesetzt; Columella mitunter fast oder ganz fehlend.

\section{Schliissel zur Bestimmung der Gattungen der Familie der Stemonitaceae.**)}

1. Columella auffallend kurz oder auch ganz fehlend.

2. Beim Schwinden der Sporangiumwand bleiben kleine scheibenförmige Fragmente in Verbindung mit den letzten Verzweigungen der Capillitiumfäden.

Clastoderma Blytt

2*. Beim Schwinden der Sporangiumwand bleibt höchstens ein Kragen am Stielende übrig.

3. Capillitiumfäden zickzackförmig hin und her gebogen.

Echinostelium de Bary.

$3^{*}$. Capillitiumfäden nicht zickzackförmig gebogen.

Lamproderma Rost.

1*. Columella deutlich wahrnehmbar, meist verlängert.

4. Capillitium der Columella an deren ganzen Länge befestigt.

5. Capillitiumfäden auch mit ihren äußersten Auszweigungen anastomosierend und so ein Oberflächennetz bildend. Stemonitis Gleditsch

\footnotetext{
*) Vergl. die Übersicht auf S. 83 u. 84 .

**) Vergl. auch den Nachtrag.
} 
5*. Äußerste Auszweigungen der Capillitiumfäden in der Regel frei, kein Oberflächennetz bildend oder nur im untern Teil zu einem solchen zusammenschließend.

Comatricha Preuss

$4^{*}$. Capillitium ausschließlich oder doch in der Regel am Columella-Ende entspringend.

6. Columella das Sporangium der ganzen Länge nach durchziehend. Enerthenema Bowman

6*. Columella meist bis ungefähr zur halben Höhe des Sporangiums reichend, im untern Teil meist frei von Capillitiumfäden.

Lamproderma Rost.

\section{Übersicht der Gattungen.}

Stemonitis. Sporangien gestielt, walzlich. Stiel als Columella bis oder bis nahezu zur Spitze des Sporangiums dieses durchziehend. Capillitiumfäden an zahlreichen Punkten längs der Columella befestigt und von dieser abgehend, die äußersten Verzweigungen zu einem feiumaschigen Netz vereinigt.
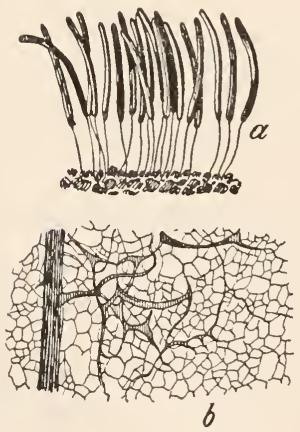

Fig. 86. Stemonitis fusca Roth (nach Lister).

a) Gruppe von Sporangien $(2 / 1)$; b) Stück des Capillitiums mit Columella $\left({ }^{180} / 1\right)$.

Comatricha. Sporangien gestielt, walzlich, eiförmig oder \pm kugelig. Stiel zur Columella verlängert, wenigstens bis zur 
Mitte des Sporangiums hinaufreichend. Capillitium wie bei Stemonitis, aber die äußersten Verzweigungen kein feinmaschiges Oberflächennetz bildend.

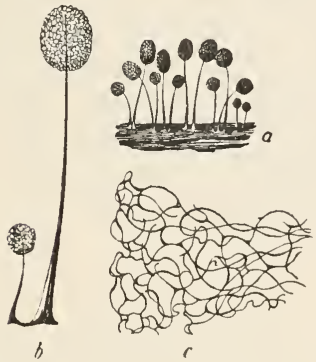

Fig. 87. Comatricha nigra (Pers.) Schröter (nach Lister).

a) und b) Sporangiengruppen, a) $\left({ }^{35} / 1\right)$, b) $(10 / 1)$; c) Stück des Capillitiums $(180 / 1)$.

Enerthenema. Sporangien gestielt, kugelig, Stiel als Columella das ganze Sporangium durchziehend und am obern Ende zu einer Scheibe, von der die Capillitiunfäden herabhängen, verbreitert. Die Capillitiumfäden nur ausnahmsweise längs der Columella befestigt.
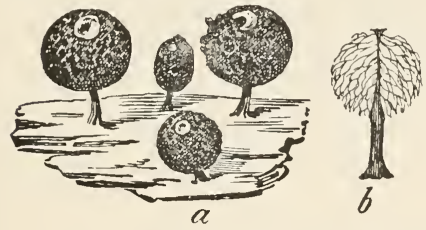

Fig. 88 .

Enerthenema papillatum

(Pers.) Rost. (nach Lister).

a) Gruppe von Sporangien $\left({ }^{\mathbf{2 0}} / 1\right)$; b) Sporangium mit entfernter $\mathrm{Pe}$ ridie, Columella oben etwas verbreitert, die Capillitiumfäden (als Ausnahme) längs der Columella befestigt $\left({ }^{30} / 1\right)$.

Lamproderma. Sporangien kugelig oder ellipsoidisch, gestielt. Stiel als Columella in das Sporangium verlängert, bis zur halben Höhe desselben oder höher hinauf reichend. Capillidiumfäden hauptsächlich vom obern Teil der Columella ausgehend.
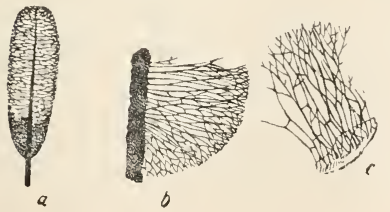

Fig: 89 .

Lamproderma columbinum (Pers.) Rost. (nach Lister).

a) ellipsoidisches Sporangium mit unterwärts erhaltener Peridie $(10 / 1)$; b) Teil der Columella mit Capillitium $\left({ }^{\mathbf{4}} / \mathrm{1}\right)$; c) an der Peridie befestigtes Capillitium der var. sessile $\left({ }^{40} / 1\right)$. 
Clastoderma. Sporangien gestielt, kugelig. Columella kurz oder fehlend. Capillitium aus wenigen, spärlich verzweigten Fäden bestehend, die an ihren Enden die bleibenden Peridiefragmente tragen.

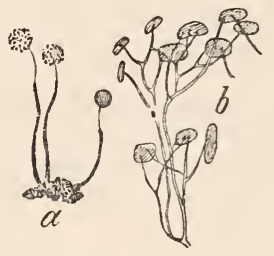

Fig. 90. Clastoderma Debaryanum Blytt (nach Lister).

a) Sporangiengruppe $(20 / 1)$; b) Capillitium mit den an deren Enden befestigten Peridiescheiben $\left({ }^{250} / 1\right)$.

Echinostelium. Sporangien kugelig, gestielt, sehr klein. Capillitium aus einigen wenigen, zickzackartig gekrümmten Fäden bestehend, die mit ihren spitzen Astenden z. T. anastomosieren.

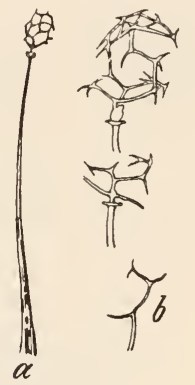

Fig. 91.

Echinostelium minutum de Bary (nach Lister).

a) Sporangium mit Capillitium $(120 / 1)$; b) Stücke des Capillitiums $(430 / 1)$.

\section{Gattung Stemonitis Gleditsch}

Meth. Fung. (1753), 140, t. IV pr. p.; Rabenh. Deutschl. Krypt.Fl. I, 268; Rost. Versuch eines Systems der Mycetozoen, 7 und Monogr., 193; Schröter in Cohn Krypt.-Fl. Schles. III 1, 116 und in Engler und Prantl Natürl. Pflanzenfam. I, 1, 28; Massee Monogr., 72 pr. p.; Ċelak. Myxom. Böhm., 45 (incl. Jundzillia Racib.); Lister ed. I, 109 und ed. 2, 143; Macbride N. A. SlimeMoulds, 113; Schinz in Mitt. Naturw. Ges. Winterthur VI, 65; Torrend in Broteria VI, 41, VII, 80 und VIII, 19.

Sporangien zerstreut oder in dicht gedrängten, rasenartigen Haufen, \pm lang gestielt, meist schlank walzlich. Stiel zur Columella verlängert, die das Sporangium bis über die Mitte des- 
selben durchzieht(selten o) und von welcher an zahllosen Punkten die Capillitiumfäden ausgehen, die vielfach verzweigt sind, reichlich anastomosieren und deren letzte Verzweigungen zu einem engmaschigen Netze vereinigt sind, welches der Sporangiumwand parallel verläuft und ein sugenanntes Oberflächennetz bildet. Sporangiumwand zarthäutig, frühzeitig schwindend.

1. Sporen im durchfallenden Lichte grau, violettgrau oder rotviolett.

2. Sporen mit netzartiger Skulptur; Maschen des Oberflächennetzes eckig (vergl. die Varietäten rufescens, flaccida und confluens von S. fusca).

3. Sporen $6-12 \mu$.

S. fusca Roth in Roem. und Usteri Mag. Bot. I, 2 (1787), 26; Rabenhorst Deutschl. Krypt.-Fl. 1, 268; Rost. Monogr., 193, fig. 40; Schröter in Cohn Krypt.-Fl. Schles. III, 1, 116; Massee Monogr., 72, fig. 155-157, 162-164 pr. p.; Čelak. Myxom. Böhm., 47; Lister Monogr. ed. I, 110, pl. XLII, B, fig. a-k, LXXVII, A, fig. $a-d$, ed. 2, 144, pl. 118, fig. a-k; Macbride N. A. Slime-Moulds, 115; Schinz in Mitt. Naturw. Ges. Winterthur VI, 66; Torrend in Broteria VII, 80, pl. V. fig. 14, pl. VII, fig. 29.

Synonyme; Clathrus nudus L. Spec. pl. ed. I (1753), 1179?

Stemonitis fasciculatus Pers. Obs. Myc. (1796), 56.

Stemonitis maxima Schwein. in Trans. Am. Phil. Soc. se. 2, IV (1832), 260; Macbride N. A. Slime-Moulds, 116.

Stemonitis dictyospora Rost. Monogr. (1875), 195; Massee Monogr., 83.

Stemonitis nigrescens Rex in Proc. Acad. Nat. Sc. Phil. (1891), 392 ; Macbride N. A. Slime- Moulds, 116.

Stemonitis castillensis Macbride in Bull. Nat. Hist. Iowa II (1793), 381.

Exsikkaten: Fuckel Fungi rhen. 1449.

Holl., Schmidt et Kunze, Deutschl. Schwämme 109.

O. Jaap Myxom. exsicc. 31 .

Plasmodium weiß. Sporangien (inkl. Stiel) $5-20 \mathrm{~mm}$ hoch, walzlich, stumpf, bräunlich dunkelrot, in \pm dichten Haufen vorkommend. Stiel 1-4 mm lang, glänzend schwarz, einem häutigen, braunen Hypothallus entspringend. Columella nahezu das Sporangiumende erreichend. Maschen des Capillitiumnetzes eckig, Maschenweite $6-16 \mu$. Sporen im durchfallenden Lichte grauoder rötlichviolett, stachelig oder netzartig skulptiert, $6-12 \mu$. 


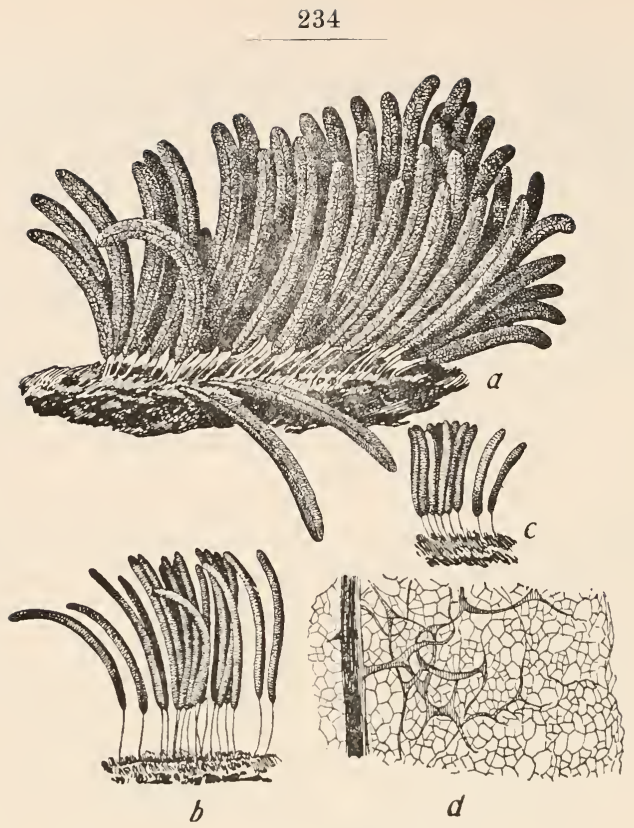

Fig. 92. Stemonitis fusca Roth

a, b, e Sporangienhaufen $(2 / 1)$; d Ausschnitte aus dem Capillitium $\left({ }^{180} / 1\right)$. a nach der Natur, b, c, d wach Lister.

Umfaßt mehrere Spielarten:

var. rufescens Lister Monogr. ed. I (1894), 110, ed. 2, 144, pl. 118, fig. d.

Sporen 5-8 $\mu$, mit feinen, zu verschwommenen Netzlinien angeordneten Stacheln.

var. trechispora (Berkeley) Torrend in Broteria VII (1908), 81; Lister Monogr. ed. 2, 144, pl. 118, fig. k.

Synonym: Stemonitis trechispora Berkeley.

Sporen $10-12 \mu$, mit erhabenem Rand bei netzartiger Skulptur. 
var. flaccida Lister Monogr. ed. 2 (1911), 144; Torrend in Broteria VII, 81 .

Sporangien schwach, Capillitium kaum ein Oberflächennetz bildend.

var. confluens Lister Monogr. ed. I (1894), 110, ed. 2, 144, pl. 118, fig. e; Torrend in Broteria VII, 81, pl. V, fig. 19, 21.

Synonym: Amaurochæte speciosa Zukal in Verh. Zool. bot. Ges.

Wien XXXV (1885, 1886), 335, t. 15, fig. 9.

Sporangien zusammenfließend, eine æthaloide Masse bildend, ohne Columella und ohne Oberflächennetz.

var. nigrescens (Rex) Torrend in Broteria VII (1908), 81; Sturgis in Bot. Gazette LV, 400.

Synonym: Stemonitis nigrescens Rex in Proc. Acad. Nat. Sc. Phil. (1891), 392; Lister Monogr. ed. 1, 110, ed. 2, 144 sub S. fusca; Macbride N. A. Slime-Monlds, 116.

Sporangien $1 / 2$ bis kaum $1 \mathrm{~mm}$ lang gestielt, meist steif aufrecht, incl. Stiel $4-5 \mathrm{~mm}$ hoch, matt rostfarbig bis tiefschwarz, Oberflächennetz meist unvollständig, die Maschen zum Teil mit Dornfortsätzen, Sporen netzartig skulptiert. (Bis anhin nur aus N.-Amerika bekannt.)

Nachdom Stemonitis nigrescens Rex von Lister als Synonym von S. fusca zu dieser gezogen worden ist, ist W. C. Sturgis (Bot. Gazette LV (1913), 400) dieser Frage neuerdings näher getreten und vertritt hierbei die Ansicht, daß S. nigrescens als eine Zwergform von S. fusca aufzufassen sei, zu welch' letztgegenannter Art sie in einem ähnlichen Verhältnis stehe wie eine ihm vorgelegene Zwergform der $S$. herbatica zu dieser. Sturgis legt in der Charakterisierung der var. nigrescens das Hauptgewicht auf den in Verbindung mit dem äußerst kurzen Stiel stehenden Zwergwuchs derselben.

Sehr polymorphe Art, von sämtlichen Arten der Gattung Stemonitis wohl diejenige, die in Europa und Amerika am häufigsten ist. Von den erwähnten Spielarten leitet var. flaccida zur Gattung Comatricha hinüber, während var. confluens sich am weitesten vom Typus entfernt.

Deutschland, Österreich, Schweiz (die Varietäten flaccida und confluens sicher im schweizerischen Jura).

$3^{*}$. Sporen $5-7 \mu$. 
S. virginiensis Rex in Proc. Acad. Nat. Sc. Phil. (1891), 391; Macbr. N. A. Slime-Moulds, 117; Meylan in Annuaire Conserv. et Jard. bot. Genève 15 me et 16 année (1913), 315.

\author{
Synonyme: Stemonitis pumila Fr. Syst. Myc. III (1829), 159 ? \\ Comatricha dietyospora Čelak. Myxom. Böhm. (1893), 49. \\ Comatricha typhoides var, heterospora Rex in Proc. Acad. Nat. \\ Sc. Phil. (1893), 367; Lister Monogr. ed. 1, 120, pl. XLVI, \\ A, fig. f-h, ed. 2, 158, pl. 125, fig. a-f.
}

Sporangien aufrecht, zumeist gebïschelt, walzlich oder länglich oval, Stiel glänzend schwarz. Sporangienwand schwindend. Columella die Sporangienspitze erreichend und durch Äste in das mindestens im untern Teil ein Oberflächennetz bildende Capillitium übergehend, letzteres zart, kleinmaschig, die Maschen kaum oder wenig größer als die Sporen. Sporen $5-6 \mu$ mit netzartiger Skulptur.

Schweiz (Jura) und wahrscheinlich auch sonst noch im Gebiet.

S. virginiensis ist eine sehr umstrittene Art. Während sowohl in der ersten wie in der zweiten Auflage Lister's Monographie dieser Schleimpilz unter Comatricha typhoides als Varietät steht, will Meylan, dem wir eine Reihe vortrefflicher Untersuchungen und auch Publikationen über die Schleimpilze des schweizerischen Jura verdanken, ihn zur Gattung Stemonitis gestellt wissen und wir sind hier diesem Vorschlage gefolgt. Für die Zugehörigkeit zu Stemonitis spricht das büschelweise Vorkommen der Sporangien, das Vorkommen eines Oberflächennetzes und die netzartige Skulptur der Sporen, die in der Regel jeglicher Warzen entbehren (ab und zu scheinen solche aber dennoch vorzukommen). Fräulein Lister, die hervorragendste Kennerin der Schleimpilze, diskutiert im Journ. of Bot. (1913), 98, unabhängig von Meylan gleichfalls die Rangstellung ihrer Varietät heterospora und kommt hierbei zu dem Schlusse, dab ihr doch wohl spezifischer Rang zuzusprechen sei, sie beläßt die Art (sie schlägt versehentlich dafür den Namen $C$. dictyospora Celak. vor) aber bei der Gattung Comatricha. Mir scheint eines daraus hervorzugehen, daß die Trennung der beiden Gattungen Stemonitis und Comatricha eine durch und durch künstliche und auf die Länge unhaltbare ist. 
Unhaltbar ist wohl anch die Belassung der beiden Lister'schen Varietäten microspora und similis bei Comatricha typhoides, denn beiden wird ja ein partielles Oberflächennetz zugesprochen, ich kenne sie aber nur aus den Beschreibungen und muß es daher einer spätern Zeit vorbehalten, auch ihnen eine zusagendere Stellung ausfindig zu machen.

$2^{*}$. Sporen fein stachelig, warzig oder wahezu glatt, ohne netzartige Skulptur.

4. Maschen des Oberflächennetzes abgerundet, $20-100$ oder mehr $\mu$ weit (unvollständiges Oberflächennetz bei var. flaccida). Sporen $7-9 \mu$.

S. splendens Rost. Monogr. (1875), 195: Lister Monogr. ed. I, 112, pl. XLIII, A, fig. a-g, in Journ. of Bot. XXXIX, 89 und Monogr. ed. 2, 145, pl. 121, fig. a-i; Schinz in Mitt. Naturw. Ges. Winterthur VI, 67.

Synonyme: Stemonitis Morgani Peck in Bot. Gazette V (1880), 33;

Massee Monogr., 86; Macbride N. A. Slime-Moulds, 118, pl. VI, fig. 6, 6a, 6c, 7, 7 a.

Stemonitis maxima Massee Monogr. (1892), 74 non Schwein.

Stemonitis Bäuerlinii Massee ex Rex in Proc. Acad. Nat. Sc. Phil. (1890), 36; Massee Monogr., 79.

Stemonitis acuminata Massee Monogr. (1892), 78.

Stemonitis fenestrata Macbride N. A. Slime-Moulds, (1899), 119.

Stemonitis Bäuerlinii Massee f. fenestrata Rex in Proc. Phil. Acad. (1890), 36.

Plasmodium rahmweib. Höhe der walzlichen, stumpfen, 1-4 mm lang gestielten, purpurbraunen, zuerst dicht gehäuften, später sich von einander trennenden Sporangien, 6-20 mm. Stiel schwarz, auf häutigem, silbergranem oder purpurrotem Hypothallus. Columella beinahe den Sporangiengipfel erreichend. Capillitium purpurbraun; die der Columella entspringenden Primanfäden meist zuerst einfach, von einander ziemlich weit entfernt, dann sich plötzlich verzweigend und ein Oberflächennetz mit abgerundeten, $20-125 \mu$ weiten Maschen bildend. Sporen im durchfallenden Lichte blaßrötlichpurpurn, nahezu glatt oder fein- und dicht warzig, $6-9 \mu$. 
Mit folgenden Varietäten:

var. Webberi (Rex) Lister ed. I (1884), 112, ed. 2, 146.

Synonym: Stemonitis Webberi Rex in Proc. Acad. Nat. Sc. Phil. (1891), 390; Macbride N. A. Slime-Moulds, 120, pl, XI, fig. 6-8.

Sporangien steif aufrecht, $8-10 \mathrm{~mm}$ hoch; Oberflächennet\% vollständig, mit $50-125 \mu$ weiten Maschen.

var. flaccida Lister Monogr. ed. I (1884), 112, pl. XLIII, A, fig. g-h, ed. 2, 146, pl. 121, fig. g, h.

Synonyme: Comatricha flaceida Morgan Myx. Miami Valley (1894',

51; Macbride N. A. Slime-Houlds, 133; Torrend in Broteria VII, 79.

Stemonitis 'Tubulina Alb. et Schwein. Consp. Fung. (1805). 102? Dermodium fallax Nees Syst. (1816), 109, fig. 103.

Jundzillia Tubulina Racib. in Hedw. XXVI (1887), III.

Stemonitis fusea b. T'ubulina Rabenhorst Deutschl. Krypt.-Fl. I (1844), 268.

Sporangien schwach, aneinanderhaftend; Capillitium locker, kaum ein Oberflächennetz bildend, stets mit anhaftenden Peridiestiicken. Deutschland (Brandenburg, Lausitz), Osterreich, Schweiz (Jura), anscheinend nicht nur im Gebiet, sondern iiberhaupt in Europa \pm selten, trotzdem aber kosmopol.

4*. Sporangien in dichten Büscheln oder Haufen, bleibend untereinander verbunden und nur an der Spitze und am Grunde (ob hier immer?) frei, meist ohne ausgesprochenes Oberflächennetz. Sporen $8-12 \mu$.

S. confluens Cooke et Ellis in Grev. V (1876), 51; Massee Monogr., 77; Macbride N. A. Slime-Moulds, 114, pl. XI, fig. 4, 4a, 5; Torrend in Broteria VII, 137, pl. V, fig. 23; Lister Monogr, ed. 2, 147.

Synonym: Stemonitis splendens Rost. var. confluens Lister Monogr. ed. I (1894), 112.

Plasmodium weib. Sporangien $3 \mathrm{~mm}$ hoch, mit kurzem, undeutlichem, am Grunde etwas verbreitertem Stiel. Capillitium zusammenfließend, unregelmäßig. Sporen im durchfallenden Lichte rötlichpurpurn, stachelig, $8-12 \mu$. 
Dentschland (Holstein), Österreich, Schweiz (Jura).

Großbritannien, Frankreich, Schweden, N.-Amerika.

Die Frage der Zugehörigkeit dieser Art zu S. splendens muß vorläufig noch offen bleiben. Auffallend sind die großen, dunkel gefärbten Sporen.

$4^{* *}$. Maschen des Oberflächennetzes winkelig, d. h. nicht abgerundet, $20 \mu$ weit. Sporen $6-8 \mu$. Sporangien gebüschelt.

S. herbatica Peck in Rep. N. York Mus. XXVI (1874), 75 ; Massee Monogr., 87; Lister Monogr, ed. 1, 114, pl. XLIII, B, fig. a-h, ed. 2, 148, pl. 120, fig. a-g; Schinz in Mitt. Naturw. Ges. Winterthur VI, 67; Torrend in Broteria VII, 83.

Synonym: Stemonitis axifera Macbride N. A. Slime-Moulds (1899), 120 pr. p.

Plasmodium weiß oder hellgelb. Sporangien (incl. Stiel) 5-9 mm hoch, walzlich, in dichten Büscheln, rötlichbraın. Stiel 0,8-2 mm. Capillitiumfäden dunkelbraun, ein sehr lockeres Netzwerk mit abgerundeten, $10-20 \mu$ weiten Maschen bildend. Sporen im durchfallenden Lichte blaßrötlichgrau, fein stachelig, $6-8 \mu$.

Deutschland, Schweiz.

Kosmopolitisch.

Diese, namentlich in den 'Tropen verbreitete Art unterscheidet sich von S. splendens durch ihre rötlichbraunen oder braunen, kleineren Sporangien, kleinere Capillitiummaschen, die blaßgraurötlichen, selten rötlichbraunen Sporen. Eine Zwergform mit etwas dunkleren Sporen nnd nicht einmal $4 \mathrm{~mm}$ hohen Sporangien erwähnt Sturgis (Bot. Gazette LV (1913), aus Colorado, er benennt sie aber nicht. Dagegen hat Fräulein Lister eine aus Großbritannien, Ceylon und N.-Amerika bekannte Spielart aufgestellt:

var. confluens Lister Monogr. ed. 2 (1911), 148, deren Sporangien eine æthaloide Masse bilden, ihre Peridien aber \pm beibehalten, indessen weder Stiel noch Columella ausbilden und deren Capillitium ein unregelmäßiges Netz bilden. Auch hier erhebt sich die Frage, inwieweit gestörte Entwicklung beteiligt sein mag. 
4.*** Maschen des Capillitiumnetzes nicht einmal $20 \mu$ weit. Sporangien zerstreut oder gebüschelt zu zerstreuten, kleinen Gruppen, aufrecht, walzlich, stumpf, schwärzlichbraun oder rötlich, abblassend, kurz gestielt. Stiel schwarz, glänzend. Columella in der Nähe des Sporangiumendes plötzlich abbrechend. Capillitiumnetz engmaschig, oberwärts wenig entwickelt. Sporenmasse dunkelbraun, im durchfallenden Lichte dunkel, nahezu glatt, $7-8 \mu$, nicht unähnlich einer trockenen Kaffeebohne.

S. pallida Wingate in Macbride N. A. Slime-Monlds (1899), 123, pl. XVIII, fig. 2; Torrend in Broteria VII, 84; Lister Monogr. ed. 2,149 , pl. 120 , fig. h, l.

Sy no n y me: Stemonitis tenerrima Morgan Myx. Miami Valley (1894), 53. Stemonitis carolinensis Macbride N. A. Slime-Moulds (1899), 122, pl. XVIII, fig. I.

N.-Amerika, Japan.

1*. Sporen im durchfallenden Lichte bla $B$ rostfarbig. 5. Sporen $7-9 \mu$.

S. flavogenita Jahn in Abh. Bot. Ver. Prov. Brandenb. XLV (1904), 165; Lister in Journ. of Bot. XLII, 135, Monogr. ed. 2, 149, pl. 119, fig. a-d; Schinz in Mitt. Naturw. Ges. Winterthur VI, 68; Torrend in Broteria VII, 84.

Synonym: Stemonitis ferruginea Fr. Syst. Myc. III (1829), 158 pr. p. non Khreub.; Rost. Honogr., 196, fig. 31-39, 41-44, 50 pr. p.; Massee Monogr., 160, fig. 160, 161 pr. p.; Celak. Myxom. Böhm., 46?; Schröter in Cohn Krypt.-Fl. Schles. III, 1, 117?; Lister Ilonogr. ed. I, 149. pl. XIIV, fig. a-d.

Plasmodium durchsichtig zitronengelb. Sporangien zimtbraun, samt Stiel, auf den 0,5-1,5 $\mathrm{mm}$ entfallen, 5-7 $\mathrm{mm}$ hoch, walzlich, stumpf, in dichten Büscheln. Stiel schwar\%. Columella mitunter die Sporangienspitze nicht erreichend, Capillitiumfäden braun oder rostbraun, ein lockeres Netz bildend, in den Maschen- 
winkeln oft verbreitert, Oberflächennetz zart, mit winkeligen, $6-16 \mu$ weiten Maschen. Sporen im durchfallenden Lichte blaßrostfarbig, schwach warzig bis nahezu glatt, $7-9 \mu$.

Deutschland, Österreich, Schweiz (Jura).

Großbritanuien, Frankreich, Schweden.

$$
5 * \text { Sporen } 4-6 \mu \text {. }
$$

S. ferruginea Ehrenb. Sylv. Myc. Berol. (1818), 25 non Fr.; Rost. Monogr., 196 pr. p.; Massee Monogr., 85 pr. p.; Jahn in Abh. Bot. Ver. Prov. Brandenb. XLV, 164; Lister Monogr. ed. 2, 150, pl. 119, fig. e-g, in Journ. of Bot. XLII, 134.

Synonyme: Trichia axifera Bull. Champ. (1791), 118, t. 477, fig. 1 ? Stemonitis fasciculata Schum. Enum. Pl. Saell. II (1803), 216? Stemonitis violacea Sehum. Enum. Pl. Saell. II (1803), 216? Stemonitis Smithii Lister Monogr. ed. 1, (1894), 115, pl. XLIV, A, fig. e-g; Macbride N. A. Slime-Moulds (1899), 121.

Stemonitis microspora Lister ex Morgan Myx. Miami Valley (1894), 54 .

Plasmodium weiß. Sporangien samt Stiel $7-20 \mathrm{~mm}$ hoch, dicht gebüschelt, walzlich, gestielt, zimtbraun. Stiel schwarz, 3 bis $7 \mathrm{~mm}$ lang. Columella hoch hinaufreichend, aber nicht die Sporangiumspitze erreichend. Das Capillitium ist mit der Columella durch nicht so zahlreiche Fäden verbunden wie bei flavogenita, auch sind die 5-10 $\mu$ weiten, abgerundeten Maschen regelmäßiger. Sporen im durchfallenden Lichte blaß rotbraun, $4-6 \mu$.

Unterscheidet sich von flavogenita durch die Farbe des Plasmodiums, höhere Sporangien, längere Stiele, mehr abgerundete Netzmaschen, kleinere Sporen.

Dentschlaud, Schweiz, Österreich.

Kosmopolitisch.

var. Smithii (Macbride) Lister Monogr. ed. 2 (1911), 150.

Synonyme: Stemonitis Smithii Macbride in Bull. Nat. Hist. Iowa II (1893), 381 und in N. A. Slime-Moulds, 121.

Stemonitis subclavata Zoll. in Flora XXX (1847), 301?

Sporangien $3-6 \mathrm{~mm}$ hoch, mit einem aus sehr zarten Fäden bestehenden Oberflächennetz.

Sicher für Deutschland und die Schweiz (Jura) nachgewiesen.

Großbritaunien, Ceylon, Java, N.-, Central- und S.-Amerika. 


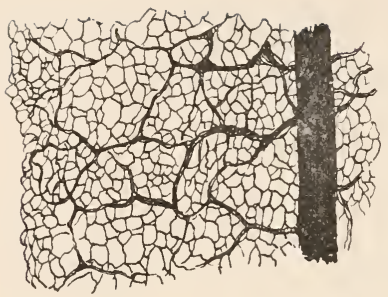

Fig. 93.

Stemonitis ferruginea Ehrenb. var. Smithii (Macbr.) Lister, Ausschnitt aus dem Capillitium mit Columella.

- $180 \times$ - Nach Lister.

var. violacea Meylan in Bull. Soc. Bot. Genève 2 me sér. II (1910), 264, mit $5 \mathrm{~mm}$ hohen, violetten Sporangien und 4-6 $\mu$ großen, glatten Sporen, ist eine weitere für den schweizerischen Jura nachgewiesene Spielart.

\section{Gattung Comatricha Preuss}

in Linnaea XXIV (1851), 140; Rost. Versuch eines Systems d. Mycetozoen, 7, Monogr., 197; Schröter in Cohn Krypt.-Fl. Schles. III, I, 117 und in Engl. und Prantl Natürl. Pflanzenfam. I, 1, 27; Čelak. Myxom. Böhm., 46; Lister Monogr. ed. 1, 116, " ed. 2, 151; Macbride N. A. Slime-Moulds, 123; Schinz in Mitt. Naturw. Ges. Winterthur VI, 69; Torrend in Broteria VI, 41, VII, 73.

Sporangien walzlich, eiförmig oder kugelig, mit vergänglicher Peridie ( \pm bleibend bei C. typhoides), + lang gestielt, der Sporangienstiel sich als Columella in das Innere des Sporangiums bis zu dessen halber Höhe oder höher hinauf fortsetzend, oberwärts verzweigt und in das dichtmaschige Capillitiumnetz übergehend, dessen letzte Ver\%weigungen ohne zu anastomosieren, frei endigen und daher abweichend von Stemonitis kein Oberflächennetz bilden.

Stemonitis und Comatricha sind zwei so nahe verwandte Gattungen, daß die Unterscheidung derselben, namentlich wenn die Spielarten von Stemonitis mit in Berücksichtigung gezogen werden, mitunter sehr schwierig ist, um so schwieriger, als beide durch Übergangsformen verbunden zu sein scheinen. Aus diesem Grunde hat denn auch z. B. Mas s e beide Gattungen zusammengezogen. 
Leider wissen wir heute noch so gut wie garnichts über den Einfluß der Witterung auf die Entwickelung der Capillitien, wir vermuten nur, daß diese als mitbestimmender Faktor in Rechnung zu setzen sein dürfte und daß daher möglicherweise verschiedene der Spielarten dieser und anderer Arten nichts weiter als "Witterungsmodifikationen" sind. In diesem selben Sinne haben sich auch Lister, Vater und Tochter, ausgesprochen (Journ. of Bot. [1899], 150 und [1901], 89).

1. Sporen im durchfallenden Lichtedunkelbräunlichviolett oder grau.

2. Sporen nahezu glatt.

3. Capillitium sich nur vom Columellaende abzweigend.

C. elegans (Racib.) Lister in Brit. Mus. Guide to British Mycet. (1909), 31 und Monogr. ed. 2, 155, pl. 124, fig. $\mathrm{h}-\mathrm{n}$.

Synonyme: Rostafinskia elegans Racib. in Rozpr. Mat. Przyr. Akad. Krak. XII (1884), 77.

Raciborskia elegans Berlese in Sace. Syll. VI1 (1888), 400: Massee Monogr., 108; Lister Monogr. ed. I, 133.

Orthotricha gracilis Racib. in Celak. Myxom. Böhm. (1893), 55?

Plasmodium weiß. Sporangien zerstreut oder herdenweise, kugelig, 0,2-0.5 mm im Durchmesser, purpurbraun. Stiel schlank, schwarz, dünn, bis $1 \mathrm{~mm}$ hoch. Columella kurz, sich verzweigend, die Äste sich wieder mehrfach verästelnd, ein lockeres Netzwerk bildend. Sporen im durchfallenden Lichte blaßbräunlichviolett, undeutlich stachelig, 8-10 $\mu$.

Österreich.

Großbritannien, Schweden, Portugal, Ceylon, Japau, N.-Amerika.

$3^{*}$. Capillitium sich von der ganzen Columellalänge, nicht blob von deren Ende abzweig end.

4. Capillitiumfäden gewunden, kraus, wenig untereinander verschieden.

5. Sporenpulver blauschwarz; Ein\% elsporen im durchfallenden Lichte purpurgrau, $9-13 \mu$. 
C. Suksdorfii (Ellis et Everh.) Macbride N. A. SlimeMoulds (1899), 132; Lister Monogr. ed. 2, 153, pl. 123, fig. i, k.

Synonyme: Stemonitis Suksdorfii Ellis et Everh. in Bull. Washburn Coll. I (1882), 5; Massee Monogr., 76.

Comatricha obtusata Lister Monogr. ed. I (1894), 118 pr. p.

Comatricha nigra var. Suksdorfii Sturgis in Colorado Coll. Publ.

Sc. Ser. XII (1907), 33.

Plasmodium? Sporangien zerstreut in kleinen Häufchen oder herdenweise, walzlich oder kugelig, beiderends stumpf, oberwärts \pm erweitert, purpurschwarz, 0,5-1 $\mathrm{mm}$ im Durchmesser, $0,3-0,7 \mathrm{~mm}$ lang gestielt. Columella dicht unterhalb ihres obern Endes in zwei oder mehr breite Äste sich verzweigend. Capillitiumfäden gewunden, ein dichtes Netzwerk bildend. Sporen im durchfallenden Lichte purpurgrau; undeutlich stachelig, 9-13 $\mu$, als Sporenmasse blauschwarz.

Schweiz (Fürstenalp).

N.-Amerika, Japan.

5*. Sporenpulver braun; Einzelsporen im durchfallenden Lichte braunviolett.

C. nigra (Pers.) Schröter. in Cohn Krypt.-Fl. Schles. III, I (1885), 118; Macbride N. A. Slime-Moulds, 128; Torrend in Broteria VII, 73, pl. V, fig. 9, 10, 13; Lister ed. 2, 152, pl. 123, fig. $\mathrm{a}-\mathrm{h}$.

Synonyme: Stemonitis nigra Pers. in Gmel. Syst. Nat. (1791), 1467.

Stemonitis atrofusca Pers, in Roem. N. Mag. Bot. I (1794), 91.

Stemonitis reticulata Trentep. in Roth Cat. Bot. I (1797), 223?

Stemonitis ovata Pers. Syu. (1801), 189.

Stemonitis globosa Sehum. Enum. Pl. Saell. II (1803), 217?

Stemonitis obtusata Fr. Syst. Myc. III (1829), 160.

Stemonitis oblonga Fr. Syst. Myc III (1829), 159.

Stemonitis Friesiana de Bary in Rabenhorst Fungi Eur. (1863),

No. 568; Massee Monogr., 82.

Stemonitis subcæspitosa Massee Monogr. (1892), 80.

Trichia alba Sow. Engl. Fung. (1803), t. 259 nom. nud.

Comatricha obtusata PrenB in Linnaea XXIV (1851), 141; Lister

Monogr. ed. 1, 117, pl. XLIV, B, fig. a-f; Schinz in Mlitt.

Naturw. Ges. Winterthur VI, 70.

Comatricha Friesiana Rost. Monogr. (1875), 199, fig. 51, 56. 
Comatricha Friesiana var. excelsa Racib, in Hedwigia XXVIII (1889), 115.

Comatricha subcæspitosa Peck in Rep. New-York Mus. XLIII (1890), 25, pl. III, fig. 6-9.

Comatricha Persoonii Čelak. Myxom. Böhm. (1893), 50, t. 2, fig. 4, 5; Macbride N. A. Slime-Moulds, 132 pr. p.

Exsikkaten: Fuckel Fungi rhen. 1446.

Rabenhorst. Fungi Eur. 568.

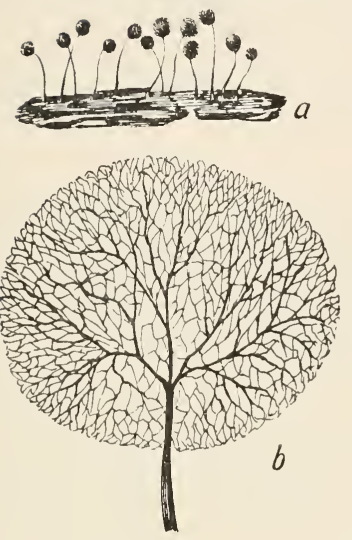

Fig. 94. Comatricha nigra (Pers.) Schröter.

a) Gruppe vou Sporangien $(4 / 1)$; b) Capillitium von Comatricha laxa Rost. (75/1). Nach Lister.

Plasmodium wässerigweiß. Sporangien (samt Stiel) $1-6 \mathrm{~mm}$ hoch, zerstreut oder herdenweiße, \pm $0,6 \mathrm{~mm}$ im Durchmesser, kugelig, ellipsoidisch oder walzlich, purpurbraun oder schwärzlich. Stiel fädlich, glänzend schwarz, bei kugeligen Sporangien 2-6 mal länger als diese, bei walzlichen Sporangien so lang oder kürzer als diese, einem deutlich wahrnehmbaren Hypothallus entspringend. Columella die halbe Sporangienhöhe erreichend, mitunter auch bis zur Sporangienspitze reichend, oberwärts sich verzweigend und in das Capillitiumnetz übergehend. Letzteres besteht aus gewundenen, netzförmig verbundenen Fäden, die fast in ihrem ganzen Verlauf von gleicher Stärke sind und die im untern Teil mitunter ein Stemonitis-ähnliches Oberflächennetz bilden; die freien Enden sind häufig zurückgekrümmt und $a b$ und $z u$ mit kurzen Dornfortsätzen versehen. Sporen 7-11 $\mu$, nahezu glatt oder fein kurzstachelig.

Deutschland, Österreich, Schweiz.

Kosmopolitisch.

var. alta (PreuB) Lister Monogr. ed. 2. (1911), 152, pl. 123, fig. d.

Synonym: Comatricha alta Preuß in Sturm Deutschl. Fl., Pilze VI (1862), 141, t. 71 . 
Sporangien \pm walzlich, das Capillitium zur Hauptsache ein Gewirr gebogener, dem Grunde der Colımella angehefteter Fäden bildend.

var. aqualis (Peck) Sturgis in Colorado Coll. Publ. Sc. Ser. XII (1907), 34; Lister Monogr. ed. 2, 153, pl. 123, fig. 1.

Synonyme: Comatricha æqualis Peck in Rep. New-York Mus. XXXI (1879), 42; Nacbride N. A. Slime-Noulds, 131.

Stemonitis æqualis Massee Monogr. (1892), 80.

Sporangien schlank walzlich, 2-4 $\mathrm{mm}$ lang und $2-2,5 \mathrm{~mm}$ lang gestielt; Capillitium ein dichtes Netzwerk violettbrauner Fäden bildend; Sporen $7^{1} / 2^{--8 \mu}$.

var. microspora (Torrend) Meylan in Annuaire Conserv. et Jard. bot. Genève 15 me et 16 me année (1913), 316.

Synonym: Comatricha laxa (Massee) Rost. var. microspora T'orrend ap. Meylan in Bull. Soc. Vand. Sc. Nat. XLV1 (1919), 50 und in Bull. Soc. Bot. Genève 2 me sér. II, 264.

Sporangien walzlich, länger als der Stiel, Capillitium sehr hinfällig und sich leicht von der Columella lösend; Sporen $5-7 \mu$.

Der Typus scheint im Gebiet nicht selten zu sein; von den drei Spielarten ist die Var. microspora häufig im Jura, die beiden andern Varietäten sind für unser Gebiet noch nachzuweisen.

4*. Die Capillitiumfäden I. Ordnung (direkt von der Columella abgehend) fast gerade, nicht kraus, kräftiger als die übrigen desselben Netzes.

C. laxa Rost. Monogr. (1875), 201; Čelak. Myxom. Böhm. 52 ; Lister Monogr. ed. 1, 118, pl. XLIV, B, fig. g-h, ed. 2, 154, pl. 124, fig. a-g; Macbride N. A. Slime-Moulds, 127, pl. V, fig. 5, 5a; Torrend in Broteria VII, 74, pl. V, fig. 11, 12; Schinz in Mitt. Naturw. Ges. Winterthur VI, 70.

Synouyme: Stemonitis laxa Massee Monogr. (1892), 79.

Badhamia penetralis Cooke et Ellis in Grev. V (1876), 49?

Lamproderma Ellisiana Cooke in Ann. Lyc. Nat. Hist. N.-York XI (1877), 397?

Comatricha macrosperma Racib, in Rozpr. Mat. Przyr. Akad. Krak. XII (1884), 76. 
Comatricha Ellisiana Ellis et Everh N. Am. Fungi ser. 2 (1891), 2696.

Comatricha Sommerfeltii Blytt in Bidr. K. Norg. Sop. III (1892), 8 ,

Comatricha Ellisii Morgan Myx. Miami Valles (1894), 49.

Orthotricha Raciborskii Čelak. Myxom. Böhm. (1893), 54?

Plasmodium wässerigweiß. Sporangien zerstreut oder herdenweise, fast kugelig oder kurz walzlich, 1,5-3,5 mm (inkl. dem $0,2-0,6 \mathrm{~mm}$ langen Stiel) lang. Stiel kräftiger als bei $C$. nigra, glänzend schwarz, als nach oben sich verjüngende Columella

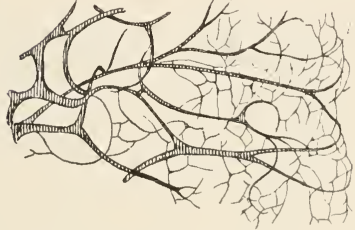

Fig. 95. Comatricha laxa Rost. Aussehnitt aus dem Capillitium $(180 / 1)$. Nach Lister.

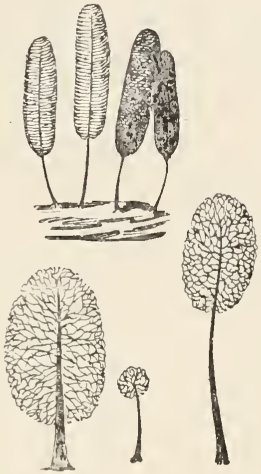

Fig. 96. Comatricha laxa Rost.; obere Sporangien 4/1, untere, Sporangiumwand geschwunden, $15 / 1$. - Nach Lister.

nahezu die Sporangienspitze erreichend. Hypothallus spärlich oder fehlend. Capillitium meist locker; die Fäden erster Ordnung fast wagrecht von der Columella abgehend, sich reichlich verzweigend, freie Enden zahlreich. Sporen $7-9 \frac{1}{2} \mu$, nahezu glatt.

Deutschland, Österreich, Schweiz.

Großbritannien, Frankreich, Skandinavien, Portugal, N.-Amerika, Japan.

Steht in jeder Hinsicht der C. nigra sehr nahe. Die langgestielten Formen von nigra besitzen meist überhängende Sporangien, wogegen diejenigen von laxa stets aufrecht sind. Formen mit kugeligen Sporangien gehören zu C. nigra.

Orthotricha Raciborskii Celak. Myxom. Böhm. (1893), 54 soll nach brieflicher Mitteilung von Frl. G. Lister, der ich auch in diesem Falle wiederum zu gröBtem Danke verpflichtet bin und die mit ilrem verstorbenen Vater ein 
Präparat des Člakovsky'schen Beleges gesehen und teilweise gezeichnet hat, zwischen Comatricha laxa und Comatricha elegans stehen, zwei Arten, die durch diesen Umstand noch näher gebracht werden. Ich belasse vorläufig, nicht ohne Fragezeichen, die Celakovsky'sche $O$. Raciborskii als synonym bei laxa, wohin sie wohl auch ohne weiteres Fräulein G. Lister stellen würde.

- Schwieriger noch ist zu sagen, was wir mit Orthotricha gracilis Racib. ap. Celakovsky (1. c., 55) anfangen sollen. Wir finden den Namen in keiner der Publikationen von Raciborski. Frl. Lister äußert die Vermutung (brieflich) und sie hat viel für sich, daß vielleicht Raciborski, noch bevor Saccardo die Pflanze Raciborskia elegans nannte, sie im brieflichen Verkehr mit Čela kovsky als Orthotricha gracilis bezeichnet habe, allermindestens läßt sich keine einzige Publikationsstelle, außer der erwähnten in den Myxom. Böhmens, mit diesem Epitheton finden.

Die in nenerer Zeit üblich gewordene Schreibweise Orthotrichia anstatt Orthotricha ist unzulässig. Wingate, der übersehen hatte, daß der vou ihm als noch unbeschrieben aufgefaBte Schleimpilz bereits 6 Jahre vordem als Clastoderma Debaryanum von Blytt beschrieben worden war, ist der Autor der Gattung Orthotricha (Journ. of Myeology II (1886), 125). Drei Jahre nach dioser Publikation (Proc. Acad. Nat. Sc. Phil. (1889), 18y) scheint (wohl in einer sitzung der Acad.) Wingate darauf hingewiesen zu haben, daß in einer Reihe vou „Journals" und auch in 'aceardo's Sylloge VII, pag. 1, die von ihm am angegebenen Orte aufgestellte Gattung irrtümlicherweise Orthotrichia geschrieben werde, daB er (Wingate) nun aber in Anbetracht des Umstandes dab bereits eine (Moos-) Gattung Orthotrichum existiere, auch seinerseits die neue Schreibweise Orthotrichia akzeptiere.

Es liegt auf der Hand, daß dieser Auffassung nicht zugestimmt werden kann und daß wir an der ursprünglichen Bezeichnung Orthotricha festzuhalten haben.

$2^{*}$. Sporen deutlich stachelig, warzig oder mit netzartiger Skulptur.

6. Sporangien kugelig. Sporangien aufrecht, $0,75 \mathrm{~mm}$ lang gestielt, $0,5 \mathrm{~mm}$ im Durchmesser, purpurbraun, zerstreut vorkommend. Stiel schwarz, sehr dünn, auf brauner Hypothallusscheibe. Columella + die halbe Höhe des Sporangiums erreichend und sich dann in zahlreiche, kräftige Äste erster Ordnung zerteilend, die bis zur Sporangiumwand reichen. Capillitium dunkelpurpurbraun mit zahlreichen freien, feinen braunen Enden. 
Sporen im durchfallenden Lichte purpurgrau, kugelig oder fast eiförmig, grob warzig, $8-10 \mu$.

C. Iurida Lister Monogr. ed. I (1894), 119, pl. XLV, B, fig. a-c, ed. 2, 155, pl. 127, fig. a-c; Torrend in Broteria VII, 75 .

GroBbritannien.

$6^{*}$. Sporangien lang, walzlich, schlank.

7. Sporen mit netzartiger Skulptur (stachelig und die Stacheln an ihrem Grunde durch feine Linien verbunden, die in ihrer Gesamtheit ein dichtes Netz bilden), im durchfallenden Lichte dunkelgrau, 8-9 $\mu$. Die Sporangien kommen ähnlich wie bei Stemonitis-Arten gebüschelt vor, sie sind samt Stiel 2-5 $\mathrm{mm}$ (auf den Stiel entfallen $1-3 \mathrm{~mm}$ ) hoch, gebogen oder bängend. Die Columella erreicht nahezu das Sporangiumende, sieist sehr schlank nach oben zu und nimmt einen zickzackförmigen Verlauf, ihre Dicke beträgt am Grunde $20 \mu$, oben noch etwa $2 \mu$. Das Capillitiumnetz ist locker, die freien Enden der Capillitiumfäden sind straff, weder gekrümmt noch kraus, gabelig verzweigt.

C. longa Peck in Rep. N.-York Mus. XLIII (1890), 24; Lister Monogr. ed. I, 119, pl. XLV, B, fig. a-i, ed. 2, 159, pl. 122, fig. a-e; Macbride N. A. Slime-Moulds, 125, pl. VI, fig. $2,2 \mathrm{a}, 2 \mathrm{~b}$.

Synonyme: Stemonitis longa Massee Monogr. (1892), 83.

Comatricha equinoctialis Torrend in Broteria VII (1908), 78, pl. IX, fig. 21, 22.

Afrika, Ceylon, Java, Japan, N.-, Central- und S.-Amerika.

$7^{*}$. Sporen dicht stachelig, im durchfallenden Lichte bräunlichpurpurfarbig, oft auf einer Seite blasser, 
$8-10 \mu$. Sporangien gebüschelt, gestielt, walzlich, $2-5 \mathrm{~mm}$ lang, sehr dunkelbraun oder sogar schwarz. Stiel 1-3 mm lang, schwarz, einem wohlentwickelten, glänzendbraunen Hypothallus aufsitzend. Columella gerade oder gewunden, nahezu die Spitze des Sporangiums erreichend und sich dann verzweigend. Die letzten Verzweigungen des meist weitmaschigen Capillitiumnetzes sind farblos. Sporenmase schwarz.

C. irregularis $\mathrm{Rex}$ in Proc. Acad. Nat. Sc. Phil. (1891), 393; Macbride N. A. Slime-Moulds, 126; Torrend in Broteria VII, 79; Lister Monogr. ed. 2, 160, pl. 122, fig. f-i.

Synonyme: Stemonitis crypta Schwein. in Trans. Am. Phil. Soc, IV (1832), 260 ?

Comatricha crypta Macbride in Bull. Nat. Hist. Iowa II (1893), 139.

Comatricha longa Peck var. irregularis Lister Monogr. ed. I (1894), 120, pl. XLV, A, fig. f-i.

N.-Amerika, Australien.

1*. Sporen im durchfallenden Lichte blaß, lila oder rötlichlila.

8. Sporen mit einigen zerstreuten Warzen, im übrigen glatt oder zart netzartig skulptiert.

C. typhoides (Bull.) Lister Monogr. ed. I (1894), 120, pl. XIJI, A, fig. a-k, ed. 2, 157, pl. 125, fig. a-q; Schinz in Mitt. Naturw. Ges. Winterthur VI, 71.

Synonyme: Mucor Stemonitis Scop. Fl. Carn. II (1772), 493?

Stemonitis typhina Wiggers Prim. Fl. Holst. (1780), 110 ?

Trichia typhoides Bull. Champ. (1791), 119, t. 477, fig. 2.

Observ. Myc. I, 57 ; Massee Monogr., 74.

Stemonitis typhoides DC. Fl. Fr. II (1805), 257; Rabenhorst Dentschl. Krypt.-Fl. I, 269.

Stemonitis pumila Corda Icon. V (1842), 59.

Stemonitis affinis Massee Monogr. (1892), 76.

Stemonitis atra Massee Monogr. (1892), 78.

Stemonitis Carlylei Massee Monogr. (1892), 84, fig. 158, 159. 
Comatricha typhina Rost. Monogx. (1875), 197, fig. 46, 47; Čelak. Myxom. Böhm., 48; Schröter in Cohn Krypt.-Fl. Schles. III, I, 118; Torrend in Broteria VII, 76.

Comatricha affinis Rost. Monogr. (1875), 202.

Comatricha Stemonitis Sheldon in Minn. Bot. Stud. (1895), 473; Macbride N. A. Slime-Moulds, 130.

Exsikkaten: Fuckel Fungi rhen. 1450.

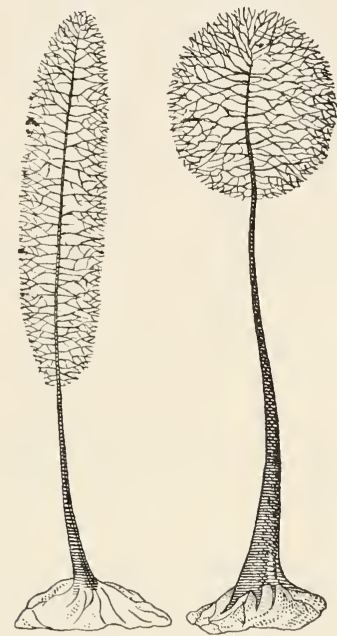

Fig. 97. Rechts Sporangium von Comatricha nigra (Pers.) Schröter, links von Comatrichatyphoides (Bull.) Lister. Beide ohne die Peridie, Capillitium und Columella zeigend $(30 / 1)$. - Nach Raunkiaer.

Plasmodium wässerig weiß. Sporangien meist herdenweise, gestielt, walzlich, aufrecht oder mitunter gebogen, stumpf, 1,5-2,3 $\mathrm{mm}$ lang, mit silbergrauer Peridie, nach deren Zerfall lilabraun. Stiel schwarz, mitunter mit der silbergrauen Sporangiumwand bekleidet, 0,5-1,3 $\mathrm{mm}$ lang, auf wohlentwickeltem Hypothallus. Die am obern Ende sich verzweigende Columella bis nahezu der Spitze des Sporangiums reichend. Capillitiumnetz aus gebogenen Fäden bestehend, der ganzen Länge der Columella entspringend, im untern Teile mitunter ein Oberflächennetz bil- 
dend. Sporen im durchfallenden Lichte blaßlilabraun, mit 3 bis 5 Warzen oder Gruppen sehr kleiner Warzen, sonst kahl oder sehr fein warzig zerstreut, $6-7 \mu$.

Deutschland, Österreich, Schweiz.

Kosmopolitisch.

var. microspora Lister Monogr. ed. I (1894), 121, pl. XLVI, A, fig. h, i, ed. 2, 158, pl. 125, fig. g-i.

Synonym: Comatricha typhina var. microspora Torrend in Broteria VII (1908), 76.

Sporangium mit Oberflächennetz; Sporen nahezu glatt, $3,5-4,5 \mu$.

Deutschland (Holstein).

var. Similis Lister Monogr. ed. 2 (1911), 158, pl. 125, fig. $\mathrm{k}, \mathrm{m}$.

Sporangium unterwärts mit Oberflächennetz; Sporen 5-7 $\mu$, mit vereinzelten größern und zahlreichen kleinern Warzen.

Schweiz (Arosa).

Die Zugehörigkeit der beiden Varietäten zu V. typhoides ist so lange noch fraglich, als wir die Variationsbreite der Art noch nicht kennen. Das Vorhandensein eines Oberflächennetzes spricht für deren Zugehörigkeit zu Stemonitis, die Sporenskulptur in Verbindung mit der Sporengröße verbietet aber vorläufig deren Angliederung an diese Gattung.

Wie Lister betont, sind die vor 1791 aufgestellten Benennungen ganz zweifelhafter Natur, dagegen kann bezüglich der Combination von $\mathrm{Bulli}$ ard kein $\mathrm{Zweifel}$ bestehen, daß unsere Art gemeint ist. Als Autor der Kombination C. typhoides kann aber nicht Rostafinsky gelten, da Rostafinsky sie nicht gebildet hat.

8*. Sporen fein stachelig oder fein warzig oder sogar nahezu glatt.

9. Sporangiumwand ganz schwindend. 
C. pulchella (Babington) Rost. Monogr. App. (1876), 27; Čelak. Myxom. Böhm., 49; Macbride N. A. Slime-Moulds, 129, pl. XIII, fig. 4; Lister Monogr. ed. 2, 156, pl. 126, fig. a-l.

Synonyme: Stemonitis pulchella Babington in Proc. Linn. Soc. I (1839), 32; Berkeley in Ann Mag. Nat. Hist. ser. I, VI, 431, t. 12, fig. II; Massee Monogr., 86.

Comatricha Persoonii Rost. Monogr. (1875), 201; Lister Monogr. ed. 1, 122, pl. XLVI, B, fig. d-i; Schinz in Mitt. Naturw. Ges. Winterthur VI, 72; Torrend in Broteria VII, 77.

Plasmodium wässerig weib. Sporangien zerstreut, eiförmig oder walzlich, 0,5-1,5 mm lang, anf $0,2-0,5 \mathrm{~mm}$ langen Stielen, lila- oder rostbraun. Columella bis zum Sporangiumscheitel reichend. Primanäste des Capillitiums wagrecht von der Columella abgehend, das Capillitium im übrigen sehr kraus, mit zahlreichen freien Enden. Sporen im durchfallenden Lichte blaßlilabraun oder fleischfarbig, feinwarzig, $6-8 \mu$.

var. tenerrima (Curtis) Lister Monogr. ed. 2 (1911), 156, pl. 126, fig. $\mathrm{f}-\mathrm{h}$.

Synonym: Stemonitis tenerrima Curtis in Sull. Am. Journ. VI (1848), 352.

Sporangien kurz walzlich, $0,5-1,5 \mathrm{~mm}$ lang gestielt. Sporen und Capillitium fleischfarbig, letzteres mitunter ein Oberflächennetz bildend.

Fräulein G. Lister (Journ. of Bot. [1913], 97) erwähnt ausdrücklich, daB an dem einen von zwei unzweifelhaft derselben Art angehörenden Sporangien die Capillitiumendigungen frei, beim andern zu einem Oberflächennetz verbunden waren.

Schweiz (Mürren).

var. fusca Lister in Journ. of Bot. XXXV (1897), 215 und Monogr. ed. 2, 156, pl. 126, fig. d.

Capillitiumfäden straffer als beim Typus, purpurbraun, Sporen im durchfallenden Lichte blaß graulichbraun.

Großbritannien.

var. gracilis (Wingate) Lister Monogr. ed. 2 (1911), 156, pl. 126, fig. i-l.

Synonyme: Comatricha gracilis Wingate in Ellis et Everh. N.-Am. Fung. ser. 2 (1888), No. 2094.

Comatricha Persoonii Macbride N. A. Slime-Noulds (1899), 132 pr. p. 
Sporangien schlank walzlich, $0,2-0,5 \mathrm{~mm}$ lang gestielt; Capillitiumfäden gewöhnlich ein Oberflächennetz bildend. Sporen im durchfallenden Lichte grau, undeutlich warzig, 5,5-7 $\mu$.

Der Typus in Deutschland, Österreich, Schweiz.

Kosmopolitisch.

9*. Sporangiumwand am Grunde des Sporangiums bleibend und nach Zerfall des obern Teiles der Wand einen häutigen Becherbildend, der durch Capillitiumfäden mit breiten Ansatzstellen mit dem Capillitium und damit mit der Columella verbunden ist. Sporangien mit Einschlub des $0,6-1,3 \mathrm{~mm}$ langen, fädlichen, glänzend schwarzen Stieles 1-2 $\mathrm{mm}$ hoch, zerstreut, verkehrteiförmig, ellipsoidisch oder \pm kugelig, rötlichbraun, unterwärts glänzend. Oolumella $2 / 3$ der Sporangiumhöhe erreichend, an der Spitze sich verzweigend. Capillitiumfäden violettbräunlich, Primärfäden breit, sich zu zarten Auszweigungen verjüngend. Sporen im durchfallenden Lichte blablila, fein stachelig, $7-8 \mu$.

C. rubens Lister Monogr. ed. I (1894), 123, pl. XiS, B, fig. d-f, ed. 2, 157, pl. 127, fig. d-f; Torrend in Broteria VII, 78. GroBbritaunien, N.-Amerika.

\section{Gattung Enerthenema Bowman}

in Trans. Linn. Soc. XVI (1828), 152; Rost. Versuch eines Systems der Mycetozen, 8, Monogr., 209; Massee Monogr., 104: Celak. Myxom. Böhm., 55; Schröter in Engl. und Prantl Natürl. Pflanzenfam. I, 1, 27; Lister Monogr. ed. 1, 124, ed. 2, 160; Macbride N. A. Slime-Moulds, 137; Schinz in Mitt. Naturw. Ges. Winterthur VI, 73; Torrend in Broteria VI, 33, VII, 71. Sporangien gestielt, der Stiel als Columella das ganze Sporangium durchziehend und am obern Ende zu einer Scheibe 
verbreitert, von der das aus freien Fäden bestehende Capillitium schirmartig herunterhängt, letzteres ausnahmsweise der ganzen Länge der Columella entspringend.

1. Sporen einzeln, nicht in Sporenhäufchen, $8-10 \mu$.

E. papillatum (Pers.) Rost. Monogr. App. (1876), 28; Člak. Myxom. Böhm., 55; Lister Monogr. ed. 2, 160, pl. 128, fig. a-e; Macbride N. A. Slime-Moulds, 137, pl. V, fig. 3; Torrend in Broteria VII, 72, pl. V, fig. $6 \mathrm{a}, 7,8$.

Synonyme: Stemonitis papillata Pers. in Roem. N. Mag. Bot. (1794), 90, t. I, fig. 4; Rabenhorst Deutschl. Krypt.-Fl., I, 269.

Stemonitis mammosa Fr. Syst. Myc. III (1829), 161.

Arcyria atra Schum. Enmm. Saell. II (1803), 215.

Enerthenema elegans Bowm. in Trans. Linn. Soc. XVI (1828), 152, t. 16; Berkeley and Broome in Aun. Mag. Nat. Hist. ser. 2, V, 366; Rost. Monogr. 209, fig. 45, 48, 49, 52, 57; Massee Monogr., 105, fig. 302-304; Lister Monogr. ed. 1, 124, pl. XLVII, A, fig. a-d; Schinz in Mitt. Naturw. Ges. Winterthur VI, 73.

? Enerthenema Berkeleyana Rost. Mlonogr. App. (1876), 29; Massee Mouogr., 106.

Ancyrophorus crassipes Ramukiaer in Bot. Tidskr. XVII (1888),

93; Massee Monogr., 107.

Comatricha papillata Schröter in Cohn Krypt.-Fl. Schles. III, 1 (1899), 118.

Exsikkat: Fuckel Fungi rhen. 2854.

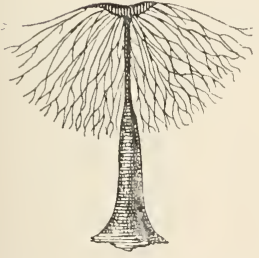

Fig. 9s. Enerthenema appillatum (Pers.) Rost. Sporangium, ohue Peridie, mit vom Columella-Ende herabhängendem Capillitium $(35 / 1)$. - Nach Lister.
Plasmodium wässerigweiß. Sporangien samt Stiel 1-1,5 mm hoch, 'herdenweise vorkommend, kugelig, aufrecht, 0,5-0,75 mm im Durchmesser, schwar' oder purpurbraun, gekrönt von einer scheibenförmigen, \pm metallisch glänzenden Papille; Sporenwand hinfällig. Columella aus kegelförmigem Grunde aufsteigend, das ganze Sporangium durchziehend und meist in einer $0,1-0,2 \mathrm{~mm}$ breiten Scheibe endigend. Die von der Columellascheibe herunter hängenden Capillitiumfäden sind schlank, schwarz, 
gerade oder gewunden, an den Enden verzweigt. Sporen im durchfallenden Lichte graubraun, stachelig, 8-10 $\mu$.

Deutschland, Österreich, Schweiz.

Kosmopolitisch.

Wir haben die Variationsbreite der Art möglichst weit gefaßt und lassen daher die von Celakovsky aufgestellten (Myxom. Böhm. [1893], 55) beiden Spielarten polytricha Celak. (Stiel und Columella schlank; Discus breit, flach oder in der Mitte schwach nabelig; Capillitium dicht, aus feinen, haarförmigen, fast glatten Fäden bestehend; Sporen hellviolett [im durchfallenden Lichte], 10-12 $\mu$ breit, glatt oder fein punktiert) und sparsa Celak. (Stiel unten oft angeschwollen; Discus eng, dafür jedoch trichter- oder trompetenförmig eingesenkt; Capillitium ziemlich locker, ans groben, unten bedeutend dümeren, soust rauhen und unebenen, stellenweise sogar gezähnten Fäden bestehend; Sporen [im durchfallenden Lichte] dunkelviolett, $11-13 \mu$ [einzehe bis $15 \mu$ ] breit, warzig oder fein granuliert) in der Art aufgehen.

Ladislav C̉elakovsky hat Gelegenheit gehabt, eine gröBere Serie offenbar znsammengehöriger Sporangien dieser Art studieren zu können und schildert die Mannigfaltigkeit in der Ausbildung des Capillitiums wie folgt (Čelak. Myxom. Böhmens, 56): „Sämtliche auf einem und demselben Ast von Pinus silvestris zerstreut oder locker beisammenstehende, vollkommen reife Exemplare bildeten eigentlich eine Reihe von Formen, deren Endglieder sehr von einander differieren und gleichsam als zwei Extreme aufzufassen sind. Das eine Endglied nähert sich am meisten der typischen Enerthenema papillata var. sparsa, mit dem Unterschied jedoch, daß die Capillitiumfäden nicht sämtlich aus dem Rande des trichter- oder trompetenförmigen Ansatzes, sondern zum kleineren Teil aus dessen äußerer Fläche entspringen. Diesen Formen folgen andere, wo die Fäden noch tiefer hinabsteigen und an die Spitze der Columella ansetzen. Ferner trifft man Exemplare, bei denen von einer Scheibe oder von dem genannten Ansatz keine Spur vorhanden ist. Vielmehr endigt die Columella mit einer scharfen oder stumpfen Spitze, während die Capillitiumfäden aus der ganzen Länge der Columella oder bloß aus ihrem oberen Teil entspringen. Endlich - und das ist das andere Extrem - findet man Individuen, bei welchen die Columella mehr oder weniger (zuweilen bis zur Hälfte der Sporangiumhöhle) verkürzt oder dick erscheint, und wo dann die Fäden aus der oberen Hälfte der Columella entspringen und (natürlich vor der Sporenaussat) nach allen Seiten ausstrahlen. In diesem Falle 
beginnen die Enden der Capillitiumfasern in der unteren Sporangiumhälfte zu anastomosieren und ein der Comatricha laxa ähnliches, lockeres Netz zu bilden. Die Fäden sind bei allen genannten Abnormitäten grob und dick wie bei E. papillat. var. sparsa, und wie bei dieser nicht zahlreich vorhanden. Auf eine abnorme Bildung lassen besonders die Sporen schließen, von denen einzelne 18 bis $24 \mu$, zuweilen aber kaum $12 \mu$ breit sind, während sie im Durchschnitt 13 bis $15,5 \mu$ an Breite messen. Ihre sonstige Beschaffenheit, Skulptur, ist von derjenigen der Enerthenema papillatum var. sparsa nicht verschieden."

\section{Sc. Nat. LI (1917), 268.}

var. carneo-griseum Meylan in Bull. Soc. Vaud.

Sporangien graurötlich oder hellviolett, Capillitiūm sehr blaß, stark geschlängelt.

Schweiz (Chasseron, $1500 \mathrm{~m}$ ).

$1^{*}$. Sporen zu 4 bis 8 in Häufchen, $11-12,5 \mu$, auf der freien Seite stachelig; Capillitiumfäden + rauh, im übrigen kaum wesentlich verschieden von obgenannter Art.

E. syncarpon Sturgis in Colorado College Publ. Gen. Ser. Nr. 8, 68, Sc. ser. XII Nr. 12 (1913), 448, pl. 2, fig. 9, 10, 11, 12.

Synony m: ? Enerthenema Berkeleyana Rost. Monogr. App. (1876), 29.

N.-Amerika (Colorado).

Sturgis (I. c.) macht darauf aufmerksam, daß die von ihm aufgestellte Art auffallende C̈bereinstimmung in mehr als einem Punkte mit der von Berkeley und Broome in Ann. Mag. Nat. Hist. ser. 2, V, 366 beschriebenen, von Rostafinski Enerthenema Berkeleyana genannten, Enerthenema elegans aufweise, die nach Berkeley und Broome gleicherweise zu Häufchen vereinigte Sporen besitzen soll. Nun haben aber Lister die in Kew befindlichen Originalexemplare von E. Berkeleyana untersucht, haben aber keine Spur von Enerthenema-Sporen mehr auffinden können. wohl aber zu kleinen Häufchen vereinigte Sporen eines mit Hyphen versehenen fremden Pilzes und es ist daher keineswegs unmöglich, daß Berkeley und Broome s. Z. die fremden Sporenhänfchen als zu Enerthenema gehörend aufgefaßt und beschrieben haben. Die Frage der Zugehörigkeit des E. Berkeleyana zu E. papillatum Schinz, Myxogasteres (Rabenhorst Krypt. Fl. I, Pilze Abt. X). 
einerseits und zu E. syncarpon anderseits muB daher wohl für alle Zeiten offen gelassen werden und wir stellen aus diesem Grunde mit Sturgis E. Berkeleyana als fragliches synonym sowohl \%u papillatum wie zu syncarpon.

Man kan sich natülich mit Sturgis auch fragen, ob die Vereinigung der Sporen zu Häufchen wirklich zu einer Artunterscheidung berechtige. Die Antwort mag so oder so ausfallen, jedenfalls kommt hier noch in Betracht, daß einerseits bei syncarpon die Capillitiumfäden rauher und andererseits die Sporen größer als bei $E$. papillatum und ungleichstachelig sind, immerhin sei an dieser Stelle nochmals auf die Beobachtungen Čelakovsky's hinsichtlich der Variabilität von E.papillatum verwiesen.

\section{Gattung Lamproderma Rost.}

Versuch eines Systems der Mycetozoen (1873), 7 und Monogr., 202; Schröter in Engl. und Prantl Natürl. Pflanzenfam. I, 1, 27 ; Massee Monogr., 94; Čelak. Myxom. Böhm., 53; Lister Monogr. ed. 1, 125, ed. 2, 161; Macbride N. Am. Slime-Moulds, 138; Schinz in Mitt. Naturw. Ges. Winterthur VI, 74.

Sporangien meist gestielt, kugelig oder ellipsoidisch (bei L. cribrarioides an deren Stelle mitunter Plasmodiokarpien); Sporangiumwand häutig, metallisch glänzend. Stiel schwarz. Colımella walzlich oder keulenförmig, bis zur halben Höhe des Sporangiums oder höher hinauf reichend. Capillitium aus verzweigten und anastomosierenden Fäden bestehend, die vom obern Teil der Columella ausstrahlen.

Lamproderma unterscheidet sich von Comatricha, derjenigen Gattung, mit der sie die engsten Beziehungen anfweist, hauptsächlich durch das Verhalten des Capillitiums, das entweder nur von der Spitze der Columella aus sich entwickelt oder doch in der Regel am obern Columellaabschnitt entspringt. Die Sporangiumwand ist weniger hinfällig als bei den Comatrichaarten, sehr oft prächtig metallisch glänzend; zerfällt sie, so bleibt häufig am Grunde eine Art Kragen stehen.

1. Sporen stachelig oder warzig (bei L. violaceum var. dictyosporum mit unregelmäBig netzartiger skulptur).

2. Sporen borstig, $15-20 \mu$, in durchfallenden Lichte dunkelgrau oder bräunlichrot. mit schwarzen Borsten. Sporangien samt Stiel 
2-4 mm hoch, herdenweise vorkommend, kugelig, 0,5-1 mm im Durchmesser. Peridie metallisch glänzend mit stahlblauem oder grünem Schimmer, bleibend. Stiel pfriemlich oder walzlich. Columella walzlich, stumpf, bis in die Mitte des Sporangiums reichend, hauptsächlich am obern Abschnitt das aus schwarzen, blaßpurpurbraunen oder farblosen, spärlich verzweigten, anastomosierenden Fäden bestehende Capillitium tragend.

1. L. echinulatum (Berkeley) Rost. Monogr., App. (1876), 25 ; Massee Monogr., 97; Lister in Journ. of Bot. XXIX, 261, Monogr. ed. 1, 126, pl. XLYIII, A, fig. a-g, ed. 2, 162, pl. 134, fig. a-k; 'Torrend in Broteria VII, 70.

Synonyme: Stemonitis echinulata Berkeley in Hook. Fl. Tasman. II (1860), 268.

Lamproderma Listeri Massee Monogr. (1892), 97, fig. 202, 203.

GroBbritannien, Schweden, Tasmanien, Neu-Seeland.

2*. Sporen stachelig oder \pm glatt.

3. Columella vorhanden.

4. Columellaende in verhältnismäßig wenige aber starke, abstehende und aufstrebende Capillitiumfäden sich verzweigend.

2. L. arcyrionema Rost. Monogr. (1875), 208; Massee Monogr., 96 ; Lister Monogr. ed. 1, 126, pl. XLVIII, B, fig. a-e, ed. ๖. 162. pl. 129, fig. a-e; Macbride N. Am. Slime-Moulds, 143, pl., V, fig. 1, 1 a; Schinz in Mitt. Naturw. Ges. Winterthur VI, 75; Torrend in Broteria VII, 69, pl. V, fig. 6.

Synonyme: Stemonitis physaroides Alb. et Schwein. var. subaenens Berkeley ex Massee Monogr. (1892), 96.

Lamproderma subaeneum Massee Monogr, (1892), 95.

Comatricha Shimekiana Macbride in Bull. Nat. Hist. Iowa II (1893), 380, t. X, fig. 3, und N. Am. Slime-Moulds, 144.

Lamproderma inconspicuum Racib. in Hedwigia XXXV (1896), 208? 
Plasmodium wässerigweiß. Die (incl. Stiel) $1-2 \mathrm{~mm}$ hohen Sporangien kommen herdenweise vor; sie sind kugelig, aufrecht, stahlgrau, blau oder bräunlich metallisch glänzend und messen $0,5 \mathrm{~mm}$. Die hinfällige Sporangiumwand läßt beim Schwinden an der Spitze des fädlichen, schwarzen, $1 \mathrm{~mm}$ langen Stieles einen Kragen zurück. Columella $1 / 3$ bis $1 / 2$ so lang wie das Sporangium,
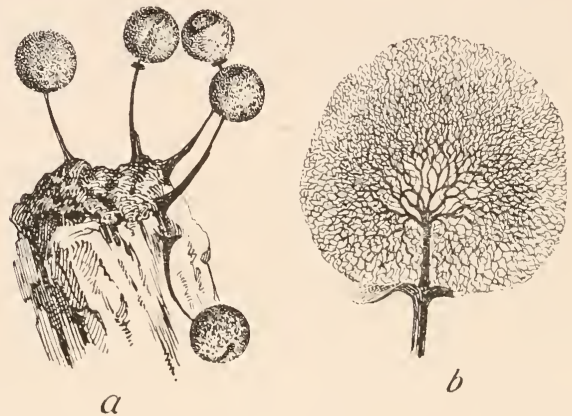

Fig. 99. Lamproderma areyrionema Rost.

a) Sporangiengruppe $(18 / 1)$; b) ein Sporangium, dessen II aut bis auf den hragen am Ende des Stieles geschwumlen ist $\left({ }^{70} / 1\right)$. - Nach Lister.

schlank, am oberen Ende plötzlich in einige wenige, starke Capillitiumfäden ausgehend; Capillitium, abgesehen von den Primanästen, zart, vielfach verzweigt und anastomosierend, ein krauses Netzwerk mit sehr kurzen freien Enden bildend. Sporen im durchfallenden Lichte blaßlila grau, sehr schwach warzig, $6-7-9 \mu$.

Schweiz (Jura, Beru).

Kosmopolitisch.

$4^{*}$. Columellaende plötzlich in sehr viele, äbereinstimmend zarte Capillitiumfäden verästelt.

5. Capillitiumfäden dunkel, an der Basis blass. 
3. L. scintillans (Berkeley et Broome) Morgan Myx. Miami Valley (1894), 47; Macbride N. Am. Slime-Moulds, 142, pl. V, fig. 2, 2a; Lister Monogr. ed. 2, 163, pl. 130, fig. a-f.

Symonyme: Stemonitis scintillans Berkeley et Broome in Journ. Limn.

Soc. Xr (1876), 84.

Lamproderma arcyrioiles Rost. var. iridea Cooke Myx. Brit. (1894), 50.

Lamproderma iridenm Massee Monogr. (1892), 95, fig. 149-151;

Lister Monogr. ed. I, 128, pl. I, A, fig. a-e.

? Enerthenema muscorum Lév. in Ann. Sc. Nat. sér. 4, XX (1863),

28!); Massee Monogr., 106.

Exsikkaten: Jaap Myxom. exsicc. 73, 115.

Plasmodium wässerigweiß. Sporangien herdenweise oder zerstreut, kugelig oder etwas niedergedrückt kugelig, aufrecht, $0,3-0,5 \mathrm{~mm}$ im Durchmesser, gestielt, stahlblau, rot oder rotbraun, metallisch glänzend, Stiel fädlich, schwarz, $\pm 1 \mathrm{~mm}$ lang. Columella walzlich, abgestutzt, kaum die Mitte des Sporangiums erreichend. Capillitiumfäden vom Columellaende ausstrahlend, gabelig verzweigt und anastomosierend, straff, schwarz oder purpurbraun; an der Basis \pm farblos. Sporen im durchfallenden Lichte violettgrau, kleinwarzig, bis $8 \mu$ groß.

Deutschland (Holstein).

Kosmopolitisch.

$5^{*}$. Capillitium purpurrot mit nahezu farblosen Enden.

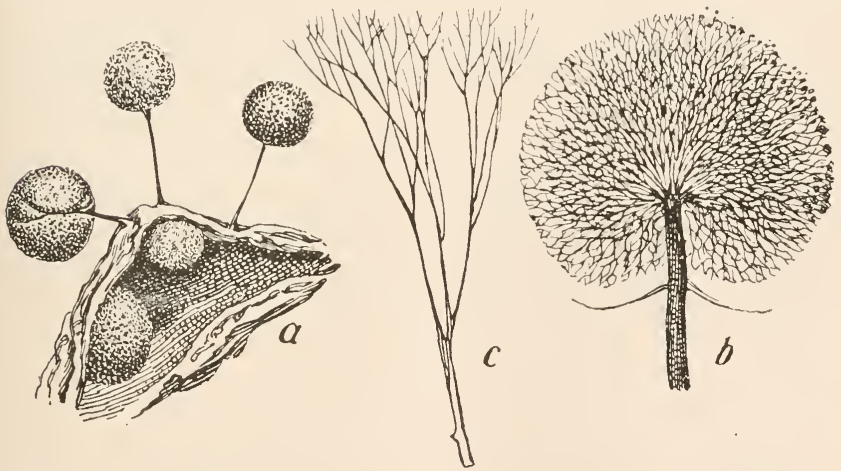

Fig. 100. Lamproderma scintillans (Berkeley et Broome) Morgan.

a) Sporangiengrupue $(20 / 1)$; b) Siprangium mit geschwundener Wrand, am Grunde mit Wandrest $\left({ }^{80} / 1\right)$; c) Capillitiumfäden $(180 / 1)$. - Nach Lister. 
4. L. columbinum (Pers.) R ost. Monogr.(1875), 203, fig.61; Massee Monogr., 100; Čelak. Myxom. Böhm., 53, t. V, fig. 6; Schröter in Cohn. Krypt.-Fl. Schles. III, 1, 119; Macbride N. Am. Slime-Moulds, 141; Lister Monogr. ed. 2, 165, pl. 131. fig. $a-m$ (excl. $h$ und i); Torrend in Broteria VIl, 67.

Synonyme: Physarum columbinum Pers. Obs. Myc. I (1796), 5; Rabenhorst Deutschl. Krypt.-Fl. 1, 275.

Trichia columbina Poiret in Lam. Encycl. Meth. VIII (1808), 52. Physarum saliciuum Schum. Enum. Pl. Saell. Il (1803), 200?

Trichia physaroides Schum. Enum. Pl. Saell. II (1803) 210?

Trichia violacea Hoffm. Veg. Crypt. Germ. (1787/90), 5, t. II, fig. 1-

Physarum bryophilum Fr. Syst. Myc. III (1829), 135; Rabenhorst Dentschl. Krypt.-Fl. I, 275.

? Stemonitis physaroides Alb. et Schwein. Consp. Fung. (1805), 103 ; Rabenhorst Deutschl. Krypt.-Fl. I, 269.

Fulgia encanstica Chev. Fl. Par. ed 2 (1836), 347.

Stemonitis porphyra Berkeley et Curtis in Grev. II (1873), 69?

Lamproderma physaroides Rost. Monogr. (1875), 202, fig. 55, 59, 62; Massee Monogr., 103; Schröter in Cohn Krypt.-Fl. Schles. 11I, 1, 118; Lister Monogr. ed. 1, 125, pl. XIVII, B, fig. $a-g$ und in Journ. of Bot. XLIII, 154; Macbride N. Am. Slime-Monlds, 139; Sehinz in Mitt. Naturw. Ges. Winterthur VI, 74.

Lamproderma Schimperi Rost. Monogr. (1875), 203, fig. 63; Massee Monogr., 100.

Lamproderma Staszyeii Racib. in Hedwigia XVIll (1889), 116. Exsikkaten: Rabenhorst Fungi eur. 2213; Jaap Myxom. exsicc. 14.
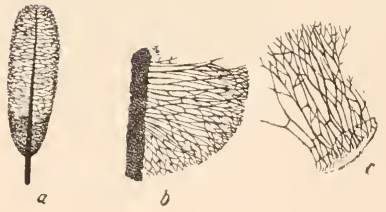

Fig. 101. Lamproderma columbin um (Pers.) Rost.

a) ellipsoidisches Sporangium mit unterwärts erhaltener Peridie $(1 \%)$; b) T'eil der Columella mit Capillitium $(4 \%)$; c) an der Peridie befestigtes Capillitium der var. sessile $\left({ }^{40} / 1\right)$.

Plasmodium farblos. Sporangien samt Stiel $2-3 \mathrm{~mm}$ hoch, herdenweise, kugelig oder ellipsoidisch, aufrecht, 0,5-0,8 mm im Durchmesser, dunkel- bis schwarypurpurrot, metallisch glänzend mit violetten oder grünen Lichtern, mitunter glänzend braunrot- 
gelb; Wand bleibend, Stiel kräftig, 1,5-2 oder bis $3 \mathrm{~mm}$ lang, längsgestreift oder höckerig. Columella bis über die Mitte des Sporangiums reichend, walzlich oder keulenförmig, oft mit kegelförmiger Spitze. Die bräunlich purpurfarbigen Capillitiumfäden

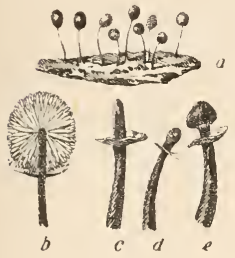

Fig. 102.

Lamproderma columbinum (Pers.) Rost.

a) Sporangiengrupe $(3 / 1)$; b) Sporangium tnit gesebwumlener Wand, am Grunde noch ein Wandrest $(20 / 1)$; e, d, e versehiedene Columellaformen $(18 / 1)$ Nach Lister.

von der ganzen Länge der Columella - oder nur von der Spitze ausstrahlend, ein ziemlich weitmaschiges Netzwerk bildend. Sporen im durchfallenden Lichte purpurgrau, dicht stachelig, 11-16 «.

Deutschland, Österreich, Schweiz.

Kosmopolitiseh.

var. sessile Lister Monogr. ed. 2 (1911), 165.

Synonyme: Physarum iridescens Berkeley in Hook. Journ. of Bot. III (1851), 20.

Lamproderma iridescens Rost. Monogr., App. (1876), 25.

Lamproderma physaroides Rost. var. sessile Lister Monogr. ed. I (1894), 126.

Mit sitzenden oder nahe\%u sit\%enden Sporangien, die der Columella entbehren und ein bald dunkles, bald blasses Capillitium besitzen.

Die Spielart, deren Verbreitung in- und außerhalb unseres Gebietes noch festzustellen ist, unterscheidet sich von Leptoderma iridescens G. Lister, mit der sie leicht verwechselt werden kann und schon vielfach verwechselt worden ist, durch die zarte Peridie und das Fehlen von Ausschußmaterial im Sporangiumstiel.

$$
\begin{aligned}
& \text { 5**. Capillitium bla } \mathrm{B} \text { oder bräun- } \\
& \text { lich purpurfarbig. Stiel } 1 \mathrm{~mm} \\
& \text { oderkürzer. }
\end{aligned}
$$

5. L. violaceum (Fr.) Rost. Monogr. (1875), 204, fig. 64; Massee Monogr., 94, fig. 152-154; Čelak. Myxom. Böhm., 53; Lister Monogr. ed. 1, 129, pl. XLIX, A, fig. a-k, fig. a-d, ed. 
2, 166, pl. 132, fig. a-l, pl. 133, fig. f-i und in Journ. of Bot. XL, 219; Macbride N. Am. Slime-Moulds, 143; Schinz in Mitt. Naturw. Ges. Winterthur VI, 75: Torrend in Broteria VII, 67, pl. V, fig. 5 .

Synonyme: Stemonitis violacea Fr. Syst. Mye. III (1829), 162;

Rabenhorst Deutschl. Krypt.-Fl. I, 270.

Stemonitis arcyrioides Somm. in Mag. Nat. VII (1827), 298;

Rabenhorst Deutschl. Krypt.-Fl. I, 270.

Lamproderma areyrioides Rost. Monogr. (1875), 206; Massee

Monogr., 102, fig. 145-148; 'Schröter in Cohn Krylt.-Fl.

Schles. III, 1, 119.

Lamproderma nigrescens Rost. Monogr. (1875), 205?

Lamproderma leucospormm Post. Monogr., App. (1876), 26?

Lamproderma minutum Rost. Monogr., App. (1876), 26.

Lamproderma nigrescens Sacc. in Michelia II (1882), 262 ?

Lamproderma tatricum Racib. in Hedw. XXVIII (1889), 117?

Lamproderma Saccardianum Massee Monogr. (1892), 101.

Tilmadoche Berkeleyi Massee MLnogr. (1892), 332 ?

Exsikkaten: Rabenhorst Fungi eur. 797, 2213.

Rabenhorst Herb. Mje. 431.

Fuckel Fungi rhen. 1447.

Plasmodium wässerigweiß. Sporangien zerstreut oder herdenweise, \pm kugelig, am Grunde \pm abgeflacht und genabelt oder kurz ellipsoidisch, aufrecht, gestielt oder sitzend, $0,4-0,9 \mathrm{~mm}$ im Durchmesser, metallisch glänzend mit blauen oder violetten oder braunroten Lichtern. Stiel schwar\%. Columella bis $\mathrm{zu}$ $1 / 3$ oder bis $z u^{2 / 3}$ der Sporangiumhöhe reichend, walzlich, stumpf, mitunter nach oben sich verjüngend. Capillitiumfäden + farblos oder braun, vom obern Teil der Columella entspringend, sich verzweigend und anastomosierend, ein dichtes Netzwerk bildend. Sporen im durchfallenden Lichte purpurgrau, fein stachelig bis nahezu glatt, $8-10 \mu$.

Kosmopolitisch.
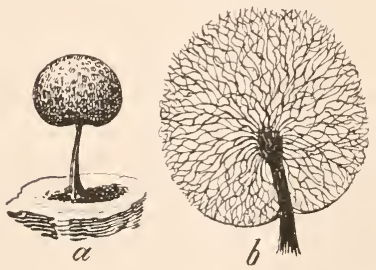

Fig. 103.

Lamproderma violaceum

(Fr.) Rost.

a) Sporangium $(18 / 1)$; b) ein solches unit geschwundener Wand $(\mathbf{4 5} / 1)$. Nach Lister. 
var. Sauteri (Rost.) Lister Monogr. ed. I (1894), 128, pl. XLIX, A, fig. f, g, ed. 2, 167, pl. 132, fig. f, g; Torrend in Broteria VII, 68.

Synonyme: Lamproderma Sauteri Rost. Monogr. (1875), 205; Massee Monogr., 100; Macbride N. Am. Slime-Moulds, 140, pl. V, fig. 4, 4 a. Lamproderma areyrioides Morgan Myx. Miami Valley (1894), ti. Stemonitis Morthieri Fuckel Symb. Myc. (1869/70), 339.

Sporangien kugelig oder eiförmig, am Grunde nicht genabelt: Capillitium braun. Sporen $11-15$ ", glatt oder dicht feinstachelig.

Durch das ganze Gebiet.

Schweden, N.-Amerika.

var. Carestiae (C'es. et de Not.) Lister Monogr. ed. 1. (1894), 130, pl. XluIX, A, fig. h, i, j, ed. 2, 167, pl. 132 , fig. $\mathrm{l}-\mathrm{k}$ und in Journ. of Bot. XLVI, 219; Schinz in Mitt. Naturw. Ges. Winterthur VI, 76; Torrend in Broteria VII, 68.

Synonym: Stemonitis Carestiae Ces. et de Not. Erb. Crit. Ital. Nr. 88.

Sporangien kugelig oder eiförmig, fast schwarz, kurz gestielt oder sitzend; Capillitium dunkelpurpurbraun, entweder ein dichtes Netzwerk bildend oder aus nahezu geraden Fäden bestehend. Sporen im durchfallenden Lichte purpurbraun, dicht fein- oder grobstachelig, 9-16 u.

\section{Schweiz.}

Großbritannien, Schweden, Rußland, Italien, N.-Amerika.

A. und G. Lister (Journ. of. Bot. XLVI [1908], 219) erwähnen eine alls dem Wallis (Arolla) stammende und ihnen dann in der Folge wieder aus dem Jura von Meylan zugekommene, der var. Carestiae im Capillitium nicht unähnliche Lamproderma mit Sporen, die zu $2 / 3$ der Oberfläche unregelmäßige, dichte Netzstruktur aufweisen, wogegen $1 / 3$ der Oberfläche warzig ist. Vielleicht handelt es sich um $L$. atrosporum oder, wie A. und G. Lister vermuten, um eine Übergangsform zwischen L. violaceum und L. cribrarioides. 
var. genuinum Lister Monogr. ed. 1 (1894), 128, pl. XLIX, A, fig. a-e; Schinz in Mitt. Naturw. Ges. Winterthur VI, 76; Torrend in Broteria VII, 68.

Sporangien am Grunde abgeflacht und genabelt. Sporen $8-11 \mu$, sehr fein stachelig.

Durch das ganze Gebiet.

Kosmopolitisch.

var. dictyosporum Lister in Journ. of Bot. XLVI (1908). 218, Monogr. ed. 2, 167, pl. 133, fig. f, h, i.

Unterscheidet sich von var. Carestiae durch die 10-14 großen Sporen, deren Exine Stachelchen und kur\%e Leisten besitzt, die ein unvollkommenes Netzwerk bilden.

Schweiz (Mürrell, Jura).

Weitere Untersuchungen werden zeigen müssen, in welchem Verhältnis diese letztgenannte Varietät zu dem von Meylan aufgestellten Lamproderma atrosporum (Neylan in Bull. Soc. Vaud. Sc. Nat. XLVI [1910], 51 und L [1914], 12) steht. Lamproderma atrosporum Meylan gehört zu der Gruppe der sogenannten nivalen Arten und ist im schweizerischen Jura nicht selten, es unterscheidet sich von allen violaceum-Varietäten durch das braunschwarze, niemals violette Capillitium, an dem in der Regel kleine Fragmente der geschwundenen Peridie haften. Die schwarzen Sporen sind 12-16 $\mu$ grob und sind in Bezug auf die Wandstruktur außerordentlich variabel, wenig stachelig (selten) oder reichlich bestachelt (häufig) oder auch netzartig skulpiert. Wie Neylan zeigt, können derartige Verschiedenheiten der Sporenskulptur an den Sporen eines und desselben Sporangiums nachgewiesen werden!

var. calciferum Meylan in Bull. Soc. Vaud. Sc. nat. L (1914), 3.

Sporangien eine weiße Umhüllung aus kugeligen, 1,5-2 $\mu$ großen Kalkgranulationen tragend.

Schweiz (Jura).

3. Columella 0. Sporangien in gedrängten Häufchen, \pm kugelig und ungestielt oder Plasmodiokarpien bildend, dunkelpurpur- 
braun, metallisch glänzend. Capillitiumfäden einfach oder spärlich verzweigt, blaßpurpurfarbig, mit vereinzelten knotenartigen Verdickurgen, mitunter im Winkel der Ver\%weigungen mit breiten Verbreiterungen. Sporen im durchfallenden Lichte dunkelpurpurbraun, dicht stachelig, $18-19 \mu$.

6. L. insessum Lister in Trans. Brit. Myc. Soc. IV (1912), 41 , t. 1, fig. $2,2 \mathrm{a}, \mathrm{b}$.

Schottlaud.

$1^{*}$. Sporen mit netzartiger WVandskulptur.

6. Netzstruktur der Sporenexine regelmäßig (vergl. anch Lamproderma atrosporum Meylan pag. 266).

7. L. cribrarioides (Fr.) R. E. Fries in Svensk. Bot. Tidskr. VI (1912), 768.

Synонуme: Lamproderma Lycopodii Raunkiaer in Bot. Tidskr. XVII (1888), 109; Lister Monogr. ed. 1, 132, ed. 2, 168, pl. 133, fig. a-e, in Jomrn. of Bot. XIN1, 218; Schinz in Mitt. Naturw. Ges. Winterthur VI, 12.2; Torrend in Broteria VII, 70.

Stemonitis cribrarioides Fr. Syst. Myc. III (1829), 163.

Stemonitis Lycopodii Nees ex Fr. Syst. Myc. III (1829), 163.

Plasmodium? Sporangien zerstreut oder gehäuft, kugelig, $0,8 \mathrm{~mm}$ groß, gestielt oder sit\%end oder Plasmodiokarpien bildend, purpurbraun, glänzend und mit metaHischen Lichtern. Stiel schwar\%, 0,2-0,5 mm lang. Columella entweder 0 (Plasmodiokarpien) oder walzlich, bis zur Mitte des Sporangiums oder auch höher hinauf reichend. Capillitiumfäden blaß purpurbraun, wellig, am Grunde gedrungener als gegen die farblosen Enden zu. Sporen im durchfallenden Lichte bräunlichpurpurfarbig, $12-18 \mu$, mit $1-1,5 \mu$ breitem Rand und 14 bis 24 Maschen im Gesichtsfeld.

Deutschland (Thüringeı), Österreich (Vaduz), Schweiz (Fürstenalp, Arosa).

Schweden, Dänemark, Lappland. 
Die Indentität von Stemonitis cribrarioides Fr. und Lamproderma Lycopodii Raunkiaer konnte von R. E. Fries an Hand der Fries'schen Originale nachgewiesen werden.

6*. Net\%struktur der Sporenexine unregelmäBig.

L. violaceum var. dictyosporum (pag. 266) (vergl. auch L. atrosporum, pag. 266).

Meylan (Bull. Soc. Vand. sc. nat. LI [1917], 264) hat neuerdings die Artengruppe Lamproderma critrariodes (Fr.) R. E. Fries und Lamproderma violaceum (Fr.) Rost. studiert und ist zu einer abweichenden. Bewertung der in Lister's Monographie L. violaceum subordinierten Varietäten gekommen, was in nachfolgendem Schlïssel zum Ausdruck gelangt:

1. Peridie ohne Metallglanz, glänzend oder matt, silbergrau, in Fragmenten dem Capillitium anhaftend. Capillitium braunschwarz oder schwarz, niemals violett schimmernd. Sporen schwarz, 12-15 $\mu$, meistens \pm stark stachelig papillös, entweder infolge reihenweiser Anordnung der Papillen netzartig skulpiert oder mit entschiedener Netzstruktur und mit einem Rand versehen.

L. atrosporum. ${ }^{1}$ )

$1^{*}$. Peridie mit Metallglanz, häntig, ganz frei vom Capillitium. Capillitium blaß oder dunkel, aber stets mit violettem Ton. Sporen dunkelpurpurbraun.

2. Sporen mit deutlicher Netzskulptur und berandet, sehr selten, infolge reihenweiser Anordunng der Papillen netzartig skulpiert.

L. cribrarioides, ${ }^{2}$ )

2*. Sporen ohne jede Netzskulptur, einfach \pm stark stachelig.

3. Sporen $12-15 \mu$. Sporangien im Durchmesser 0,8-1,5 mm, kugelig oder eiförmig, bald sitzend, bald auf einem Stiel von höchstens der Länge des Sporangium-Durchmessers. Art des Frühlings und der Gebirgsregion, deren Plasmodium sich nur unterm Schnee entwickelt. 
4. Sporangien kugelig und leicht genabelt. mit lockerm, hellem oder dunkler gefärbtem Capillitium. Sporen stachelig.

L. Sauteri, ${ }^{3}$ )

$4^{*}$. Sporangien eiförmig, stets sehr kur\% gestielt. Capillitium sehr dicht, stets dunkelgefärbt. Sporen stets stark stachelig papillös.

L. Sauteri var. Carestiae. ${ }^{4}$ )

$3^{*}$. Sporen $8-11 \mu$. Sporangien $0,5-0,8 \mathrm{~mm} \mathrm{im}$ Durchmesser, abgeflacht und genabelt am Grunde, mit einem Stiel von der einfachen bis $2 \frac{1}{2}$ fachen Länge des Durchmessers des Sporangiums. Capillitium gewöhnlich sehr blaß, mit farblosen Enden. Art des Herbstes und häufiger in der Ebene als im Gebirge.

L. violaceum. ${ }^{5}$ )

1) L. atrosporum Meylan in Bull. Soc. Vaud. sc. nat. XLVI (1910). 51, in Bull. Soc. Bot. Genève 2 me sér. II (1910), 264 und in Bull. Soc. Tand. sc. nat. L (1914), 12 und LI (1917), 266 .

2) L. cribrarioides (Fr.) R. E. Fries in Svensk Botanisk Tidskr. TI (1912), 768 (= L. Lycopodii Raunkiaer).

3) L. Sauteri Rost. Monogr. (1875), 205 (= L. violaceum var. Sauteri) (Rost.) Lister.

4) L. Sauteri Rost. var. Carestiae (Cesati et de Notaris) Meylan in Bull. Soc. Vaud. sc. nat LI (1917), 268 nov. comb. (= L. violaceum var. Carestiae [Cesati et de Notaris]) Lister.

5) L. violaceum var. dictyospora Lister in Journ. of Bot. XLVI (1908), 218 und Monogr. ed. 2 (1911), 167 soll nach Meylan sowohl Formen von atrosporum wie von cribrarioides mit netzartiger Sporenskulptur umfassen und wäre daher ein Mixtum. 


\section{Gattung Clastoderma Blytt}

in Bot. Zeitung XXXVIII (1880), 343; Lister Monogr. ed. 1, 132, ed. 2, 169; Schröter in Engl. und Prantl Natïrl. Pflanzenfam. 1, 1, 27: Macbride N. Am. Slime-Moulds, 138; Schinz in Mitt. Naturw. Ges. Winterthur VI. 76; Torrend in Broteria VI, 41, VII, 65.

Mit nur einer Art:

C. Debaryanum Blytt in Bot. Zeitung XXXVIIl (1880), 343; Lister Monogr. ed. 132, pl. L. B, fig, a-f, ed. 2, 169, pl. 135, fig. a-g; Macbride N. Am. Slime-Moulds, 138, pl. XIII, fig. 6; Beardslee in Torreya VIII. 253.

synonym: Orthotrichia microcephala Wingate in Journ. Myc. II (1886), 126; Massee Mologr., 109.

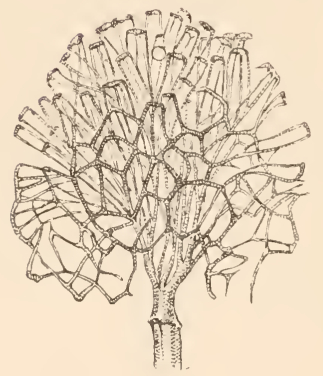

Fig. 104.

Clastoderma Debaryanum Blytt. Sporangium mit geschwundener Wand, kleine Wandfragmente den Enden der Capillitiumfäden aufsitzend $(250 / 1)$. - Nach Lister.

Plasmodium? Sporangien im Durchmesser 0,15-0,8 mm, zerstreut oder herdenweise, samt Stiel 1-11/4 mm hoch, kugelig. braun. Stiel schlank, unterwärts höckerig, dunkel, oberwärts glatt und blasser. Columella (mitunter kaum wahrnehmbar) kurz. sich in die Primanäste des Capillitiums ver\%weigend. Capillitiumfäden blaßbraun, 3-tfach gabelig verzweigt, spärlich anastomosierend oder frei, einzeln - oder zu mehreren mit ibren Enden mit kleinen, scheibenförmigen Wandfragmenten verbunden. Sporen im durchfalleuden Lichte blaßbraun, glatt, $7-10 \mu$. 


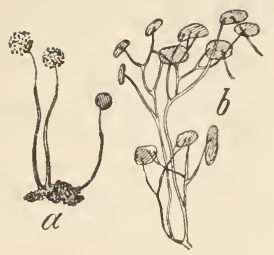

Österreich.

Portugal, Skandinavien, Ceylon, Borneo, Japran, Anstralien, NeuSeeland, N.- u. S.-Amerika.

Zweifelsohne weiter verbreitet, aber der auBerordentlichen Kleinheit wegen leicht zu übersehen.

\section{Gattung Echinostelium de Bary}

in Rost. Versuch eines Systems der Mycetozoen (1873), 7; Rost. Monogr., 215; Massee Monogr., 108; Lister Monogr. ed. 1, 133, ed. 2. 170; Schröter in Engl. und Prantl Natürl. Pflanzenfam. I, 1, 27; Schinz in Mitt. Naturw. Ges. Winterthur VI, 73; 'Torrend in Broteria V'I, 49, VII, 64.

Mit nur einer Art:

E. minutum de Bary ex Rost. Monogr. (1875), 215, fig. 53, 54, 58, 68; Nassee Monogr., 109, fig. 202; Lister ed. 1, 133, ed. 2, 170, pl. 128, fig. f-i, in Journ. of Bot. XLII, 135, und in Trans. Brit. Myc. Soc. (1904), 54: Torrend in Broteria VII, 64, pl. V, fig. 1, 2.

Plasmodium farblos. Sporangien zerstreut, kugelig, $40-50 \mu$ im Durchmesser, 0,t $\mathrm{mm}$ lang gestielt, die Sporangiumwand hinfällig und schlieblich nur am Grunde des Sporangiums als kleiner Kragen zuriickbleibend. Stiel pfriemlich, nach oben sich verjüngend, im Innern \pm farbloses Ausschubmaterial fülirend. Columella schlank, $3-4 \mu$ lang. Capillitium aus 2 oder 3 farblosen, zickzackartig verlaufenden, einfachen oder spärlich und kurz ver- 
ästelten und anastomosierenden Fäden bestehend, mit freien Dornfortsätzen. Sporen im durchfallenden Lichte farblos, glatt, $6 \mu$.

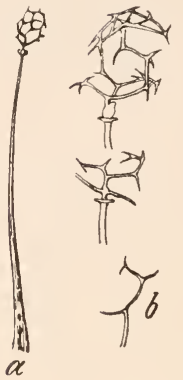

Fig. 106. Echinostelium minutum de Bary.

a) Sporanginm mit Capillitium $(12 \%)$;

b) Stücke des Capillitiums $\left({ }^{\mathbf{4 8 0}} / \mathbf{1}\right)$. Nach Lister.

Dentschland, Österreich.

Großbritannien, Rumänieu, Australien, Neu-Seeland.

Auch dieser Schleimpilz ist sicherlich verbreiteter, wird aber wohl seiner Kleinheit wegen meist übersehen oder mit irgend einem Schimmelpilz verwechselt.

Mit Clastoderma teilt Echinostelium die Eigentïmlichkeit, daß der Sporangiumstiel mit Ausschußmaterial erfüllt ist; bei allen ïbrigen Gattungen der Stemonitaceen sind die Sporangiumstiele entweder in ihrer ganzen Länge solid oder sie führen in ihrem untern hohlen Teil ein dichtes Netzwerk von eingeflochtenen Strähnen ohne Ausschußmaterial (vergl. G. Lister in Journ. of Bot. (1915), 8).

\section{Familie Amaurochaetaceae Rost.}

Versuch eines Systems der Mycetozoen (1873), 8 und Monogr., 210; Lister Monogr. ed. 1, 22, 133, ed. 2, 22, 170; Macbride N. Am. Slime-Moulds, 107; Schinz in Mitt. Naturw. Ges. Winterthur VI, 76. 
Sporangien zu Äthalien vereinigt. Capillitium dunkelpurpurbraun, aus Strähnen und Fäden bestehend.

\section{Schliissel zur Bestimmung der Gattungen der Familie der Amaurochaetaceae.}

1. Capillitium aus unregelmäßig sich verzweigenden Fäden und Strähnen bestehend.

Amaurochate Rost.

1*. Capillitium aus wagrecht verlaufenden, gekammerte Blasen führenden Fäden bestehend.

Brefeldia Rost.

\section{Übersicht der gattungen.}

Amaurochaete. Polsterförmige, aus langgestreckten, dicht verbundenen, zusammenfließenden Einzelfruchtkörpern bestehende Äthalien. Capillitium von der breiten, häutigen Basis aus-

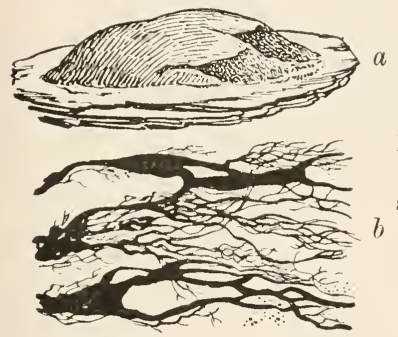

Fig. 107. Amaurochaete fuliginosa (Sowerby) Macbride.

a) Äthalium $(12 / 1)$; b) Capillitium $(15 / 1)$. Nach Lister.

strahlend, aus zahlreichen, geraden, dunkelpurpurbraunen, abgeflachten, zottigen Strähnen bestehend, die sich in viele, anastomosierende, ungleich dicke Äste teilen.

Brefeldia. Aethalium polsterförmig, aus \pm walzlichen, größtenteils zusammenfließenden Sporangien bestehend, die sich vom Grunde eines schwammigen, sterilen Gewebes erheben, das sich zwischen die untern Sporangienpartien einschiebt, gleichsam die Sporangien oder die einzelnen Columellen trennend. Capillitium reichlich, aus wagrechten Fäden bestehend, die an der Grenze der Einzelsporangien sich zu vielkammerigen Blasen verbinden.

Schinz, Myxogasteres (Rabenhorst Krypt. Flora 1, Pilze Abt. X). 


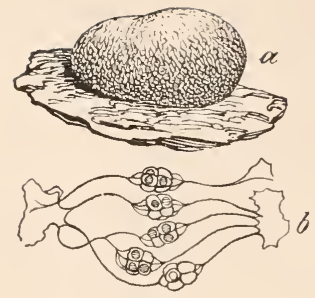

Fig. 108. Brefeldia maxima (Fr.) Rost. a) Äthaliım $(1 / \mathrm{s})$; b) Capillitiumfädeu mit den gekammerten Blasen $(180 / 1)$. Nach Lister.

Schröter u. A. nahmen eine engere Verwandtschaft von Amaurochaete und Reticularia an, fußend auf der habituellen Ähnlichkeit beider Gattungen: gegen eine Unterstellung beider Gattungen ein und derselben Familie spricht der verschiedene Ursprung des Capillitiums, das bei Reticularia von der Sporangiumwand gebildet wird.

\section{Gattung Amaurochaete Rost.}

Versuch eines Systems der Myceto\%oen (1873), 8, Monogr., 2210: Schröter in Cohn Krypt.-Fl. Schlesien, III, 1, 115 und in Engl. und Prantl Natürl. Pflanzenfam. I, 1, 25; Celak. Myxom. Böhm., 44; Massee Monogr., 89; Lister Monogr. ed. 1, 134, ed. 2, 171: Macbride N. Am. Slime-Monlds, 108; Schinz in Mitt. Naturw. Ges. Winterthur VI, 77; Torrend in Broteria VI, 41, VII, 62.

Nur eine Art:

A. fuliginosa (Sowerby) Macbride N. Am. Slime-Moulds (1899), 109, pl. V, fig. 8, 8a; Lister Monogr. ed. 2, 171, pl. 136, fig. a-c.

Synonyme: Lycoperdon fuliginosum Sowerby Engl. Fung. (1803), t. 257.

Lycogala atrum Alb. et Schwein. Consp. Fung. (1805), 83.

Dermodium ,inquinans Link in Mag. Ges. Naturf. Fr. Berlin 111 (1809), 25.

Reticularia Strongylium Schwein. Syu. Fung. ('arol. (1822), 35. Strongylium atrum Swartz in Handl. K. Svenska Vet. Acad. (1815), 110.

Strongylium majus Fr. Syst. Orb. Veg. (1825), 148 ? 
Synonyme: Reticularia atra Fr. Syst. Myc. III (1829), 86; Rabenhorst Deutschl. Krypt.-Fl. I, 254.

Amaurochaete atra Rost. Versuch eines Systems der Mycetozoen (1873), 8, Monogr., 210, fig. 67; Schröter in Cohu Krypt.-Fl. Schles. III, 1, 115 ; Massee Monogr., 89; Celak. Myxom. Böhm., 44; Lister Monogr. ed. 1, 134, pl. LI, A, fig. a, b; Schinz in Mitt. Naturw. Ges. Winterthur 11, 77.

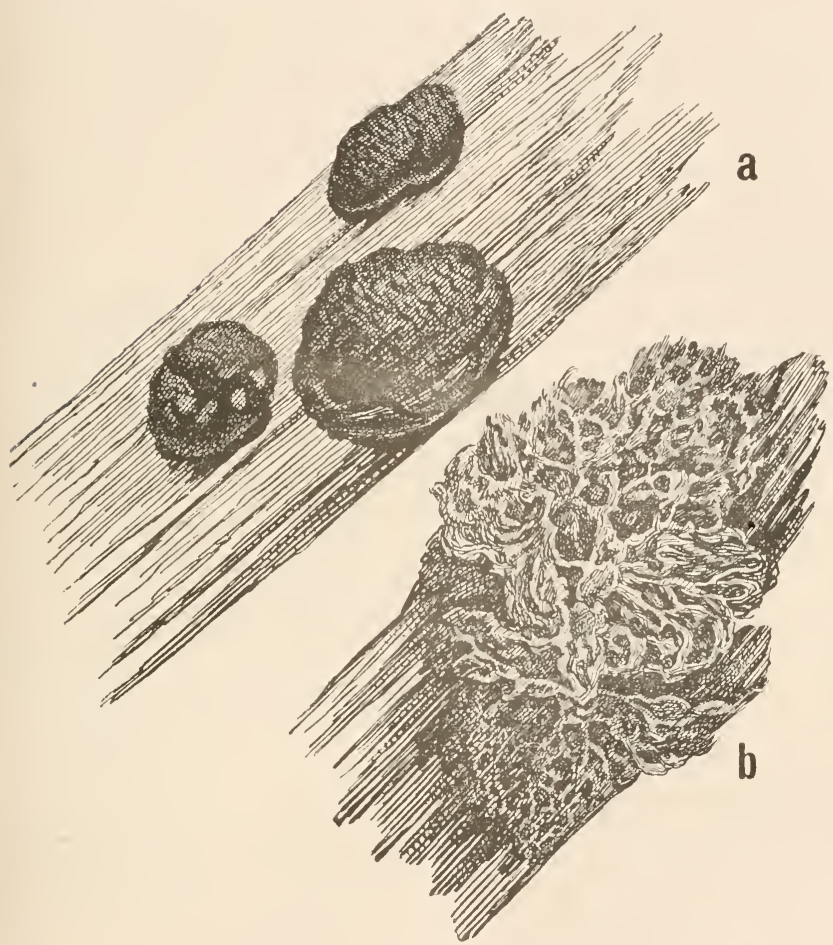

Fig. 109. Amaurochaete fuliginosa (Sowbery) Macbride. a) Alte, berinlete Aethalien $\left({ }^{2}{ }_{1}\right)$; b) von der Pinde entblößtes Aethalinm $(\% / 1)$. - Original.

Plasmodium gelblichweiß, sich rosenrot verfärbend. Āthalium polsterförmig oder gestreckt, 2-60 $\mathrm{mm}$ breit, schwarz, von einer sehr hinfälligen, anfänglich silberfarbigen Haut bedeckt. WVandungen 
der Einzelsporangien nicht entwickelt. Capillitiumfäden ans flachem und dickem Grunde sich verjüngend, zottig. Sporen im durchfallenden Lichte mattpurpurfarbig, auf einer Seite heller, fein stachelig, $11-13 \mu$.

Deutschland, Österreich, Schweiz.

Europa, Japan, N.-Amerika.

\section{Gattung: Brefeldia Rost.}

Versuch eines Systems der Mycetozoen (1873), 8, Monogr., 212: Massee Monogr., 90; Lister Monogr. ed. 1. 135, ed. 2. 172: Schröter in Engl. und Prantl Natiirl. Pflanzenfam. I, 1, 28: Macbride N. Am. Slime-Moulds, 110: Schin\% in Mitt. Naturw. Ges. Winterthur VI, 77; Torrend in Broteria VI, 41, VII, 63.

Nur eine Art:

1. B. maxima (Fr.) Rost. Monogr.. 213, fig. 60, 65, 66. 69, 70; Massee Monogr., 91, fig. 254-256: Lister Monogr. ed. 1. 135, pl. LI, A, fig. c-e, ed. 2, 172, pl. 136, fig. d-f: Macbride N. Am. Slime-Moulds, 110, pl. V, fig. 7,7 a, 7 b; Schinz in Mitt. Naturw. Ges. Winterthur VI, 78; Torrend in Broteria VII, 63, pl. IV, fig. 36 .

Synonyme: Dermodium inquinans Fr. Syst. (rast. (1817), 9 ?

Reticularia maxima Fr. Syst. Urb. leg. 1 (1825), 147; Rabenhorst Deutschl. Krypt.-Fl, I, 254.

Licea perreptans Berkeley in Gard. Chron. (1848), $45 \mathrm{l}$.

Exsikkaten: Fuckel Fungi rhen. 1473, 2583; Jaap Myxom. exsice. 33,50 .

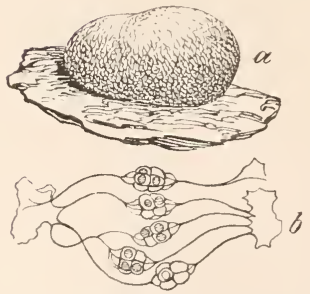

Fig. 110. Brefelılia maxima (Fr.) lost. a) Äthalium $(1 / 1)$; b) Capillitiumfäden mit den gekammerten Blasen $\left(180_{11}\right)$. Nach Lister.

Plasmodium gelblichweiß. Äthalien polsterförmig. 2 bis $30 \mathrm{~cm}$ oder mehr, 5-10 mm dick, purpurbraun, aus walylichen, verzweigten, mindestens am Rande des Äthaliums distinkten, gegen die Mitte des Polsters zusammenfließenden, $0,3-0,5 \mathrm{~mm}$ 
breiten Sporangien bestehend. Columella straff, in jedem Sporangium mittenständig, schwarz, am Grunde in das schwammige Gewebe ïbergehend. Capillitiumfäden frei von der Columella, wagrecht gegen die Sporangiumperipherie ausstrahlend, dort an eine entsprechende Verbreiterung eines korrespondierenden Fadens eines anstoßenden Sporangiums ansetzend und mit dieser zusammen eine gleichsam von zwei Fäden getragene Blase mit einer kleinen oder größern Zahl von Kammern bildend. In den Blasenkammern mitunter Sporen. Letztere purpurbraun im durchfallenden Lichte, sehr fein stachelig, 9-12 $\mu$.

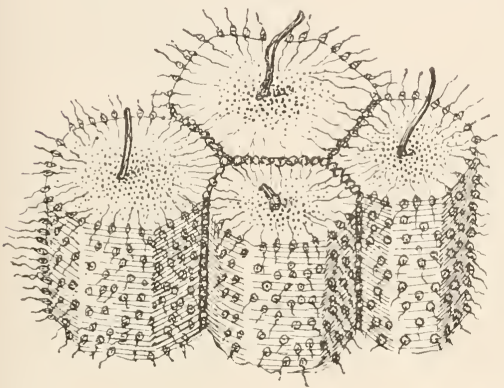

Deutschland, Österreich, Schweiz, Europa, N.-Amerika.
Fig. 111.

Brefeldia maxima

(Fr.) Rost.

Schemat. Darstellung eines Abschnittes von vier säulenartigen Sporangien. In der Mitte eines jeden Sporaugiums findet sich eine Columella und ringsum an den Seiten wänden zahl reiche Blasell, von denen ans kurze Capillitiunfäden in die anstoßenden Sporangien ausstrahlen $\left({ }^{50} / 1\right)$. - Nach Lister.

\section{Reihe LAMPROSPORALES Lister}

Monogr. ed. 1 (1894), 22, 136, ed. 2, 22, 173.

Capillitium vorhanden oder fehlend. Sporen verschieden gefärbt, mit Ausnahme von Licea minima und Listerella niemals violettbraun oder purpurgrau.

\section{Unterreihe ANEMINEAE Rost.}

Versuch eines Systems der Mycetozoen (1873), 4, Monogr., 219; Lister Monogr. ed. 1, 22, 136, ed. 2, 22, 173.

Ohne Capillitium oder doch kein System gleichartiger Fäden (Ausnahme: Alwisia). 


\section{Familie Heterodermaceae Rost.}

Versuch eines Systems der Mycetozoen (1873), 5. Monogr., 229: Lister Monogr. ed. 1, 2ะ, 136, ed. 2, 22, 173.

Sporangiumwand häutig, mit mikroskopisch kleinen, kugeligen, plasmatischen Granulationen besetzt, die mit Ausnahme von Lindbladia zur Zeit der Sporenentlassung mindestens im obern Teil der Sporangien ein Netz bilden. Capillitium fehlend.

\section{Schliissel zur Bestimmung der Gattungen der Familie der Heterodermacene.}

1. Sporangien ungestielt, dicht gedrängt, mitunter \%u Äthalien vereinigt.

Lindbladia Fr.

1*. Sporangien gestielt.

2. Wandverdickungen ein maschenreiches Netz bildend, dessen Fäden in den Maschenwinkeln meistens ververbreitert sind.

Cribraria Pers.

$2^{*}$. Sporangiuınwand hinfällig, die erhalten bleibenden W andverdickungen eine große Zahl paralleler, meridian verlaufender, durch zarte Querbrücken verbundener Fäden bildend.

Dictydium Schrad.

Ubersieht der Gattungen der Heterodermaceae.

Lindbladia. Sporangien selten frei, mitunter sehr dicht gedrängt neben- oder ïbereinander, oder ein kissenartiges Äthalium bildend. Sporangiumwand mit dunkeln, plasmatischen Granulationen besetzt.

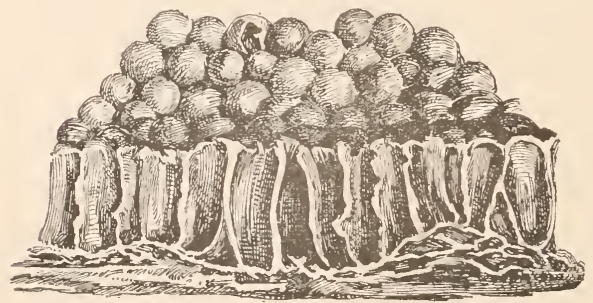

Fig. 112

Lindbladia eff $n$ sa (Ebremb.) Riost. var. simplex liex. Sporangien zu Ïthalieı zusammengedrängt $(10 / 1)$.

Nach Lister. 
Cribraria. Sporangien frei, gestielt, kugelig oder \pm birnförmig. Sporangiumwand entweder schwindend bis auf eine basale Scheibe oder einen Becher, oberwärts fortgesetzt als ein Netz.

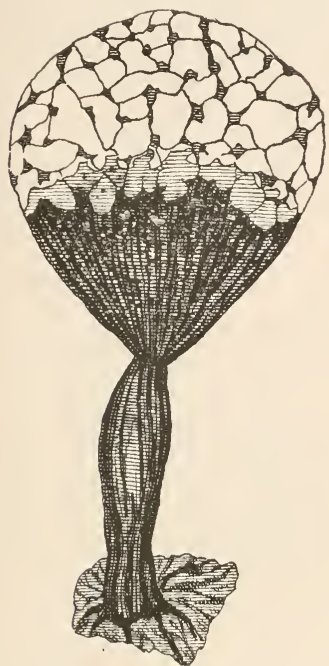

Fig. 113.

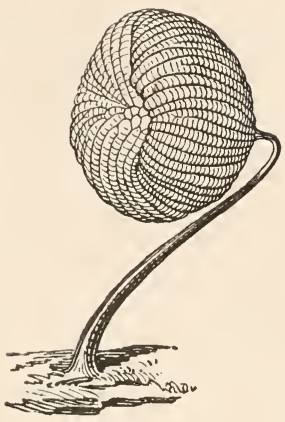

Fig. 114.

Dictydium cancellatum (Batsch) Macbride. Sporangium mit geschwundener Wandung $(35 / 1$.$) - Nach Jahn.$

Cribraria pyriformis Schrader. Sporangium $(\$ 0 / 1)$. - Nach Rostafinski.

Dictydium. Sporangien frei, gestielt. Beim Schwinden der Sporangiumwand bleibt ein meist sehr regelmäBiges Netz erhalten, das von meridian verlaufenden stärkern Fäden gebildet wird, die durch zahlreiche feine, parallele Querbrücken verbunden sind.

\section{Gattung: Lindbladia Fr.}

Summ. Veg. Scand. (1849), 449; Rost. Versuch eines Systems der Mycetozoen, 4, Monogr., 223; Schröter in Cohn Krypt.-Fl. Schles. III, 1, 103 und in Engl. und Prantl Natürl. Pflanzenfam. I, 1, 17; Ċelak. Myxom. Böhm., 18; Lister Monogr. ed. 1, 137, ed. 2, 174; Schinz in Mitt. Naturw. Ges. Winterthur VI, 78; Torrend in Broteria VI, 9, VII, 21. 
Sporangien entweder dicht gedrängt, über- oder nebeneinander, aber frei von einander oder mit den Seitenwänden fest verwachsen und zu einer flachen, polsterförmigen, äthaloiden,

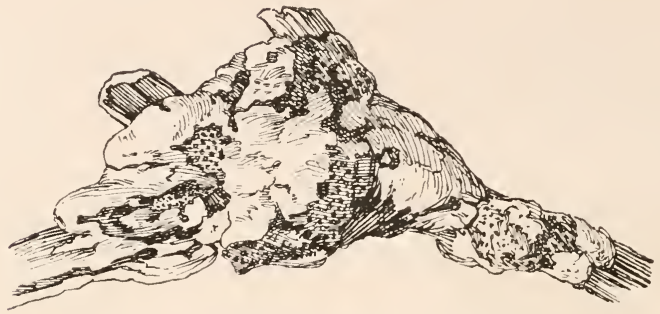

Fig. 115. Lindbladia effusa (Ehrenb.) Rost. Aethalium mit zum T'eil verwitterter Rinde $\left({ }^{2} / 1\right)$. - Original.

2-10 mm dicken, entweder schwarzen und von einer Decke unvollständig entwickelter Sporen berindeten oder dunkelbraun und von den gewölbten Enden der Einzelsporangien überdachten Masse zusammengepackt. Sporangiumwand häutig, besetzt mit mikroskopisch kleinen, plasmatischen Granulationen.

Nur eine Art:

L. effusa (Ehrenb.) Rost. Monogr. (1875), 223; Schröter in Cohn Krypt.-Fl. Schles. III, I, 103; Lister Monogr. ed. 2, 174, pl. 137, fig. a-f; Macbride N. Am. Slime-Moulds, 154, pl. I, fig. 3 , 3 a, pl. XII, fig. 1, 2; Torrend in Broteria VII, 21, pl. 1, fig. $1 \mathrm{a}, 1 \mathrm{~b}, 26,27, \mathrm{pl}$. II, fig. 1 .

Synonyme: Licea effusa Fhrenb. Sylv. Mye. Berol. (1818), 26.

Reticularia maxima Corda Icon. VI (1837/54), 14, t. 11, fig. 35 Lindbladia tubulina Fr. Summ. Veg. Scand. (1849), 449; Celak. Myxom. Böhm., 18; Lister Mouogr. ed. I, 137, pl. LI, B, fig. a-f; Schinz in Mitt Naturw. Ges. Winterthur VI, 78. Aethalium atrum Preuss in Linnaea XXIV (1851), 141. Tubulina effusa Massee Monogr. (1892), 41. Aethalium melaenum Chevallier in Fung. et Byss. Illustr. fasc. I (1837), Nr. 32.

Aethaliumform flach, kuchenförmig ausgebreitet, mit häufig höckeriger Oberfläche, aus verlängerten Sporangien bestehend. 


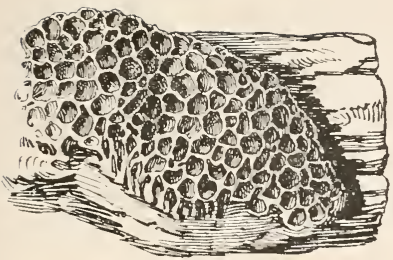

Fig. 116. Iindbladia effusa (Ehrenb.) Rost.

Horizontalschnitt dureh ein polsterfirmiges Aethalium $(9 / 1)$. - Original.

Hypothallus kräftig entwickelt, \pm schwammig. Sporangiumwand entweder ganz oder durchlöchert, gelbbraun. Sporen im durchfallenden Lichte ockerbrann, schwach warzig, $4-6 \mu$.

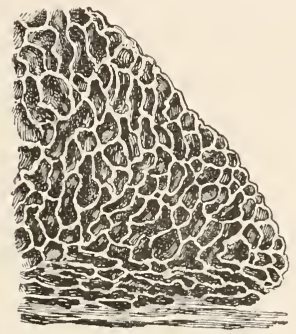

Fig. 117.

Lindbladia effusa (Ehrenb.) Rost. Vertikalschnitt dureh ein polsterfirmiges Äthalium $(\% / 1)$. Nach Lister.

Deutschland, Oesterreich, Schweiz.

Europa, Ceylon, Japan, N.-Amerika.

var. simplex Rex in Bot. Ga\%. XVII (1892), 202; Lister Monogr. ed. 1, 138, pl. 41, B, fig. c, d, e, ed. 2, 174, pl. 137, fig. c-e, Torrend in Broteria VII, 21, pl. 1, fig. 1a, 1b, pl. II, fig. 1.

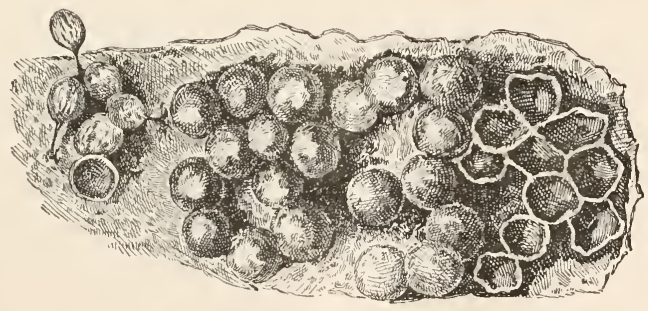

Fig. 118.

Lindbladia effusa (Ehrenb.) Rost. var. simplex liex. - Zum Teil gestielte, zum Teil ungestielte, freie oder verwachsene sporangien $\left({ }^{10} / 1\right)$. - Nach Lister. 
Synonyme: Licea spermoides Berkeley et Cnrtis in Grev. II (1873), 68.

Physarum caespitosum Peck in Rep. N.-York Mus. XXVT(1874), 75.

Perichaena caespitosa Peck in Rep. N.-York Mus. XXVI (1874), 57.

'T'ubulina spermoides Massee Monogr. (1892), 37.

Tubulina caespitosa Massee Monogr. (1892), 43.

Sporangien als Einzelsporangien auftretend, zerstrent oder dicht gedrängt, sitzend oder kurz gestielt, \pm kurz zylindrisch.

N.-Amerika, Japan.

\section{Gattung: Cribraria Pers.}

in Roem. Neues Mag. Bot. I (1794), 91; Rost. Versuch eines Systems der Mycetozoen, 5 und Monogr., 231; Massee Monogr.., 54; Schröter in Cohn Krypt.-Fl. Schles. III, 1, 104 und in Engl. und Prantl Natürl. Pflanzenfam. 1, 1, 19; Celak. Myxom. Böhm., 20; Schinz in Mitt. Naturw. Ges. Winterthur VI, 79; Torrend in Broteria VI, 44, VII, 12.

Sporangien kugelig oder birnförmig. Sporangiumwand im untern Teil bleibend, einen häutigen, mitunter durchlöcherten Becher oder Korb bildend, Verdickungen im obern Teil zu einem Netzwerk mit rundlichen oder polygonalen Maschen verbunden, deren Leisten an den Vereinigungsstellen (Maschenwinkeln) + verbreitert sind. Beim Schwinden der Sporangiumwand bleibt dann, abgesehen vom Becher oder Korb, nur das Netzwerk erhalten.

Die Plasmodien der Cribraria- und Dictydium-Arten sind ausgezeichnet durch das Vorkommen überaus zahlreicher Farbkörner, von Jahn (Ber. Deutsch. Bot. Ges. XIX [1901], 103) Dictydinkörner genannt, die schon von De Bary (Die Mycetozoen [Schleimpilze, 1864], 53) beobachtet und erwähnt wurden. Bei Cribraria sind diese Dictydinkörner schwar\%, bleifarben oder grünlich, bei Dictydium schwarzblau. Diese, unseres Wissens bei keiner anderen Gruppe der Schleimpilze vorkommenden Farbkörner, die bald kugelig, bald eine langgestreckte oder polygonale Gestalt mit abgerundeten Ecken haben und bis $6 \mu$ groß sind, zeigen eine auffallende Resistenz gegen Säuren und Alkalien. Da es sich nicht um Eiweißverbindungen handelt, wie Jahn nachweist, so vermutet dieser, daß wir in den Dictydinkörnern Nebenprodukte des Stoffwechsels vor uns haben, die bei manchen 
Arten der in Frage stehenden Gruppe (Cribraria und Dictydium), vor allem bei Dictydium eine wichtige Verwendung bei der Bildung der Leisten des Spangenkorhes dieser Fattung gefunden haben.

1. Maschenwinkel nicht oder nur wenig verbreitert. 2. Sporangium lehmfarbig; Sporangiumwand erst spät schwindend, Becher nicht deutlichals solcherausgeprägt. Netzunordentlich.

1. C. argillacea Pers. in Roem. Neues Mag. Bot. I, (1794), 91 ; Rabenhorst Deutschl. Krypt.-Fl. I, 265; Rost. Monogr., 238, Massee Monogr., 65, fig. 105-107; Schröter in Cohn Krypt.-F'l. Schlesien III, I, 106; ('elak. Myxon. Böhm., 24, t. I, fig. 3, 4; Lister Monogr. ed. I, 140, pl. LII, A, fig. a-c, ed. 2, 175, pl. 138, fig. a-d; Macbride N. Am. Slime-Moulds, 161, pl. XII, fig. 12, 13, pl. XVII, fig. 1; Schinz in Mitt. Naturw. Ges. Winterthur VI. 80: Torrend in Broteria VII, 13.

Synonyme: Stemonitis argillacea Pers. in Gmel. Syst. Nat. II (1794), 1469.

Stemonitis sphaerocarpa Schrank in Roem. und Usteri Mag. Bot. XII (1790), 20 ?

Cribraria micropus Schrad. Nov. Gen. Pl. (1797), 3.

Jicea brumea Frensis in Limaea XXVI (1850), 709 ?

Exsikkaten: Jaap Myxom, exsice, 157, 198.

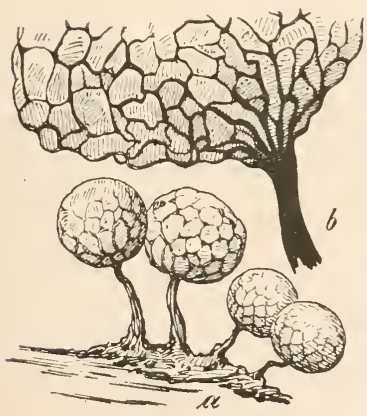

Fig. 119 .

Cribraria argillacea Pers. a) Sporangiengruppe $(20 / 1) ; b)$ unterer Teil des Sporangiums bei geschwundener Wand $(45 / 1)$.

- Nach Lister. 
Plasmodium bleifarbig oder rötlich olivenfarbig. Sporangien mit Stiel $0,75-1,5 \mathrm{~mm}$ hoch, herdenweise, kugelig, gestielt oder fast sitzend, $0,5-0,8 \mathrm{~mm}$ im Durchmesser, im reifen Zustande lehmfarbig. Sporangiumwand erst spät hinfällig werdend, mit unregelmäBigen Verdickungen, die schließlich als grobes Netz mit polygonalen Maschen und ohne Verbreiterungen in den Maschenwinkeln zurïckbleiben. Wandbecher kaum ausgebildet, indem die Netzfäden + direkt an den Stiel ansetzen. Stiel $0.1-0.8 \mathrm{~mm}$ lang. gefurcht, dunkelbraun. Sporen im durchfallenden Lichte ockergelb, nahezu glatt bis fein stachelig. $5-6 \mu$.

Im ganzen Gebiet sehr häufig.

Kosmopol.

var. oligostata Čelak. Myxom. Böhm. (1893), 25.

Sporangien deutlich gestielt; Wandnet» mit ungefähr 15 vom Stiel bogig aufsteigenden, etwa in das erste Fünftel der Sporangienhöhe reichenden Rippen, deren je 2 oft durch gerade oder bogenförmige Verbindungsleisten zusammenhängen.

(i)sterreich.

$2^{*}$. Sporangien matt karmesinrot; Netz engmaschig.

2. C. rubiginosa Fr. Syst. Myc. III (1829), 172; Rabenhorst Deutschl. Krypt.-Fl. I, 266; Lister Monogr. ed. 1, 140, pl. LII, B, fig. a-d, ed. 2, 177, pl. 139, fig. a-e; Schinz in Mitt. Naturw. Ges. Winterthur VI, 81; Torrend in Broteria VII, 18, pl. I, fig. 24, 25.

Plasmodium purpurschwarz. Die in dichten Haufen vorkommenden, dunkelbraunen, gestielten, aufrechten, ellipsoidischen oder fast kugeligen Sporangien haben incl. Stiel eine Höhe von $2-4 \mathrm{~mm}$ und sind $1-1,7 \mathrm{~mm}$ lang und $1-1,5 \mathrm{~mm}$ breit. Der gegen das Netz zu unscharf begrenzte Wandbecher reicht bis $z u \quad 1 / 3$ bis $1 / 3$ der Sporangiumhöhe und ist durchsetzt mit plasmatischen Granulationen. Die rotbraunen Netzfäden sind straff und entbehren in den Maschenwinkeln der Verbreiterungen; die Maschenweite beträgt ungefähr $0,1 \mathrm{~mm}$. Die Sporen sind im durchfallenden Lichte rotbraun, nahezu glatt, $5-6 \mu$. 
Schweiz (Jura, Arosa); weitere als C. rubiginosa Fr. bezeichnete mul publizierte Fumle aus der Schweiz dürften eher zu C. macrocarpa Seluraler var. ferruginea (Meylan) Schinz $(=C$. ferruginea Meylan) gehören (vergl. G. Lister in Jouru. of. Bot. LII (1914), 102).

Schwedel.

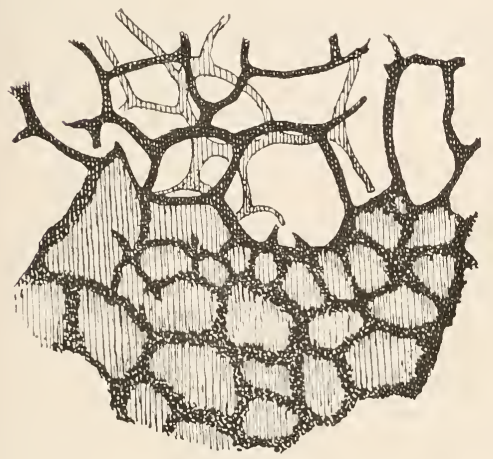

Fig. 120.

Cribraria rubiginosa lir. 'T'eil des Sporanginmetzes und des Raudes des Wanlbechers $(180 / 1)$. Nach Lister.

var. longipes Meylan in Bull. Soc. Vaud. Sc. Nat. XLIV (1908), 294 und XLVI, 52.

Sporangiumstiel bis $3 \mathrm{~mm}$ lang.

Schweizerischer Jura.

$2^{* *}$. Sporangien nubraun oder rostfarbig.

3. Sporangien im Durchmesser $0,6 \mathrm{~mm}$; Netz lockermaschig.

3. C. rufa (Roth) Rost. Monogr. (1875), „232, fig. 15; Schröter in Cohn Krypt.-Fl. Schles. III, 1, 105; Massee Monogr., 63, fig. 103; Lister Monogr. ed. 2. 177, pl. 140, fig. a-c: Torrend in Broteria, VII, 16.

Synonyme: Stemonitis rufa Roth Fl. Germ. I (1788), 548.

Cribraria rufescens Pers. in Roem. Neues Mag. Bot. I (1794), 91 : Celak. Myхom. Böhm., 21: Lister Monogr. ed. 1, 140, pl. LIII, A, fig. a-c; Schinz in Mitt. Naturw. Ges. Winterthur VI, 81. Cribraria fulva Schrader Nov. Geu. Pl. (1797), 5; Rabenhorst Deutschl. Krypt.-Fl. I, 265. 
Cribraria intermedia Schrader Nov. Gell. Pl. (1797), 4.

Trichia rufescens Poiret in Lam. Encycl. Meth. VIII, (1808), 55. Exsikkaten: Jaap Myxom. exsice. 15, 52.

Plasmodium milchweiß. Sporangien zerstreut, gestielt, autrecht, samt Stiel $1,5-2 \mathrm{~mm}$ hoch, \pm kugelig oder kreiselförmig, glänzend braungelbrot; Wandbecher ungefähr den 3. Teil des Sporangiums bildend, am Rande seichtbuchtig gezähnt und längs-

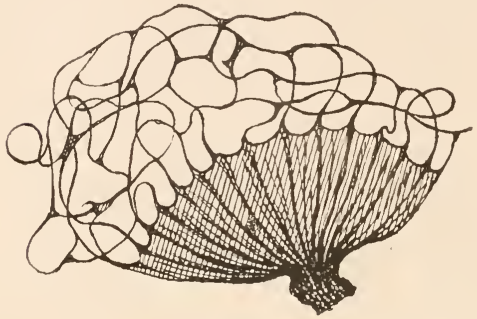

Fig. 121.

Cribraria rufa (Roth)

Riost.

Sporangiumnetz und sporangiumbecher $\left({ }^{50} / 1\right)$. -

Nach Lister.

gerippt, wobei die dickeren Rippen sich als Fäden in das weitmaschige Netz fortsetzen. Maschenwinkel nicht oder gan\% unbedeutend verbreitert. Stiel $0,2 \mathrm{~mm}$ dick. Sjporen im durchfallenden Lichte blaß gelblichrot, sehr fein warzig, $5-8 \mu$.

Deutschland, Österreich, Schweiz.

Enropa verbr., N.-Amerika.

$3^{*}$. Sporangien im Durchmesser $0,1-0,2 \mathrm{~mm}$.

4. C. minutissima S'chwein. in Trans. Am. Phil. Soc. new ser. IV (1832), 260; Rost. Monogr. App., 31; Lister Monogr. ed. 1, 141, pl. LIll, A, fig. d-g, ed. 2, 178, pl. 14", fig. d-g; Macbride N. Am. Slime-Moulds, 162. pl. XVI, fig. 6, 6 a: Torrend in Broteria VII, 14: Beardslee in Torreya VIII, 253.

Synonyme: Cribraria minima Berkeley et Curtis in Grev II (1873), 67. Massee Monogr., 59.

Cribraria microscopica Berkeley et Curtis in Grev. II (1873), 67: Rost. Monogr., App., 31; Massee Monogr., 62.

Plasmodium blanschwarz (nach Meylan). Sporangien zerstreut, samt Stiel 0, aufrecht oder nickend, 0,1-0,2 mm im Durchmesser, nußbraun. 
Wandbecher veränderlich, mitunter halb so hoch wie das Sporangium, mitunter auch vollständig fehlend, wenn vorhanden blaß nußbraun, an der Begrenzung gegen das Netz seicht wellig ansbuchtet, fein längsgestreift durch vom Stielansat\% gegen die Maschenansatzstellen zulaufende Linien; Net\% weitmaschig, Maschen nicht oder nur unbedentend verbreitert in den Netzknoten, in deuen 3 bis 5 zarte, flache Fäden zusammenlaufen. Stiel pfriemlich, $1 \frac{1}{2}$ bis 4 mal länger als das Sporangium, braun. Sporenmasse gelbbraun; Sporen in durchfallenden Lichte ockerbraun, fein stachelig, $5-6,5 \mu$.

Schweiz (Jura).

Ceylon, N.-Amerika.

1*. Netzknoten verdickt.

4. Sporangien nubraun.

5. Wandbecher gerippt, am liande durchlöchert, allmählich in das Net\% übergehend.

5. C. macrocarpa Schrader Nov. Gen. Pl. (1797), 8, t. II. fig. 3. 4; Rabenhorst Deutsch. Krypt.-Fl., I, 265; Rost. Monogr., 238; Schröter in Cohn Krypt.-Fl. Schles. III, 1, 106; Čelak. Myxom. Böhm., 23; Massee Monogr., 56, fig. 110; Lister Monogr. ed. 1, 141, pl. VIII, A, fig. d-g, ed. 2, 178, pl. 141, fig. a-d; Macbride N. Am. Slime-Moulds, 162, pl. XVII, fig. 2; Schin\% in Mitt. Naturw. Ges. Winterthur VI, 82; Torrend in Broteria VII, 13.

Synonyme: 'Trichia macrocarpa Poiret in Lam. Encycl. VIII (1808), 55.

Cribraria tatrica Racib. in Hedwigia XXIV (1885), 170.

Heterodictyon Bieniaszii Racib. in Hedwigia XXVIII (1889), 121.

Cribraria Bieniaszii Massee Monogr. (1892), 60; Racib. ex Torrend in Broteria VII, 14.

Cribraria ferruginea Meylan in Ann. Conserv. et Jard. bot. Genève $15 \mathrm{me}$ et $16 \mathrm{me}$ anuées (1913), 319.

Plasmodium schiefergrau. Die samt Stiel $2 \mathrm{~mm}$ hohen S'porangien zerstreut oder herdenweise, kugelig, verkehrteiförmig oder 
kegelförmig, aufrecht oder nickend, rotbraun, 0,6-1 mm im Durchmesser. Wandbecheretwa $1 / 3$ der Sporangiumhöhe erreichend, orangegelbbraun, mit vielen längs verlaufenden dunkeln Rippen, oberwärts durchlöchert, am obern Rande unregelmäßig und tiefgezähnt und in dieser Art allmählich in das im untern Teile unregelmäßige

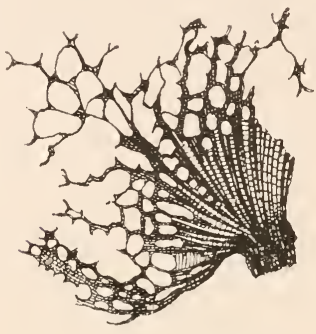

Fig. 122.

Cribraria macruearpa

Schrader.

Teil des Sporangiumnetzes nebst dem Becher $\left({ }^{50} / 1\right)$. -

Nach Lister.

Netz ïbergehend. Maschenknoten im untern 'l'eil verlängert und zusammenlaufend, flach, oberwärts regelmäßig, mehreckig, die Ecken in die Verbindungsfäden ausgehend; Rippen und Knoten mit dunkeln, plasmatischen Granulationen. Stiel $0.8-1 \mathrm{~mm}$ lang. $0.1 \mathrm{~mm}$ dick, dunkelbraun, gefurcht. Sporen im durchfallenden Lichte blaß ockergelb bis rostrot, nabezu glatt, $4-7 \mu$.

Dentschland, Österreich, Schweiz.

Großbritamnien, Norwegen, Schweden, Rumänien, N.-Amerika.

C. argillucea, die. schon wegen der übereinstimmenden Größe der Sporangien etwa mit der obigen Art verwechselt werden könnte, hat kugelige Sporangien und einen kürzern Wandbecher, deutlich ausgebildete, meist abgeflachte, eckige, verzweigte Maschenkuoten und regelmäßigere Netzmaschen. C. ferruginea Meylan unterscheidet sich wohl nur durch die rostroten Sporen und dürfte allerböchstens den Rang einer Spielart (C. macrocarpa Schrader var. ferruginea [Meylan] Schinz) beanspruchen: sie ist bis anhin nur in schweizerischen Westjura gefunden worden.

5*. Wandbecher wohlausgebildet: oberwärts kaum durchlöchert; Maschenknoten meist abgeflacht, eckig, verzweigt. 
6. C. aurantiaca Schrader Nov. Gen. Pl. (1797), 5, t. I, fig. 3, 4: Rabenhorst Deutschl. Krypt.-Fl. I, 266; Rost. Monogr., 233, fig. 21; Massee Monogr., 57, fig. 104; Schröter in Cohn Krypt.-Fl. Schles. III, 1, 105; Celak. Myxom. Böhm., 22; Lister Monogr. ed. 1, 142, pl. LIV, A, fig. a-c, ed. 2, 179, pl. 142, fig. a-c; Macbride N. Am. Slime-Moulds, 164, pl. XVII, fig. 3; Schinz in Mitt. Naturw. Ges. Winterthur VI, 82; Torrend in Broteria VII, 15.

Synonyme: Cribraria vulgaris Schrader Nov. Gen. Pl. (1797), 6, t. 1, fig, 5; Rabenhorst Dentschl. Krypt.-Fl, I, 266; Rost. Monogr., 234; Schröter in Cohn Krrypt.-FI. Schles., III, 1, 105; Cial. Mrxom. Böhm., 21.

Cribraria vulgaris Schrater var. amrantiaca Pers. Syn. Fung. . (1801), 194.

Cribraria variabilis Ficin. et. Schnb. Fl. Dresden II (1823), 296? Cribraria amrantiaca Schrader var. sulphurea Wallr. Fl. Germ. (1833). Cribraria intermedia Berkeley in Sm. Engl. Fl. V, 2 (1836), 318. Stemonitis semitrichioides Gmel. Syst. Nat. (1791), 1468?

Trichia semicancellata DC. Fl. Fr. (1815), 255.

Exsikkaten: Fuckel Fungi rhen.; Jaap Myxom. exsicc. 34, 74, 158, 179; Hofmus. Wien Krypt. exsiceatae 403.

Plasmodium grünlich oder schiefergrau. Sporangien herdenweise, samt Stiel 1-2 $\mathrm{mm}$ hoch, kugelig, aufrecht oder nickend, uußbraun, im Durchmesser $0,4-0,7 \mathrm{~mm}$. Wandbecher $1 / 3 \mathrm{der}$ Sporangiumhöhe erreichend, gewöhnlich mit zahlreichen feinen, vom Stielansat\% zum Becherrand ausstrahlenden Linien; Becherrand tief gezähnt, die Zähne das halbkugelige Netz tragend. Netzknoten flach, breit. verzweigt und kantig oder schmal, die Ecken in feine Verbindungsfäden oder in freie Enden ausgehend. Becherrand ab und zu durchlöchert. Stiel pfriemlich, dunkelbraun, häufig kurz, aber auch bis 4 mal länger als das Sporangium. Sporenmasse goldgelb oder ockerfarbig: Sporen im durchfallenden Lichte blasser bis nahezu farblos, fast glatt. $5-7 \mu$.

Deutschland, Oesterreich, Schweiz.

Kosmopolitisch.

Ch. Meylan (Anunaire Conserv. et Jardin bot. Genève, 15me et 16me années (1913), 317) unterscheidet unter den im schweizerischen Jura vertretenen Formen dieser Art drei Formengruppen :

Schinz, Myxogasteres (Rabenhorst Krypt.-Flora I, Piize Abt. X). 
1. Sporangien rötlichgelb, immer klein; Becher ungefähr $1 / 3$ der Sporangiumhöhe erreichend. Maschenknoten vieleckig, verbreitert. Plasmodium grïn. Tritt im .Jura selten in größerer Zahl auf; namentlich im Juni und Juli fruktifizierend.

2. Sporangien mit rötliclıgrauen Sporen. Netz mit mittelgroßen Knoten oder derselben entbehrend; der Becher $1 / 3$ bis $1 / 2$ so hoch wie das ganze Sporangium. Plasmodium graublau. Im Juli und August außerordentlich l’äufig, oft ganze moderude Baumstämme überkleidend.

3. Sporangien von grautoniger Farbe. Net\% fast stets ohne Knotenverbreiterungen; der Becher oft schwärlich, eine Cribraria macrocarpa vortäuschend. Tritt hauptsächlich in Herbst auf.

Meylan belegt nun die häufigste Form (2) mit der Bezeichnung C. vulgaris Schrader var. genuina Meylan, unterstellt dieser die f. macropoidea Meylan (der Gruppe 3 entsprechend) und benennt die Gruppe 1 var. aurantiaca (Schrader) (wohl richtiger Pers.. vorausgesetzt, daß sich beide Formen decken). Tar. aurantiaca soll sich, wie Meylan berichtet, im Jura hauptsächlich auf trockenen, modernden Baumstämmen, var. genuina dagegen auf fenchten Stämmen finden, aurantiaca wäre daher. wie sich Meylan ausdrückt, gewissermaßen eine xerophile Form der genuina.

Čelakovsky trägt der Vielgestaltigkeit dieser recht häufigen Cribraria-Art gleicherweise Rechnung und unterscheidet nachfolgende Spielarten (sub. C. vulgaris)

var. genuina Celak. Myxom. Böhm. (1893), 22.

Knoten polygonal, $30 \mu$ breit, oft länglich. Zähne des Bechers 15 bis 20 , tief eingeschnitten.

var. delicatula (Rost.) C’elak. Myxom. Böhm. (1893), 22.

Synonym: Cribraria vulgaris Sehrader var. delieatula Rost. Mlonogr. (1875), 235 .

Knoten schwach entwickelt, kaum $10 "$ breit, manche vicht breiter, als der Durchmesser von Sporen lieträgt. Zähne des Bechers gewöhnlich weniger als 15 .

var. inconspicua Čelak. Myxom. Böhm. (1893), 22.

Sporangien mit bloßem Auge kaum sichtbar, am Substrat sehr zerstreut, etwa $0,15 \mathrm{~mm}$ breit, lichtbraun, auf mehrbis 10 mal längeren, dünnen, hin und her gebogenen nußbraunen Stielen. Becher auf der Außenseite schwarz oder 
braunkörnig, seicht ausgerandet, mit kürzeren oder läıgeren, 6 bis 10 Zähnen, welche sich in dünne Fäden verlängern, die ihrerseits ein sehr lockeres Netz mit wenig Maschen bilden. Knoten dementsprechend wenige, drei- oder mehrkantig, isodiametrisch oder einseitig verlängert, selten auch zu zweien verbunden, auf der Außenseite auch mit Körnchen besetzt.

$5^{* *}$. Becher durch starke Rippen ersetzt; Knoten nicht abgeflacht.

7. C. splendens (Schrader) Pers. Syn. Fung. (1801), 191; Rost. Monogr., 236; Massee Monogr., 64; Ċelak. Myxom. Böhm., 23; Lister Monogr., ed. 1, 143, pl. LIII, B, fig. e-g, ed. 2, 180, pl. 1+1, fig. e-h; Macbride N. Am. Slime-Moulds, 163; Torrend in Broteria VII, 14.

Sy nonyme: Dictydium splendens Schrader Nov. Gen. Pl. (1797), 14.

Trichia splendens Poir. in Iam. Encyel. VIII (1808), 55.

Exsikkaten: Jaap Mухон. exsiec. 180.

Plasmodium? Sporangien zerstreut, samt Stiel 1,5 mm hoch, kugelig, aufrecht oder nickend, nußbraun, $0,3 \mathrm{~mm}$ im Durchmesser. Sporangiumwand im untern Teil bei in der Regel ganz mangelnder Becherbildung aus zirka 9 freien Rippen bestehend, die in ein lockeres Netz mit kleinen, oft dreieckigen Knoten überführen. Stiel schlank, braun, 4 bis 5 mal länger als das Sporangium. Sporen im durchfallenden Lichte blabockerfarbig, nahezu glatt, $5 \mu$.

Dentsihland, Oesterreich, Schweiz.

Großbritamuien, Schweden, Dänemark, Rußland, Rumänien, Japan, N.- und S.-Amerika.

Raciborski und mit ihm Ċelakovsky unterscheidet folgende Spielarten:

var. gracilis Racib. in Hedwigia XXVIII (1889) 122, Sporangien gesellig stehend, gestielt, braun, kugelig, bis $0,4 \mathrm{~mm}$ breit, Stielchen sehr dünn, der Länge nach gefältelt, nach oben verdünnt, $1-\not, 5 \mathrm{~mm}$ hoch. Sporangiumwand entweder ganz fehlend oder in Form eines rudimentären Körbchens an der Basis des Sporangiums zwischen den Rippen vorhanden; letztere zu 10-22, 
ziemlich gleichbreit, entweder ganz isoliert oder mittelst der erwähnten rudimentären Sporangiumwand unten verbunden. Yet\% regelmäßig, alle Knoten verdickt, rundlich oder 3- bis 4 kantig, an den Ecken gerundet, isodiametrisch, mit benachbarten mittelst dünner Verbindungsfäden verbunden, welche von jedem Knoten zu 3 bis 4 entspringen.

var. oligocostata Racib. 1. e. 122.

Sporangien gesellig. auf dünnen. bis 1 mm langen stielen. kugelig, 0,3 bis $0,4 \mathrm{~mm}$ breit. Sporangiumwand ganz unentwickelt: von der Basis der Sporangien laufen wenige, 7 his 12 ziemlich breite, flache Rippen, welche unten etwas breiter als oben und entweder ganz isoliert oder ansnahmsweise hie und da mit dünnen transversalen Yerbindungsfäden rerbunden sind. Diese Rippen. welche zu:' 3 der Höhe des Sporanginms verlanfen, bilden höh@r oben durch ihre Verästelungen ein unregelmäBiges Cribrarianet\%. Die Knoten sind länglich, von unregehmäbiger Gestalt, bald durch dünne Verbindungsfäden verbunden. bald zusammenfließend.

Hierzu fügt Čelakovsky" noch eine dritte Spielart hinzu:

var.polybrachia C'elak. Myxom. Böhm. (1893), 24. Sporangien (1),3 bis $0,4 \mathrm{~mm}$ breit, Stiele 3 bis 6 mal länger als die sporangien. Knoten ziemlich grob, isodiametrisch oder ein wenig verlängert. braun, 6 bis 10 seitig, ausgerandet, mit ebensovielen strahlenartig divergierenden Auszweigungen.

Celakovsky hat alle drei Formen für Osterreich nachgewiesen: ob sie wirklich als Formen oder V'arietäten anfrecht erhalten werden können, werden weitere Untersuchungen erweisen.

5***. Wandbecher entweder ausgebildet, rudimentär oder fehlend: die Netzknoten verdickt, vorstehend. zahlreich.

b. Knoten des $\mathbb{W}$ andnetzes unter einander durch je 4 bis 5 \%arte Verbindungsäden rerkn̈̈pft. mit 3,4 und mehr frei in die II aschen ausstrahlenden Fäden. 
8. C. intricata Schrader Nov. Gen. Pl. (1797), 7, t. III, fig. 1; Rabenlorst Dentschl. Krypt.-Fl., 1, 266; Rost. Monogr., 237, fig. 27; Massee Monogr.. 59. fig. 11 - 13; Lister Monogr. ed. 1, 143, pl. LIV, B, fig. a-c, ed. 2, 180, pl. 143, fig. a-c; Macbride N. Am. Slime-Moulds, 166; Schinz in Mitt. Naturw. Ges. Winterthur VI, 83; Torrend in Broteria VII, 15, pl. 1, fig. 19, 20.

Synonym: Trichia intricata Poiret. in Iam. Encycl. VIII (1808), 56.

Plasmodium? Sporangium samt Stiel 1,5 -3 mm hoch, herdenweise, kugelig. gestielt, aufrecht oder nickend, 0,5-0,7 mm im Durchmesser, ockerbraun. Wandbecher ${ }^{1 /}$ der Sporangiumhöhe erreichend, gelbbraun, mit braunen, zn vom Stielansatz dicht meridianartig $z 11 m$ entgegengesetzten Pol verlaufenden Linien angeordneten Granulationen besetzt; Becherrand unregelmäBig gezähnt und mittelst dieser länglichen Zähne allmählich in das regelmäßige und abgesehen von den Knoten, zarte Netz übergehend. Netzknoten in großer Zahl, dunkelbraun, oft zu 2, 3 und mehr zusammenlaufend, mehreckig, oft verzweigt, mit 3,4 und mehr, frei in die Maschen auslaufenden Fäden, durch $5-8$ zarte Fäden unter einander verbunden. Stiel pfriemilich, schlank, 2-4 mal länger als das Sporangium. Sporenmasse dunkelolivenfarbig; Sporen im durchfallenden Lichte blaßockerfarbig, nahezu glatt oder fein warzig, $5-7 \mu$.

Im Gebiet wohl nur vertreten durch:

var. dietydioides (Cooke et Balfour) Lister Monogr. ed. 1 (1894), 144, pl. LIT, B, fig. d, ed. 2, 181, pl. 143, fig. d.

Synonyme: Cribraria dictydioides Cooke et Balfour in Rav. N.

Amer. Fungi (1881), No. 475: Massee Monogr., 65; Macbride

N. Am. Slime-Moulds, 165, pl. 1. fig. 5, 5a, 5b; Torrend in Broteria VII, 16.

Cribraria microcarya Massee Monogr. (1892), 64 non Pers.

Wandbecher ganz oder fast ganz fehlend, Netzknoten im untern Teil des Netzes verlängert und zusammenfließend, gegen den Stielansatz zu konvergierende Rippen bildend.

Schweiz (Warmhäuser im Botanischen Garten in Zürich), Jura.

Der 'Typus scheint bis jetzt nur ans Großbritamien, Dänemark, Skandinavien, Rumänien, Westafrika, N.- und S.-Amerika, Borneo, die var. dictydioides anBerdem ans Dänemark, Java, Westindien, Japan, Australien, S.- und N.-Amerika bekannt geworden zu sein. 
$6^{*}$. Netzknoten im Umriß abgerundet, ohne oder nur mit sehr wenigen, 1 bis 2, frei endigenden Fäden, unter einander durch 2 bis 6 \%arte Verbindungsäden verbunden.

9. C. tenella Schrader Nov. Gen. Pl. (1797), 6, t. III, fig. 2, 3; Rabenhorst Dentschl. Krypt.-Fl., I, 267; Rost. Monogr., 235, fig. 23; Massee Monogr., 58: Čelak. Myxom. Böhm., 22; Schröter in Cohn Krypt.-Fl. Schles., III, 1. 105; Lister Monogr. ed. 1. 144, pl. LIV, B, fig. f-i, ed. 2, 181, pl. 143. fig. f-i; Macbride N. Am. Slime-Mloulds, $167, \mathrm{pl}$. XVII, fig. 5; Schinz in Mitt. Naturw. Ges. Winterthur VI, 84; Torrend in Broteria VII, 16. Symonym: Cribraria elata Massee Monogr. (1892), 61.

Plasmodium mehr oder minder asplialtschwar\% oder braunschwar\%. Sporangien herdenweise, von C. intricata in Größe, Gestalt, Farbe kaum verschieden, bald mit, bald ohne oder mit nur unvollkommenem Wandbecher, in ersterem Falle letzterer zirka 1/3 der Sporangiumhöhe erreichend. Netz regelmäßig und engmaschig, mit dunkelbraunen, abgerundeten, selten verlängerten Netzknoten, die durch je 3 bis 6 V erbindungsfäden unter einander verknüpft sind, der frei in die Maschen ausstrahlenden Fäden dagegen meistens entbehren. Sporenmasse ockerolivengrün; Sporen im durchfallenden Lichte blaß ockergelb, glatt, $5-7 \mu$.

Deutschland, Österreich, Schweiz.

Großbritannien, Frankreich, Rumänien, Cẹlon, Java, Japan, Westindien, N.- und S.-Amerika.

Steht $C$. intricata sehr nahe und ist mit dieser durch unverkennbare Übergänge verbunden; nach Macbride sollen die Sporangien der $C$. tenella durchgehends weniger hoch als jene typischer $C$. intricata sein.

Č̉elakovsky hat (Myxom. Böhm. [1893], 23) eine var. gracilis Čelak. aufgestellt, die sich, nach der kurzen Beschreibung \%u urteilen, vom Typus der C. tenella durch längere Stiele und ein weniger stark entwickeltes Netz unterscheidęn soll.

$4^{*}$. Sporangien dunkel- oder rotbraun, gelblichbraun bei C. pyriformis.

7. Stiel 2-oder 3 mal länger als das sporangium. 
10. C. pyriformis Schrader Nov. Gen. Pl. (1797), 4. t. III, fig, 4, 5; Rabenhorst Deutschl. Krypt.-Fl., I. 265; Rost. Monogr., 237, fig. 14; Massee Monogr., 55; Lister Monogr. ed. 1, 145, pl. LV, A, fig. a-h, ed. 2, 182, pl. 14t, fig. a-h; Macbride N. Am. Slime-Moulds, 166, pl. XVII, fig. 9; Schinz in Mitt. Naturw. Ges. Winterthur VI, 84; Torrend in Broteria VII, 17, pl. I. fig. 21.

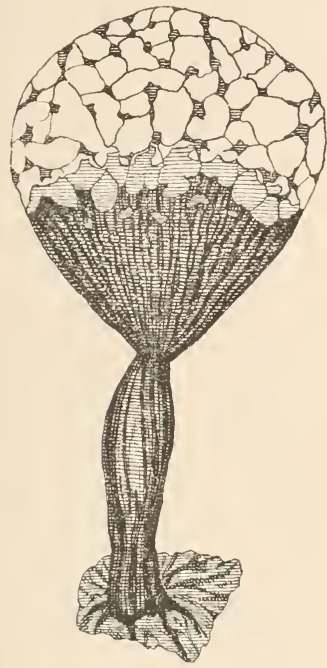

Fig. 123.

Cribraria pyriformis Schrader. Sporangium $(40 / 1)$. - Nach Rostafinski.

Plasmodium? Sporangien herdenweise, samt Stiel $1-1,7 \mathrm{~mm}$ hoch, kugelig oder kegel- oder kreiselförmig, gestielt, aufrecht, $0.3-0,9 \mathrm{~mm}$ im Durchmesser, rötlich- oder gelblichbraun; Stiel $0,5-1,5 \mathrm{~mm}$ lang, nach oben verjüngt, längs gefurcht, dunkelpurpurbraun. Wandbecher sehr deutlich ausgebildet, 1/3 der Sporangiumhöhe erreichend, blaß bräunlichgelb, ungerippt, mit durchlöchertem und unregelmäßig oder regelmäßig gezähntem Rande, mit entweder regellos zerstreuten oder zu breiten, meridianartig verlaufenden Linien angeordneten, rundlichen, $2-2,5 \mu$ großen, purpurbraunen, plasmatischen Granulationen besetzt. Netzknoten in sehr mannigfaltiger Gestaltung, flach, \pm dreieckig, oft verzweigt, häufig unter einander durch blaß bräunlichgelbe Verbindungsfäden verknüpft, selten mit freien Enden. Sporenmasse matt gelblichbraun; Sporen im durchfallenden Lichte ockerfarbig oder salmrötlich, $5-6,5 \mu$.

Deutsehland, Österreich, Schweiz (Jura, Arosa).

Großbritannien, Frankreich, Schweden, Portugal, Rumänien, N.- und S.-Amerika.

var. notabilis Rex ap. Lister Monogr. ed. 1 (1894), 145, pl. LV, A, fig. e, ed. 2, 182, pl. 144, fig. e; Schinz in Mitt. Naturw. Ges. Winterthur VI, 84; Torrend in Broteria VII, 17. 
Sporangien stets kugelig; Netzknoten vorstehend. nicht flach, abgerundet oder von unregelmäßigem Umriß. Stiel schlank.

Schweiz (Jura, N-Zürich).

Portugal, N.-Amerika.

var. fusco-purpurea Meylan in Anmuaire Conserv. et Jard. bot. Genève 15 me et $16 \mathrm{me}$ années (1913), 319 .

Sporen im durchfallenden Lichte purpurrot; Netzknoten kaum verbreitert.

Schweiz (Jura).

$$
\begin{aligned}
& 7^{*} \text {. Stiel } \pm 4 \text { bis } 6 \mathrm{mal} \text { länger als das } \\
& \text { Sporangium. }
\end{aligned}
$$

8. Wandbecher $1 / 3$ der Sporangiumhöhe erreichend: Netzknoten riele ckig.

11. C. languescens Rex in Proc. Nat. Se. Phil. (1891), 394: Lister Monogr. ed. 1, 145, pl. LV. B, fig. a c, ed. 2, 182, pl. 145, fig. a-c; Macbride $\mathrm{N}$. Am. Slime-Monlds, 170: Torrend in Broteria VII, 19.

Synonym: Cribraria euprea Morgan Myx. Miami Vall. (1893), 16; Macbride N. Am. Slime-1Ionlds, 171, pl. XTIl, fig. 7; Torrend in Broteria VII, 20.

Plasmodium? Sporangien samt Stiel 2,5-3 mm hoch, zerstreut, kugelig, auf schlankem Stiel hängend, 0,25-0,35 mm im Durchmesser, mattrot. Wandbecher ungefähr $1 / 3$ der Sporangiumhöhe erreichend, rotbraun, glänzend mit purpurbraunen, zu dichten, vom Grunde ausstrahlenden Linien angeordneten plasmatischen Granulationen besetzt, mit gezähntem Raude. Net\%knoten purpurbraun, verdickt, mit wenigen freien Fäden und mit zarten Verbindungsfäden; Maschen oft regelmäßig dreieckig. Sporen im durchfallenden Lichte blaßrot, fast glatt, $5-6.5 \mu$. Österreich.

Japan, Ceylon, Westindien, N.-Amerika, W.-Afrika.

$8^{*}$. Becher sehr klein oder fehlend; Netzknoten abgerundet.

12. C. microcarpa (Schrader) Pers. Syn. (1801), 190; Rost. Monogr., 235; Schröter in Cohn Krypt.-Fl. Schles. III, 1, 105; Massee Monogr., 63, fig. 13t-136; Lister Monogr. ed. 1, 146, 
pl. LV, B, fig. d h, ed. 2, 183, pl. 145, fig. d-h; Schinz in Mitt. Naturw. Ges. Winterthur VI, 85; Torrend in Broteria V1I, 17.

Synonyme: Cribraria capillaris Fr. Stirp. Femsj. (1825), 84?

Dictydium microcarpum Sehrader Nov. Gen. Pl. (1797), 13.

Trichia mierocarpa Poiret. in Lam Eneyel. V1 (1804), 54.

Exsikkaten: Fuckel Fung. rhen. 2099.

Plasmodium trübgelblich oder rotbraun (Jahn). Sporangien gesellig, samt dem purpurbraunen, schlanken, + bis 10 mal längeren Stiel 0,7 bis $2 \mathrm{~mm}$ hoch, kugelig, anfrecht oder nickend, purpurrot, $0,1 \cdots 0,3 \mathrm{~mm}$ im Durchmesser. Net\% dicht, regelmäßig; Netzknoten + rundlich, dicht besetzt mit purpurbraunen plasmatischen Granulationen, unter sich verbunden durch je 5 bis 6 zarte, rosenrote Fäden. Sporen im durchfallenden Lichte blabrot, fein stachelig, $5-6 \mu$.

\section{Deutschland, (̈)sterreich, Schwei\%.}

Frankreich, Portugal, Ceylon, liußland, Ruminien, Java, Japan, N.Amerika.

$4^{* *}$. Sporangien purpurfarbig.

9. Becher 1/3 der sporangiumhöhe erreichend, $0,7 \mathrm{~mm}$ im D) urchmesser.

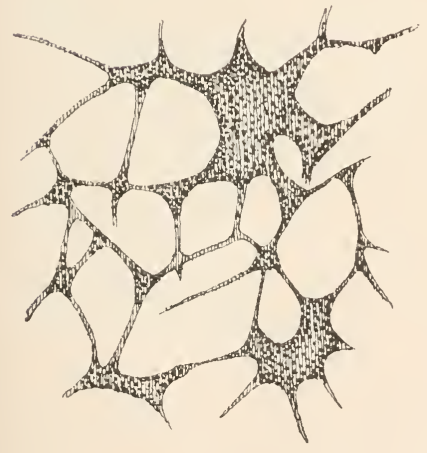

Fig. 124 .

Cribraria purpurea schrader. Teil des Sporangiumnetzes $(180 / 1)$. - Nach Lister.

13. C. purpurea Schrader Nov. Gen. Pl. (1797), 8; Rabenhorst Deutschl. Krypt.-Fl. I. 266; Rost. Monogr., 233; Massee Monogr., 57, fig. 109; Schröter in Cohn Krypt.-Fl. Schles. III, 1, '106; 
Lister Monogr. ed. 1, 146, pl. LVI, A, fig. a-c, ed. 2, 183. pl. 146, fig. a-c; Macbride N. Am. Slime-Moulds, 169; Schinz in Mitt. Naturw. Ges. Winterthur VI, 85: Torrend in Broteria VII, 19.

Plasmodium? Sporangien mit zylindrischem, gefurchtem, 1,5 mm langem, dunkelpurpurrotem Stiel, 2,5 $\mathrm{mm}$ hoch (samt Stiel), kugelig, aufrecht oder geneigt, purpurrot, gesellig. Becherrand gezähnt. Netzfäden zart, nur wenige der Knoten flach und eckig; Netzmaschen von wechselnder Gestalt und Größe; Becher und Netz dicht mit kugeligen, purpurroten, plasmatischen Granulationen besetzt. Sporen im durchfallenden Lichte purpurrot, fein warzig, $5-6 \mu$.

Deutschland, Österreich, Schweiz.

Frankreich, Skandinavien, Rumänien, Java, Japan, N.-Amerika.

$9^{*}$. Becher halb so hoch wie das Sporangium, letzteres im Durchmesser $0,5 \mathrm{~mm}$.

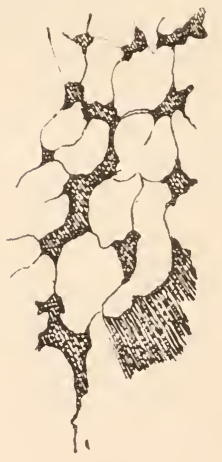

Fig. 125 .

Cribraria elegans

Berkeley et Curtis.

Teil des sporangiumnetzes und des Becherrandes ( $\left.{ }^{180} / 1\right)$.

- Nach Lister.

14. C. elegans Berkeley et Curtis in Grev. II (1873). 67: Rost. Monogr., App., 31; Massee Monogr., 55; Lister Monogr. ed 1, 146, pl. LVI, A, fig. d-f, ed. 2, 184, pl. 146, fig. d-f; Macbride N. Am. Slime-Moulds, 168, pl. XVII, fig. 4; Schinz in Mitt. Naturw. Ges. Winterthur VI, 85; Torrend in Broteria VII, 19. 
Plasmodium? Sporangien samt dem pfriemlichen, 0,6 bis $1 \mathrm{~mm}$ langen, dunkelpurpurroten Stiel $0,7-1,3 \mathrm{~mm}$ hoch, gesellig, kugelig, anfrecht oder geneigt, purpurrot. Becherrand tief gezähnt und durchlöchert; zahlreiche, durch sehr starke Netzfäden verbundene, flache Knoten. Netz und Becher dicht mit kugeligen, purpurroten, plasmatischen Grannlationen beset»t. Sporen im dırchfallenden Lichte blaßviolett, nahezı glatt, 4-6 $\mu$.

Schweiz (Wengernalp, Jura).

N.-Amerika.

$4^{* * *}$. Sporangien violettblau, $0,25 \mathrm{~mm}$ im Durchmesser.

15. C. violacea Rex in Proc. Acad. Nat. Sc. Phil. (1891), 393; Lister Monogr. ed 1, 147, pl. LVl, A, fig. g-k, ed. 2, 184, pl. 146, fig. g-k; Macbride N. Am. Slime-Moulds, 168, pl. XVII, fig. 8; Torrend in Broteria VII, 20.

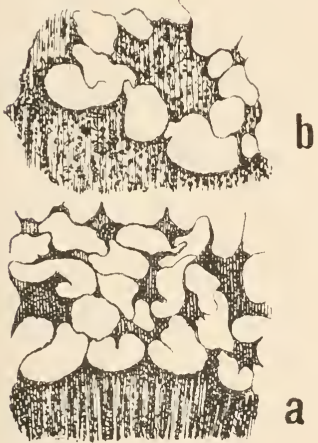

Fig. 126.

Cribraria violacea Rex.

a) T'eil des Sporangiumnetzes und des Becherrandes $(180 / 1)$; b) Teil des Becherrandes $(180 / 1)$. - Nach Tister.

Plasmodium schwarzviolett. Sporangien samt dem pfriemlichen, schlanken, violettschwarzen Stiel 0,5-1 mm hoch, gesellig, kugelig oder ellipsoidisch, aufrecht oder nickend, mit Metallglanz. $\mathrm{W}^{r}$ andbecher $1 / 3$ bis $2 / 3$ oder mehr der Sporangiumhöhe erreichend, häutig, am Rande mit vereiuzelten Zähnen. Netzfäden zart, Netzknoten flach, breit, eckig. Sporen im durchfallenden Lichte lila, fein- und dichtwarzig, $6-8 \mu$. 
Bei dieser Art unterbleibt mitunter die Bildung eines $\mathrm{W}$ andnetzes und es bilden sich an dessen stelle in der obern Mandcalotte 3 bis 4 ovale Öfnungen.

Dentschland, ïsterreich.

(Aroßbritamien, Rumänien, ('ẹlon, Japan, Westimlien, X.-Amerika, IV.-Afrika.

\section{Gattung: Dictydium Schrader pr. p.}

Nov. Gen. Pl. (1797), 11: Rost. Versuch eines Systems der Myceto\%oen, 5, Monogr., 229: Schröter in Cohn Krypt.-Fl. Schles. III, 1, 106, in Engl. und Prantl Natürl. Pflanzenfam. I, 1, 19: Massee Monogr., 67; Čelak. Myxom. Böhm., 20; Lister Monogr. ed. 1, 148, ed. 2, 185; Macbride N. Am. Slime-Moulds, 171; Schinz in Mitt. Naturw. Ges. Winterthur VI, 86; Torrend in Broteria II, 44, VII, II; Jahn in Ber. Deutsche Bot. Ges. XIX. 97.

Mit nur einer Art:

D. cancellatum (Batsch) Macbride X. Am. Slime-Moulds (1899), 172; Lister Monogr. ed. 2, 185. pl. 147, tig. a-h; Torrend in Broteria V'II, II, pl. I, fig. 16, 17.

Synonyme: Mucor cancellatus Gmel. Elench. Fung. Il (17x9), 1:35, fig. 232, a-c.

Stemonitis cancellata Gmel. Syst. Nat. (1791), 1468.

Cribraria cernua Pers. Obs. Myc. l (1796), 91.

Dictydium renosum Schraler Nov. (ren. Pl. (1797), 14, t. 111, fig. 6. Dictydium ambiguum Schrader Nov. Gen. Pl. (1797), 11, t. IY, tig. 2.

Inctydium mmbilicatum Schrader Nov. Gen. Pl. (1797), 11, t. $1 \mathrm{Y}$, fig. 1; Rabenhorst Deutschl. Krypt.-Fl. 1, 267; Lister Monogr. erl. 1, 148, pl. LVI. B, fig. a-b; schiız in Mitt. Naturw. (ies. Winterthur $\mathrm{V} 1,86$.

Dictydium cernuum Nees Syst. Pilze (1816), 120, fig. 117; Rost. Monogr. 229, tig. 17, 19, 22; Massee Monogr., 67, fig. 133; Schröter in Cohn Krypt.-Fl. Schles. III, 1, 116; Celak. Myxom. Böhm., 20, t. 1, fig. 1, 2.

Dictydium trichioides (hev. Fl. Par. I (1826), 327.

Cribraria exilis Macbride in Bull. Nat. Hist. lowa II (1893), 378. Dictydium longipes Morgan Myx. Miami Vall. (1893), 17.

Exsikkaten: Fuckel Fung. rhen. 1445, 2099; Sydow Mycol. March.

164; Rabenhorst Fung eur. 2519; Jack, Leiner und Stitzenberg 422; Jaар Мухоm. exsice. 35, 53, 159, 199; Hofmus. Wien Lrypt. exsiccatae 4. 
Plasmodium erst dunkelpurpurrot, später schwarzhlan, reich an schwarzblauen Dictydinkörnern. Sporangien meist gesellig, samt stiel 1-3 und selbst mehr mm hoch, dunkelrotbraun oder purpurrot. kugelig. gewöhnlich hängend. Stiel $\pm 2 \mathrm{~mm}$ lang, schlank, p friemlich, oft gerunzelt, unterhalb des Sporangiums gekniet oder gedreht, meist mehrmals länger als das Sporangium. Sporangium-

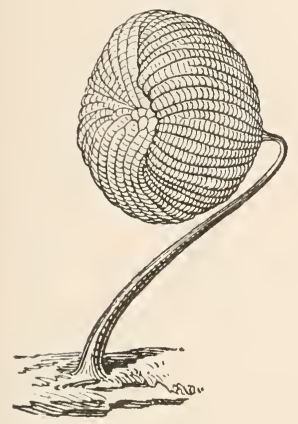

Fig. 127.

Dictydium eancellatum (Batsch) Macbride. Sporangium mit geschwumlener Wandumg $(35,1$.$) - Nach Jahn.$ wand aut der Innenseite verdickt in Gestalt zahlreicher $(40-50)$, vom stielansatz nach oben meridianartig verlaufender Rippen, welche mittelst zarter Querfäden unter einander leiterartig verbunden sind: die längsrippen am sporenentlassenden Sporangium, von dessen $\mathbb{V}$ and alsdann nur am Grumcle oberhalb des stielansatzes eine kleine. runde Wandscheibe erhalten bleibt. sind oben \pm tief einwärts gekrümmt. sodab das Rippennet\% in der Regel oben einwärts genabelt ist. Sporen im durchfallenden Lichte blaßrot, fein warzig, 4-7 $\mu$, mit zerstrenten, 2-4, Granulationen (Dictydinkörnern) auf der sporenwand.

Über den Aufban der Spangen oder Längsleisten und der zarten, die Spangen verbindenden Querbricken geben uns die sehr sorgfältigen Untersuchungen I ahn's (Ber. Deutsch. Bot. Gies. XIX (1901), 97) AufschluB. „Man sieht", sagt Jahn, „die Membran der Plasmakngel. die sich zur Sporangiumbildung anschickt, an den Meridianlinien, wo die Spangen entstehen sollen, sich nach außen ausbauchen. Dichteres, an Dictydinkörnern reiches Plasma scheint an der Faltung und Verdickung der Membran an diesen Stellen beteiligt zu sein. Der durch die Faltung entstandene und deutlich sichtbare Hohlraum ist nach innen durch eine zarte Membran, an der Dictydinkörner kleben, abgeschlossen. Die Spangen sind also ursprünglich hohl. Die zarten Querleisten zwischen den Spangen sind nur Verdickungen der Plasmahaut und in der Regel nicht mit Dictydinkörnern besetzt. Bei einem reifen Sporangium von Dictydium sind die 
Körnchen der Innenseite der Spangen angeklebt. Sie bilden dort aber nur eine innere Schicht, während die Spangen selbst aus der gefalteten, verdickten Membran bestehen."

Im ganzen Gebiet iiberaus häufig.

Kosmopolitiseh.

Von Spielarten erwähnt Lister:

var. fuscum Lister in Journ. of Bot. XXXVI (1898), 120, Monogr. ed. 1, 148, pl. LVI, B. fig. c, ed. 2, 185, pl. 147, fig. b.

Sporangien hängend, kleiner und branner als beim Typus, mit wohlausgebildetem Kelchbecher, von dessen Rande ans die Meridianrippen ausstrahlen.

Dentschland (Holstein), Sehweiz.

(irobbritanuien, Schweden, Japan, N.-Amerika, W--Afrika.

var. anomalum (Jahu) Schin\%.

Synonyme: Dictydium anomalum Jahn in Ber. Deutseh. Bot. Lies. XIX (1901), 99; Meylan in Bull. Soc. Vaud. Sc. nat. 5 me sér. XLIV (1908), 295 nnd in Bull. Soc. Bot. Genève 2 me sér. II (1910), 265.

Heterodictyou mirabile Rost. Monogr. (1875), 231.

Cribraria mirabilis Massee Monogr. (1892), 60.

Dictydinm umbilicatum Schrader var. anomalum Jahı in Ber. Deutsche Bot. Fes. XIX (1901), 115, t. V, fig. 3.

Dictydium cancellatum Macbride var. alpinum Lister Monogr. ed. 2 (1911), 185, ll. 147, fig. f-h.

Sporangien meist aufrecht, braun, mit oder ohne Wandbecher, Meridianrippen 20-30, oberwärts sich verästelnd und so ein unregelmäßiges Cribrarianetz bildend. Stiel gegen das Sporangium zu nicht oder kaum verjüngt.

Dentschland (Berlin), Schweiz (Jura, Arosa).

N.-Amerika und sicherlich auch noch anderwärts.

S'chrader's Dictydium venosum (Schrader Nov. gen. pl. [1797], 14, t. III, fig. 6) dürfte wohl, wie J ahn (Ber. Dentsch. Bot. Ges. XIX [1901], 100) mit Recht vermutet, einer weiteren Form dieser vielgestaltigen Art entsprechen, die aber seit Schrader keine weitere Beachtung mehr gefunden zu haben scheint, es sei denn, daß eine von Jahn (I. c.) erwähnte, in wechselnder Menge unter der Spielart fuscum auftretende Form mit jener 
identisch ist. "Hier", sagt $\mathrm{J}$ a h $\mathrm{n}$, , ist der Napf nicht zusammenhängend entwickelt, sondern in etwa vier dreieckige Lappen gospalten, von denen die Spangen symmetrisch gekrümmt abgehen, etwa wie die Hanptnerven vom Mittelnerv eines Dikotylenblattes.

Die so entstehende Keichnnng erinnert ganz an die Form eines Sporangiums, die 1797 Schrader als eigene

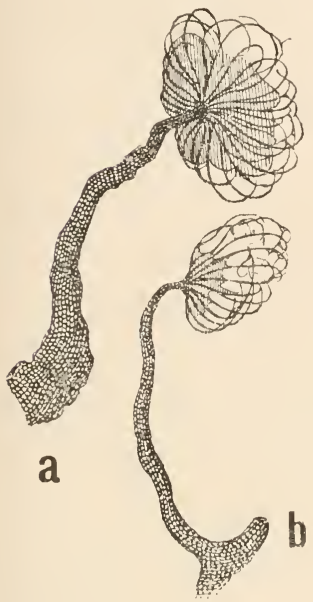

Flg. 128.

Dictydium cancellatum (Batsch) Macbride var. anomalum (Jahu) schinz.

a) und b) sporangien mit uuregelmäBigem Netz $\left({ }^{70} / 1\right)$.

- Nach Lister. Art in seiner für die Systematik der Cribrariaceen grundlegenden Schrift (oben erwähnt) unter dem Namen. Dictydium venosum beschrieben nnd abgebildet hat. Sie hat seitdem niemand wieder gesehen. Die Abbildung und die Beschreibung (stipes gracilis, flexuosus, fuscescentis coloris. Peridium cernuum, paulo minus ac in Dictydio umbilicato) lassen kaum einen Zweilel, daß es sich um eine Form von Dictydium fuscum handelt."

Me y lan hat sich mehrfach (Bull. soc. Vaud. Sc. Nat. 5 me sér., XLIV [1908], 295 und Bull. Soc. Bot. Genève 2 me sér. II $[1910], 264)$ mit der Gattung Dictydium beschäftigt; am «weiterwähnten Orte betont er hauptsächlich, im Gegensatz zur Auffassung Torrend's (Broteria VII [1908], 12), daß der sogenannte Calyculus, d. h. der Wandbecher nicht als Hauptcharakter zur Unterscheidung der Spielarten verwertet werden könne, da es keineswegs selten sei, dab in einer Ansammlung von Sporangien die Hälfte derselben einen Calyculus aufweise, wogegen die andere Hälfte entweder eines solchen entbehre oder nur Rudimente aufweise. Auf Grund seiner eingehenden Untersuchungen stellt Meylan nachstehenden Varietätenschlüssel auf, dem wir gerne den Vorzug vor Torrend's Versuch einräumen: 
1. Sporangien nickend, oben mit nabelartigem Eindruck.

2. Sporen purpurfarbig.

3. Ohne Wandbecher.

4. Stiel lang: Netz regelmäBig.

var. genuinum Torrend.

4*. Stiel kurz; Net\% unregelmäBig.

var. purpureum Macbride.

$3^{*}$. Mit 11 andbecher.

var. exilis (Macbride) Torrend.

2*. Sporen braun.

5. Ohne Wandbecher.

var. fuscum Lister forma.

$5^{*}$. "Iandbecher vorhanden.

6. Net\% regelmäbig. var. fuscum Lister.

$6^{*}$. Net\% unregelmäBig.

forma renosum (Schrader) Torrend.

$1^{*}$. Sporangien aufrecht, nicht genabelt, mit (ribraria-Netz im obern Teil.

7. Sporen purpurfarbig.

8. Wandbecher fehlend: Net\% regelmäßig, mit Querfäden zwischen den Längsrippen.

var. genuinum (Merlan).

8*. Wandbecher vorhanden; Netz unregelmäBig, Längsrippen frei. verästelt.

var. heterodictyon (Rost.).

$7^{*}$. Sporen lirann.

9. Ohne W'andbecher; Netz im untern Teil ziemlich regelmäßig.

var. cribrarioides (Meylan) forma.

$9^{*}$. Mit Wandbecher; Netzrippen verästelt und anastomosierend, mit häufig verbreiterten Knoten.

var. cribrarioides (Meylan). 


\section{Familie Liceaceae Rost.}

Versuch eines Systems der Mycetozoen (1873), 4 und Monogr., 218; Schröter in Cohn Krypt.-Fl. Schles. III, 1, 102 pr. p. and in Engler und Prantl Natürl. Pflanzenfam. I, 1, 16 pr. p.; Lister Monogr. ed. 1, 22 und 149, ed. 2, 22 und 186; Schinz in Mitt. Naturw. Ges. Winterthur VI, 87; Torrend in Broteria YI, 43, VII, ว.

Sporangien oder Plasmodiokarpien bildend; Sporangiumwand meist pergamentartig, nur selten häutig. Capillitium und Columella fehlend.

\section{Schlïssel zur Bestimmung der Gattungen der Familie der Liceacear.}

1. Entweder sitzende, + kugelige Sporangien oder Plasmodiokarpien

Licea Schrader.

1*. Sporangien gestielt, sich öffnend durch Abwerfen eines häutigen Deckels

Oreadella Wingate.

\section{Übersicht der Gattungen.}

Licea. S'porangien ungestielt, kugelig, halbkugelig oder Plasmodiokarpien. Sporangiumwand pergamentartig, bei L. biforis häntig. Sporen entweder nahezu farblos, olive- oder lilabraun.

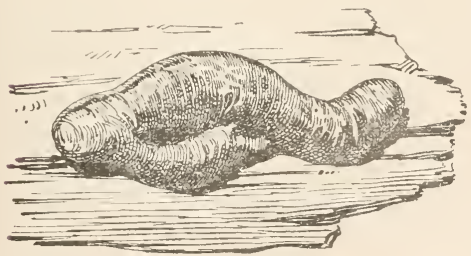

Fig. 129 .

Licea flexuosia Pers. Plasmodiokarp $\left({ }^{20} / 1\right)-$ Original.

Orcadella. Sporangien gestielt. Sporangiumwand undurchsichtig. mit Granulationen besetzt mit Ausnahme der obern, einen häutigen, flachen Deckel bildenden Partie. 


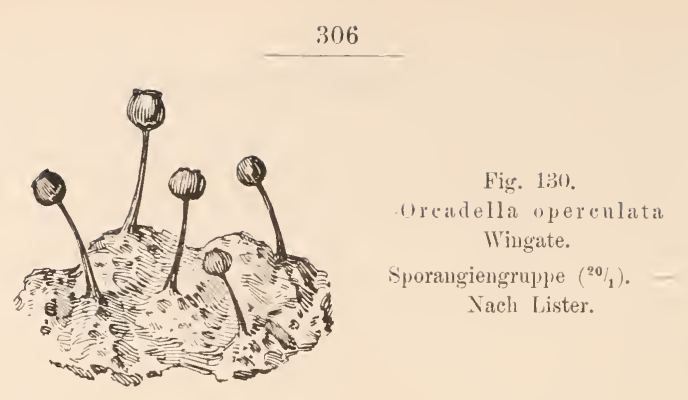

\section{Gattung: Licea Schrader}

Nov. Gen. Pl. (1797), 16; Rost. Versuch eines Systems der Mycetozoen, 7 und Monogr.. 218; Rabenhorst Dentschl. Krypt.-Fl. 1, 263 pr. p.: Schröder in Engler und Prantl Natïrl. Pflanzenfam. I, 1. und in Cohn Krypt.-Fl. Schles. III, 1, 102; Lister Monogr. ed. 1, 150, ed. 2, 187; Macbride N. Am. Slime-Moulds, 145: Schin\% in Mitt. Naturw. Ges. Winterthur VI.; Torrend in Broteria VI, 43 und V'II, 5.

1. Sporangiumwand pergamentartig, nicht häutig.

2. Sporangien halbkugelig, mit Lappen aufspringend; Sporen braun, 9-12 ".

L. minima Fries Syst. Myc. III (1829), 199; Rabenhorst 1)eutschl. Krypt.-Fl. 1, 263; Lister Monogr. ed. 1, 150, pl. LV'II. A, fig. d-h, ed. 2, 187, pl. 148, fig. d-f; Macbride $\mathrm{N}$. Am. Slime-Moulds, 148; Torrend in Broteria VII, 6, pl. I, fig. 2.

synouyme: Tubulina minima Nassee Nonogr. (1892), 36.

Kleistobolus pusillus Iippert in Verl. Zool.-Bot. Ges. Wien XLIV (1894), 70, t. Ill, fig. $1-2$.

Plasmodium gelb. Sporangien \%erstreut. halbkugelig, mit breitem Grunde, etwas niedergedrückt, braun bis nahezu schwar\%, $0,2-0,5 \mathrm{~mm}$ im Durchmesser, zur Zeit der sporenreife mittels 3 bis 4 Lappen sich öfnend. Sporanginmwand dunkelbraun. undurchsichtig, mit Ausnahme der Räuder der Lappen mit feinen Granulationen besetzt; Lappenränder innenseits gefleckt. Sporenmasse rötlich bis dunkelbraun. Sporen im durchfallenden Lichte olivebraun oder lilabraun, fein stachelig, 9-12 ", Exine einseitig verdïnnt.

Dentschland, Oesterreich, Schweiz (Arosa, Jura). Rußland, Skandinavien, Portıgal, N.-Amerika. 
$2^{*}$. Sporangien \pm kugelig oder an deren Stelle polsterförmige Plasmodiokarpien, mittels Lappen sich öffnend; Sporen im durchfallenden Lichte fast farblos, $8-10 \mu$.

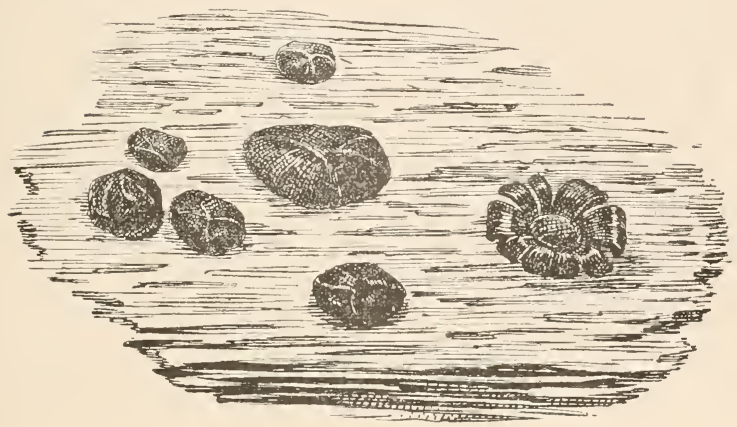

Fig. 131. Licea minima Fr.

Sporangiengruppe, eines der Sporangien mit zurückgeschlagenen Lappen $\left({ }^{50} / 1\right)$. - Nach Lister.

L. castanea Lister in Journ. of Bot. XLIX (1911), 61 et Monogr. ed. 2. 188.

Sporangien zerstreut. \pm kugelig oder $0,2-0,9 \mathrm{~mm}$ lange und $0,2-0,4 \mathrm{~mm}$ breite, polsterförmige, kastanien- oder blaßbraune. glatte oder gefältelte Plasmodiokarpien, Sporangiumwand oft mit einer lïckenlosen schicht bramner Granulationen belegt, längs vorgezeichneter Dehiszenzlinien in Lappen oder Platten aufspringend. Sporenmasse olivegelb, im durchfallenden Lichte die Sporen nahezu farblos, 8-10 $\mu$; die Exine einseitig verdünnt.

Sehweiz (Jura).

Grobbritannielı.

$2^{* *}$. Sporangien kissenförmig, mittels Lappen sich öffnend; Sporen $16-20 \mu$.

L. pusilla Schrader Nov. Gen. Pl. (1797), 19, t. IV, fig. 4; Lister Monogr. ed. 1, 151, pl. LV'll, B, fig. a-ce, ed. 2, 188, pl. 149, fig. a-c; Macbride N. Am. Slime-Moulds, 148: T'orrend in Broteria VII, 6, pl. 1, fig. 4. 
Synonyme: Physarum Licea Fr. Syst. Myc. III (1829), 143; Rabenhorst Deutschl. Krypt.-Fl. I, 273.

Protoderma pusilla Rost. Monogr. (1875), 90; Schröter in Cobn Krypt.-Fl. Schles. III, 1, 103.

Protodermium pusillum Berl. in Sace. syll. I11 (1888), 328:

Massee Monogr., 43.

T'ubulina pusilla Poiret in Lam. Encyel Vill (1808), 131.

Sporangien zerstrent, halbkugelig oder kissenförmig, 0.6-1 mm breit und ebenso lang, dunkelpurpurbram, glänzend anf der Innenseite, unregelmäBig in Lappen aufspringend. Sporangiumwand kastanienbraun. Lappenränder gewöhnlich gekerbt oder wellig. Sporenmasse schwarz. Sporen im durchfallenden Lichte olivefarbig. $16-20, \mu$, dicht- und fein warzig: Exine einseitig verdünnt.

Dentschland, Schweiz.

schottland, Schweden, Ríßlaul, Iiumänien.

***:**. Verlängerte, $2-4 \mathrm{~mm}$ lange. unregelmäßig sich öffnende Plasmodiokarpien.

L. flexuosa Pers. Syn. Fung. (1801), 197, t. I, fig. 5. 6: Rabenhorst Deutschl. Krypt.-FI. I, 264: Rost. Monogr., 218; Schröter in Cohn Krypt.-Fl. Schles. III, 1, 102; Lister Monogr. ed. 1. 150, pl. LVII. A, fig. a-c, ed. 2, 189, pl. 148, fig. a-c; Schinz in Mitt. Naturw. Ges. Winterthur VI, 88; Torrend in Broteria VII, 7, pl. I, fig. 6.

Synonyme: ? Licea variabilis Schrater Nov. Gen. PI. (1797), 18, t. I1. fig. 5, 6; Rabenhorst Dentschl. Krypt.-FI. I, 264; Lister Monogr. ed. 1, 151; Maciride $\mathrm{Y}$. Am. Slime-IIonlds, 146, pl. XI1, fig. 7; Schinz in Mitt. Naturw. (ies. Winterthur W1, or; 'Torrend in Broteria VII, 7, [1. I, fig. 5.

T'ubulina variabilis Poiret in Lam. Enerel. VIII (1808), 130.

T'ubulina Hexuosa Poiret in Lam. Fneycl. IIII 1s0s), 131; Nassee Monogr, 37.

Licea Serpula Fr. Symb. (iast. (1817), I2; Liabenhorst Dentschl. liry pt.-Fl, 1, 264

? licea alutacea Wallr. Fl. Krypt. Trem. (1833), :344: Rabenhorst Dentschl. Krypt-Fl., 1, 263

? Licea Schönleinii Johow Esturl. Fl. Jnan Fernand. (1896), 195? Exsikkaten: Jaap, Myxom Exsice. 75, 137, 160. 
Plasmodium dunkelgelb oder rosarot. Plasmodiokarpien zerstreut, niedergedrückt kissenförmig, wurmförmig gekrïmmt oder gestreckt und 1-6 mm lang, oft ringförmig in sich zurïcklaufend, mitunter verästelt, glänzend braun oder dunkelbraun: Peridie pergamentartig, durchscheinend, blaßpurpurbraun, gewöhnlich von einer Schicht aus olivebraunen, ausgestoßenen Granulationen iiberkleidet, unregelmäßig sich öfnend, Sporenmasse gelblichbraun. Sporen im durchfallenden Lichte blaßolivebrann, fein stachelig, $2-14 \mu$.

Dentschland, Österreich, schweiz, (Mïrren, Thun, Jura).

Großbritanien, Frankreich, Skandinavien, Rußland, Rumänien, Afrika, Java.

Macbride und Torrend betrachten Licea variabilis und flexuosa als verschiedene Arten und zwar auf Grund der Sporenfarbe, die bei variabilis hellgelb oder gan\% blab, bei flexusa olivebraun sein soll. Die Entscheidung für die eine oder andere Auffassung bleibt weiteren Untersuchungen vorbehalten.

$1^{*}$. Sporangiumwand häutig, fein papillös, mit Granulationen. Plasmodium zuerst wässerigweiß, dann schmutriggrau und schließlich blabkupferfarbig. Plasmodiokarpien $\pm 0,2 \mathrm{~mm}$ lang und $\pm 0,1 \mathrm{~mm}$ breit, $d u r c h$ einen Längsriß sich öffnend. Sporenmasse blaßockerfarbig. Sporen im durchfallenden Lichte \pm fast farblos, glatt, \pm eiförmig, $12 / 9 \mu$; Exine einseitig verdünnt.

L. biforis Morgan Myx. Miami Valley (1893), 5, fig. 1; Macbride N. Am. Slime-Moulds, 147, pl. XII, fig. 5; Lister Monogr. ed. 2, 189, pl. 149, fig. $g-k$ und in Journ. of. Bot. XLIII, 135.

N.-Amerika, Japan.

\section{Gattung: Orcadella Wingate}

in Proc. Acad. Nat. Sc. Phil. (1889), 280; Massee Monogr., 49; Lister Monogr. ed. 1, 152, ed. 2, 190; Macbride N. Am. SlimeMoulds, 158; Schinz in Mitt. Naturw. Ges. Winterthur VI, 88; Torrend in Broteria VI, 43, VII, 8. 
Mit nur einer Art:

O. operculata Wingate in Proc. Acad. Nat. Sc. P'bil. (1889), 280 mit Fig.; Massee Monogr., 49, fig. 201; Lister Monogr. ed. 1, 152, pl. LVII, B, fig. d-f, ed. 2, 190, pl. 149, fig. d-f; Macbride N. Am. Slime-Moulds, 158. pl. XII, fig. 11; Torrend in Broteria VII, 8, pl. I, fig. 10.

Plasmodium? Sporangien samt Stiel 0.4 bis $0,9 \mathrm{~mm}$ hoch, zerstreut, urnenförmig oder nahezu kugelig, dunkelbraun oder schwärzlich, gestielt und aufrecht, 0,1 bis $0,3 \mathrm{~mm}$ im Durchmesser. mit einfacher, dicker Sporangiumwand und mit einem auswärts gewölbten oder kuppenartigen, zarten, dünnhäutigen, gelblichund metallisch glänzenden, frühzeitig abfallenden Deckel versehen. Stiel \pm walzlich oder pfriemlich, gefurcht, \pm schwarz, eingefüllt mit AusschuBmaterial. Sporenmasse gelblich; Sporen im durchfallenden Lichte fast farblos, glatt, kugelig, 8-11 $\mu$.

Deutschland (Holstein).

(irobbritamien, N.-Amerika.

\section{Familie Tubulinaceae Lister}

Monogr. ed. 1 (1894), 152, ed. 2, 190; Schinz in Mitt. Naturw. Ges. Winterthur V1, 89.

Sporangien gehäuft, zylindrisch oder ellipsoidisch. sitzend oder gestielt. Sporangiumwand häutig, blaßrotbraum, ohne plasmatische Granulationen.

\section{Schlïssel zur Bestimmung der Gattungen der Familie der Tubulinaceae.}

1. Sporangien zylindrisch, zu sehr vielen dicht gedrängt.

Tubifera Gmelin.

1*. Sporangien zи 4 bis 8 gebüschelt, ellipsoidisch.

Alwisia Berkeley et Broome.

\section{Übersicht der Gattungen.}

Tubifera. Sporangien zylindrisch, zu sehr vielen dicht gedrängt, seitlich kantig, von prismatischer Gestalt, mit oder ohne Columella. ohne Capillitium. 


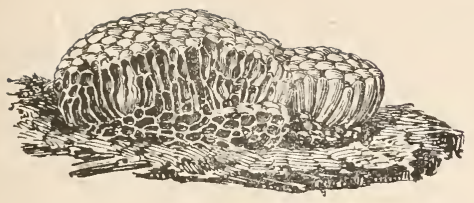

Fig. 132.

T'ubifera ferruginosa

(Batsch) Gmelin.

sporangieuhaufen auf schwanmiger Basis ( $\left.{ }_{i 1}\right)$. - Nach Iister.

Alwisia. Sporangien ellipsoidisch, gestielt und zu wenigen, 4 bis 8, gebïschelt. Sporangiumwand oberwärts hinfällig, beim schwinden eine steife Bürste von Capillitiumfäden freilegend.

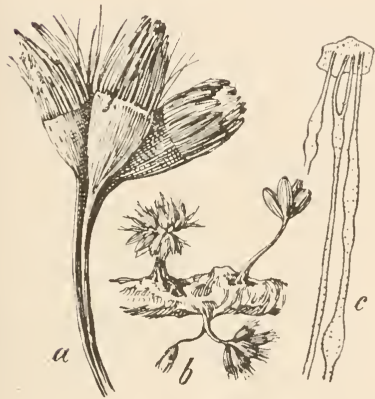

Fig. 133.

Alwisia Bombarda

Berkeley et Broome.

a) eine Gruppe von 3 Sporangien; der obere Teil der Peridie ist entfernt, dafür treten die Capillitiunfäden zutage $\left({ }^{20} / 1\right)$; b) 3 Sporangiengruppen $\left({ }^{5}{ }_{11}\right)$; c) oberes Ende dreier, an iler Peridie befestigter Capillitimmfärlen $(160 / 1)$. Nach Lister.

\section{Gattung Tubifera Gmelin}

Syst. Nat. II (1791). 72; Nacbride N. Am. Slime-Moulds, 155; Lister Monogr. ed. 2, 191: Torrend in Broteria VI. 45 und VII, 21.

Sporangien zylindrisch, in großer /ahl dicht gedrängt auf gemeinsamem Hypothallus, \pm blaß rotbraun; Sporangiumwand dünn, apikal schwindend.

1. Sporangien einer Columella entbehrend. 
2. Sporangien auf breitem Hypothallus dicht gedrängt; Sporen 5-8

T. ferruginosa (Batsch) Gmelin Șrst. Nat. II (1791), 1472: Macbride N. Am. Slime-Moulds, 156, pl. I, fig. 4, pl. VII, fig. \&. pl. XII, fig. 14; Lister Monogr. ed. 2. 191, pl. 150. tig. a-c; Torrend in Broteria VIl, 22, pl. II, fig. 2-6.

Synonyme: Tubulifera ceratum Miill. Fl. Wan. (1777), t. 659, tig. 2? Stemonitis ferruginosa Batsch Elench. Fung. (1786), 261, fig. $113,175$.

T'ubulifera aranchnoidea. Jacq. Hisc. I (1778), 144, t. 15?

Lycoperdon Havaceum Schrauk Baier. Fl. II (1789), 667.

Sphaerocarpus cylindricus Bull. Champ. (1791), 140, t. 470, fig. 3. Tubifera cyliudrica Gmel. Syst. Nat. (1791), 1472.

T'ubifera fragiformis (imel. syst. Nat. (1791), 1472.

sphaerocarpus fragiformis Bull. Champ. (1791), 141, t. 384.

Trublina fragiformis Pers. in Roem. X. Mag. I (1794), 91; Rabenhorst Deutschl. Krypt.-FI. I, 264: Lister Monogr. erl. 1, 1 is. pl. LVIII, A, fig. a-c; Schinz in Mitt. Naturw. (ies. Winterthur VI, 89.

T'ubulifera coccinea T'rentep. in Roth ('at. Bot. I (1797), 24:3.

Licea clavata Schrader Nov. Gen. PI. (1797), 18.

Licea Tubulina Schrader Nov. Gen. PI. (1797), 16.

Tubulina fallax Pers. (Observ. Nye. II (1799), 28.

Tubulina fragifera Poiret in Lam. Encyel. 11 (1804), 130.

T'ubnlina eylindrica DC. FI. Frane. II (1805), 249; Rabenhorst Deutschl. Krypt.-Fl. 1, 264; Rost. Monogr., 220, fig. 1-6: Massee Monogr., 39; Celak. Myxom. Bïhm, 17; sihröter in Coln Krypt.-FI. Schles. III, 1, 102.

Licea fragiformis Nees syst. (1816), 107.

Licea eylindrica Fr. Syst. Hyc. III $(1829), 195$.

Licea irieslor Zollinger in Flora XXY (1847), 300.

Tubulina conglobata Prenb in limmaea XXIV (1851), 140.

Licea rubiformis Berkeley et Curtis in Proc. Am. Acad. Arts ant Se. IV $(1860), 125$.

Licea microsperma Berkeley et Curtis in Grer. II (1873), 68.

Tubnlina nitidissima Berkeley in Journ. Limn, Soc. XVIII (1881), 387.

Tubulina speciosa Speg. in Atti soc. Critt. Ital. ser. 2, III (1881), 62.

Exsikkaten: Sydow Myc. March. 1498; Fuckel Fungi rhen. 1470; Jaap. Myxom. exsice. 36; Hofmus. Wien, Krypt. exsiccatae 404 .

Plasmodium wässerigweiß, selten leuchtend gelb, zur Zeit der Sporangienbildung in eine fleischrötliche oder scharlachrote 
Färbung äbergehend. Einzelsporangien zylindrisch, am Scheitel abgerundet, auf einem glänzenden Hypothallus, zu sehr vielen dicht gedrängt. infolge des gegenseitigen seitlichen Druckes prismatisch, $3 \mathrm{~mm}$ lang und $0,4 \mathrm{~mm}$ breit, rötlichbraun bis dunkelbraun, einen bramroten, $2-7 \mathrm{~cm}$ breiten, wabesähnlichen Fruchtkörper bildend. Sporenmasse rostfarbig. sporen im durchfallenden Lichte blabrostbraun, dicht- und fein netzartig skulptiert ïber dem größern Teil der śporenoberfläche, zum kleinern Teil nahezu glatt oder mit unterbrochenen Leisten versehen, $5-8 \mu$.

Dentschland, Oesterreich, Schweiz; überall sehr hänfig.

Kosmopol.

2*. Siporangienzu vielengedrängt und gebüschelt auteinem sich zu einer 2 bis $3 \mathrm{~mm}$ hohen säule erhebenden, dunkelbraunen, \pm schwammartigen Hypothallus. Einzelsporangien mit abgerundeten obern Enden und sehr dünner Peridie. Sporenmasse dunkelbraun. Sporen im durchfallenden Lichte blabrostbraun, $3-5$ r. Im Uebrigen durchaus mit, voran-1 - stehender Art iilereinstimmend.

T. stipitata (Berkeley et Rav.) Macbride N. Am. Slime-Moulds (1899), 157; Lister Monogr. ed. 2. 192, pl. 150, fig. d-e.

Synonyme: Licea stipitata Berkeley et Rav. in Proc. Ami. Ac. Arts and se. IV (1860), 125 .

Tubulina stipitata Rost. Monogr. (1875), 223, fig, 2; Massee Monogr., 38; Lister Wonogr ed. 1. 154, pl. LWIII, A, fig. d-e.

Tubifera fermginosa (Batsch) (imel. var. stipitata Torrend in Brot. VII (1908), 2.2.

Ceylon, Java, Japan, N.- und S.-Amerika, Westindien.

$1^{*}$. Sporangien dicht gedrängt, prismatischwalzlich, der Länge nach von einer hohlen Pseudokolumella. durchzogen, die mittelstzahlreicher röhren-oder bandartiger Querversteifungen mit der Peridie verbunden ist. Sporenmasse dunkelbraun oder 
umbrabraun. Sporen im durchfallenden Lichte blaßrosthraun und deren ()berfläche zum größern Teil mit dichtnetzartiger, zum kleinern Teil mit lockernetzartiger Skulptur, 6-7

T. Casparyi (Rost.) Macbride N. Am. Slime-Monlds (1899). 157, pl. XII, fig. 9; Lister Monogr. ed. 2, 193, pl. 150, fig. f-h und in Trans. Brit. Myc. soc. (1914). 80; Torrend in Broteria VII 22, pl. II, fig. 7 .

Synonym: Siphoptyehium Casparyi Rost. Monogr. App. (1876), 32, fig. 245; Massee Monogr., 89, fig. 111; Lister Monogr. erl. 1. 155, pl. LVIII, A, fig. f-h.

Schweden, N.-Amerika, Guyana, Japan,

\section{Gattung Alwisia Berkeley et Broome}

in Journ. Linn. Soc. XIV (1873), 86: Lister Monogr. ed. 1, 155, ed. 2. 193; Torrend in Broteria VI, 45. VII, 23.

Mit nur einer, bis jetzt nur aus den Tropen bekannten Art:

A. Bombarda Berkeley et Broome in Journ. Linn. Soc. XIV (1873), 87; Lister Monogr. ed. 1, 156. pl. LVIII, B. fig. $\mathrm{a}-\mathrm{f}$, ed. 2, 193, p]. 151, fig. a-f und in Journ. of. Bot. XLIII, 135; Fischer in Mitt. Naturf. Ges. Bern (1906) (1907), 121. fig. 11-14; Torrend in Broteria VII, 24, pl. II, fig. 8, 9.

Synonyme: Trichia fragilis Rost. Nonogr. App. (1876), 39 pr. p. Prototrichia Bombarda Massee Monogr. (1892), 128.

Plasmodium? Sporangien zu $4-8-12$ mit ihren $2,5 \mathrm{~mm}$ langen und $0,15 \mathrm{~mm}$ dicken bräunlichroten, zylindrischen Stielen gebüschelt, zylindrischellipsoidisch, $1-1,5 \mathrm{~mm}$ lang, rotbraun. Sporangiumwand häutig, oberwärts schwindend, unterwärts bleibend, innenseits mit kleinen Granulationen besetzt. Vom Grunde des Sporangiumbecher's erhebt sich ein Büschel schlanker, gerader, meist nur unterwärts verzweigter und daselbst oft durch Querbrücken anastomosierender, oberwärts mit den Spitzen an dem hinfälligen sporangiumende befestigter, glatter oder stacheliger, 
mitunter mit länglich blasigen Ansehwellungen versehener Capillitinmfäden. Sporen im durchfallenden Lichte blabrötlichbraun, ungefähr $2 / 3$ der Sporenoberfläche netzartig skulptiert. 5-6 «. (eylon, Jamaica.

\section{Familie Reticulariaceae Rost.}

Yersuch eines Systems der Mycetozoen (1873), 6 und Monogr., 241 em. Lister Monogr. ed. 1, 156, ed. 2, 194: Macbride N. Am. Slime-Moulds, 149; Schin\% in Mitt. Naturw. Ges. Winterthur 11, 91: Torrend in Broteria VII, 23.

Sporangien dicht gedrängt, in der Regel Aethalien bildend. Sporangiumwände unvollständig durchbohrt oder ein unechtes Capillitium bildend; ein echtes Capillitium nur bei Liceopsis.

\section{Schliissel zur Bestimmung der Gattungen der Familie der Reticulariaceae.}

1. Sporangien Aethalien (oder bei Enteritium olivaceum var. gestreckte oder net\%artige Plasmodiokarpien) bildend.

2. Sporangien säulenförmig prismatisch, mit kuppelartigen apikalen Enden

Dictydiaethalium Rost.

2*. Sporangien nicht säılenförmig.

3. Wand der Einzelsporangien durchbohrt, ein System von Platten bildend. Enteridium Ehrenberg.

$3^{*}$. Wand der Einzelsporangien in anastomosierende Strähnen und Fäden aufgelöst.

Reticularia Bulliard.

1*. Einzelsporangien oder Plasmodiokarpien.

Liceopsis 'Torrend.

\section{Uebersicht der Gattungen.}

Dictydiacthalium. Aethalium flach, von aufrechten, säulenförmigen Einzelsporangien gebildet. Sporangiumwand am apikalen Ende kuppelförmig und abwärts fortgeset»t in Form von 5 oder 6 geraden Fäden. Ohne Capillitium. 


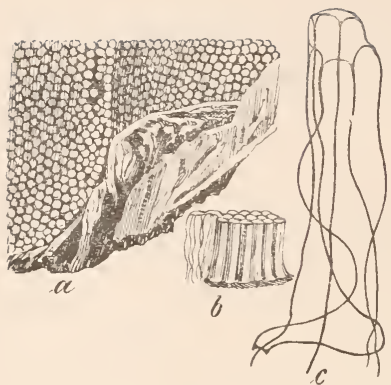

Fig. 134

I)ictydiaethalium plumbeum (Schum.) liost

a) Aethalium rom oben gesehen $\left({ }^{20}{ }_{11}\right)$ : b) Ausschnitt aus einem Aethalium, zwei der sporangien mit eutlassenen sporen $(20 / 1)$; c) ein einzelnes Sporanginm mit Kappe und Kantenfärlen $\left({ }^{50}{ }_{11}\right)$. - Nach Lister.
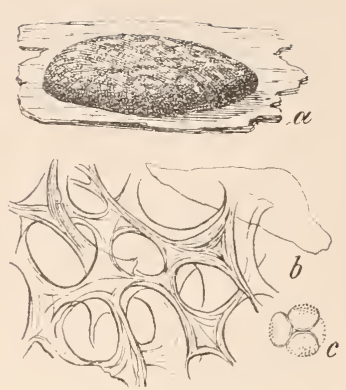

Fig. 135.

Euteridium olivacenm Ehrenberg.

a) Aethalium $(1 / 1)$; b) durchbohrte suorangiumwände $\left({ }^{80} / 1\right)$; c) Sporengruppe $\left({ }^{550} / 1\right)$. - Nach Lister.

Enteridium. Aethalien ans zusammenfließenden, unter einander verwobenen Sporangien hestehend. Sporangienwände mit groben Durchbrechungen. Ohne Capillitium.

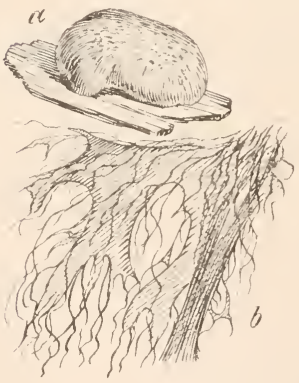

Fig. 136 .

Reticularia Lyeoperdon (Bull.).

a) Aethalium $(1 / 2)$; b) ('apillitimm $(100 / 1)$. Nach Lister.

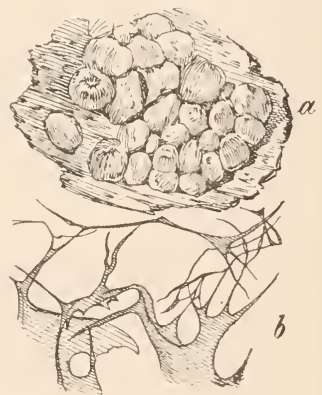

Fig. 137.

Liceopsis lobata (Lister) Torrend.

a) Sporangiengruppe $(s / 1)$; b) (apillitium $\left({ }^{60} / 1\right)$; - Nach Lister. 
Reticularia. Aethalium aus zatrlreichen, verlängerten, verwobenen Sporangien bestehend, deren Wandungen zum Teil schwinden, zım 'Teil erhalten bleiben als Platten und strähnen, die in zarte capillitiumartige Fäden auslaufen.

Liceopsis. Sporangien keine Aethalien bildend, dicht gedrängt, kugelig, mit zerbrechlichen $\mathbb{W}$ andungen. ('apillitium entweder fehlend oder aus schlanken, verzweigten Fäden oder Strähnen mit häutigen Verbreiterungen in den V'erweigungswiukeln bestehend.

\section{Gattung: Dictydiaethalium Rost.}

Versuch eines Systems der Mycetozoen (1873), 5; Lister Monogr. ed. 1, 157, ed. 2, 196: Macbride N. Am. Slime-Moulds, 152; Schinz in Mitt. Naturw. Ges. Winterthur YI, 91; Torrend in Broteria VI, 43. VII, 10.

Mit nur einer Art:

D. plumbeum (Schum.) Lister Monogr. ed. I. 157, pl. LXXVI, B, fig. a-k, ed. 2, 197, pl. 15\%, fig. a-k; Macbride N. Am. Slime-Moulds, 152, pl. I, fig. 2, 2a, 2b; Schinz in Mitt. Naturw. Ges. Winterthur VI, 91; Torrend in Broteria VII, 10, pl. I, fig 14,15 .

Syuonyme: Fuligo plumbea schum kinm Pl. Saell. II $(1803,193$.

Reticularia plumbea Fr. Syst. Hyc. III (1829), 88; Rabenhorst Dentschland Krypt.-Fl. I, 255.

Licea mgulosa Wallr. Fl. Krypt. Germ. II (1833), 345.

Licea applanata Berkeley in Hook. Lond Journ. of Bot. IV (1845), 67. Lycogala lenticulare Dur. et Hont. in Exil. Scient. de l'Algérie $(1846,401$.

lieticularia entuxantha Berkeley in Hook. Joum. of Bot. III (1851), 201.

Dictydiaethalium applanatım Rost. in Fuckel Symb. Myc. Nachtr. (1873/74), 69 .

Reticularia lurida Berkeley et Broome in Jomru. Limm. Soc. XIV $(1873), 82$.

Licea cimmabarina Berkeley et Broome in Journ. Limm. Suc. XII (1873), 86

Licea tenuissima Berkeley et Broome in Journ. Limm. Soe. XIV (1873), 86 . 
Synouyme: Clathroptychium rugulosum Rost. Monogr. (1875), 225, fig. 25, 28, 29, 30; Schröter in Cohn Kirypt.-Fl. Schles. III,

1. 104; Čelak. Myxom. Böhmı., 19; Massee Monogr., 51, tig. $25-28$.

Dictydiaethalium dissiliens Hazslinsky in Uest. Bot. Zeitschr. XXVII (1877), 85.

Clathroptychium cimnabarium sace. in Michelia I (1879), 545; Massee Mologr., 53.

('lathroptychium Berkeleyi Massee Momogr. (1892), 53.

Clathroptychium dissiliens Massee Monogr., (1892), 53.

Ophiuridium dissiliens Hazslinsky in Oest. Bot. Zeitsehr. XXVII (1877), 84.

Plasmodium rosarot. Aethalium niedrigpolsterförmig, nahezu Hach, lehmfarbig. Sporangien aufrecht, $0,5-1 \mathrm{~mm}$ hoch, $0,2 \mathrm{~mm}$ breit, vier- bis sechsseitig, infolge gegenseitigen Druckes prismatisch. Peridie am apikalen Ende kuppelartig gewölbt, seitlich fichlend und an deren stelle ersetzt durch vier bis sechs die Kanten gewissermaßen ersetzende. gerade, unverzweigte Fäden. Sporenmasse lehmfarbig oder dunkelbräunlichgelb. Sporen in durchfallenden Lichte blaßgelb, stachelig, $9-12 \mu$.

Deutsehland, Oesterreich, Schweiz.

Kosmopol.

\section{Gattung Enteridium Ehrenberg}

in Link. Jahrb. Gew. I, 2. Teil (1818), 5ॅ; Rabenhorst Dentschland Krypt.-Fl. I, 254; Rost. Monogr., 227. Schröter in Cohn Krypt.-Fl. Schles. III. 1, 103 und in Engler u. Prantl. Natïrl. Pflunzenfam. I. 1, 18: Čelak. Myxom. Böhm., 18; Lister Monogr. ed. 1, 158, ed. 2, 197; Macbride N. Am. Slime-Moulds, 150; Schinz in Mitt. Naturw. Ges. Winterthur VI, 92; Torrend in Broteria VI, 43, VII, 9.

Aethalium (mit Ansnahme der Plasmodiokarpien bildenden var. liceoides von $E$. olixaceum) ans zusammenflieBenden und verwobeneı, unregelmäbig durcheinander gelagerten, einzeln nicht crkennbaren sporangien bestehend, von einer gemeinsamen Haut überzogen, flach gewölbte, polsterförmige Massen bildend. Seitenwandungen der Sporangien zur \%eit der sporenreife von rundlichen Löchern durchbohrt, ein System anastomosierender Platten bildend. 
1. Sporen warzig, neist zu Gruppen verbunden.

E. olivaceum Ehrenberg in Link Jahrb. Gew. I, 2. Teil (1818), 57, t. I. fig. 5; Rabenhorst Dentschland Krypt.-Fl. I, 254; Rost. Monogr., 227, fig. 5; Schröter in Cohn Krypt.-Fl. Schles. III, 1. 104: C̆elak. Myxom. Bölım., 18; Massee Monogr. 44, fig. 14-18: Lister Monogr. ed. 1, 159. pl. LIX, A, fig. a-c, ed. 2, 197, pl. 153, fig. a-d; Torrend in Broteria VII. 9. pl. I, fig. $11-13$.

Synonyme: Lycoperdon ungulinum Schum. Enmm. Pl. Saell 11 (I $80: 3$, 192 ?

Reticnlaria versicolor Fr. Syst. Orb. Veg. 1 (1825), 147.

lieticularia olivacea Fr. Syst. Myc. III (1829), 89).

lieticularia ungulina Fr. Syst. Myc. III (1829), 89?

Luteridium atrum Prenss in limmea XXIV (1851), 142.

Leticularia applanata Berkeley et Broome in Am. Mag. Nat. Hist. ser. 3 XYlll (1866), i6, t. tig. 3.

Licea olivacea Fuckel Syml, Hyc. (1869), 338.

Licea glomulifera de Bary et Rost. in Alexaudrovicz structure and devel. of the Myxom. (1872), ex Massee Monogr, 45 .

licaethalium olivacenm liost. Versuch eines Systems der Mycetozoen (1873), t.

Lindbladia versicolor liost. ap. Fuckel simb. Nye. Nachtrag II $(1873 / 71), 68$.

Euteridium simulans Rost Monogr. App. (1876), 30.

Enteridium antaretienm sjeg. in Bol. Acad. Nac. Cienc Gord. XI (1887), 36:3.

Linteridium Rostrupii liaunk. in Bot. Tilsskr. XVII (18s9), 106. Enteridiun macrosporum liauk. in Bot. 'Tidsskr. XVIII (1889). 106, t. 2, fig. 1 .

Exsikkaten: Jaay Myxom exsice. 76.

Plasmodinm rosarot. Aethalium flach kissenförmig, $1-30 \mathrm{~mm}$ breit und $1-3 \mathrm{~mm}$ dick, glatt oder höckerig, dunkelolivebraun, oft glänzend. Sporangiumwände gelblicholivefarbig. mit großen Löchern versehen, sodaß ein weitmaschiges Netz mit breiten Maschenwänden entsteht. Sporen gruppenweise zu to his 20 verbunden, mitunter anch einzeln, im durchfallenden lichte blaßolivefarbig, bilateral, mit einer stark gewölbten. größeren, breite. stumpfe Warzen tragenden -- und einer nur mäBig gewölbten. glatten Seite, $9-12 \mu$.

Deutschland, Oesterreich. 
Europa, X-Amerika, W.-Anstralien.

Eine Spielart mit verlängerten, ver»weigten A thalien, deren Aeste oft netzartig anastomosieren, nennt Lister var. liceoides (.Journ. of Bot. XXXIV [1896]. 211: Mongr. ed. 2, 197. pl. 153. fig. d; Torrend in Broteria VII. 9); sie wurde in England, in der Mark Brandenburg und auch in Frankreich gefunden.

1* Plasmodium fleischfarbig. Aetlalien halbkugelig oder fast kngelig. 5-60 mm im Dnrchmesser, rotbraun, mitunter gelappt, von einer auberordentlich dünneu, meist glatten, glänzenden, nie weißen Haut bedeckt. Sporangienwandungen ähnlich der voranstehenden Art durchbohrt, mitunter in strähnen aufgelöst. Sporenmasse umbrabraun. Sporen im durchfallenden Lichte blaB, frei, 23 der Sporenoberfäche net\%artig skulptiert. 1/3 schwach warzig, $7-9 \mu$.

E. Rozeanum (Rost). Wingate in Proe. Acad. Nat. Sc. Phil. (1889), 156; Massee Monogr., 46, fig. 108; Lister Monogr. ed. 1, 159, pl. LIX, A, fig. d-f. Monogr. ed. 2, 198. pl. 153, fig. $\mathrm{e}-\mathrm{g}$.

Syuouyme: Reticularia (?) Rozeana Rost. Monogr. App. (1א76), 23. Reticularia splentens Morgan Myxom. Miami Valley (1893) 11.

Enteridium splendens Morgan ap. Macbride N, Am. Slime-Moulds (1899), 15l, pl. I, fig. 1, la, 1b, pl. XII, tig. 4, 5; Torreud in Broteria VIl, 10, pl. I, fig. 8, 9.

Frankreich, N-Amerika, Japan.

\section{Gattung: Reticularia Bulliard.}

('hamp. (1791), 95: Rabenhorst Deutschl. Krypt.-Fl. I, 254 pr. p.: Rost. Versuch eines systems der Mycetozoen, 6, Momogr., 24 ; Schröter in Cohn Krypt.-Fl. Schles. III, 1. 116 u. in Engler und Prantl Natürl. Pflanzenfam. I, 1. 25: Celak. Myxom. Böhm.. 44: Massee Monogr.. 92; Lister Monogr. ed. 1, 160. ed. 2. 198: Macbride N. An. Slime Moulds, 149: Schinz in Mitt. Naturw. Ges. Winterthur VI: Torrend in Broteria VI, 40 V'Il, 60. 
Mit nur einer Art:

R. Lycoperdon Bull. Champ. (1791), 95, t. 446, fig. 4; Rost. Monogr., 240, fig. 3, 4, 6, 13; Schröter in Cohn Krypt.-Fl. Schles. III, 1. 116; Čelak. Myxom. Böhm., 44; Massee Monogr., 93, fig. 311, 312; Lister Monogr. ed. 1, 160, pl. LIX, B, fig. a-c, ed. 2, 199, pl. 154, fig. a-c; Macbride N. Am. SlimeMoulds, 149, pl. X, fig. 7, 7a, pl. XII, fig. 3, pl. XVIII, fig. 3; Torrend in Broteria VII, 60, pl. IV, fig. 35.

Synouyme: Lycoperdon fuscum Huds. Fl. Angl, ed. 2 (1778), 645?

Mucor Lycogalus Bolton Hist. Fung. III (1789), 133, t. 133, fig. 2 ?

Lycogala argentea Pers, in Roem. N. Mag. Bot. I (1794), 87.

Lycogala turbinata Pers. Syn. Fung. (1801), 158.

Fuligo Lycoperdon Schum. Enum. Pl. Saell. II (1803), 193.

Reticularia argentea Poiret in Lam. Encycl. Meth. VI (1804), 183.

Strongylium fuliginoides Ditm, in Schrad. Neues Journ. Bot. III (1809), 3, t. 2 , fig. 1 .

Exsikkaten: Fuckel Fungi rhen. 2583.

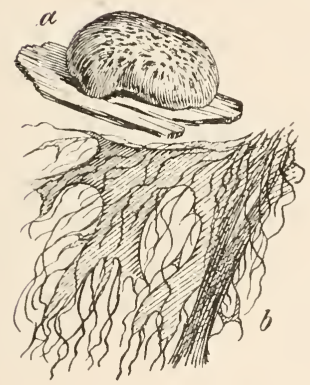

Fig. 138.

Reticularia Lycoperdon

Bull.

a) Aethalium ( $1 / 2)$; b) Capillitium

$(10 \%)$. - Nach Lister.

Plasmodium rahmweiß. Aethalium kissenförmig oder fast kugelig, 5-60 mm im Durchmesser, auf stark entwickeltem, strähnigem Hypothallus, kupferbraun oder von einer silberglänzenden, papierartigen Haut überkleidet. Sporangiumwände in unregelmäßig verzweigte, vom Grunde aufstrebende, oberwärts in zahlreiche schlanke, abgeflachte, rostbraune, \pm baumartig sich zerteilende oder zerschlit»te Strähnen aufgelöst. Sporenmasse umbrabraun; Einzelsporen \pm gedrungen eiförmig, im durchfallenden Lichte rostbraun; Sporenwand der breiteren Kalotte Schinz, Myxogasteres (Rabenhorst Krypt.-Flora I, Pilze Abt. X). 
verdickt, wohl ${ }^{3 \prime}{ }_{4}$ der Gesamtoberfläche mit netzartiger Skulptur, sonst zerstreut warzig, $6-8 \mu$.

Deutschland, Oesterreich, Schweiz.

Kosmopol.

\section{Gattung: Liceopsis Torrend}

in Bull. Soc. Port. Sc. Nat. II (1908), 63 et in Broteria VII, 61; Lister Monogr. ed. 2, 199.

Mit nur einer Art:

L. lobata (Lister) Torrend in Bull. Soc. Port. Sc. Nat. II (1908), 63 et in Broteria VII, 61, pl. 1X, fig. 15, 16, 16a; Lister Monogr. ed. 2, 199, pl. 154, fig. d-f.

Synonyme: Reticularia lobata Lister Monogr. ed 1. (1894), 161, pl. $\mathrm{LIX}, \mathrm{B}$, fig. $\mathrm{d}-\mathrm{f}$.

Reticularia Rozeana Lister in Journ. of Bot. XXIX (1891), 263 non Rost.

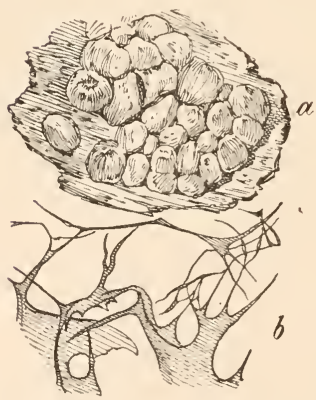

Fig. 139 .

Lic eopsis lobata (Lister) 'Torrend.

a) Sporangiengruppe $(8 / 1)$;

b) Capillitium $\left({ }^{80} / 1\right)$;

Nach Lister.

Plasmodium wässerigweiß. Sporangien vereinzelt oder \pm dicht gedrängt, \pm kugelig bei seitlicher Abflachung infolge gegenseitigen Druckes, $0,4-0,7 \mathrm{~mm}$ im Durchmesser, rostbraun oder schwärzlich, mit Metallglanz, sitzend oder kurz gestielt. Peridie dünn, im obern Teil hinfällig. Capillitium spärlich, von hyalinen, unverzweigten und anastomosierenden Fäden und Strähnen gebildet, mit dïnnen, kleineren und größeren V'er- 
breiterungen der Maschenknoten. Sporenmasse rostbraun; Sporen im durchfallenden Lichte blasser, mit enger Netzskulptur auf $2 / 3$ der Gesamtoberfläche, $6-10 \mu$.

Schweiz (Jura).

Großbritannien, Frankreich, Portugal, Rumänien.

Abgesehen davon, daB die Sporangien frei sind und nicht zur Aethalienbildung zusammentreten, mit Enteridium Rozeanum übereinstimmend.

\section{Familie Lycogalaceae de Bary}

in Rost. Versuch eines Systems der Mycetozoen (1873), 3; Lister Monogr. ed. 1, 207, ed. 2, 200: Čelak. Myxom. Böhm., 16; Schinz in Mitt. Naturw. Ges. Winterthur VI, 118; Macbride N. Am. Slime-Moulds, 174; Torrend in Broteria VI, 45, VII, 26.

Mit nur einer Gattung:

\section{Gattung: Lycogala Adanson}

Fam. Plant. II (1763), 6; Pers. in Roem. N. Mag. Bot., 87; Rabenhorst Deutschl. Krypt.-Fl. I, 256; Rost. Versuch eines Systems der Mycetozoen, 3, Monogr., 285; Schröter in Cohn Krypt.-Fl. Schles. III, 1, 111 und in Engler und Prantl Natürl. Pflanzenfam. I, 1, 23; Massee Monogr., 119; Čelak. Myxom. Böhm., 42; Lister Monogr. ed. 1, 207, ed. 2, 200; Schinz in Mitt. Naturw. Ges. Winterthur VI, 118; Macbride N. Am. SlimeMoulds, 174; Torrend in Broteria VI, 45, VII, 26, VIII, 24.

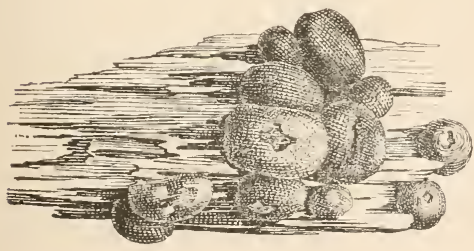

Fig. 140.

Lycogala Epidendrum

(L.) Fr.

Gruppe von Aethalien

$(1 / 1)$.

Original. 
Fruchtkörper Aethalien bildend, diese polsterartig, \pm kugelig oder kegelförmig, mit einer dicken, aus 2 oder mehr Schichten bestehenden Rinde. Äußere dritte Rindenschicht mit großen, entweder eingebetteten oder oberflächlichen, zellenartigen und anfangs Kerne führenden Blasen versehen und durchsetzt von zahlreichen, doppelwandigen, röhrigen Fäden, die in die innerste homogene Rindenschicht eindringen und mit ihren innern Wandungen in die Röhren des Capillitiums überführen; letzteres aus grauen oder farblosen, gefältelten oder glatten, veræweigten Röhren bestehend, deren freie abgerundete Enden an der Innenseite der Rinde befestigt sind.

1. Aethalien glatt oder vertieft gefeldert.

L. flavo-fuscum (Ehrenberg) Rost. Monogr. (1875), 288; Schröter in Cohn Crypt.-FI. Schles. III, 1. 111; Massee Monogr., 124, fig. 123; Čelak. Myxom. Böhm., 43; Lister Monogr. ed. 1, 208, pl. LXXV, A, fig. a-f, ed. 2, 201, pl. 155, fig. a-f; Macbride N. Am. Slime-Moulds, 176; Schinz in Mitt. Naturw. Ges. Winterthur VI, 118; Torrend in Broteria VII, 27, pl. II fig. 20 a.

Synonyme: Diphtherium flavo-fuscum Ehrenberg Sylv. Myc. Berol. (1818), 27.

Reticularia flavo-fusea Fr. Syst. Myc. III (1829), 88; Rabeuhorst Deutschl. Krypt.-Fl. I, 255.

Reticularia testacea Wallr. Fl. C'rypt. Germ. (1833). 340; Rabenhorst Deutschl. Krypt.-Fl. I, 255.

Lycogala repletum Morgan in Journ. Cinc. Soc. Nat. Hist. XVIII (1895), 40?

Plasmodium weiß oder blaßrosa. Aethalien meist vereinzelt, kugelig und sitzend oder \pm birnförmig und kurz gestielt, von der Größe einer Haselnuß bis zu der einer mittelgroßen $(5 \mathrm{~cm})$ Kartoffelknolle, gelb- oder purpurbraun, glatt oder durch silberweiße, netzartig verbundene Adern gefeldert. Rinde dreischichtig, äußerste Schicht häutig, mittlere aus gelben, $50-80 \mu$ großen Blasen bestehend, durchsetzt von den Enden der PseudocapillitiumSchläuche, innere durchwachsen von letzteren und im übrigen von homogener Struktur. Pseudocapillitium aus unregelmäßig verzweigten und anastomosierenden, nahezu farblosen, glatten oder \pm gefältelten, warzigen, in den Astwinkeln verbreiterten, 
$6-20 \mu$ weiten Schläuchen mit abgerundeten, freien, mitunter Sporen führenden Enden bestehend. Sporenmasse graulehmgelb; Sporen im durchfallenden Lichte farblos, 5-6 $\mu$, der größere Teil der Oberfläche fein netzartig skulptiert.

Deutschland, Oesterreich, Schweiz.

Großbritannien, Frankreich, Schweden, Rumänien, Ceylon, Japan, N.-Amerika.

Brandza (Annales scientif. de l'Univers. de Jassy, VIII [1914], 265, fig. 1) beschreibt eine var. argentea Brandza aus Rumänien, die sich vom Typus zur Hauptsache dadurch unterscheiden soll, daß neben dem oben skizzierten, aus Schläuchen bestehenden Pseudocapillitium noch ein zweites, von sehr feinen, $2-3 \mu$ breiten Fäden gebildetes Capillitium vorkommt. Weitere Untersuchungen dürften angezeigt sein.

$1^{*}$. Rinde des Aethaliums warzig.

2. Aethalium kugelig.

L. Epidendrum (L.) Fr. Syst. Myc. III (1829), 80; Rabenhorst Deutschl. Krypt.-Fl. I, 256; Rost. Monogr., 85, fig. 1, 7-12; Schröter in Cohn Krypt.-Fl. Schles. III, 1, 111; Čelak. Myxom. Böhm., 43; Massee Monogr., 121, fig. 121, 122; Lister Monogr. ed. 2, 202, pl. 156, fig. a-e; Macbride N. Am. SlimeMoulds, 175; Torrend in Broteria VII, 26, pl. II, fig. 18-20.

Synonyme: Lycoperdon Epidendrum L. Spec. PI. ed. I (1753), 1184.

Lycoperdou sphæricum Gled. Meth. (1753), 150.

Mucor secundus Schaeff. Fung. Bav. (1762), t. 193.

Lycogala sessile Retz. Ac. Holms. (1769), 254.

Mucor Lycogala Scop. Fl. Carn. II (1772), 496.

Mucor fragiformis Schaeff. Fung. Bav. IV (1774), 283.

Lycoperdon pyriforme Jacq. Misc. Austr. I (1778), 119, t. 7.

Lycoperdon epiphyllum Huds. Fl. Angl. (1778), 645.

Lycoperdon variolosum Huds. Fl. Augl. (1778), 645.

Galoperdon epidendrum Wiggers Fl. Holsat. (1780), 109.

Lycoperdon chalybeum Batsch Elench. Fung. (1783), 155.

Lycoperdon verrucosum Batsch Elench. Fung. (1783), 155 .

Lycoperdon pineum Batsch Elench. Fung. (1783), 155?

Lycogala miniatum Pers. in Roem. N. Mag. Bot. I (1794), 87; Lister Monogr. ed. 1, 209, pl. LXXV, B, a-e; Schinz in Nitt. Naturw. Ges. Winterthur VI, 119. 
Reticularia rosea DC. in Bull. Soc. Philom. I (1798), 105, fig. 8, A-C.

Lycogala punctata Pers. Syn. (1801), 158.

Lycogala ferruginea Schum. Pl. Saell. II (1803), 192.

Lycogala cinerea Schum. Enum. P1. Saell. II (1803), 193?

Lycogala plumbea Schum. Enum. Pl. Sael. Il (1803), 193?

Reticularia miniata Poiret in Lam. Encyel Meth. VI (1804), 184.

Reticularia punctata Poiret in Lam. Encycl. Meth. VI (1804), 184.

Lycogala plumbeum Fr. Symb. Gaster. (1817/18), 11.

Lycogala affine Berkeley et Broome in Journ. Linn. Soc. XIV (1873), 82.

Lycogala exiguum Morgan Myx. Miami Valley (1893), 8; Macbride, N. Am. Slime-Moulds, 178.

Lycogala platense Speg. in Anal. Mus. Nac. Buenos Aires VI (1898/99), 203.

Exsikkaten: Fuckel Fungi rhen. 1745; Jack, Leiner und Stitzenberger 330; Rabenhorst Fung. Eur. 2140; Sydow Myc. Mareh. 186; O. Jaap Myxu1n. exsice. 54; Hofmus. Wien Krypt. exsicc. 409.

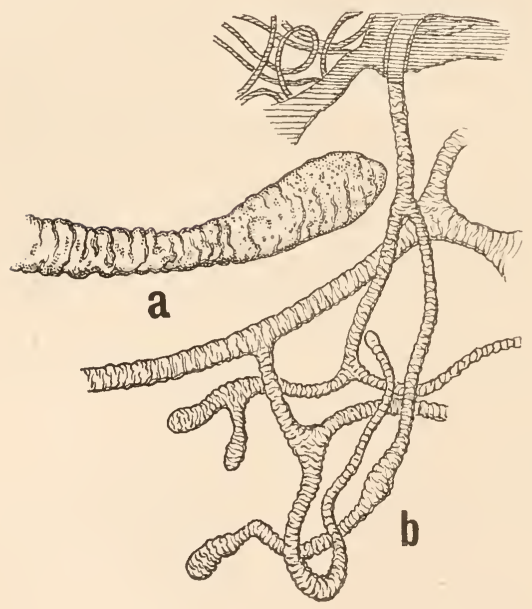

Fig. 141.

Lycogala Epidendrum (I.) Fr.

a) Ende eines Pseudocapillitium - Schlauches $(600 / 1)$;

b) Pseudocapillitium $(180 / 1)$. Nach Lister.

Plasmodium korallenrot, seltener rahmfarbig oder gelb. Aethalien zerstreut, häufiger zu mehreren gehäuft, \pm kugelig, sitzend, 2-15 mm im Durchmesser, meist haselnubgrob, zur '/eit der Reife zuerst rosen- bis fleischrot, später lehmgelb bis graubraun bis dunkelbraun, feinwarzig. Rinde bald dicker, bald 
dünner, mit zerstreuten, als Warzen vortretenden Blasen. Pseudocapillitium aus locker verzweigten und anastomosierenden, dünnwandigen, $3-20 \mu$ weiten, meist dicht quer gefältelten Schläuchen bestehend; Schlauchenden zahlreich, keulenförmig oder abgerundet; Verbreiterungen in den Astwinkeln unbedeutend. Sporenmasse und Capillitium zuerst rosarot, dann graurosa und schließlich \pm dunkelgrau oder lehmgelbgrau. Sporen im durchfallenden Lichte nahezu farblos, der größere Teil der Oberfläche dicht netzartig skulptiert, der Rest mit weitmaschigerem Netz oder mit kurzen Leisten oder Warzen beset/t, $4-7 \mu$.

Kosmopol.

var. tesselata Lister ap. Penzig Myx. Buitenz. (1898), 77 und Monogr. ed. 2, 203, mit 2-10 mm großen, dunkelbraunen Aethalien; Rindenblasen dunkel, gelappt und flach, gekammert. gefunden.

Bis anhin nur auBerhalb Europa (Ceylon, Java, Kamerun, N.-Amerika)

2*. Aethalien kegelförmig.

L. conicum Pers. Syn. I (1801), 159; Fr. Syst. Myc. III, 82; Rabenhorst Deutschl. Krypt.-Fl. I, 256; Massee Monogr., 123; Lister Monogr. ed. 1, 210, pl. LXXVI, A, fig. a-c, ed. 2, 204, pl. 157, fig. a-e; Macbride N. Am. Slime-Moulds, 177.

Synonyme: Dermodium conicum Rost. Monogr. (1875), 284.

Lycogala nitidum Berkeley et Broome in Journ. Linn. Soc. XIV (1873), 81.

Lycogala atropurpureum Berkeley et Broome in Jourı. Linn. Soc.

XVI (1873), 82.

Plasmodium rosa- oder scharlachrot. Aethalien bei breiter Basis kegelförmig, zerstreut, seltener zu 2 oder 3 zusammen, 1,5-3 $\mathrm{mm}$ hoch, 0,8-1,5 $\mathrm{mm}$ breit, mitunter \pm kugelig, blaßgelb- oder graubraun, mit dunkeln, zusammenlaufenden Rindenblasen die dunkle Flecken bilden und \%war namentlich im obern Teil des Fruchtkörpers. Rinde zweischichtig, dünn; äußere Rindenschicht gleich der innern von flachen, $2-10 \mu$ breiten Schläuchen durch\%ogen, letztere sich gegenseitig selten kreuzend, 
meist \pm parallele Reihen bildend. Die Schläuche durchset\%en auch die innere Rindenschicht und setzen an die meist einfachen, selten verzweigten, grauolivenfarbigen, fein runzeligen, auffallend dünneren Pseudocapillitiumschläuche an. Enden der letzteren

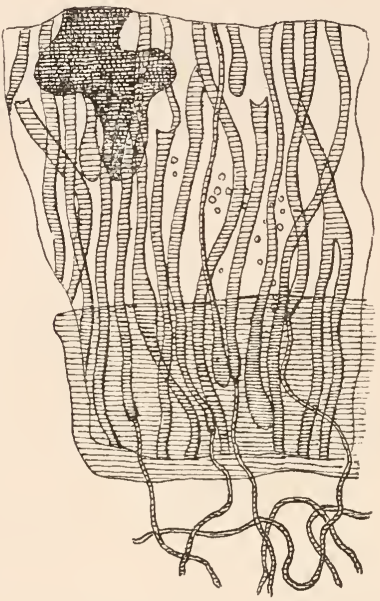

Fig. 142 .

Ly cogala conicum Pers. Rindenpartie: oben Schnitt dureh die äußere Schicht, mit einer dunkelgefärbten Blase, unten die homogene innere von dünnen Pseudocapillitium-Schläuchen durchzogen. (180/1.)

Nach Lister.

keulenförmig oder stumpf. Sporenmasse ockerfarbig; Sporen im durchfallenden Lichte farblos bis \pm gelblichgrau, fein netzartig (Lister) oder fein warzig (Macbride) über den größern Teil der Oberfläche, $4-5 \mu$.

Deutschland, Schweiz.

Frankreich, Skandinavien, Ceylon, Japan, Westindien, N.- und S.Amerika.

IV. Unterreihe CAIONEMINAA Rost.

Versuch eines Systems der Mycetozoen (1873), 14, Monogr., 242; Lister Monogr. ed. 1, 161, ed. 2, 204.

Sporangien nicht zu Aethalien zusammentretend. Capillitium stets vorhanden, aus lauter gleichartigen, freien oder verästelten und anastomosierenden Fäden bestehend. 


\section{Familie Trichiaceae Rost.}

Versuch eines Systems der Mycetozoen (1873), 14 pr. p. pr. p., Monogr., 243; Lister Monogr. ed. 1, 161, ed. 2, 204.

Capillitium entweder aus freien Fäden, Elateren, bestehend oder ein elastisches Net»werk bildend: Verdickungen der Capillitiumfäden spiralig oder ringförmig.

\section{Schliissel zur Bestimmung der Gattungen der Familie der Trichiaceae.}

1. Capillitium aus freien Fäden, Elateren, bestehend.

2. Capillitium reichlich entwickelt; Elateren mit Spiralverdickungen.

Trichia Haller.

2*. Capillitium spärlich entwickelt; Elateren mit unvollständigen Spiralverdickungen. Oligonema Rost.

$1^{*}$. Capillitiumfäden ein Netzwerk bildend.

3. Verdickungen der Capillitiumfäden höchst unregelmäßig

Calonema Morgan.

$3^{*}$. Verdickungen der Capillitiumfäden regelmäßig

4. Capillitiumfäden mit Spiralverdickungen

Hemitrichia Rost.

$4^{*}$. Capillitiumfäden mit ringförmigen Verdickungen

Cornuvia Rost.

\section{Uebersicht iber die Gattungen der Trichiaceac.}

Trichia. Sporangien gestielt oder sitzend. Peridie häutig oder pergamentartig. Capillitium aus freien, selten verzweigten, kürzern oder längern, spitzen, mit spiraligen Verdickungsleisten versehenen Fäden bestehend. Sporen warzig, stachelig oder mit netzartiger Skulptur, in letzterm Falle berandet.

Oligonema. Sporangien ungestielt, dicht gehäuft. Peridie häutig. Elateren spärlich, mit nur undeutlich hervortretenden, unvollständigen Spiralverdickungen. 


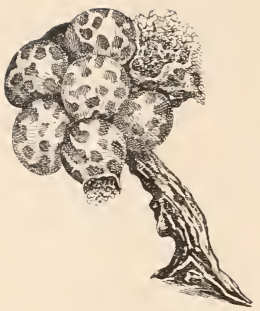

Fig. 143.

T'richia Botrytis Pers. Sporangiengruppe, Sporangien mit den Stielen verwachsen $(15 / 1)$. Nach Lister.
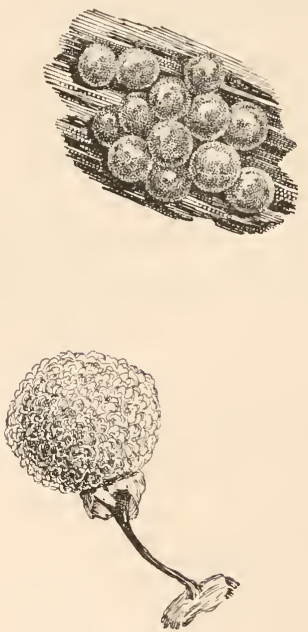

Fig. 146.

Hemitrichia clavata (Pers.) Rost. Sporangium mit zu 'lage tretendem Capillitium (18/1). - Nach Lister.

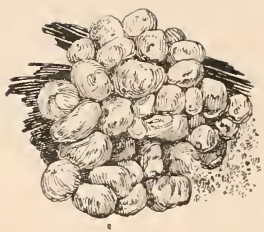

Fig. 144.

Oligonema niteus (Libert) Rost. Syorangien $(15 / 1)$. Nach Lister.

Fig. 145 .

Calonema aureum Morgan.

Sporangien $(18 / 1)$. - Original.

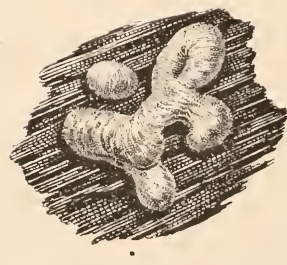

Fig. 147 .

Cormuvia Serpula Rost. Sporanginm $(25 / 1)$. - Nach Iister. 
Calonema. Sporangien ungestielt, gehäuft. Peridie häutig. Capillitiumfäden verzweigt, \pm anastomosierend und ein Netzwerk bildend, mit unregelmäßigen Verdickungen.

Hemitrichia. Sporangien gestielt oder sitzend. Peridie unregelmäßig- oder mit Ieckel aufspringend. Capillitium ein elastisches Netz spiralig verdickter Fäden.

Cornuvia. Sporangien ungestielt. Capillitiumfäden verzweigt und anastomosierend, ein Netzwerk bildend, mit ringförmigen Verdickungen.

\section{Gattung: Trichia Haller}

Hist. Stirp. Helv. III (1768), 114 pr. p.; Rabenhorst Deutschl. Krypt.-Fl. I, 259; Rost. Versuch eines Systems der Mycetozoen (1873), 14, Monogr., 243; Schröter in Cohn Krypt.-Fl. Schles. III, 1, 111 und in Engler und Prantl Natürl. Pflanzenfam. 1, 1, 23; Ċelak. Myxom. Böhm., 31; Massee Monogr., 173; Lister Monogr. ed. 1, 163, ed. 2, 205; Macbride N. Am. Slime-Moulds, 209; Schinz in Mitt. Naturw. Ges. Winterthur V1, 93; Torrend in Broteria VI, 47, VII, 51, VIII, 24.

Einzelsporangien, sitzend oder gestielt, gelb oder rotbraun. Capillitiumfäden frei, einfach oder spärlich ver»weigt, mit freien, zugespitzten Enden, außen von 2 bis 5 spiraligen Linien umzogen. Sporenmasse gelb, seltener braunrot.

1. Sporen + deutlich netzartig skulptiert.

2. Elateren $7-8 \mu$ breit. Sporen deutlich net $\%$ artig skulptiert, mit $2 \mu$ breitem Rand. Sporangien ungestielt.

T. favoginea (Batsch) Pers. in Roem. N. Mag. Bot. I (1794), 90; Schum. Enum. Pl. Saell. II, 207; Lister Monogr. ed. 1, 163, pl. LX, A, fig. a-c, ed. 2, 206, pl. 159, fig. a-b; Macbride N. Am. Slime-Moulds, 214, pl. IV, fig. 5, 5a, 5b; Schinz in Mitt. Naturw. Ges. Winterthur V1, 95; Torrend in Broteria VII, 52, pl. IV, fig. $10-12$. 
Synonyme: Lycoperdon favogineum Batseh Elench. Fung. Cent. (1786), 257.

Clathrus turbinatns Huds. Fl. Angl. ed. 2 (1778), 632 ?

Stemonitis favoginea Gmel. Syst. Nat. Il (1791), 1470.

Sphærocarpus chrysospermus Bull. Champ. (1791), t. 417, fig. 4.

'Trichia nitens Pers. Obs. I (1796), 62.

'I'richia ovata Pers. Obs. I (1796), 61?

Trichia olivacea Pers. Obs. I (1796), 62 pr. p.

T'richia turbinata Sow. Engl. Fung. (1799), t. 85?

Trichia chrysosperma DC. Fl. Fr. II (1805), 250; Rabenhorst Deutschl. Krypt.-Fl. I, 259; Rost. Monogr., 255, fig. 209, 213, 240; Schröter in Cohn Krypt.-Fl. Schles. III, 1, 113; Čelak. Myxom. Böhm., 32; Massee in Journ. Mier. Soc. (1889), 341, fig. 10, Monogr., 189.

Exsikkaten: Fuckel Fungi rhen. 1432; Rabenhorst Fungi Eur. 567, 2137; Jack, Leiner und Stitzenberger 62.2.

Plasmodium weiß oder (nach Macbride) gelb. Sporangien auf häutigem Hypothallus herdenweise sitzend, meist \pm dicht gedrängt, seltener vereinzelt, \pm kugelig, eiförmig oder keulenförmig, ockergelb. Peridie häutig. Capillitium und Sporenmasse goldgelb. Elateren lang zylindrisch, $7-8 \mu$ breit, glatt oder mit vereinzelten Stacheln, mit 4 bis 5 Spiralleisten von $1 \mu$ Breite, mit zarten, parallel der Elaterenlängsachse die Spiralwindungen kreuzenden Längslinien. Elaterenenden mit kegelförmiger, 3-8 $\mu$ langer Spitze. Sporen im durchfallenden Lichte gelb, mit Leisten besetzt, welche zu einem aus regelmäßigen, 5 - bis 6 eckigen Maschen bestehenden Netz vereinigt sind, und zwar entfallen auf die Halbkugel 3 bis 5 Maschen. Sporen einschließlich des deutlichen, $1,6-2 \mu$ breiten Randes $13-15 \mu$ groß.

Kosmopol.

$2^{*}$. Plasmodium weiB. Sporangien $1 \frac{1}{2}-4 \mathrm{~mm}$ hoch, und zwar entfallen hiervon $1-2 \mathrm{~mm}$ auf den häutigen, gelbroten oder dunkelbraunen Stiel, meist $\mathrm{zu} 3-4$ gebüschelt, birn-, ei-oder keulenförmig, ockergelb, mit goldgelbem Capillitium und goldgelber Sporenmasse. Peridie auf der Innenseite feinund dicht papillös, häutig. Elateren kurz kegelförmig zugespitzt, mit $3-5$ schmalen 
Spiralleisten und deutlichen Längslinien, glatt oder mit einigen wenigen zerstreuten Stacheln, 4-6 $\mu$ breit. Sporen $13-16 \mu$, mit kräftiger netzartiger Skulptur und $1 \mu$ breitem Rand, die Netzleisten schmal, fein durchlöchert.

'T. verrucosa Berkeley in Hooker Fl. T'asman. II (1860), 269; Massee in Journ. Microsc. Soc. (1889), 343, fig. 9, Monogr., 191; Lister Monogr. ed. 1, 165; pl. LX, B, fig. a-c, ed. 2, 208, pl. 161, fig. $a-b$; Macbride N. Am. Slime-Moulds, 215; Torrend in Broteria VII, 51, pl. IV, fig. 6, 7.

Synonym: 'Trichia superba Nassee in Journ. Mlier. Soc. (1889), 345, fig. 6, Monogr., 194.

Großbritannien, Portugal, Mexico, N.- und S.-Amerika, Java, Japan, Neuseeland, Tasmanieu, Australien.

$2^{* *}$. Elateren $4-6 \mu$ breit. Sporen mit netzartiger Skulptur und 0,5 bis $1 \mu$ breitem Rand; die Netzleisten breit und senkrecht zur Oberfläche durchlöchert, Sporangien ungestielt.

T. affinis de Bary in Fuckel Symb. Myc. (1889), 336; em. Rost. Monogr., 257, fig. 241; Ċelak. Myxom. Böhm., 32 pr. p. (var. genuina Celak.); Schröter in Cohn Krypt.-Fl. Schles. III, 1, 113; Massee Journ. Micr. Soc. (1889), 344, fig. 7, Monogr., 194; Lister Monogr. ed. 1, 165, pl. LX, B, fig. d-e, ed. 2, 209, pl. 160, fig. c-d; Schinz in Mitt. Naturw. Ges. Winterthur VI, 95; Torrend in Broteria VII, 53, pl. IV, fig. 13-15.

Synonyme: 'Trichia Kalbreyeri Massee in Journ. Hicr. Soc. (1889), 344, fig. 8, Monogr., 191.

Trichia intermedia Massee in Journ. Mier. Soc. (1889), 341, fig. 1, Monogr., 188, fig. 180-182.

Trichia pulchella Rex in Proc. Acad. Nat. Sc. Phil. (1893), 366; Macbride N. Am. Slime-MIoulds, 215.

Trichia persimilis Macbride N. Am. Slime-Noulds, 213 pr. p. nou Karsten.

Exsikkat: Fuckel Fungi rhen. 1432 . 
Plasmodium wässerigweiß. Sporangien auf häutigem Hypothallus meist dicht gehäuft sitzend, kngelig oder verkehrteiförmig, 0,6-1 mm im Durchmesser, glänzend goldbraun oder ockerfarbig, mit goldgelbem Capillitium und ebenso gefärbter Sporenmasse. Elateren $4-6 \mu$ breit, mit meist $4-5$ dicht gestellten Spiralleisten und \pm deutlichen, die letztern kreuzenden Längslinien, glatt, seltener stachelig; Elaterenenden mit kegelförmiger Spitze. Sporen im durchfallenden Lichte gelb, 13-15 $\mu$ (incl. den 0,5 bis $1 \mu$ breiten Rand), unterbrochen berandet und mit breiten oder schmalen, senkrecht zur Oberfläche durchlöcherten, netzförmig verbundenen Leisten.

Deutschland, Oesterreich, Schweiz.

Kosmopol.

Die Unterscheidung dieser Art gegenüber Trichia persimilis Karsten ist mitunter recht schwierig, wie bereits Lister und Torrend hervorheben und Macbride hat denn auch beide Arten vereinigt. De Bary hat seine $T$. affinis auf Fuckel Fung. rhen. 1432 gegründet, von welcher Nummer mir eine Reihe von Belegen vorliegen und darunter ein Exemplar, auf dessen Etiquette anscheinend von De Bary's Hand "Trichia affinis de Bary" notiert ist; letztere Aufsammlung ist von Rostafinski handschriftlich als $T$. Jackii n. sp. bestimmt! Ich habe alle diese Nummern untersucht und $m u B$ sie, bessere Belehrung vorbehalten, als $T$. persimilis Karsten ansprechen. Anderseits liegt mir je ein von Lyme Regis, dem Lister'schen Landsitze, von Lister gesammeltes ( $\mathrm{Nr} .74$ in Herb. Schinz) und aus Otto Jaap's Myx. exsicc. Nr. 77 aus Schleswig-Holstein stammendes Exemplar vor, die beide sehr deutliche Netzskulptur der Sporenexine erkennen lassen und die überhaupt der Beschreibung von $T$. affinis entsprechen. Lister hat 8. \%. de Bary's Originalexemplare in Straßburg untersucht und sagt, daß deren Elateren und Sporen nahezu identisch seien mit Massee's Belegen der T. intermedia Massee von Scarborough. Hinsichtlich der Sporen seiner $T$. intermedia sagt aber Massee "bands in the spore not being uniformly combined with a netwerk". was meinem Befund nahezu entspricht, die da\%u gehörenden Figuren sind indessen so roh, daß ich nicht darauf abstellen möchte. So komme ich dazu, will ich nicht affinis und persimilis vereinigen, Fuckel 1432 zu T. persimilis zu 
stellen. Wenn Rostafinski seine Fig. 241 auf Tafel XII als affinis bezeichnet, so ist jene Figur sicherlich nicht nach Material von Fuckel gezeichnet worden oder dann hat Fuckel unter 1432 typische affinis und persimilis ausgegeben. Schließlich sei noch erwähnt, daß de Bary (Fuckel Symb. Myc.) kein Wort von den Sporen sagt, sondern seine ganze Diagnose beschränkt auf den Satz "ausgezeichnet durch die in lange Spitzeu ausgezogenen Flocken des Capillitiums", welcher Sat\% wohl aus dem Briefe de Bary's an Fuckel ausgezogen ist.

$2^{* * * *}$. Elateren $4-6 \mu$ breit. Sporen mit $0,5 \mu$ breitem, unterbrochenem Rande, entweder. mit unterbrochen netzförmiger Skulptur oder an Stelle letzterer unregelmässig angeordnete, löcherig vertiefte Warzen. Sporangien sitzend.

T. persimilis Karsten in Not. Saellsk. pro Fauna et F'lora Fenn. Forh. IX (1868), 353; Lister Monogr. ed, 1, 166, pl. LX, A, fig. g-h, ed. 2, 210, pl. 160, fig. a, b; Macbride N. Am. Slime-Moulds, 213, pl. IV, fig. 1, 1a, $1 \mathrm{~b}, 1 \mathrm{c}, 6,6 \mathrm{a}, 6 \mathrm{~b}, 6 \mathrm{c}$, $6 \mathrm{~d}$ pr. p; Schinz in Mitt. Naturw. Ges. Winterthur VI, 96; Torrend in Broteria VII, 3, pl. IV, fig. 16-22.

Synonyme: Trichia Jackii Rost. Monogr. (1875), 258, fig. 242; Čelak. Myxom. Böhm., 33; Massee in Journ. Micr. Soc., 340 , fig. 5, Monogr., 188.

Trichia proximella Karsten in Bidr. Känn. Finl. Nat. IV (I879), 139; Massee in Journ. Micr. Soc. 335, Monogr., 180.

Trichia abrupta Cooke in Ann. Lyc. Nat. Hist. N. York XI (1877), 104; Massee in Journ. Micr. Soc. (1889), 340, fig. 2, Monogr., 187.

'Trichia Balfourii Massee in Jouru.' Micr. Soc. (1889), 339, tig. 4, Monogr., 186.

Trichia sulphurea Massee in Journ. Micr. Soc. (1889), 339, fig. 3, Monogr., 186.

Plasmodium wässerigweib. Sporangien meist gehäuft auf einem häutigen Hypothallus, sitzend, kugelig oder verkehrteiförmig, 0,5-0,8 mm, \pm metallisch glänzend, brann oder gelbbraun. Capillitium und Sporenmasse gelb oder gelbbraun. Elateren $4-6$ " breit, mit $t$ dicht stehenden, meist \pm kurzstacheligen 
Spiralleisten; die Elaterenenden kurzkegelförmig, einfach spitz oder auslaufend in 2 oder 3 spreizende Spitzen. Längslinien der Elateren undeutlich. Sporen im durchfallenden Lichte gelb oder gelbbraun, 11-14 $\mu$, mit unterbrochener Netzstruktur oder mit zerstreuten, mitunter auch \pm netzartig angeordneten, durchlöcherten Warzen, mit unterbrochenem Rande.

Auf die Beziehungen dieser Art zu T. affinis habe ich im Anschlub an letztgenannte Spezies hingewiesen; von $T$. favoginea unterscheidet sich $T$. persimilis durch die Skulptur der Sporenexine, die bei $T$. favoginea sehr dentlich netzartiger Natur ist.

Deutschland, Oesterreich, Schweiz.

Kosmopol.

$2^{* * * *}$. Elateren $4-6 \mu$ breit. Sporen mit kleinmaschigem Net\%, ohne Rand. Sporangien sitzend.

T. scabra Rost. Monogr. (1875), 258, fig. 214-217, 239; Celak. Myxom. Böhm., 33; Schröter in Cohn Krypt.-Fl. Schles. III, 1, 113; Massee in Journ. Micr. Soc. (1889), 337, fig. 13 (Sporenskulptur falsch!), Monogr., 192; Lister Monogr. ed. 1. 167, pl. LX, A, fig. d-f, ed. 2, 211, pl. 159, fig. c-d; Macbride N. Am. Slime-Moulds, 213, pl. IV, fig. 4, 4a, 4b; Schinz in Mitt. Naturw. Ges. Winterthur VI, 96; Torrend in Broteria VII, 54, pl. IV, fig. 23-25.

Synonyme: Trichia anomala Karsten in Not. Saellsk. Fauna et Fl. Fenn. IX (1868), 354?

Oligonema aneum Karsten in Bidr. Kämn. Finl. Nat. IV (1879), 131.

Trichia minima Massee in Journ. Micr. Soc. (1889), 336, Monogr., 182.

Trichia nitens Fr. ex Massee in Journ. Nicr. Soc. (1889), 333, fig. 11, Monogr., 179.

Areyria Bucknalli Massee Mouogr. (1892), 161, fig. 270, 271.

Hemiarcyria Bucknalli Massee in Grev. V (1889), 27.

Ophiotheca anomala Massee Monogr. (1892), 135?

Oligonema fulvum Morgan Myx. Miami Valley (1893), 42.

Perichæna annulifera Boud. in Bull. Soc. Myc. Fr. XVIll (1902)

144, t. VIII, fig. 3.

Cornuvia anomala Karsten in Bidr. Känn. Finl. Nat. IV (1879), 131.

Exsikkaten: Fuckel Fungi rhen. 8198? 
Plasmodium wässerigweiß. Sporangien auf häutigem Hypothallus dicht gedrängt sitzend, kugelig, $0,6-0,9 \mathrm{~mm}$, glänzend goldgelb, olivenfarbig oder gelbbraun. Peridie dünn, gelb, sehr fein gestreift. Capillitium und Sporenmasse glänzend orangegelb.

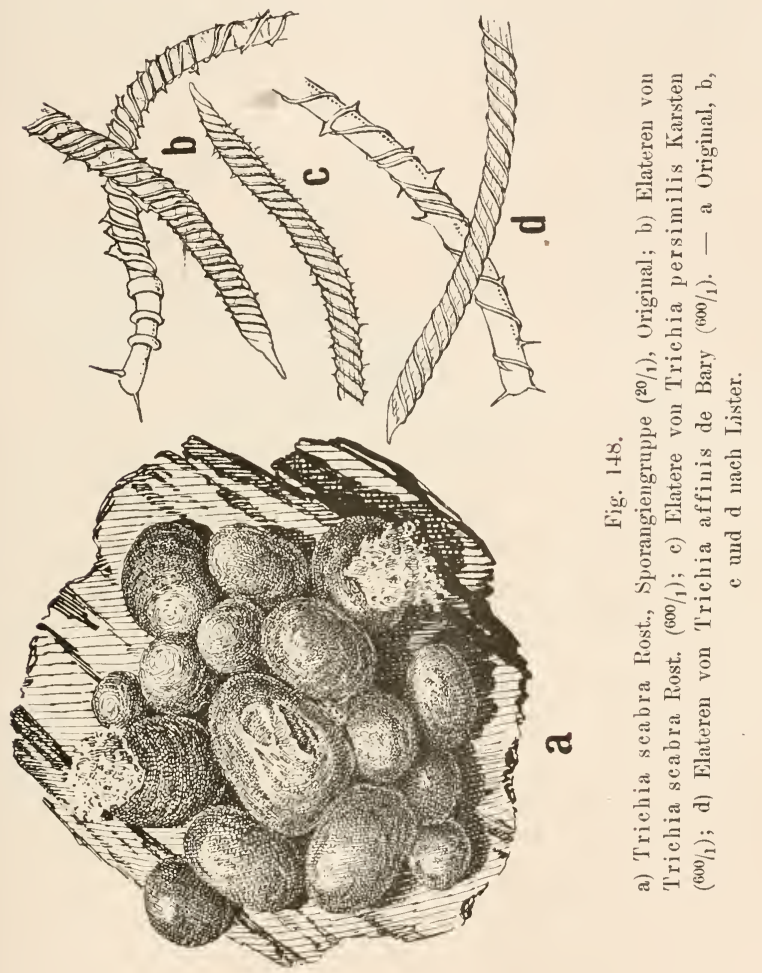

Capillitiumfäden glänzend gelb, $4-6 \mu$ breit, an beiden Enden einfach- oder zweifach spitzig und in diesem Falle die Spitzen divergierend, mit + oder 5 mitunter etwas unregelmäBigen, glatten oder stacheligen Spiralleisten; Längslinien meist undeutlich. Sporen im durchfallenden Lichte gelb, fein- und engmaschig netz- 
artig skulptiert, mit bis zu 40 Maschen auf einer Halbkugel, mitunter unregelmäßig warzig, $9-12 \mu$.

Deutschland, Oesterreich, Schweiz; im ganzen Gebiet bäufig.

Kosmopol.

Unter var. Iutea Meylan (Bull. Soc. Bot. Genève, 2me sér. Il (1910), 266) ist eine im Jura von Meylan gefundene Spielart mit „lebhaft gelbgefärbtem Capillitium und entsprechend gefärbten Sporen" zu verstehen.

$1^{*}$. Sporen fein warzig (mitunter [bei $T$. decipiens] mit fein engmaschiger Netzstruktur).

3. Elateren mit 2 Spiralleisten.

T. varia Pers. in Roem. N. Mag. Bot. I (1794), 90; Fries Syst. Myc. III, 188; Rabenhorst Deutschl. Krypt.-Fl. I, 259; Rost. Monogr., 251, fig. 191, 202, 208, 212, 218, 237; Massee in Journ. Micr. Soc. (1889), 333, fig. 17, Monogr., 178, fig. 169 bis 172; Celak. Myxom. Böhm., 35; Schröter in Cohn Krypt.-Fl. Schles. III, 1, 112; Macbride N. Am. Slime-Moulds, 212, pl. IV, fig. 3, 3a, 3b; Lister Monogr. ed. 1, 168, pl. LXI, A, a-c, ed. 2, 212, pl. 164, fig. a-c; Schinz in Mitt. Naturw. Ges. Winterthur VI, 97; Torrend in Broteria VII, 54, pl. IV, fig. 26.

Syuonyme: Stemonitis varia Pers. in Gmel. Syst. Nat. (1791), No. 1470 .

Mucor pyriformis Scop. Fl. Caru. ed. 2, II (1772), 492?

Lycoperdon vesiculosum Batsch Elench. Fung. I (1786), 283?

Trichia vesiculosa Gmel. Syst. Nat. (1791), No. 1470?

Trichia olivacea Pers. Obs. Myc. I (1796), 62?

Trichia vulgaris Pers. Obs. Myc. II (1799), 32 ?

Trichia cordata Pers. Obs. Myc. II (1799), 33.

Trichia cylindrica Pers. Obs. Mye. II (1799), 33.

Trichia pyriformis Pers. Obs. Myc. II (1799), 33.

Trichia nigripes Pers. Syn. (1801), 178; Rabeuhorst Deutschl. Krypt.-Fl. I, 260.

'I'richia craterioides Corda Icou. Il (1838), 21, t. XIl, fig. 85. 'I'richia aculeata C'elak. Myxom. Böhm. (1893), 34.

'Trichia turbinata Wither. Brit. PI. IV (1792), 480 ; Rabenlıorst. Dentschl. Krypt.-Fl. I,_260. 
Exsikkaten: Jack, Leiner und Stitzenberger 419; Fuckel Fungi rhen. 1431, 1433; Rabenhorst Fungi Eur. 799, 2137, 2138; Sydow Mycoth. germ. 549; 0. Jaap Myxom. exsice. 19, 37, 55, 95.

Plasmodium wässerigweiß. Sporangien sitzend oder gestielt, an deren Stelle mitunter Plasmodiokarpien, \pm kugelig, ei- oder kegelförmig, gehäuft oder zerstreut, ocker- oder olivenfarbig, 0,6 bis $0,9 \mathrm{~mm}$. Der Stiel, sofern ein solcher vorkommt, ist schwarz,
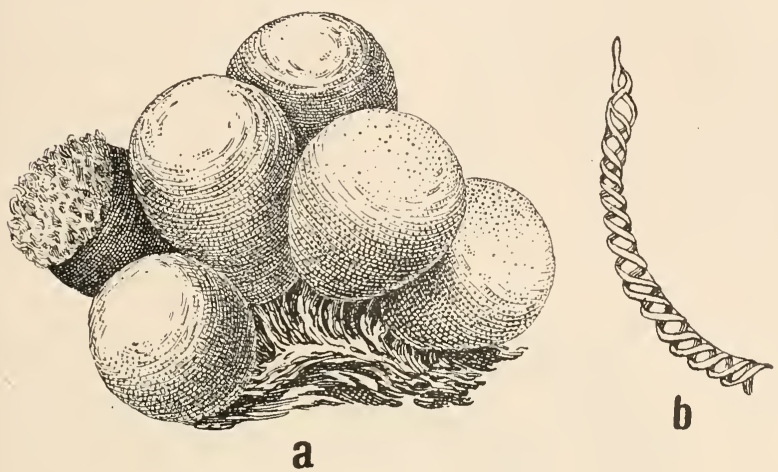

Fig. 149. Trichia varia Pers.

a) Sporangiengruppe $(20 / 1)$; b) Elateren $\left({ }^{600} / 1\right)$. - a) Original, b) nach Lister.

gefurcht, bis $0,5 \mathrm{~mm}$ lang und bis $0,3 \mathrm{~mm}$ dick. Elateren ockergelb, $3-5 \mu$ breit, in eine kurze, \pm gekrümmte Spitze zugespitzt, mit 2 einseitig stärker vortretenden Spiralleisten mit \pm lockeren Windungen. Sporen im durchfallenden Lichte ockergelb, fein warzig, berandet, $11-16 \mu$.

Durch unser ganzes Gebiet überaus bäufig.

Kosmopol.

Von Spielarten sind zu erwähnen:

var. aurata Meylan in Bull. Soc. Vaud. Sc. nat. XLIV (1908), 299, mit lenchtend gelbem Capillitium, das aus auffallend langen, stellenweise mit ring- oder schmalmanschettenförmigen Verdickungen versehenen Elateren besteht.

Schweiz (Jura). 
var. fimicola Marchal in Bull. Soc. Roy. Bot. Bélg. XXXIV (1895), 125, mit 7-91/2 $\mu$ großen, blaßockerfarbigen Sporen und $3 \mu$ breiten Elateren.

Aus unserm Gebiet noch nicht bekannt.

Belgien. Auf Hasenmist, fehlt in der von Jahn publizierten Liste der coprophilen Myxomyceten (Verh. Bot. Ver. Prov. Brandenb. LVII [1916], 207).

$3^{*}$. Elate'ren mit 3 und mehr spiralleisten.

4. Elateren kurz zugespitzt.

5. Sporangien meist ungestielt. Peridie durch Granulationen gleichmäßig verdickt. Spiralleisten der Elateren bald dentlich vortretend, bald schwach, zum Teil auch un regelmäßig.

T. contorta (Ditm.) Rost. Monogr. (1875), 259, fig. 229; Schröter in Cohn Krypt.-Fl. Schles. III, 1, 113; Massee in Journ. Micr. Soc. (1889) 337, Monogr., 182; Lister Monogr. ed. 1, 168, pl. LXI, B, fig. a-f, ed. 2, 213, pl. 162, fig. a-d; Macbride N. Am. Slime-Moulds, 2d0, pl. XIIl, fig. 7, 7 a; Schinz in Mitt. Naturw. Ges. Winterthur VI, 98; Torrend in Broteria VII, 55.

Synonyme: Lycogala contortum Ditm. in Sturm Deutschl. Fl., Pilze (1813), 8, t. 5 .

Perichæua contorta Fr. Syst. Myc. III (1829), 192.

Licea contorta Wallr. Fl. Crypt. Germ. II (1833), 345; Rabenhorst Deutschl. Krypt.-Fl. I, 264.

Trichia reniformis Peck in Rep. N. lork Mus. XXVI (1874), 76. Trichia heterotrichia Balf. in Grev. X (1881), 117.

Trichia pachyderma Čelak. Myxom. Böhm. (1893), 38.

Trichia intermedia Čelak. Myxom. Böhm. (1893), 38.

Trichia ovalispora Hollós in Math. Nat. Wiss. Ber. Ungar. XX (1905), 324?

Oligonema fulvum Pavillard et Lagarde in Bull. Soc. Mye. Fr. XIX (1903), 99 non Morgan.

Plasmodium wässerigweiß. Sporangien gehäuft oder zerstreut, 土 kugelig, 0,5-0,8 mm, sitzend oder mitunter mit einem sehr kurzen, schwarzen Stiel versehen, an deren Stelle nicht selten verlängerte, gekrïmınte oder \pm nierenförmige Plasmodiokarpien, 
matt gelbbraun oder dunkelrotbraun. Peridie häutig oder pergamentartig mit braunen Granulationen, seltener mit Kalkkristallen besetzt, gelb oder rotbraun. Elateren wenig zahlreich, einfach oder verzweigt,

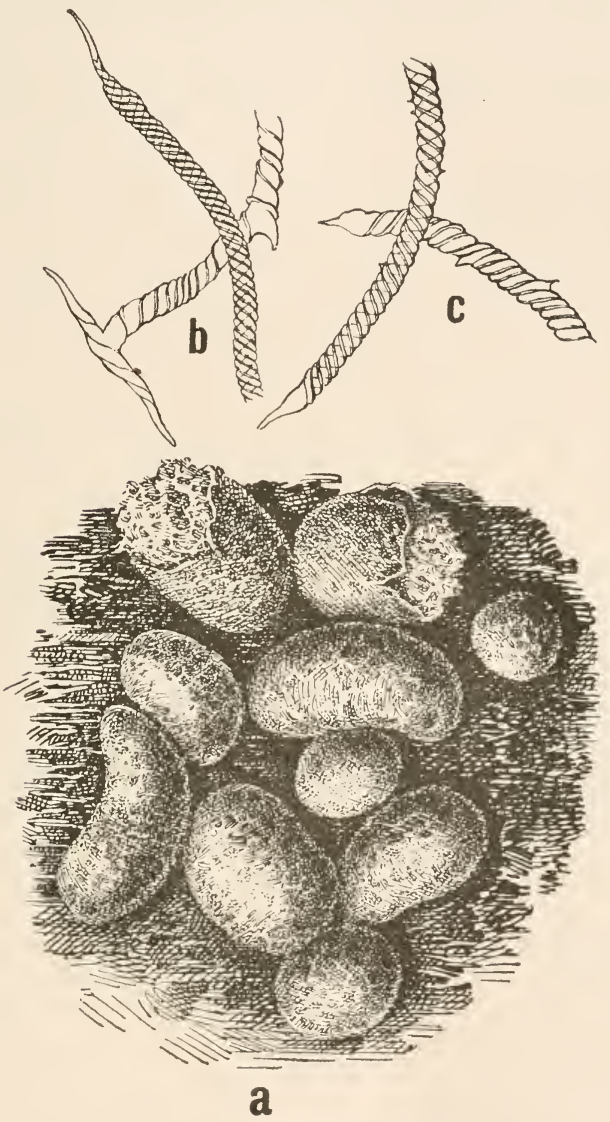

Fig. 150. Trichia contorta (Ditm.) Rost.

a) Sporangiengruppe $\left({ }^{20} / 1\right)$; b) zwei Elateren, eine davon mit unregelmäßigen Spiralwindungen, die andere (var. ineonspicua [Rost.], Lister) mit regelmäBigen Spiralen $\left({ }^{600} / 1\right)$; c) Elateren der var. alpina R. E. Fr. $\left({ }^{600} / 1\right)$. - a Original, $\mathrm{b}$ und $\mathrm{c}$ nach Lister. 
3-5 $\mu$ breit, mit 4-5, oft undeutlichen Spiralleisten, die Enden meist angeschwollen und in eine kurze, \pm aufgesetzte und \pm gekrümmte Spitze auslaufend, gelb oder gelbbraun. Sporen im durchfallenden Lichte gelb, $9-14 \mu$, fein stachelig.

Deutschland, Oesterreich, Schweiz.

Europa, N.-Amerika.

var. inconspicua (Rost.) Lister Monogr. ed. 1 (1894), 169, pl. LXI, B, fig. e, ed. 2, 213, pl. 162, fig. b; Schinz in Mitt. Naturw. Ges. Winterthur VI, 99; Torrend in Broteria VII, 55.

Synonyme: Trichia inconspicua Rost. Monogr. (1875), 259; Massee in Jouru. Micr. Soc. (1889), 335, Monogr., 180; Ćlak. Myxom. Böhm., 36; Macbride N. Am. Slime-Moulds, 210.

Trichia Andersoni Rex in Proc. Acad. Nat. Sc. Phil. (1891), 395. Trichia advenula Massee in Journ. Micr. Soc. (1889), 336, fig. 38 Monogr., 181, fig, $142-144$.

Trichia Rostafinskii Čelak. Myxom. Böhm. (1893), 37.

Elateren mit deutlichen, regelmäßigen Spiralleisten mit dichtstehenden Windungen, Enden unterhalb der Spitze angeschwollen. Sporangien klein.

Deutschland, Oesterreich, Schweiz.

var. Iowensis (Macbride) Torrend in Broteria VII (1908), 55.

Synonym: Trichia iowensis Macbride in Bull. Nat. Hist. Iowa II (1892), 133, N. Am. Slime-Moulds, 211, pl. III, fig. 3, 3a, $3 \mathrm{~b}$, pl. X, fig. 5 .

Elateren mit schlanken, 5-10 $\mu$ langen Stacheln, oft verzweigt, mit 3 bis 4 unregelmäßig windenden Spiralleisten.

Schweiz (Jura).

N.-Amerika.

var. alpina R. E. Fr. in Ark. Bot. Stockholm VI (1906), 5; Lister in Journ. of Bot. XLVI, 219 und Ll, 100, Monogr. ed. 2, 213, pl. 162, fig. c, d; Meylan in Bull. Soc. Vaud. Sc. nat. 5 me sér. L, 14 (Sonderabdruck). 
Kugelige Sporangien oder 2 bis $10 \mathrm{~mm}$ lange und 0,6 bis 0,8 mm breite Plasmodiokarpien, purpurbraun oder schwarz. Peridie pergamentartig, rot- oder olivenbraun bis schwarz. Elateren gelb, mit regelmäßigen nnd mitunter stacheligen Spiralleisten, $13-20 \mu$.

$\mathrm{N}$-Oesterreich (Somntagberg), Schweiz (hänfig in den obern Regionen des Jura und in den Alpen, an Rande des schmelzenden Schnees).

Schweden.

var, corticola Martin in Bull. Soc. Bot. Genève IX (1899), 76.

Elateren mit seitlichen kurzen Ästeu; Spiralen regelmäßig, dicht und häufig mit schmalen manschettenförmigen Verdickungen.

Schweiz (Jura).

f. attenuata Meylan in Annuaire Conserv. et Jard. bot. Genève 15 me et 16 me années (1913), 320.

Elateren ganz allmählich zugespitzt, daher sehr schlank. Peridie und Stiel, insofern ein solcher entwickelt ist (sich dadurch von $T$. decipiens [Pers.] Macbride unterscheidend), reichlich mit Granulationen versehen.

Schweiz (Jura).

Schwierig ist manchmal die Unterscheidung gegenüber der Gattung Hemitrichia und zwar nicht nur im Hinblick auf T. contorta, sondern ebenso sehr hinsichtlich der nachfolgen Art, T. lutescens, indem mitunter, unter aller Wahrung der Gesamttracht, der Größenverhältnisse, der Zahl der Spiralleisten der Elateren, der Größe der Sporen und deren Skulptur, das Capillitium anstatt aus freien Elateren, aus einem Netzwerk verzweigter und anastomosierender Fäden besteht. Formen dieser Art sind mit Hemitrichia Karstenii. vereinigt worden.

5*. Sporangien ungestielt. Peridie ohne granulöse Verdickungen. Elateren mit unaufälligen Spiralleisten.

T. Intescens Lister in Journ. of Bot. XXXV (1897), 216, Monogr. ed. 2, 215, pl. 161, fig. c-e; Torrend in Broteria VII, 56. 
Synonyme: Oligonema furcatum Bucknall in Massee Monogr. (1892), 173.

T'richia contorta var. lutescens Lister Monogr. ed. 1 (1894), 169;

Sehinz in Mitt. Naturw. Ges. Winterthur VI, 99.

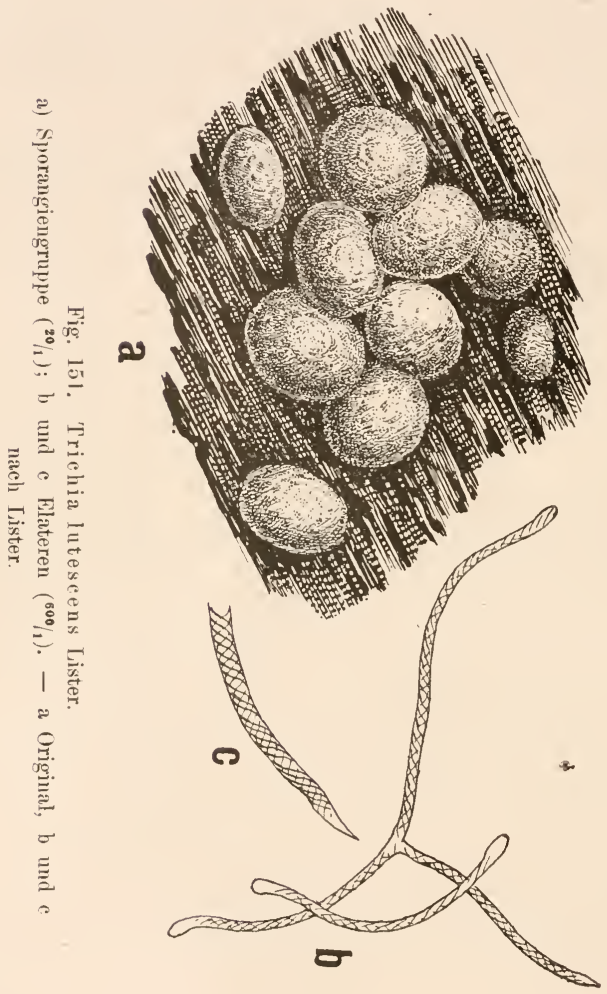

Plasmodium? Sporangien sitzend, zerstreut oder in wenigzähligen Gruppen, kugelig oder polsterförmig, 0,15-0,7 mm, glänzend, leuchtend chrom- oder olivengelb. Peridie häutig, ohne Granulationen. Elateren bald länger, bald kürzer, einfach oder verzweigt, blaßgelb, $0,3-0,45 \mu$ breit, mit $4-5$ deutlichen oder 
sehr schwachen Spiralleisten, zugespitzt oder stumpf oder die Enden etwas angeschwollen. Sporen leuchtend gelb oder olivengelb, dicht warzig oder stachelig, $10-12 \mu$.

Deutschland, Schweiz (Jura); im Gebiet anscheinend selten.

Großbritannien, Skandinavien, Portugal.

Lister und Torrend geben dem Epitheton lutescens mit Recht den Vorzug im Hinblick auf die noch unaufgeklärte Trichia furcata Wigand, die möglicherweise eine Form von $T$. decipiens ist.

Auch T. lutescens scheint in Formen mit netzartig anastomosierenden Capillitiumfäden vorzukommen; solche sind, in Anlehnung an Torrend zu Hemitrichia Karstenii gestellt.

$5^{* *}$. Sporangien gestielt, selten fast sitzend, kugelig oder kreiselförmig, zerstreut oder zu 2 bis 3 gehäuft, $0,5-0,7 \mathrm{~mm}$, bei gelbem Untergrund nuBbraun gescheckt. Stiel dunkelbraun, undurchsichtig, zweimal länger als das Sporangium. Elateren glänzend gelb, $3-4 \mu$ breit mit 4 grob stacheligen, unregelmäbig windenden Spiralleisten, einfach oder verzweigt und anastomosierend; Enden kurz bespitzt. Sporenmasse gelb; Sporen im durchfallenden Lichte blaBgelb, fein warzig, $11-13 \mu$.

T. erecta Rex in Proc. Acad. Nat. Sc. Phil. (1890), 193; Massee Monogr., 184; Lister ed. 1, 170, pl. LXII, A, fig. e-g, ed. 2, 215; Torrend in Broteria VII, 56.

Wurde bis anhin im Gebiete noch nicht nachgewiesen.

Großbritannien, N.-Amerika, Neuseeland, Australien, Tasmanien.

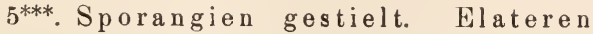
glatt. 
T. subfusea Rex in Proc. Acad. Nat. Sc. Phil. (1890), 192; Massee Monogr., 183; Macbride N. Am. Slime-Moulds, 217; Lister Monogr. ed. 2, 219, pl. 163. fig. l-n.

Sy nonym: Trichia Botrytis var. sulfusea Lister Mlonogr. ed. 1 (1894), 172, pl. LXII, B, fig. l-n.; Torrend in Broteria VIl, 58.

Plasmodium? Sporangien gestielt, herdenweise, einzeln oder zu zweien vereinigt, \pm kugelig oder birnförmig, 0,5-0,9 mm im Durchmesser, braun bis dunkelbraun, gelblich oder rotbraun. Stiel braun oder purpurbraun, gedrungen, gefurcht. Capillitium leuchtend strohgelb; Elateren lang, $3-4 \mu$ breit, mit 3 bis 4 zum Teil vorstehenden, glatten Spiralleisten und kurzen, spitzigen, häufig etwas gekrümmten Enden. Sporen im durchfallenden Lichte gelb, fein stachelig, $11-13 \mu$.

Deutschland (Holstein).

Großbritannien, Skandinavien, Ceylon, N.-Amerika.

4*. Elateren allmählich nach den Enden zu verjüngt, glatt. Sporangien gestielt.

6. Sporangienstiele mit sporenartigen Zellen erfüllt.

T. decipiens (Pers.) Macbride N. Am. Slime-Moulds (1899), 218, pl. IV, fig. 2, 2a, 2b; Lister Monogr. ed. 2, 216, pl. 158, fig. $a-d$.

Synonyme: Arcyria decipiens Pers. in Usteri Ann. Bot. XV (1795), 35. Trichia fallax Pers. Obs. Myc. 1 (1796), 59; Fr. Syst. Myc. IlI, 185; Rabenhorst Deutschl. Krypt.-Fl. I, 260; Rost. Monogr., 243, fig. 211, 221, 222, 233-236; Nassee in Journ. Micr. Soc. (1889), 332, fig. 21, 27, Monogr., 192; Čelak. Myxom. Böhm., 40; Schröter in Cohn Krypt.-Fl. Schles. Ill, 1, 111; Lister Monogr. ed. 1, 170, pl. LXII, A, fig. a-d; Schinz in Mitt. Naturw. Ges. Winterthur VI, 100; Torrend in Broteria VIl, 57, pl. IV, fig. 27-30.

Trichia virescens S'chum. Enum. Saell. II (1803), 208.

Trichia cerina Ditm. in Sturm Deutschl. Fl., Pilze, (1817), 41, t. 25 .

Mucor miniatus Jacq. Misc. austr. III (1778), 54, t. 299,

Sphærocarpus piriformis Bull. Champ. (1791), 129, t. 417. fig. 2?

Stemonitis flarescens Schrank in Roem. N. Mag. Bot. XII (1790), 19 ?

Trichia fulva Purton Midl. Fl. III (1821), 290. 
Trichia clavata Wigand in Pringsheim Jahrb. Bot. III (1863), 28.

Trichia furcata Wigand in Pringsheim Jahrb. Bot. IIl (1863), 29, t, I, fig. I-II.

Trichia obtusa Wigand in Pringsheim Jahrb. Bot. III (1863), 30? 'Trichia nana Zukal in Verh. Zool.-bot. Ges. Wien XXXV (1886), $33 \downarrow$, t. XV, fig. 8 .

Trichia Stuhlmanni Eichelb. in Verh. Naturw. Ver. Hamburg, ser. 3, XIV (1907), 32.

Exsikkaten: Fuckel Fungi rhen. 1435; Jack, Leiner und Stitzenberger 120; Rabenhorst Fung. Eur. 1666; O. Jaap Myx. exsicc 96.

Plasmodium rosafarbig oder weiß. Sporangien gestielt, samt Stiel (0,5-1 mm lang) 1,5-3 $\mathrm{mm}$ hoch, herdenweise vorkommend, kreiselförmig, glänzend olivenfarbig oder gelbbraun; Peridie zweischichtig, häutig, gelb. Stiel olivenfarbig oder dunkelbraun, bis zum Grunde mit sporenartigen Zellen angefüllt. Capillitium gelblich oder olivgelblich; Elateren einfach oder verzweigt, 4,5 bis 5,5 $\mu$ breit, glatt, mit 4-5 regelmäßig windenden Spiralleisten, deren Windungen um die Dicke der Leisten oder sogar mehr von einander entfernt sind, allmählich zugespitzt. Sporenmasse olivenfarbig oder ockergelb; Sporen im durchfallenden Lichte gelbbraun, rundum fein warzig oder fein stachelig oder auf einer Seite sehr dicht- und oft unregelmäßig netzartig skulptiert, $9-12 \mu$.

Deutschland, Österreich, Schweiz; häufig.

Kosmopol.

var. gracilis (Meylan) Schinz nov. comb.

Synonym: 'Trichia fallax var. gracilis Meylan in Bull. Soc. Vaud. Sc. nat. XLVI (1910), 53.

Plasmodien zuerst weiß, dann blaßgelb, schließlich braun. Sporangien braun, klein, 0,5 mm groß, der dünne Stiel 2- bis 3 mal länger als das Sporangium.

Schweiz (Jura).

var. olivacea (Meylan) Schinz nov. comb.

Synouym: Trichia fallax var. olivacea Meylan in Bull. Soc. Vaud, Sc. nat. XLIV (1908), 300. 
Sporangien sehr klein, mit Ausnahme einer matten, ungefähr den dritten Teil der Sporangienkugel beanspruchenden Kalotte leuchtend olivenfarbig. Die von der leuchtend olivenfarbigen äußern Wandschicht nicht bedeckte Kalotte schwindet beim Öfnen des Sporangiums, sodaß dieses dann die Gestalt eines Fußglases oder eines Pokals besitzt.

Sehweiz (Jura).

f. rubiformis Meylan in Ann. Conservat, et Jardin bot. Genève 15 me et 16 me années (1913), 320.

Sporangien gegen die Basis zu nicht verjüngt, kaum gestielt, in der Gestalt an jene von $T$. favoginea und varia erinnernd. Schweiz (Jura).

f. sublevis (Meylan) Schinz nov. comb.

Synonym: Trichia fallax f. sublevis Moylan in Bull. Soc. Vaud. Sc. nat. XLIV (1908), 300.

Stacheln der Elateren selbst bei starker Vergrößerung kaum wahrnehmbar.

Schweiz (Jura).

Aus Rumänien erwähnt Brandza zwei neue, von ihm aufgestellte Formen (Ann, scient. Université Jassy VIII [1914], 272) auf die in der Folge zu achten sein wird:

f. nodulosa Brandza, mit stark verzweigten, kurzen Elateren, die an den Enden und auch sonst an zahlreichen Punkten ihrer Längsausdehnung Nodositäten aufweisen, um die sich die Verzweigungen gruppieren.

f. hemitrichioides Brandza, mit selten verzweigten, nach Art von Hemitrichia intorta vielfach um sich selbst gedrehten Elateren und glänzend goldgelben Sporangien.

$6^{*}$. Sporangienstiele ohne sporenartige Zellen in ihrem Innern oder nur solche am Grunde, (ausnahmsweise) in den Falten der Stielwand oder in Schläuchen, besitzend. 
7. S'tiel ein Netzwerk zerzauster, verzweigter, mit AusschuBmaterial angefüllter Schläuche einschliebend, \pm undurchsichtig.

T. Botrytis Pers. in Roem. N. Mag. Bot. I (1794), 89 pr. p.; Schröter in Cohn Krypt.-Fl. Schles. III, 1, 112 pr. p.; Lister Monogr. ed. 1, 171 pr. p., pl. LXII, B, fig. a-d, ed. 2, 217 pr. p., pl. 163, fig. a-d und in Journ. of. Bot. LIII, 210; Macbride N. Am. Slime-Moulds, 216 pr. p., pl. XIII, fig. 8, 8 a; Schinz in Mitt. Naturw. Ges. Winterthur VI, 101 pr. p.; Torrend in Broteria VII, 57 pr. p., pl. IV, fig. 31 .

Synonyme: Stemonitis Botrytis Pers. in Gmel. Syst. Nat. (1791), 1468 .

Sphærocaryms ficoides Bull. Champ. (1791), 129, t. 417, fig. 2. Trichia serotina Schrader in Schrad. Journ. Bot. V (1799), 67. Sphærocarpus fragilis Sow. Fngl. Fung. (1803), t. 279.

Trichia pyriformis Fr. Syst. Mic. III (1829), 184 non Pers.

Trichia Lorinseriana Corda Icon. I (1837), 23, fig. 228 D; Rabenhorst Deutschl. Krypt.-Fl. I, 261.

Trichia purpuraseens Nyll. in Saellsk. Fann. Fl. Femm. IV (1859), 126; Massee in Journ. Nier. Soc. 332, Monogr., 177, fig. 183,184 .

Trichia fragilis Rost. Monogr. (1875), 246, fig. 203, 204, 225, 226 pr. p; Nasssee in Joum. Nier. Soc. (1889), 330, fig. 14, 28, Monogr., 175, fig. $7-10$.

Trichia Carlyleana Massee in Journ. Micr. Soc. (1889), 329, fig. 15, Monogr., 174, fig. 173-175.

Diese Synonymenreihe umfaßt, da erst ganz jüngst die beiden, bis anhin umbestritten zu einer Art, Trichia Botrytis, vereinigten Arten T. Botrytis und T. lateritia wieder als zwei von einander versehiedene Spezies aufgefaßt werden, die Synonyme beider Arten; eine Ausseheidung nach der Zugehörigkeit zu der einen oder andern Art ist unmöglich, der Versuch, soweit nicht untersuchbare Belege vorliegen, geradezu aussichtslos.

Exsikkaten ('T. Botrytis und T. lateritia): Fuckel Fungi rhen. 1436; Jack, Leiner und Stitzenberger 329; Rabenh. Fung. Fur. 241; 0. Jaap Myxom. exsice. 56.

Plasmodium purpurbraun. Sporangien herdenweise, oft zu Tausenden nebeneinander, samt Stiel $1 \frac{1}{2}$ bis $5 \mathrm{~mm}$ hoch, birnoder kreiselförmig, einzeln gestielt oder zu $3-8$ mit ihren Stielen büschelweise verwachsen, $0,6-0,8 \mathrm{~mm}$ im Durchmesser, gelblicholivenfarbig, rotbraun, purpurfarbig oder nahezu schwarz, oft bei 
dunkelm Grundton mit blasseren Dehiszenzlinien. Peridie zwejschichtig, äußere Schicht mit braunen Granulationen, innere häutig. Stiel zylindrisch, einfach oder mit mehreren andern verwachsen, ein Gewirr zerzanster, verzweigter Röhren einschließend, die mit Ausschußmaterial angefüllt sind; der Stiel ist daher in Glyzerinpräparaten \pm undurchsichtig. Capillitiummasse gelbbraun, Elateren

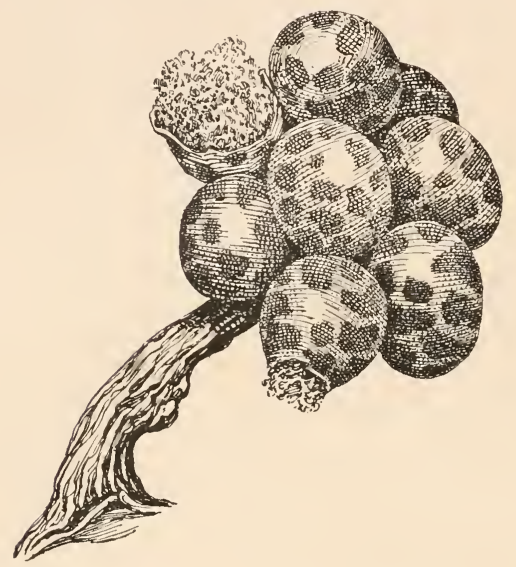

Fig. 152 .

T'richia Botrytis Pers. Sporangiengruppe mit gemeiusamem Stiel $(25 / 1)-$ Nach Lister.

lang, $4-5 \mu$ breit, einfach oder mitunter verzweigt, allmählich zugespitzt, mit 3 bis 5 glatten Spiralleisten, deren Windungen $\pm 1 \mu$ entfernt und mitunter unregelmäßig sind, die schlanken, spitzen Enden in der Regel ohne Spiralleisten. Sporenmasse purpurrot oder ockerfarbig; Sporen im durchfallenden Lichte blasser, fein stachelig, $9-12 \mu$.

Durch das ganze Gebiet sehr häufig.

Kosmopol.

var. munda Lister in Journ. of. Bot. XXXV (1897), 216, Monogr. ed. 2, 217.

Elateren blaßbraun oder gelblichbraun, mit dichtwindenden und regelmäßigen spiralleisten. Sporen gelb oder bräunlichgelb.

Oesterreich.

Großbritannien, Portugal, N.-Amerika. 
var. flavicoma Lister Monogr. ed. 1 (1894), 172, pl. LXII, B, fig. i-k, ed. 2, 217, pl. 163, fig. i, k.

Sporangien sehr klein, mit ihren Stielen zı mehreren verwachsen, purpurbraun mit gelben Dehiszen\%linien; Elateren und Sporen leuchtend gelb.

Schweiz.

Großbritamien, Portugal.

var. cerifera G. Lister in Journ. of Bot. LIII (1915), 211.

Sporangiumstiel und Peridie mit einem Belag einer schwefelgelben, wachsartigen oder harzigen Substanz. Der Belag besteht bald aus zerstreuten, kleinen Granulationen, bald aus größern, scheibenförmigen Stückchen, die entweder frei der Oberfläche aufsitzen oder blasenförmigen 'Taschen der Peridie eingelagert sind. Bei reichlichem Vorkommen färben sie Stiel wie Peridie gelb. Diese Masse wird durch Alkannatinktur tief rot gefärbt. Wachsartige Belage sind sonst wohl nur für Diachaa cerifera G. Lister bekannt.

Ist im Gebiet erst nachzuweisen.

Großbritannien, Nenseeland.

$$
\begin{aligned}
& \text { 7*. Sporangienstiele höchstens am } \\
& \text { Grunde etwas Ausschumaterial } \\
& \text { und(ausnahmsweise)inden Falten } \\
& \text { der Stielwand kleine Ansamm- } \\
& \text { lungen sporenartiger Zellen } \\
& \text { führend. }
\end{aligned}
$$

T. Lateritia Lév. in Ann. Sc. nat. Bot. sér. 3, V (1846), 167; Rost. Monogr., 250, fig. 219, 220; Lister in Journ. of. Bot. LIII, 211.

Syuonyme: 'Trichia Decaisnea de Bary in Rost. Monogr. (1875), 250; Massee in Journ. Microse. Soc., 338, Monogr., 185; Sebröter in Cohn Krypt.-Fl. Sehles. III, 1, 112.

Trichia Botrytis var. lateritia Lister Monogr. ed. 1 (1891), 171, pl. LXII, B, fig. e-i, ed. 2, 217, 1,. 163, fig. e-i; Schinz in Mitt. Naturw. Ges. Winterthur VI, 102; Torrend in Broteria VII, 58. 
Unterscheidet sich von vorstehender Art, mit der sie bis auf die allerjüngste Zeit, wenn auch als Varietät, unbestritten vereinigt worden ist, durch nachfolgende Merkmale: Sporangien dunkelziegelrot; Sporangienstiel in Glycerin durchsichtig, aus einer

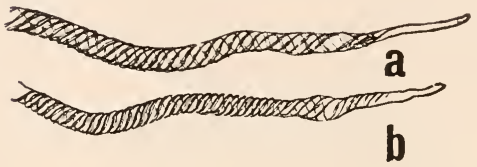

Fig. 152.

Trichia lateritia Lév. Elateren $(600 / 1)$. - Nach Lister.

dichtgefältelten, hellrotbrannen Wand bestehend, einige wenige unansehnliche schmale Strähnen und schlanke Fäden, sowie etwas Ausschußmaterial am Grunde und ausnahmsweise einige sporenartige Zellen zwischen den Falten der Stielwand führend. Elateren intensiver rot gefärbt, kürzer zugespitzt.

Sicherlich im ganzen Gebiet vorkommend; bereits nachgewiesen aus Deutschland und der Schweiz.

Kosmopol.

\section{Gattung: Oligonema Rost.}

Monogr. (1875), 291; Massee in Journ. Microsc. Soc. (1889), 345, Monogr., 169; Schröter in Cohn Krypt.-Fl. Schles. III, 1, 108 und in Engler und Prantl Natürl. Pflanzenfam. I, 1. 2l; Lister Monogr. ed. 1, 173, ed. 2, 219; Macbride N. Am. SlimeMoulds, 219; Schinz in Mitt. Naturw. Ges. Winterthur VI, 102; Torrend in Broteria VI, 48, VII. 58. VIII, 25.

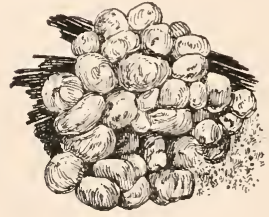

Fig. 153.

Oligonema nitens (Libert) Rost. sporangien $(15 / 1)$. Nach Lister. 
Sporangien klein, gewöhnlich dicht über- und nebeneinander gehäuft. Capillitium meist spärlich, aus kurzen oder langen Fäden mit undeutlichen oder feblenden, meist unregelmäßigen Spiralleisten oder zum Teil ringförmigen Verdickungen bestehend. Sporen mit netzartiger Skulptur.

1. Sporangien kugelig, in $\mathrm{Haufen.}$ Peridie glatt. Sporen mit unregelmäßiger Netzskulptur.

O. nitens (Libert) Rost. Monogr. (1875), 291, fig. 198; Schröter in Cohn Krypt.-Fl. Schles. III, 1, 108; Massee in Journ. Microsc. Soc. (1889), 347, fig. 29, Monogr. 170, fig. 193-195; Lister Monogr. ed. 1, 173, pl. LXI, A, fig. d-f, ed. 2, 219, pl. 164, fig. d-f; Macbride N. Am. Slime-Moulds, 221, pl. II, fig. 8, 8a, 8b; Schinz in Mitt. Naturw. Ges. Winterthur VI, 103; Torrend in Broteria VII, 58, pl. IV, fig. 32.

Synonyme: Trichia nitens Libert Fl. Crypt. Ard. Fasc. III (1834) No. 277 noll Pers.

Physarum Schweinitzii Berkeley in Grev. II (1873), 66.

'Trichia Kickxii Rost. Monogr. App. (1876), 40.

'Trichia bavarica de Thuemen Myc. Univ. (1879), No. 1497.

Trichia pusilla Schröter in Cohn Krypt.-Fl. Schles. III, I (1885) 114.

Oligonema bavaricum Balf. et Berlese in Sacc. Syll. VII (1888), 437,

Oligonema minutula Massee in Journ. Microsc. Soc. (1889), 348.

fig. 20, Monogr., 171 (0. minutulum),

Cornuvia nitens Rost. ap. Lister Monogr. ed. 1 (1894), 173.

Wxikkaten: Fuckel Fung. rhen. 2198.

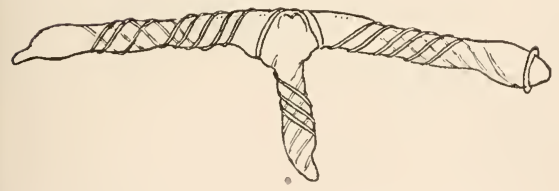

Fig. 154 .

Oligonema nitens

(Libert) Rost.

Elatere $\left({ }^{620 / 1}\right)$. - Nach Lister.

Plasmodium wässerigweiß. Sporangien in Haufen, \pm kugelig, $0,2-0,4 \mathrm{~mm}$, glänzend stroh- oder olivengelb. Capillitium aus meist kurzen, einfachen oder verzweigten, mitunter auch ringförmig schließenden Elateren bestehend. Elateren mit 1-4 unregelmäBigen, \pm verschwommenen Spirallinien oder -leisten, Schinz, Myxogasteres (Rabenhorst Krypt. Flora 1, Pilze Abt. X). 
mitunter auch mit ringförmigen Verdickungen und zerstreuten Stacheln versehen. Sporenmasse leuchtend gelb; Sporen im durchfallenden Lichte gelb, $11-16 \mu$ breit, zum Teil unterbrochen berandet, mit \pm breiten, der Exine aufgesetzten, durchlöcherten Leisten, die zu einem weitmaschigen, unregelmäßigen Netz zusammenschließen.

Deutschland, Österreich, Schweiz; anscheinend nicht häufig. Großbritanuien, N.-Afrika, N.-Amerika.

$1^{*}$. Sporangien in gedrängten Haufen, eiförmig. Peridie mit sehr kleinen Granulationen versehen. Sporen mit regelmäBiger Netzskulptur.

O. Havidum Peck in Rep. N. York Mus. XXXI (1879), 42; Massee Monogr.. 171; Lister in Journ. of. Bot. XIII, 137, Monogr. ed. 2, 220, pl. 165, fig. a-c; Machride N. Am. SlimeMoulds, 220; Torrend in Broteria VII. 59. pl. IX, fig. 17.

Synonyme: Perichrena flavida Peck in Rep. N.-York Mus. XXII (1874), 76.

Oligonema brevifilum Peck in Rep. N.-York Mus. XXXI (1879), 42; Macbride N. Am. Slime-Moulds, 221.

Oligonema nitens Lister Monogr. ed. 1 (1894), 173 pr. p.

Plasmodium wässerigweiß? Sporangien gedrängt, eiförmig oder \pm kugelig, 0,3-0,6 mm, glänzend gelb. Peridie mit Granulationen besetzt, diese \pm fächerartig angeordnet. Elateren kurz oder lang, einfach oder verzweigt, $3-5 \mu$ breit, häufig in ihrem Längsverlauf stellenweise angeschwollen, ohne deutliche Spiralleisten, an deren Stelle regellos zerstreute oder zu Spirallinien angeordnete kleine Warzen. Sporen im durchfallenden Lichte gelb, 12-13 $\mu$, mit $1 \mu$ breitem Rand und regelmäBiger Netzskulptur, bei der 3-5 Maschen auf die Halbkugel entfallen.

Deutschland (Holstein).

Großbritannien, Portugal, N.-Amerika.

\section{Gattung: Calonema Morgan}

Myx. Miami Valley (1893), 33; Macbride N. Am. Slime-Moulds, 208; Lister Monogr., ed. 2, 221; Torrend in Broteria V1, 47, VII, 51 . 
Mit nur einer, in unserm Gebiet noch nicht nachgewiesenen Art:

C. aureum Morgan Myx. Miami Valley (1893), 33; Macbride N. Am. Slime-Moulds, 208, pl. XIII, fig. 2, 2 a, 2b, 2c; Lister Monogr. ed. 2, 221, pl. 165, fig. d-f; Torrend in Broteria VII, 51 , pl. IV, fig. $4,8,9$.

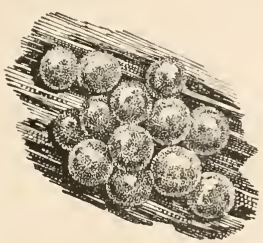

Synonym: Oligonema Havidum var. auremm Lister in Mitt. Naturw. Ges. Winterthur VI (1906), 103 und in Jouru. of Bot. XLV, 193; T'orrend in Broteria V111, 26.

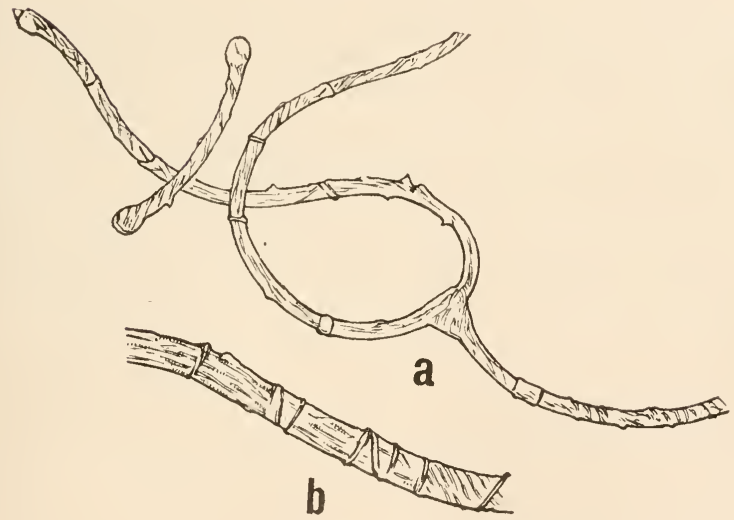

Fig. 156. ( Calonema a ureum Morgan.

a) Elatere $(300 / 1)$; b) Stiick einer Elatere $\left({ }^{820} / 1\right)$. - Nach Lister.

Plasmodium? Sporangien sitzend, gehäuft, 士 kugelig, 0,3 bis $0,6 \mathrm{~mm}$, glänzend goldgelb. Peridie häutig, durchsichtig, mit fächerartig von einem Zentrum ansstrahlenden zarten Verdickungslinien. Capillitiumfäden verzweigt, \pm ein Netz bildend, $3-5 \mu$ 
breit, mit zum Teil ringförmigen, zum Teil unterbrochen spiralförmigen Verdickungslinien oder \pm besetzt mit kleinen War\%en, die entweder reihenartig angeordnet sind oder eine netzartige Aderung bewirken, mitunter stachelig; die freien Enden angeschwollen und stumpf kegelförmig. Sporenmasse gelb; Sporen im durchfallenden Lichte leuclitend gelb, 13-16 «, 1-1,5 $\mu$ breit berandet, Netzskulptur regelmäßig bei $5-6$ Maschen auf einer Halbkugel.

N.-Amerika.

\section{Gattung Hemitrichia Rost.}

Versuch eines Systems der Mycetozoen (1873), 14; Lister Monogr. ed. 1, 174, ed. 2, 222; Macbride N. Am. Slime-Moulds, 200; Torrend in Broteria VI, 47, VII, 44, VIII, 26.

Sporangien sitzend oder gestielt, mitunter Plasmodiokarpien. Stiel solid oder hohl. Capillitium aus einem \pm elastischen Netz verzweigter, häufig stacheliger Fäden mit $2-6 \pm$ deutlichen Spiralleisten bestehend. Sporen glatt, fein warzig oder mit Netzskulptur versehen.

1. Sporen \pm glatt oder fein warzig.

2. Capillitium rot, stachelig.

H. Vesparium (Batsch) Macbride N. Am. Slime-Moulds (1899), 203; Lister Monogr. ed. 2, 223, pl. 166, fig. a-c; Torrend in Broteria VII, 47, pl. IV, fig. 3, 5.

Synonyme: Lycoperdon Vesparium Batsch Elench. Fung. (1786), 253, fig. 172 .

Lycoperdon Bombaciumm Batsch Flench. Fung. (1786), 153?

Stemonitis cinnabariua Roth Fl. Germ. (1788), 547?

Trichia pyriformis Hoffin. Veg. Crypt. II (1790), 1, t. 1, fig. 1. Stemonitis Vesparia Gmel. Syst. nat. (1791), 1470.

Trichia rubiformis Pers, in Röm. N. Mag. Bot. I (1794), 89; Fr. Syst. Myc. III, 183.

T'richia chalybea Chev. Fl. Par. I (1826), 323.

'Trichia Neesiana Corda Icon. I (1837), 23.

T'richia Ayresii Berkeley et Broome in Amn. Mag. Nat. Hist. ser.

2, V (1850), 367.

T'richia fragiformis Wither. Brit. Pl. ed. 2, Ill (1792), 393. 
Craterium porphyrium Schwein, in Trans. Am. Phil. Soc, n. ser. 11 (1832), 258?

Hemareyria rnbiformis Rost. Monogr. (1875), 262, fig. 201, 230, 231.

Hemiarcyria rubiformis var. Neesiana Rost. Monogr. (1875), 263; Massee in Jonru. Mierose. Soc. (1889), 353, fig. 31: Sehröter in Cohn Krypt.-Fl. Schlesien III, 1, 114; Ċelak. Myxom. Böhm., 40.

Areyria rubiformis Massee Monogr. (1892), 158, fig. 262-264. Hemitrichia rubiformis Lister Monogr. ed. 1 (1894), 175, pl. LXIII, A, fig. a-c.

Exsikkaten: Jack, Leiner und Stizenberger 421; Fuckel Fung, rhen. 1438: 0. Jaap Myxom exsicc. 57.

Plasmodium purpurrot. Sporangien herdenweise, einzeln und gedrängt oder zu 6 bis 12 gebüschelt, gestielt oder sitzend, 士 zylindrisch, ketlen-, birn- oder kreiselförmig, samt Stiel 1,3 bis 2,5 $\mathrm{mm}$ hoch, 1-1,3 $\mathrm{mm}$ lang und $0,5-0,7 \mathrm{~mm}$ breit, dunkelrot, rotbraun oder olivenschwarz, oft schön metallisch glänzend. Peridie zweischichtig. Stiele oft zu mehreren der Länge nach verwachsen, $0,2-1 \mathrm{~mm}$ hoch, gefurcht oder höckerig, von der Farbe der Sporangien, keine sporenartigen Zellen einschließend. Capillitiummasse rot oder orangerot, aus gewundenen, spärlich verzweigten, orangeroten, $5-6 \mu$ breiten, mit $3-5$ regelmäßigen Spiralleisten versehenen und zerstreut bestachelten, seltener unbewehrten, anastomosierenden Fäden mit wenigen freien, zugespityten Enden bestehend. Sporenmasse schwarzrot; Sporen im durchfallenden Lichte bla $B$ orangerot, warzig, 10-12 $\mu$.

Im ganzen Gebiet recht häufig.

Kosmopol.

2*. Capillitium gelh, gelbbraun oder gelbgrau. 3. Sporangien in der Regel gestielt.

4. Stiel nicht hohl, ab und zu fehlend.

5. Sporangien orangegelb. Capillitium stachelig, mit deutlichen Spiralleisten. Plasmodium wässerigweiß. Sporangien samt Stiel $1-1,5 \mathrm{~mm}$ hoch, gestielt, \pm kugeligkreiselförmig oder birnförmig, 
$0,3-0,8 \mathrm{~mm}$, glänzend orangegelh. Peridie oberwärts häutig, unterwärts verdickt. Stiel oberwärts sich verdickend, gegen den Grund zu mit 2-4 Längsfurchen, 0,5 bis $0,7 \mathrm{~mm}$ hoch, glänzend purpur-

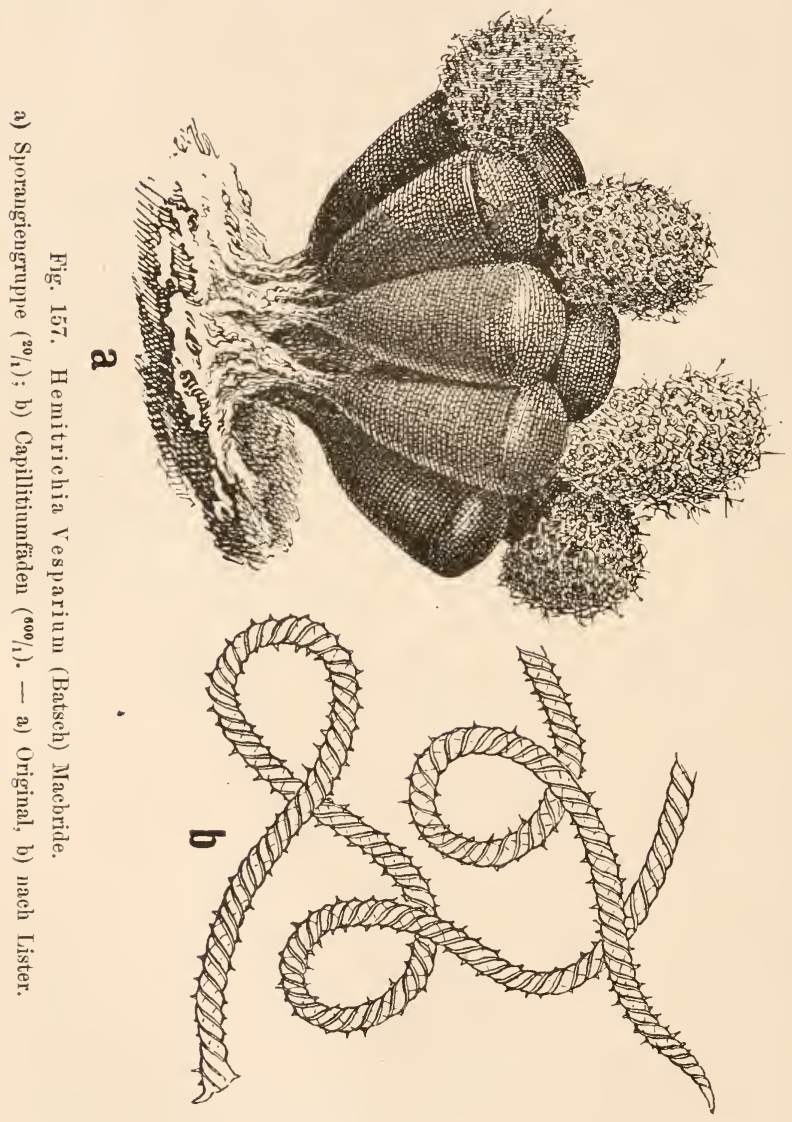


braun. Capillitiumfäden orangegelb, $4 \mu$ breit, mit $4-5$ dichten Spiralleisten, stachelig und mit \pm deutlichen Längslinien. Sporenmasse orangegelb; Sporen im durchfallenden Lichte blasser, fein warzig, $9-10 \mu$.

H. intorta Lister Monogr. ed. 1 (1894), 176, pl. LXIII, B, fig. a-d, ed. 2, 223, pl. 172, fig. a-b; Macbride N. Am. SlimeMoulds, 205; Torrend in Broteria VII, 49.

Synonyme: Hemiareyria intorta Lister in Journ. of Bot. (1891), 268.

Hemiarcyria longifolia Rex in Proc. Acad. Nat. Sc. Phil. (1891), 396.

In unserm Gebiet noch nicht nachgewiesen.

Großbritannien, Skandinavien, N.-Amerika.

$$
\begin{aligned}
& \text { 5*. Sporangien } \pm \text { olivengelb; Capil- }^{\text {litium unbewehrt, die Spiral- }} \\
& \text { leisten wenig deutlicl. }
\end{aligned}
$$

H. leiotricha Lister Monogr. ed. 2. (1911), 224, pl. 172, fig. $c--d$.

Synonyme: Hemitrichia intorta var. leiotricha Lister Monogr. ed. 1 (1894), 17i, pl, LXIII, B, fig. e, d; Torrend in Broteria VII, 49 ; R. F. Fries in Ark. Bot. IV, 5; Petch in Ann. Perad. IV, 363 .

Plasmodium wässerigweiß. Sporangien gestielt, seltener ungestielt, zerstreut, \pm kugelig, 0,5-0,9 mm, glänzend dunkelgelb oder olivenfarbig. Stiel dunkelbraun oder schwarz, gedrungen, $0,1-0,3 \mathrm{~mm}$ hoch. Capillitiumfäden gelb, unbewehrt, spärlich verzweigt, Enden abgerundet oder spitz, mit 3-6, oft undeutlichen Spiralleisten. Sporen im durchfallenden Lichte gelb oder olivenfarbig, $9-13 \mu$, fein warzig.

N.-Deutschland, Schweiz.

Großbritannien, Schweden, Ceylon. 
$5^{* *}$. Plasmodium wässerigzimtbraun. Sporangien gestielt oder sitzend, mitunter Plasmodiokarpien, zerstreut oder paarweise, kugelig, glänzend blaßgelblich; Stiel schwarz, zylindrisch, mit A usschuBmaterial angefüllt, 0,1 bis $0,2 \mathrm{~mm}$ hoch. Capillitiumfäden schlaff, gelblich, $3-4 \mu$ breit, mit $3-4$ wenig deutlichen Spiralleisten, nahezu glatt oder mit zahlreichen, schlanken, 1 bis $4 \mu$ langen Stacheln versehen. Die Fäden oft stellenweise blasig verbreitert. Sporen im durchfallenden Lichte gelb, dicht- und fein warzig, $9-10 \mu$.

H. minor G. Lister in Journ. of Bot. XLIX (1911), 62, Monogr. ed. 2, 225, pl. 187, fig. d-f.

Japan.

- - var. pardina Minakata ap. Lister in Trans. Brit. Myc. Soc. I (1914), 82, pl. I, fig. 3, 3a, 3b, 3c.

Plasmodiokarpien getigert, d. h. dunkelgefleckt. Japan.

$4^{*}$. Stiel hohl, gefüllt mit sporenartigen Zellen.

6. Wandbecher papillös.

H. clavata (Pers.) Lister Monogr. ed. 1, (1894), 177, pl. LXIX, A, fig. a-g, ed. 2, 225, pl. 167, fig. a-f; Macbride N. Am. Slime-Moulds, 206, pl. III, fig. 1, 1 b; Schinz in Mitt. Naturw. Ges. Winterthur VI, 105; Torrend in Broteria VII, 49, pl. IV, fig. 1, 2. 
Synonyme: Trichia clavata Pers. in Röm. N. Mag. Bot. I (1794),

90 ; Rabenhorst Deutschl. Kry],t.-FI. I, 260.

Trichia citrina Schnm. Enum. Pl. Saell. II (1803), 209.

Arcyria decipiens Berkeley in Am. Mag. Nat. Hist. ser. I, IX (1812), 447.

Trichia obtusa Wigand in Pringsheim Jahrb. Bot. III (1863), 30, t. 2, fig. 4 .

Hemiarcyria clavata Rost. Monogr. (1875), 264, fig. 205, 207, 210, 235; Hassee Momogr., 355; Schröter in Cohn Krypt.-Fl. Schles. III, 1, 114; Celak. Myxom. Böhm., 41.

Cornuvia leocarpoides Spegazz. in Ann. Soc. Cient. Argent. XII (1881), 256.

Hemiarcyria calyculata Spegazz. in Ann. Soc. Cient. Argent. X (1880), 152; Massee in Jouru. Microsc. Soc. (1889), 356.

Hemiarcyria stipitata Massee in Journ. Hicrosc. Soc. (1889), 3ð̆4, fig. 32 .

Arcyria clavata Massee Honogr. (1892), 65, fig. 124.

Arcyria calyculata Massee Monogr. (1892), 162.

Areyria stipitata Massee Monogr. (1892), 163.

Arcyria leocarpoides Massee Monogr. (1892), 167.

Hemiarcyria ablata Morgan Myx. Miami Valley (1893), 30.

Hemiarcyria funalis Morgan Myx. Miami Valley (1893), 32.

Hemiarcyria plumosa Morgan Myx. Miami Valley (1893), 29.

Hemitrichia stipitata Macbride N. Am. Slime-Moulds (1899), 207.

Hemitrichia montana Morgan ex Macbride N. Am. Slime-Moulds (1899), 208.

Exsikkaten: Fuckel Fnng. rhen. 1434; Jack, Leiner und Stizenberger 621 .

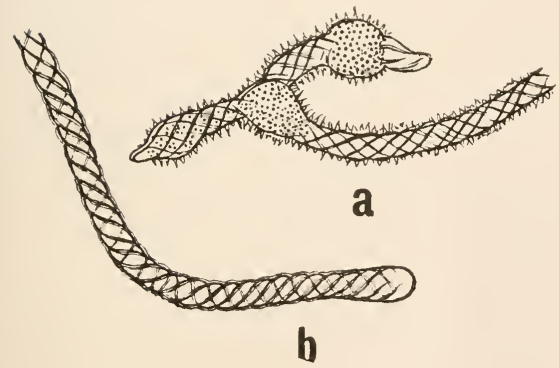

Fig. 158.

Hemitrichia clavata (Pers.)

Lister.

a) und b) Capillitiumfäden $\left({ }^{600} \%_{1}\right)$. - Nach

Lister.

Plasmodium wässerigweiß. Sporangien gestielt, herdenweise, 1-3 mm (samt Stiel), keulen- oder kreiselförmig, selten \pm kugelig, ockergelb, gelblicholivenfarbig oder bräunlich, glänzend, ohne Stiel 
0,7-1,5 mm. Peridie häutig, auf der Innenseite \pm fein papillös, oberwärts zur Zeit der Sporenreife schwindend, wogegen der untere T'eil als Wandbecher zurückbleibt. Stiel $0,5-1,5 \mathrm{~mm}$ hocb, rötlich, rotbraun oder schwärzlich, hohl und mit sporenartigen Zellen angefüllt. Capillitiumfäden gelblicholivenfarbig, verzweigt, $5-6 \mu$ breit, mit 5-6 deutlichen, dicht- oder locker windenden Spiralleisten, glatt oder \pm stachelig. Enden, soweit solche vorhanden, abgerundet oder sogar angeschwollen; Sporenmasse ockergelb; Sporen im durchfallenden Lichte blasser, fein warzig, 8-10 $\mu$.

Durch unser ganzes Gebiet häufig.

Kosmopol.

$6^{*}$. Wandbecher glatt.

H. Jeiocarpa (Cooke) Lister Monogr. ed. 1 (1894), 177, pl. LXIV, B, fig. a-d, ed. 2, 227, pl. 168, fig. a-b; Macbride N. Am. Slime-Noulds, 205; Torrend in Broteria VII, 48, pl. III, fig. 23 .

Synonyme: Hemiarcyria leiocarpa Cooke in Ann. Lyc. Nat. Hist. N.-York XI (1877), 405; Massee in Journ. Mierose. Soc. (1889), 352, fig, 33.

Hemiarcyria Varneyi Rex in Proc. Acad. Nat. Sc. Phil. (1891), 396.

Lachnobolus Rostafinskii Racib. in Rozpr. Mat.-Przyr. Ak. Krak. XII (1884), 80.

Areyria leiocarpa Massee in Jourı. Microsc. Soc. (1889), 167.

Plasmodium? Sporangien zerstreut, gestielt, verkehrteiförmig, birnförmig oder kugelig, samt Stiel 1,5 mm hoch, blaßgran oder ockergelbgrau, 0,7 mm breit. Stiel $0,7 \mathrm{~mm}$ hoch und $0,05 \mathrm{~mm}$ dick, gefurcht, grauockergelb, hohl und mit sporenartigen Zellen angefüllt. Capillitiumfäden \pm blaßgrau bis ockergelb, $2-5 \mu$ breit, mit 3-5 deutlichen Spiralleisten, glatt oder mit zahlreichen langen Stacheln besetzt, freje Enden \pm keulig oder blasig erweitert, stachelig. Sporenmasse blaßgrau; Sporen im durchfallenden Lichte desgleichen, glatt, $6-8 \mu$.

Österreich, Schweiz.

N.-Amerika. 
3*. Sporangien ungestielt.

7. Capillitiumfäden mit $1-3$ vorstehenden Spiralleisten; Peridie durchsichtig.

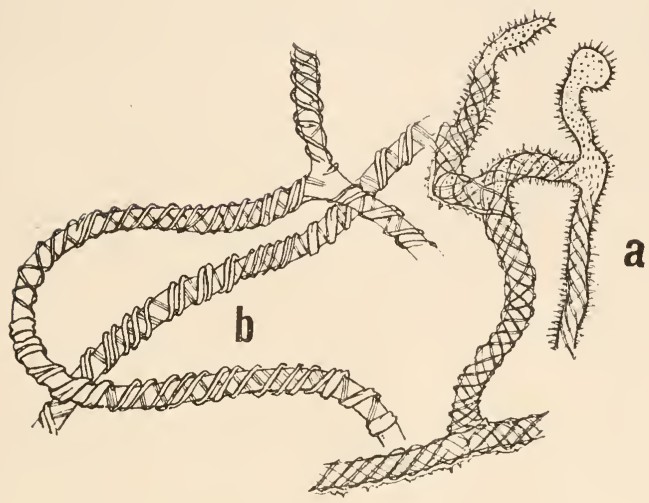

Fig. 159.

a) Capillitiumfäden von Hemitrichia leiocarpa (Cooke) Lister $\left({ }^{600} / 1\right)$; b) Capillitiumfäden von Hemitrichia abietina (Wigand) Lister $\left({ }^{60 \%} / 1\right)$. - Nach Lister.

H. abietina (Wigand) Lister Monogr. ed. 2 (1911), 227, pl. 168, fig. $\mathrm{c}-\mathrm{e}$.

Syuonyme: Trichia abietina Wigand in Pringsheim Jahrb. Bot. III (1863), 33, t. II, fig. 11.

T'richia naua Massee in Journ. Microse. Soc. (1889), 336, fig. 12, Monogr., 181.

Hemiarcyria Wigandii Rost. Monogr. (1875), 267, fig. 232; Massee in Journ. Hicrose. Soc. (1889), 356.

Areyria Wigandii Massee Monogr. (1892), 163.

Hemitrichia ovata Macbride N. Am. Slime-Moulds (1899), 202; Torrend in Broteria VII, 46, pl. III, fig. 25.

Trichia ovata Macbride N. Am. Slime-MIoulds (1899), 202 non Pers. Exsikkaten: 0. Jaap Myxom. exsicc. 58.

Plasmodium rosarot. Sporangien herdenweise, oft gedrängt, ganz kurz gestielt oder sitzend, \pm kugelig oder kreiselförmig, 0,3-0,7 mm, matt oder glänzend, gelb, ockergelb oder aprikosen- 
farbig. Peridie im untern Teil meist als Becher hleilend. Stiel 0,1-0,3 $\mathrm{mm}$ hoch, mit sporenartigen Zellen erfüllt. Capillitiumfäden spärlich verzweigt, schlaff, ockergelb, $3-5 \mu$ breit, mit $1-3$ vorstehenden, \pm locker windenden, unregelmäßigen Spiralleisten, freie Enden nicht selten blasig erweitert und abgerundet. Sporenmasse gelb oder ockergelb; Sporen im durchfallenden Lichte blaßgelb, fein warzig, $9-12 \mu$.

Deutschland, Schweiz.

Großbritannien, Portugal, Skandinavien, N.-Amerika.

- f. lutea Meylan in Bull. Soc. Vand. Sc. nat. XLVI (1910), 53 .

Sporangien und Capillitiummasse lebhaft gelb. Jura.

- - f. aurantiaca Meylan in Bull. Soc. Vand. Sc. nat. XLVI (1910), 53.

Sporangien und Capillitiummasse orangegelh. Jura.

$7^{*}$. Capillitiumfäden mit 3 oder mehr wenig deutlichen Spiralleisten. Peridie granulös verdickt (vergl. indessen var. lutescens).

H. Karstenii (Rost.) Lister Monogr. ed. 1 (1894), 178, pl. LXV, A, fig. a-c, ed. 2, 228, p]. 171, fig. a-d; Macbride N. Am. Slime-Moulds, 202; Schinz in Mitt. Naturw. Ges. Winterthur VI, 106; Torrend in Broteria VIl, 45, pl. III, fig. 22, IX, fig. 24 .

Synonyme: Hemiarcyria Karstenii Rost. Honogr. App. (1876), 41; Massee in Journ. Microse. Soc. (1889), 3ă2, fig. 36; Schröter in Cohn Krypt.-Fl. Schles. III, 1, 115.

Hemiarcyria paradoxa Massee in Journ. Nicrose. Soc. (1889), 356, fig. 35 .

Hemiarcyria obscura Rex in Proc. Acad. Nat. Sc. Phil. (1891), 395. Areyria Karstenii Massee Monogr. (1892), 168.

Arcyria paradoxa Massee Monogr. (1892), 160, fig. 272. 
Hemitrichia helvetica Meylan in Bull. Soc. Vaud. Sc. nat. XLVI (1910), 54?

Perichæna cornuvioides Celak. Hyxom. Böhm. (1893), 26, pl I, fig. 6,7 .

Plasmodium wässerigweiß oder wässerigzimtbraun (nach $\mathrm{Mi-}$ nakata). Sporangien sitzend, zerstreut, \pm kugelig, oft an Stelle solcher längliche, gewundene, $0,25-0,5 \mathrm{~mm}$ breite Plasmodiokarpien, blaßgelblichbraun, rot- oder purpurbraun. Capillitiumfäden gelblich oder rötlichbraun, ein lockeres Netzwerk bildend, 3-5 " breit, mit sehr undeutlichen Spiralleisten, mit zerstreuten, aber \pm zahlreichen, ringförmigen Verdickungen und Verbreiterungen der Netzknoten; die Fäden sind überdies stellenweise lokal verbreitert und besitzen spitze oder stumpfe freie Enden. Sporenmasse gelb oder goldgelb: Sporen im durchfallenden Lichte gelb, $9-15 \mu$, fein war\%ig.

Deutschland, Österreich, Schweiz.

Großbritamien, Frankreich, Portugal, skandinavien, kußlant, kumänien, Ceylon, N.-Amerkia.

- var. lutescens Torrend in Broteria VII (1908), 46.

Fruchtkörper goldgelb, nie mit Granulationen.

H. Karstenii ist sozusagen eine Verlegenheitsart, umfassend verschiedenartige Elemente, denn wir bringen in ihr vorläufig mit Lister und Torrend Formen unter, die möglicherweise doch nichts anderes sind als hemitriche Formen von Trichia-Arten ('T. contorta, T. lutescens, 'T. affinis); vielleicht ist auch $\mathrm{H}$. helvetica Meylan eine solche hemitriche Form von T. affinis.

$1^{*}$. Sporeu mit Netzskulptur.

8. Capillitiumfäden \pm stachelig.

H. Serpula (Scop.) Lister Monogr. ed. 1 (1894), 179, pl. LXVI, A, fig. a c, ed. 2, 229, pl. 170, fig. a-c; Macbride N. Am. Slime-Moulds, 201; Schinz in Mitt. Naturw. Ges. Winterthur VI, 106; Torrend in Broteria VII, 44, pl. III, fig. 21.

Sунопуше: Mucor Serpula Scop. Fl. Carı. ed. 2, II (1772), 493.

Iycoperdon lumbricale Batsch Fung. Cont. I (1786), 259, t. 30,

fig. 174 . 
Trichia spongioides Vill. Pl. Danph. (1789), 1061.

Stemonitis lumbricalis Gmel. Syst. Nat. (1791), 1470.

Trichia Serpula Pers. in Röm. N. Mag. Bot. I (1794), 90.

Trichia reticulata Pers. in Röm. N. Mag. Bot. 1 (1794), 90.

Trichia venosa Schum. Enum. Pl. Saell. II (1803), 207.

Hemiarcyria Serpula Rost. Monogr. (1875), 266, fig. 200, 227, 228; Massee in Journ. Microse. Soc. (1889), 357, fig. 34; Schröter in Cohn Krypt.-Fl. Schles. III, 1, 115; Celak. Myxom. Böhm., 41.

Arcyria Serpula Massee Monogr. (1892), 164, fig. 273, 274a. Exsikkaten: Fuckel Fungi rhen. 2692.

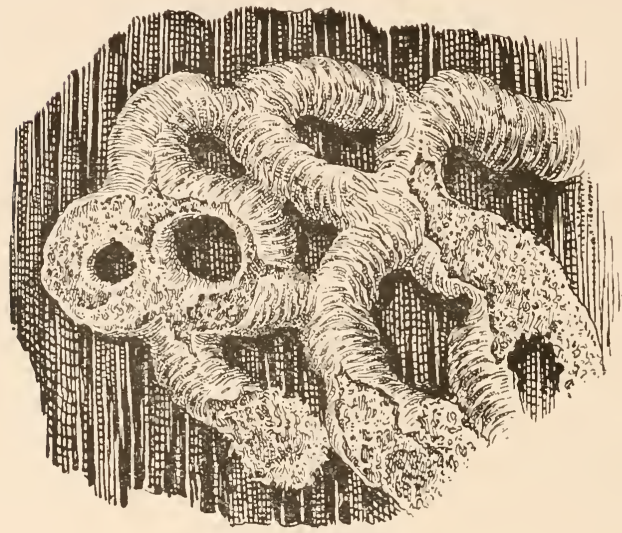

Fig. 160.

Hemitrichia Serpula (Scop.) Lister. Plasmodiokarp $\left({ }^{20} / 1\right)$. - Nach Lister.

Plasmodium gelb. Plasmodiokarpien kriechend, \pm wurmförmig, meist netzartig verbunden und oft mehrere Quadratzentimeter bedeckend, goldgelb bis bräunlichgelb. Capillitium eine elastische Masse durcheinander gewirkter und gewundener, spärlich verzweigter, $5-6 \mu$ breiter, mit $3-4$, seltener $5-6$ deutlich wahrnehmbaren Spiralleisten versehener, regelmäßiger, glatter oder stacheliger Fäden, deren freie Enden spitz oder zugespitzt sind. Sporenmasse goldgelb; Sporen im durchfallenden Lichte gelb, $0,5-1$ " breit berandet, netzartig skulptiert, mit 9 bis 12 oder mehr Maschen im Gesichtsfeld, 10-12 $\mu$. 
Dentschland, Österreich, Schweiz.

Kiosmoprolit.

8*. Capillitiumfäden unbewehrt.

H. chrysospora Lister Monogr. ed. 1 (1894). 180, pl. LXV, B, fig. a-c, ed. 2, 230, pl. 169, fig. a-c; Torrend in Broteria VII, 45 .

Synonyme: Hemiarcyria chrysospora Lister in Grev. XV (1887), 126; Massee in Joum. Microse. Soc. (1899), 357, fig. 37.

Arcyria chrysospora Massee Monogr. (1892), 164, fig. 268, 269.

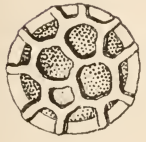

a

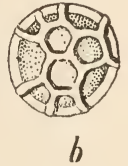

Fig. 161.
Sporen: a. von Hemitrichia chryrospora Lister.

b. von Hemitrichia Serpula (Scop.) Rost. - $1200 \times$ - Nach Massee.

Plasmodium? Entweder sitzende, gedrängte oder zerstreute, — kugelige, 0,5-1 mm im Durchmesser messende Sporangien oder an deren Stelle polsterförmige Plasmodiokarpien; Fruchtkörper dieser oder jener Art glänzend gelb. Capillitiumfäden gelb, $4-5 \mu$ breit, mit 4-5 dicht windenden, regelmäßigen Spiralleisten und Längslinien, mit zahlreichen, kurz bespitzten, vielfach an der Peridie befestigten freien Enden. Sporen im durchfallenden Lichte gell, $1,5-2 \mu$ breit berandet, netzartig skulptiert, mit nur 6-9 Maschen im Gesichtsfeld, 14 bis $18 \mu$.

Deutschland (Holstein).

(iroßbritamien.

\section{Gattung Cornuvia Rost.}

Versuch eines Systems der Mycetozoen (1873), 15 pr. p., Monogr., 289 pr. p.; Lister Monogr. ed. 1, 181, ed. 2, 231; Schinz in Mitteil. Naturw. Ges. Winterthur VI, 107; Torrend in Broteria VI, 47, VII, 43, VIII, 26. 
Mit nur einer Art:

C. Serpula (Wigand) Rost. in Jahrb. Nass. Ver. Naturk. XXVII/XXV'llI (1873/74), 76 und in Monogr., 289 pr. p; Lister Monogr. ed. 1, 181, pl. LXVI, A, fig. d-f, ed. 2, 231, pl. 170, fig. d, e; Torrend in Broteria VII, 43, pl. III, fig. $18-20$.

Synonyme: Areyria Serpula Wigand in Pringsh. Jahrb. Bot. III (1863), 44, t. III, fig. 18.

Ophiotheca Serpula Massee Monogr. (1892), 135.

Plasmodium rahmweiß. Entweder sitzende, \pm kugelige. $0,3 \mathrm{~mm}$ große, glänzend goldgelbe Sporangien oder verzweigte, netzartig anastomosierende, wurmförmig gekrimmte, gleich den Sporangien gefärbte Plasmodiokarpien. Capillitium ein Netzwerk reichlich verzweigter, gelber, $3-5 \mu$ breiter Fäden mit vorstehenden, ringförmigen Verdickungen, die entweder \pm regellos zerstreut oder gruppenweise dichter gestellt sind. Sporen im durchfallenden Lichte gelb, $0,5-1 \mu$ breit berandet, netzartig skulptiert, mit 8-12 Maschen im Gesichtsfeld, 10-12 $\mu$.

Deutschland.

Großbritamien, Ceylon, Australien, Japan, W.-Indien, N.-Amerika, 0.-Afrika.

\section{Familie Arcyriaceae}

Rost. Versuch eines Systems der Mycetozoen (1873), 15, Monogr.. 267; Čelak. Myxom. Böhm., 27; Lister Monogr. ed. 1, 182, ed. 2, 231; Schröter in Engler u. Prantl Natürl. Pflanzenfam. I, 1, 22 pr. p.; Schinz in Mitt. Naturw. Ges. Winterthur VI, 107; Macbride N. Am. Slime-Moulds, 186; Torrend in Broteria VI, 45, VII, 29, VIII, 26.

Sporangien meist gestielt, kugelig oder \pm zylindrisch. meist durch einen Kreisriß sich öfnend. Peridie oberwärts schwindend, unterwärts als Becher am Stiel stehen bleibend (bei A. occidentalis durch Längsrisse sich aufspaltend). Capillitium netzartig, 
entweder mittelst \pm zahlreicher freier Enden an der Innenfläche des Bechers befestigt oder einzelne Capillitiumfäden eingekeilt zwischen die sporenartigen \%ellen, die das Füllmaterial des hohlen Stieles bilden oder das Capillitium ganz frei vom Becher.

\section{Schlüssel zur Bestimmung der Gattungen der Familie der Arcyriaceae.}

1. Capillitium elastisch, beim Öffnen des Sporangiums sich gewissermaßen aufblähend.

Arcyria Wiggers.

$1^{*}$. Capillitium nicht elastisch.

2. Sporangien ungestielt, über- und nebeneinander gehäuft zu polsterartigen Haufen. Sporen $6-8 \mu$.

Lachnobohus Fr.

$2^{*}$. Sporangien ungestielt (mitunter Plasmodiokarpien) oder gestielt, zerstreut oder \pm dicht nebeneinander oder gehäuft überund nebeneinander; dann aber Sporen $\mathbf{1 5}$ bis 17 ( $P$. pulcherrimu) $\mu$.

Perichæna Fr.

\section{Übersicht der Gattungen.}

Arcyria. Einzelsporangien, meist \pm deutlich gestielt. Peridie meist durch einen Kreisriß zerreißend, oberer Teil der Peridie schwindend, der untere als Becher erhalten bleibend, bei $A$. occidentalis längs einreißend. Capillitiumnetz elastisch, Fäden meist mit Verdickungen in Form von Kämmen, halben oder ganzen Ringen.

Lachnobolus. Einzelsporangien ungestielt, in halbrunden, polsterförmigen Haufen dicht neben- und übereinander. Capillitiumnetz nicht elastisch, Fäden mit warzenartigen Verdickungen.

Perichæna. Einzelsporangien meist ungestielt oder Plasmodiokarpien. Capillitiumfäden verzweigt oder einfach, nicht elastisch, meist ohne eigentliche Verdickungen, aber häufig mit zahlreichen Einschnürungen und Stacheln oder Warzen. 


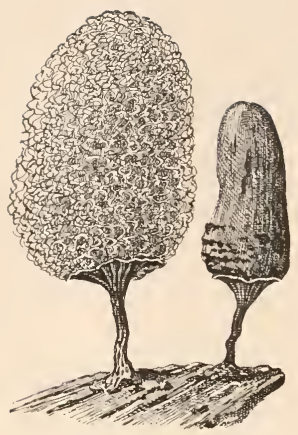

Fig. 162 .

Arcyria deundata (L.) Wettstein.

Sporangiengruppe $(15 / 1)$. -

Nach Lister.

Fig. 164.

Perichana corticalis (Batseh) Rost.

Sporangiengruppe $(20 / 1)$ - Original.

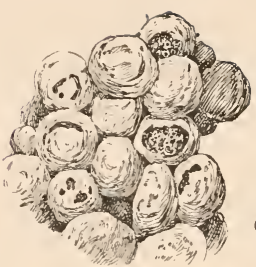

a

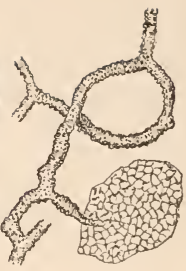

b
Fig. 163.

Lachnobolus congestus (Sommerfelt) Lister.

a) Sporangiengruppe $\left({ }^{15} / 1\right)$; b) Capillitiumfaden mit einem Stück der Peridie $\left({ }^{\mathbf{4 0 0}} / \mathbf{1}\right)$.

\section{Nach Lister.}

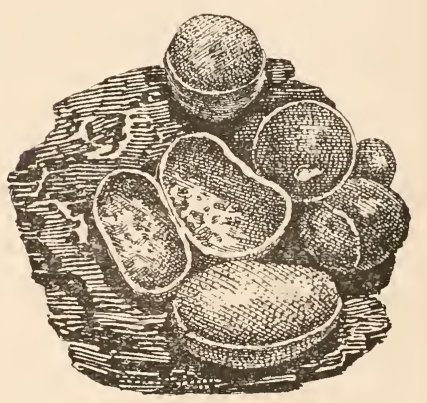

\section{Gattung Arcyria Wiggers}

Fl. Holsat. (1780), 109; Rost. Versuch eines Systems der Mycetozoen, 16, Monogr., 268; Rabenhorst Deutschl. Krypt.-Fl. 1, 257; Schröter in Cohn Krypt.-Fl. Schles. III, 1, 109, in Engler u. Prantl Natürl. Pflanzenfam. I, 1, 22; Čelak. Myxom. Böhm., 27; Massee Monogr., 141 pr. p.; Lister Monogr. ed. 1, 183, ed. 2, 232; Macbride N. Am. Slime-Moulds, 189; Schinz in Mitt. Naturw. Ges. IVintherthur VI, 108; Torrend in Broteria VI, 46, VII, 37, VIII, 26. 
Sporangien meist gestielt, \pm kugelig oder häufiger verlängerteiförmig, durch einem Querriß oder, bei $A$. occidentalis durch Längsrisse sich öffnend oder Peridie \pm unregelmäßig zerreißend; oberer Teil der Peridie schwindend, unterer mit Ausnahme von $A$. occidentalis als kelchartiger Becher bleibend. Stiel mit sporenartigen Zellen erfüllt. Capillitumnetz \pm elastisch, entweder gan\% frei vom Becher oder mit \pm zahlreichen freien Enden der Capillitiumfäden dem Becherinnern angewachsen oder die freien Enden zwischen die sporenartigen Zellen im Stiel eingekeilt. Fäden mit Verdickungen in Form von halben, bei A. annulifera sehr kleinen ganzen Ringen, Kämmen, Stacheln oder \pm undeutlichen Spirallinien.

1. Sporen 9-11 $\mu$. Sporangien orangerot oder lederbraun.

2. Sporangien \pm eiförmig, Peridie auf der Innenseite mit rundmaschiger Netzzeichnung.

A. ferruginea Sauter in Flora XXIV (1841), 315; Rost. Monogr., 279, fig. 194; Massee Monogr., 144, fig. 250-253; Schröter in Cohn Krypt.-Fl. Schles. III, 1, 110; Lister Monogr. ed. 1, 184, pl. LXVI, B, fig. a-g, ed. 2, 234, pl. 173, fig. $\mathrm{a}-\mathrm{h}$ und in Journ. of. Bot. XXXY, 216 und XLII, 139, pl. 459, fig. 5; Macbride N. Am. Slime-Moulds, 194; Schinz in Mitt. Naturw. Ges. Winterthur VI, 109, Torrend in Broteria VII, 37, pl. III, fig. $8-12,14$.

Synonyme: Sphærocarpus coccineus Bull. Champ. (1791), 126, t. 368, fig. 1 ?

Stemouitis coccinea Gmel. Syst. Nat. (1791), 1468?

Arcyria dictyonema Rost. Monogr. (1875), 279, fig. 195; Čelak.

Myxom. Böhm., 27; Massee Monogr., 154.

Areyria intricata Rost. Monogr. App. (1876), 37.

Arcyria cimnamomea Hazsl. in Öst. Bot. Zeitschr. XXVII (1877), 84.

Arcyria bonariensis Speg. in Ann. Soc. Cient. Argent. X (1880), 151?

Arcyria macrospora Peck in Rep. N.-York State Mus. XXXIV (1881), 43.

Trichia coccinea Lam. et DC. Fl. Fr. II (1815), 255.

Arcyria coccinea Duby Bot. Gall. 11 (1828/30), 857?

Arcyrella inermis Racib. in Pozpr. Mat. Przyr. Ak. Krak. XII (1884), 82. 
Arcyrella decipjens Racib. in Rozpr. Mat. Przyr. Ak. Krak. XII (1884), 84?

Arcyria aurantiaca Raunk. in Bot. Tidsskr. (1888), 61, t. 3, fig. $4,9,11$.

Areyria Raciborskii Berlese in Sacc. SylI. VII (I888), 430?

Areyrella cornuvioides Racib. in Hedw. XXVIII (1889), 123? Arcyria clavata Čelak. Myxom. Böhm. (I893), 29.

Trichia polymorpha Sow. ap. Lister Monogr. ed. 2 (1911) 234. Exsikkaten: Fuckel Fungi rhen. 1444.

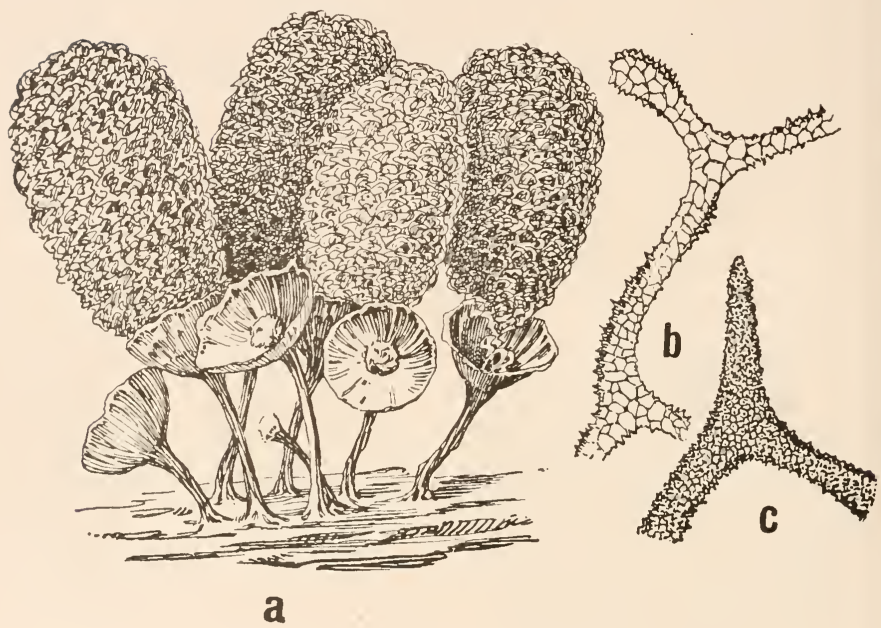

Fig. 165. Arcyria ferruginea Sauter.

a) Sporangiengruppe $(20 / 1)$; b) und c) Stücke der Capillitiumfäden $\left({ }^{600} / 1\right)$. Nach Lister.

Plasmodium rosarot oder rahmgelb. Sporangien samt Stiel 1-2 $\mathrm{mm}$ hoch, herdenweise, kreisel- oder eiförmig oder zylindrisch, $0,7-1,3 \mathrm{~mm}$ lang und $0,5-1 \mathrm{~mm}$ breit, ziegel- oder orangerot, fleischrot bis rot, seltener gelb, mit stehenbleibendem glänzendem, trichterförmigem oder schließlich fast flachem, auf der Innenseite netzartig rundmaschig geadertem oder gefälteltem Wandbecher. Stiel walzlich, 0,3-0,8 mm lang und bis $1,5 \mathrm{~mm}$ dick, rot oder weiß, aus gut ausgebildetem Hypothallus sich erhebend. Capillitiumfäden, abgesehen von vereinzelten schlankeren und 
glatteren in den Stiel eindringenden Fäden, vom Wrandbecher frei, reichlich verzweigt, rötlichgelb bis gelb, 5-6 $\mu$ breit (gegen den Grund des Netzes werden die Fäden dünner und sind dann nur noch 2--3 $\mu$ breit), im Querschnitt dreieckig oder oval, meist dicker auf einer Seite und mit querverlaufenden, dicht stehenden, netzartig verbundenen und in lockerer Spirale angeordneten Leisten versehen; auf den beiden anderen Seiten des dreieckigen Querschnittes mit schwachen, unterbrochen netzartigen V'erdickungen oder mit Warzen, häufig stachelig. Freie Capillitiumfadenenden nicht selten, diese abgerundet oder spitz. Sporenmasse rötlich oder \pm ockerfarbig; Sporen im durchfallenden Lichte blabrot oder ockergelb, undeutlich dicht warzig, 8-11 $\mu$.

- var. Heterotrichia (Massee) Torrend in Broteria VII (1908), 38; Lister Monogr. ed. 2, 234, pl. 173, fig. f.

Synonyme; Heterotrichia Gabriellæ Massee Monogr. (1892), 140, fig. 205-207; Macbride N. Am. Slime-Moulds, 198, pl. XIII, fig. 1, 1 a.

Arcyria Gabriellæ Rav. in Macbr. N. Am. Slime-Moulds (1899), 198. Trichia fulva Wither. Brit. Pl. 2, ed. 2, IV (1796), 391?

Capillitiumnetz mit zahlreichen zugespitzten freien Enden, dicht netzartig skulptiert und dicht stachelig, 5-8 " breit.

Deutschland, Österreich, Schweiz.

Kosmopol.

2*. Sporangien \pm keulenförmig; Peridie auf der Innenseite papillös.

A. versicolor Phillips in Grev. V (1877), 115, t. 88, fig. 8, a-e; Massee Monogr., 149; Lister Monogr. ed. 1, 185, pl, LXVII, A, fig. a-c, ed. 2, 235, pl. 175, fig. a-c; Torrend in Broteria VII, 39.

Synonym: Arcyria vitellina Phillips in Grev. V (1877), 115, t. 88, fig. 7, a, e; Macbride N. Am. Slime-Moulds, 192.

Plasmodium? Sporangien samt dem $0,2 \mathrm{~mm}$ langen Stiel 2,5-3 mm hoch, mitunter sitzend, herdenweise, birn- oder keulenförmig, 1-2 mm dick, gelb oder olivengelb, \pm glänzend, nur das oberste Drittel der auf der Innenseite papillösen Peridie 
schwindend; Stiel gelbbraun, auf wohlentwickeltem Hypotallus. Capillitiumnetz aus reichlich verzweigten, $4-6 \mu$ breiten Fäden von dreieckigem oder ovalem Querschnitt bestehend; Capillitiumfäden entweder gleichmäßig stachelig und unterbrochen netzartiger Skulptur oder einseitig verdickt und mit Warzen oder Querleisten. Sporenmasse gelb; Sporen im durchfallenden Lichte blaßgelb oder fast farblos, glatt, $8-10 \mu$.

Schweiz (Jura).

N.- und S.-Amerika.

1*. Sporen $6-8 \mu$.

3. Wandbecher sich nicht in Lappen aufteilend.

4. Capillitium am Wandbecher befestigt.

5. Sporangien rot oder rosarot.

6. Capillitiumfäden mit kammartigen Verdickungen und halben Ringen.

C. denudata (L.) Wettstein in Verh. Zool.-bot. Ges. Wien (1885) (1886), 585; Sheldon in Minnes. Bot. Stud. I (1895), 470; Lister Monogr. ed. 2, 239, pl. 174, fig. a-c; Macbride N.-Am. Slime-Moulds, 195, pl. II, fig. 5, 5 a.

Synonyme: Clathrus denudatus L. Syst. Nat. (1753), 1179.

Mucor clathroides Scop. Fl. Carn. ed. 2, 11 (1772), 493.

Mucor pyriformis Leers Fl. Herborn. (1775), 288.

Lycoperdon rufum Dickson Pl. Crypt. Brit. I (1785), 25?

Embolus crocatus Batsch Elench. Fung. Cont. I (1786), 265, fig. 177.

Stemonitis coccinea Roth Fl. Germ. (1788), 548.

Trichia denudata Vill. Pl. Dauph. (1789), 1060.

Trichia graniformis Hoffm. Veg. Crypt. I (1790), 3.

Stemonitis crocea Gmel. Syst. Nat. (1791), 1467.

Trichia cinnabarina Bull. Champ. (1791), 121, t. 502, fig. 1, b, c. Trichia rufa Wither. Brit. Pl. ed. 2. II (1792), 478.

Areyria punicea Pers. in Röm. N. Mag. Bot. I (1794), 90;

Rabenhorst Deutschl. Krypt.-Fl. 1, 258; Rost. Monogr., 268, fig. 190, 192, 197; Schröter in Cohn Krypt.-F]. Schles. III, 1, 109; Čelak. Myxom. Böhm., 27; Lister Monogr. ed. 1, 188, pl. LXVIII, A, a, b; Schinz in Mitt. Naturw. Ges. Winterthur VI, 186; Torrend in Broteria VII, 40.

Stemonitis crocata Roth Cat. Bot. I (1797), 220. 
Trichia purpurea Sehum. Enum. Pl. Saell. II (1803), 211?

Areyria carnea Schumann Enum. Pl. Saell. 11 (1803), 213?

Arcyria dentata Schum. Enum. Pl. Saell. Il (1803), 213?

Areyria rufa Schum. Enum. Pl. Saell. II (1803), 214?

Arcyria melanocephala Schum. Enum. Pl. Saell. 11 (1803), 214.

Arcyria cincta Schum. Enum. Pl. Saell. II (1803), 215?

Arcyria conjugata Schum. Enum. Pl. Saell. II (1803), 215.

Arcyria cylindrica Schum. Enum. Pl. Saell. Il (1803), 215.

Arcyria fusca Fr. Symb. Gastr. (1818), 17?

Arcyria vernicosa Rost. Monogr. App. (1876), 36.

Exsikkaten: Rabenhorst Fung. eur. 1914; Fuckel Fung. rhen. 1441; Jack, Leiner u. Stizenberger 613; Sydow Myc. Mareh. 915; Wien Hofmus. Krypt. exsicc. 408; O. Jaap Myxom. exsicc. 59.

Plasmodium weiß. Sporaugien samt Stiel 2-3 $\mathrm{mm}$ hoch, gehäuft oder herdenweise, eiförmig oder zylindrisch, $0,9-1,8 \mathrm{~mm}$ lang und 0,8-1 $\mathrm{mm}$ breit, karmin- oder dunkelrot bis rötlichbraun oder braun, mitunter blaßrot. Wandbecher glänzend, gefältelt oder gestreift, auf der Innenseite glatt oder zerstreut papillös oder unterbrochen netzartig verdickt. Stiel bis $1 \mathrm{~mm}$ hoch, rotbraun, gefurcht. Capillitiumfäden ziemlich stark abgeflacht oder im Querschnitt rund, blaßrot, $2-5 \mu$ breit; Verdickungen der Fäden in F'orm von halben Ringen oder von Stacheln abwechselnd mit spiralig angeordneten halben Ringen, das Netz ohne oder mit nur wenigen freien Fadenenden. Sporenmasse rot oder rotbraun; Sporen im durchfallenden Lichte blaßrot bis nahezu farblos, fast völlig glatt, abgesehen von einigen zerstreuten Warzen, $6-8 \mu$.

Durch das ganze Gehiet verbreitet und häufig.

Kosmopol.

$6^{*}$. Capillitiumfäden mit Verdikkungen in Form von Querleisten und mit sehr kleinen Stacheln, mitunter auch fast glatt.

A. insignis Kalchbr, et Cooke in Grev. X (1882), 143; Massee Monogr., 148; Lister Monogr. ed. 1, 188, pl. LXVIII, A, fig. c, d, ed. 2, 240, pl. 181, fig. a, b; Torrend in Broteria VII, 39. 


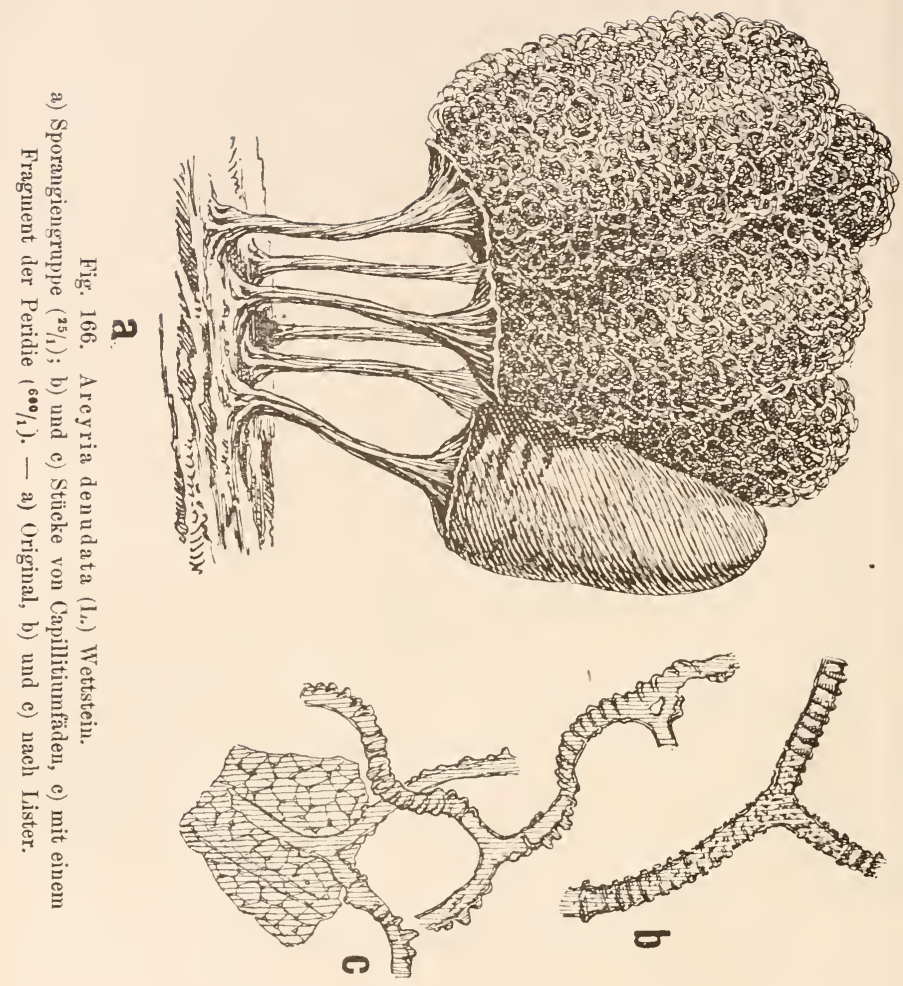

Plasmodium wässerigweiß. Sporangien samt Stiel 0,5-1,5 mm hoch, herden- oder gruppenweise, eiförmig oder zylindrisch, 0,3 bis 0,4 mm breit, blaß-oder leuchtend rosenrot. W Wandbecher gefältelt, fein stachelig oder \pm glatt. Stiel rot, gefurcht, $0,2-0,4 \mathrm{~mm}$ hoch. Capillitium aus nahezu farblosen, zarten, $2-5 \mu$ breiten, abgeflachten Fäden mit schwach angeprägten Querleisten, kurzen. spiralig angeordneten Stacheln; im iibrigen die Capillitiumfäden sehr fein stachelig oder nahezu glatt. Sporen im durchfallenden Lichte fast farblos, nahezu glatt, $6-8 \mu$. 
Deutschland, Österreich.

Großbritannien, Portugal, Rumänien, Afrika, ('eylon, Java, Jajan, W.-Indien, N.- und S.-Amerika.

$5^{*}$. Sporangien blaß seegrün, gestielt, in Gruppen von 4 bis 20, eiförmig oder zylindrisch, $0,4-2,5 \mathrm{~mm}$ hoch und $0,4-0,8 \mathrm{~mm}$ breit. Wandbecher etwas gefältelt, trichterförmig. Stiel blaßgrün oder graubraun, gekrümmt und schwach, 0,2-0,3 $\mathrm{mm}$ hoch. Capillitiumfäden blaß, 2,5-3 $\mu$ breit, mit wenigen freien, stumpfen Enden, mit vorstehend kammartigen Querleisten, sonst glatt oder mit zerstreuten, sehr kleinen Stacheln, unregelmäßiger Netzskulptur oder mit 3-4 Spirallinien. Sporen im durchfallenden Lichte bla $B$ seegrün, nahezu glatt, $7 \mu$.

A. glauca Lister ex Minakata in Bot. Mag. Tokyo XXII (1908), 322, Monogr. ed. 2, 241, pl. 182, fig. a, b.

Japan, Australien.

$5^{* *}$. Sporangien keulenförmig, grau oder gelblich. Capillitium dicht stachelig oder warzig.

A. cinerea (Bull.) Pers. Syn. Fung. (1801), 184; Rabenhorst Deutschl. Krypt.-Fl. I, 257; Rost. Monogr., 272, fig. 182-185, 193; Massee Monogr., 151, pr. p., fig. 137-139, 248, 249; Schröter in Cohn Krypt.-Fl. Schles. III, 1, 109; Čelak. Myxom. Böhm., 28; Macbride N. Am. Slime-Moulds, 196, pI. II, fig. 3, 3 a; Torrend in Broteria VII, 41; Lister Monogr. ed. 2, 236, pl. 176, fig. a-e. 
S ynonyme: Trichia cinerea Bull. Champ. (1791), 120.

Stemonitis einerea Gmel. Syst. Nat. (1791), 1467.

Arcyria albida Pers. in Röm. N. Mag. Bot. I (1794), 90; Lister ed. 1, 186, pl. IxXVII, B, fig. a-i; Schinz in Mitt. Naturw. Ges. Winterthur V1, 110.

Stemonitis glauca Trentep. in Roth Cat. Bot. I (1797), 221.

Stemonitis digitata Schwein. in Trans. Am. Phil. Soc. 1. s. IV (1832), 260.

Arcyria straminea Wallr. Fl. Crypt. Germ. IV (1833), 383?; Rabenhorst Deutschl. Krypt.-FI. 1, 257.

Arcyria trichioides Corda Icon. II (1838), 23, t. 12, fig. 86; Rabenhorst Deutschl. Krypt.-Fl. 1, 258.

Stemonitis grisea Opiz in Lotos (1855), 215.

Arcyria Leprieurii Montagne in Ann. Sc. nat. Bot. sér. 4, III (1855), 141.

Arcyria bicolor Berkeley et Curtis in Journ. Limn. Soc. X (1869), 349.

Arcyria pallida Berkeley et Curtis in Grev. II (1873), 67.

Arcyria digitata Rost. Monogr. (1875), 274; Massee Monogr., 157; Macbride N. Am. Slime-Moulds, 197.

Lachnobolus Arcyrella Rost. Monogr. (1875), 431; Massee Monogr. 138 ?

Areyria stricta Rost. Monogr. App. (1876), 36.

Arcyria Friesii Berkeley et Broome in Ann. Mag. Nat. Hist. ser. 4 XVII (1876), 140.

Comatricha albida Schulzer in Öst. Bot. Zeitschr. XXVII (1877), 67 und in Just. Bot. Jahrb. (1877), 155.

Areyria Cookii Massee Monogr., (1892), 154.

Areyria tenuis Schröter in Hedw. XXXY (1896), 207.

Exsikkaten: Fuckel Fung. rhen. 1440; Sydow Myc. March. 1499; Rabenhorst Fungi eur. 369; Wien. Hofmus. Krypt exsice. 407; O. Jaap Myxom. exsicc. 78, 200.

Plasmodium grauweiß. Sporangien gestielt, vereinzelt, herdenweise oder zu kleinen Grüppchen dicht zusammentretend, samt Stiel $0,8-4 \mathrm{~mm}$ hoch, oder bis zu 18 gebüschelt, eiförmig oder zylindrisch, seltener kugelig, 0,5-1,2 mm dick, blaßgrau, bläulichgrau, grünlichgran oder graufleischfarbig, mitunter trübgelb; Wandbecher blaßgrau oder gelblich. Stiel aufrecht, gefurcht, dunkelgrau oder braun, bis $2 \mathrm{~mm}$ lang und bis $0,15 \mathrm{~mm}$ dick. Capillitiumfäden grau oder gelblichgrau, die den Grund des dichten Netzes bildenden untersten Fäden an zahlreichen Punkten am Wandbecher befestigt, $4-6 \mu$ breit, entweder glatt oder mit schwach ausgeprägter warziger oder netzartiger Skulptur, 
mittlere und obere Capillitiumfäden $2-4 \mu$ breit, dicht warzig, quer bebändert oder \pm ungleich stachelig. Sporenmasse farblos; Sporen im durchfallenden Lichte nahezu farblos, zerstreut, wenig warzig, $6-8 \mu$.

In ganzen Gebiet vorkommend.

Kosmopol.

Es werden folgende Abänderungen unterschieden:

- - var. carnea Lister Monogr. ed. 2 (1911), 236.

Sporangien keulenförmig oder zylindrisch, fleischrot. Capillitiumfäden mit einer lockern Spirale flacher oder fast hakenförmig gekrümmter Stacheln, im Übrigen fein warzig.

Deutschland, Österreich.

_ - var. subleionema Celak. Myxom. Böhm. (1893), 28.

Innenseite der Capillitiumfäden völlig glatt, äußere fein stachelig.

Österreich.

- f. subglobosa (Meylan) Schinz nov. comb.

Synonym: Areyria digitata (Schwein.) Rost. f. subglobosa Meylan in Annuaire Conserv, et Jardin Bot. Genève 15 e et 16 me aunées (1913), 321.

Sporangien fast kugelig oder kurzellipsoidisch.

Schweiz (Jura).

Macbride, Torrend und Meylan betrachten $A$. cinerea und A. digitata als verschiedene Arten und zwar sollen bei cinerea die Sporangien stets einzelu, bei digitata gebüischelt sein, ferner soll bei digitata der Sporangienstiel länger als bei cinerea und das Capillitium soll bei letzterer stacheliger sein.

Scherffel (Ungar. Bot. Blätter XIII (1914), 197) hat gefunden, daß die Skulptur des Wandbechers ein sehr gutes Merkmal abgebe, um Arcyria cinerea von $A$. insignis zu unterscheiden. Die Oberfläche des Wandbechers zeigt nämlich, wie Scherffel ausführt, bei $A$. cinerea netzförmige Verdickung, aber die Maschen dieses Netzes sind so klein und dicht, ca. $2 \mu$ im Durchmesser, daB sie bei mittlerer Vergrößerung (ca. 250 facher) mehr als Punktierung erscheinen; 
anf dem Wandbecher $\operatorname{der} A$. insignis sind die gerade nicht leicht wahrnehmbaren, polyedrischen, verschieden großen Maschen des Verdickungsnetzes auffallend größer, nngefähr $4 \mu$ im Durchmesser und bei der gleichen Vergrößerung bereits deutlich erkenubar. Das Vorhandensein dieses Netzes unterscheidet die A. insignis zugleich von der ähnlich gefärbten A. incarnata.

\section{$5^{* * *}$. Sporangien $\pm k u g e l i g$ oder eiförmig, gelb. Capillitiumfäden mit spiralig angeordneten Stacheln.}

A. pomiformis (Leers) Rost. Monogr. (1875), 271 ; Schröter in Cohn Krypt.-Fl. Schles. III, 1, 190; Ćelak. Myxom. Böhm., 28; Lister in Journ. of Bot. XLV, 194, Monogr. ed. 2, 237, pl. 176, fig. f, fi; Macbride N. Am. Slime-Moulds, 197; Torrend in Broteria VII, 41.

Synonyme: Mucor pomiformis Leers Fl. Herborn. (1775), 218? Stemonitis pomiformis Roth Fl. Germ. (1788), 548?

Stemonitis ochroleuca Trentep. in Roth Cat. Bot. I (1797), 221. Stemonitis lutea Trentep. in Roth Cat. Bot. I (1797), 221.

Areyria umbrina Schum. Enum. Pl. Saell. II (1803), 213?; Rabenhorst Deutschl. Krypt.-Fl. 1, 257?

Arcyria silacea Ditm. in Sturm Deutschl. Fl. Pilze (1817), 15, t. 8 .

Arcyria lutea Schwein. Syn. Fung. Carol. (1822), 37.

Arcyria ochroleuca Fr. Syst. Myc. III (1829), 181; Rabenhorst Deutschl. Krypt.-Fl. 1, 257.

Arcyria albida var. pomiformis Lister Monogr. ed. I (1894), 186.

Exsikkaten: O. Jaap Myxom. exsicc. 20.

Plasmodium weiß. Sporangien zerstrent, \pm kugelig oder eiförmig, $0,3-0,7 \mathrm{~mm}$ lang, auf einem nur wenig kürzern, schlanken, ledergelben Stiel, ockergelb, mit am Grunde gefälteltem Wandbecher. Capillitiumnetz locker, \pm blaßocker- oder honiggelb, aus $\pm 3 \mu$ breiten, dicht- aber unordentlich bestachelten Fäden mit Querleisten bestehend. Die untersten Fäden mit 3-4 schwachen Spirallinien oder -leisten. Sporen im durchfallenden Lichte fast farblos, $7-8 \mu$, mit einzelnen zerstreuten Warzen.

Deutschland, Österreich.

Kosmopol. 
Unterscheidet sich von A. cinerea, mit welcher Art pomiformis durch Übergänge verknüpft ist, durch die blaßgelbe Farbe der kugeligen, sehr kleinen, vereinzelt stehenden Sporangien, die sehr kurzen Stiele und das sehr stark bestachelte Capillitium.

$$
\begin{aligned}
& \text { 5****. Sporangien kugelig, weißlich, }^{\text {blaßgelb oder bräunlich, schlank }} \\
& \text { gestielt. Capillitium dicht stachelig } \\
& \text { oder warzig, die Warzen gewöhn- } \\
& \text { lich } \pm \text { in Spiralreihen. }
\end{aligned}
$$

A. globosa Schwein. Syn. Fung. Carol. (1822), 38; Lister Monogr. ed. 2, 238, pl. 176, fig. g-h.

Synonyme: Craterium globosum Fr. Syst. Myc. III (1829), 154. Lachnobolus globosus Rost. Mouogr. (1875), 283; Massee Monogr., 137, fig. 204; Macbride N. Am. Slime-Moulds, 187; Torrend in Broteria VII, 35.

Arcyria albida var. globosa Lister Monogr. ed. 1 (1894), 186, pl. , LXVII, B, fig. g-i.

Plasmodium? Die $0,2-0,5 \mathrm{~mm}$ lang gestielten, 0,3-0,6 $\mathrm{mm}$ dicken, kugeligen Sporangien sind weiß, blaßgelb oder bräunlich, mit fast die halbe Sporangiumhöhe erreichendem Wandbecher. Stiel blaßgelb oder braun. Capillitiumnetz dicht aber wenig elastisch; Fäden fast farblos, $2-4 \mu$ breit, mit auf 3 oder 4 Spirallinien stehenden Stacheln oder Warzen. Die Spirallinien, verglichen mit denen der Trichia-Elateren entgegengesetzt läufig. Sporenmasse blaßgelb; Sporen im durchfallenden Lichte farblos, $6-8 \mu$, mit einigen wenigen, zerstreuten Warzen.

Deutschland, Schweiz (Jura).

Frankreich, Portugal, N.- und S.-Amerika.

$5^{* * * * *}$. Plasmodium? Sporangien zerstreut, $0,2-0,4 \mathrm{~mm}$ lang gestielt, \pm kugelig, ei- oder birnförmig, 0,5 bis $0,6 \mathrm{~mm}$ dick, 士 rehbraun, Wandbecher mit unregelmäBigem Rande und unterwärts faltig. Stiel bräunlich bis schwärzlich. Capillitiumnetz 
schlaff, wenig elastisch; Fäden schlank, gelblich, $1-1,5 \mu$ breit, mit ringförmigen Verdickungen; untere Fäden mit $2-3 \mu$ langen, perlschnurartigen Verdickungen. Sporen im durchfallenden Lichte blaßgelb, entweder glatt oder mit wenigen, zerstreuten Warzen, $6-7 \mu$.

A. annulifera Torrend in Broteria VII (1908), 42, pl. IX, fig. 1-3; Lister Monogr. ed. 2, 239, pl. 185, fig. c-d.

Portugal.

4*. Capillitium nahezu oder völlig frei vom W andbecher.

7. Capillitiumnetz zur Zeit der Sporenentlassung nicht überhängend.

8. Capillitiumfäden ohne Spiralleisten. -

A. incarnata Pers. Obs. Myc. I (1796), 58, t. V, fig. 4, 5; Rabenhorst Deutschl. Krypt.-FI. 1, 258; Rost. Monogr., 275, fig. 187, 199; Massee Monogr., 145; Schröter in Cohn Krypt.-Fl. Schles. III, 1, 110; Čelak. Myxom. Böhm., 29; Macbride N. Am. Slime-Moulds, 193; Lister Monogr. ed. 1, 189, pl. LXVIII, B, fig. a, b, ed. 2, 242, pl. 177, fig. a, b; Schinz in Mitt. Naturw. Ges. Winterthur VII, 111; Torrend in Broteria VII, 40.

Synonyme: Clathrus adnatus Batsch Elench. Fung. (1783), 141? Stemouitis Trichia Roth Fl. Germ. I (1788), 549?

Stemonitis incarnata Pers. in Gmel. Syst. Nat. (1791), 1467. Stemonitis caruea Trentep. in Roth. Cat. Bot. I (1797), 222. Stemonitis globosa Trentep. in Roth. Cat. Bot. I (1797), 222? Trichia flexuosa Schum. Enum. Pl. Saell. II (1803), 209. Arcyria lilacina Schum. Enum. Pl. Saell. II (1803), 212. Arcyria minor Sehwein. in Trans. Am. Phil. Soc. n. s. IV (1832), 259 ?

Arcyria adnata Rost. Monogr. App. (1876), 36.

Arcyrella irregularis Racib. in Rozpr. Mat. Przyr. Ak. Krak. XII (1884), 83.

Exsikkaten: Fuckel Fungi rhen. 1442; 0. Jaap Myxom. exsicc. 39. 
Plasmodium weiß. Sporangien dicht beisammen, auf kurzen schwachen, fleischfarbigen Stielen oder fast sitzend, \pm zylindrisch, eiförmig oder ellipsoidisch, 1-1,5 mm lang und 0,6 mm dick, rosarot oder fleischfarbig; Wandbecher mit \pm flachem Rand, mitunter gefältelt, fein stachelig. Capillitiumfäden $3-5 \mu$ breit, spärlich und unregelmäßig ver»weigt, an den Ver»weigungsstellen oft angeschwollen, mit Verdickungen in Form scharfer Kämme, halber Ringe oder Stacheln auf lockerer Spirale und zerstrenten, sehr kleinen Stacheln, mit \pm zahlreichen freien, keulenförmigen oder spit»en, stacheligen Enden. Sporenmasse rosarot; Sporen im durchfallenden Lichte blaßrosarot bis nahezu farblos, glatt oder mit wenigen zerstreuten IVarzen, 6-8 (bei der Spielart 10-12) $\mu$.

Deutschland, Österreich, Schweiz.

Kosmopol.

- - var. nodulosa Macbr. N. Am. Slime-Moulds (1899), 194, pl. III, fig. 8; Torrend in Broteria VII, 40.

Sporangien dunkelrot oder bräunlich; Capillitiumfäden mit knotenartigen Verdickungen. Sporen \pm stachelig, 10-12 $\mu$. N.-Amerika.

- - var. fulgens Lister Monogi. ed. 2 (1911), 242 und in Journ. of Bot. LIII, 10.

Synonyme: Arcyria affinis Rost. Monogr. (1875), 276.

Arcyrella similis Racib. in Rozpr. Mat. Przyr. Ak. Krak. XII (1884), 81 ?

Wandbecher derber als beim Typus; Sporangien karminrot, Stiel dunkelrotbraun, straff. Capillitium und Sporen glänzend hochrot.

GroBbritannien, Australien, Neuseeland.

- f. helvetica Meylan in Bull. Soc. Vaud. Sc. nat. XLVI (1910), 55.

Stiel $1 \mathrm{~mm}$ lang; Sporangien \pm kugelig. Peridie \pm bleibend, glänzend purpurrot mit Metallglanz, zur Zeit der Sporenreife oberwärts unregelmäßig zerreißend. Capillitium braunviolett, in 
der Stielröhre aber nicht oder kaum an der Peridie befestigt, nur wenig elastisch. Sporen glatt, $7 \mu$. Fräulein G. Lister vermutet, daB diese Form wohl richtiger bei Arcyria denudata (L.) Wettstein untergebracht würde.

Schweiz (Jura).

$8^{*}$. Capillitiumfäden mit Verdikkungen in Form von Kämmen, Stacheln und $3-4$ undeutlichen Spiralleisten.

A. stipata (Schwein.) Lister Monogr. ed. 1 (1894), 189, pl. LXX, A, fig. a-g, ed. 2, 243, pl. 178, fig. a-g.

Synonyme: Leangium stipatum Schwein. in Trans. Am. Phil. Soc. n. s. IV (1832), 258.

Hemiarcyria stipata Rost. Honogr. App. (1876), 41.

Homitrichia stipata Macbride N. Am. Slime-Moulds (1899), 204, pl. I, fig. 8, 8a, 8b; Torrend in Broteria VII, 47, pl. III, fig. $24,26$.

Plasmodium? Sporangien samt Stiel 1,5-2 $\mathrm{mm}$ hoch, gedrängt oder in Gruppen, zylindrisch, aufrecht oder gekrümmt, $1-1,5 \mathrm{~mm}$ hoch und $0,6 \mathrm{~mm}$ dick bei $0,1-1 \mathrm{~mm}$ langem Stiel, kupferbraun oder dunkelbraun mit karminrotem Glanz. Peridie oberwärts unregelmäßig zerreißend, einen Becher zurücklassend. Stiel rot- oder schwarzbraun. Capillitium \pm elastisch, aus reichlich verzweigten, 2,5-3,5 $\mu$ breiten Fäden bestehend, letztere mit einer Spirale am Grunde b verbreiterter Stacheln oder Querleisten und 3-4 schwach ausgeprägten Spiralleisten, mit zahlreichen freien, keulenförmigen Enden, nur zu wenigen an der Peridie befestigt. Sporenmasse rötlich; Sporen im durchfallenden Lichte blaßrot, mit wenigen zerstreuten Warzen, $6-8 \mu$.

Deutschland.

GroBbritannien, RuBIand, Ceylon, O.-Indien, Südsee-Inseln, N.-Amerika.

Die Art bildet eine Art Verbindungsbrücke zu Hemitrichia, immerhin sprechen für die Zugehörigkeit zu Arcyria das Vorhandensein eines Wandbechers und das nicht gerade seltene Fehlen von Spiralleisten. 
7*. Capillitiumnet\% stark verlängert nach dem Offnen des Sporangiums und überhängend.

9. Sporangien ocker- oder blaBledergelb; Peridie auch am Scheitel des Capillitiums völlig $\mathrm{sch}$ windend.

A. nutans (Bull.) Grev. Fl. Edinb. (1824), 455; Rabenhorst Deutschl. Krypt.-Fl. 1, 257; Rost. Monogr., 277; Schröter in Cohn Krypt.-Fl. Schles. III, 1, 110; Massee Monogr., 150, fig. 140, 141; Macbride N. Am. Slime-Moulds, 191, pl. II, fig. 6, $6 \mathrm{a}, 6 \mathrm{~b}$; Torrend in Broteria VIl, 36, pl. III, fig. 7; Lister Monogr. ed. 2 , 243, pl. 179, fig. a, b.

Synonyme: Trichia nutans Bull. Champ. (1791), 129, t. 502, fig. 8. Stemonitis nutans Gmel. Syst. Nat. (1791), 1467.

Arcyria flava Pers. in Roem. N. Mag. Bot. I (1794), 90; Čelak. Myxom. Böhm., 30; Lister Monogr. ed. 1, 190, pl. LXIX, A. fig. a, b; Schinz in Mitt. Naturw. Ges. Winterthur VI, 121. Stemonitis amœna Trentep. in Roth Cat. Bot. I (1797), 222. Trichia elongata Schum. Enum. Pl. Saell. II (1808), 209. Areyria alutacea Schum. Enum. Pl. Saell. II (1803), 212. Arcyrella nutans Racib. in Hedw. XXIII (1884), 170.

Exsikkaten: Fuckel Fungi rhen. 1439; O. Jaap Myrom. exsicc. 97.

Plasmodium wässerigweiß. Sporangien dicht stehend, kurz gestielt, zylindrisch, 1,5-2 $\mathrm{mm}$ hoch und $0,3-0,5 \mathrm{~mm}$ breit (in noch nicht geöffnetem Zustande), ocker- bis ledergelb. Wandbecher häutig, schlaff, gefältelt, oft fein stachelig auf der Innenseite. Stiel mitunter nahezu 0 , ledergelb. Capillitium sehr elastisch, nach dem Aufspringen des Sporangiums sich ausdehnend und verlängernd, 8-12 $\mathrm{mm}$ lang werdend und nun eine stark überhängende Netzsäule bildend. Netzfäden blaßgelb, zylindrisch oder $\cdot f l a c h$, $3-4 \mu$ breit, mit Verdickungen in Form von in lockerer Spirale angeordneten scharfen Stacheln und halben Ringen nebst zerstrenten kleinen Stacheln und unregelmäßig netzartig zusammenschließenden Verdickungslinien, mit \pm zahlreichen keulenförmigen, freien Euden. Sporenmasse ockergelb bis rehbraun; Sporen im durchfallenden Lichte blaßgelb, nahezu glatt, mit einzelnen zerstreuten Warzen, $6-8 \mu$.

Schinz, Myxogasteres (Rabenhorst Krypt.-Flora I, Pilze Abt. X). 
Duutschland, Österreich, Sclíweiz.

Kowmopol.

9*. Sporangien rot; Capillitium meist nach seiner Entfaltung am obern Scheitel vereinzelte, I schildartige Peridiefragmente tragend.

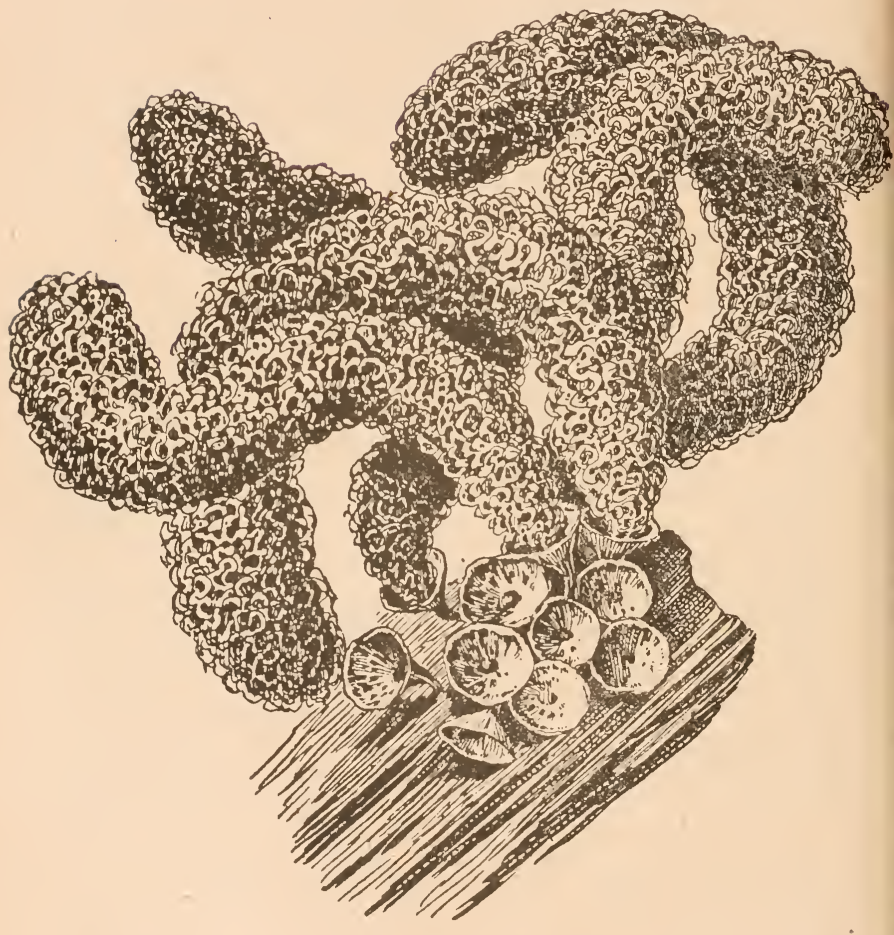

Fig. 167.

Arcyria nutans (Bull.) Grev.

Sporangiengruppe $\left({ }^{20} / 1\right)$.

Original. 
A. Oerstedtii Rost. Monogr. (1875), 278, fig. 196; Massee Monogr., 147; Čelak. Myxom. Böhm., 31; Lister Monogr. ed. 1. 190, pl. LXIX, B, fig. a-c, ed. 2, 244, pl. 180, fig. a-c; Macbride N. Am. Slime-Moulds, 191; Schinz in Mitt. Naturw. Ges. Winterthur VI, 113; Torrend in Broteria VII, 36.

Synonyme: Areyria vermicularis Schum. Knum. Pl. Saell. Il (1803), 212 ?

Arcyria punicea Pers. var. vermieularis Fr. Syst. Myc. 111 (1829), 178? Areyria incarnata Pers, var. flexuosa Fr. Syst. Myc. III (1829), 179. Arcyria magna Rex in Proc. Ac. Nat. Sc. Phil. (183!)), 364, Macbride N. Am. Slime-Moulds, 190.

Arcyria flexuosa Rabenhorst Deutschl. Krypt.-Fl. 1 (1844), 258? Hemiarcyria fuliginosa Cooke et Massee in Grev. XVI (1888), 74. Arcyria fuliginosa Cooke et Massee in Massee Monogr. (1892); 169, fig. 113.

P'asmodium wässerigweiß. Sporangien dicht gedrängt, meist kurz gestielt, zylindrisch und leicht gebogen, dunkelkarminrot, vor der Sporenentlassung $0,6-1,5 \mathrm{~mm}$ hoch und $0,3-0,5 \mathrm{~mm}$ breit. Peridie entweder völlig schwindend bis auf den innenseits papillösen Wandbecher oder Fragmente derselben dem obern Scheitel des Capillitiums aufsitzend. Stiel blaßrot. Capillitium sich stark verlüngernd; Fïden blaßrot, zylindrisch, $3-5 \mu$ breit, mit Verdickungen in Form von in lockerer Spirale angeordneten halben Ringen und $1-3 \mu$ langen scharfen Stacheln, außerdem mit zerstreuten kleineren Stacheln. Sporenmasse \pm karminrot oder rötlichbraun; Sporen im durchfallenden Lichte blaßrot, fast glatt, mit wenigen vereinzelten $\mathrm{W}$ arzen, $7-8 \mu$.

Deutschlaud, Österreich, Schweiz.

Großbritannien, Dänemark, Skandinavien, Portugal, Ceylon, Java. Japaii, Australien, Afrika, N.- und S.-Amerika

$3^{*}$. Wandbecher sich schließlich durch Lăngsrisse in $4-6$ Lappen spaltend.

Plasmodium? Sporangien gestielt oder sitzend, zerstreut oder dicht gedrängt und daher von \pm prismatischer Gestalt, $0,7-0,9$ $\mathrm{mm}$ hoch und $0,4-0,5 \mathrm{~mm}$ breit, zuerst rosa- oder fleischrot, später bräunlich oder ockerfarbig, zur Zeit der Sporenreife sich schließlich durch Längsrisse in $4-6$ Lappen spaltend. Peridie überaus dünn, durchsichtig, oberwärts schwindend; Stiel gelblich- 
braun, 0,1-0,3 $\mathrm{mm}$ hoch. Capillitiumnetz locker, wenig elastisch, aus rötlichgelben, 2,5-4 $\mu$ breiten, da und dort an der Peridie befestigten Fäden mit \pm zahlreichen, keulenförmigen, papillösen Enden bestehend; Verdickungen der Capillitiumfäden in Form von spiralig angeordneten Stacheln, Warzen und Querleisten. Sporenmasse gelblichfleischrot; Sporen im durchfallenden Lichte beinahe farblos, abgesehen von einigen zerstreuten Warzen glatt, $6-9 \mu$.

A. occidentalis (Macbride) Lister Monogr. ed. 2 (1911), 245, pl. 192, fig. a, b.

Synonyme: Lachnobolus incarnatus Macbride in Bull. Nat. Hist. Iowa II (1892), 126, non Schröter.

Lachnobolus occidentalis Macbride N. Am. Slime-Houlds (1899), 188, pl. II, fig. 2, 2a, $2 \mathrm{~b}$; Torrend in Broteria VII, 35, pl. . III, fig. 4,5 .

N.-Amerika.

Anhangsweise sei erwähnt:

Arcyria spec. Brandza in Ann. scient. Université Jassy VIII (1914), 269, fig. 2, a-d.

Plasmodium rotbraun. Sporangien vor der Sporenentlassung 0,3-0,8 mm, nach der Sporenentlassung mit Einschluß des gestreckten Capillitiums $2-3 \mathrm{~mm}$ hoch, sehr kurz gestielt, zylindrisch, glänzend, rosarot, $0,1-0,3 \mathrm{~mm}$ breit, mitunter in Gruppen von 10 bis 150 Individuen. Peridie hinfällig und nur am Grunde in Form eines fast flachen, kreisrunden, am Rande regelmäBig 'gezăhnten und radialgefältelten Bechers erhalten bleibend. Stiel, sofern vorhanden, 0,1-0,2 $\mathrm{mm}$ hoch, von der Farbe der Sporangien, hohl und mit braunorangegelben sporenartigen Zellen angefüllt. Capillitium elastisch, sich sehr rasch streckend nachdem die Peridie einmal zerrissen ist, am Peridiebecher befestigt; die Capillitiumfäden rosarot, bald blasser, bald dunkler, mit warzigen Verdickungen oder mit Verdickungen in Form von halben Ringen, 4-6 $\mu$ breit. Sporenmasse blaß- oder dunkelrosarot; Sporen im durchfallenden Lichte sehr blaßbraunrosarot, mit spärlichen Warzen, $6-8$ «.

Rumänion. 


\section{Gattung Lachnobolus Fr.}

Fl. scand. (1835), 356; Rost. Versuch eines Systems der Mycetozoen, 15 pr. p., Monogr., 281 pr. p.; Schröter in Cohn Krypt.-Fl. Schles. III, 1, 110 und in Engler und Prantl Natürl. Pflanzenfam. I, 1, 23; Lister Monogr. ed. 1, 194, ed. 2, 246; Schinz in Mitt. Naturw. Ges. Winterthur VI, 113; Torrend in Broteria VI, 46 pr. p., VII, 34 pr. p., VIII, 27 pr. p.

Mit nur einer Art:

L. congestus (Sommerfelt) Lister Monogr. ed. 2 (1911), 246, pl. 183, fig. a, b.

Synonyme: Physarum congestum Sommerfelt Fl. Lapp. (1826), 241. Arcyria circinans Fr. Stirp. Femsion. (1827?), 83?; Rabenhorst Deutschl. Krypt.-Fl. 1, 259?

Perichæna congesta Fr. Syst. Myc. III (1829), 192.

Licea congesta Wallr. Fl. Crypt. Germ. (1833), 345.

Lachnobolus circinans Fr. Summ. Veg. Scand. II (1849), 457?;

Rost. Monogr., 282; Lister Monogr. ed. 1, 194, pl. LXX, B, fig. a, b. Schinz in Mitt. Naturw. Ges. Winterthur VI, 114. Lachnobolus Sauteri Rost. in Fuckel Symb. Myc. Nachtr. (1873), 76. Arcyria (Lachnobolus) congesta Berkeley et Broome in Ann. Mag.

Nat. Hist. ser. 4, XVII (1876), 140.

Lachnobolus incarnatus Schröter in Cohn Krypt.-Fl. Schles. III, 1, (1885), 110: Massee Monogr., 138; Torrend in Broteria VII, 34, pl. IIl, fig. 6 .

Arcyria Hariotii Massee Monogr. (1892), 155.

Plasmodium rahmweiß. Sporangien \pm kugelig, sitzend, gedrängt und gehäuft, $0,5-0,8 \mathrm{~mm}$, blaßkupferfarbig oder-ockergelb, glänzend. Peridie häutig, zerbrechlich, ockergelb, fleischrot oder rötlich. Capillitium aus vielfach verzweigten, zu einem lockern Netz vereinigten, ockergelben oder roten, $2-8 \mu$ breiten, an zahlreichen Punkten an der Peridie befestigten Fäden mit Verdickungen in Form dicht stehender Warzen bestehend. Sporenmasse \pm hell fleischfarbig; Sporen im durchfallenden Lichte blaßrot oder gelb, mit kleinen und wenigen größeren Warzen, $6-8 \mu$.

Deutschland, Österreich, Schweiz.

Großbritannien, Frankreich, Belgien, Skandinavien, Rumänien. 


\section{Gattung Perichæna Fr.}

Symb. Gaster. (1817), 11; Rabenhorst. Deutschl. Krypt.-Fl. 1, 262 pr. p.; Rost. Versuch eines Systems der Mycetozoen, 16. Mlonogr., 292; Massee Monogr., 113; Schröter in Cohu Krypt.-Fl. Schles. III, 1, 107 und in Engler und Prantl Natürl. Pflanzenfam. I, 1, 20; Čelak. Myxom. Böhm., 25 pr. p.; Lister Monogr. ed. 1, 195, ed. 2, 247; Macbride N. Am. Slime-Moulds, 183; Schinz in Mitt. Naturw. Ges. Winterthur VI, 114; Torrend in Broteria VI, 45, VII, 29, VIII, 27.

Sitzende oder kurzgestielte, gewöhnlich am Scheitel deckelartig sich öffnende Sporangien oder Plasmodiokarpien. Peridie (mit Ausnahme von $P$. microcarpa) 2 schichtig, innere Schicht meist häutig, äußere mit kantigen Granulationen. Capillitium entweder aus einfachen oder verzweigten, nicht elastischen. stacheligen, feinwarzigen oder nahezu glatten, gewöhnlich mit unregelmäßiges Einschnürungen versehenen Fäden bestehend.

1. Peridie \pm dick, zweischichtig.

2. Sporangien braun oder grau.

3. Sporangien \pm kugelig (oder anderen stelle Plasmodiokarpien); Capillitium stachelig. Sporen $8-10 \mu$.

P. chrysosperma (Currey) Lister Monogr. ed. 1 (1894), 196, pl. LXXI, A, fig. a, b, ed. 2, 248, pl. 184, fig. a, b: 'T'orrend in Broteria VII, 30, pl. II, fig. 24, 25.

Synonyme: Trichia circumseissa Wallr. F. Crypt. Germ. (1833), 378? Areyria glomerata Fr. Summ. Veg. Scand. (1849), 457?

Ophiotheca chrysosperma Currey in Quart. Micr. Journ. II (1854), 240 , t. IX, fig. 1-5; Macbride N. Am. Slime-Moulds, 182. Trichia Curreyi Crouan Fl. Finist. (1867), 16.

Uphiotheca Wrightii Berkeley et Curtis in Journ. Linn. Soc. X (1869), 349; Massee Monogr., 132, fig. 197; Macbride N. Am.

Slime-Noulds, 182, pl. XI, fig, 7, 7 a, 7 b.

Cornuvia circtumseissa Rost. Monogr. (1875), 290.

Cornuvia Wrightii Rost. Monogr. App. (1876), 36.

Hemiarcyria melanopeziza Speg. in Anu. Soc. Cient. Argent. X (1881), 257. 
Ophiotheca circumscissa Massee Monogr. (1892), 131.

Perichæna circumscissa Dalla Torre et Sarnth. Fl. Tirol III (1905), 7?

Perichæna chrysosperma Lister var. Wrightii Torrend in Broteria VII (1908), 31.

Exsikkaten: (1. Jaap Myxom. exsicc. 80.

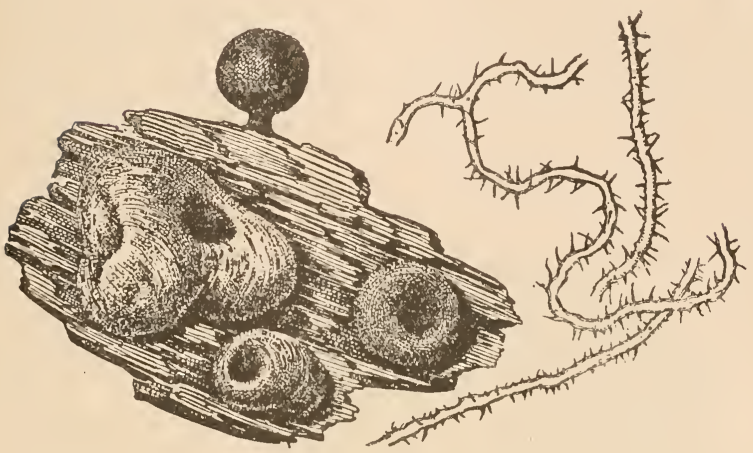

Fig. 168.

Perichæua chrysosperma (Currey) Lister.

Sporangium, Plasmodiokarpien $(20 / 1)$ und Capillitiumfäden $(600 / 1)$.

Nach Lister.

Plasmodium blaßrosa (oder blaßbraun). Entweder zerstreute, sitzende oder gestielte, \pm kugelige Sporangien oder wurmförmige, gekrümmte oder ringförmige, $0,4-1 \mathrm{~mm}$ breite Plasmodiokarpien, rot- oder schwarzbraun, .unregelmäßig sich öffnend. Āußere Wandschicht bald mit, bald ohne braune, mitunter eine Kruste bildende Granulationen. Stiel, wenn vorhanden, gedrungen, 0,1-0,7 mm hoch. Capillitiumfäden spärlich "verzweigt, gelb, $2-4 \mu$ breit, mit unregelmäßigen Einschnürungen und geraden oder gekrümmten Stacheln, ein lockeres Netz bildend. Sporenmasse zitronengelb; Sporen im durchfallenden Lichte etwas blasser, fein warzig, $9-10 \mu$, selten $7-8 \mu$.

Deutschland, Österreich, Schweiz.

GroBbritannien, Frankreich, Portugal, Ceylon, Japan, N.- und S.Amerika, Westindien, 0.-Afrika. 
$3^{*}$. Abgeflachte Sporangien oder Plasmodiokarpien, Capillitium fein warzig oder nahezu glatt, reichlich entwickelt; Sporen $8-12 \mu$.

P. depressa (Corda) Libert Fl. Crypt. Ard. fasc. IV (1837), 378; Rost. Monogr., 292; Schröter in Cohn Krypt.-Fl. Schles. III, 1, 106; Massee Monogr., 114, fig. 118-120; C̉elak. Myxom. Böhm., 25; Lister Monogr. ed. 1, 197, pl. LXXI, B, fig. a-c, ed. 2, 249, pl. 189, fig. a-c; Macbride N. Am. Slime-Moulds, 183, pl. XVII, fig. 10; Torrend in Broteria VII, 32, pl. III, fig. 1.

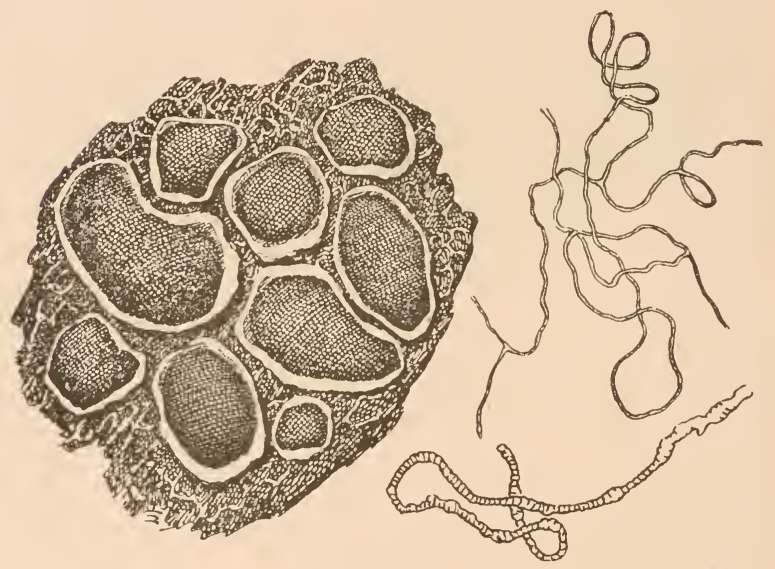

Fig. 169 .

Perichæna depressa (Corda) Libert.

Plasmodiokarpien $(20 / 1)$ und Capillitiumfäden $(600 / 1)$.

Nach Lister z. T.

Syuonyme: Stegasma depressum Corda Icon. V (1842), 58, t, III, fig. 34 .

Perichæna artocreas Berkeley et Rav. in Grev. II (1873), 68. Perichæna irregularis Berkeley et Curtis in Grev. II (1873), 68. Stegasma australe Cesati in Hedw. XIII (1874), 186.

Perichæna marginata Berkeley et Broome in Journ. Linn. Soc. XV (1876), 84 non Schwein.

Hemiarcyria applanata Cooke et Massee in Grev. XVI (1887), 20. 
Perichæua anstralis Berlese in Saccardo Syll. VIl (1888), 422;

Massee Monogr., 119.

Perich:ena Krupii Racib. in Hedw. XXVIII (1889), 124,; Torrend in Broteria VII, 34 ?

Perichæna applanata Massee Monogr. (1892), 116.

Ophiotheca irregularis Massee Monogr. (1892), 132.

Ophiotheca nitens Massee Monogr. (1892), 133.

Perichæna depressa Libert var. quadrata Torrend in Broteria VII, (1908), 32.

Exsikkaten: Fuckel Fung. rhen. 2200; O. Jaap Myxom. exsicc. 139.

Plasmodium milchweiß. Sporangien sitzend, meist dicht gedrängt, vom gegenseitigen Druck mehreckig, stark abgeflacht, 0,5-1 mm, an deren Stelle mitunter Plasmodiokarpien, purpur- oder rotbraun, ledergelb oder grau, mit einem scharf abgeschnittenen, flachen Deckel aufspringend. Äußere Peridieschicht mit braunen Granulationen und oft mit Kalkkristallen. Capillitium reichlich entwickelt, aus gelben, $1,5-4 \mu$ breiten, warzigen oder \pm regelmäßigen, dicht aufeinanderfolgenden und regelmäßig mit Erweiterungen abwechselnden Einschnürungen. Sporen goldgelb im durchfallenden Lichte, fein warzig, $8-12 \mu$.

Deutschland, Österreich, Schweiz.

Kosmopol.

$3^{* *}$. Sporangien \pm kugelig. Capillitiumfäden warzig oder nahezu glatt, meist spärlich entwickelt. Sporen $10-($ selten $9-$ ) bis 15 - und selbst bis $17 \mu$.

P. corticalis (Batsch) Rost. Monogr. (1875), 293, fig. 188; Schröter in Cohn Krypt.-Fl. Schles. III, 1, 107; Massee Monogr., 115, fig. 114-117; Macbride N. Am. Slime-Moulds, 185, pl. II, fig. 1, $1 \mathrm{a}, 1 \mathrm{~b}$; Torrend in Broteria VIl, 33, pl. III, fig. 2, 3; Lister Monogr. ed. 2, 250, pl. 186, fig. a-c.

Sy un yme: Mucor lycoperdoides Scop. in Ann. Hist. Nat. IV (1772), t. 1, fig. 11 ?

Lycoperdon corticale Batsch Elench. Fung. (1783), 155.

Sphærocarpus sessilis Bull. Champ. (1791), 132, t. 417, fig. 5. Trichia fusco-atra Sibth. Fl. Oxon. (1794), 407.

Trichia gymnosperma Pers. Obs. MIyc. I (1796), 63, t. VI, fig. 1, 2. Trichia circumscissa Schrader Nov. Gen. Pl. (1797), 19.

Licea circumscissa Pers. Syn. Fung. (1801), 196.

Physarum luteo-album Schum. Enum. Pl. Saell. II (1803), 199. Tubulina circumscissa Poiret Eucycl. Méth. VIII (1808), 131. 
Perichina populina Fr. Symb. Gaster. (1817), 12; Lister Monogr. ed. 1, 198, pl. LXXII, A, fig. a-c; Schinz in Mitt. Naturw. Ges. Winterthur V1, 115.

Perichæna quercina Fr. Symb. Gaster. (1817), 12?; Rabenhorst

Deutschl. Krypt.-Fl., 1, 262 ?

Perichaena abietina Fr. Symb. Gaster. (1817), 11; Rabenhorst Deutschl. Krypt.-Fl., 1, 262.

Perichæna marginata Schwein. in T'rans. Am. Phil. Soc. n. s. IV (1832), 258.

Perichæna vaporaria Schwein. in Trans, Am. Phil. Soc. n. s. IV (1832), 258?

Licea nitens Schwein. in Trans. Am. Phil. Soc. n. s. IV (1832), 259 ?

Licea quercina Wallr. Fl. Crypt. Germ. (1833), 344.

Perichæna fusco-atra Rost. Monogr. (1875), 294; Schröter in Cohn Krypt.-Fl. Schles. III, 1, 108.

Perichæna Rostafinskii Karsten in Bidr. Känn. Finl. Nat. (1879), 130. Perichæna microcarpa Schröter in Cohn. Krypt.-Fl. Schles. 111, 1, 108? Cornuvia dictyocarpa in Cosmos (1886), 377?

Perichæna cano-flavescens Raunk. in Bot. Tidsskr. (1888), 54? Perichæna nitens Raunk. in Bot. Tidsskr. (1888), 55?

Oligonema Broomei Massee in Journ. Micr. Soc. (1889), 346, Monogr.., 172, fig. 185, 186.

Exsikkaten: Fuckel Fung. rhen. 1899; Sydow Myc. March. 1669; O. Jaap Myxom. exsicc. 40, 68, 98, 119.

Plasmodium wässeriggrau. Sporangien zerstreut oder gehäuft, 土 kugelig, oft niedergedrückt sitzend oder fast gestielt oder polsterförmige Plasmodiokarpien, 0,5-1 $\mathrm{mm}$ (in amerikanischen Exemplaren nach Sturgis sogar nur 0,14-0,29 mm) im Durchmesser, dunkelpurpurfarbig oder purpurbraun, nußbraun, grau oder weiß, häufig mit einem \pm kreisförmig abgegrenzten, flachgewölbten Deckel aufspringend. ĀuBere Peridieschicht gelblichbraun, mit braunen Granulationen und oft mit Kalkkristallen, die schließlich eine graue oder weiße Kruste bilden können, besetzt. Capillitium mitunter sehr spärlich entwickelt, entweder netzartig (var.. liceoides; Sturgis in Mycologia IX [1917], 331) oder aus schlanken, langen und kurzen, einfachen oder verzweigten, mit Einschnürungen, feinen Warzen und kurzen Stacheln versehenen oder fast glatten Fäden bestehend oder (var, liceoides) ganz fehlend (Sturgis 1. c.). Sporenmasse goldgelb; Sporen im durchfallenden Lichte gelb, fein- und dichtwarzig, $10-14 \mu$.

Deutschland, Österreich, Schweiz.

Kosmopol. 


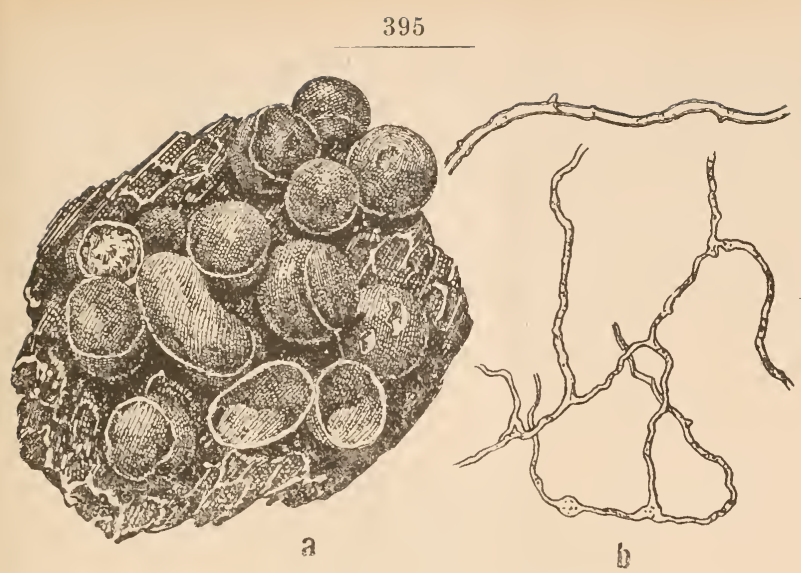

Fig. 170. Perichena corticalis (Batsch) Rost.

a) Sporangien $\left({ }^{20}{ }_{1}\right)$; b) Capillitiumfäden $(280 / 1$; oberes Fadenstück $600 ; 1)$. Nach Lister.

- var. affinis Lister Monogr. ed. 2 (1911), 251.

Synonym: Perichæna populina Fr. var. affinis Lister ap. Meylan in Bull. Soc. Bot. Genève 2 me sér. II (1910), 267.

Sporangien purpurrot oder rotbraun, unregelmäßig am Scheitel sich öffnend; Capillitium reichlich entwickelt, ein Netzwerk aus straffen, gelblichbraunen, $2-3 \mu$ breiten Fäden. Sporen $10-12 \mu$.

Schweiz (Jura).

- var. liceoides (Rost.) Lister Monogr. ed. 2 (1911), 251. Synonyme: Perichæna liceoides Rost. Monogr. (1875), 295; Massee Monogr., 118.

Licea paunorum Cienk. in Pringsh. Bot. Jahrb. 11 (1863), 407. Lachuobolus pygmæus Zukal in Österr. Bot. Zeitsehr. XLIII (1893), 136.

Sporangien \pm kugelig oder polsterförmig, nußbraun, nur 0,2-0,5 mm groß, unregelmäBig sich öffnend; Capillitium meist spärlich entwickelt, mitunter netzartig oder anch fehlend. Sporen $10-15 \mu$.

Deutschland, Österreich.

N.-Amerika (Florida).

- var. ochrospora (Peck) Torrend in Broteria VII (1908), 33. 
Synonym: Perichæna ochrospora Peck in Rep. N.-York St. Mus. (1901), 56.

Sporangien ohne Kalkkruste; Sporen $15-17,5 \mu$. N.-Amerika.

$2^{*}$. Sporangien glänzend purpurrot oder purpurnuBbraun, zerstreut und gestielt oder gehäuft und nahezu sitzend, kugelig, $0,5 \mathrm{~mm}$ im Durchmesser. Peridie unregelmäßig zerreißend, äußere Schicht mit zerstreuten Granulationen, innere häutig. Stiel 0,1 bis $0,3 \mathrm{~mm}$ lang, rotbraun, mit granulösem AusschuBmaterial angefüllt. Capillitium ein lockeres Netrwerk, kaum elastisch, aus rötlichbraunen, $3-4 \mu$ breiter Fäden mit Verdickungen in Form zerstreuter Warzen, geraden und gekrümmten, $1-2 \mu$ langen Stacheln bestehend. Sporenmasse purpurbraun; Sporen im durchfallenden Lichte blab rötlichbraun, dicht stachelig, $15-17 \mu$.

P. pulcherrima Petch in Ann. Perad. IV (1909), 305; Lister Monogr. ed. 2, 252, pl. 188, fig. a-d.

Ceylon.

1*. Peridie häutig.

4. Sporangien bla $B$ umberfarbig oder ledergelb. Sporen $10-15 \mu$.

P. vermicularis (Schwein.) Rost. Monogr. App. (1876), 34; Torrend in Broteria VII, 29, pl. 11, fig. 21-23; Lister Monogr. ed. 2, 253, pl. 187, fig. a-c.

Synonyme: Physarum vermiculare Schwein. in Trans. Am. Phil. Soc. n. s. IV (1832), 257.

Ophiotheca pallida Berkeley et Curtis in Journ. Limn. Soc. X (1869), 350.

Ophiotheca umbrina Berkeley et Curtis in Grev. II (1873), 68. Licea reticulata Berkeley et Broome in Journ. Linn. Soc. XVI (1873), 86. 
Perichæna variabilis Rost. Monogr. (1875), 295; Lister Monogr. ed. 1, 199, pl. LXXII, B, fig. a-d; Schinz in Mitt. Naturw. Ges. Winterthur VI, 115.

Perichæna Friesiana Rost. Monogr. (1875), 296.

Perichæna reticulata Rost. Monogr. App. (1876), 35.

Perichæna confusa Massee Monogr. (1892), 117.

Ophiotheca vermicularis Massee Monogr. (1892), 134, fig. 198, 198 a ;

Macbride N. Am. Slime-Moulds, 181.

Ophiotheca reticulata Massee Monogr. (1892), 133, fig. 199, 200.

Exsikkaten: O. Jaap Myxom, exsicc. 140.

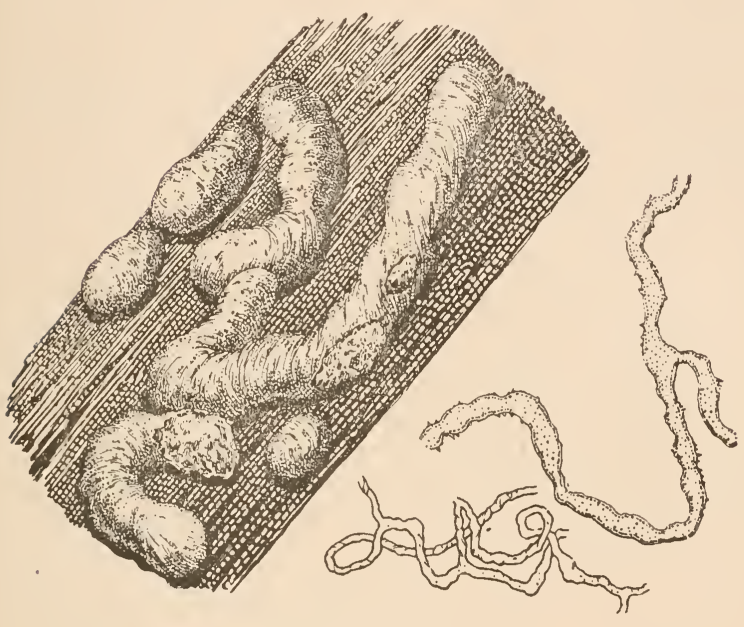

Fig. 171.

Perichæna vermicnlaris (Schwein.) Rost.

Oben Plasmodiokarpien $(20 / 1)$, unten Capillitiumfäden $\left({ }^{210} ;\right.$ und $\left.600 / 1\right)$. Z. T. Original, z. T. nach Lister.

Plasmodium wässerig- oder gelblichweiß. Sporangien zerstreut, kugelig und sitzend oder (var. pedata) kurzgestielt, viel häufiger an deren Stelle auffallend schlanke, wurmförmig gekrümmte, ringoder netzartige Plasmodiokarpien, ockergelb, blaß umberfarbig oder grau. Äußere Peridieschicht mit dunkeln Granulationen und mitunter mit Kalkkristallen. Capillitium meist reichlich 
entwickelt, aus verzweigten, gelben, $2-4 \mu$ breiten, fein warzigen und mit unregelmäßigen Einschnürungen versehenen Fäden bestehend. Sporenmasse ockergelb; Sporen im durchfallenden Lichte blaßgelb, fein warzig, $10--15 \mu$.

Deutschland, Österreieh, Schweiz.

Kosmopol.

- - var. pedata Lister in Journ. of. Bot. Xlall (1904), 139, t. 459, fig. 3a, b, Monogr. ed. 2, 253: Torrend in Broteria VII, 30.

Sporangien kugelig oder nierenförmig, sitzend oder gestielt, blak nuBbraun oder óckerbraun; Stiel $0.1-0.3 \mathrm{~mm}$, schwär»lichhraun, höckerig.

Deutschland.

GroBbritaunien, N.-Amerika.

4*. Plasmodiokarpien salmrot. glänzend, schlank, kurz oder verlängert oder netzartig, (),25-0,35 mmbreit. Peridie nurgegen den Grund \% pillitiumfäden ein lockeres Netzwerk bildend, schlank, zerbrechlich, gelblichrot, 1,5-2 " breit, mit feiner Bestachelung und mit dicht sich folgenden seichten Einschnürungen. Sporenmasse rötlichgelb; Sporen im durchfallenden Lichte blabgelblich, dicht- und feinstachelig, $6-8 \mu$.

P. microspora Penzig et Lister in Penzig Myx. Buitenz. (1898), 76; Torrend in Broteria VII, 31: Lister Monogr. ed. 2, 254, pl. 185, fig. a, b.

Synonym: Perichæna pseudicidium speg. in Ann. Soc. Cient. Argent. XXII (1886), 187; Massee Monogr., 119; Lister Monogr. ed. 1, 201; Torrend in Broteria VII, 31.

Ceylon, Java, Brasilien. 


\section{Familie Margaritaceae Lister}

pr. p. Monogr. ed. 1 (1894), 202, em. ed. 2, 25t; pr. p. Schinz in Mitt. Naturw. Ges. Winterthur VI, 115; pr. p. Torrend in Broteria VI, 45, VII, 23 VIII, 28.

Sporangien gewöhnlich sitzend. Peridie ein- oder zweischichtig, meist durchsichtig. Capillitiumfäden nicht netzbildend, haarartig und aufgerollt oder + gerade und z. T. + straff, an der Peridie befestigt, einfach oder spitzwinkelig ver»weigt.

\section{Schlïssel zum Bestimmen der Gattungen der Familie der Margaritaceae.}

1. Peridie unregelmäßig zerreißend.

2. Capillitium reichlich entwickelt, aus geschlängelten. aufgewickelten, kaum verzweigten Fäden bestehend.

Margarita Lister.

2*. Capillitiumfäden nahezu gerade, mit beiden Enden an den gegeniiberliegenden Peridiewänden befestigt.

Dianema Rex.

$2^{* * *}$. Capillitiumfäden mit Spiralverdickungen, am Grunde kräftig, am obern Ende pinselartig anfgelöst, beiderends an der Peridie befestigt. Prototrichia Rost.

$1^{*}$. Peridie mittelst Lappen, längs sichtbarer Dehiszenzlinien aufspringend.

Listerella Jahn.

\section{Übersicht der Gattungen.}

Ilargarita. Sitzende, kugelige Sporangien oder Plasmodiokarpien, metallisch glänzend. Capillitiumfäden zart, meist einfach, sehr lang und sehr fein stachelig, gleich Haarlocken aufgerollt.

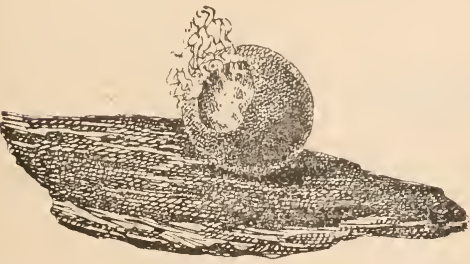

Fig. 172 .

Margarita metallica (Berkeley et Broome) Lister Sporangium $(25 / 1)$. Nach Lister. 
Dianema. Halbkugelige, sitzende Sporangien oder Plasmodiokarpien. Capillitiumfäden fast ganz gerade, einfach oder verzweigt, beiderends an der Peridie befestigt.

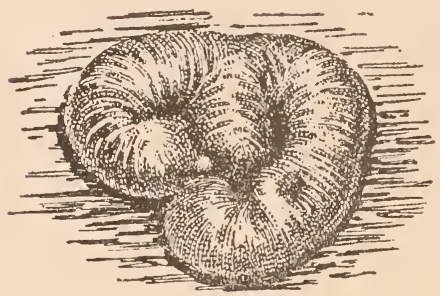

Fig. 173

Dianema corticatum Lister. Plasmodiokarp $(20 / 1)$. Nach Lister.

Prototrichia. Metallisch glänzende, sitzende oder seltener gestielte Sporangien oder Plasmodiokarpien. Capillitiumfäden am ' Grunde kräftig, mit Spiralleisten, am obern Ende pinselartig in kurze, an der Peridie befestigte Äste sich zerteilend.

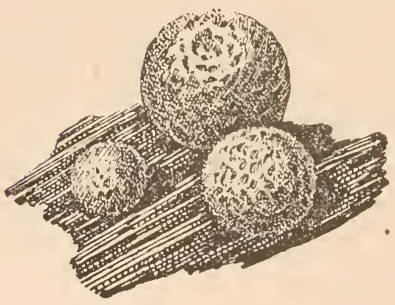

Fig. 174.

Prototrichia metallica (Berkeley) Massee

Sporangiengruppe $(20 / 1)$.

Nach Iister.

Listerella. Sporangien laalbkugelig, äuBerst klein, mittelst. Lappen längs vorgebildeter Dehiszenzlinien sich öffnend, Capillitiumfäden schlank, perlschnurartig, jedenfalls mindestens mittelst eines Endes an der Peridie befestigt.

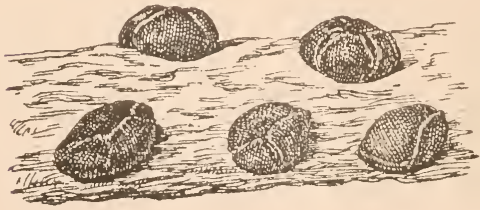

Fig. 175 .

Listerella paradoxa Jahı.

Sporangiengruppe $(50 / 1)$.

Nach Lister. 


\section{Gattung Margarita Lister}

Monogr. ed. 1 (1894), 203, ed. 2. 256; Schinz in Mitt. Naturw. Ges. Winterthur VI, 116; Torrend in Broteria VI, 45, VII, 25, VIII, 28.

Mit nur einer Art:

M. metallica (Berkeley et Broome) Lister Monogr. ed. 1 (1894), 203, pl. LXXIII, A. fig. a-c, ed. 2, 256, pl. 196, fig. $\mathrm{a}-\mathrm{d}$; Torrend in Broteria VII, 25.

Synouyme: Licea incarnata Alb. et. Schwein. Consp. Fung. (1805), 109 ?

Perichina incaruata Fr. Syst. Myc. III (1829), 193?

Lycogala incarnatum Swartz in Handl. K. Svenska Vet. Acad. (1815), 112?

Physarum metallicum Berkeley et Broome in Mag. .Zool. and Bot. I (1838), 49, t. 3, fig. 8 .

Cornuvia metallica Rost. Monogr. App. (1876), 35.

Margarita pictoviana Moore in Proc. Nova Scotia Inst. Sc. XII (1910), 96?

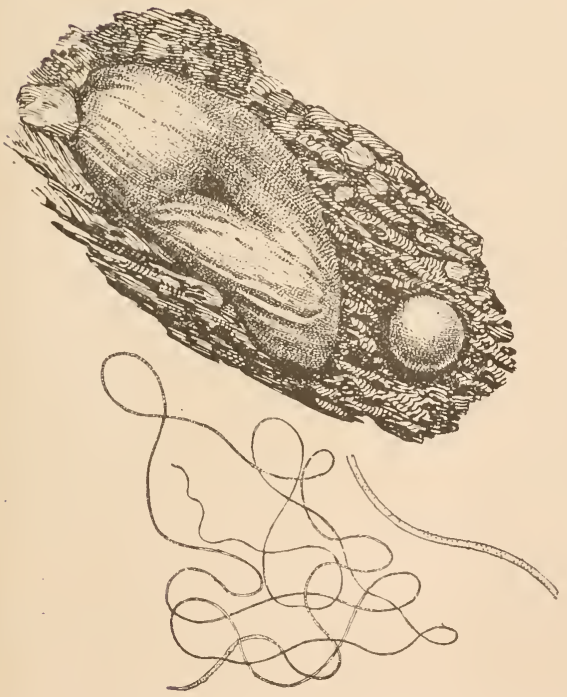

Fig. 176.

Margarita metallica (Berkeley et Broome)

\section{Lister.}

(Oben Plasmodiokarp und sporangium (20,1), unten Capillitiunfäden $(280 / 1$ und $600 / 1$ ).

Nach Lister 
Plasmodium wässerigweiß. Sporangien einzeln oder gehäuft, + kugelig, sitzend, $0,5-1 \mathrm{~mm}$, an deren Stelle mitunter gerade oder gekrümmte Plasmodiokarpien, perlgrau oder kupferrot, leuchtend und metallisch glänzend. Peridie einschichtig, grangrünlich oder gelblich. Capillitiumfäden in diffusen Haufen, grau oder gelblich, zart, sehr lang, biegsam und geschlängelt, kaum verzweigt, haarartig, mit sehr kleinen, spiralig angeordneten Stacheln, ab und zu an der Sporangiumwand befestigt. Sporenmasse blaßgraurot, sich im Alter gelblich verfärbend; Sporen im durchfallenden Lichte fast farblos, fein warzig, $10-13 \mu$.

Deutschland, Schweiz.

Großbritannien, Frankreich, Portugal, Skandinavien, Japan, S.-Amerika.

- var. intermedia Meylan in Bull. Soc. Vaud. Sc. nat. XLVI (1910), 56 et in Bull. Soc. Bot. Genève 2 me sér. II, 267.

Synonym: Dianema corticatum Meylan in Bull. Soc. Vaud. Sc. nat. 5 me Sér. XLIV (1908), 801 non Lister, et XLVI, 56.

Plasmodium zuerst weiß, hierauf dunkelgelb und schließlich braun oder zuerst weißlich, später rosarot und alsdann braun. Plasmodiokarpien buchtig, 2-15 mm lang und 0,5-1,5 mm breit, kupferfarbig. Capillitium wohlentwickelt, bald körnig verdickt, bald glatt und Verdickungen in Form von Ringen aufweisend. Sporen warzig, oft in Gruppen zu 3-6.

Schweiz (Jura).

- var plasmodiocarpa (Blytt) R. E. Fries in Svensk. Bot. Tidskr. VI (1912), 800.

Synonym: Perichæna plasmodiocarpa Blytt in Bidr. K. Norg. Sop. III (1892), 10.

Plasmodiokarpien bandförmig, unverzweigt oder verzweigt, gewöhnlich zu scheibenförmigen, bis ein paar Zentimeter großen Bildungen gehäuft.

Schweden, Norwegen.

Weitere Untersuchungen werden zeigen müssen, ob es sich hiel wirklich un Formen oder nur um gelegentliche, durch Wachstumsstörungen bedingte Vorkommnisse handelt. 


\section{Gattung Dianema Rex}

in Proc. Acad. Nat. Sc. Phil. (1891), 397; Lister Monogr. ed. 1, 204, ed. 2, 257; Macbride N. Am. Slime-Moulds, 181; Schinz in Mitt. Naturw. Ges. Winterthur VI, 116; Torrend in Broteria VI, 45, VII, 2t, VIII, 28.

Entweder sitzende, \pm kugelige Sporangien oder Plasmodiokarpien. Capillitiumfäden \pm gerade, meist beiderends an der Peridie befestigt, einfach oder verzweigt, untereinander frei oder anastomosierend.

1. Peridie durchsichtig, häutig; Sporen frei.

2. Capillitiumfäden nahezu einfach, mittelst kurzer Äste an der Peridie befestigt.

D. Harveyi Rex in Proc. Acad. Nat. Sc. Phil. (1891), 397; Lister Monogr. ed. 1, 204, pl. LXXIV, A, a-c, ed. 2, 257, pl. 191, fig. a-c; Macbride N. Am. Slime-Moulds, 180; Torrend in Broteria VII, 24.

Synonym: Lamprodermopsis nivalis Meylan in Bull. Soc. Vaud Sc. nat. XLVI (1910), 56?

Plasmodium? Sporangien einzeln oder in kleinen Gruppen. sitzend, kugelig, halbkugelig oder kissenförmig, abgeflacht, 0,5 bis $2 \mathrm{~mm}$ breit und $0,35-1 \mathrm{~mm}$ hoch, mitunter verlängert oder 土 ringförmig, dunkelrot oder bronzefarbig, metallisch glänzend; Peridie häutig, unregelmäßig aufspringend, blaßpurpurrot oder olivenfarbig, auf der Innenseite mit den Ansatzstücken abgebrochener Capillitiumfäden besetzt. Capillitium aus zahlreichen, schlanken, bräunlichgelben, 1,5-2 $\mu$ breiten, einfachen oder spärlich verzweigten und zum Teil anastomosierenden, oft in zarte Ästchen an der Ansatzstelle verzweigten, unter sich \pm parallelen, geraden oder wellig von der untern zur obern Ansatzstelle verlaufenden Fäden bestehend. Sporenmasse ziegelrot, dunkelrot oder bräunlichgelb; Sporen im durchfallenden Lichte blaßgelb, fein warzig, $8-10 \mu$.

Schweiz?

Großbritannien, N.-Amerika. 


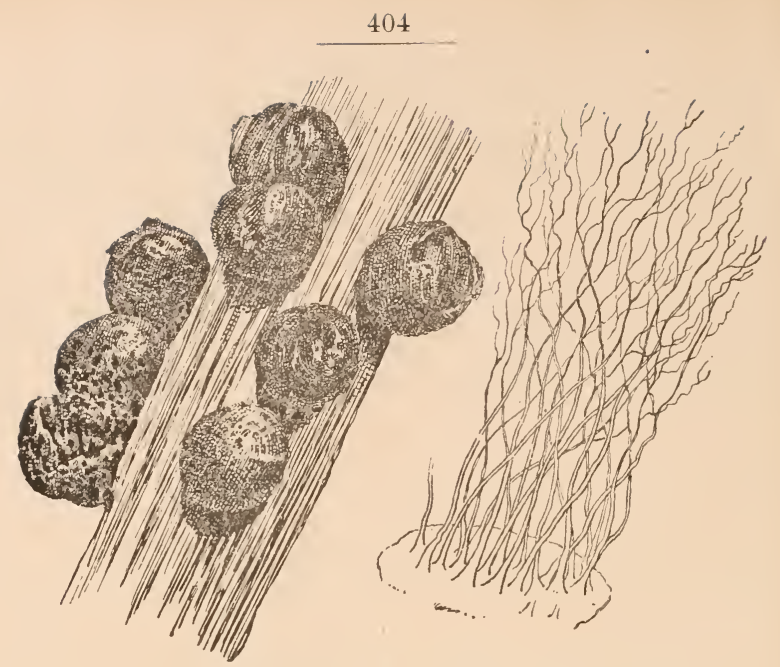

Fig. 177. Dianema Harveyi Rex.

Links Sporangiengruppe (20/1), rechts Partie des Capillitiums $(280 / 1)$. Original.

Ich habe vorstehend Lamprodermopsis nivalis Meylan als Synonym zu D. Harveyi gestellt, da es mir mit Fränlein G. Lister vorlänfig unmöglich ist, zwischen letzterer und Meylan's Lamprodermopsis einen generellen, ja auch nur spezifischen Unterschied aufzufinden. Meylan beschreibt seine $L$. nivalis wie folgt:

Sporangien vereinzelt, sitzend oder gestielt, kugelig, im Durchmesser 1-1,5 mm, fahlgelb mit Metallglanz. Stiel von derselben Farbe, 0 bis $1 \mathrm{~mm}$ lang:- Peridie häutig, glatt, am Grunde lange erhalten bleibeud. Columella fehlend. Capillitium von der Spitze des Stieles und dem untern Viertel der Peridie ausgehend, aus anfangs straffen und einfachen, sich alsdann unter offenem Winkel verzweigenden Fäden bestehend. Die äußersten Verzweigungen der Capillitiumfäden anastomosieren mit zahlreichen freien Enden, sodaß das der Peridie entblößte Capillitium einem kleinen Schwanme gleicht. Die Fäden sind glatt, straff oder wellig. Sporen im durchfallenden Lichte sehr blaßgelb, fein warzig, 10-12 $u$. Schweiz: Prise Bornand et la Gittaz bei Ste. Croix, 1200-1280 in (Jura), Mai 1910: dicht am Schnee anf alten Grasstengeln.

Wie mir Fräulein G. I,ister, die unbestritten beste Kennerin der Schleimpilze schreibt, haben ihr im Laufe der letzten Jahre Exemplare der D. Harveyi von sechs verschiedenen Lokalitäten Englands vorgelegen, die sich in bezug anf die Ausbildung der Capillitien recht verschieden verhalten. Die einen 
Exemplare besitzen, bei mehr spärlicher Entwicklung des Capillitiums, straffe, gröBtenteils einfache Fäden, andere im Gegensatz dazu ein reichlich entwickeltes Capillitium, bestehend aus schlanken, welligen uıd verzweigten Fäden, deren Äste, anastomosierend, ein Netzwerk bilden, ja in einem Fall ist das Netzwerk so dicht, daß man versucht wäre, hierauf eine besondere Spielart zu gründen, wemn nicht zum Typus überleitende Zwischenformen vorhanden wären. Das mir zur Verfügung stehende Naterial der Meylan'schen Art ist zu spärlich, als $\mathrm{da} B$ es eine gründliche Nachuntersuchung gestatten würde und ich stelle daher, bessere Belehrung vorbehalten, vorläufig Meylan's Lamprodermopsis nivalis als var. nivalis (Meylan) Schinz nov. comb. zu D. Harveyi, allerdings nicht ohne hervorzuheben, daß, wemn es sich bestätigen sollte, daB in der Tat die Capillitiumfädeu konstant vom Grunde des Sporangiums ausstrahlen und am Grunde straffer sind als oberwärts, diese beiden Merkmale eine Abtrennung als Dianema nivalis (Meylau) Lister Monogr. ed. 2 (1911), 258 rechtfertigen würden.

2.* Plasmodium weib oder rosarot. Plasmodiokarpien einzeln oder in Gruppen, polsterförmig, 2-10 $\mathrm{mm}$ breit, $\pm 0,3 \mathrm{~mm}$ hoch, violettglänzend im Zustande der Entwicklung, später, d. h. im Zustande der Sporenreife, glänzen'd graubraun. Peridie auf der Innenseite mit den Ansatzstücken der abgebrochenen Capillitiumfäden besetzt. Capillitiumfäden blaßgelblichgrau, straff, $0,5-2 \mu$ breit, spitzwinkelig gegabelt, büschelig verbunden an beiden Enden und beidendig an der Peridie befestigt; ohne freie Enden. Sporenmasse lilagrau oder schwarzbraun; Sporen im durchfallenden Lichte blaßgelblichgrau, 0,5-1 $\mu$ breit berandet, der größere Teil der Oberfläche unterbrochen netzartig skulptiert, $6-9 \mu$.

D. depressum Lister Monogr. ed. 1. (1894), 204, pl. LXXIV, B, fig. a-c, ed. 2, 258, pl. 190, fig. a-c; Torrend in Broteria VII, 25, pl. II, fig. 10-12.

GroBbritannien, Schweden, Portugal.

1*. Sporangien oder häufiger Plasmodiokarpien mit pergamentartiger, undurchsichtiger Peridie. Sporen zu 4 bis 6 in Gruppen. 
D. corticatum Lister Monogr. ed. 1 (1894), 205, pl. LXVII, B, fig. a-d, ed. 2, 259, pl. 193, fig. a-c; Schinz in Mitt. Naturw. Ges. Winterthur VI, 116; Torrend in Broteria VII, 24, pl. II, fig. 13-15.

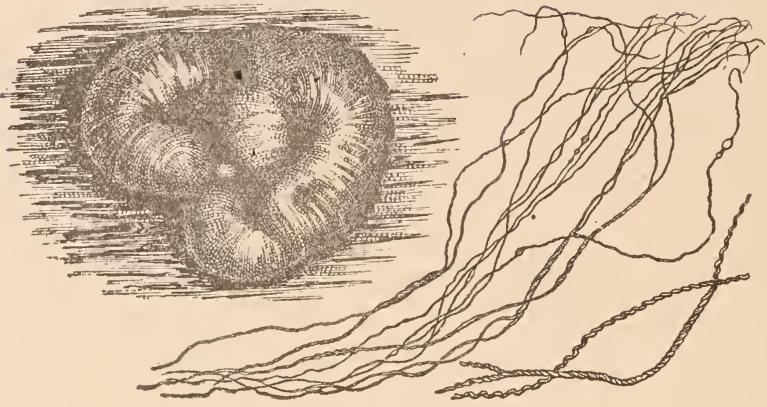

Fig. 178. Dianema corticatum Lister.

Links Plasmodiokarp (20/1); rechts Capillitiumfäden $(280 / 1$, die beiden untern Fäden etwas stärker vergrößert.) - Nach Lister.

Plasmodium rosa- oder salmrot. Sporangien halbkugelig, \pm $1 \mathrm{~mm}$ im Durchmesser, an der Stelle solcher aber häufiger verlängerte, netzartige oder ringförmig geschlossene, $3-30 \mathrm{~mm}$ lange Plasmodiokarpien, glänzend oder matt, kastanien- oder purpurbraun ; äußere Schicht der Peridie pergamentartig, \pm olivockergelb, mit reichlichen Granulationen. Capillitium \pm spärlich entwickelt, aus blaßbraunen, schlanken, einfachen oder spitzwinkelig sich verästelnden, $0,5-1,5 \mu$ breiten Fäden bestehend. Capillitiumfäden entweder \pm glatt oder mit entfernten, an eine Perlenschnur erinnernden Verdickungen oder mit 1, stellenweise sogar 3 Spiralleisten, mittelst sehr zarter Enden beidendig an der Peridie befestigt. Sporenmasse braunrötlich; Sporen im durchfallenden Lichte hlasser oder nahezu farblos, von ellipsoidischer Gestalt, zu 4 (oder 2) bis 6 zu Gruppen verbunden, auf der freien Seite warzig, $10-12 \times 8-9 \mu$.

Österreich, Schweiz.

Großbritannien, Skundinavien, N.-Amerika, Australien. 


\section{Gattung Prototrichia Rost.}

Monogr. App. (1876), 38; Massee Monogr., 126 pr. p.; Lister Monogr. ed. 1, 206, ed. 2, 260, Macbride N. Am. SlimeMoulds, 199; Schinz in Mitt. Naturw. Ges. Winterthur VI, 118; Schröter in Engler und Prantl Natürl. Pflanzenfam. I, 1, 24 pr. p.; Torrend in Broteria VI, 47, VII, 71, VIII, 28.

Mit nur einer Art:

P. metallica (Berkeley) Massee in Journ. Micr. Soc. (1889), 350, fig. 26, Monogr. 127; Lister ed. 2, 260, pl. 195, fig. a-e.

Sy n on y me: Trichia metallica Berkeley in Hook. Fl. Tasm. II'(1860), 268.

Trichia flagellifera Berkeley et Broome in Ann. Mag. Nat. Hist. ser. 3, XVIII (1866), 56, pl. 2, fig. 4.

Prototrichia flagellifera Rost. Monogr. App. (1876), 38; Massee in Journ. Micr. Soc., 350, fig. 23; Monogr., 127, fig. 130-132; Lister Monogr. ed. 1, 206, pl. LXXIII, B, fig. a-d; Macbride N. Am. Slime-Moulds, 199; Torrend in Broteria VII, 43, pl. III, fig. 16, 17.

Prototrichia elegantula Rost. Monogr. App. (1876), 39, fig. 246. Prototrichia cuprea Massee in Journ. Micr. Soc. (1889), 351, fig. 24; Monogr., 129, fig. 127-129.

Prototrichia chamæleontina Massee Monogr. (1894), 130 pr. p,

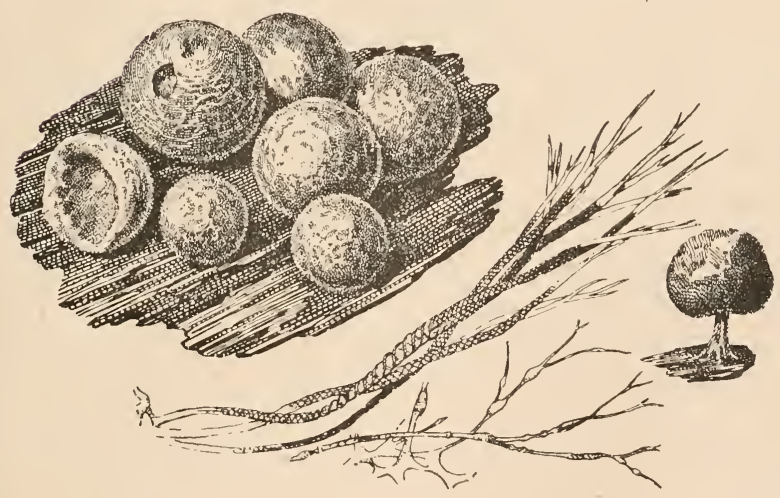

Fig. 179. Prototrichia metallica (Berkeley) Massee. Sitzende und gestielte Sporangien $(20 / 1)$; unten Capillitiumfäden $(280 / 1)$. Nach Lister. 
Plasmodium weiß. Sporangien zerstreut oder bisweilen gehäuft, selten mit einem $0,1-0,4 \mathrm{~mm}$ langen, $0,15 \mathrm{~mm}$ dicken, nicht hohlen, gelblichbraunen stiel versehen, meist sitzend, \pm kugelig, 0,5-1 mm, mitunter zu Plasmodiokarpien entwickelt, braun oder kupferfarbig, metallisch glänzend. Peridie dünnhäutig, durchsichtig, auf der Innenseite die zarten Enden abgebrochener Capillitiumfäden tragend. Capillitium aus zahlreichen, rot- oder olivbraunen, ziemlich derben, \pm straffen, unverzweigt aufsteigenden, sich dann aber mehrfach verzweígenden Fäden mit Verdickungen in Form von 2-4 Spiralleisten bestehend, die Fäden schlieBlich bürstenartig auslaufend in zarte Spitzen, mittelst derer sie wiederum an der Peridie befestigt sind. Sporenmasse braunrötlich; Sporen im durchfallenden Lichte blasser, rosarot oder blab rosarotbraun, fein warzig, $9-11 \mu$.

Deutschland, Schweiz.

Großbritannien, Skandinavien, Tasmanien, N.-Amerika.

\section{Gattung Listerella Jahn}

in Ber. Deutsch. Bot. Ges. XXIV (1906), 540; Torrend in Broteria VII, 26, VIII, 28; Lister Monogr. ed. 2, 261.

Mit nur einer Art:

L. paradoxa Jahn in Ber. Deutsch. Bot. Ges. XXIV (1906), 538, t. XXII, fig. 1-8; Torrend in Broteria VII, 26, pl. IX, fig. 18; Lister Monogr, ed. 2, 261, pl. 191, fig. d-f.

Exsikkaten: O. Jaap Мyxom. exsicc. 99; Fungi sel. 401.

Plasmodium? Sporangien als mit dem unbewaffneten Auge eben noch wahrnehmbare, kleine schwarze Punkte auf dem Thallus von Cladonia rangiferina auftretend, \pm halbkugelig, 0,2-0,3 mm groß, am Grunde abgeflacht, schwarzbraun, mit etwas helleren, sich deutlich abhebenden Dehiszenzlinien. Peridie einfach, purpurbraun, mit AusschluB der Dehiszenzlinien mit einer Kruste dunkler Ausschußgranulationen überkleidet, zur Zeit der Sporenreife in 4-6 Lappen zerreißend. Capillitium spärlich entwickelt, aus blassen purpurbraunen, schlanken, geschlängelten, ein- (?) oder beiderends (?) an der Peridie hefestigten Fäden bestehend. Bei schwacher Vergrößerung erscheinen die Fäden als lange Perlenschnüre; sehr stark ver- 
größert zeigen sie sich aus lauter kelchförmigen oder birnförmigen Gliedern zusammengesetzt. Die Knoten sind am abgerundeten Ende ein wenig dunkler, die Stiele farblos. Die beschriebene Skulptur hat der Faden nur in der Mitte und am Ende. Nahe der Ansatzstelle entwickelt sich die Gliederung erst allmählich, und zwar kommen hier Fäden von zweierlei Art vor. Entweder ist der Faden zunächst doppelt so dick wie die normalen und dunkel gefärbten und es treten an ihm Einschnïrungen auf, die sich in helle stiele und Knoten gliedern und ganz allmählich schmäler werden und die Kelchgestalt annehmen oder der Faden ist vom Anfang an heller gefärbt und die Knoten entwickeln sich ziemlich schnell aus kragenartigen Einschnürungen. Sporenmasse schwarzbraun; Sporen im durchfallenden Lichte bräunlichgelb, einseitig dïnnwandiger, verschwommen fein stachelig, $7-8 \mu$.

Dentschland.

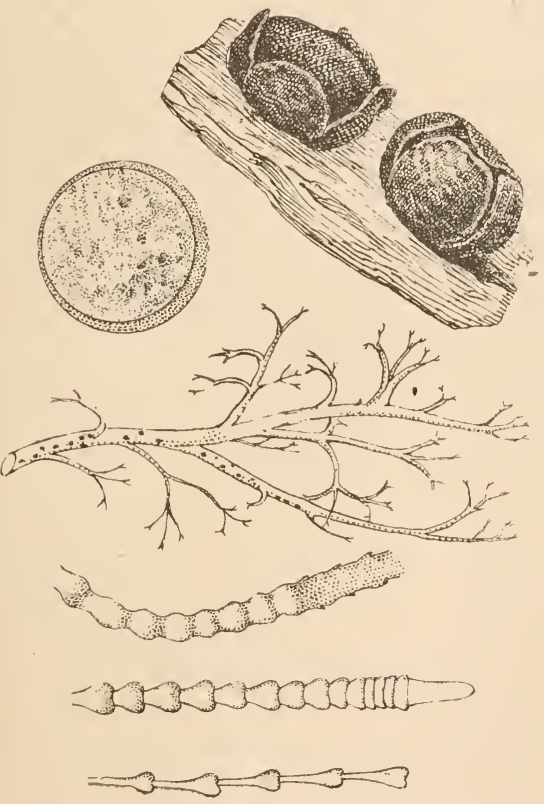

Fig. 180.

Listerella paradoxa Jahn.

Oben zwei Sporangien $(60 / 1)$, das eine geöffnet; eine Spore $(3000 / 1)$, ein Ästchen einer Cladonia rangiferina mit aufsitzenden Sporangien $(1 / 1)$, drei Capillitiumfäden, die zwei oberen nahe der Ursprungsstelle, die untere Figur einem mittleren 'T'eil eines Fadens entsprechend $(3000 / 1)$.

Nach Jahn.

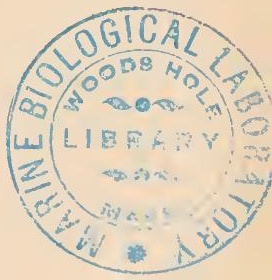




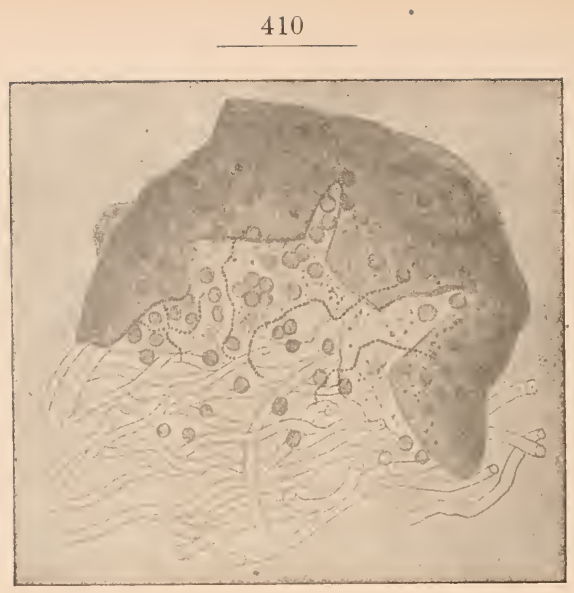

Fig. 181. Listerella paradoxa Jahn.

Ein den Hyphen der Cladonia aufsitzendes, zerquetschtes Sporangium $(200 / 1)$. Nach Jahn.

Gattung von vorläufig noch nicht gesicherter Stellung.

Barbeyella. Sporangien sehr klein, gestielt, kugelig. Columella lang, in wenige Fäden ausstrahlend die an den Peridielappen, in die das Sporangium zur Sporenreife zerreißt, befestigt sind. Stiel mit protoplasmatischem Ausschußmaterial angefüllt.

\section{Barbeyella Meylan}

in Bull. Soc. Bot. Genève 2me sér. VI (1914), 89.

Mit nur einer Art:

B. minutissima Meylan 1. c. (1914), 89.

Sporangien sehr klein, kugelig, 0,15 bis $0,2 \mathrm{~mm}$ im Durchmesser, 0,3 bis $0,7 \mathrm{~mm}$ lang gestielt, schwarzbraun oder schwarzviolett, kaum glänzend, zur Zeit der Sporenreife von oben gegen den Grund zu in oblonge Lappen einreißend. Stiel b̧raunschwarz, gegen den Grund zu verdickt und daselbst mit plasmatischem Ausschußmaterial angefüllt. Peridie oberwärts mit plasmatischen Granulationen besetzt, gegen den Grund zu von solchen \pm frei. 
Columella lang, am obern Ende in 7 bis 10 einfache oder selten gegabelte, braune, straffe Capillitiumfäden ausstrahlend, die einzeln, selten zu zweien an den Peridielappen befestigt sind. Sporen im durchfallenden Lichte braun, warzig, seltener nahezu glatt, $7-9 \mu$.

Schweiz (Jura: Chasseron, auf Lebermoosen wie Lophozia longiflora, L. longidens, Blepharostoma trichophyllum, bei $1400 \mathrm{~m}$; La Vaux, zwischen dem Chasseron und dem Creux-du- Van, $1300 \mathrm{~m})$.

B. minutissima, deren Sporangien von unbewaffnetem Auge kaum, warnehmbar sind, gehört zu den allerkleinsten bis auhin beobachteten Schleimpilzen. Wenn sich die Fruchtkörper öffnen, erinneru sie an eine sehr kleine Blüte, die Peridielappen täuschen
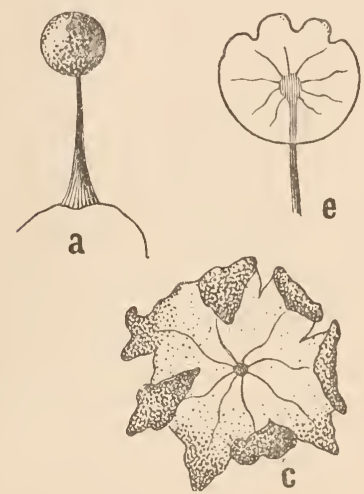
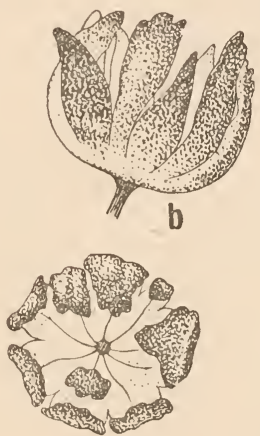

d

Fig. 182. Rarbeyella minutissima Meylan.

a) Sporanginm $\left({ }^{80} / 1\right)$; b) bis e) geöffuete Sporangien, b) von der Seite, c) und d) von oben $\left({ }^{200} / 1\right)$; e) Peridie durchsichtig $\left({ }^{15 \%} / 1\right)$. - Nach Meylan.

Blütenhüllblätter, die Columella und die Capillitiumfäden Staubfäden und Griffel vor. Je nach der Größe der plasmatischen Granulationen erscheint di§ Peridie papillös oder glatt. Bei unregelmäßigem Einreißen der Peridie kommt es vor, daß sich der Peridielappen ganz losreißt und dann von ein oder zwei Capillitiumfäden getragen wird. Die Art erinnert durch ihre Fruchtkörper an ein sehr kleines Lamproderma, die Öfnungsart 
und die Capillitiumausbildung läßt sie indessen als Vertreterin einer besonderen Gattung erkennen. Für die Zugehörigkeit zu den Stemonitaceen spricht der hohle, mit Ausschußmaterial angefüllte Sporangiumstiel; das Verhalten der Peridie und die Befestigung der Capillitiumfäden an den Peridiefragmenten ähnelt Clastoderma, Columella und Habitus nähern der Gattung Lamproderma und Comatricha; Peridiegranulationen sind für Leptoderma charakteristisch, bei dieser kommen sie aber namentlich gegen den Grund der Sporangien in größerer, nach oben in geringerer Zahl vor, während sich Barbeyella in dieser Hinsicht gerade umgekehrt verhält. 


\section{ANHANG.}

\section{Nachträge und Berichtigungen.}

Das Studium der Myxogasteres ist im Lanfe der letzten Jahre ein außergewöhnlich reges gewesen, sowohl in floristischer wie in systematischer Hinsicht, beeinflußt zur Hauptsache durch die Arbeiten von E. Jahn. C. Torrend, Ch. Meylan, Th. H. Macbride, W. C. Sturgis, Rob. E. Fries u. A., namentlich aber durch die zweite Auflage der ganz vorzüglichen Monographie des leider allzufrüh verstorbenen Arthur Lister, der glücklicherweise eine hochbegabte Mitarbeiterin in seiner Tochter, Fräulein Gulielma Lister besaß, die nun heute unbestritten die beste Kennerin dieser kleinen Organismen ist. Was ich persönlich Lister Vater und Tochter, was der Monographie zu verdanken habe, das läbt sich nicht in Worten ausdrücken. Die vorliegende Bearbeitung ist schließlich ja auch nichts weiter als eine abgekürzte deutsche Reproduktion der Lister'schen; mehr und besseres zu bieten war zur Stunde nicht wohl möglich, so sorgfältig und so genau sind die sämtlichen Lister'schen Beschreihungen. Der Zukunft bleibt vorbehalten das cytologische Studium der Schleimpilze, das Studium ihrer Entwicklung, der Entstehung der Capillitien usw., dann aber auch die monographische Bearbeitung der einzelnen Gattungen.

Vom Anwachsen der Literatur gerade in den letzten Jahren gibt dieser Nachtrag ein sprechendes Bild. Er hätte ja gekürzt werden können wenn ich davon abgesehen hätte, der Vorkommnisse außerhalb unseres Gebietes zu gedenken, aber je weiter die floristischen Kenntnisse vorschreiten, um so mehr befestigt sich die Über\%engung, daß eigentlich die große Mehrahl aller Schleimpilze, vielleicht überhaupt alle, Ubiquisten sind und wir 
dürfen oder müssen jederzeit damit rechnen, daß z. B. eine bis heute nur aus Australien bekannte Art plötzlich auch bei uns auftaucht.

Brandza's neue, noch unbenannte, aber diagnostizierte Arten kenne ich nur aus den Beschreibungen und Figuren, und ich wage es daher nicht, deren Stellung im Schlüssel irgendwie festzulegen, übergehen wollte ich sie aber auch nicht, sondern ziehe es vor, darauf hinzuweisen, in der Gewißheit, daß früher oder später doch eine Klärung folgen wird.

S. 29. Ergänze das Literaturverzeichnis durch:

1917. Skupienski, François-Xavier. Sur la sexualité chez les Champignons Myxomycètes. Comptes rendus Acad. Sciences Paris t. 165 (1917), 118.

1918. - Sur la sexualité chez les Champignons Myxomycétes. l. c. t. 167 (1918), 31.

S. 83. Ceratiomyxa caesia Jahn in Ber. Deutsch Bot. Ges. XXXVI (1919), 660.

Plasmodium blaugrün, Fruchtkörper vom Aussehen solcher von C. fruticulosa var. porioides (Alb. et Schw.) Lister. Die Poren scheinen ein wenig unregelmäßiger, die sie trennenden, ein Netz bildenden Wände ein geringes breiter zu sein. Sporen farblos, $12-14 \mu$ lang und $6 \mu$ breit, also ungefähr so breit und meist ein wenig länger als die von $C$. porioides.

Deutschland (Uckermark).

S. 83. Ceratiomyxa sphærospora Skupienski in Bull. Soc. Mycol. France XXXII (1916), 4, fig. 3.

Plasmodium gelb. Sporophore unverzweigt, kurz, \pm $0,75 \mathrm{~mm}$ lang. Sporen vollständig kugelig, im durchfallenden Lichte farblos, $3 \mu$.

Frankreich (Fontainebleau).

S. 94. zu Badhamia capsulifera (Bull.) Berkeley füge hinzu: Dänemark, Belgien, Rumänien, Java.

S. 95. zu Badhamia papaveracea Berk. et Rav. füge hinzu: Java, S.-Amerika. 
S. 96. zu Badhamia nitens Berkeley füge hinzu:

B. nitens Berkeley var. reticulata (Berkeley et Broome) G. Lister nov. comb. in Trans. Brit. Mycol. Soc. 5 (1914) 71, pl. 1, fig. 2, 2a, $2 b$.

Synonyme: Badhamia Alexandrowiezii Rost. Monogr. (1875), 146.

Didymium reticulatum Berkeley et Broome in Journ. Linn. Soc. XV (1876), 83.

Lepidoderma reticulatum Nassee Monogr. (1892), 252.

Schlanke, zerstreute, schwefelgelbe, kürzere oder längere Plasmodiokarpien von Q- oder V-Gestalt, Capillitium gelb. Die Sporen zu sechs bis zwölf locker zu Haufen vereinigt, warzig, die Warzen auf der freien Seite stärker ausgebildet.

Großbritannien, Polen, Ceylon, Japan.

S. 97. zu Badhamia utricularis (Bull.) Berkeley füge hinzu: Dänemark, Belgien, Rumänien, Rußland, Australien.

S. 100. zu Badhamia foliicola Lister füge hinzu: Rumänien. S. 100. im AnschluB an B. foliicola Lister ist einzusetzen:

Badhamia alpina G. Lister in Journ. of Bot. LII (1914), 99.

Synonym: Badbamia foliicola Lister var. alpina G. Lister in Rabenh. Krypt.-Fl. X (1912), 100.

Plasmodium blaßgelb oder gelblichweiß. Sporangien sitzend, gehäuft oder zerstreut, nahezu kugelig oder halbkugelig und mit breiter Basis dem Substrat aufsitzend, 0,5-0,9 $\mathrm{mm}$ im Durchmesser, grau oder dunkelbraun und, wenn kalkfrei, metallisch glänzend. Peridie häutig, zerbrechlich, mit oder ohne Kalkauflagerungen. Capillitium ein dichtes Netzwerk schlanker Schläuche, mit verbreiterten und spärlich Kalkgranulationen führenden Knoten. Sporen sehr schwach warzig, im durchfallenden Lichte graulila, $10-12 \mu$.

Schweiz, alpin und subalpin (Arosa, Trimmis, Fürstenalp, Jura). Schweden?

Unterscheidet sich von B. foliicola durch die blasse Farbe des Plasmodiums, die ausprochener halbkugeligen Sporangien und die blassen, nahezu glatten Sporen, von B. panicea durch den gelblichen Ton des Plasmodiums, das dichtere Netzwerk des zudem häufig kalkfreien Capillitiums und die blassen Sporen; zudem sind die Sporangien von B. alpina am Grunde niemals rot. 
S. 101. zu Badhamia macrocarpa (Ces.) Rost. füge hinzu: Java, Dänemark, Rumänien.

S. 102. zu Badhamia panicea (Fries) Rost. füge hinzu: Dänemark, Rumänien.

S. 104. Badhamia ovispora Racib. kommt nach Jahn (Ber. Deutsch. Bot. Ges. XXXVI [1919], 662) auch in Deutschland vor.

S. 104. zu Badhamia lil acina (Fries) Rost. füge hinzu: Rumänien.

S. 106. Badhamia rubiginosa (Chev.) Rost. var. concinnum G. Lister ist an dieser Stellle zu streichen. Fräulein Lister glaubt hierin eine Craterium-Art zu erkennen, die sie C. rubronodım G. Lister nennt und die an der betreffeuden Stelle (Nachtrag) erwähnt und diagnostiziert wird.

S. 108. zu Physarum leucopus Link füge hinzu: Finnland, Rumänien.

S. 109. zu Physarum melleum (Berk. et. Br.) füge hinzu: Australien.

S. 109. Physarum sulphureum Alb. et Schw., scheint nach newesten Untersuchungen von Sturgis (Mycologia XIX (1917), 325) von Plyssurum varialile Rex nicht verschieden zu sein. Fräulein Lister hat sich dieser Auffassung angeschlossen nnd weist (Notiz bei Sturgis) auf den Umstand hin, daß wenu der Kalk in der Peridie und in den Kalkknoten der Sporongien beider Arten (nunmehr zu vereinigen unter der Bezeichnung $P$. sulphureum) durch Säuren gelöst wird, kleine, grünliche. kugelige Granulationen auftreten.

S. 110. zu Physarum variabile Rex füge hinzn: Ceylon, Japan.

S. 112. Physarum globuliferum (Bull.) Pers. kommt anch in Grobbritannien vor.

Physarum pulchripes Peck auch in Großbritannien.

S. 113. zu Physarum pulcherrimum Berk. et Rav. ist als weiteres Synonym aufzuführen:

Stemonitis porphyra Berkeley et Curtis in Grev. II (1873), 69. 
Vergl. Sturgis in Mycologia VIII (1916) 208.

S. 114. zu Physarum citrinum Schumacher füge hinzu: Dänemark, Finnland, Rumänien, Java, Australien, NeuSeeland.

S. 115. zu Physarum tenerum Rex füge hinzu: Java.

S. 116. Physarum compactum (Wing.) Lister: das Epitheton compactum ist zu ersetzen durch columbinum und die Art daher zu nennen Physarum columbinum (Rost.) Sturgis in Mycologia VIII (1916), 200. Als weiteres Synonym kommt hinzu:

Tilmadoche columbinum Rost. Monogr. App. (1876), 13.

Vergl. Sturgis 1. c., 200.

S. 117. zu Physarum roseum Berkeley et Broome füge hinzu: W.-Afrika.

S. 118. zu Physarum psittacinum Ditm. füge hinzu: Däıemark, Rumänien, Java.

S. 119. anstatt Physarum dictyosporum Líster lies P. dictyo spermum Lister und fiige hinzu: Australien (die Exemplare aus Neu-Süd-IVales haben gleichmäßig schlanke Sporangienstiele. Die Funde aus dem Jura unterscheiden sich vom Typus dadurch, daß die Sporen an Stelle regelmäßiger Netzstruktur ein uuregelmäßiges, unterbrochenes Net\% verdickter Leisten und Warmen zeigen).

S. 119. zu Physarum viride (Bull.) Pers. ist als weiteres Synonym hinzuzufügen:

Chondrioderma exiguum Raciborski in Hedwigia XXVIIl (1889), 118.

S. 120. zu Physarumviride var. Bethelii (Macbride) Sturgis füge hinzu: S.-Amerika.

S. 12ะ. жu Physarum polycephalum Schwein. füge hinzu: S.-Amerika, Java und zu var. obrusseum Lister: S.Amerika, Java.

S. 122. zu Physarum flavicomum Berkeley füge hinzu: S.Amerika, Java, Australien.

Schinz Myxogasteres (Rabenhorst Krypt. Flora I, Pilze Abt. X). 
S. 123. zu Physarum galbeum Wingate füge hinzu: S.-Amerika.

S. 123. zu Physarum maydis (Morgan) Torrend füge binzu: S.-Amerika.

S. 124. zu Physarum fulvum (Macbride) Lister füge als weitere Literaturangabe hinzu: G. Lister in Journ. of Bot. LII, (1914), 100.

S. 125. zu Physarum fulvum (Macbride) Lister füge zu Wiesen hinzu: Arosa, Jura.

S. 125. zu Physarum penetrale Rex füge hinzu: S.-Afrika, S.-Amerika.

S. 126. Physarum carneum G. Lister et Sturgis. Der bibliographische Passus ist zu ergänzen durch: H. J. Howard in Journ. R. Microsc. Soc. (1917), 265, pl. XVIII. -- Füge ferner hinzu: Plasmodium (nach Howard) milchweiß; Sporangien braungelb. Sporen im durchfallenden Lichte auf einer Seite blasser und glätter als auf der anderen.

Von H. J. Howard ist diese, in obiger Publikation durch Frl. G. Lister meisterhaft abgebildete Art nun auch in Großbritannien (in Norfolk) und von Torrend in Portugal nachgewiesen worden.

S. 127. zu Physarum brunneolum Phillips füge hinzu: Großbritannien, S.-Amerika, Java, Neusüdwales.

S. 128. zu Physarum nucleatum Rex füge hinzu: W.-Afrika.

S. 128. zu Physarum straminipes Lister füge hinzu: S.-Amerika.

S. 129. zu Physarum pusillum (Berkeley et Curtis) Lister füge hinzu: Afrika, Neu-Seeland.

S. 130. zu Physarum didermoides (Achar.) Rost. füge hinzu: Rumänien, und setze anstatt W.-Afrika kurzweg Afrika.

S. 133. zu Physarum nutans Pers. füge hinzu: var. iricolor Brandza nov. var. in Ann. scient. Université Jassy VIII (1914), 283, fig. 3, a-e.

Sporangien samt Stiel 1-1,5 mm hoch, kugelig, am Grunde nicht genabelt, $0,5-0,8 \mathrm{~mm}$ im Durchmesser, aufrecht und nicht 
nickend, dunkelindigofarbig, runzelig, grün, blau und bräunlichviolett irisierend. Stiel $0,5-1 \mathrm{~mm}$ hoch, blaßgelbbraun oder braunorangegelb. Peridie häntig, durchsichtig, mit netzartiger Skulptur, mit Kalkgranulationen. Capillitium spärlich, mit abgerundeten oder unregelmäßig geformten, $10-20 \mu$ großen, grünlichgelben oder blaßbraunen Kalkknoten die unter eiuander durch farblose oder blaßbraune Fäden verbunden sind. Sporenmasse dunkelkastanienbraun; Sporen glatt, im durchfallenden Lichte braunviolett, $8-9 \mu$.

Rumänien.

S. 134. Zu Physarum javanicum Racib. ist zu bemerken, daß diese Art neuerdings für N.-Amerika (Florida) nachgewiesen worden ist.

S. 134. zu Physarum crateriforme Petch füge hinzu: Großbritannien, W.-Afrika.

S. 137. zu Physarum reniforme (Massee) Lister füge hinzu: IV.-Afrika.

S. 137. Schlïsselsatz "13. Peridie einschtig" soll heißen: 13. Peridie einschichtig (nach Meylan bei P. vernum zweischichtig.)

S. 138. zu Physarum ve rnum Sommerfelt füge hinzu: Rumänien, Australien.

S. 139. Die Beschreibung der forma badhamioides Meylan in Bull. Soc. Vaud. Sc. nat, 5 me sér. L (1914), 5 erweitere wie folgt: die hyalinen Fäden, welche die in diesem Falle sehr zahlreichen Kalkknoten des Capillitiums verbinden, sind so kurz, daß sie zu fehlen scheinen; das Innere eines Sporangiums, das die Sporen entlassen hat, erinnert dann an ein solches von Badhamia.

S. 139. var. iridescens Lister ist auch in Großbritannien nachgewiesen (G. Lister -in Journ. of Bot. LVII [1919], 106).

S. 140. zu Physarum atrum Schwein. füge hinzu: S.-Amerika.

S. 141. zu Physarum gyrosum Rost. füge hinzu: WV.-Afrika, Australien, Japan. 
S. 142. Schlüsselsatz "13.* Peridie zweischichtig" soll heißen: 13.* Peridie zweischichtig (so nach Meylan auch bei $P$. vernum).

S. 144. zu Physarum bogoriense Racib. setze anstatt: W.Afrika, kurzweg Afrika.

S. 145. zu Physarum bitectum Lister fïge hinzu: Australien.

S. 146. zu Physarum contextum Pers. füge hinzu: Australien.

S. 147. den Schlüsselsatz "19. Sporangien rot oder braun" erweitere durch folgende Einfügung in Klammer: (Sporan'gien"oder Plasmodiokarpien mitunter gelb bei P. lateritium Berkeley et Rav.)

S. 149. im Schlüsselsatz $2 l^{*}$ ersetze das gelb durch orangerot oder gelb.

S. 149 P. lateritium Berkeley et Rav. Das Plasmodium ist nach H. J. Howard (Journ. R. Microsc. Soc. [191i], 26i) von orangegelber Farbe.

Ferner füge hinzu: Großbritannien, Neu-Seeland.

S. 149. Nach. 19.*, vor 22 , füge in den Schlüsselsatz ein: 19 a. Sporen stachelig, einseitig etwas blasser und weniger stachelig.

Physarum Serpula Morgan nov. spec. Myxom. Miami Valley (1896), 101; Lister in Journ. of. Bot. XXXVI, 116 und Monogr. ed. 2. 81 , pl. 57, fig. a-c; Macbride N-Am. Slime-Moulds, 29; Torrend in Broteria VII, 119, pl. V, fig. 28.

Synonyme: Physarum gyrosum Massee Monogr. (1892), 307 pr. p. Badhamia decipiens Lister Monogr. ed. I (1894), 32 pr. p.

Plasmodium? Sporangien sitzend und nahezu kugelig oder an deren Stelle lange, gerade oder gekrümmte, einfache oder verzweigte, mitunter ringförmige Plasmodiokarpien, $0,3 \mathrm{~mm} \mathrm{im}$ Durchmesser, gelb oder ockerfarbig. Peridie dicht mit gelben, gleichmäßig aufgelagerten Kalkgranulationen besetzt. Capillitium aus zahlreichen, kantigen und verzweigten, blaßgelben, durch spärliche, kurze, hyaline Fäden verbundene Kalkknoten bestehend. 
Sporen im durchfallenden Lichte purpurbraun, stachelig, einseitig etwas blasser und weniger stachelig, $10-12 \mu$.

N.-Amerika.

$19 a^{*}$. Sporen nahezu glatt (P. virescens, $7-10 \mu$ groß) oder dicht warzig (P. alpinum, 9-14 $\mu$ groß).

22. Sporangiumwand einschichtig. Sporangien u. s. w.

S. 150. zu Physarum virescens Ditm. füge hinzu: Rumänien, S.- Amerika.

S. 152. anhangsweise sind folgende weitere, zum Teil sicher gestellte, zum Teil vermutlich neue Physarum-Arten zu erwähnen :

Physarum digitatum G. Lister et Farquharson nov. spec. in Journ. of Bot. LIV (1916), 128, pl. 541, fig 1.

Plasmodium graugelb. Sporangien zylindrisch, aufsteigend, oft verzweigt oder unregelmäßig gelappt, dicht.gebüschelt, sitzend, lehmfarbig, 0,1-0,2 $\mathrm{mm}$ im Durchmesser, 0,5-1 $\mathrm{mm}$ hoch, auf einem häutigen, gelben Hypothallus, Peridie häutig, mit reichem Belag lehmfarbiger Kalkgranulationen und mit wenigen, scheibenförmigen, kristallinen, zerstreut zwischen den Granulationen liegenden Kalkkörpern von $10-20 \mu$ Durchmesser. Capillitium ein Netzwerk hyaliner Fäden, mit wenigen, eiförmigen oder kantigen, gelblich braunen Kalkknoten. Sporen im durchfallenden Lichte blaßviolettgrau, $5-5,5 \mu$, mit kleinen Gruppen kleiner Warzen, und zwar sind auf einer Halbkugel 3-5 solcher Warzengruppen wahrzunehmen.

Westafrika.

Fräulein G. Lister stellt diese Art in die Nähe von $P$. virescens Ditm., deren Sporen aber $6-10 \mu$ groß sind.

Physarum lilacinum Sturgis et Bilgram nov spec. in Mycologia IX (1917), 324.

Plasmodium? Sporangien herdenweise, gestielt, kugelig, aufrecht, blaßlila bis blaßrot, $0,5 \mathrm{~mm}$ im Durchmesser. Peridie häutig, mit abgerundeten Granulationen lilafarbigen oder rötlichen 
Kalkes besetzt. Stiel am Grunde breit, oberwärts verjüngt, kalkig, gefurcht, entweder blasser als das Sporangium oder gleichfarbig, 0,7 bis $0,9 \mathrm{~mm}$ hoch. Columella kegel- oder säulenförmig. Capillitium zart, straff, bleibend, Kalkknoten klein, rundlich, aus großen, blaßlilafarbigen oder rötlichen, kugeligen Granulationen bestehend. Sporen im durcbfallenden Lichte blaßbraun, nahezu glatt, 8 bis $9 \mu$.

N.-Amerika.

Die Sporangien dieser Art sollen, abgesehen von der Farbe, auffallend solchen von $P$. globuliferum gleichen und man kann sich fragen, ob nicht eine Unterstellung als Varietät des $P$. globuliferum angezeigt wäre. $P$. pulcherrimum unterscheidet sich nicht nur durch die Farbe der Sporangien und der Sporen, sondern auch durch die Gestalt der Columella.

Physarum melauospermum Sturgis nov. spec. in Mycologia IX (1917), 323, pl. 1 fig. $1-3$.

Plasmodium? Sporangien gestielt, herdenweise oder zerstreut, kreis- oder scheibenförmig, gewöhnlich oberseits nabelartig, 0,4 bis $0,7 \mathrm{~mm}$ im Durchmesser, graulichweiß, höckerig. Sporangiumwand häutig, nach oben zu reichlich mit weißen Kalkablagerungen und daher rauh, dunkler und rötlichbraun gegen den Ansatz des Stiels \%u, letzterer ungefähr $0,2 \mathrm{~mm}$ hoch und $0,1 \mathrm{~mm}$ dick. schwarz, gefurcht, stämmig und gegen den Grund zu verdickt. Capillitium aus zahlreichen gerundeten, länglichen oder eckigen weißen Kalkknoten bestehend, die unter sich durch viele zarte, hyaline Fäden verbunden sind. Sporen im durchfallenden Lichte dunkelpurpurbraun, dicht fein stachelig, auf einer Seite etwas heller und glätter, 12,5 bis $16 \mu$.

N.-Amerika.

Von $P$. compressum und $P$. connatum sich durch die Gestalt und den Habitus der Sporangien, deren Kleinheit und durch die größeren Sporen, deren Wand einseitig verdickt ist, unterscheidend.

Physarum spec.

Brandza in Ann. scient. Université Jassy VIII (1914), 286, fig. 4, $\mathrm{a}-\mathrm{f}$.

Plasmodium weißgrau. Sporangien einzeln oder in Gruppen, stets ungestielt, kissenförmig, kugelig, 0,8-1 mm im Durclımesser 
oder an deren Stelle verlängerte, wurmartig gekrüınmte, $2-15 \mathrm{~mm}$ breite Plasmodiokarpien, grauweiß, blaßweißblau, blaßgrünlichweiß oder seltener grünlichgrau oder orangegrau, glatt oder ausgestochen. Peridie lederig, mit einer ziemlich dicken Kruste aus gelben oder farblosen Kalkgranulationen. Columella wohlentwickelt, selten rudimentär oder fehlend, weiß oder grau, einzeln in den kissenförmigen oder kugeligen Fruchtkörpern, zu mehreren in den Plasmodiokarpien. Capillitium reichlich entwickelt, mit kreisrunden, ovalen oder polygonalen, blaßgelblichgrauen oder grüngraulichen, $10-20 \mu$ großen, mit Kalkgranulationen angefüllten Kalkknoten, deren Ecken abgerundet sind und die von zarten, hyalinen, verzweigten, farblosen oder den Kalkknoten gleichfarbigen Fäden verbunden sind. Sporenmasse dunkelkastanienfarbig bis schwarz; Sporen im durchfallenden Lichte blaßviolettbraun, glatt, $6-8 \mu$.

Rumänien.

\section{Physarum spec.}

Brandza in Ann. scient. Université Jassy VIII (1914), 287, fig. 5, a-e.

Plasmodium zitronengelb. Sporangien samt Stiel 1,5-2 mm hoch, verkehrteiförmig, sehr lang gestielt, vereinzelt oder herdenweise, $0,5-0,8 \mathrm{~mm}$ im Durchmesser, runzelig, blaß, grünlichgelb grünlichgrau oder mitunter weiß. Peridie häutig, unregelmäßig aufreißend, durchsichtig, dünn, gelb oder blaßgrünlichgelb, mit Kalkgranulationen. Stiel 1-1,5 $\mathrm{mm}$ hoch, aufrecht oder geneigt, glänzend karminrot, durchsichtig, längsfurchig, ohne Kalkgranulationen und ohne sporenartige Zellen. Columella fehlend. Capillitiumfäden reichlich, Kalkknoten zahlreich, abgerundet oder elliptisch, oft unregelmäßig mit abgerundeten Ecken, $10-30 \mu$ groß, grünlichgrau und mehr oder minder blaß, verbunden von hyalinen, sehr dünnen und stark verzweigten, farblosen oder blaßgrünlichen Fäden. Sporenmasse dunkelkastanienfarbig; Sporen im durchfallenden Lichte blaß braunviolett, glatt, $5-7 \mu$.

\section{Physarum spec.}

Brandza in Ann. scient. Université Jassy X (1916), 192, pl. II, fig. 4, a-d.

Plasmodium zuerst milchweiß, später ziegelrot. Sporangien vereinzelt oder in Gruppen, gestielt oder sitzend, kugelig, eiförmig 
oder bisweilen asymetrisch, 0,5-0,8 $\mathrm{mm}$ im Durchmesser, an deren Stelle häufiger verlängerte, wurmförmige, hufeisenförmige oder unregelmäßig gestaltete, bis $5 \mathrm{~mm}$ lange, bleischwarze, metallisch glänzende, gleichsam lackierte Plasmodiokarpien mit leicht runzeliger Oberfläche. Stiel, sofern vorhanden, walzlich, gegen den Grund zu etwas verbreitert, 0,4-0,6 $\mathrm{mm}$ hoch, ziegelrot, durchsichtig und weder mit Kalkgranulationen, noch mit sporenartigen Zellen, noch mit plasmatischem Ausschußmaterial angefüllt. Bei fehlendem Stiel sitzen die Fruchtkörper einzeln einem abgeflachten, ziegelroten Kissen auf. Peridie häutig, dünn, durchsichtig, graublau, ohne jede Spur von Kalkgranulationen. Columella 0. Capillitiun reichlich entwickelt, aus zahlreichen, farblosen, an den Verzweigungsstellen leicht verbreiterten Fäden bestehend, mit schmutzig gelbbraunen, kreisrunden, ovalen oder mitunter kantigen Kalkknoten. Sporenmasse von der Farbe des Kaffeesatzes; Sporen im durchfallenden Lichte blaß bräunlichviolett, stachelig, $8-10 \mu$.

Rumänien.

Brandza vergleicht seine unbenannte Art mit $P$. aneum R. E. Fries, macht aber darauf aufmerksam, daß letzteres eine doppelte Peridie besitzt, deren äuBere, pergamentartige, braune Schicht reich an Kalkgranulationen ist, ferner sind die Kalkknoten von $P$. aneum dunkelbraun, die Sporen nur $6-8 \mu$ gro $B$ und glatt. Ebensowenig sollen in Betracht kommen $P$. vernum Somm. oder $I$ '. plumbeum Fr., obschon beide allerdings habituell mindestens an die oben diagnostizierte Art erinnern.

\section{Physarum spec.}

Brandza in Anu. scient. Université Jassy $\mathrm{X}$ (19/6), 194. pl. II, fig. $2, \mathrm{a}-\mathrm{d}$.

Plasmodium weiß. Sporangien-sitzend, kugelig oder eiförmig, zu 5 bis 30 und mehr in Gruppen, dicht gedrängt und mitunter zusammenfließend aber nicht übereinander gelagert, mattgraubraun, $0.5-0,8 \mathrm{~mm}$ im Durchmesser, auf schmutzigweißem Hypothallus, dessen Strähnen die Gruppen untereinander verbinden. Peridie häıtig, dünn, durchsichtig, mit wenigen gelblichen Kalkgranulationen und bepudert mit sehr kleinen weißen Kalkflucken. (apillitum reichlich entwickelt, sehr zart, aus zahl- 
reichen, hyalinen, kurzen, an den Verzweigungsstellen verbreiterten Fäden bestehend, mit sehr zahlreichen, gelblichbraunen, kreisrundlichen, eiförmigen, spindelförmigen oder unregelmäßigen, $15-30 \mu$ großen Kalkknoten. Sporenmasse von der Farbe des Kaffeesatzes; Sporen im durchfallenden Lichte blaß braunviolett, fast glatt, $6-8 \mu$.

·Rumänien.

Obige Art erinnert an P. murinum Lister, letztere Art weicht indessen ab durch runzelige Sporangien und größere Sporen.

S. 158. Fuligo cinerea (Schwein.) Morgan: ersetze Hannover und Mark Brandenburg durch Deutschland und füge hinzu: Schweiz (Jura) - Java.

S. 160. Trichamphora peziz oidea Jungh., füge hinzu: Rumänien, Java.

S. 167. Nach Craterium concinnum Rex schalte als weitere Art ein :

Craterium rubronodum G. Lister nov. spec. in Trans. Brit. Mycol. Soc. (1914), 74, pl. I, fig. I a -Id.

Synonym: Badhamia rubiginosa (Chev.) Rost. var. concinnum G. Lister ap. Ninakata in Bot. Mag. Tokyo XXVII (1913), 408.

Plasmodium zuerst primel-, später orangegelb. Sporangien herdenweise oder zerstreut, gestielt, becher- oder napfförmig, $0,2-0,4 \mathrm{~mm}$ hoch, $0,2-0,6 \mathrm{~mm}$ breit, glatt oder leicht längsrunzelig, oberwärts blaßleder- oder perlgrau, dunkelrotbraun gegen den Grund zu; Deckel entweder auswärts gekrümmt oder nahezu flach mit aufwärts gerichtetem Rand, weiß oder rötlichgrau, glatt oder etwas runzelig. Peridie rötlichgrau, Kalkgranulationen einschließend und auf der Innenseite mit kalkführenden Taschen. Stiel dunkelrotbraun, schlank, 0,1-0,2 mm lang, mitunter fehlend, Capillitium aus eirunden oder unregelmäßig gestalteten, abgerundeten, blaßbräunlichroten Kalkknoten bestehend, die durch zarte Fäden untereinander verbunden sind, bäufig mit einer großen, mittelständigen, vom Stiel freien, unregelmäßig eiförmigen und soliden oder kugelrunden, hohlen Pseudocolumella. Sporen im durchfallenden Lichte purpurgrau, 10--12 ", mit zerstreuten Stacheln versehen, deren Basis mitunter durch linien- 
artige Verdickungen der Exine verbunden sind, sodaß eine netzartige Skulptur zu Stande kommt.

Japan.

Die Art unterscheidet sich von C.concinnum, dem sie in Gestalt und Größe am ähnlichsten ist, durch das Vorlıandensein der großen Pseudocolumella, die großen, stacheligen Sporen und die kreisrundlichen, abgerundeten, bräunlichroten Kalkknoten ; letztere entfärben sich rasch am Licht und heben sich dann auffallend von den dunkeln Sporen ab, viel stärker als dies der Fall ist bei den kantigen, gelben oder gelblichbraunen Kalkknoten von C. concinnum.

S. 168. Craterium paraguayense (Spegazz.) Lister ist auch für Florida nachgewiesen worden.

S. 168. zu Craterium leucocephalum (Pers.) Ditm. füge als weitere Synonyme hinzu:

Cupularia mutabilis Rabenhorst Deutsehl. Krypt.-Fl., I (1841), 271. Craterium mutabile Fuekel Symb. (1869/70), 342.

S. 169. zu Craterium leucocephalum (Pers.) Ditm. füge hinzu: Neu-Seeland.

S. 170. nach Meylan (Bull. Soc. Vaud. Sc. Nat. LI [1916-1917] [1917], 261) findet sich im Jura außer der Var. scyphoides (Cooke et Balf.) Lister von Craterium beucocephalum Ditm. noch eine, vorläufig noch unbenannt gelassene Form mit grünlichen obern Sporangiumkalotten und gelben Capillitiumkalkknoten.

S. 170. Craterium a ureum (Schum.) Rost. Sturgis (Mycologia) XIX (1917), 326 berichtet von Sporangien dieser Art aus Colorado, die goldgelb, kugelig und unterwärts von pergamentartiger Beschaffenheit sind; Stiele orangegelb, aus häutigem Hypothallus aufsteigend, Capillitium dicht, die weißen Kalkknoten oft zu einer mittelständigen Masse zusammenfließend, Sporen 8-9,5 $\mu$. In dieser Ausbildung kaum zu unterscheiden, von Physarum citrinellum Peck. $\mathrm{Zu}$ Craterium aureum (Schum.) Rost. ist des Weiteren zu bemerken, daß Fuckel Fung. rhen. 1455 zu Craterium leucocephahum gehört, desgleichen das Synonym

Cupularia mutabilis Rabenhorst. Deutsehl. Krypt.-Fl. I (1844), 271. 
Ferner ist hinzuzufügen: Schweiz und die Literaturangaben zu erweitern durch: Meylan' in Bull. Soc. Bot. Genève 2me sér. VI (1914), 88.

S. 176. zu Diderma effusum (Schwein.) Morgan füge hinzu: Rumänien, N.-Afrika, Australien.

S. 178. zu Diderma spumarioides Fr. füge hin»u: Rumänien.

S. 179. zu Diderma globosum Pers. var. alpinum Meylan setze als Synonym:

Diderma alyinum MIeylan in Bull. Soc. Vaud. sc. nat. LI (1916/17) (1917), 261.

S. 181. zu Diderma niveum (Rost.) Macbride ssp. Lyallii (Massee) Lister füge hinzu: S.-Amerika.

S. 181. zu Diderma niveum (Rost.) Macbride ssp. deplanatum (Fr.) Lister füge hinzu: Portugal, Rumänien.

S. 182. zu Diderma testaceum (Schrader) Pers. füge hinzu: Rumänien, S.-Amerika.

S. 183. Diderma simplex (Schroet.) Lister var. echinulatum Meylan nov. var. in Bull. Soc. Vaud. Sc. Nat. LII (1919), 450.

Plasmodium schön gelb mit einem leichten, fahlroten Stich. Sporangien gelb oder etwas ockerfarbig, zu dreien, Sporen 10$12 \mu$, stark stachelig; etwas dunkelfarbiger als beim Typus.

Schweiz (Jura).

S. 184 zu Diderma Trevelyani (Grev.) Fr. ist zu bemerken, daß die Plasmodiokarpien mitunter gleichmäßig chokoladefarbig sind und blasser Dehiszenzlinien entbehren.

S. 186. zu Diderma floriforme (Bull.) Pers. füge hinzu: Rumänien.

S. 187. zu Diderma Sauteri (Rost.) Macbride füge hinzu: Rumänien.

S. 189. zu Diderma radiatum (L.) Lister füge hinzu: Rumänien, N.-Afrika, Australien.

S. 189. Meylan hält, im Gegensatz zu Frl. Lister und Schinz an der Artberechtigung von Diderma montanum Mey- 
lan fest und benennt eine von La Chaux im schweiz. Jura stammende Form mit rotem Plasmodium und blabrosaroten Sporangien var. rosea Meylan (Bull. Soc. Vaud. Sc. nat. LII [1919], 450).

S. 191. Diderma asteroides Lister auch in Großbritannien.

S. 192. Diderma rugosum (Rex) Macbr. Sporen von Fruchtkörpern dieser Art aus Florida maßen 11,5-14,5

S. 193. Diderma arboreum (Petch) G. Lister et Petch kommt auch in Großbritannien und Ost-Indien vor.

S. 193. Als weitere Diderma-Art ist anzufügen:

Diderma antaretica (Spegazz.) Sturgis nov. comb. in Mycologia VIII (1916), 37.

Synonym: Licea antarctica Spegazz. in Bol. Acad. Nac. Ciencias Cordoba XI (1889), 5.

Plasmodium? Sporangien in dicht gedrängten Haufen sitzend, \pm kugelig oder \pm prismatisch infolge des gegenseitigen Druckes, dunkelrötlichbraun. Peridie dick, oberwärts spröde und zerbrechlich, pergamentartig und unterwärts bleibend, bekieidet mit einer zarten Kruste aus sehr kleinen, schneeweißen Kalkgranulationen. Columella unbestimmt, kalkführend, blaßgelb. Capillitium in der Regel aus spärlichen, groben oder schlanken Fäden, die in der Mitte dunkelfarbig und gegen die Enden hyalin sind, mitunter aber auch aus breiten, blaßbraunen, häutigen, kantigen Verbreiterungen, von denen die Fäden ausstrahlen, bestehend. Sporenmasse schwarz; Sporen im durchfallenden Lichte dunkelpurpurbraun, blasser auf einer Seite, fein stachelig und oft mit ein oder zwei erhöhten Leisten versehen, 10,5-11,5 $\mu$.

Chile.

Herr und Fräulein Lister haben Licea antarctica als fragliches Synonym zu Perichcena corticalis gestellt; Sturgis überführt nun diese Art aber in die Gattung Diderma und zwar in die Untergattung Leangium. Sturgis hat allerdings die Spegazzinischen Originalien nicht untersuchen können, da aber die Beschreibung, die uss Spegazzini gibt, von einem Capillitium spricht, kann es sich wohl nicht um eine Licea-Art handeln. Sturgis lagen Exemplare vor, "die Thaxter in Punta Arenas (Chile) auf 
Fagus antarctica gefunden hatte und da auch die Exemplare Spegazzini's auf demselben Substrat vorkommen und von derselber Lokalität stammen, hat die Identifikation allerdings viel für sich.

S. 193. zu Colloderma oculatum (Lippert) G. Lister ist hinzufügen: N.-S.-Wales.

S. 195. Frl. G. Lister bestätigt neuerdings (Memoirs Essex Field Club VI [1918], 39) das Fehlen vou Kalkgranulationen auf der Peridie von Colloderma-Sporangien und glaubt, Colloderma als Typus einer besonderen, in die Nähe der Stemonitaceae zu stellenden Familie der Collodermaceae auffassen $\mathrm{zu}$ sollen.

S. 202. Als weitere Dia chæa-Art ist anzufügen :

Diachaa radiata G. Lister et Petch nov. spec. in Journ. of Bot. LIV (1916), 130, pl. 541, fig. 2.

Plasmodinm orangegelb. Sporangien dicht herdenweise oder gedrängt, halbkugelig oder kugelig, 0,4-0,5 mm im Durchmesser, metallisch" grau- oder bräunlich glänzend, selten kurz gestielt, auf einem weißen, bald häutigen, bald strähnigen Hypothallus. Peridie häutig, farblos. Stiel, sofern vorhanden, kurz, kräftig, gefurcht, 0,1 bis $0,2 \mathrm{~mm}$ hoch, weiß und gleich dem Hypothallus reichlich mit Kalkgranulationen besetyt. Columella weiß, konvex, kegelförmig oder kurz zylindrisch. Capillitium ein Netzwerk zarter purpurbranner, von der Colımella ausstrahlender Fäden. Sporen im durchfallenden Lichte blaßviolettgrau, stachelig, 8-11 $\mu$.

Ceylon und Westafrika.

S. 206. zu Didymium difforme (Pers.) Duby füge hinzu: Rumänien, N.-Afrika, Australien.

S. 209. zu Didymium dubium Rost. füge hinzu: Rumänien.

S. 208. Didymium tubulatum Jahn in Ber. Deutsch. Bot. Ges. XXXVI (1919), 663, t. XVIII, fig. 1, 2, 3. Pasmodiokarpien 2-8 $\mathrm{mm}$ lang, krustenförmig, etwa $0,2 \mathrm{~mm}$ dick, äußerlich ganz an $D$. dutium oder $D$. difforme erinnernd. Die obere weiße, oft etwas grubige Kalkkruste liegt ganz wie bei D. difforme einer zarten, durchsichtigen, kaum 
bräunlich gefärbten Haut auf, Unterseite der Fruchtkörper gleichfalls von einer zarten, im auffallenden Lichte schwach gelblichen Haut gebildet, die von zerstreuten Kalkkristallen bedeckt ist und von der sich bis zur Höhe von etwa $0,18 \mathrm{~mm}$ die dichotom sich verzweigenden Capillitiumfäden erheben. Die feinsten obern Verzweigungen sind an der obern Haut befestigt. Zwischen diesen Fäden erheben sich ebenfalls aus der untern Haut gelb gefärbte hohle Röhren, die wie Säulen zwischen den Fasern \pm regelmäßig verteilt sind. Am zahlreichsten stehen sie in der Randregion der Fruchtkörper. Sie haben eine durchschnittliche Breite von $30-50 \mu$ und tragen auf der Innenseite der Haut auch oft Kristallgruppen. Oben erweitern sie sich zu einer Art Trichter, der sich mit einem schön gefärbten, roten Saum an die obere Haut ansetzt. In der Randregion ist der Pfeiler oft sehr dünn und der Trichter sehr groß, sodaß die ganze Röhre wie ein großer Trichter aussieht. Die obern Offnungen der Trichter sind durch besondere Kalkpropfen ausgefüllt. Sporen dunkelschwarzbraun, 14-16 $\mu$ groß, glatt, aber mit charakteristischen Reifen versehen. Sie umziehen, sich in unregelmäßigen Abständen gabelnd, die Kugeloberfläche und grenzen auf jeder Halbkugel 2 bis 3 Felder ab, oft sind sie gekrümmt oder sehr verkürzt.

Deutschland (auf faulen Kartoffelstengeln), vielleicht nächst verwandt mit $D$. quitense Torrend.

S. 209. zu Didymium Trochus Lister füge hinzu: Deutschland, Frankreich.

S. 210. zu Didymium complanatum (Batsch) Rost. füge hinzu: Rumänien.

S. 210. Didymium Clavus (Alb. et Schwein.) Rost. kommt nach Meylan (Bull. Soc. Vaud. Sc. Nat. LI [1916-1917] [1917], 261) im Jura (und sicherlich auch anderwärts) in der Form von Plasmodiokarpien vor.

S. 218. Didymium Wilczekii Meylan: Fräulein G. Lister (Journ. of Bot. LII (1914), 101) bespricht einen Fund dieser Art von der Ochsenalp (Arosa im Ct. Graubünden). 
Die Capillitiumfäden dieser Sporangien sind blaßpurpurfarbig, spärlich verzweigt, mit einigen dunkeln Verdickungen in Form von Knoten nach Art einer Perlschnur und überdies mit drei oder vier dicht gestellten Spiralleisten versehen, deren Windungsrichtung jener der Trichia Elateren entspricht. Damit büßt das Merkmal des Vorkommens von Spiralleisten erheblich an systematischem Werte ein.

S. 220. zu Didymium crustacenm Fr. füge hinzu: Rumänien.

S. 222. Als weitere DidymiumArten sind anzufügen:

Didymium discoideum Torrend nov. spec. in Broteria XIII (1915), 82 mit Fig.

Plasmodium? Fruchtkörper scheibenförmig, nahezı $2 \mathrm{~mm}$ im Durchmesser, entweder auf mittelständigem Stiel oder oft ungestielt und zusammenfließend nach Art von Plasmodiokarpien. Oberflächenkristalle breit sternförmig, wie bei $D$. crustaceum eine schneeweiße, pulverige, abfällige Schale bildend. Stiel kurz, nahezu $1 / 2 \mathrm{~mm}$, dunkelfarbig. Columella unbestimmt, vom verdickten Sporangiumgrund gebildet, blaßbraunrötlich. Capillitiumfäden violett, blasser gegen die Enden, $150-160 \mu$ lang und $2 \mu$ breit. Sporen braunviolett, nahezu glatt, $8-9 \mu$.

Brasilien.

Didymium crustaceum und D. hemisphcericum sind nahe stehende Arten. Āußerlich, abgesehen von der kristallinischen Schale, durchaus letztgenannter Art entsprechend. Ton ersterer abweichend durch die scheibenfömigen Sporangien, die glatten und kleineren Sporen.

Didymium fulvum Sturgis nov. spec. in Mycologia IX (1917), 327, pl. 14, fig. 4-6.

Sporangien herdenweise, ungestielt, etwas in die Breite gezogene oder gekrümmte, mitunter zusammenfließende Plasmodiokarpien bildend, selten fast kugelig, unterseits konkav, blaßbraun, 0,5-0,8 $\mathrm{mm}$ im Durchmesser, mitunter auf einem gleichfarbigen, häutigen, kalkführenden Hypothallus der eine Art Stiel zu bilden vermag. Peridie häutig, gelbgefleckt, gesprenkelt mit Gruppen großer, nadelförmiger, blaßgelblicher Kalkkristalle. Colımella sehr abgeflacht. Capillitium aus einem Netzwerk zarter, nahezu 
gerader oder gewundener Fäden bestehend, blaßpurpurfarbig oder nahezu farblos, häufig mit dunkeln an Mucilago erinnernden kelchartigen Verdickungen und ab und zu spindelförmige, kristallinische Blasen aufweisend. Sporen grobwarzig (die Warzen gewöhnlich in Kurven angeordnet), im durchfallenden Lichte dunkelpurpurbraun, blasser und glätter auf einer Seite, 12,כ -14,5 $\mu$. N.-Amerika (Colorado).

Die Art scheint eine isolierte Stellung innerhalb der Gattung Didy mium einzunehmen, gleichzeitig einerseits gegen Lepidoderma, anderseits gegen Mucilago Anlehnung zeigend.

S. 225. zu Lepidoderma tigrinum (Schrader) Rost. füge hinzu: Rumänien.

S. 225. zu Lepidoderma Carestianum (Rabenhorst) Rost. füge hinzu: forma gracile Meylan in Bull. Soc. Bot. Genève, 2 me sér. II (1910), 263, Stiel 2- bis 3mal länger als das Sporangium (Schweiz).

S. 227. zu Leptoderma iridescens Lister füge hinzu: Lister Monogr. ed. 2, pl. 131, fig. h, i (sub L. columbinum) und in Trans. Brit. Mycol. Soc. (1912) 40 und: Deutschland.

S. 228. Leptoderma iridescens G. Lister ist von Jahn (BerDeutsch. Bot. Ges. XXXVI [1919], 665) auch für Dentsch. land nachgewiesen worden.

S. 233. zu Stemon itis fusca Roth füge hinzu: kosmopol.

S. 234. Stemonitis fusca Roth var. trechispora (Berkeley) Torrend wird von Meylan (Bull. Soc. Vaud. sc. nat. LI [1916-17] [1917], 262) als Art bewertet und entsprechend den Nomenklaturregeln S. dictyospora Rost. genannt. Rostafinsky hat die Art unter diesem Namen in seiner Monogr. (1875), 195 anfgestellt. Meylan weist zur Begründung darauf hin, daß $S$. dictyospora (var. trechispora) sich durch sehr konstante Merkmale von S. fusca unterscheide und erwähnt von solchen die schokoladebraune Farbe der Sporangien und die Netzstruktur der Sporen. Die Sporen von dictyospora sollen nämlich stets deutlich berandet sein und es sollen auf eine Halbkugel 12 bis 15 Maschen der sehr dentlichen Netz- 
struktur der Sporenexine entfallen, wogegen die Sporen von fusca und der übrigen Spielarten dieser Spezies unberandet sind und auf einer Halbkugel 30 bis 40 Netzmaschen anfweisen.

S. 236. Stemonitis virginieusis Rex: erweitere die Literaturangaben um Torrend in Broteria VII, 81 und fïge hinzu: Böhmen, N.- und S.-Amerika.

S. 236. Stemonitis virginiensis Rex: die Synonyme Comatricha dictyospora C̈elak. und Comatricha typhoides var. heterosprara Rex sind zu streichen. Meylan (Bull. Soc. Vaud. Sc. Nat. 52 [1918], 96) stellt nummehr mit Bestimmtheit fest, dab 1. S. virginiensis Rex eine gute, von Comatricha typhoides durchaus verschiedene Art ist und daß 2. S. virginiensis Rex auch verschieden ist von Comatricha typhoides var. heterospora Rex, welche letztere von Meylan in die Gattung Stemonitis übergeführt, zum Range einer Art erhoben und S. hyperopta Meylan benannt wird.

S. hyperopta Meylan (= Comatricha typhoides var. heterospora Rex in Proc. Acad. Nat. Sc. Phil. [1891] 367, Lister Monogr. ed. 1, 120, pl. XLVI, A, fig. f-h, ed. $2,158, \mathrm{pl}$. 125, fig. a $\mathrm{f}=-=$ ? Comatricha dictyospora Celak. Myxom. Böhm. [1893], $49=$ Stemonitis virginiensis Lister 1. c. non Rex) in Bull. Soc. Vaud. Sc. Nat. 52 (1918), 97, unterscheidet sich von S. virginiensis Rex durch netzartig skulptierte, nicht warzige Sporen von Comutrichu typhroides. Die 5-6 $\mu$ großen Sporen von S. hyperopta sind fein netzartig- aber nicht polyedrisch skulptiert, das Oberflächennetz ist oft unvollständig oder unregelmäßig und zwar sind im Gesichtsfeld 12-20 Maschen wahrnehmbar; die Sporen von S. virginiensis sind $4-5 \mu$ (die von Comatricha typhoides $6-7 \mu$ ) grob und mit 6-9 polyedrischen Maschen im Gesichtsfeld. Vergl. auch G. Lister in Journ. of Bot. LVII (1919), 108.

S. 237. zu Stemonitis splendens Rost. füge hinzu: S.-Amerika. S. 240. zu Stemonitis flavogenita Jahn füge hinzu: Rumänien. S. 241. zn Stemonitis ferruginea Ehrenb. var. Smithii (Macbride) Lister füge hinzu: Neu-Guinea. 
S. 243. Com atricha elegans (Racib.) Lister kommt auch in der Schweiz (Jura) vor.

S. 244. zu Comatricha Suksdorfii (Ellis et Everh.). Macbride füge hinzu: S.-Amerika.

S. 250. Comatricha typhoides (Bull.) Lister. Lister stellt in der ersten Auflage seiner Monographie (1894) 116 hiezu als kleine Form Stemonitis fluminensis Speg. (=Comatricha fluminensis [Speg.] Torrend in Broteria VII [1808], 75 und 1. c. XIII [1915], 83), die Fräulein G. Lister in der zweiten Auflage genannter Monographie, Seite 269, zu den nicht näher zu identifizierenden Arten stellt.

S. 252. Comatricha microspora Lister entspricht der zur Art (G. Lister in Journ of Bot. LVII [1919], 108) erhobenen var. microspora Lister von C. typhoides (Bull.) Lister. (Deutschland, Großbritannien, N.-Amerika.)

S. 253. Comatricha pulchella (Babington) Rost. var. tenerrima (Curtis) Lister; typische Exemplare haben blaßrote, schmaleiförmige Sporangien auf langen, schlanken Stielen, wogegen die der Art kurzgestielt und breiteiförmig sind. Frl. Lister spricht sich daher, wenn auch mit Zaudern für die Artberechtigung aus und prägt den Namen C. tenerrima (Curtis) G. Lister.

S. 254. zu Comatricha sind inzwischen neu hinzugekommen:

Comatricha cornea G. Lister et Cran nov. spec. in Journ. of Bot. LV (1917), 121, pl. 548, fig. 1, 1 a, 1 b, 1 c, 1 d. Plasmodium farblos. Sporangien zerstreut oder einzeln, gestielt, kugelig, 0,12$0,32 \mathrm{~mm}$ im Durchmesser, dunkelbraun. Stiel pfriemlich, schlank, aufrecht, 0,17-0,2 $\mathrm{mm}$ hoch, oberwärts dunkelbraun, abwärts in einen bräunlichgelben Ton übergehend, auf kleinem, scheibenförmigem Hypothallus, am Grunde der Colımella mit einem deutlichen Kragen versehen. Columella zylindrisch, schlank, 1/3 bis 1/2 der Sporangienhöhe erreichend, oberwärts gegabelt oder in die wenigen Primanäste des Capillitiums sich teilend. Capillitiumfäden \pm straff, ${ }_{{ }^{*}}^{*}$ dunkelbraun, gegabelt und wiederholt-, oft unter weitem Winkel, verzweigt, nicht- oder selten anastomosierend, an ihren Enden mit kurzen, divergierenden Verzweigungen. 
Sporen im durchfallenden Lichte grau, 8,5-9 $u$, bei starker Vergrößerung sind zerstreute, sehr kleine Warzen bemerkbar.

Schweiz (Jura).

GroBbritannien.

Comatricha fimbriata G. Lister et Cran nov. spec. in Journ. of Bot. LV (1917), 122, pl. 548, fig. 2, 2b, 2c, $2 \mathrm{~d}$.

Plasmodium farblos. Sporangien zerstreut, gestielt, kugelig. 0,1 bis $0,3 \mathrm{~mm}$ im Durchmesser, dunkelbraun. Stiel schwarz, oft geneigt, aus dicklichem Grunde sehr schlank, oberwärts 0,007 bis $0,02 \mathrm{~mm}$ dick, am Grunde 0,02 bis $0,07 \mathrm{~mm}$ dick, 0,3 bis $0,5 \mathrm{~mm}$ hoch. Columella schlank, zylindrisch, oberwärts abgestutzt oder verjiingt, $1 / 3$ bis $1 / 2$ der Sporangienhöhe erreichend. Capillitium vom obern Teil der Columella und deren Ende abgehend, aus äußerst schlanken, blaßpurpurbraunen, einfachen oder spärlich verzweigten Fäden bestehend, die Fäden gegen ihr Ende z! gewöhnlich dunkler und gewöhnlich gegabelt, mit keulenförmigen oder unregelmäßig verbreiterten Spitzen. Sporen im durchfallenden Lichte purpurgraulich, blasser auf einer Seite, fein- und dicht stachelig, $10-12 \mu$.

Großbritannien.

\section{Comatricha spec.}

Brandza in Ann. scient. Université Jassy X (1916), 195, pl. II, fig. $1, a-d$.

Plasmodium hyalin. Sporangien samt Stiel $1 \mathrm{~mm}$, gruppenweise vorkommend, kugelig, gestielt, aufrecht, purpurrot, $0,3-0,4$ mm in Durchmesser. Peridie häutig, dünn, durchsichtig, blaßrotbraun, zeitig schwindend. Stiel pfriemlich, 0,6-0,7 $\mathrm{mm}$ hoch, aufrecht oder geneigt, schwarz oder dunkelpurpurrot, glatt. Columella bis zur Mitte des Sporangiums vordringend, am obern Ende leicht erweitert. Capillitium spärlich, straff, dunkelpurpurbraun, fast ganz vom obern Ende der sich in vier bis sechs Primanäste teilenden Columella abgehend; die Columellaäste tragen dann ihrerseits wieder eine beschränkte Zahl von Åsten zweiter und dritter Ordnung die frei zu endigen pflegen, sodaß kein eigentliches Netz zu Stande kommt. Sporenmasse purpur- 
braun; Sporen im durchfallenden Lichte blabviolottbraun, sehr foin stachelig oder nahezu glatt, $8-10 \mu$.

. Rumänien.

Brandza vergleicht diese Art mit C. laxa Rost., immerhin darauf hinweisend, daB sie sich von letztgenannter Art. unterscheide durch die nur bis zur Sporangiummitte reichende Collumella und das Fehlen eines ausgesprochenen Capillitiumnetzes, dessen Verzweigungen überhaupt nicht reichlich vorhanden sind.

S. 255. Fig. 98 lies Enerthenema papillatum.

S. 259. Nachdem Lamproderma echinulatum (Berkely) Rost. nun auch innerhalb des Gebietes nachgewiesen worden ist, bodarf unsere Beschreibung oiner dem Charakter des Buches entsprechende Erweiterung:

Plasmodium? Sporangien herdenweise, kugelig, $1-2,7 \mathrm{~mm}$ lang gestielt, eine Höhe von $2-4 \mathrm{~mm}$ erreichend, aufrecht, mit bleibender, metallisch glänzender, stahlblauer oder grünlich schimmernder Peridie. Stiel pfriemlich oder walzlich, stump̄if, als Columella bis in die Mitte des Sporangiums reichend; Capillitium aus schwarzen, blabpurpurbraunen oder farblosen, spärlich verzweigten, anastomasierenden und zur Hauptsache dem oberen Abschnitte der Columella entspringenden Fäden bestehend. Sporen im durchfallenden Lichte dunkelgrau oder bräunlich purpurrot, mit schwarzen' Strche!n besetzt, $15-20 \mu$.

Schweiz (Jura).

GroBbritannien, Schweden, Tasmanien, Neu-Seelaud.

S. 262. Stemonitis porphyra Berk. et Curt. ist als Synonym von Lamproderma columbinum (Pers.) Rost. zu streichen.

5. 263. Lamprodermu Gulama Meylan nov. spec. in Bull. Soc. Vaud. Sc. Nat. LII (1919), 449.

Plasmodium? Sporangien kugelig, nicht genabelt, $0,5 \mathrm{~mm}$ im Durchmesser, glänzend stahlgran, mit zerstrenten metallisch blauen Lichtern, auf düunen, schwarzen, 1 1,2 mm langen Stielen. Peridie höckerig, zur Zeit der Sporenreife in eine Anzahl + unregelmäbiger, meist abgerundeter Fragmente zerfallend, von deuen einzelne längere Zeit in Verbiudung mit dem Capil- 
litium verbleiben; der untere Teil der Peridie verbleibt am Stiel. Columella ungefähr die halbe Höhe des Sporangiums erreichend, oberwärts nicht keulig verdickt. Capillitium von zur Hauptsache von der Spitze der Columella als rerzweigte Fäden abgehend; letztere mit Ausnahme des gelhlichen Grundes hyalin. Sporen schwärzlich purpurfarbig, ziemlich stark stachelig, 12-15 $\mu$.

Schweiz (zwischen der Còte-aux Fúes und dem Val Travers).

Unterscheidet sich von dem wahestehenden $L$. violaceum durch die viel kleineren, kugeligen Sporangien, deren Stiole mindestens zweimal so lang wie die Sporangien sind, durch die Struktur und die Farbe der Peridie und die viel größeren Sporen.

S. 26t. zu Lamproderma violacoum (Fr.) Rost. füge als weiteres Synonym hinzu:

Stemonitis Morthieri Fuckel in Jahrb. Nassauisch. Ver. Naturk. XXIII/XXIV (1869/70), 339.

S. 266. Lamproderma violaceum (Fries) Rost. var. debfle G. Lister et Howard in Journ. of Botany LVII (1919), 25 , pl. 552, fig. $1,1 \mathrm{a}-1 \mathrm{~d}$.

Sporangien entweder gedrängt oder zerstreut, dunkelbraunmetallglänzend, sitzend, nahezu kugelig oder auf breiter Basis halbkugelig, 0,5-0,8 $\mathrm{mm}$ im Durchmesser, an Stelle der Sporangien mitunter lange, stellenweise eingeschnürte Plasmodiokarpien. Sporangiumwand purpurn gefleckt, schließlich in grobe Fragmente zerfallend. Columella in einzelnen Sporangien nur in Form einer unbedeutenden, mittelständigen Verdicliung der häutigen Sporangiumwand, in andern in Form einer kurzen, schwarzen Säule, die ungefähr ein Drittel der Sporangiumhöhe erreicht, seltener kräftiger entwickelt und unterwärts einen rudimentären Stiel bildend. Die blaßpurpurfarbigen Capillitiumfäden bilden ein dichtes Netzwerk mit häutigen Verbreiterungen im Winkel der Verzweigungen, einzelne dieser Verbreiterungen bilden auch schwarze Strähnen. Sporen im durchfallenden Lichte blabpurpurbraun, dicht- und kleinstachelig, $10-11 \mu$.

Großbritannien.

Die Variationsfähigkeit von L. violaceum wird illustriert durch einen von Frl. G. Lister gemachten und im AnschluB an die Beschreibung von L. violaceum var. debile behandelten Fund 
vom Weißenstein im Schweizerischen Jura. In diesem Fall waren die Sporangiumwände der irisierenden Exemplare vollständig frei von granulösem Ausschußmaterial, wogegen die der bronzefarbigen Exemplare reichlich braune Granulationen führten; die Sporen waren fein stachelig und $9-10 \mu$ groß. Die vorhandenen Plasmodiokarpien, von ringförmiger Ausbildung, erinnern an die der var. debile.

S. 267. zu den schweizerischen Fundorten von Lamproderma cribrarioides (Fr.) R. E. Fries füge hinzu: hăufig im Jura.

S. 269. Lamproderma atrosporum Meylan var. anglieum G. Lister \& Howard in Journ. of Bot. LVII (1919), 26.

Sporangien gehäuft oder gebüschelt, metallglänzend oder matt blauschwarz, schmal verkehrteiförmig oder nahezu kugelig, entweder sehr kurz gestielt oder sitzend, vereinzelt auch mit einem schlanken, schwarzen, $0,2 \mathrm{~mm}$ langen Stiel versehen. Sporangiumwand blaßpurpurfarbig. Columella lang, schlank und oft oberwärts unregelmäßig verbreitert. Capillitiumfäden schlank, dunkelbraun, biegsam, von allen Teilen der Columella ausstrahlend, mit den verbreiterten Enden an der Sporangiumwand befestigt. Sporen dicht netzförmig skulptiert, durchschnittlich $11 \mu$, im Einzelnen 10 bis 13 bis mehr $\mu$ groß, im durchfallenden Lichte purpurbraun.

GroBbritannien.

Die Spielart unterscheidet sich vom Typus hauptsächlich durch den schlankern Habitus der Sporangien.

G. Lister macht darauf aufmerksam, daß mindestens hinsichtlich Lamproderma atrosporum Größe, Farbe und Skulptur der Sporen keine zuverlässigen Artmerkmale sind, wie denn auch z. B. die Sporen mitunter stachelig, schwarz und $10-13 \mu$ groß, in andern Sporangien purpurgrau und $12-15 \mu$ groß und stachelig sind, zudem zeigen alle Sporen die Tendenz, die Stacheln zu niedrigen Leisten zusammenfließen zu lassen.

S. 269. Lamproderma Crucheti Meylan in Bull. Soc. Vaud. Sc. Nat. 52 (1918), 96.

Plasmodium dunkelgelb, licht fahlrot. Sporangien kugelig, $0,4-0,7 \mathrm{~mm}$ im Durchmesser, $0,3-0,8 \mathrm{~mm}$ lang gestielt. Stiel 
schwarz. Sporangien zuerst gelb, dann braungrünlich, schließlich braunschwarz, ohne metallischen Glanz und ohne violette Lichter. Die keulenförmige Columella erreicht ungefähr die Mitte des Sporangiums. Capillitium braun, aus auch an ihrer Basis feinen Fäden bestehend. Sporen $13-15 \mu$, im durchfallenden Lichte hellbraungelb, fein warzig, Sporenmasse grünlich braunschwarz.

Schweiz (Chasseron).

Nähert sich am meisten L. columbinum, unterscheidet sich aber durch die Farbe des Plasmodiums, die der Sporangien, deren Form, die Länge des Stiels, die Farbe der Sporen.

S. 271. Clastoderma Debaryanum Blytt: füge Großbritannien hinzu.

S. 271. Echinostelium minutum de Bary kommt auch in N.Amerika vor.

S. 274. Amaurochaete cribrosa (Fr.) Macbr. ap. Sturgis in Mycologia IX (1917), 328 (= Lachnobolus cribrosus Fr. Syst. Orb. Veg. [1825], 148.) dürfte neben A. fuliginosa (Sow). Macbr. eine weitere Art dieser Gattung sein. Das Capillitium besteht aus sehr zarten, gekrümmten Fäden die eckige oder verlängerte, häutige Capillitiumverbreiterungen verbinden, als Ganzes ein sehr offenes, unvollständiges Netz mit zahlreichen freien Enden bildend. Sporen dunkler im durchfallenden Lichte als jene von $A$. fuliginosa, blasser und glätter auf einer Seite, fein stachelig, $12-15 \mu$.

Großbritannien, Skandinavien, N.-Amerika.

S. 288. C. macrocarpa Schrader var. ferruginea (Meylan) Schinz.

Synonym: Cribraria ferruginea Meylan in Annuaire Conserv. et Jard. bot. Genève $15 \mathrm{me}$ et $16 \mathrm{me}$ années (1913), 319.

Neuerdings auch im Wallis gefunden. (Meylan bält an der Artberechtigung fest [briefl.].)

S. 293. Cribraria intricata Schrader kommt im schweiz. Jura auch in der typischen Form vor (Meylan briefl.).

S. 297. zu Cribraria purpurea Schrader ist zu bemerken, daß 
möglicherweise zu ihr als Form Cribraria elegans Berk. et Curt. gehört.

S. 298. Cribraria elegans Berk. et Curt. ist, wie eben bemerkt, möglicherweise nur eine Form von Cribraria purpurea Schrader.

S. 305. Den Schlüssel zur Bestimmung der Gattungen der Familie der Liceaceae erweitere in folgender Weise:

1. Entweder sitzende, \pm kugelige oder halbkugelige Sporangien oder Plasmodiokarpien.

z. Peridie pergamentartig.

Licea Schrader.

2*. Peridie häutig, Sporangien sich durch Abwerfen eines häutigen Deckels öffnend.

Hymenobolus Zukal.

1*. Sporangien gestielt, sich beim Öffnen wie Hymenobolus verhaltend.

Orcadella Wingate.

S. 306. Licea minima Fries: füge Großbritannien hinzu.

S. 308. Licea tenera Jahn in Ber. Deutsch. Bot. Ges. XXXVI (1919), 665, Taf. XVII fig. 4, 5, 6. Sporangien 0,3$0,4 \mathrm{~mm}$ groß, unscheinbar, kugelig, mit breiterer Flächenaufsitzung, hellbräunlich, glitzernd wenn sie noch mit der Haut bedeckt sind. Sporangienhaut gelblichbraun, durchsichtig und glatt, anf der Innenseite nur hier und da mit Körnchen besetzt, ohne vorgebildete Aufrißstellen, bei der Reife oder bei Berührung in unregelmäBige Fetzen zerreißend. Sporen hell, schwach bräunlich fleischfarben, kugelig, mit zahlreichen, kurzen Stacheln besetzt, auf der einen Seite mit einem hellen Pol, $\pm 12 \mu$ groß.

Deutschland (Oberbayern) auf Riude von Acer Pseudoplatauus.

Unzweifelhaft $L$. flexuos n nahestehend.

S. 309. Vor Oreadella schalte ein: XXXa. Gattung: Hymenobolus Zukal in Österr. Bot. Zeitschr. XLIII (1893), 73; Lister Monogr. ed. 2, 262; G. Lister Guide to the British Mycetozoa 4 th ed., 47.

H. parasiticus Zukal in Österr. Bot. Zeitschr. XIIII (1893), 73, t. V. flg. 1-10; Lister Monogr. ed. 2, 26\%; G. Lister Guide to the British Mycetozoa 4 th ed., 47. 
Plasmodium rosarot. Sporangien zerstrent, einzeln, sitzend, + kugelig oder halbkugelig oder von unregelmäßiger Gestalt, 0,05 bis $0,2 \mathrm{~mm}$ im Durchmesser, braungrau bis schwärzlich und matt oder glänzend, sich mittels eines häutigen Deckels öffnend. Peridie mit einem Belag ausgestoßenen Materials. Capillitium fehlend. Sporen im durchfallenden Lichte blaßbraun mit rötlichem Inhalt, die Sporenwand ungleich dick, 13-15 $\mu$.

Österreich.

Großbritamien.

Dieser parasitisch (?) auf Rindenflechten und epiphytischen Algen lebende Schleimpilz ist in die zwoite Auflage von Lister's Monographie als zweifelhafte Schleimpilz-Gattung aufgenommen worden, hat nun aber in dem von Frl. Gulielma Lister in vierter Auflage (1919) herausgegebenen Guide to the British Mycetozoa exhibited in the Department of Botany, British Museum, seine Stellung innerhalb der Familie der Liceaceae gefunden. Weitere Untersuchungen werdeu lehren, ob es damit sein Bewenden hat.

S. 309. Licea singularis Jahn in Ber. Deutsch. Bot. Ges. XXXVI (1919), 655, Taf. XVIII, fig. 7-12.

Sporangien ca. $0,2 \mathrm{~mm}$ groß, bräunlich, mit gelblichbrauner Peridie; letztere mit feiner Skulptur in Form kleiner Wärzchen, die erst bei Anwendung einer 1/12 Öl-Immersion hervortreten, oft nahe zusammensitzen und geschlängelte Reihen bilden, die in bestimmtem Abstand voneinander bleiben und ein zierliches Muster bilden. AufriBlinien? Sporen glatt, bräunlich, $12 \mu$ groß. Sporenhàut stellenweise dünn, stellenweise dick, sodaß die Sporen je nach ihrer Lage bald kugelig, bald abgestutzt, fingerhutartig aussehen.

Deutschland (Oberbayern), auf Rinde von Acer Pseudoplatanus.

S. 310. Orcadella operculata Wingate kommt auch in Japan vor.

S. 320. Enteridium minutum Sturgis in Mycologia IX (1917), 329 , pl. 15 nov. spec.

Plasmodium? Aethalien abgerundet oder verlängert, kissenförmig, blauumberbraun, breiter, häutiger Basis aufgesetzt, 1,5$2 \mathrm{~mm}$ im Durchmesser. Wandung runzelig und meist mit 
kleinen, zerstreuten, blaßgelben Gruben, häutig. Peridie der Einzelsporangien häutig, fein rauh, mit rundlichen Perforationen, deren Ränder zahlreiche freie Fadenenden zeigen, oder reduziert zu unregelmäßigen, anastomosierenden, vom Grunde des Aethaliums aufstrebenden Strähnen mit häutigen oder netzartigen Verbreiterungen in den Verzweigungswinkeln und vielen freien, zarten Enden. Sporen im durchfallenden Lichte blaßgelb, gewöhnlich zu 2 oder 3 verbunden, dann eiförmig oder abgeflacht auf einer Seite, wenn frei, kugelig, sehr fein staehelig, 9,5-10,5 $\mu$.

N.-Amerika (Colorado).

S. 320. Enteridium liceoides G. Lister in Journ. of Bot. LVII (1919), 109 unterscheidet sich von E. olivaceum Ehrenberg, dem es l. c. als Varietät unterstellt ist, durch die stets flachen Plasmodiokarpien und durch das Pseudocapillitium, das nicht aus einem Netzwerk breiter Strähnen sondern aus säulenförmigen Pfropfen besteht.

Deutschland; Großbritannien, Frankreich, N.-Amerika.

S. 323. Liceopsis lobata (Lister) Torrend ist von Jahn (Ber. Deutsch. Bot. Ges. XXXVI [1919] 666) auch für Deutschland nachgewiesen worden.

S. 333. zu Trichia affinis de Bary ist Hemitrichia helvetica Meylan in Bull. Soc. Vaud. Sc. nat. XLVI (1910), 54 als weiteres Synonym zu nennen (Meylan briefl.).

S. 345. Trichia erecta Rex: Vorkommen in GroBbritannien fraglich; vergl. G. Lister in Journ. of Bot. LVII (1919), 111.

S. 346. T. subfusea Rex: Plasmodium tief dunkelbraun, ohne Stich ins Purpurne. Sporangien hellbraun, schwarzbraun, mitunter am Grunde einen leichten Stich ins Purpurne zeigend; einzeln oder sehr selten paarweise auf 0,2 bis $1 \mathrm{~mm}$ langem Stiel, ab und zu einfarbig, mitunter auch mit helleren Dehiscenzlinien. Capillitium und Sporen gelb oder grünlichgelb. Elateren plötzlich auf eine Länge von $20-40 \mu$ zugespitzt; Spitze häufig gekrümmt und am Grunde etwas aufgeblasen, ähnlich wie bei $T$. contorta. 
S. 346. zu Trichia decipiens (Pers.) Macbride füge hinzu:

f. nodulosa Brandza in Ann. scient. Université Jassy VIII (1914), 272 .

Sporangien kugelig, kurzgestielt oder sitzend, dunkelbraun, dichtgedrängt auf gemeinsamem Hypothallus; 0,8-1 $\mathrm{mm}$ im Durchmesser; Stiel, sofern vorhanden, bis $1 \mathrm{~mm}$ hoch und angefüllt mit sporenartigen Zellen. Elateren kurz, reich verzweigt, 5-6 $\mu$ breit, entweder an den Enden oder auch an andern beliebigen Stellen $9-10 \mu$ breite Verdickungen aufweisend, von denen aus nach allen Seiten Äste ausstrahlen.

Rumänien.

f. hemitrichioides Brandza l. c. (1914), 272.

Sporangien kreiselförmig, sehr langgestielt, samt Stiel bis $3 \mathrm{~mm}$ hoch, leuchtend goldgelb. Peridie gelb, durchsichtig; Elateren sehr lang, mit seltenen Verzweigungen, ein Netzwerk bildend, das an jenes von $H$. intorta Lister erinnert. Neben Elateren dieser Art finden sich auch solche normaler Ausbildung. Sporen im durchfallenden Lichte blaßgelb, $9-12 \mu$.

Rumänien.

S. 349. T. Botrytis Pers.: Plasmodium wie bei $T$. lateritia. Sporangien einzeln oder zu zweien-, selten zu mehreren mit den Stielen verwachsen; dunkelpurpurrot mit hellen Dehiszenzlinien. Capillitium und Sporen gelb oder bräunlich. Elateren lang ausgezogen, 75-100 $\mu$ lang, Spiralleisten vor den Spitzen verschwindend.

S. 351. 7u var. cerifera G. Lister füge Neusüdwales hinzu.

S. 351. Trichia lateritia Lév.: Plasmodium dunkelpurpurrot, mitunter fast schwarz. Sporangien rotbraun, oft purpurschwarz oder sogar schwarz, einfarbig, immer zu 4 bis 10 mit den Stielen verwachsen. Capillitium und Sporen ziegelrot, selten mit einem Stich ins Gelbliche. Elateren ziemlich lang ausgezogen, . $30-50 \mu$ lang, selten so lang wie die von T. Botrytis, Spiralleisten bis in die Spitzen. 
S. 351. zu Trichia lateritia Lév. 1) ist als weiteres Synouym zu nennen:

Craterium floriforme Schwein. in Trans. Am. Soc. Phil. ser. 2 IV (1832), 258.

S. 359. bei Hemitrichia leiotricha Lister ist "Schweiz" zu streichen.

S. 360. Hemitrichia. minor G. Lister; bei dieser Art scheinen Capillitiumfäden mit rechts- und linkswindenden Spiralleisten vorzukommen. Vergl. G. Lister in Journ. of Bot. LVII (1919), 110 und 111 (sub. H. leiocarpa [Cooke] Lister).

S. 360. Hemitrichia minor G. Lister ist auch in Großbritannien nachgewiesen, desgl. var pardina Minakata.

S. 361. als weiteres Synonym zu H. clavata (Pers.) Lister ist hinzuzufügen:

Hemiarcyria montana Morgan in Journ Cincimn. Soc. Nat. Hist XVII (1895), 40, pl. II, fig. 13.

S. 362. Hemitrichia leiocarpa (Cooke) Lister auch in Großbritannien, nicht aber in der Schweiz. Hinsichtlich dieser Art berichtet Frl. G. Lister (Journ. of Bot. LVII [1919], 111), daß die Spiralleisten def Capillitiumfäden des Typus rechtswindend, die des unter dem Synonym Hemiarcyria Varneyi Rex gehenden Typus linkswindend seien. Künftige Untersuchungen werden festzustellen haben, ob diesem Merkmal diagnostischer Charakter zukommt.

S. 364. Hemitrichia obrussea Meylan nom. nov. in Bull. Soc. Vaud. Sc. Nat. LII (1919), 494 (= Hemitrichia. Karstenii [Rost.] Lister var. lutescens Torr.).

S. 365. Hemitrichia helvetica Meylan in Bull. Soc. Vaud. Sc. nat. XLVI (1910), 54 ist nach Meylan nur eine Form, von Trichia affinis de Bary (Meylan briefl.).

1) Das spezifiische Epitheton lateritia ist, wie Frl. G. Lister in Journ. of Bot. LVII (1919), 110 nachweist, zu ersetzen durch floriforme, und an Stelle der Bezeichnung Trichia lateritia hat daher zu treten: Trichia floriforme (Schwein.) G. Lister (= Craterium floriforme) Schwein. in Trans. Am. Phil. Soc. Philad. ser. 2 IV (1832), 258. 
S. 368. Cornuvia Serpula (Wigand) Rost., Vorkommen außerhalb Deutschland, Großbritannien, Dänemark und Usambara fraglich.

S. 380. Arcyria pomiformis (Leers) Rost. kommt auch in der Schweiz (Jura) vor.

S. 387. Arcyria Oerstedtii Rost. Nach Sturgis (Mycologia IX [1917], 331) trägt das entfaltete Capillitium am Scheitel nicht immer Peridiefragmente; das Merkmal hat demnach keine diagnostische Bedeutung.

Ferner setze zu A. Oerstedtii Rost. als weiteres Synonym:

Areyria magna Rex var. rosea Rex in Proc. Ac. Nat. Sc. Phil. (1893), 365 .

S. 390. setze zu Perichana chrysosperma (Currey) Lister als weiteres Synonym:

Ophiotheca Wrigthii Berkeley et Curtis var. stipitata Rex in Proc. "Ac. Nat. Sc. Phil. (1893), 364.

S. 393. Bezüglich Perichæna corticalis (Batsch) Rost. var. liceoides (Rost.) Lister vergl. auch G. Lister in Journ. of Bot. LVII (1919), 111.

S. 398. Perich æna vermicularis var. pedata Lister. Die Varietät basiert auf Sporangien, die Herr A. und Frl. G. Lister in Lyme Regis (England) entdeckt hatten und die $0,3 \mathrm{~mm}$ lang gestielt waren und $8-9 \mu$ große Sporen einschlossen. Gleichzeitig hatte Hugo Bilgram in Philadelphia ähnliche Fruchtkörper mit meist kürzeren Stielen gefunden und Herrn Lister eingesandt, die von ihm und seiner Tochter als identisch mit den oben erwähnten englischen erachtet wurden, obschon den Bilgram'schen Sporangien die eigentümliche feinwarzige Skulptur der farblosen Innenhaut fehlte. 19.14 (Trans. British. Mycolog. Soc. (1914), 83 berichtete sodann Frl. G. Lister von einem entsprechenden Funde des japanischen Sammlers Minakata. In diesem Falle waren die Sporangien gestielt, zeigter Aufrißlinien und enthielten teils stache- 
lige, teils glatte und unregelmäßig angeschwollene Capillitiumfäden bei leicht warziger Skulptur der Peridie. Dieser Befund veranlaßte Frl. Lister sowohl die englischen, wie die amerikanischen und japanischen in Frage stehenden Fruchtkörper als eine Form mit gestielten Sporangien und nahezu glattem Capillitium von $P$. chrysosperma (Currey) Lister aufzufassen. Nun sind 1917 Jahn auf Polyangidenkulturen Sporangien einer Perichona-Art entstanden, die die Frage neuerdings verwirrt haben. Die Jahn'schen Sporangien sind von wechselnder Größe, 0,3-0,6 mm groß. Der Stiel ist verschieden lang, bisweilen $0,7 \mathrm{~mm}$, schwarz. Die Farbe der Sporangien ist ockergelb bis bräunlichgelb. Die Peridie besteht aus einer farblosen Schicht und einer äußern Kruste aus Körnchen, die etwa $2 \mu$ groß sind. Im Stiel finden sich schwarze Klumpen von Auswurfstoffen. Das Capillitium fehlt entweder überhaupt oder ist durch kurze, mit Körnchen besetzte Stränge vertreten, die der Haut meist in der untern Hälfte des Sporangiums in der Stielgegend aufsitzen. Die Sporen sind gelb, $11-14 \mu$ groß.

Die Größe der Sporen spricht gegen die Zugehörigkeit 'zu $P$. chrysosperma, desgleichen das eigentümliche Capillitium. Jahn spricht die Vermutung aus, daß es sich vielleicht um eine eigene Art aus der weitern Verwandtschaft der $P$. corticalis handle. Jedenfalls liegt aller Grund vor, auch die eingangs erwähnten, zuerst als Varietät zu vermicularis, dann zu chrysosperma gestellten Funde nicht aus den Augen zu verlieren. Vergl. Jahn in Ber. Deutsch. Bot. Gesellsch. XXXVI (1918, 1919), 667, fig. 14-16. Nenerdings (Journ. of Bot. LVII [1919], 111) vertritt Frl. G. Lister die Anschaung, die Varietät pedata stehe P. chrysosperma (Currey) Lister näher und sie daher jedenfalls bei $P$. vermicularis (Schwein.) Rost. zu streichen. 


\section{Alphabetisches Verzeichnis.}

Die Ziffern berzeichnen die Seitenzahlen.

Die nicht gesperrt gedruckten Namen sind Syuonyme.

Die mit * ausgezeichnete Ziffer gibt die Seite an, auf der die Species abgebildet ist.

Aethaliopsis stercoriformis Zopf

Äthalium Link

Aethalium atrum Preuß

- candidum Schlechtd.

- ferrincola Schwein.

- flavum Link

- melaenum Chevallier

- rufum Alexandrowicz Strojen.

- rufum Wallr.

- septicum Fr.

- vaporarium Fr.

- violaceum Spreng.

Alwisia Berkeley et Broome

- Bombarda Berkeley et

$$
310,311,314
$$

$$
\text { Broo'me }
$$$$
311^{*}, 214
$$

Amaurochaetaceae Rost.

Amaurochaete Rost.

84 und 272

- atra Rost.

273,274

275

- eribrosa (Fr.) Macbr.

439

- fuliginosa (Sowerby) Macbride $273^{*}, 274,275^{*}$

- speciosa Zukal

235

A maurochaetineae Rost.

Amaurosporales

84,229

83,85

Ancyrophorus crassipes Raunk.

Anemineae Rost. em. Lister

84 und 277

Angioridium sinuosum Grev.

Arcyrella cornuvioides Racib.

- decipiens Racib.

- inermis Racib.

- irregularis Racib.
Arcyrella nutans Racib.

385

- similis Racib.

383

Areyria Wiggers

369,370

- adnata Rost.

382

383

378

- albida Pers.

381

- - var. globosa Lister

380

- var. pomiformis Lister

385

- alutacea Schum.

382

- annulifera Torrend

255

- atra Schum.

372

- aurantiaca Raunk.

378

- bicolor Berkeley et Curtis

371

- Bucknalli Massee 336

- calyculata Massee 361

- carnea Schum. 375

- chrysospora Nassee 367

- cincta Schum. 375

- cinerea (Bull.) Pers. $\quad 377$

- - var. carnea Lister 379

- f. subglobosa (Meylan) Sehinz

_ - var. subleionema Čelak.

- cinnamomea Haszl.

- circinans Fr.

- clavata Čelak.

- clavata Massee

- coccinea Duby

371

-- (Lachnobolus) congesta Berkeley et Broome

389

- conjugata Schum.

375

378

375 
Arcyria decipiens Berkeley

- decipiens Pers.

- dentata Schum.

361

346

375

- denudata

(L.) Wettstein $370^{*}, 374,376^{*}$

- dictyonema Rost.

- digitata Rost.

- - f. subglobosa Meylan

- ferruginea Santer $371,372^{*}$

- - var. Heterotrichia (Massee) Torrend

- flava Pers.

373

- flexuosa Rabenhorst

- Friesii Berkeley et Broome

- fuliginosa Cooke et Massee

- fusca Fr.

- Gabriellae Rav.

- glauca Lister

- globosa Schwein.

- glumerata Fr.

- Hariotii Massee

- incarnata Pers.

- - var. flexuosa Fr.

- - var. fulgens Lister

385

387

378

387

375

373

377

381

390

389

382

387

383

- - f. helvetica Meylan

383

- - var. nodulosa Macbride

383

- iusignis Kalchbr. et Cooke

375

- intricata Rost.

371

- Karstenii Massee

- leiocarpa Massee

- leocarpoides Massee

- Leprieurii Montague

- leucocephala Hoffm.

- lilacina Schum.

- lutea Schweiu.

- macrospora Peck

- magna Rex

- - var. rosea Rex

- melanocephala Schum.

- minor Schwein.

364

362

361

378

168

382

380

371

387

445

375

382

- nutaus (Bull.) Grev. 385, 386*

- occidentalis (Macbride)

Lister

- ochroleuca Fr.

388

380
Arcyria pallida Berkeley et Curtis 378

- paradoxa Massee

364

- pomiformis (Leers) Rost. 380 ,

- punicea Pers.

445

$37 t$

- - var. vermicularis Fr. 387

- Raciborskii Berlese 372

- rubiformis Massee 357

- rufa Schum.r 375

- Serpula Massee

366

- Serpula Wiegand

368

- silacea Ditm.

380

- stipata (Schwein.) Lister 384

- stipitata Massee

361

- straminea Wallr.

378

- stricta Rost.

378

- tenuis Schröter

378

- trichioides Corda

378

- umbrina Schum.

380

- vermicularis Schum.

387

- veruicosa Rost.

375

- versicolor Phillips 373

- vitellina Phillips

373

- Wigandii Mlassee

363

Arcyriaceae Rost. em. Lister

85 und 368

Badhamia Berkeley 86, 87, 93

- affinis Rost.

102

- Alexaudrowiczii de Bary et Rost. 96,415

- alpina G. Lister

415

- capsulifera (Bull.) Berkeley 94,414

- capsulifera Berk.

- - var. papaveracea Torrend 95

- chrysotricha Rost.

- citrinella Celakovsky

124

- coadnata Rost.

157

- Curtisii Rost.

105

- decipiens (Curt.) Berkeley 99

- decipiens Lister

96

- dictyospora Rost.

106

- fasciculata Rost.

137

- foliicola Lister $87 *, 100^{*}$

- - var. alpina G. Lister 100

- var. alpiua Lister $\quad 415$

- Fuckeliaua Rost. 
Badhamia fulvella Berkeley

- granulifera Massee

- hyalina Berkeley

- - var. papaveracea Lister

- inaurata Currey

- lilacina (Fr.) Rost.

- macrocarpa (Ces.) Post.

- - var. sessilis Rost.

- - var. stipitata Rost.

- macrocarpa Lister

- magna Peck

- microcarpa Schröter

- nitens Berkeley

- - var. reticulata Berkeley et Broome) G. Lister $\mathrm{N} 415$

- nodulosa Massee

129

- orbiculata Rex

102

- ovispora Racib.

104

- pallida Berkeley

96

- panicea (Fries) Rost.

102

- papaveracea Berk. et Rav. 95

- penetralis Cooke ét Ellis

216

- populina Lister

- pulcherrima Spegazz.

96

130

- rubiginosa (Chev) Rost. 105

- - var. concinnum G. Lister

106

- - var. conciunum G. Lister

N 425

- - var. dietyospora Lister

106

- - var. genuina Lister

196

- - var. globosa Lister

- subaquila Macbride

106

105

- utricularis (Bull.) Berkeley

$97,98^{*}$

- varia Massee

$95,97,100$

- verna Rost.

- versicolor Lister

Barbeyella Meylan

- minutissima Meylan

Brefeldia Rost.

$410,411^{*}$

- maxima (Fr.) Rost. 276*,277*

Byssus fruticulosa Müller

Calcarineae Rost.

Calonema Morgan

$329,331,354$
Calonema aureum IIorgan

$330^{*}, 355^{*}$

Calonemineae Rost. em. Lister 85,328

Carcerina conglomerata Fr. $\quad 147$

- spumarioides Fr.

177

- valvata Fr.

143

Ceratiomyxa Schröter $\quad 80$

- caesia Jahn N 414

- fruticulosa Macbride 81

- fruticulosa (Müller) Macbr. em. Lister

80

- var. flexuosa Lister

$81^{*}, 82$

- - var. hydnoides (Jacquin)

Schinz

83

- - var. porioides (Alb. et Schw.) Lister

- mueida Schröter

- - var. flexuosa Lister

82

- - var. porioides Lister 82

- porioides Schröter

- sphärospora Skupieuski

Geratiomyxaceae Schröter $\quad 80$

Ceratium arbuscula Berk, et Broome

- filiforme Berk. et Broome 82

- hydnoides Alb. et Schw. 81, 83

- mucidum Pers. 81

- porioides Alb. et Schw.

82

- pyxidatum Alb. et Schw. 81, 83

Cliondrioderma aculeatum Rex 186

- affine Rost.

178

- albescens Phillips

180

- anomalum Rost.

217

- asteroides Lister

191

- Berkeleyanum Rost. $\quad 160$

- calcareum Rost. 207

- Carmichaelianum Cooke 188

- Charmichaelianum Massee 192

- Cookei Rost.

217

- erustaceum Berlese

178

- cubense Rost.

182

174

- dealbatum Massee

181

- deplanatum Rost.

206

Schinz, Myxogasteres (Rabenhorst Krypt. Flora 1, Pilze Abt. X). 
Chondrioderma exigumm Raciborski

- farinacemm Link

- floriforme Post.

- Friesianum Rost.

- frustulosum Patouill.

- geasteroides Phillips

- globosum Piost.

- hemisphaericum Torrend

- Hookeri Lister

- inflatum Rost.

- leptotrichum Racib.

- liceoides Rost.

- lobatum Spreng.

- lucidnm Cooke

- Lyallii Massee

- Michelii Rost.

- montanum Meylau

- Muelleri Rost.

- mutabile Schröter

- niveum Rost.

- - var. deplanatum Lister

- - var. genuimum Lister

- - var. Lyallii Lister

- ochraceum Schröter

- Oerstedtii Piost.

- pezizoides Rost.

- physaroides Rost.

- quitense Patouill.

- radiatum Rost.

- - var. genuimm Torrend

- reticulatum Rost.

- - var. effusum (Schwein.) Meylan

- roanense Rex

- rugosum Rex

- Saundersii Berkeley et Broome

- Sauteri Rost.

- similans Rost.

- simplex Schröter

- spumarioides Rost.

- squamulosuu Spreng.

- stromateum Rost.

- subdictyospermum Rost.

- sublateritium Rost.

- testaceum Rost.
176

190
Chondrioderma 'Trevelyani Rost. 184

- vaccinum Rost.

- virgineum Massee

- zeylanicum Rost.

Cienkowskia Rost. $\quad 86,90,163$

- reticulata (Alb. et Sehwein.) Rost. $80^{*}, 163,164^{*}$

Cionium iridis Ditm.

214

- stellare Spreng.

188

- tigrinmm Link

224

- xauthopus Ditm.

214

Clastoderma Biytt $229,232,270$

- Debaryanum Blytt $270^{*}, 271^{*}$

Clathroptychium Berkeleyi Massee 318

- cimnabarium Sace.

318

- dissilieus Massee

318

- rugulosum Rost.

318

Clathrus adnatus Batsch 382

- denudatus I.

374

- nudus L.

233

- turbinatus Huds.

ช3:

Claustria didermoides Fr. $\quad 130$

Clavaria byssoides Bull. 81

- puccinia Batsch

Colloderma G. Lister 87, 91, 193

- oculatum (Lippert) G.

$$
\text { Lister 92*, 193, 194* }
$$

Comatricha Preuß 230, 242

- aequalis Peck 246

- affinis Rost. 251

- albida Schulzer $\quad 378$

- alta PreuB 245

- caespitosa Sturgis 201

- cornea G. Lister et Cran

- crypta Macbride

250

- dictyospora Čelak. $\quad 236$

- elegans (Racib.) Lister 243

- Ellisiana Ellis et Everh. $\quad 947$

- Ellisii Morgan 247

- equinoctialis Torrend 249

- fimbriata G. Lister et Cran

- flaceida Morgan

435

238

- Friesiana Rost.

- var. excelsa Racib. 245

- gracilis Wingate 
Comatricha irregularis Rex 250

- laxa Rost.

$246,247^{*}$

- - var. microspora Torrend

- longa Peck

- - var. irregularis Lister

- lurida Lister

- macrosperma Racib.

- microspora Lister

- nigra (Pers.) Schröter

$231^{*}, 244,245^{*}, 25 l^{*}$

- var. aequalis (Peck) Sturgis

- - var. alta (PrenB) Lister

- - var. microspora ('Torrend) Meylan

- - var. Suksdorfii Sturgis

- obtusata Lister

- obtusata PreuB

- papillata Schröter

- Persoonii Ċelak.

- Personii Macbride

- Personii Rost.

- pulchella (Babingtou) Rost.

- var. fusca Lister

253

- - var. graeilis (Wingate) Lister

- var. tenerrima (Curtis)

$$
\text { Lister }
$$

- rubens Lister

- Shimekiana Macbride

- Sommerfeltii Blytt

- Stemonitis Sheldon

- subeaespitosa Peck

- Suksdorfii (Ellis et Everh.) II acbride

- tenerrima (Curtis) G. Lister

- typhina Rost.

- - var. microspora Torrend

- typhoides (Bull.) Lister

$$
250,251^{*}
$$

- - var. heterospora Rex

- - var. microspora Lister
Comatricha typhoides var. similis Lister

252

\section{Cornuvia Rost.}

$329,331,367$

- anomala Karsten

336

- circunscissa Rost.

390

- dictyocarpa

394

- leocarpoides Spegazz. 361

- metallica Rost.

401

- nitens Rost.

3 5ิ3

- Serpula (Wigand) Rost.

- Wrigthii Rost.

$330^{*}, 368$

Crateriachea mutabilis Rost. 116

Craterium Trentepohl 87, 90, 165

- aureum (Schum.) Rost. 170

- citrinellum Lister

126

- concinnum Rex 167

- confusum Massee 165

- convivale Morgan 168

- Curtisii Massee 105

- cylindricum Massee 169

- deoperculatum Fr. $\quad 168$

- dictyospermum Massee 106

- flavum Fr. $\quad 109$

- floriforme Schwein. $\quad 44$

- Friesii Rost. 165

- Fuckelii Massee 168

- globosum Fr. 381

- leucocephalum Ditm.

- - var. genninum Čelak. 168

- - var. inclusum Celak. 168

- leucocephalum (Pers.) Ditm.

168

- - var. cylindricum (Massee) Lister

169

- - var. seyphoides (Cooke et Balf.) Lister

169

- lilaciuum Massee

104

- maydis Morgan

- minimum Berkeley et Curtis 169

- minutum (Leers) Fr.

$90^{*}, 165,166^{*}$

_ - var. campanulatum Čelak. 166

- - var. pyriforme Čelak. 1 ti6

- mutabile Fr.

- mutabile Fuckel 426 
Craterium nodulosum Cooke et Balf.

- obovatum Peck

129

- Oerstedtii Rost.

105

- paraguayense (Spegazz.)

Lister

- pedunculatum Trentep.

- porphyrium Schwein.

- pruinosum Corda

- pyriforme Ditm.

- rubescens Rex

- rubiginosum Massee

- rubronodum G. Lister

- turbinatum Fr.

- vulgare Ditm.

- xanthopus Wallr.

Cribraria Pers.

- argillacea Pers. 278, 279, 282

- - var. oligostata Čelak. 284

- aurantiaca Schrader

- - var. delicatula (Rost:) Celak.

- - var. genuina Čelak.

- - var. inconspicua Čelak.

- - var. sulphurea Wallr.

- Bieniaszii Massee

- capillaris Fr.

- cernua Pers.

- cuprea Morgan

- dictydioides Cooke et Balfour 293

- elata Massee 294

- elegans Berkeley et Curtis

- exilis Macbride

- ferruginea Meylan

- fulva Schrader

- intermedia Berkeley

- intermedia Schrader

- intricata Schrader

- - var. dictydioides (Cooke et Balfour) Lister

- languescens Rex

- macrocarpa Schrader

$287,288^{*}$

- - var. ferruginea (Meylau) Schinz

167

165

357

168

165

168

105

425

165

16 วั

168

$283^{*}$

289

290

290

289

287

297

300

296

298*

300

287, 439

285

289

293
Cribraria microcarpa Massee

- microcarpa (Schrader) Pers.

296

- micropus Schrader

283

- microscopica Berkeley et Curtis

290

286

293

296

- minima Berkeley et Curtis

286

- minutissima Schwein.

286

- mirabilis Massee

286

302

- purpurea schrader

297 *

- pyriformis Schrader

$279 *, 295 *$

- - var. fusco-purpurea II eylan

296

- - var. notabilis Rex 295

- rubiginosa Fr. 281, 285*

- - var. longipes Meylan 285

- rufa (Poth) Rost. 285. 286*

- rufescens Pers.

285

- splendens (Schrader) Pers.

291

- - var. gracilis Racib. 291

- - var. oligostata Racib. 292

- - polybrachia Čelak. 292

- tatrica Racib.

287

- tenella Sehrader

294

- variabilis Ficin. et Sehub. 289

- violacea Rex

- vulgaris Schrader

299*

- - var. amrantiaca Pers. 289

- - var. delicatula Rost. 290

Capularia leucocephala Link $\quad 168$

- mutabilis Rabenhorst 170,426

- xanthopus Rabenhorst $\quad 168$

Cyathus minutus Hoffm. 165

Cytidium citrinum Morgan $\quad 114$

- globuliferum Morgan 111

- melleum Morgan $\quad 109$

- penetrale Morgan 125

- pulcherrimum Morgan 114

- Ravenelii Morgan 113

Dermodium conicum Rost. $\quad 327$

- fallax Nees 238

- inquinans Fr. $\quad 276$

- inquinans Link 274

Diachaea Fries $\quad 87,92,196$ 
Diachaea bulbillosa (Berkeley et Broome) Lister

197

- caespitosa (Sturgis) Lister

- cerifera G. Lister

- confusa Massee

- eylindrica Bilgram

- elegans Fr.

- Hookeri Massee

- leucopoda (Bull.) Rost.

- var. globosa Lister

- radiata G. Lister

- splendens Peck

- splendens Racib.

- subsessilis Peck

- Thomasii Rex

- - var.? Lister

Diachaeella bulbillosa von Höhnel

197

Dianema Rex

$399,400,403$

- corticatum Lister 400*, 406*

- corticatum Meylan

- depressum Lister

- Harveyi Rex

Dictydiaethalium Rost.

- applanatum Rost.

- dissiliens Haßlinsky

- plumbeum (Schum.) Lister

$316^{*}, 317$

Dictydium Schrad. 278, 279, 300

- ambiguum Schrader

- anomalum Jahn

- cancellatum (Batsch) Macbride $279^{*}, 300,301^{*}$

- - var. alpinum Lister

302

- - var. anomalum (Jahn) Schinz

$302,303^{*}$

- - var. cribrarioides (Meylan)

304

- - var. exilis (Macbride) Torrend

- - var. fuscum Lister 302, 304

- - var. genuinum (Meylan)
Dictydium cancellatum var. heterodictyon (Rost.) 304

- - var. purpureum Macbride 304

- - f. venosum (Schrader) Torrend

- cernuum Nees

304

- longipes Morgan 300

- magnum Peck 100

- microcarpum Schrader 297

- splendens Schrader 291

- trichioides Chev. 300

- umbilicatum Schrader 300

- - var. anomalum Jahn 302

- venosum Schrader $\quad 300$

Diderma Pers. $\quad 87,91.172$

- albescens Phillips $\quad 180$

- alpinum Meylan 427

- antarctica (Speg.) Sturgis

428

- arboreum (Petch) G. Lister et Petch 193

- asteroides Lister $\quad 191$

- atrovirens Fr. 171

- brunneolum Phill. 127.

- Carmichaelianum Berkeley 188

- chalybeum Weinm. 206

- cinereum Morgan 177

- citrinum Berk. 224

- citrinum Peck 126

- concinnum Berkeley et Curtis 188

- conglomeratum Fr. $\quad 147$

- contextum Pers. 146

- contortum Hoffm. 181

- crassipes Schum. 188

- crustaceum Peck 178

- cubense Berkeley et Curtis 182

- cyanescens Fr. 206

- deplanatum Fr. 181

- depressum Fr. 174

- difforme Pers. 205

- effusum (Schwein.) Morgan

- flavidum Peck 146

- flavum Weinm. 147

- floriforme (Bull.) Pers. 185

- globosum Pers. 
Diderma globosum var. alpiunm II eylan

179

- globuliferum Fr.

- granulatum Fr.

- hemisphaericum (Bu1l.) Hornem.

- - f. sessilis host.

175

- - f. stipitata (Rost.)

175

- Hookeri Berk.

- laciniatum Phillips

- lepidotum Fr.

- Libertianum Fres.

- liceoides Fr.

- lobatum Somm.

- lucidum Berkeley et Broome

- Lyallii Macbride

- Mariae-Wilsoni Clinton

- minutum Fr.

- montauum Meylan

- montanum Meylan

- var. rosea Meylan

- Neesii Corda

- nitens Klotzsch

— niveum (Rost.) Macbride 179

- - ssp. deplanatum (Fr.) lister

- - ssp. Lyallii (IIassee) Lister

- - ssp. niveum (Rost.) Sehinz

-oblongum Fries

- oblongum Schum.

130

- ochraceum G. C. Hoffm. 187

- ochroleucum Berkeley et Curtis

146

- pallidun Berkeley et Curtis 144

- papaverium Wallr.

94, 97

- Personii Macbride 206

- radiatum (L. sens. lat.)

\begin{tabular}{rr} 
Lister & $91^{*}, 188^{*}$ \\
- var. genuiumm & ('lorrend) \\
Schinz & 189 \\
- - f. album Torreud & 189 \\
- & - f. flavogenitum (II y - \\
\hline lan) & I89
\end{tabular}

Diderma radiatum var. mouta. uum (Meylan) Schinz 189

- - var. radiatum (L. sens. strict.) Sehinz

189

$\begin{array}{lr}\text { - var. rubrum. Rönı } & 190 \\ \text { - reticulatum Berk et Br. } & 97\end{array}$

- reticulatum Fr. $\quad 146$

- reticnlatum Morgan 176

- roanense" (Rex) Macbride 190

- rufipes Fr.

112

- rugosum Petch 193

- rugosum (Rex) Macbride 192

- rugulosum Weinm. $\quad 147$

- Sauteri (Rost) 186

- simplex (Schröter) Lister 183

- - var. echinulatum Meylan

427

- spumariaterine Wallr.

223

- spumarioides Fr. 176, 177*

- spurium Schum.

185

- squamnlosum Alb. et Sehwein.

- stellare Pers.

188

- stromateum Morgan

177

- subdictyospermum (Rost.)

Lister

174

- sublateritinm Berkeley et Broome

182

- testaceum (Schrader)

$$
\text { Pers. }
$$

182. $183^{*}$

- Trevelyaui (Grev.) Fr. 184

- - var. nivale Meylan 185

- umbilicatum Pers.

- valvatuis Fr.

188

143

- veruicosum Pers.

171

Didymiaceae Rost. 84 und 202

Didymium Schrader 202, 203, 204

- affine Rannk.

217

- Alexandrowiczii Massee 217

- anellus Morgan $\quad 218$

- angulatum Peck 216

- anomalum Sturgis $\quad 222$

- australe Massee 160

- Barteri Massee 116

- Bonianum Patouill. 217

- bulbillosum Berkeley et Broome 
Didymium candjdum Schrat.

178

- Chrondrioderma de Bary et Rost.

216

- chrysopeplum Berk. et Curt. 109

- cinereum Fr. .

138

- Clavus (Alb. et Schwein.) Rost.

- comatum Lister 207

- commutabile Berkeley et Broome

211

- complanatum (Batseh)

Post.

- complanatum Fuckel

210

- complanatum Schrader

- confluens Rost.

188

- congestum Berkeley et Broome

130

- commatum Peck

136

- Cookei Raunk.

217

- costatnm Fr.

215

- croceoflavum Berkeley et Broome

149

- crustacenm Fr.

220

- Curtisii Berk.

105

- cyanescens Fr.

206

- dealbatum Berkeley et Curtis 174

- difforme (Pers.) Duby

$205,207^{*}$

— - var. connatum Lister 207

- - var. geu uinum Torrend

- discoideum Rost.

- discoideum T'orreud

- dubium Rost.

- echinospora Massee

- effusum Link

- - var. tenue Lister

- elegantissimum Massee

- excelsum Jahu

- eximium Peck

- Fairmani Sace.

- farinaceum Schrad.

- - var. minus Lister

- filamentosum Wallr.

- flavicomum Massee

- flavidum Peck

- floriforme Schrad.

431

208

137

215

218

214

221

224

211
Didymium Fuckelianum Rost.

- fulvellum Massee

- fulvipes Fries

- fulvum Sturgis

- furfuraceum Fr.

- Geaster Link

- glaucum Phill.

- globosum Chevall.

- grannliferum Phillips

- guarapiense Spegazz.

- gyrocephalum Mont.

- hemisphaericum (Bull.) Hornem.

- hemisphaericum Fr.

- herbarum Fries

174,211

- humile Hazslinszky

215

- intermedium Schröter

213

221

- iridis Fr.

214

- lateritium Berkeley et Rav. 149

- leoninum Berkeley et Broome

221

- leucopus Fr. 108,215

- Libertianum de Bary 206

- Listeri Massee 208

- Iobatum Nees 212

- - var. stipitatum Fr. 214

- longipes Massee 111

- luteogriseum Berk. et Curt. 121

- macrospermum Rost. 216

- margiuatum Fr. 131

- Masseeaumm Sace. et Syd. 211

- megalosporum Berkeley et Curtis

212

213

215

122

125

185
214

- melanopus Fr. 212

- var. Clavus Fr. 211

- melanospermum (Pers.) Macbride

211

- - var, minus Lister 213

- melleum Berk. et Br. - 109

- Michelii Lib. 174

- microcarpon Rost. 213

- microcephalum Chevall. 213

- minus Morgan 213

- nectriaeforme Berkeley et Curtis

- neglectum Berkeley et Broome 
Didymium neglectum Massee

221

- nigripes (Link) Fr. 20I*, 421

- var. eximinm (Peck) Lister

133

- - var. xanthopus (Ditm.) Lister

214

- oculatum Lippert

193

- oxalinum Peck

138

- paraguayeuse Spegazz.

167

- parasiticum Sacc. et Syd.

160

- pertusum Berkeley

- pezizoideum Massee

214

- physaroides Fr.

- platypus Hazsliuszky

- polycepbalnm Fries

- polymorphum Mont.

160

212

216

121

121

- porphyropns Durien et Montagne

213

- praecox de Bary

215

- proximum Berkeley et Curtis 214

- pusillum Berkeley et Curtis 129

- quitense (Patouill.) Torrend

208

- radiatum Berkeley et Curtis 215

- radiatum Nassee

211

- reticulatum Berkeley et Broome

- reticulatum Rost.

$$
96,415
$$

175

-- rufipes Fr.

224

- scrobiculatum Berkeley

138

- Serpula Fr.

- siuapinnu Cooke

210

150

- spumarioides Fr.

- squamulosum (Alb. et

Schweiu.) Fr. 214, 215*, 216*

- stellare Schrades

188

- suberosmm Peck

111

- tenue Patouill.

213

- terrestre Fr.

133

- testaceum Schrader

182

- tigrinum Schrader

224

- Trochus Lister

- tubnlatum Jabn

- Tussilaginis Nassee

- versipelle Fr.

209

$4 ะ 9$

217

224

- Wilezekii Meylau

- xanthopus Fr.

$218,219^{*}$

214
Didyminm zeylanicum Berkeley et Broome

- flavo-fuscum Ehrenberg

Echinostelium de Bary

$229,232,271$

- minutum de Bary ex Rost.

271,271

Embolus crocatus Batsch

374

Endosporeae Rost.

80,83

Enerthenema Bowman

$230,231,254$

- Berkeleyana Rost.

255, 257

- elegans Bowm.

255

- muscorum Lév.

261

- papillatum (Pers.) Rost. $231^{*}, 255^{*}$

- - var. carneo-griseum Meylan

- syucarpon Sturgis

Enteridium Ehreuberg

$315,316,318$

- antarcticum Speg

319

- atrum Preub

319

- cinereum Schwein.

167

- liceoides G. Lister

- macrosporum Raunk.

319

- minutum Sturgis

- olivaceum Ehrenberg

$316^{*}, 319$

- Rostrupii Rannk.

$31 y$

- Rozeaum (Rost.) Wiugate

320

- simulans Rost.

319

- sulendens Morgan

320

Erionema Peluig

$86,88,158$

- anrenm Penzig 98*, 158, 159*

Eudiderma Lister

173

Eudidymium Lister

$205^{\circ}$

Exosporeac Rost.

80

Fulgia eneaustica Chev.

262

Fuligo Haller

$86,88,152$

- candida Pers.

153

- carnea Schum.

153

- carnosa Duby

153

- cerebrina Brondeau

153

- cinerea (Schwein.) Morgan 
Fuligo ellipsospora Lister

- fiava Pers.

- flavesceus Schum.

- gyrosa Jahn

- hortensis Duby

- laevis Pers.

- Lycoperdon Schum.

- megaspora Sturgis

- muscorum Alb. et Sehwein.

- ochracea Peck

- ovata Macbride

- pallida Pers.

- plumbea Schum.

- rufa Pers.

- septica (L.) Gmelin $88^{*}, 152,154^{*}, 155^{*}$

- - var. flava (Pers.)

- var. rnfa (Pers.)

- - var. vaporaria (Pers.)

- - var. violacea (Pers.)

- septica Lister

- simulaus Karst.

- stercoriformis Racib.

- tatriea Racib.

- vaporaria Pers.

- varians Somm.

- violacea Pers.

Galoperdon epidendrum Wiggers

Hemiarcyria ablata Morgan

- applauata Cooke et Massee

- Buckualli Massee

- calyculata spegazz.

- chrysospora Lister

- clavata Rost.

- fuliginosa Cooke et Massee

- fuualis Morgan

- intorta Lister

- Karsteuii Rost.

- leiocarpa Cooke

- longifolia Rex

- melanopeziza Speg.

- montana Morgan

- obscura Piex

- paradoxa Massee

- plumosa Morgan

- rubiformis Rost.

156

153

153

317

153

154

154

140

156

157

153

153

150

153

325

361

392

$336^{\circ}$

361

367

361

387

361

359

364

362

359

390

444

364

364

361
157 Hemiarcyria rubiformis var. Neesiana

1 Rost. 357

153 - Serpula Rost. 366

143 - stipata Rost. 384

150 - stipitata Massee 361

153 - Varneyi Rex 362

321 - Wigandii Rost. 363

158 Hemitrichia Rost. 329, 331, 356

- abietina (Wigand) Lister

363

357

- - f. aurantiaca Meylan 364

- - f. Iutea Iteylau 364

- chrysospora Lister $367^{*}$

- clavata (Pers.) Lister $330^{*}, 360,361^{*}$

- helvetica Meylan

365,442

- intorta Lister

359

- - var. leiotricha Lister 359

- Karstenii (Rost.) Lister 364

_ - var. lutescens Torrend

365

- leiocarpa (Cooke) Lister

$362,363^{*}$

- leiotricha Lister $\quad 359$

- minor G. Lister

360

- - var. pardina Minakata

360

- montana Morgan ex Macbride

361

- obrussea Meylan

- ovata Macbride 363

- rubiformis Lister 3

- Serpula (Scop.) Lister

- stipata Macbride $365,366^{*}, 367^{*}$

- stipitata Macbride

384

- Vesparium (Batsch) Maebride $356,358^{*}$

Heterodermaceae Rost. em.

$$
\text { Lister }
$$

84, 278

Heterodictyon Bieniaszii Racib. 287

- mirabile Rost.

302

Heterotrichia Gabriellae Massee 373

Hymenobolıs Zukal 440, 441

- parasiticus Zukal $\quad 440$

Iocraterium paraguayense Torrend 168

- rubescens Jahn

168 
Isaria mucida Pers.

Jundzillia Tubulina Racib.

Kleistobolus pusillus Lippert

Lachnobolıs Fr.

- Arcyrella Rost.

369,389

- circinans Fr.

- congestus (Sommerfelt)

Lister

$370^{*}, 389$

- globosus Rost.

- incarnatus Macbride

381

388

- incarnatus Schröter

- occidentalis Macbride

- pygmaeus Zukal

- Rostafinskii Racib.

- Sauteri Rost.

Lamproderma Rost.

- arcyrioides Morgan

$229,2 j 0,231,258$

- arcyrioides Rost.

265

- - var. iridea Cooke

$27 t$

261

- arcyrionema Rost. 259. 260*

- atrosporum IIeylan 268, 269

- var. anglicum G. Lister et Howard

438

- columbinnm (Pers.) Rost. $262 *, 2 \hbar 3^{*}$

- - var. sessile Lister 263

- cribrarioiles (Fr.) R. E. Fries $267,268,269$

- Crucheti Meylan 438

- echinulatum (Berkeley)

Rost.

259

- Ellisiana Cooke

- Fuckelianum Rost.

- - f. cracoviensis Racib.

- - f. rhenana Racib.

- Gulielmae Meylan

- Hookeri Rost.

- inconspicuum Racib.

- insessin Lister

- iridescens Rost.

- irideum Massee

- leucosporum Rost.

- Listeri Massee

- Lycopodii Paunkiaer

- minutim Rost.
259

267

263

261

264

259

267, 269

264

Lamproderma nigrescens Rost.

264

- nigrescens Sacc.

264

- physaroides Rost.

262

- - var. sessile Lister

263

- Saceardiaum Massee

264

- Sauteri Rost.

269

- var. Carestiae (Ces. et de Not.) Meylau

269

- Santerie Rost.

265

- Schimperi Rust.

262

- scintillaus (Berkeley et

Broome) II orgau

$261^{*}$

- Staszycii Racib.

262

- subaeneum Massee

259

- tatricum Racib.

264

- violaceum (Fr.) Rost. $263,2 b 4^{*}, 269$

_ var. calciferum Meylan

266

- var. Carestiae (Ces. et de Not.) Lister

265. 269

- - var. debile G. Lister et How ard

437

- - var. dictyosporum Lister $266,268,269$

_ - var. genuinum Lister 266

- - var. Sauteri (Rost.) Lister 265,269

Lamprodermopsis nivalis Meylan 403

Lamprosporales Lister 84,277

Leanginm Lister

- atrovirens Fr.

171

- floriforme Link

185

- lepidotum Ditm.

185

- squamulosum Fr.

221

- stellare Link

188

- stipatum Sehwein.

384

- Trevelyani Grev.

184

- vernicosum Fr.

171

Leocarpus Link em. Rost.

$87,91,170$

171

207

146

- contextus Fries

- fragilis (Dickson) Rost.

$91^{*}$. 171, $172^{*}$

- - f. Lignicola Meylan 
Leocarpus fulvus Macbride

- granulatus Fr.

- minutus Fr. .

- ramosus Fr.

- spermoides Link

-- vernicosus Link

Lepidoderma de Bary 203, 204, 224

- Carestianum (Rabenlorst) Rost.

$225,226^{*}$

- - var. Chailletii (Rost.) Lister

- - f. gracile Meylan

- - var. granuliferum (Phillips) Lister

- Chailletii Rost.

- fulvum Massee

- granuliferum Fr.

- Kurzii Berk.

- obovatum Massee

- reticulatum Massee

- stellatum Massee

- tigrinum Rost.

- tigrinum (Schrader) Rost.

$204^{*}, 224,225^{*}$

Lepidodermopsis Lister

- leoninus v. Höhnel

221

I.eptoderma G. Lister

203, 204, 227

- iridescens Lister 204*, 227

$228^{*}$

Licaethalium olivacenm Rost.

319

Licea Senrader

- alba Nees

- alutacea Wallr.

- antarctica Spegazzini

- applanata Berkeley

- biforis Morgau

$305,306,440$

206

308

428

317

309

- brumuea Prenb

283

- caesia Schum.

- castanea Lister

- ciunabarina Berkeley et Broome

- cirenmscissa Pers.

- clavata Schrader

- eongesta Wallr.

- contorta Wallr.

- cylindrica Fr.

205

307

317

394

312

389

340

312
Licea effusa Whrenb.

280

- flexuosa Pers.

305*, 208

- fragiformis Nees

- glomulifera de Bary et Rost. 319

- incarnata Alb. et Schwein. 401

— iricolor Zollinger

312

- Lindheimeri Berkeley

153

- macrospora Schwein.

206

- microsperma Berkeley et Curtis

312

- miuima Fries

$306,307^{*}$

-- nitens Schwein.

394

- ochracea Peck

156

- olivacea Fuckel

319

- pannorum Cienk.

395

- perreptans Berkeley

276

- pusilla Schrader

307

- quercina Wallr.

394

- reticulata Burkeley et Broome

396

- rubiformis Berkeley et Curtis 312

- rugulosa Wallr.

317

- Schönleinii Johow

308

- Serunla Fries

308

- singularis Jahn

- spermoides Berkeley et Curtis

282

- stipitata Berkeley et Rav. 313

- stipitata DC

215

- tenuissima Berkeley et Broome

- Tubulina Scirader

- variabilis Schrader

312

308

Liceaceae Rost. em. Lister

84,305

Liceopsis Torrend $315,317,322$

- lobata (Lister) Torrend

$316^{*}, 322^{*}$

Lignidium griseoflavum Link 156

- muscicola Fr.

156

- reuiforme Fr.

140,156

Lindbladia Fr.

278,279

- effusa (Ehrenb.) Rost.
$280^{*}, 281^{*}$

- - var. simplex Rex 278*, 281*

- tubulina Fr. 
Lindbladia versicolor Rost.

319

Lycoperdon luteum Schrank

Listerella $\mathrm{J}$ ahn 399, 400, 408

- paradosa Jahn $400^{*}, 408,409^{*}, 410^{*}$

Lycogala Adanson

- affine Berkeley et Broome

- argentea Pers.

321

- atropurpureun Berkeley et Broome

- atrum Alb. et Schwein.

- cinerea Schum.

326

- conicum Pers.

- contortum Ditm.

340

- Epidendrum (L.) Fr.

- pineum Batsch

- pyriforme Jaeq.

- radiatum $\mathrm{L}$.

- rufum Dickson

- sphaericum Gled.

- ungulinum Sehum.

- variolosum Huds.

- verrucosum Batsch

- vesiculosum Batsch

- Vesparium Batsch

Margarita Lister 399, 401

- metallica (Berkeley et Broome) Lister 399*, 401* $323^{*}, 325,326^{*}$

- - var. tesselata Lister 327

- exiguum Morgan

- ferruginea Schum. 326

- flavo-fuscum (Ehrenberg) Rost.

- incarnatum Swartz

- lenticulare Dur. et. No.t.

317

- miniatum Pers.

325

- minutum Grev.

- nitidum Berkeley et Broome 327

- platense Speg.

326

- plumbea Schum.

326

- plumbeuin Fr.

- punctata Pers.

326

- repletum Morgan

324

- sessile Retz.

- turbinata Pers.

321

Lycogalaceae de Bary

85,323

Lycoperdon Bombacinum Batsch

- chalibeum Batsch

356

- cinereum Batsch

325

138

- complanatum Batsel

- corticale Batsch

- Epidendrum L.

- epiphyllum Huds.

- favogineum Batseh

- flavaceum Schrank

- fragile Dickson

- fuliginosum Suwerby

— fuscum Huds.

- Iumbricale Batseh

- Iuteum Jacq.

\section{0}

393

325

325

332

312

171

274

321

365

146
- - var. intermedia Meylan

402.

- var. plasmodiocarpa (Blytt) R. E. Fries 402

- pictoviana Moore

401

Margaritaceae Lister 85 u. 399

Mucilago Adanson 203, 222

- spongiosa (Leyßer) Morgan 203*, 222, 223*

Mueor L.

152

- eancellatus Gmel.

300

- elathroides Scop.

374

- fragiformis Schaeff.

325

- Lycogala Scop.

325

- Lycogalus Belton

321

- lyeoperdoides Scop.

393

- miniatus Jaeq.

- Nueilago seop.

346

- pomiformis Leers

152

380

- primus (ovatus) Schaeff. 152

- pyrifurmis Leers

- pyriformis Scop.

- secundus sehaeff.

374

338

325

- septicus L.

152

- Serjula seop.

365

- spongiosus LeyBer

222

- Stemonitis Scop.

250

Mycetozoa de Bary 79

IIycetozoa Rost. $\quad 79$

Myxogasteres (Fries em. Sehröter)

Myxogastres Fries 
Myxomycetes Link

Myxomycetes Wallroth

Oligonema Rost.

- aeneum Karsten

- bavaricum Balf. et Berlese

- brevifilum Peck

- Broomei Massee

- flaridum Peck

- - var. aureum Lister

- fulvum Morgan

- fulvum Pavillard et Lagarde 340

- furcatum Bucknall

- minutula Massee

- niteus (Libert) Rost.

- niteus Lister $330^{*}, 352^{*}, 353^{*}$

Ophiotheca anomala Massee

- chrysosperma Currey

- cirenmscissa Massee

- irregularis Massee

- vitens Massee

- pallida Berkeley et Curtis

- reticulata Massee

- Serpula Massee

- umbrina Berkeley et Gurtis

- vermicularis Massee

- Wrightii Berkeley et Curtis

- - var. stipitata Rex

329,352

336

353

354

394

354

355

336

344

353

Ophiuridium dissiliens Haszliusky 318

Oreadella Wingate

305. 309,440

- operculata Wingate

Orthotricha gracilis Racib.

$306^{*}, 310$

- Raciborskii Celak.

243

247

Orthotrichia microcephala Wingate

270

Perichaena Fr.

369,390

- abietina Fr.

- annulifera Boud.

- applanata Bassee-

- artocreas Berkeley et Rav.

- australis Berlese

- caespitosa Peck

- cano-flavescens Rannk.

- chrysosperma (Currey)

Lister
9 Perichaena chrysosperma var.

9 Wrightii Torrend

391

- circumscissa Dalla Torre

391

- confusa Massee

397

- congesta Fr.

389

- contorta Fr.

- cornuviojdes Čelak.

340

365

- corticalis (Batsch) Rost.

$370^{*}, 393,395^{*}$

_- var. affinis Lister 395

- - var. liceoides (Post.)

I. is ter

395

- var. ochrospora (Peck)

- depressa (Corda) Libert 392*

- _ var. quadrata Torrend 393

- flavida Peck

354

- Friesiana Rost.

397

- fusco-atra Rost. 394

- incaruata Fr.

401

- irregularis Berkeley et Curtis

- Krupii Racib.

393

- liceoides Rost.

395

- margiuata Berkeley et Broome

392

- marginata Schwein.

394

- microcarpa Schröter

398

- mierospora Penzig et

$$
\text { Lister }
$$

398

- nitens Raunk.

394

- ochrospora Peck

396

- plasmodiocarpa Blytt

402

- populina Fr.

394

- - var. affinis Lister

395

- pseudaecidium Speg.

398

- puleherrima Peteh

396

- quercina Fr.

394

- reticulata Rost.

397

- Rostafinskii Karsten 394

- vaporaria Schwein. $\quad 394$

- variabilis Rost.

397

- vermicularis (Schwein.)

Rost.

396, 397

- - var. pedata Lister

Peziza couvivale Batseh

398 u. 445

168

165 
Physaraceae Rost.

83,86

Pliysarum bullatum Link

Physarella Peck

- mirabilis Peck

- oblonga (Berkeley et

Curtis) Morgan $88^{*}, 161,162^{*}$

- caespitosum Peck

- caespitosum Schwein.

125

- calidris Lister

129

- cancellatum Wallr.

Physariua von Höhnel

- echinocephala von Höbnel

$87,92,195$

$92^{*}, 195^{*}$

Physarum Pers.

$86,88,107$

- aenenm Rob. E. Fries.

148

- affine Rost.

135

- alatum Fr.

217

- albicans Peck

- candidum Rost.

135

- capense Rost.

138

- eapitatum Link.

212

- capsuliferum Chev.

- Carlylei Massee

118

- carneum G. Lister et

126

Sturgis

153

- cerebrinum Massee

153

- cernum Fr.

131

- albipes de Bary

133

- albipes Link

131

- albo-punctatum Schum.

131

- album Fr.

206

- Alexandrowiezii Rost.

- alpinum (Lister) G Lister

- var. badhamioides II ylan

- anceps de Bary

- antiades Fr.

- atrorubrum Peck

- atrum Schwein.

- chrysotrichum Berk. et Curt. 99

- chrysotrichum Massee 148

- cinerascens Schum.

- cinereum (Batsch) Pers. 138

- cinereum Ellis

139

- cinereum Link

- cinereum Lister

- var. ovoideum Sacc.

130

- citrinellum Peck

- citrinum Schumacher

- var. sessile Meylan 114

- Clavus Alb. et Schwein. 210

- columbinum Macbride 111

- aurantiacum Alb. et Schw.

- aurantium Pers.

- columbiumm Pers.

262

-_ aureum Pers.

- columbinum (Rost.) Sturgis

- - var. chrysopus Lev.

114

- auriscalpium Cooke

124

- auriscalpium Macbride

- Berkeleyi Rost.

- Bethelii Macbride

- bitectum Lister

- bivalve Pers.

- bogoriense Facilo.

- botryoides Fr.

- - var. hyalinum Fr.

- botrytes Somm.

- Braunianum de Bary ex Rost.

- Braunianum Lister

- brunneolum Phillips

- bryophilum Fr.

-_ bulbiforme Schum.

- compactum (Wingate)

Lister

- compressum Alb. et Sehw.

- - var. Lister

136

- compressum Lister

137

- concinnum Massee

104

- confluens Link

132

- confluens Pers.

- - var. muscigeunm Alb. et Schwein.

- conglobatum Fr. 
Physarum conglomeratum Massee 146

- commatum Ditm.

- connatum (Peck) Lister 136

- comnexum Link

- connexum Morgan

- contextum Pers.

- Crateriachea lister

- crateriforme Petch

- cupripes Berk. et Rav.

- decipiens Curtis

- decipiens Lister

- delicatissimum speg.

- depressum Schum.

- dictyospermum Lister

- dietyosporum Lister

- Diderma Lister

- didermoides (Achar.) Rost.

129

- - var. lividum Lister 130, 145

- Didymium Schum.

- difforme Link

- digitatum G. Lister

- Ditmari Rost.

- - var. croceoflavum Rost.

- var. lateritium Rost.

- ecninosporum Lister

- effusum Schwein.

- ellipsospormm Rost.

- Fam intzini Post.

- farinaceum Pers.

- fasciculatum Jungh.

- flavicomum Berk.

- flavum Fr.

- fulgens Patonill.

- fulvum Fries

- fulvum (Macbride) hister

- furfuraceum schum.

- galbeum Wingate

- glancum Massee

- globosum Schum.

- globulifernm (Bull.) Pers.

- gracilentum Fr.

- gracilentum Fuckel

- granulatum Balf.

116

134

122

99

420

111

174

417

118

144

109

124

131

123

135
Physarum gravidum Morgall

- grisenm Link

135

- Gulielmae Penzig

141

- gyrosmm Massee

420

- gyrosum Rost.

$140^{*}, 156$

- hyalium Pers.

94

- - var. chalybaeum Alb. et Schw.

- lıрpuorum Link

- javanicum Racib.

133

- imitans Racib.

134

- - f. Hexuosa Racib.

133

133

-_ f. stipitata Racib. $\quad 133$

- inaequale Peck 149

- iridescens Berkeley 263

- Kalchbremeri Massee 109

- lateritium Berkeley et liav.

- lepidodermoides Blytt $\quad 109$

- lencophaeum Fr. 133

- leucopns Link 108

- leucostictum Chevall. $\quad 169$

- Leveillei Piost. 114

- Licea Fries 308

- Licea Fuckel 197

- liceoides Duby 215

- lilacinum Fr. 104

- lilacinum Sturgis et Bilgram

422

- lividum var. conglobatum Rost.

- - var. licheniforme Schwein.

- Iuteo-album Lister $\quad 110$

149 - - var. aureum Rönn 111

148 - luteo-album Schum. 394

- Juteolum Peck 151

- luteum Pers. 120

- macrocarpon Ces.

101

- macrocarpum Fuckel $\quad 160$

- maculatum Macbride 115

- marginatum Schum. 131

- maydis (Morgan) Torrend

- melanospermum Pers.

- melanospermum Sturgis 
Physarum melleum (Berk. et Br.)

109

- metallicum Berkeley et Broome

- Michelii Corda

- microcarpum Fr.

- mucoroides Schilberczky

- Muelleri Berkeley

- murinum Lister

- - var. aeneum Lister

- mutabile (Rost.) Lister

- nefroideum Rost.

135

- Newtoni Macbride

- nicaraguense Macbride

- nigripes Link

- nigrum Fr.

- vitidum Schum.

- nodulosum Cooke et Balf.

- nucleatum Rex

- uutans Pers.

- - var, aureum Fries

$131,132^{*}$

- var. coccineum Fries

- var. iricolor Brandza

- - ssp. leucophaeum (Fr.) Lister

- - var. ovicarpum Meylan

- - var. viride Fries

- oblatum Macbride

- obrusseum Macbride

- ornatum Peck

- ovoideum Schum.

- pallidum Lister

- paniceum Fr.

- penetrale Rex

- Petersii

- - var. Farlowii Rost.

- Phillipsii Balf.

- Pini Scbum.

- platense Spegazz.

- plumbeum Fr.

- polycephalum Schwein. 121

- - var. obrusseum Lister 122

- polymorphum Rost.

- - var. gyrocephalum Lister 121

- psittacinum Ditm.
121

401

213

129

160

113

148

116

117

137

213

212

171

129

127

119

120

419

132

133

119

124

115

124

97

144

102

125

111

135

131

130

138

118
Physarum psittacinum var.

fulvum Lister

118

- pulcherrimum Berk. et Rav.

113

- pulchripes Peck

112

- pusillum (Berkeley et

Curtis) Lister

129

-. Raveuelii Macbride 113

- Readeri Massee 133

- relatum Morgan 111

- reniforme (Massee) Lister

137

- reticulatum Alb. et Schwein. 164

- reticulatum Berl.

139

- roseum Berk, et Broome.117

- Rostafinskii Massee 147

- rubiginosum Chev. 105

- rubiginosum Fries $\quad 148$

- rubropunctatum Pat. 109

- rufibasis Berkeley et Broome

- rufipes Macbrile-

- rufipes Macbride

112

- salicinum Schum. 262

- Schröteri Rost. 114

- Schumacheri Spreng. 114

- - var. mellenm Rost. $\quad 109$

- Schweinitzii Berkeley 353

- serobiculatum Massee $\quad 138$

- scyphoides Cooke et Balf. 169

- Serpula Morgan N 420

- simile Rost. 128

— sinuosum (Bull.) Weinm. 143

- sinuosum Link 212

- solutum Schum.

131

- sphaeroidala Chevall. $\quad 176$

- squamulosum Pers. 224

- straminipes Lister 128

- striatum var. coccineum Fries

120

- stromateum liuk 176

- sulcatum Link 131

- sulphureum Alb. et Sehw.

- sulphureum Stmrgis

- teuerum Rex

- testaceum Sturgis

145

- thejoteum Fr. 
Physarum tigrinum Pers.

224 Reticularia argentea Poiret

- tropicale Macbride

- atra Fr.

- tucumanense Speg.

- Carestiana Rabeuhorst

- turbinatum Schum.

109

- carnea Fr.

153

- carnosa Bull.

153

- Tussilaginis Berkeley et Broome

- utriculare Fries

217

- variabile Rex entoxantha Berkeley

- flavo-fusea Fr.

- - var. sessile Lister

110

- hemisphaerica Bull.

174,210

- hortensis Bull.

152

_- vermieulare Schwem.

396

- Lobata Lister

- vernicosmm Schum.

171

- vernum Sommerfelt

138

- f. badhamioides Meylan

- lurida Berkeley et Broome

317

- lutea Bull.

152

- Lyeoperdon Bull. 316*, 321*

- maxima Corda

280

139, N 419

- var. iridescens G. Lister

- maxima Fr.

276

- miniata Poiret

- violaceum Schum.

138

- muscorum Fr.

156

- virescens Ditm.

150

- - var. alpina Lister

- - var. genuinum Lister

150

- - var. nitens Lister

- - var. obseurum Lister 150

— viride (Bull.) Pers. 88*, 119*

_ var. aurantium (Bull.)

$$
\text { Lister }
$$

- - var. Bethelii (Macbride) Sturgis

_ - var. incanum Lister

- var. luteum Lister

_ - var. rigidum Lister

- xanthopus Wallr.

Protoderma pnsilla Rost.

Protoderminun pusillum Berl. 308

Prototrichia Rost. $\quad 390,400,407$

- Bombarda Massee

- chamaeleontina Massee

- cuprea Massee

- elegantula Rost.

- flagellifera Rost.

- metallica (Berkeley) Massee $400^{*}, 407^{*}$

Puceinia byssoides Gmelin

Raciborskia elegans Berlese

Reticularia Bulliard 315, 317, 320

- alba Bull.

- angulata Pers.

205

- applanata Berkeley et Broome 319
- olivacea Fr.

- ovata var. Withering

319

- - var. 2 Withering

- plumbea Fr.

- punctata Poiret

- rosea DC.

- Rozeana Lister

- (?) Rozeana Rost.

- rufa Schwein.

- Schmitzii Debey

- septica Withering

153

222

317

326

327

322

320

153

102

- sinuosa Bull.

153

$-176$

- sphaeroidalis Bull. $\quad 176$

- splendens Morgan 320

- Strongylium Schweiu. 274

- testacea Wallr. 324

- ungulina Fr. $\quad 319$

_ vaporaria Chevall. 153

- versicolor Fr. $\quad 319$

Reticulariaceae Rost. em. Lister 84,315

Rostafinskia elegaus Racib. $\quad 243$

Seyphinm rubiginosum Rost. 105 Siphoptychium Casparyi Rost. 314 Sphaerocarpa opereulata Schum. 165 Sphaerocarpus albus Bull. 131, 132

- antiades Bull. 185

- aurantius Bull. $\quad 120$

-. capsulifer Bull. 94

- cbrysospermus Bull. 332 
- Sphaerocarpus coccinens Bull.

- eylindricus Bull.

- ficoides Bull.

- floriformis Bull.

- fragiformis Bull.

- fragilis Sow.

- globulifer Bull.

- Iuteus Bull.

- piriformis Bull.

- sessilis Bull.

- turbinatus Bull.

- utricularis Bull.

- viridis Bull.

Spumaria alba DC.

- cornuta Sehum.

- didermoides Achar.

- granulata Schum.

- licheniformis Schwein.

- minuta Schum.

- Mucilago Pers.

- physaroides Pers.

Stegasma australe Cesati

- depressum Corda

Stemonitaceae Rost.

371 Stemonitis cinerea Gmel.

378

312

- cinnabarina Roth

356

349

- coccinea Gmel.

371

185

- coccinea Roth

- confluens Cooke et Ellis

349

238

111 - cribrarioides Fr. 267

120

- crocea Gmel.

374

346

- erocata Rotl

374

393

- erypta Schwein.

250

165

- dictyospora Rost.

233, 432

97

- digitata Schwein.

378

119

- echinulata Berkeley

259

222

- elegans Trentep.

199

222

- fasciculata Schum.

241

129

- fasciculatus Pers.

233

147

130

- favoginea Gmel.

332

- fenestrata Macbride 237

147

- ferruginea Ehrenb.

241

222

176, 212

392

392

- - var. Smithii (Macbride) Lister

$241,242^{*}$

- var. violacea Meylau 242

- ferruginea Fr.

240

- ferruginosa Batseh

312

- flavescens Schrank

346

Stemonitis Gleditsch

- acuminata Massee

$229,230,232$

- flavogenita Jahn

240

- Friesiana de Bary

- fusca Roth 230*, 233, 334*

- aequalis Massee

237

- affinis Massee

- alba Gmelin

250

- amoena Trentep.

- arcyrioides Somm.

131

385

- argillacea Pers.

264

- atra Massee

283

- atrofusca Pers.

252

244

- aurantia Gmel.

120

- axifera Macbride

- Bäuerlinii Massee

- - f. fenestrata Rex

- bicolor Gmel.

- Botrytis Pers.

- cancellata Gmel.

- Carestiae Ces. et de Not.

- Carlylei Massee

- carnea Trentep.

- carolinensis Macbride

- castillensis Macbride

- - var. confluens Lister 235

- - var. flaceida Lister 235

- - var. nigresceus (Rex) Torrend

_ - var. rufescens Lister 234

- var. trechispora (Berkeley) Torrend

234,432

- - var. Tubulina Rabenhorst 238

- glauea Trentep.

378

- globosa Schum.

- globosa Trentep.

- globulifera Gmel. $\quad 111$

- grisea Opiz 378

- berbatica Peck 239

- - var. confluens Lister 239

- hyperopta Meylan 433

240 - incarnata Pers. 382

233 - laxa Massee 
Stemonitis leucocephala Pers.

- leucopodia DC.

- leucostyla Pers.

- Ionga Massee

- lumbricalis Gmel.

- Iutea Trentep.

- Lycopodii Nees ex Fr.

- mammosa Fr.

- máxima Massee

- maxima Schwein.

- microspora Lister

- Morgani Peck

- Morthieri Fuckel

- nigra Pers.

- nigrescens Rex

- nutans Ginel.

- oblonga Fr.

- obtusata Fr.

- ochroleuca Trentep.

- ovata Pers.

- pallida Wingate

- papillata Pers.

- physaroides Alb. et Schwein. 262

- - var. subaeneus Berkeley ex Massce

- pomiformis Roth

- porphyra Berkeley et Curtis

- pulchella Babington

262, N 417

- pumila Corda

- pumila Fr.

- reticulata Trentep.

- rufa Koth

- scintillaus Berkeley et Broome

- semitrichioides Gmel.

- Smithii Lister

- Smithii Macbride

- sphaerocarpa Schrank

- splendens Rost.

- - var. confluens Lister

- - var. flaceida Lister

- - var. Webberi (Rex)

Lister

- subcaespitosa Massee

- subclavata Zoll..

- Suksdorfii Ellis et Everb.
168

199

199

249

366

380

267

255

237

233

241

237

265, 437

244

233, 235

385

244

244

380

244

240

255

259

380

253

250

236

244

285

261

289

241

241

283

237

238

238
Stemonitis tenerrima Curtis

- tenerrima Morgan

- trechispora Berkeley

- Trichia Roth

- Tubulina Alh. et Schwein.

- typhina Wiggers

- typhoides DC.

- varia Pers.

- Vesparia Gmel.

- violacea Fr.

- violacea Roth

- violacea Schum.

- virginiensis Rex

- viridis Gmel.

- Webberi Rex

Strongylium atruın Swartz

- fuliginoides Ditm.

- majus Fr.

- minus Fr.

Tilmadoche alba Mecbride

- anomala Massee

- Berkeleyi Massee

- columbinum Rost.

- compactum Wingate

- gracilenta Rost.

- gyrocephala Rost.

- hians Rost.

- minuta Berl.

- mutabilis Rost.

- var. aurantiaca Rost.

- var. lutea Rost.

- nephroides Celak.

- nutans Rost.

- oblonga Rost.

- Pini Rost.

- polycephala Macbride

- reniformis Massee

- soluta Fr.

- viridis Sacc.

Tremella hydnoidea Jacquin

- hydnoides Jacquin

Trichamphora Junghuhu

87, 89, 189

- Fuckeliana Rost.

160

- oblonga Berkeley et Curtis 161

- pezizoidea Jungh. 89*, 160* 
Trichia Haller

- abietina Wigand

- abrupta Cooke

- aculeata Celak.

- advenula Massee

- affinis de Bary

- alata Trentep.

- alba Sow.

- Andersoni Rex

- anomala Karsten

- aurantia DC.

- aurea schum.

- axifera Bull.

- Ayresii Berkeley et Broome

- Balfourii Massee

- bavarica de Thuemen

- Botrytis Pers.

$$
330^{*}, 349,350^{*}, 443
$$

_ - var. cerifera G. Lister

- _ var. flavicoma Lister 351

_ - var. lateritia Lister

351

_ var. munda Lister

- var. subfusea Lister

- capsulifer DC.

- Carlyleana Massee

- cerina Ditm.

- cernua Schum.

- chalybea Chev.

- chrysosperma DC.

- cinerea Bull.

- cinnabarina Bull.

- circumscissa Schrader

- circumscissa Wallr.

- citrina Schum.

- clavata Pers.

- clavata Wigand

- coccinea Lam. et DC.

- coerulea Trentep.

- columbina Poiret

- compressa Trentep.

- contorta (Ditms.) Rost.

$340,341^{*}$

- var. alpina R. E. Fr.

$$
341,342 *
$$

- var. corticula Martin

361

361

347

371

97, 138

262

212
Trichia coutorta var. corticola f. attenuata Meylan 343 - _ var. inconspicua (Rost.) Lister $341^{*}, 342$

- - var. iowensis (Macbride) Torrend

- - var. lutesceus Lister $\quad 344$

- cordata Pers.

338

- craterioides Corda 338

- Currey Crouan 390

- cylindricá Pers. 338

- Decaisuea de Bary 351

- decipiens (Pers.) Macbride

- var. gracilis (Meylau) Schinz

- - f. hemitrichioides Braudza.

— f. nodulosa Braídza

348,443

_ var. olivacea (Meylan) Sehinz

- f. rubiformis Meylan 348

— f. sublevis Meylau) Schiuz

- denudata Vill.

- depressa Trentep.

212

- elongata Schum.

385

- erecta Rex

- fallax Pers. 346

- - var. gracilis Meylan 347

- - var. olivacea Meylau 347

- f. sublevis Meylan 348

- fariuosa Poiret 212

- favoginea (Batsch) Pers.

- flexuosa Schum.

331

- filamentosa 'I'rentep.

132

- flagellifera Berkeley et Broome

382

- floriforme (Schwein.)

$$
\text { G. Lister }
$$

- fragiformis Wither.

- fragilis Rost.

- fulva Purton

- fulva Wither.

- furcata Wigand 
Trichia fusco-atra Sibth.

- globulifera DC.

- graniformis Hoftm.

- gymnosperma Pers.

- hemisphaerica Trentep.

- heterotrichia Balf.

- Jackii Rost.

- inconspicua Rost.

- intermedia Čelak.

- intermedia Massee

- intricata Poiret

- iowensis Macbride

- Kalbreyeri Massee

- Kickxii Rost.

- lateritia Lév.

- Ieucopodia Bull.

- Lorinseriana Corda

- lutea DC.

- Iutea T'rentep.

- lutesceus Lister

- macrocarpa Poiret

- metallica Berkeley

- mierocarpa Poiret

- minima Massee.

- nana Massee

- nana Zukal

- Neesiana Corda

- nigripes Pers.

- nitens Fr. ex Massee

- nitens Libert

- nitens Pers.

- nutans Bull.

- uutans Trentep.

_ obtusa Wigand

- olivacea Pers.

- ovalispora Hollós

- ovata Macbride

- ovata Pers.

- pachyderma Celak.

- persimilis Karsteu

- persimilis Macbride

- physaroides Scbum.

- polymorpha Sow.

- proximella Karsteu

- pulchella Rex

- purpurascens Nyll.
393 | Trichia purpurea Schum.

- pyriformis Fr.

393 - pyriformis Hoffin. 356

131 - pyriformis Pers. 338

340 - reniformis Peck 340

335 - reticulata Pers. 366

342 - Rostafinskii Čelak. 342

340 - rubiformis Pers. 356

333 - rubiformis Purt. 97

293 - rufa Wither. 374

342 - rufescens Poiret 286

333 - rugosa Treutep. 215

353 - scabra Rost. 336, 337*

$351,352 * 444$ - - var. Iutea Meylan 338

199 - semicancellata DC. 289

349 - serotina Schrader 349

120 - Serpula Pers. 366

171 - sphaerica Trentep. 215

$343,344^{*} \quad$ - sphaerocephala Sow. 212

287 - splendens Poir. 291

407 - spongioides Vill. 366

297 - squamulosa Poir. 224

336 - Stuhlmanni Eichelb. 347

363 - subfusca Rex 340̄, 442

347 - sulphurea Massee 335

356 - superba Massee 333

338 - tigrina Poir. 224

336 - turbinata DC. 165

353 - turbinata Sow. 332

332 - turbinata Wither. 338

385 - typhoides Bull. 250

131 - utricularis DC. 97

347, 361 - varia Pers. 338, 339*

332, 338 - - var. aurata Meylan 339

340 - -var. fimicola Marchal.

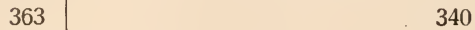

332 - vemosa Schum. 366

340 - verrucosa Berkeley 333

- vesiculosa Gmel. 338

- violacea Hoffm. 262

262 - viridis DC. 119

372 - vulgaris Pers. 338

335 Trichiaceae Rost. em. List: $r$

333 85. $32 n$

349 Tripotrichia elegans rith 171 


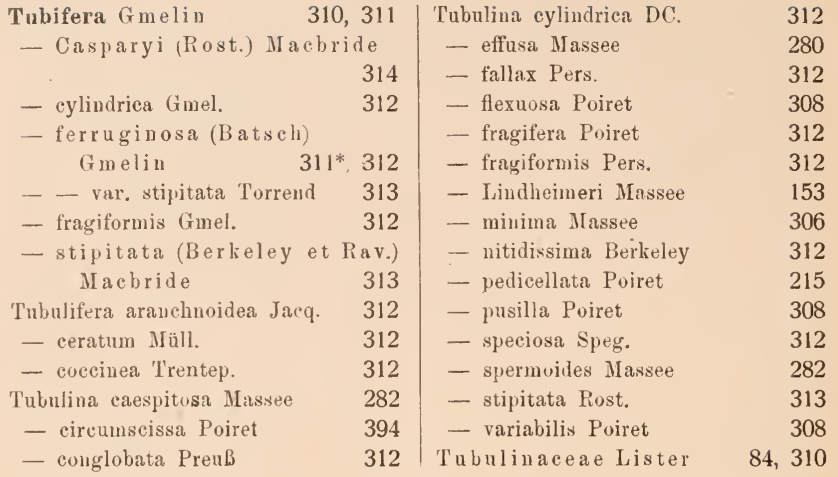




\title{
Alphabetisches Verzeichnis der Abbildungen.
}

\author{
Die Ziffern bezeichnen die Seitenzahlen.
}

Alwisia Bombarda Berkeley et Broome

113.

Amaurochate fuliginosa (Sow.) Macbr. $24,25,273,275$

Arcyria denudata (L.) Wettstein 13, 58 (374), 370, 376

- ferruginea Sauter 372

- nutans (Bull.) Grev. 386

Badhamia foliicola Lister $\quad 87,100$ - utricularis (Bull.) Berkeley 98 Barbeyella minutissima Meylan 411

Brefeldia maxima (Fr.) Rost.

$$
274,276,277
$$

Calonema aureum Morgan 330, 3.5 Ceratiomyxa fruticulosa (Muell.) Macbr. $9,28,42,44,45$

- - var. flexuosa Lister

Cienkowskia reticulata (Alb, et Schwein.) Rost.

Clastoderma Debaryanum Blytt 90,164 232, 270, 271

Colloderma oculatum (Lippert)

$$
\text { G. Lister }
$$

Comatricha laxa Rost.

- nigra (Pers.) Schröter

$47,48,59,231,245,251$

- typhoides (Bull.) Lister

59 (250), 251

Cornuvia Serpula (Wigand) Rost. 330 (368).

Craterium minutum (Leers) Fr.

Cribraria argillacea Pers. 99, 166

- elegans Berkeley et Curtis

- macrocarpa Schrader
Cribraria purpurea schrader

- pyriformis Schrader

- rubiginosa Fr.

54, 279. 295

- rufa (Roth) Rost.

285

- violacea Rex

Diachaea leucopoda (Bull.) Rost.

93, 199

Dianema corticatum Lister 400, 406 - Harveyi Rex

Dictydiaethalium plnmbeum (Schum.) Lister 316 (317)

Dictydium cancellatum (Batsch) Macbr. 54, 279, 301

- var. anomalum (Jahn) Schinz 303

Diderma radiatum (L. sens. lat.)

\section{Lister}

91, 188

- spumarioides Fries.

63,177

- testaceum (Schrad.) Pers. 183

Didymium difforme (Pers.) Duby 14, 207 (205)

- nigripes (Link) Fr. 203

- squamulosum (Alb. et Schwein.) Fr.

215,216

- Wilczekii Meylan

215

Echinostelium minutum de Bary

$$
\text { 232, } 272
$$

Enerthenema papillatum (Pers.) Rost. 231, 255

Enteridium olivaceum Ehrenberg 316 Erionema aureum Penzig 88, 159 Fuligo muscorum Alb, et Schwein.

63,156 
Fuligo septica (L.) Gmelin

$30,56,88,154,155$

Hemitrichia abietina (Wigand) Lister 363

- chrysospora Lister

- clavata (Pers.) Lister 330 (360), 361

- leiocarpa (Cooke) Lister 363

- Serpula (Scop.) Lister 17 (365), 366, 367 (365)

- Vesparium (Batsch) Macbride 358 Lachnobolus congestus (Sommerfelt) Lister

Lamproderma arcyrionema Rost. 260 - columbinum (Pers.) Rost. 231, 262, 263

- scintillans (Berkeley et Broome) Morgan

261

- violaceum (Fr.) Rost. 264

Jeocarpus fragilis (Dicks.) Rost.

11, 91, 172

Lepidoderma Carestianum (Pabenhorst) Rost.

226

- tigrinum (Schrad.) Rost.

57, 204, 225

Leptoderma iridescens Lister 204, 228

Licea flexuosa Pers.

- minima Fries

Liceopsis lobata (Lister) Torrend

316,322

Lindbladia effusa (Ehrenb.) Rost. 307

$60,280.281$

- var. simplex Rex

$$
60,62,278,281
$$

Listerella paradoxa Jahn

Lycogala conicum Pers.

$$
400,409,410
$$

- Epidendrum (I.) Fr. 323, 326

Margarita metallica (Berkeley et Broome) Lister 399, 401

Mucilago spongiosa (Leyßer) Morgan $56,203,223$

Myxogasteresschwärmer 21

Oligonema nitens (Libert) Rost. $330,352,353$

Orcadella operculata Wingate 306
Perichaena ehrysosperma (Currey) Lister

- corticalis (Batsch) Rost.

- depressa (Colai) Libert 392

- vermicularis (Schwein.) Rost. 397 Physarella oblonga (Berkeley et Curtis) Morgan

89,162

Physarina echinocephala v. Höhnel

92. 195

Physarum didermoides (Acharius) Rost.

- gyrosum Rost.

10,140

- nutans Pers. $57,132(131)$

- viride (Bull.) Pers.

88,119

Prototrichia metallica (Berkeley) Massee 400,407

Reticularia Lycoperdon Bull. 316, 321 Stemonitis ferruginea Ehrenb.

- - var. Smithii (Hacbride) Lister 59 (241), 242

- flaceida (Morg.) Jahn

24, 25

- flavogenita Jahn

- - var. Smithii (Macbr.) Lister

- fusca Roth

13, 230, 234

- splendens Rost.

- - var. flaceida (Morg.) Lister 24,25

Trichamphora pezizoidea Jungh.

89,160

Trichia affinis de Bary

13,337

- Botrytis Pers.

$9,330,350$

-. contorta (Ditm.) Rost.

341

- - var. alpina R. E. Fr.

341

- - var. inconspicua (Rost.) Lister

- erecta Rex

341

favoginea (Batsch) Pers 13,58

- lateritia Lév.

352

- lutescens Lister

344

- persimilis Karsten

13, 58, 337

- scabra Rost.

58, 337

- varia Pers. 339

Tubifera ferrnginosa (Batsch) Gmelin 311 
Krspla t n. - it una

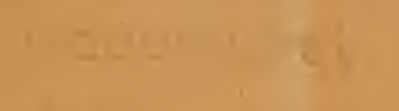





\section{Zeit des Erscheinens der einzelnen Lieferungen.}

Lieferung 121 Seite 1-64 wurde abgeschlossen

am 20. Juli 1912.

Lieferung 122 Seite $65-128$ wurde abgeschlossen

am 18. Februar 1914.

Lieferung 123 Seite 129-192 wurde abgeschlossen

am 17. Mai 1915.

Lieferung $12 \pm$ Seite 193-256 wurde abgeschlossen

am 9. Dezemder 1915.

Lieferung 125 Seite $257-320$ wurde abgeschlossen

am 28. August 1917.

Lieferung 126 Seite $321-384$ wurde abgeschlossen

am 20. März 1918.

Lieferung 127 Seite $385-47+$ und $\mathrm{I}-\mathrm{Xl}$ wurde abgeschlossen am 8. Dezember 1920. 


\section{Exsikkaten-Werke.}

Berücksichtigt wurden nur solche Exsikkaten-Werke, die meines Wissens Schleimpilze von deutschen, österreichischen oder schweizerischen Standorten ausgegeben haben.

Fuckel, L.: Fungi rhenani exsiccati. 15 Fasz. und 12 Supplement-Fasz.; 1863-1874.

Holl, Fr. und J. K. Schmidt: Deutschlands Schwämme. Lief. I-II; 1815. Fortsetzung J. K. Schmidt und G. Kunze: Lief. III-IX; 1816-1819.

Jaap, Otto: Myxomycetes exsiccati. Nr. 1-200. 1907-1916. Jack, J. B., Leiner, und L. \& E. Stitzenberger: Kryptogamen Badens. 21 Fasz.; 1857-1875.

Rabenhorst, L.: Fungi europaei. Cent. I-XXVI; 1859-1880. Rabenhorst, L.: Herb. viv. Mycologic.; Ser. I Cent. I-II, 1832

(J. F. Klotzsch); Cent. III-XX, $1842-1855$ (L. Rabenhorst); Ser. sec. (ed. nov.) Cent. I-XXVI, 1855-1880. Rabenhorst, L. - Winter, G.: Fungi europaei et extraeuropaei exsiccati. Cent. XXVII-XXXVII, 1881-1890; cura O. Pazschke: Cent. XXXVIII-XLV, $1891-1905$.

Sydow, P.: Mycotheca Marchica. Cent. I-XLIX; 1880-1899. Wartmann, B. und Schenk, B.: Schweizerische Kryptogamen. Fasz. I-XIV; $1862-1869$.

Wartmann, B und Winter, G.: Schweizerische Kryptogamen. Fasz. XV-XVIII; $1880-1882$.

Wien: Kryptogamae exsiccatae, editae a Museo Palatino Vindobonensi. Cent. I-XXIV; 1894-1916. 





